\title{
Kulturlandschaften in Deutschland und Polen
}

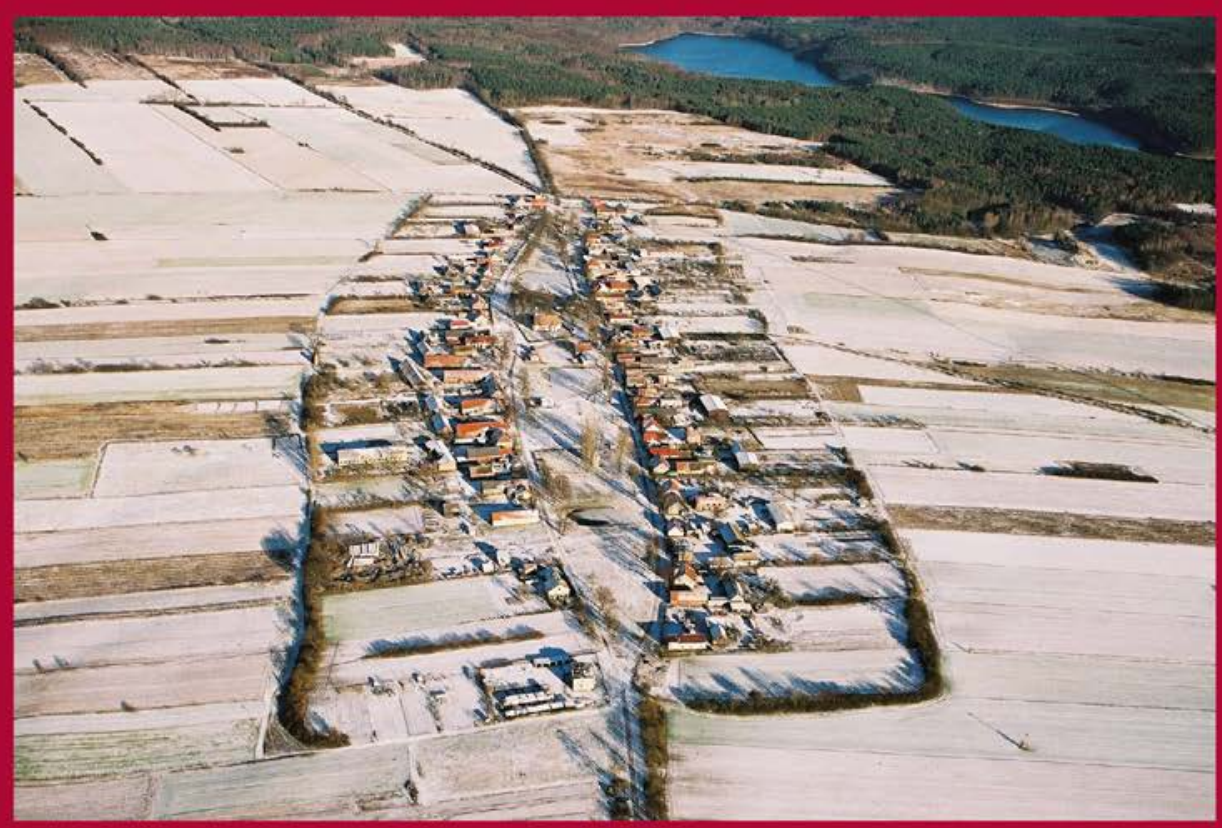




\section{Eckert. Die Schriftenreihe}

\section{Studien des Georg-Eckert-Instituts}

zur internationalen Bildungsmedienforschung

Band 144

Herausgegeben von Eckhardt Fuchs

Redaktion

Wibke Westermeyer und Andreas R. Hofmann

Die Reihe ist referiert. 


\section{Olaf Kühne / Thomas Strobel / Robert Traba / Marcin Wiatr (Hg.)}

\section{Kulturlandschaften in Deutschland und Polen}

Akteure und Modi ihrer Konstruktion und Narration

Mit 28 Abbildungen

V\& R unipress 

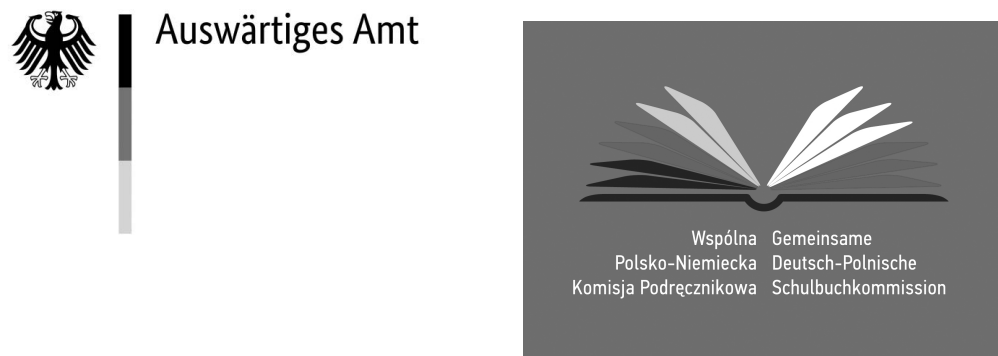

Bibliografische Information der Deutschen Nationalbibliothek

Die Deutsche Nationalbibliothek verzeichnet diese Publikation in der Deutschen Nationalbibliografie; detaillierte bibliografische Daten sind im Internet über https://dnb.de abrufbar.

Gedruckt mit freundlicher Unterstützung des Auswärtigen Amtes.

(C) 2020, Vandenhoeck \& Ruprecht GmbH \& Co. KG, Theaterstraße 13, D-37073 Göttingen Dieses Werk ist als Open-Access-Publikation im Sinne der Creative-Commons-Lizenz BY International 4.0 (»Namensnennung«) unter dem DOI 10.14220/9783737007504 abzurufen. Um eine Kopie dieser Lizenz zu sehen, besuchen Sie https://creativecommons.org/licenses/by/4.0/. Jede Verwertung in anderen als den durch diese Lizenz zugelassenen Fällen bedarf der vorherigen schriftlichen Einwilligung des Verlages.

Umschlagabbildung: Neumärkisches Dorf Jemiołów (bis 1945: Petersdorf), (C) Włodzimierz Rączkowski

\section{Vandenhoeck \& Ruprecht Verlage | www.vandenhoeck-ruprecht-verlage.com}

ISSN 2198-6320

ISBN 978-3-7370-0750-4 


\section{Inhalt}

\section{Einführung der Herausgeber}

Robert Traba / Olaf Kühne

Kulturlandschaften. Einige Vorbemerkungen zu Forschungsstrategien und Interpretationen $\ldots \ldots \ldots$. . . . . . . . . . . 9

\section{Theorien und Methoden}

Olaf Kühne

Raum, Landschaft und Kulturlandschaft - Annäherungen an komplexe

Begriffe .................... 23

Violetta Julkowska

Kulturlandschaft als erkenntnisleitende Begriffskategorie der

Geschichtsdidaktik . . . . . . . . . . . . . . . . . 43

Winfried Schenk

Der Wert von Kulturlandschaften für die Umweltbildung in Deutschland aus kulturgeografischer und ideengeschichtlicher Perspektive . . . . 63

\section{Landschaften Lesen - Variable Identitäten von Kulturlandschaft}

Gabi Dolff-Bonekämper

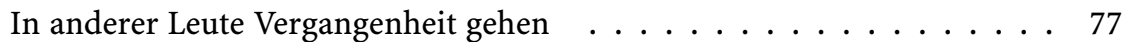

Alexander Tölle

(Re-)konstruierter Raum als Ausdruck gesellschaftlichen Wandels die Beispiele Elbing/Elbląg und Glogau/Głogów . . . . . . . . . . . . 111

Włodzimierz Rączkowski

Historische Landschaften aus der Perspektive der Fernerkundung . . . . 133 
Tadeusz Stryjakiewicz

Kulturlandschaft in Veränderung: Konin und Umgebung . . . . . . . . 153

Markus Schwarzer

Wandel von Kulturlandschaften durch den Braunkohletagebau . . . . . . 171

Antje Otto / Andrzej Ancygier / Karolina Jankowska

Windenergienutzung und Landschaftsdebatten - Erfahrungen aus Polen

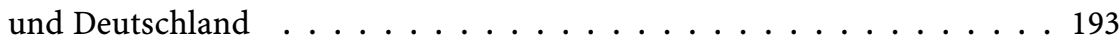

Ewa Wojtoń

Vergangene Arbeitswelten. Sosnowiec und die Umgestaltung der postindustriellen Landschaft . . . . . . . . . . . . . . . . 217

Przemysław Czapliński

Dekolonisierung der Berge. Zwei Abstiege nach Schelmenart . . . . . . 235

\section{Kulturlandschaften im Spannungsfeld von Wissenschaft und Didaktik}

Thomas Strobel

Kulturlandschaften in deutschen Geschichtsschulbüchern . . . . . . . . 251

Bartosz Dziewanowski-Stefańczyk

Kulturlandschaften in polnischen Geschichtsschulbüchern . . . . . . . 263

Joanna Plit / Florian Plit

Kulturlandschaften in polnischen Geografieschulbüchern . . . . . . . . 289

Péter Bagoly-Simó

Der ausgeblendete Mensch: Kulturlandschaften in Berliner

Geografieschulbüchern . . . . . . . . . . . . . . . 305

Stephanie Zloch

Die Region als Landschaft: Ostpreußen/Warmia i Mazury in Geschichtsund Geografieschulbüchern . . . . . . . . . . . . . . 327

Marcin Wiatr

Eine klaffende Lücke. Zur Präsenz Oberschlesiens als deutsch-polnische Kulturlandschaft in polnischen Bildungsmedien nach 1989 . . . . . . . . 349 


\section{Einführung der Herausgeber}


Open-Access-Publikation im Sinne der CC-Lizenz BY 4.0

(c) 2020, Vandenhoeck \& Ruprecht GmbH \& Co. KG, Göttingen ISBN Print: 9783847107507 - ISBN E-Lib: 9783737007504 


\section{Kulturlandschaften. Einige Vorbemerkungen zu Forschungsstrategien und Interpretationen}

Wenn sich die Gemeinsame Deutsch-Polnische Schulbuchkommission der Historiker und Geografen - seit beinahe 50 Jahren ein wichtiger Pfeiler des akademischen Dialogs zwischen Deutschland und Polen - des Themas Kulturlandschaften annimmt, ist eine doppelte Perspektivdualität vorbestimmt: Einerseits trifft die Wissenschaftstradition der Geschichte auf jene der Geografie, andererseits eine deutsche auf eine polnische. Allein diese Konstellation bringt unterschiedliche Blickwinkel auf Kulturlandschaften und ihre vielfältigen Bedeutungen mit sich, zudem forschen deutsche und die polnische Geografie oder Geschichte innerhalb eines Geflechts interdisziplinärer oder internationaler Bezüge. Insofern ist die Einbeziehung von weiteren disziplinären (und interdisziplinären) Überlegungen ebenso eine logische, erkenntnisleitende Konsequenz für die Befassung mit dem Thema Kulturlandschaften durch die Gemeinsame Deutsch-Polnische Schulbuchkommission wie eine Weitung des Blickes in internationale Kontexte.

Geschichte ist eine Wissenschaft über den Menschen in der Zeit. Sie konstruiert Narrationen, die Ereignisse in der Zeit zu Sinnzusammenhängen verbinden. Denn erst die »Dauer schafft eine Atmosphäre, in der der Gedanke des Historikers ruhig atmen kann «, ${ }^{1}$ so Marc Bloch. Der größte Gegner der Zeit ist der geografische Raum, fügt Fernand Braudel, der bekannteste Historiker der nächsten Generation der Annales-Schule, hinzu. ${ }^{2}$ Und laut Karl Schögel, einem weiteren historischen Raumdeuter, ist die Geschichte der Menschheit »ein Kampf gegen den horror vacui, als unentwegte Anstrengung zur Bewältigung des Raumes, seiner Beherrschung und schließlich seiner Aneignung. ${ }^{3}$

1 Marc Bloch, Pochwała historii czyli o zawodzie historyka [Lob der Geschichte oder über den Beruf des Historikers], Warschau: Antyk Marek Derewiecki, 2009, 50.

2 Fernand Braudel, La Méditerranée et le monde méditerranéen à l'époque de Philippe II, Band 1, Paris: Armand Colin, 1976, 326.

3 Karl Schlögel, Im Raume lesen wir die Zeit. Über Zivilisationsgeschichte und Geopolitik, München u. a.: Carl Hanser Verlag, 2003, 9. 
An dieser Stelle wird die Schnittmenge zwischen den Wissenschaftsgebieten Geschichte und Geografie deutlich: Ist Geschichte eine Wissenschaft über den Menschen in der Zeit, eines Verhältnisses, das sich räumlich manifestiert, ist Geografie eine Wissenschaft über Räume, die sich im zeitlichen Kontext verändern. Der Plural »Räume« ist hier sehr bewusst gewählt, schließlich befasst sich die Geografie spätestens seit den 1960er Jahren mit der Frage, was denn unter »Raum « zu verstehen sei. ${ }^{4}$ Die Antworten darauf fallen - in Abhängigkeit von der wissenschaftlichen, aber auch kultur- und bildungsgeschichtlichen Tradition - sehr unterschiedlich aus, lassen sich aber gedanklich einem Dreieck zuordnen, in denen die soziale Konstruktion, das individuelle Erleben und materielle Objekte die jeweiligen Ecken definieren. ${ }^{5}$ Die Komplexität der verschiedenen Auffassungen und Lesarten von Landschaften wird dadurch noch gesteigert, wenn die soziale Konstruktion wie auch die Welt der materiellen Objekte nicht statisch zu verstehen sind, sondern zeitlichen Variabilitäten - durchaus in unterschiedlichen Geschwindigkeiten - unterliegen.

Die Forschung zu Kulturlandschaften begann in der deutschen Geografie in den 1830er Jahren ${ }^{6}$ und erfuhr mit den Arbeiten von Paul Vidal de La Blache und Carl Sauers grundlegender Morphology of Landscape im frühen 20. Jahrhundert eine über die Fachgrenzen hinausreichende Popularität. ${ }^{7}$ Auch Philosophie (Martin Heidegger, Georg Simmel) und Anthropologie (u. a. Tim Ingold, Eric Hirsch) befassten sich mit dem Themenfeld der Kulturlandschaften und auch schlug sich mit der Zeit das Thema in der Historiografie nieder, etwa in Form von Albert Demangeons und Lucien Febvres Le Rhin von 1935 bis zu Karl Schlögels Im Raum lesen wir die Zeit von 2003. Seit der Wende von den 1980er zu den 1990er Jahren wurde diese Forschung durch den spatial turn bestärkt. Die Thematisierung des Räumlichen wurde nicht zuletzt durch die angelsächsische Humangeografie angeregt, etwa durch David Harveys »Between Space and Time: Reflections on the Geographical Imagination ${ }^{8}$ oder Edward Sojas Postmodern Geographies: The Reassertion of Space in Critical Social Theory. ${ }^{9}$

4 Unter vielen: Stuart C. Aitken und Gill Valentine (Hg.), Approaches to Human Geography. Philosophies, Theories, People and Practices, Los Angeles: SAGE Publications, 2015; Heike Egner, Gesellschaft, Mensch, Umwelt - beobachtet. Ein Beitrag zur Theorie der Geographie, Stuttgart: Franz Steiner Verlag, 2008; Gerhard Hard, Landschaft und Raum. Aufsätze zur Theorie der Geographie, Osnabrück: Rasch Druckerei und Verlag, 2002.

5 Ausführlicher in Bezug auf Landschaft: Olaf Kühne, Landscape Theories, Wiesbaden: Springer VS, 2019.

6 Kerstin Potthoff, »The use of `cultural landscape in 19th century German geographical literature«, in: Norsk Geografisk Tidsskrift - Norwegian Journal of Geography 67, 1 (2013), 49-54.

7 Paul Vidal de La Blache, Principes de géographie humaine. Publiés d'après les manuscrits de l'auteur, Paris: A. Colin, 1921; Carl Ortwin Sauer, The Morphology of Landscape, Berkeley: University of California Press, 1925.

8 David Harvey, »Between Space and Time: Reflections on the Geographical imagination«, in: Annals of the Association of American Geographers 80, 3 (1990), 418-434. 
Der spatial turn bedeutete eine fundamentale Wende der Befassung mit Räumlichkeiten in den Geistes-, Kultur- und Sozialwissenschaften, die bis zu diesem Zeitpunkt - in Deutschland unter anderem infolge der Raumideologie der Nationalsozialisten - zeitliche Aspekte des menschlichen Agierens für ihre Untersuchungen und Reflexionen bevorzugte. Doreen Massey brachte dies auf die griffige Formel: „Die Zeit schreitet voran, während der Raum herumlungert. ${ }^{10}$ Raum erschien als nicht weiter hinterfragtes materielles Grundsubstrat, in dem sich - zeitlich strukturiert - Aktivitäten des Menschen abspielten. Unter dem Begriff spatial turn lässt sich die zentrale Überlegung zusammenfassen, dass Räume kulturell und sozial konstruiert sind: Raumvorstellungen werden durch menschliche Tätigkeit bedingt und überformt, umgekehrt wirken sie aber auch auf den Menschen zurück. Der spatial turn in den Geistes-, Sozial- und Kulturwissenschaften wurde von der Humangeografie nicht ohne Kritik beobachtet, insbesondere Gerhard Hard ${ }^{11}$ sah hinter den konstruktivistischen Redewendungen einen eher essentialistischen Raumbegriff verborgen. Unabhängig von der Kritik lässt sich aber feststellen: Das Verständnis von (Kultur-) Landschaften verschob sich damit weg von dem materiellen Eckpunkt des oben genannten Dreiecks in Richtung der Ecke der sozialen Konstruktion. Die Beiträge dieses Bandes finden entsprechend - meist implizite - Anknüpfungen an die Diskussionen um den spatial turn.

Nicht allein im Kontext des spatial turn finden konstruktivistische Verständnisse von Raum Verbreitung, auch generell hat sich das Verständnis von Landschaft gewandelt. Konstruktivistisch orientierte Verständnisse von Landschaft finden ein erstes Auftreten in der englischen Geografie und reichen bis in die 1950er Jahre zurück, wobei William George Hoskins Werk The Making of the English Landscape hier als bahnbrechend gilt, ${ }^{12}$ wenngleich dieser Ansatz seit den 1980er Jahren eigens durch die Arbeiten von Denis Cosgove, Stephen Daniels und James und Nancy Duncan weltweit an Einfluss gewann ${ }^{13}$ und auch

9 Edward W. Soja, Postmodern Geographies: The Reassertion of Space in Critical Social Theory, London/New York: Verso, 1989.

10 Doreen Massey, »Raum, Ort und Geschlecht. Feministische Kritik geographischer Konzepte«, in: Elisabeth Bühler u. a. (Hg.), Ortssuche. Zur Geographie der Geschlechterdifferenz, Zürich: Efef Verlag, 1993, 109-122, hier 118.

11 Gerhard Hard, »Der Spatial Turn, von der Geographie her beobachtet«, in: Jörg Döring und Tristan Thielmann (Hg.), Spatial Turn: Das Raumparadigma in den Kultur-und Sozialwissenschaften, Bielefeld: transcript, 2008, 263-316.

12 William George Hoskins, The Making of the English Landscape, London: Hodder and Stoughton, 2005 [Erstdruck 1955].

13 Denis E. Cosgrove, Social Formation and Symbolic Landscape, London/Sydney: Croom Helm Ltd., 1984; Denis E. Cosgrove und Stephen Daniels (Hg.), The iconography of landscape. Essays on the symbolic representation, design and use of past environments, Cambridge: Cambridge University Press, 1988; James Duncan, "Landscape geography, 1993-94", in: 
in Nordamerika und Kontinentaleuropa seine Anhänger in Geografie, Soziologie, Kulturwissenschaften, Politologie und nicht zuletzt Geschichte und Literaturwissenschaft fand. Auch wenn sich die Forschungsrichtung in Polen und Deutschland zeitlich parallel entfaltete, wurden in den beiden Ländern doch unterschiedliche Schwerpunkte gesetzt. Hier wie dort gaben Soziologie und Geografie den Ton an, doch übernahmen in den historischen Wissenschaften in Deutschland die historisch orientierten Kulturwissenschaften die Führungsrolle, während in Polen die Mediävistik voranschritt ${ }^{14}$ und die in der Literaturwissenschaft beliebte Geopoetik ${ }^{15}$ dafür sorgte, den Ansatz in den Mainstream der Wissenschaftsdebatte zu bringen. Nahezu zeitgleich wurde Maurice Halbwachs' Gedächtnistheorie wiederbelebt, gefolgt von immer zahlreicheren, fachübergreifenden Untersuchungen zum kulturellen Gedächtnis, was besonders seit den 1990er Jahren unzählige neue Studien mit sich brachte, die sich auf Jan Assmanns Konzeption bezogen. Der Begriff des "Mnemotopos« und die Definition von Kulturlandschaft als räumlicher Erinnerungsrahmen, der durch Gemeinschaftsidentität prägende Symbole und Artefakte abgesteckt wird, etablierten endgültig eine anthropologisch basierte historische Landschaftsforschung.

Der Begriff der »Kulturlandschaft» wird nicht nur in der Geografie, sondern auch in den Geistes- und Sozialwissenschaften sehr unterschiedlich verstanden. Diese Verständnisse variieren deutlich in dem Dreieck aus Individuellem, Sozialem und Materiellem. Gemeinsam ist diesen Verständnissen jedoch, dass, erstens, Kulturlandschaften räumlich dimensioniert sind, zweitens, sie durch den Menschen bestimmt sind (also auch in der materiellen Dimension) und drittens, dass sie prozedural verstanden werden, sich also in stetem Wandel befinden. Viertens bedeutet Kulturlandschaft stets eine Auseinandersetzung mit den Gegebenheiten der Natur. Wie Beata Frydryczaks treffend bemerkt, erhält dabei auch die Natur erst durch Kultur, ja durch eine kulturgeschichtliche Vermessung Sinn und Bedeutung für den Menschen. ${ }^{16}$ Kulturlandschaft lässt sich

Progress in Human Geography 19, 3 (1995), 414-422; James und Nancy Duncan, »(Re)reading the landscape«, in: Environment and Planning D: Society and Space 6, 2 (1988), 117-126.

14 Adam Krawiec, ")Zwrot przestrzenny< w mediewistyce« [Der spatial turn in der Mediävistik], in: Jarosław Nikodem und Dariusz Andrzej Sikorski (Hg.), Vademecum historyka mediewisty [Vademecum des Mediävisten], Warschau: Wydawnictwo Naukowe PWN, 2012, 536-540; Doris Bachmann-Medick, Cultural Turns. Neuorientierungen in den Kulturwissenschaften, Reinbek bei Hamburg: Rowohlt, 2014, über den »spatial turn « 284-328.

15 Elżbieta Rybicka, Geopoetyka. Przestrzeń i miejsce we współczesnych teoriach i praktykach literackich [Geopoetik. Raum und Ort in zeitgenössischen literarischen Theorien und Praktiken], Krakau: Universitas, 2015.

16 Beata Frydryczak, »Krajobraz« [Landschaft], in: Magdalena Sariusz-Wolska und Robert Traba (Hg.), Modi Memorandi. Leksykon kultury pamięci [Lexikon der Erinnerungskultur], Warschau: Wydanwnictwo Naukowe Scholar, 2014, 195. 
entsprechend als soziale Konstruktion verstehen, die »dem Ästhetischen aufgesetzt, durch das Gesellschaftliche bedingt und aus dem Natürlichen erzeugt wurde. ${ }^{17}$ Ähnlich wie der Mensch der Geschichte unterschiedliche, mit der Zeit wechselnde Bedeutungen zuschreibt, so tut er das Gleiche - sozialkonstruktivistisch formuliert - mit materiellen Objekten, denen er landschaftliche Qualitäten zuschreibt. Ein solches Verständnis ist heute sowohl den Geschichtswissenschaften wie der Kulturgeografie geläufig.

Der vorliegende Band befasst sich einerseits mit unterschiedlichen disziplinären und interdisziplinären Verständnissen von (Kultur-)Landschaft, andererseits aber auch mit Fragen des empirischen Zugriffs auf (Kultur-)Landschaften und deren Ergebnissen, die sich auf deutsche, polnische und bilaterale Untersuchungen stützen. Ziel des vorliegenden Bandes ist dabei nicht allein, Verständnisse von Landschaft und deren (sozialwissenschaftlicher) empirischer Beforschung im deutsch-polnischen Vergleich (und darüber hinaus) darzulegen, sondern im Sinne einer interdisziplinären Ausrichtung auch alternative Verständnisse und empirische Herangehensweisen als Option für die eigene Forschung zu erkunden und anzubieten. Demgemäß beginnt der Band mit einem theoretisch-methodologischen Teil und schreitet fort zu Fallbeispielen empirischer Forschung. Der anschließende Teil über das "Lesen von Kulturlandschaft « am Beispiel der Deutsch-Polnischen Schulbuchkommission leitet zu den abschließenden Beiträgen zur didaktischen Praxis über.

Olaf Kühne bietet einen Querschnitt von aktuellen theoretischen Zugängen in Geografie und Sozialwissenschaften, indem er vor dem Hintergrund der deutschen und angelsächsischen Forschung die Begrifflichkeiten von »Kulturlandschaft «, »Raum « und nicht kulturell geprägter »Landschaft « unterscheidet. Diese breite zeitliche und kulturelle Perspektive verdeutlicht Veränderlichkeit, Brüche, aber auch Kontinuitäten und nationale sowie sprachliche Besonderheiten. So zeigt er, wie sehr die Forschung zur Kulturlandschaft von einer Polyphonie unterschiedlicher fachlicher Methoden und Ansätze bestimmt wird und nicht von einem einheitlichen fachübergreifenden Konsens. Anhand dieses Beitrages wird deutlich, wie groß die Vielfalt an Raum- und Landschaftsverständnisse - auch angestoßen durch die Diskussionen um den spatial turn - heute ist.

Spezifische Zugänge zum Thema Kulturlandschaft haben die Archäologen Włodzimierz Rączkowski und die Restauratorin und Kunsthistorikerin Gabi Dolff-Bonekämper. In der aktuellen Archäologie wurde in den vergangenen Jahren ein eigenes Programm zur Kulturlandschaft entwickelt. Zurzeit schwankt dieses zwischen auf Systemtheorie basierenden prozessualen und postprozessualen Ansätzen. Rączkowski positioniert sich in dieser theoretischen Diskussion bei ersteren und verwendet in der eigenen Forschung eine seit den 1960er

17 Ebd., 200. 
Jahren bekannte Methode der Fernerkundung. Er fügt diese in einen Katalog von Forschungsfragen ein, die darauf abzielen, archäologisch untersuchte Kulturlandschaften als Palimpsest zu verstehen, womit er deutlich stärker als andere Autoren des spatial turns, die materielle Dimension von Raum fokussiert.

Ein Schlüsselbegriff in dem Beitrag von Gabi Dolff-Bonekämper ist das "Hinzutreten« zu einer anderen Gruppe, die sich mit einem bestimmten Ort identifiziert. Dies ist der Moment, in dem sich eine Person von ihrer kulturellen Referenzgruppe entfernt, um sich einer bisher unbekannten Gruppe anzunähern. Solche Momente der Begegnung ermöglichen es, Andersartigkeit zu erleben. Sie sind auch Knotenpunkte im System der europäischen Erinnerungsgemeinschaft, soweit von einer solchen überhaupt bereits die Rede sein kann. Eines der Fallbeispiele ist das kulturelle Gedächtnis der polnischen Stadt Konin, das mit dem urbanen Raum verwoben ist und das der individuellen Erinnerung eines ihrer früheren jüdischen Bewohner gegenübergestellt wird. Der erste Impuls für den Beitrag rührte aus dem Lesen der Landschaft, als die Autorin im Rahmen der 2014 in Ciążeń ausgerichteten Schulbuchkonferenz, deren Ergebnisse der vorliegende Band dokumentiert, an einer Studienreise der DeutschPolnischen Schulbuchkommission teilnahm. Dies sei hier deswegen hervorgehoben, weil schon seit einigen Jahren "Lesen der Landschaft " ein festes Modul bei den Konferenzen der Gemeinsamen Schulbuchkommission ist. Das Lesen der Kulturlandschaft versteht die Beziehung zum Raum als komplexe Methode zur Entdeckung und didaktischen Vermittlung kultureller Welten. Kulturlandschaft kann durch nationale Identifizierungen und Deutungen angeeignet oder aber als überlappende Schichten historischer Wechselwirkungen entschlüsselt werden.

Genau dies erkunden die Beiträge der Kunsthistorikerin Gabi Dolff-Bonekämper und des Literaturwissenschaftlers Przemysław Czapliński, aber auch Ewa Wojtoń und Tadeusz Stryjakiewicz nehmen in ihren Studien über Sosnowiec/Sosnowitz und Konin diesen Ansatz auf, die einen deutlichen Bezug zum spatial turn aufweisen, indem sie die kulturellen und sozialen Raumbezüge fokussieren. Przemysław Czapliński bricht mit den Konventionen der Forschung zur Kulturlandschaft in zweierlei Weise. Erstens schreibt er nicht explizit über Kulturlandschaft, und zweitens schlägt er vor, zwei Bücher über das polnische Karpatenvorland (Podhale) literarisch zu interpretieren, ohne dabei auf wissenschaftliche Methodik zu achten, um so zu konventionellen Deutungen und Bewertungen alternative entwickeln zu können: Antoni Krohs Sklep potrzeb kulturalnych (Der Laden für Kulturbedarf, 1999) und Wojciech Kuczoks Spiski. Przygody tatrzańskie (Zipser Verschwörungen. Abenteuer aus der Tatra, 2010). Diese beiden Werke sind Gegenerzählungen rund um den polnischen Mythos vom idyllischen Podhale. Landschaft wird bei Kuczok und Kroh nicht als materieller Raum erkundet, sondern als das imaginäre, symbolträchtige und 
von Legenden umrankte Land, von dem sich seit dem 19. Jahrhundert viele Schriftsteller und Künstler inspirieren ließen. Im Anschluss an Czapliński ließe sich sagen, die Kulturlandschaft müsse immer wieder neu erzählt werden, um die Dynamik der Veränderungen zu erfassen und im Kontext der zivilisatorischen Transformationen zu positionieren.

Was der Band nicht wiedergeben kann, ist eine Performance, welche die Konferenzteilnehmerinnen und -teilnehmer in Ciążeń erleben durften und die auf besondere Weise die Interpretation von Kulturlandschaften ergänzt. Mit Hilfe audiovisueller Mittel und eigener Kommentare präsentierte Stefan Stroux seine multimediale Installation »Pamięć pracy/Droga przemysłowa 13« (Erinnerung an die Arbeit/Industrieweg 13), deren Uraufführung 2013 im Zinkwalzwerk der stillgelegten Hütte in Katowice-Szopienice/ Kattowitz-Schoppinitz stattgefunden hatte. Stroux' Intention war es, die Erinnerung der oberschlesischen Gesellschaft an ihre Industrieräume wiederzubeleben. Der Autor beschreibt seine Absichten so:

Das künstlerische Ziel des Projektes ist es, ausgewählte Positionen von Künstlern zu präsentieren, die eine wichtige Stimme in der Diskussion über die Verwandlung der Welt sind, bei der industrielle Revolution und Modernisierungsdynamik zentrale Kategorien moderner Industriegesellschaften bilden. Dank der Ausstellung an früheren Industriestätten, z. B. 2012 im Essener Zollverein oder 2013 im Zinkwalzwerk der stillgelegten Hütte Kattowitz-Schoppinitz, wollen wir die Erinnerung an solche »Tempel der Arbeit « wiederbeleben und den Künstlern ermöglichen, an der Diskussion über die Verwandlungen der einst durch physische Arbeit bestimmten Welt teilzunehmen. ${ }^{18}$

Die Initiatoren des Projekts sind Künstler aus Polen und Deutschland, die an Zygmunt Baumans Konzept der »flüchtigen Moderne« anschließen. Sie fragen nach der Rolle postindustrieller Räume in einer sich dynamisch verändernden Realität, in der die »Tempel der Arbeit« mit der industriell verwüsteten Naturlandschaft verschmelzen, um Konsumtempel zu werden. Bei der Metamorphose postindustrieller Räume als Erinnerungsorte sind weitere Fragen von Bedeutung: Wie kann in den örtlichen Gemeinschaften die Erinnerung an Industrieräume gepflegt bzw. wiederbelebt werden? Ist es möglich, Erinnerung in kreative Aktivitäten einfließen zu lassen, die in stillgelegten Bergwerken, Eisenhütten und Fabriken stattfinden, etwa in Gestalt von Kunst- und Fotoausstellungen, multimedialen Installationen und Performances, um im Nebeneffekt Impulse für Inter- und Transdisziplinarität zu geben?

18 Stefan Stroux, „Droga Przemysłowa 13. Pokaż mi swoje rany« [Industrieweg 13. Zeige mir deine Wunden], (Textabschnitt aus dem Ausstellungsflyer); vgl. auch »Pamięć pracy. Dramatyzowana instalacja o historii i współczesności pracy/Erinnerung an Arbeit. Dramatische Installation über Geschichte und Gegenwart von Arbeit", Idee und Komposition: Stefan Stroux, Katowice, 2013. 
Diese künstlerische Herausforderung wird in den Texten von Ewa Wojtoń, Alexander Tölle und Tadeusz Stryjakiewicz aufgenommen, die sich - im Sinne des spatial turns - kulturelle und soziale Einschreibungen und Deutungen von Räumen befassen. Ihre Fallstudien zu Sosnowitz im Dąbrowa-Revier, zu Elbląg/ Elbing und Głogów/Glogau als zwei Grenzpunkte in den polnischen West- und Nordgebieten sowie zum großpolnischen Konin nahe der Grenze zu Kongresspolen untersuchen stadt- und raumplanerische Konzepte sowie darauf bezogene kulturelle Überlieferungen. Ewa Wojtoń und Tadeusz Stryjakiewicz wenden zwei verschiedene methodische Ansätze, nämlich Kulturerbe als materialisierter Erinnerungsträger des Ortes bzw. path dependence nach Mahoney, auf zwei Rechtsakte an: auf das polnische Gesetz über den Schutz von Denkmälern und Denkmalpflege von 2003 sowie auf die Europäische Landschaftskonvention von 2006. Die Kulturlandschaft wird in der Konvention als Ergebnis eines sozial konstituierten, dynamischen Prozesses aufgefasst, was nach Stryjakiewicz eine gute Voraussetzung zur Integration historischer und geografischer Forschung bildet. Auch Dichtung und Erinnerungsliteratur gehören mit zu diesem Komplex; hier lohnt ein vergleichender Blick auf die unterschiedliche Verwendung von Erinnerungsliteratur bei Dolff-Bonekämper und Stryjakiewicz. Beim Gestaltwandel der materiellen Grundlagen von Landschaften legen beide Autoren den Schwerpunkt auf die Rolle des Menschen und seine nicht zuletzt durch Überlieferung und Tradition geprägten Bedürfnisse.

Alexander Tölle unternimmt einen Vergleich zweier städtischer Räume, in denen die im Zweiten Weltkrieg zerstörte Altbausubstanz nach dem von der Denkmalpflegerin Maria Lubocka-Hoffmann begründeten Konzept der retrowersja (Retroversion) wieder aufgebaut wurde. Dieses 1983 initiierte Programm verfolgt das Ziel, nicht lediglich die alten Stadtquartiere äußerlich wiederherzustellen, sondern auch zum »Geist« der Altbausubstanz zurückzukehren. Die Altstädte Elbings und Glogaus sind bei den Bewohnerinnen und Bewohnern akzeptiert; daher lassen sie sich auch als Ergebnis einer gelungenen lokalen Identitätsbildung verstehen. Tölle erkundet die bis heute andauernde Rekonstruktion der Altstädte in Elbing und Glogau unter dem Gesichtspunkt, welche Schlussfolgerungen die Architektur aus dem sozialen Wandel im Postsozialismus zu ziehen habe, und ordnet sie raumplanerischen Erfahrungen im europäischen Ausland zu. Er geht dabei zwei zentralen Fragen nach: Auf welche Konzeption einer postsozialistischen Stadtgesellschaft stützen sich die rekonstruierten Altstadträume? Und welche in der postsozialistischen Gesellschaft herrschende Vorstellung über Stadt kommt umgekehrt darin zum Ausdruck?

Die Untersuchungen von Markus Schwarzer sowie Antje Otto, Andrzej Ancygier und Karolina Jankowska, tangieren in unterschiedlicher Intensität den spatial turn, hier aus Perspektive des Sozialkonstruktivismus. Diese beiden Beiträge befassen sich mit aktuellen Herausforderungen des Wandels von ma- 
teriellen Grundlagen von Landschaft in Bezug auf gesellschaftliche Vorstellungen von Landschaft, so den Folgen des Braunkohletagebaus (Schwarzer) und der Windenergie in Polen und Deutschland (Otto/Ancygier/Jankowska).

Die komplementären Beiträge von Violetta Julkowska und Winfried Schenk ergeben in der Zusammenschau eine Einführung in die Didaktik der Kulturlandschaft. Schenk wirft einen weiten Blick auf das Kulturlandschaftskonzept in der Bildungsdiskussion. Er beschreibt, dass sich der essentialistische, auf Landschaftsschutz orientierte Ansatz in der gegenwärtigen deutschen Diskussion gegenüber dem konstruktivistischen oder diskursiv-reflexiven Ansatz durchgesetzt hat und zeichnet damit einen Weg der deutschen Geografie nach, der in den Geistes-, Kultur- und Sozialwissenschaften unter der Entwicklung des spatial turns gerahmt wird. Auf ersteren beziehen sich zahlreiche soziale Initiativen, die sich etwa für die Rettung historischer Baudenkmäler einsetzen. Beide Ansätze sind durch das geografische Konzept des Schutzes von Kulturlandschaften begründet, das auf die klassische Denkmalpflege zurückgeht, aber auch solche Landschaftselemente berücksichtigt, die an sich nicht denkmalwürdig, doch für die Landschaft konstitutiv sind. Die permanent erfolgende Aushandlung von Bedeutung und Stellenwert der Kulturlandschaften lässt einen befruchtenden zivilgesellschaftlichen Diskurs entstehen. Schulische und politische Bildung liefert wesentliche Voraussetzungen für den Schutz von Kulturlandschaften. Sie fördert das Bedürfnis nach Kontakt mit der Landschaft und regt eine Reflexion zum Umgang mit dieser an, was wiederum emotionale Bindung und größere Wertschätzung für landschaftliche Eigenarten erzeugt, gleichbedeutend mit einem bewussteren Umgang mit dem darin überlieferten kulturellen Erbe.

Der Beitrag von Violetta Julkowska stützt sich in erster Linie auf die polnische Geschichtsschreibung, ist aber dennoch nicht sehr weit von geografischen Konzepten entfernt. Der historische Ansatz ergänzt die geisteswissenschaftlichen und geografischen Methoden um einen konstitutiven Bestandteil, nämlich um den "historischen Menschen«, der durch den von ihm besetzten Raum in einer bestimmten historischen Zeit und den durch seine Aktivitäten geprägten Ort definiert ist. Der physische Raum ist das Resultat der Aktivitäten vieler Generationen, die der Historiker als eine Synthese von sich überlappenden kulturellen Schichten, also als Palimpsest, betrachtet. Die Anstrengungen, die Kulturlandschaft als Form des historischen und kulturellen Erbes zu schützen, sind Ausdruck des modernen Geschichtsbewusstseins. Die geschichtswissenschaftliche Erschließung eines konkreten Raums erfolgt aus einer anderen Perspektive als der geografischen, verfolgt aber ähnliche praktische Zwecke, zu denen die (Re-)Konstruktion und der Schutz von Kulturlandschaften gehören.

Die Beiträge von Bartosz Dziewanowski-Stefańczyk, Thomas Strobel, Péter Bagoly-Simó sowie Joanna und Florian Plit befassen sich mit Kulturlandschaften 
in polnischen und deutschen Schulbüchern und machen damit deutlich, welch erstaunlich geringe Bedeutung dem Thema in aktuellen Bildungsmedien zugemessen wird. So stellen Joanna und Florian Plit fest, dass der Begriff der Kulturlandschaft polnischen Abiturientinnen und Abiturienten nicht hinreichend vermittelt wird. Die jungen Leute assoziierten diesen, falls sie sich mit dem Begriff überhaupt beschäftigen, lediglich mit den von Menschen verursachten Umweltveränderungen, was auf die exklusive Durchsetzung des analytischen Ansatzes im Geografieunterricht zurückzuführen sei. Ähnlich kritisch urteilt Thomas Strobel über deutsche Geschichtsschulbücher. Übereinstimmend betonen alle Autoren das didaktisch positive, bislang allerdings wenig genutzte Potential, das eine stärkere Thematisierung von Kulturlandschaften mit sich bringe. Wie Strobel darlegt, verweisen aktuelle Schulbücher verstärkt auf den hohen Preis des technischen Fortschritts und die menschgemachten schädlichen Folgen für die Umwelt.

Joanna und Florian Plit setzen einige Hoffnung auf das neuerwachte Interesse für Regionalgeschichte. Zwar wurde in Polen im Jahr 2008 das interdisziplinär angelegte Unterrichtsfach »Regionalbildung: Kulturerbe in der Region« abgeschafft, aber das Interesse an Regionen sei nach wie vor groß. Als Wegweiser für regionalgeschichtliche Bildung entstanden seitdem zahlreiche Publikationen, die regionale oder lokale Besonderheiten von Kulturlandschaften thematisieren und als solche fließen sie nach wie vor in die Schulcurricula ein. Zwei weitere Beiträge zu deutsch-polnischen Grenzregionen eruieren gleichfalls das Potential von Kulturlandschaften für den Schulunterricht (Marcin Wiatr über Oberschlesien und Stephanie Zloch über Ermland-Masuren und Ostpreußen). Die Befassung mit Kulturlandschaften lässt sich - so die mit Blick auf die Vermittlung didaktischer Impulse zugeschnittenen Beiträge - als eine wertvolle geografiewie geschichtsdidaktische Ergänzung in und jenseits von Schulbüchern nutzen. Die Beschäftigung mit mehrfach codierten kulturellen und geschichtlichen Zuschreibungen von Landschaften, die in europäischen Grenzregionen in Erscheinung treten, könne überdies besonders viele didaktisch verwertbare Potenziale für die Erkundung und Umsetzung digitaler Unterrichtskonzepte freisetzen. Eigens die Auseinandersetzung mit dem Thema Landschaft im Bildungswesen verdeutlicht die Potenziale, der Befassung mit sozialen und kulturellen Konstruktions- und Konstitutionsprozessen von Räumen, wie sie der spatial turn umreißt.

Die Multidisziplinarität und begriffliche Polyphonie der unterschiedlichen Forschungsansätze, wie sie dieser Band deutlich macht, stellen keine Hindernisse für die Weiterentwicklung der Forschung dar, sondern schärfen das Bewusstsein für inspirierende Differenzen. Der normative Status der Europäischen Landschaftskonvention von 2006, die damals auch den Stand der interdisziplinären Forschung aufnahm, öffnete die Tür für neue Möglichkeiten einer um- 
fassenden zivilgesellschaftlichen Partizipation an der Gestaltung der Kulturlandschaft als mehrschichtiges Kulturerbe und ihrer stärkeren Implementierung in der Bildung. Wir sind zuversichtlich, dass dieser Band die Forschungsdebatte befruchten und zu weiteren spannenden Bildungsprojekten beitragen wird. Vor allem aber hoffen wir, dass mit diesem Band ein Wegweiser voller Anregungen vorliegt, der eine wichtige Scharnierleistung meistert - nämlich aufschlussreiche Narrationen zu konstruieren, die bei der Erkundung, Entdeckung und Entschlüsselung von Kulturlandschaften zu neuen, tieferen Sinnzusammenhängen verhelfen.

\section{Literatur}

Aitken, Stuart C. und Gill Valentine (Hg.). Approaches to Human Geography. Philosophies, Theories, People and Practices, Los Angeles: SAGE Publications, 2015.

Bachmann-Medick, Doris. Cultural Turns. Neuorientierungen in den Kulturwissenschaften, Reinbek bei Hamburg: Rowohlt, 2014.

Bloch, Marc. Pochwała historii czyli o zawodzie historyka [Lob der Geschichte oder über den Beruf des Historikers], Warschau: Antyk Marek Derewiecki, 2009.

Braudel, Fernand. La Méditerranée et le monde méditerranéen à l'époque de Philippe II: Les événements, la politique et les hommes, Band 1, Paris: Armand Colin, 1976.

Cosgrove, Denis E. Social Formation and Symbolic Landscape, London/Sydney: Croom Helm Ltd., 1984.

Cosgrove, Denis E. und Stephen Daniels (Hg.). The iconography of landscape. Essays on the symbolic representation, design and use of past environments, Cambridge: Cambridge University Press, 1988.

Duncan, James. »Landscape geography, 1993-94«, in: Progress in Human Geography 19, 3, (1995), 414-422.

Duncan, James und Nancy Duncan. "(Re)reading the landscape«, in: Environment and Planning D: Society and Space 6, 2 (1988), 117-126.

Egner, Heike. Gesellschaft, Mensch, Umwelt - beobachtet. Ein Beitrag zur Theorie der Geographie, Stuttgart: Franz Steiner Verlag, 2008.

Frydryczak, Beata. "Krajobraz« [Landschaft], in: Modi Memorandi. Leksykon kultury pamięci [Lexikon der Erinnerungskultur], Magdalena Sariusz-Wolska und Robert Traba (Hg.), Warschau: Wydanwnictwo Naukowe Scholar, 2014, 195.

Hard, Gerhard. »Der Spatial Turn, von der Geographie her beobachtet«, in: Spatial Turn: Das Raumparadigma in den Kultur-und Sozialwissenschaften, Jörg Döring und Tristan Thielmann (Hg.), Bielefeld: transcript, 2008, 263-316.

Ders. Landschaft und Raum. Aufsätze zur Theorie der Geographie, Osnabrück: Rasch Druckerei und Verlag, 2002.

Harvey, David. "Between Space and Time: Reflections on the Geographical imagination", in: Annals of the Association of American Geographers 80, 3 (1990), 418-434.

Hoskins, William George. The Making of the English Landscape, London: Hodder and Stoughton, 2005 [Erstdruck 1955]. 
Krawiec, Adam. "'Zwrot przestrzenny^ w mediewistyce« [Der spatial turn in der Mediävistik], in: Vademecum historyka mediewisty [Vademecum des Mediävisten], Jarosław Nikodem und Dariusz Andrzej Sikorski (Hg.), Warschau: Wydawnictwo Naukowe PWN, 2012, 536-540.

Kühne, Olaf. Landscape Theories, Wiesbaden: Springer VS, 2019.

Massey, Doreen. «Raum, Ort und Geschlecht. Feministische Kritik geographischer Konzepte«, in: Ortssuche. Zur Geographie der Geschlechterdifferenz, Elisabeth Bühler u. a. (Hg.), Zürich: Efef Verlag, 1993, 109-122.

Potthoff, Kerstin. »The use of >cultural landscape in 19th century German geographical literature «, in: Norsk Geografisk Tidsskrift - Norwegian Journal of Geography 67, 1 (2013), 49-54.

Rybicka, Elżbieta. Geopoetyka. Przestrzeń i miejsce we współczesnych teoriach i praktykach literackich [Geopoetik. Raum und Ort in zeitgenössischen literarischen Theorien und Praktiken], Kraków: Universitas, 2015.

Sauer, Carl Ortwin. The Morphology of Landscape, Berkeley: University of California Press, 1925.

Schlögel, Karl. Im Raume lesen wir die Zeit. Über Zivilisationsgeschichte und Geopolitik, München u. a.: Carl Hanser Verlag, 2003.

Soja, Edward W. Postmodern Geographies: The Reassertion of Space in Critical Social Theory, London/New York: Verso, 1989.

Stroux, Stefan. »Droga Przemysłowa 13. Pokaż mi swoje rany« [Industrieweg 13. Zeige mir deine Wunden], Ausstellungsflyer, Katowice, 2013.

Vidal de La Blache, Paul. Principes de géographie humaine. Publiés d'après les manuscrits de l'auteur, Paris: A. Colin, 1921. 


\section{Theorien und Methoden}


Open-Access-Publikation im Sinne der CC-Lizenz BY 4.0

(c) 2020, Vandenhoeck \& Ruprecht GmbH \& Co. KG, Göttingen ISBN Print: 9783847107507 - ISBN E-Lib: 9783737007504 


\section{Raum, Landschaft und Kulturlandschaft - Annäherungen an komplexe Begriffe}

\section{Einführung}

Der Mensch agiert in einem Kontinuum aus Raum und Zeit. Befasst sich die Geschichtswissenschaft insbesondere mit der zeitlichen Komponente des Kontinuums, ist die räumliche primär Gegenstand der Geografie - wobei die jeweils andere Komponente stets von Bedeutung bleibt. Der vorliegende Beitrag befasst sich primär mit Räumen und zwar aus der Perspektive der Geografie und teilweise auch der Raumsoziologie. Neben Räumen werden im vorliegenden Beitrag auch der Spezialfall von Raum, die »Landschaft«, und der Spezialfall von »Landschaft», die »Kulturlandschaft«, behandelt. Dabei geht es darum, den aktuellen Stand der Diskussion um diese schillernden Begriffe aufzuzeigen. Der vorliegende Beitrag weist dabei eine sozialkonstruktivistische Grundhaltung auf. Das bedeutet, dass insbesondere die Frage behandelt wird, wie Räume, Landschaften und Kulturlandschafen gesellschaftlich - und damit auch wissenschaftlich - konstruiert und kommuniziert werden. Dazu werden zunächst aktuelle Raumbegriffe in Geografie und Raumsoziologie dargestellt. Im Anschluss daran wird der Fokus auf den Begriff der Landschaft gelegt. Dabei wird zunächst ein Abriss der Geschichte des deutschsprachigen Landschaftsbegriffs gegeben, wobei auch die Differenzierung des Begriffsinhaltes von Experten und Nicht-Experten thematisiert wird. Im Anschluss daran wird die Differenziertheit der wissenschaftstheoretischen und paradigmatischen Deutungen von Landschaft bei Experten behandelt. Es folgen eine Diskussion des Begriffs der Kulturlandschaft sowie Überlegungen, wie räumliche Hybridisierungen in der Landschaftsforschung repräsentiert werden können. Abschließend werden kulturelle Spezifika räumlicher Deutungen im landschaftlichen Kontext betrachtet. 


\section{Zu Raumbegriffen in Geografie und Raumsoziologie}

Dem Wort und dem Begriff »Raum« kommt in der Geografie eine - wenn nicht sogar die - zentrale Bedeutung der Selbstdefinition der Wissenschaftsdisziplin zu. ${ }^{1}$ Die Diskussion in der Geografie, aber auch der Raumsoziologie, um Raumbegriffe hat mittlerweile eine schwer überschaubare Vielzahl an Raumverständnissen hervorgebracht. Kürzlich hat Helmut Köck für die Geografie 21 unterschiedliche Raumbegriffe ausmachen können, die er mit der ironischen Frage kommentiert: ")Jedem seinen Raum?^ Ist das der gemeinsame und doch verwirrende Nenner? «. Im Folgenden sollen jedoch »lediglich» acht Landschaftsverständnisse vorgestellt werden, wobei es sich um solche Verständnisse handelt, die einerseits mehrere differenziertere Konzepte synthetisieren, die andererseits aber auch für die spätere Untersuchung der Landschaftsbegriffe im deutschen Sprachraum und ausgewählten nicht-deutschen Sprachräumen aufgegriffen werden können.

(1) Anthropozentrische traditionell-gesellschaftlichen Raumvorstellungen entspringen lebensweltlichem Raumerleben, in dem Raum in nur begrenztem Maße eine intersubjektive Eindeutigkeit beigemessen wird. Deutlich wird der lebensweltlich-anthropozentrische Bezug in vormodernen Maßeinheiten wie Fuß, Elle, Morgen und Tagwerk. Auch die etymologische Herkunft des Wortes "Raum», im Sinne von Lichtung, die zwecks Urbarmachung in die Wildnis geschlagen wird, verweist auf den lebensweltlichen Kontext des Menschen. ${ }^{3}$

(2) Der Behälter- bzw. Containerraum stellt demgegenüber eine Abstraktionsleistung dar. Hier wird Raum als physikalische - vom Menschen unabhängige - dreidimensionale euklidische, eindeutig vermessbare Größe gefasst. Raum ist gemäß dieser Vorstellung »eine Art Behältnis, in das man etwas hinein tun kann und [das] mit Objekten ausgestattet (möbliert) ist «. ${ }^{4}$ Zwar geht dieses Raumkonzept in seinen Grundzügen auf die griechische Antike zurück, erhielt jedoch zwischen dem 13. und dem 17. Jahrhundert seine verbindliche Ausprägung und lässt sich als eine Vereinfachung des Newtonschen Raumverständnisses verstehen (der den absoluten Raum als einen unendlichen Raum und nicht als geschlossenen Behälter konzipiert hatte).

1 Vgl. auch Helmut Köck, »Raumkonzepte in der Geographie - methodologisch analysiert«, in: Geographie und Schule 36, 209 (2014), 3-14.

2 Ebd., 13.

3 Z. B. Otto Friedrich Bollnow, Mensch und Raum, Stuttgart: Kohlhammer, 1963; Dieter Läpple, »Gesellschaftszentriertes Raumkonzept«, in: Martin Wentz (Hg.), Stadt-Räume, Frankfurt am Main, New York: Suhrkamp, 1991, 35-46.

4 Heike Egner, Theoretische Geographie, Darmstadt: Wissenschaftliche Buchgesellschaft, 2010, 98. Auch Gerhard Hard, »Zu den Landschaftsbegriffen der Geographie«, in: Alfred Hartlieb von Wallthor (Hg.), "Landschaft « als interdisziplinäres Forschungsproblem, Münster: Aschendorff, 1977, 13-24. 
(3) Das Konzept des relationalen Ordnungsraums betrachtet das Verhältnis von Raum und Dingen in umgekehrter Weise: Raum wird nicht mit Dingen gefüllt, durch die Existenz von zueinander angeordneten Dingen entsteht Raum, d.h. »[o]hne Dinge gibt es keinen Raum «. ${ }^{5}$

(4) Im Konzept des Raum-Zeit-Kontinuums werden Raum und Zeit zu immanenten Kategorien: »Jede Veränderung im >Raum` ist eine Veränderung der `Zeit`, jede Veränderung in der `Zeit` ist eine Veränderung im `Raum «". ${ }^{6}$

(5) Bei dem Konzept des Raumes als logische Struktur bzw. Ordnungsstruktur wird Raum nicht als etwas per se Existentes konzipiert, sondern er steht für »immaterielle Relationen, etwas Gedachtes«. ${ }^{7}$ Wie bei Gradnetzen, topografischen und thematischen Karten bezeichnet Raum »damit einen Akt des Ordnens ${ }^{8}{ }^{8}$

(6) Das Verständnis von Raum als Medium der Kommunikation schließt an die Systemtheorie von Niklas Luhmann an. ${ }^{9}$ Dabei wird Raum »zunächst als Medium der Wahrnehmung, sowie zunehmend als Medium der Kommunikation verstanden ${ }^{10}{ }^{10}$ Raum entsteht dabei durch Kommunikation. Wird Raum nicht kommunikativ erzeugt bzw. aktualisiert, ist er gesellschaftlich nicht vorhanden.

(7) Im Konzept des Erlebnis- bzw. Handlungsraum lassen sich Räume als durch kollektives Handeln verräumlichte soziale Strukturen fassen. ${ }^{11}$ Dabei entsteht zwischen der physischen und der sozialen Welt ein rekursives Verhältnis: Einerseits beziehen die handelnden Subjekte in ihrem alltagsweltlichem Handeln die Welt auf sich, andererseits gestalten sie die externe Welt. ${ }^{12}$

(8) Das Raumkonzept des französischen Soziologen Pierre Bourdieu (1991) bezieht drei Raumvorstellungen aufeinander: ${ }^{13}$ (a) Der soziale Raum ist eine Metapher für Gesellschaft, er bezeichnet die relationale Anordnung von Posi-

5 Peter Weichhart, Entwicklungslinien der Sozialgeographie. Von Hans Bobek bis Benno Werlen, Stuttgart: Steiner, 2008, 79.

6 Norbert Elias, Über die Zeit. Arbeiten zur Wissenssoziologie II, Frankfurt am Main: Suhrkamp, 1994 [Erstdruck 1984], 75.

7 Egner, Theoretische Geographie, 98.

8 Ebd.

9 Siehe Helmut Klüter, Raum als Element sozialer Kommunikation, Gießen: Selbstverlag des Geographischen Instituts der Justus-Liebig-Universität Gießen, 1986.

10 Egner, Theoretische Geographie, 99.

11 Anssi Paasi, „Finnish Landscape as Social Practice. Mapping Identity and Scale«, in: Michael Jones (Hg.), Nordic Landscapes. Region and Belonging on the Northern Edge of Europe, Minneapolis/London: University of Minnesota Press, 2008, 511-539.

12 Benno Werlen, Sozialgeographie alltäglicher Regionalisierungen. Band 1: Zur Ontologie von Gesellschaft und Raum, Stuttgart: Steiner, 1995 und Ders., Sozialgeographie alltäglicher Regionalisierungen. Band 2: Globalisierung, Region und Regionalisierung, Stuttgart: Steiner, 1997.

13 Pierre Bourdieu, »Physischer, sozialer und angeeigneter physischer Raum«, in: Martin Wentz (Hg.), Stadt-Räume. Die Zukunft des Städtischen, Frankfurt am Main: Campus-Verlag, 1991, 25-34. 
tionen bestimmter Formen von Macht (oder Kapital) in der Gesellschaft. ${ }^{14}$ (b) Der physische Raum lässt sich als Ergebnis eines willentlichen von dem Bewohnt-Sein und der Aneignung des Menschen befreiten Raumes verstehen. ${ }^{15}$ Er liefert die physische Grundlage für die Aneignungs- und Umgestaltungsprozesse des Menschen. (c) Im angeeigneten physischen Raum werden selektiv Relationen des sozialen Raumes in den physischen Raum eingeschrieben:

Der auf physischer Ebene realisierte (oder objektivierte) soziale Raum manifestiert sich als im physischen Raum erfolgte Verteilung unterschiedlicher Arten gleichermaßen von Gütern und Dienstleistungen wie physisch lokalisierter individueller Akteure und Gruppen (im Sinne von an einen ständigen Ort gebundenen Körpern beziehungsweise Körperschaften) mit jeweils unterschiedlichen Chancen der Aneignung dieser Güter und Dienstleistungen wie physisch lokalisierter individueller Akteure und Gruppen. ${ }^{16}$

\section{Genese und Ausprägungen gegenwärtiger Landschaftsbegriffe im deutschen Sprachraum}

Im deutschen Sprachraum hat der Begriff "Landschaft» in seiner Geschichte einen großen semantischen Hof $^{17}$ aus $»$ Assoziationen, Emotionen, Evokationen ${ }^{18}$ gebildet. Die Bezeichnung der Landschaft entstand im frühen Mittelalter (siehe Abb. 1) als eine Zusammenschau von sozialen Normen und Gebräuchen, wobei dieses Verständnis aber mit der Entwicklung alternativer Inhalte an Bedeutung verlor. Im hohen Mittelalter wurde mit dem Wort »Landschaft« eine politische regionale Einheit gefasst. Diese Bedeutung persistiert durchaus bis heute (wie bei der Bezeichnung des Schweizer Kantons »Basel Landschaft «). ${ }^{19}$ Im späten Mittelalter wurde unter Landschaft eine räumliche Zusammenschau von Objekten jenseits der Wildnis als »Landschaft« verstanden. Eine religiöse Konnotation erhielt das Wort "Landschaft" in der Malerei des Mittelalters in Form der Allegorie für das Paradies mit seinen typischen gartenassoziierten Repräsentanten. Einen wirkmächtigen Bedeutungswandel erfuhr der Begriff in der

14 Pierre Bourdieu und Loic Wacquant, „Die Ziele der reflexiven Soziologie. Chicago-Seminar 1987 «, in: Dies. (Hg.), Reflexive Anthropologie, Frankfurt am Main: Suhrkamp, 1996, 95-249.

15 Martina Löw, Raumsoziologie, Frankfurt am Main: Suhrkamp, 2001.

16 Bourdieu, »Physischer, sozialer und angeeigneter physischer Raum«, 29.

17 Gerhard Hard, „Das Wort Landschaft und sein semantischer Hof. Zur Methode und Ergebnis eines linguistischen Tests«, in: Wirkendes Wort 19 (1969), 3-14, 10.

18 Gerhard Hard, "Zu Begriff und Geschichte von >Natur` und >Landschaft` in der Geographie des 19. und 20. Jahrhunderts«, in: ders. (Hg.), Landschaft und Raum. Aufsätze zur Theorie der Geographie, Osnabrück: Rasch, 2002 [Erstdruck 1983], 171-210, 178.

19 Gunter Müller, "Zur Geschichte des Wortes Landschaft«, in: Alfred Hartlieb von Wallthor (Hg.), "Landschaft " als interdisziplinäres Forschungsproblem, Münster: Aschendorff, 1977, 3-13 und Gerhard Hard, »Zu den Landschaftsbegriffen der Geographie«, 13-24. 
Renaissance: Einerseits wurde »Landschaft « - in Rückgriff auf die griechische Antike - als erweiterter locus amoenus verstanden ${ }^{20}$, eine Vorstellung, die bis heute landschaftliche Sollvorstellungen mitbestimmt, andererseits wurde auch die Landschaftsmalerei entwickelt. Diese bedeutete zum einen die Formierung eines ästhetischen Blickwinkels auf das Thema Landschaft, ${ }^{21}$ zum anderen wurde der deutschsprachige semantische Hof um eine gesamteuropäische Komponente erweitert, denn Landschaft als gemaltes Bild zu begreifen, hatte in den Niederlanden, aber auch England, Frankreich und anderen Teilen Europas eine konstitutive Bedeutung für das Verständnis von Landschaft erhalten. ${ }^{22}$ Die Landschaftsmalerei trug zur Erzeugung sozialer Sehkonventionen bei. ${ }^{23}$ Diese wiederum bildeten die Basis der Gestaltung und Anordnung physischer Objekte in Form des englischen in Abgrenzung zum französischen Garten. ${ }^{24}$

In der Romantik erfuhr »Landschaft« eine ethische Aufladung im Kontext der Ablehnung von Aufklärung, Industrialisierung und gesellschaftlicher Modernisierung. Dabei waren es insbesondere gebildete Städter, die - angeregt durch die Landschaftsmalerei - in physischen Räumen Landschaften schauten. Schließlich waren Städter der Anforderung enthoben, täglich den Elementen zu trotzen, wodurch sie sich in die Lage versetzt sahen, "die Realität mit den Augen des Malers und so auch die Natur mit den Augen des Landschaftsmalers zu sehen; unter dem Einfluss solcher Sehgewohnheiten wurde in der [...] >gehobenen Sprache $[. .$.$] die Bezeichnung >Landschaftı auch auf die Realität, den$ >malerischen Naturausschnitt` übertragen «. ${ }^{25}$ Insbesondere ländliche Landschaft wurde so zum Symbol von Gemeinschaftlichkeit und des Einklanges von Kultur und Natur, Landschaft wurde (und wird) so als ein physisches Substrat für

20 Julius Böheim, Das Landschaftsgefühl des ausgehenden Mittelalters, Dissertation, Universität Leipzig, 1930 und Nils Büttner, Geschichte der Landschaftsmalerei, München: Hirmer, 2006.

21 Unter vielen Martin Warnke, Politische Landschaft. Zur Kunstgeschichte der Natur, München, Wien: Hanser, 1992 und Heinrich Spanier, »Mensch und Natur - Reflexionen über unseren Platz in der Natur", in: Karl-Heinz Erdmann (Hg.), Naturschutz im Kontext einer nachhaltigen Entwicklung. Ansätze, Konzepte, Strategien, Bonn-Bad Godesberg: Bundesamt für Naturschutz, 2008, 269-292.

22 Dóra Drexler, Landschaft und Landschaftswahrnehmung: Untersuchung des kulturhistorischen Bedeutungswandels von Landschaft anhand eines Vergleichs von England, Frankreich, Deutschland und Ungarn, Saarbrücken: Südwestdeutscher Verlag für Hochschulschriften, 2010.

23 Herbert Lehmann, Formen landschaftlicher Raumerfahrung im Spiegel der bildenden Kunst, Erlangen: Palm und Enke, 1968.

24 Douglas Davies, »The Evocative Symbolism of Trees«, in: Dennis Cosgrove (Hg.), The Iconography of Landscape. Essays on the Symbolic Representation, Design and Use of Environments, Cambridge u. a.: Cambridge University Press, 1988, 32-42.

25 Hard, »Zu den Landschaftsbegriffen der Geographie«, 14. 


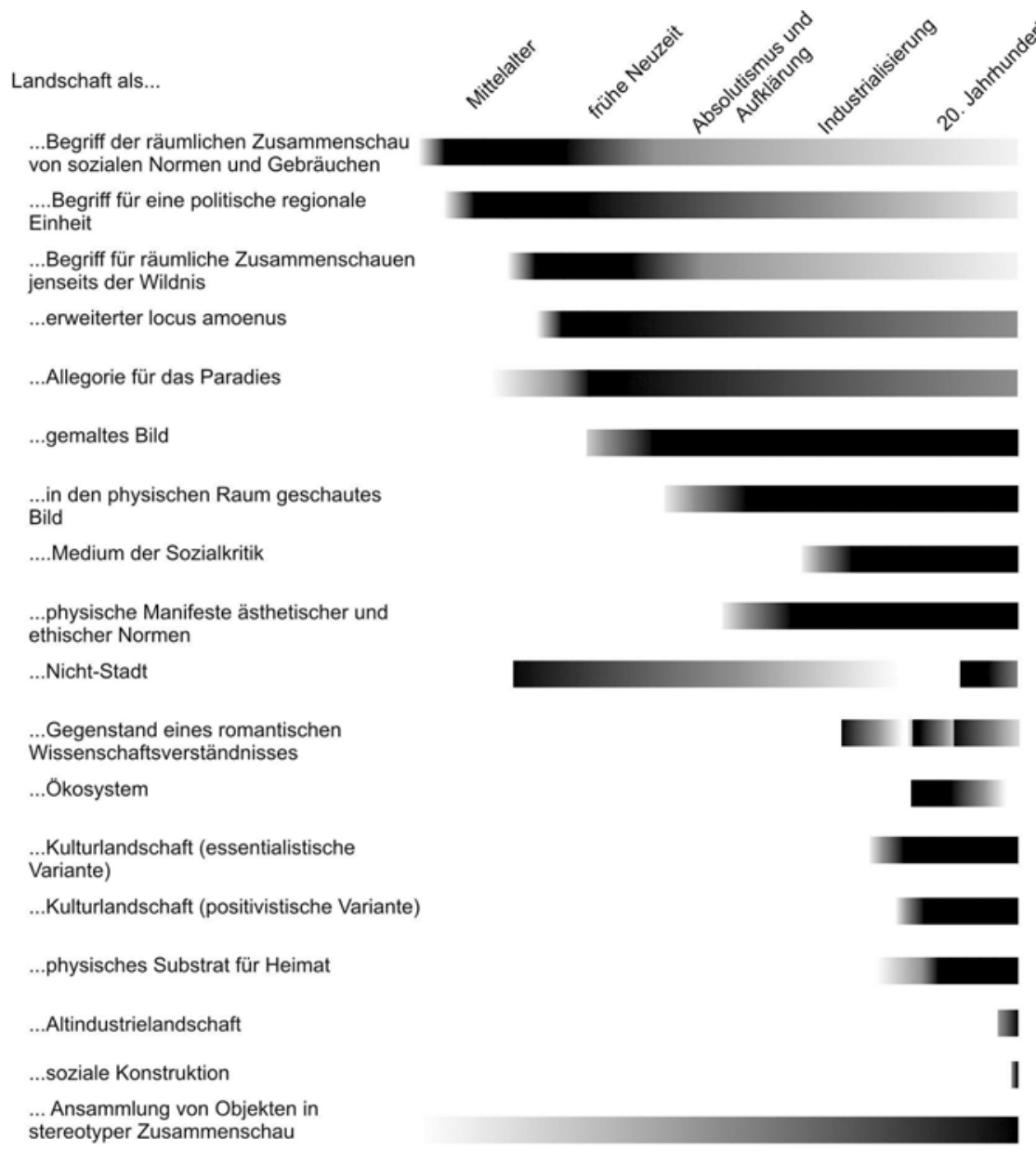

Abb. 1: Die Entwicklung des semantischen Hofes von Landschaft in zeitlicher Abfolge. Die Intensität der Graufärbung symbolisiert die Intensität der jeweiligen Ausprägung (aus: Kühne 2013).

die »heile Welt« der Heimat erlebt. ${ }^{26}$ In der so formulierten essentialistischen Variante von "Kulturlandschaft« wird dieser ein eigenes Wesen zugeschrieben, das durch Industrialisierung, Verstädterung und Modernisierung bedroht wird. Alternativ zu der essentialistischen Deutung von Kulturlandschaft entstand - in der Denktradition der Aufklärung - eine positivistische Deutung, in der Kul-

26 Stefan Körner, »Die neue Debatte über Kulturlandschaft in Naturschutz und Stadtplanung«, 2006, www.bfn.de/fileadmin/MDB/documents/service/perspektivekultur_koerner.pdf, zuletzt geprüft am 03. April 2019. 
turlandschaft als von Einzelphänomenen abstrahierbares und empirisch fassbares Mehrebenengefüge begriffen wird. Positivistische Vorstellungen von Landschaft wurden wiederum zum ökosystemischen Verständnis fortentwickelt. ${ }^{27}$ Ende des 20. Jahrhunderts wurde der semantische Hof von Landschaft um zwei weitere Dimensionen erweitert: Erstens entstand im Kontext der Deindustrialisierung das Konzept der Altindustrielandschaft, in dem die physischen Repräsentanten der Industriegesellschaft - im Zuge postmoderner Wertschätzung des Historischen - eine positive symbolische Konnotation von Strukturiertheit und Sicherheit der Industriegesellschaft erhielten. ${ }^{28}$ Zweitens knüpft die deutschsprachige Landschaftsforschung stärker an konstruktivistische Denktraditionen an, womit sie eine höhere Anschlussfähigkeit einerseits gegenüber der internationalen Diskussion, ${ }^{29}$ andererseits an die aktuelle (zumeist konstruktivistisch ausgerichtete) kulturgeografische Forschung erhält. ${ }^{30}$

Gesellschaftliche Landschaftsdeutungen eignet sich der Einzelne im Prozess der Sozialisation an. In diesem Prozess entstehen die »heimatliche Normallandschaft " und die "stereotype Landschaft «. ${ }^{31}$ Die heimatliche Normallandschaft wird durch die Konfrontation mit physischen Objekten im Wohnumfeld des Heranwachsenden unter Vermittlung von Eltern, anderen Familienangehörigen und Freunden der Familie unter Aushandlung in der Gleichaltrigengruppe gebildet. Die stereotype Landschaft entsteht hingegen durch Vermittlung stark idealisierter Vorstellungen von Landschaften insbesondere in Schulbüchern, Bilderbüchern, Bildbänden, Prospekten, Spielfilmen, Fernsehdokumentationen u. a. Damit werden insbesondere stereotype und normative Vorstellungen davon erzeugt, wie eine »schöne« bzw. natürliche (denn präferiert werden Elemente, denen das Attribut »natürlich« zugeschrieben werden kann) Landschaft zu er-

27 Stefan Körner, »Landschaft und Raum im Heimat- und Naturschutz«, in: Michael Weingarten (Hg.), Strukturierung von Raum und Landschaft. Konzepte in Ökologie und der Theorie gesellschaftlicher Naturverhältnisse, Münster: Westfälisches Dampfboot, 2005, 107117.

28 Vlg. hierzu Zygmunt Bauman, Flüchtige Zeiten. Leben in der Ungewissheit, Hamburg: Hamburger Edition, 2008.

29 Z.B. in der Tradition von Denis E. Cosgrove, Social Formation and Symbolic Landscape, London u. a.: Croom Helm, 1984 und ders., The Palladian Landscape: Geographical Change and Its Representation in Sixteenth-Century Italy, Leicester: Leicester University Press, 1993.

$30 \mathrm{Vgl}$. Marc Antrop, »Interacting cultural, psychological and geographical factors of landscape preference«, in: Diedrich Bruns, Olaf Kühne, Antje Schönwald und Simone Theile (Hg.), Landscape Culture - culturing landscapes, Wiesbaden: Springer, 2015, 53-68, und Olaf Kühne, »Weltanschauungen in regionalentwickelndem Handeln - die Beispiele liberaler und konservativer Ideensysteme«, in: Olaf Kühne und Florian Weber (Hg.), Bausteine der Regionalentwicklung, Wiesbaden: VS, 2015.

31 Olaf Kühne, Distinktion - Macht - Landschaft. Zur sozialen Definition von Landschaft, Wiesbaden: VS, 2008; ders., Landschaftstheorie und Landschaftspraxis. Eine Einführung aus sozialkonstruktivistischer Perspektive, Wiesbaden: VS, 2013. 
scheinen habe. Eine solche normative ästhetische Deutung ist nicht Teil der heimatlichen Normallandschaft: Heimatliche Normallandschaft muss vertraut, nicht stereotyp schön oder im Sinne der Eignung für präferierte Freizeitaktivitäten funktional sein. Dem Deutungsmuster der heimatlichen Normallandschaft liegt allerdings auch ein normativer Anspruch zugrunde: jener der Stabilität. Veränderungen der physischen Grundlagen von Landschaft wird in diesem Deutungsmodus zunächst kritisch gegenübergestanden. Unter dem Deutungsmodus der stereotypen Landschaft werden diese Veränderungen dann befürwortet, wenn sie der Vorstellung stereotyp "schöner« Landschaft entsprechen, andernfalls werden sie abgelehnt. ${ }^{32}$

Während die heimatliche Normallandschaft aufgrund der starken individuellen Prägung hinsichtlich ihrer Komponenten verallgemeinernd fassbar ist (für den Einen sind Almen, für die Andere der Geruch verbrannter Braunkohle Elemente heimatlicher Normallandschaft) und somit insbesondere mit den Methoden qualitativer Sozialforschung zugänglich werden, lassen sich die Elemente stereotyper Landschaft auch quantitativ annähernd erfassen (immer in dem Bewusstsein, dass diese Herangehensweise nicht eine "objektive gesellschaftliche Realität« darzustellen imstande ist, sondern ebenfalls eine Komponente der sozialen Konstruktion von Welt liefert). Da das Internet heute die Funktion eines zentralen Expertisemediums einnimmt, ${ }^{33}$ erscheint die Untersuchung von Internetinhalten für das Verständnis sozialer Zusammenhänge von zunehmender Bedeutung. Bei der Nutzung der Bildersuche der Internet-Suchmaschine google zum Stichwort "Landschaft» lassen sich entsprechend wesentliche Komponenten stereotyper Landschaft ermitteln. Gemäß der Untersuchung der 120 ersten Treffer bei google auf das Stichwort "Landschaft " präsentierten Bilder, werden insbesondere Landflächen und Himmel gezeigt. Diese Kombination lässt sich somit als eine Art "Mindestausstattung" von Landschaft verstehen. Am dritthäufigsten finden sich Wolken in den vorgeschlagenen Bildern. Häufig kommen auch Wiesen/Weiden (interessanterweise nicht das intensiver genutzte Offenlandpendant, die Äcker) vor, aber auch einzelne Bäume und Sträucher, Hügel und Wald. Deutlich weniger häufig dargestellt sind stehende bzw. fließende Gewässer.

Werden die bisher dargestellten Ergebnisse der Landschaftsforschung einer abstrahierten Synthese unterzogen, lassen sich die gesellschaftlichen Deutungen von Landschaft in vier Dimensionen gliedern: die kognitive (Wissen über das, was Landschaft genannt wird, z.B. in der Landeskunde), funktionale (z.B. in Bezug auf die Freizeit- oder landwirtschaftliche Nutzung), ästhetische (insbe-

32 Siehe weiteres bei Kühne, Landschaftstheorie und Landschaftspraxis.

33 Vgl. Stefan Münker, Emergenz digitaler Öffentlichkeiten. Die Sozialen Medien im Web 2.0, Frankfurt am Main: Suhrkamp, 2009. 


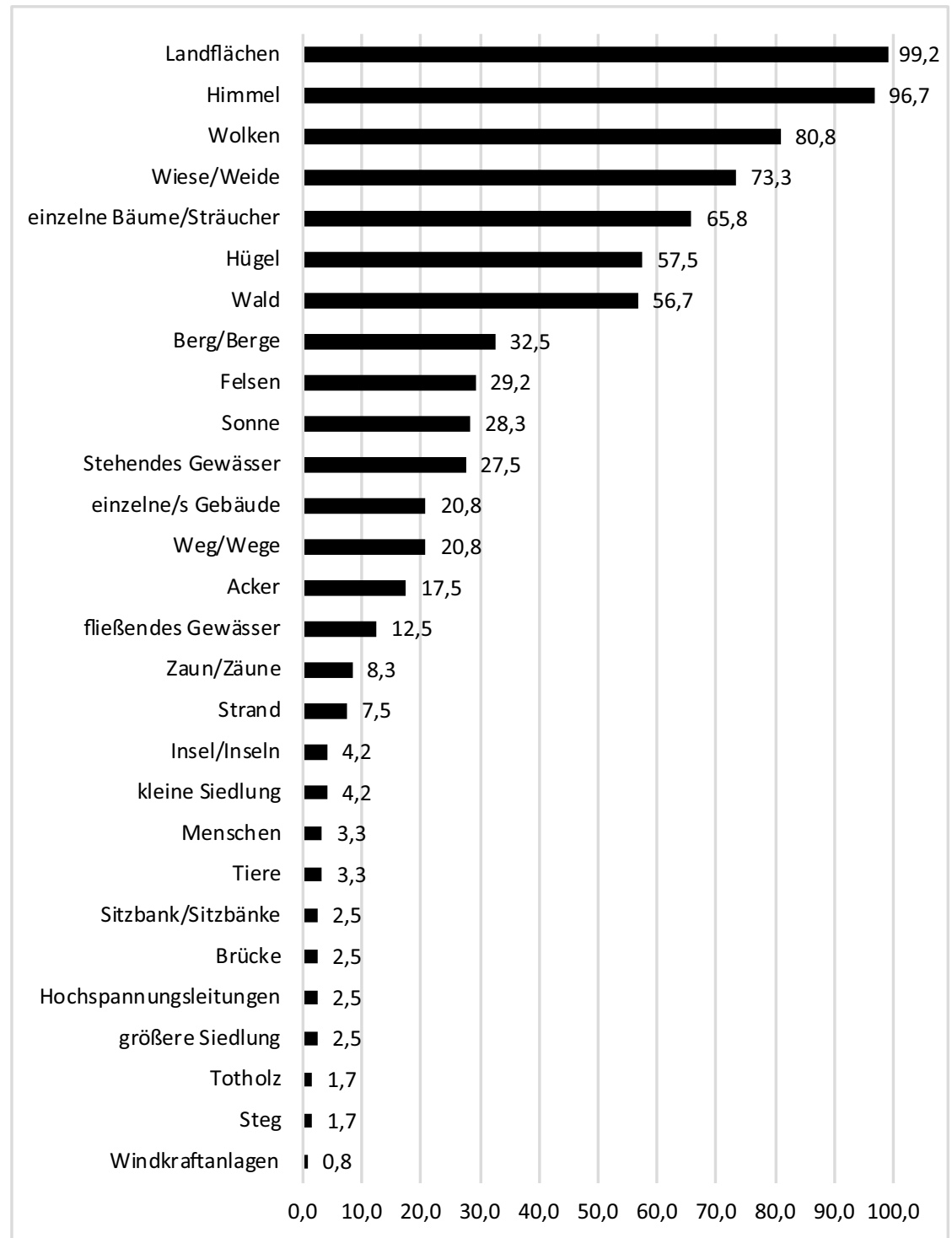

Abb. 2: In Internetbildern dargestellte landschaftliche Elemente; $n=120$, Tag des Zugriffs: 7. Juli 2014.

sondere stereotype Vorstellungen) und emotionale (insbesondere in Bezug auf Heimatgefühl) Dimension. Diese Dimensionen werden bei unterschiedlichen teilgesellschaftlichen Ansprüchen an Landschaft in unterschiedlicher Weise akzentuiert und kombiniert. Dominiert bei Alteingesessenen der emotional 
geprägte Zugang der »heimatlichen Normallandschaft«, z. T. in Verbindung mit dem funktionalen Interesse das, was Landschaft genannt wird, zu nutzen (als landwirtschaftliche Fläche, für die Brennholzgewinnung), finden sich bei Touristen eher ästhetische Ansprüche an Schönheit, Pittoreskheit und bestenfalls Erhabenheit von Landschaft (unter Ablehnung von Hässlichkeit), aber auch an Funktionalität (als Raum für Wanderungen, Skifahrten, Motorradtouren etc.). Personen mit einem expertenhaften Zugriff auf das, was Landschaft genannt wird, insbesondere also Personen mit landschaftsbezogenem Studium (wie Landschaftsarchitektur und -planung, Geografie, aber auch Forst- oder Agrarwissenschaften u. v. m.), deuten Landschaft eher kognitiv (indem Wissen erzeugt, gesammelt, geordnet und verbreitet wird) oder funktional (indem z. B. die »Leistungsfähigkeit der Landwirtschaft « gesteigert wird). ${ }^{34}$ Dieser expertenhafte Zugriff auf Landschaft soll im Folgenden einer genaueren Untersuchung unterzogen werden.

\section{Landschaftskonzepte von Expertinnen und Experten}

Wie in vorangegangenen Abschnitt angesprochen, unterscheiden sich die landschaftlichen Konstruktionen von Expertinnen und Experten deutlich von jenen, die sich nicht professionell mit Landschaft befassen - wobei infolge der Bildungsexpansion eine deutliche Differenzierung zwischen Laien- und Expertentum festzustellen ist. ${ }^{35}$ Zentral für die expertenhafte Definition von Landschaft ist dabei die Möglichkeit, die eigene Fachsprache als legitim gegenüber der Alltagssprache von Personen durchzusetzen, die sich nicht professionell mit Landschaft befassen: »Der Entwerfer erlangt definitorische Macht, wenn es ihm gelingt, die Sprache zu okkupieren. Diese schlägt in reale Macht über die Lebensverhältnisse um, wenn die Maßnahmen, die die Menschen ihres selbstbestimmten Alltags, Freiraums berauben, durchgesetzt werden. ${ }^{36}$ Die Definition von Landschaft im expertenhaften Diskurs erfolgt dabei nicht einheitlich, sondern fachspezifisch bzw. paradigmatisch differenziert sowie vor dem Hintergrund unterschiedlicher wissenschaftlicher Weltverständnisse. Hinsichtlich

34 Marcel Hunziker, „Die Bedeutungen der Landschaft für den Menschen: objektive Eigenschaft der Landschaft oder individuelle Wahrnehmung des Menschen?«, in: Forum für Wissen 21 (2010), 33-41; Olaf Kühne, Landschaft in der Postmoderne. Das Beispiel des Saarlandes, Wiesbaden: VS, 2006; ders., Distinktion - Macht - Landschaft. Zur sozialen Definition von Landschaft; Ders., Landschaftstheorie und Landschaftspraxis.

35 Don Mitchell, „Cultural Landscapes: Just Landscapes or Landscapes of Justice?«, in: Progress in Human Geography 27, 6 (2003), 787-796.

36 Frank Lorberg, Metaphern und Metamorphosen der Landschaft. Die Funktion von Leitbildern in der Landespflege, Dissertation, Universität Kassel, 2006, 101. 
dieser lassen sich gegenwärtig drei unterschiedliche Deutungen finden: essentialistische, positivistische und konstruktivistische. ${ }^{37}$ Essentialistische Ansätze gehen davon aus, Landschaft habe ein eigenes "Wesen", das sich in den sie bildenden Objekten ausdrücke und Ergebnis eines zumeist Jahrhunderte dauernden Prozesses der gegenseitigen lokalen bis regionalen Anpassung von Natur und Kultur sei; entsprechend werden Objekte, die auf nicht-lokale bzw. -regionale Prozesse verweisen (von Neophyten bis hin zu globalisierten Baustilen) abgelehnt. Gemäß positivistischer Auffassungen wird Landschaft als ein Gegenstand verstanden, der empirisch durch Messen, Wiegen und Zählen zumindest an die Objektivität angenähert analysierbar ist. Die konstruktivistische Position wurde bereits im Vorangegangenen beschrieben, hier wird Landschaft als ein soziales bzw. individuelles Konstrukt verstanden, das in physischen Räumen geschaut wird.

Diese wissenschaftlichen Weltverständnisse haben eine besondere Bedeutung bei der Bildung landschaftsbezogener Paradigmen, hier lassen sich nach Kühne $^{38}$ gegenwärtig vier Diskurse, verbunden mit spezifischen Eigenlogiken und landschaftsbezogenen Normvorstellungen, feststellen:

1. Das Paradigma der Erhaltung und Wiederherstellung der physischen Grundlagen von Landschaft ist mit dem Ziel verbunden, einen normativ definierten Idealzustand, nämlich den des klassischen Paradigmas der »historisch gewachsenen Kulturlandschaft « zu erhalten bzw. zumindest wiederherzustellen. Hinter dieser Norm finden sich zumeist essentialistische Vorstellungen von Landschaft und eine fortschrittskritische Weltsicht. Eine positivistische Variante dieses Paradigmas findet sich im Kontext des Artenschutzes, wenn für den Erhalt bestimmter Arten bestimmte Lebensraumtypen erhalten werden sollen. Dieses Paradigma wird (mit unterschiedlichen Schwerpunkten) insbesondere von Geografen, Naturschützern und Denkmalschützern, aber auch Stadt- und Raumplanern, vertreten.

2. Der Paradigma der sukzessionistischen Entwicklung ist normativ von einem passiven Verständnis der Strukturierung der physischen Grundlagen von Landschaft als Nebenfolge ökologischer bzw. gesellschaftlicher Entwicklungen geprägt. Wissenschaftstheoretisch liegt diesem Paradigma in der Regel ein positivistischer Ansatz zugrunde. Es wird zum einen von einem Teil von Naturschützern (mit der Konsequenz des Verzichts auf "Landschaftspflege«), zum anderen häufig von Ökonomen (insbesondere in Bezug auf die Anpassung von Landschaft an ökonomische Bedürfnisse) vertreten.

37 Ausführlich bei Kühne, Landschaftstheorie und Landschaftspraxis.

38 Kühne, Landschaft in der Postmoderne; ders., Distinktion - Macht - Landschaft. Zur sozialen Definition von Landschaft. Vgl. auch Michael Jones und Karoline Daugstad, »Usages of the scultural landscape concept in Norwegian and Nordic landscape administration ", in: Landscape Research 22, 3 (1997), 267-281. 
3. Das Paradigma der reflexiven Gestaltung der physischen Grundlagen von Landschaft wird durch die Auffassung geprägt, mit Hilfe gezielter gestalterischer Veränderungen der Elemente des physischen Raumes, alternative Bewertungen hinsichtlich der Konstruktion gesellschaftlicher Landschaft erzeugen bzw. verbreiten zu können. Dieses Paradigma basiert in der Regel auf konstruktivistischen Landschaftskonzepten. Dieses Paradigma wird zumeist von Künstlern, Landschaftsarchitekten und Architekten, bisweilen auch Stadt- und Raumplanern vertreten.

4. Das Paradigma der Umdeutung von gesellschaftlichen Landschaftsvorstellungen bezieht sich nicht auf die Veränderungen der physischen Grundlagen von Landschaft, sondern von gesellschaftlichen Wertungen von Landschaften. So sollen nicht die physischen Grundlagen an die Vorstellungen des "Schönen" oder »Typischen« angepasst werden, sondern es sollen die Vorstellungen dessen, was als "schön« bezeichnet wird, revidiert werden, indem z. B. altindustrielle Objekte nicht unter dem Deutungsmuster des "Schönen«, sondern des »Erhabenen « beurteilt werden, oder es wird dekonstruiert, ob das »Typische« denn wirklich eine normative Konnotation besitzen muss. Dieses Paradigma, das auf konstruktivistischen Ansätzen basiert, wird vornehmlich von Sozialwissenschaftlern, bisweilen auch von Planern und Landschaftsarchitekten vertreten.

\section{Von der Konstruktion der Dichotomie von Kultur- und Naturlandschaft zur hybriden Landschaft}

Ein Thema, das die Landschaftsforschung seit mehr als einem Jahrhundert immer wieder diskutiert, ist das der Kulturlandschaft und ihres Verhältnisses zu Natur bzw. Naturlandschaft. So sieht Hans Carol Kulturlandschaft als »im Gegensatz zur Naturlandschaft organisiert ${ }^{39}{ }^{39}$ und Josef Schmithüsen definiert in positivistischer Denktradition Kulturlandschaften als »historisch geprägte Gebilde, in denen die Lebensformen und Ideen früherer Gesellschaften auch in der Gegenwart noch in vielfältiger Weise wirkende Realität sind. ${ }^{40}$ In jüngerer Zeit rücken die Fragen zunehmend in das Zentrum des Interesses, ob (a) eine dichotome Trennung von Kultur- und Naturlandschaft überhaupt möglich ist, ob es (b) gegenwärtig überhaupt noch Naturlandschaften gibt und ob es (c) über-

39 Hans Carol, "Grundsätzliches zum Landschaftsbegriff», in: Karlheinz Paffen (Hg.), Das Wesen der Landschaft, Darmstadt: Wissenschaftliche Buchgesellschaft, 1973 [Erstdruck 1957], 142-155, 147.

40 Josef Schmithüsen, »Was ist eine Landschaft?», in: Paffen (Hg.), Das Wesen der Landschaft, 156-174. 
haupt sinnvoll ist, einen von dem allgemeinen Begriff der Landschaft geschiedenen Begriff der Kultur- (und eingeschränkt auch der Natur-) Landschaft zu fassen. Die letzte Frage beantwortet Wolfgang Haber damit, Landschaft sei - historisch bedingt - ein Ausdruck von Kultur und werde allein in kultureller Wahrnehmung ausgeprägt, ${ }^{41}$ eine Auffassung, die Heinrich Spanier pointiert: »Es gibt keinen Gegensatz zwischen Kulturlandschaft und Naturlandschaft. Es gibt nur Kulturlandschaft. $\aleph^{42}$, wodurch auch eine Antwort auf Frage (a) impliziert wird. Auch lassen sich gegenwärtige keine Teile der Erdoberfläche finden, die keine Beeinflussung durch den Menschen (z.B. durch die direkten oder indirekten Folgen der Emissionen von Treibhausgasen) erfuhren und erfahren. ${ }^{43}$ Auf ein weiteres Problem der geografischen (nicht nur landschaftsbezogenen) Forschung und Schulpraxis weist Georg Stöber bei der unterschiedlichen - zumeist nicht reflektierten - Verwendung des Kulturbegriffs hin: "Zum einen wird alles Menschliche darunter subsumiert, zum anderen ist es eine gesellschaftliche Institution neben verschiedenen weiteren. ${ }^{44}$ Andererseits werden aber auch Argumente für die Weiterverwendung des Begriffes der Kulturlandschaft bzw. von Kultur- und Naturlandschaft angeführt, wobei diese eher auf strategischer und idealtypisierender Ebene angesiedelt sind: So sieht Winfried Schenk in der Verwendung des Wortes »Kulturlandschaft« einen »strategischen Pleonasmus», "um die Raumwirksamkeit des Menschen in einer historischen Perspektive in den Mittelpunkt [des] Interesses zu markieren ${ }^{45}{ }^{45}$ Stefan Heiland plädiert für die weitere Verwendung der Termini von Naturlandschaft und Kulturlandschaft, da es in der Landschaftsforschung keineswegs ausschließlich darum gehe, aktuelle Zustände abzubilden, vielmehr sei es deren Aufgabe, "vergangene und zukünftige oder auch nur denk- oder wünschbare Zustände und Phänomene abzubilden (ansonsten gäbe es wohl kaum die Begriffe des Guten, der Wahrheit, der Freiheit, Gottes usw.) «. ${ }^{46}$

Die dichotome Betrachtungsweise von Kultur und Natur lässt sich als Teil des modernen Denkens in Dichotomien verstehen. So gelten neben Kultur und Natur

41 Wolfgang Haber, »Kulturlandschaft zwischen Bild und Wirklichkeit«, in: Karolina BeguschPfefferkorn (Hg.), Die Zukunft der Kulturlandschaft zwischen Verlust, Bewahrung und Gestaltung, Forschungs- und Sitzungsberichte der ARL, Band 215, Hannover: ARL, 2001, 6-29.

42 Heinrich Spanier, "Natur und Kultur«, in: ANL 25 (2001), 69-86, 81.

43 Kühne, Landschaftstheorie und Landschaftspraxis.

44 Georg Stöber, "Kulturraumkonzepte in Curricula, Schulbüchern und Unterricht«, in: Geographie und Schule 33, 199 (2011), 15-31, 17.

45 Winfried Schenk, Historische Geographie, Darmstadt: Wissenschaftliche Buchgesellschaft, $2011,14$.

46 Stefan Heiland, «Zwischen Wandel und Bewahrung, zwischen Sein und Sollen: Kulturlandschaft als Thema und Schutzgut in Naturschutz und Landschaftsplanung", in: Ulf Matthiesen (Hg.), Kulturlandschaften als Herausforderung für die Raumplanung. Verständnisse - Erfahrungen - Perspektiven, Hannover: ARL, 2006, 43-70, 49. 
auch Stadt und Land, Siedlung und Landschaft, aber auch das Gute und das Böse, Mann und Frau und vieles weiteres als dichotom getrennt. Gemäß postmodernen Auffassungen lösen sich diese Dichotomien in Hybride auf. Auch Landschaft lässt sich als Hybrid verstehen: Landschaft bezieht sich, erstens, sowohl auf gesellschaftliche wie physische Zusammenhänge; auf der Ebene der Objekte besteht sie, zweitens, aus Objekten, die stets natürlichen Ursprungs sind, aber in unterschiedlicher Weise anthropogen überformt sind; drittens fußt sie sowohl auf individueller als auch sozialer Konstruktion. Im Prozess der Postmodernisierung finden sich auch die modernen Gleichungen Stadt $=$ Kultur und Land $=$ Natur aufgelöst: So dringt Natur in Form von Ruderalvegetation entlang von Bahn- und Straßendämmen in die Stadt ein, Pflanzen aus Stadtgärten wildern aus, Wildtiere (wie z. B. Wildschweine in Mitteleuropa oder Kojoten in Südkalifornien) passen sich städtischen Lebensbedingungen an, während die Nachkommen von ehemaligen Haustieren städtische und außerstädtische Natur bevölkern (Spirn 1988, Jorgensen/Tylecote 2007, Kühne 2012). ${ }^{47}$ Im Zuge der Suburbanisierung drang bereits - von modernistisch denkenden Planern heftig kritisiert - die Bebauung in ehemals ländliche Gebiete vor, mit einer Architektur, die eher ländlichen Vorbildern folgte.

Die gesellschaftliche Gebundenheit von Natur verdeutlicht Zierhofer : "Natur und Kultur liegen der Erkenntnis nicht voraus, sondern umgekehrt, bestimmte Praktiken gehen der Unterscheidung von Natur und Kultur voran. ${ }^{48}$ Entsprechend können wir »Objekte nicht mehr als feststehende Gegenstände vor unserer Erfahrung auffassen, sondern nur noch als Gegenstände, die erst durch unsere Interaktionen konstituiert werden. ${ }^{49}$ Natur lässt sich dieser Auffassung entsprechend nicht als eindeutig definierbarer Bereich von Welt verstehen: "Sie ist immer definiert, domestiziert und zugerichtet $\varkappa^{50}$, sie ist stets mit dem Gesellschaftlichen hybridisiert.

47 Anne Whiston Spirn, »The Poetics of City and Nature. Towards a New Aesthetic for Urban Design «, in: Landscape Journal 7 (1988), 108-126; Anna Jorgensen und Marian Tylecote, "Ambivalent landscapes - wilderness in the urban interstices", in: Landscape Research 32, 4 (2007), 443-462; Olaf Kühne, Stadt - Landschaft - Hybridität. Ästhetische Bezüge im postmodernen Los Angeles mit seinen modernen Persistenzen, Wiesbaden: Springer VS, 2012.

48 Wolfgang Zierhofer, «Natur - das Andere der Kultur? Konturen einer nicht-essentialistischen Geographie«, in: Hans Gebhardt und Harald Bathelt (Hg.), Kulturgeographie. Aktuelle Ansätze und Entwicklungen, Heidelberg/Berlin: Spektrum Akad. Verlag 2003, 193-212, 199.

49 Ebd., 210.

50 Konrad Köstlin, »Kultur als Natur - des Menschen«, in: Rolf Wilhelm Brednich (Hg.), Natur Kultur. Volkskundliche Perspektiven auf Mensch und Umwelt, Münster/New York/München/ Berlin: Waxmann, 2001, 1-10, 7. 


\section{Kulturelle Vielfalten und Hybriditäten - landschaftliche Raumkonstrukte in globalem Maßstab}

Die Vorstellungen dessen, was im deutschen Sprachraum mit "Landschaft» konnotiert wird, werden in anderen sprachlichen Kontexten zum Teil deutlich anders gefasst. Entsprechend unterliegen bestimmte Verständnisse von Landschaft auch kulturellen Prägungen. So ist die Entwicklung eines konstruktivistischen Landschaftsverständnisses im internationalen Kontext stark durch die britische Landschaftsforschung dominiert. Sie geht auf William G. Hoskins und sein Buch The Making of the English Landscape ${ }^{51}$ zurück, in dem er die affektiven Aneignungsprozesse von Landschaft in den Fokus seiner Untersuchung der historischen Entwicklung der Art, England zu konstruieren, rückt. Interessanterweise erfolgte diese Hinwendung zu konstruktivistischen Deutungen von Landschaft in der britischen Landschaftsforschung, nicht der US-amerikanischen. Während in Großbritannien mit landscape insbesondere ästhetische Deutungen verbunden sind, wurde die US-amerikanische Fachsprache stark durch den in den 1920er Jahren mit seiner Berkeley-Schule einflussreichen deutschen Geografen Carl Otto Sauer geprägt. Sauer führte in den US-amerikanischen Fachdiskurs den positivistischen (mit gewissen essentialistischen Komponenten versehenen) Landschaftsbegriff in deutscher Forschungstradition in den Vereinigten Staaten ein. ${ }^{52}$

Nicht allein in der US-amerikanischen Landschaftsforschung konnte sich der "traditionelle« Landschaftsbegriff der deutschsprachigen Geografie aus der Zeit der Wende vom 19. zum 20. Jahrhundert durchsetzen. Dieses Verständnis von Landschaft wurde auch in Teile der Welt eingeführt, in denen landschaftsartige Raumverständnisse deutlich differenzierter ausgeprägt waren als in Deutschland bzw. in Europa. Dies gilt z. B. für Japan und von dort aus für China. ${ }^{53}$ So finden sich heute im Chinesischen neun Begriffe, die Aspekte bezeichnen, die im deutschen Sprachraum mit dem Wort "Landschaft« verbunden werden. Eines davon ist Jingguan, das in etwa dem deutschen Begriff der Landschaft in der traditionellen Lesart der deutschen Geografie entspricht. Infolge seiner Bedeu-

51 William G. Hoskins, The Making of the English Landscape, London: Hodder \& Stoughton, 2006 [Erstdruck 1956].

52 Antrop, »Interacting factors of landscape preference«; Kühne, Weltanschauungen in regionalentwickelndem Handeln.

53 Vgl. Diedrich Bruns, »Landschaft, ein internationaler Begriff?«, in: Diedrich Bruns und Olaf Kühne (Hg.), Landschaften: Theorie, Praxis und internationale Bezüge, Schwerin: Oceano Verlag, 2013, 153-170; Hirofumi Ueda, "The Concept of Landscape in Japan «, in: Bruns und Kühne (Hg.), Landschaften: Theorie, Praxis und internationale Bezüge, 115-132; Zhao Zhang und Diedrich Bruns, "Landschaftsbegriffe in China", in: Bruns und Kühne (Hg.), Landschaften: Theorie, Praxis und internationale Bezüge, 133-152. 
tung als Fachterminus ist Jingguan gegenüber den traditionellen chinesischen Begriffen von "eine[r] leicht elitäre[n] Aura ${ }^{54}$ umgeben. Ein weiterer wesentlicher Unterschied zwischen - allgemeiner gefasst - europäischen und fernöstlichen Landschaftsverständnissen findet sich im Bereich der Ästhetik: Während die abendländische Ästhetik zwischen Schönheit und Erhabenheit differenziert, findet sich in den fernöstlichen Philosophien diese Differenzierungen nicht. ${ }^{55}$ Ein anderer Unterschied besteht in dem Verhältnis von Mensch und Natur: „Der Mensch steht hier nicht der Natur gegenüber, er ist einbezogen in das allem Seiende gemeinsame $>$ ch'i 1 , die Lebenskraft, die alles durchdringt ${ }^{56}{ }^{56}$

Wie deutlich landschaftsbezogene Begriffe - nicht allein - im Deutschen Transformationen unterworfen sind, zeigen Józef Hernik und Robert DixonGough am Beispiel des Polnischen: Fand sich bis in das frühe 19. Jahrhundert kein Landschaftsbegriff, gelangte dann das Lehenswort »landszaft« als Blick auf die umliegende Gegend und diese Gegend selbst aus dem Deutschen in die polnische Sprache. ${ }^{57}$ Heute dominiert das Wort "krajobraz ( wobei »kraj « = Land, Gegend; »orbraz« = Blick). Das Wort »krajobraz« zeigt sich als ein stark auf das Individuum und die Ästhetik zentrierter Begriff und lässt sich als eine Emanzipation von dem deutschen Landschaftsbegriff verstehen, der jedoch noch immer in der polnischen räumlichen Forschung präsent ist, insbesondere in dem Terminus der Kulturlandschaft »krajobraz kulturowy» mit seiner stark gegenständliche Komponente und Parallelen zum traditionell-geografischen Landschaftsbegriff im deutschen Sprachraum. Ähnliche Prozesse der Adaption von Landschaftsverständnissen (nicht allein des deutschen traditionell-geografischen), wie insbesondere des französischen, sehr auf Ästhetik und die Gestaltung physischer Räume ausgerichteten "paysage« finden sich in unterschiedlichen Teilen der Welt (z. B. in Ungarn oder der Türkei) ${ }^{58}$

54 Johannes Küchler und Xinhai Wang, "Vielfältig und vieldeutig. Natur und Landschaft im Chinesischen «, in: Thomas Kirchhoff (Hg.), Vieldeutige Natur. Landschaft, Wildnis, Ökosystem als kulturgeschichtliche Phänomene, Bielefeld: transcript, 2009, 201-220, 216.

55 Ueda, »The Concept of Landscape in Japan".

56 Lehmann, Formen landschaftlicher Raumerfahrung im Spiegel der bildenden Kunst, 15.

57 Józef Hernik und Robert Dixon-Gough, »The concept and importance of landscape in Polish language and in Poland«, in: Bruns und Kühne (Hg.), Landschaften: Theorie, Praxis und internationale Bezüge, 2013, 83-98.

58 Siehe Drexler, Landschaft und Landschaftswahrnehmung; Fatma Aycim Türer Baskaya, "Landscape Concepts in Istanbul, Turkey», in: Bruns und Kühne (Hg.), Landschaften: Theorie, Praxis und internationale Bezüge, 101-113; zusammenfassend Kühne, Landschaftstheorie und Landschaftspraxis. 


\section{Fazit}

Der vorliegende Beitrag hat die Differenzierung der Begriffe Raum und Landschaft verdeutlicht. Angesichts der Vielfalt der Vorstellungen von Räumen und Landschaften, erscheint es schwierig, von dem Raum oder der Landschaft zu sprechen. Räume wie Landschaften werden im wissenschaftlichen Kontext stets in Abhängigkeit von dem eigenen Forschungsinteresse, paradigmatischer Prägungen und fachlicher Deutungshoheiten konstruiert. Dabei steht die wissenschaftliche Konstruktion von Räumen und Landschaften in einem rekursiven Verhältnis mit gesellschaftlichen Konstruktionen derselben. Die wissenschaftliche Konstruktion von Räumen und Landschaften ist in den alltagsweltlichen Begriffskontext ebenso eingebettet, wie wissenschaftliche Deutungen in alltagsweltliche Kommunikationen eindringen können. Dennoch lassen sich zwischen wissenschaftlicher und alltagsweltlicher Landschaftsbefassung Unterschiede festmachen: Ist der wissenschaftliche Zugriff auf das, was Landschaft genannt wird, stärker durch den Wunsch des kognitiven Durchdringens der Materie geprägt, ist die alltagsweltliche Konstruktion von Landschaft hingegen stärker emotional, ästhetisch und in Bezug auf die Nutzung der Landschaft für eigene (Freizeit-)Zwecke dominant. Neben der zeitlichen Variabilität der Vorstellungen von Räumen und Landschaften finden sich aber auch kulturelle Unterschiede. Der landschaftliche Blick auf Raum ist einerseits hochgradig kulturell differenziert, andererseits auch von interkulturellen Austauschbeziehungen geprägt. Diese komplexen Verhältnisse bilden sich dabei im Wesentlichen nicht in einem machtfreien Kontext, sondern sind in hohem Maße machtgebunden: Expertendiskurse dominieren landschaftsästhetische Vorstellungen von Laien, tradierte kulturelle Vorstellungen von landschaftlich betrachteten Räumen werden durch neue aus anderen kulturellen Kontexten herausgefordert oder sogar ersetzt. Diese Prozesse bieten einer konstruktivistisch ausgerichteten Landschaftsforschung auf viele Jahre hinaus ein erhebliches Forschungspotenzial.

\section{Literatur}

Antrop, Marc. »Interacting cultural, psychological and geographical factors of landscape preference«, in: Landscape Culture - culturing landscapes, Diedrich Bruns, Olaf Kühne, Antje Schönwald und Simone Theile (Hg.), Wiesbaden: Springer, 2015, 53-68.

Baumann, Zygmunt. Flüchtige Zeiten. Leben in der Ungewissheit, Hamburg: Hamburger Edition, 2008.

Böheim, Julius. Das Landschaftsgefühl des ausgehenden Mittelalters, Dissertation, Universität Leipzig, 1930.

Bollnow, Otto Friedrich. Mensch und Raum, Stuttgart: Kohlhammer, 1963. 
Bourdieu, Pierre. "Physischer, sozialer und angeeigneter physischer Raum«, in: StadtRäume. Die Zukunft des Städtischen, Martin Wentz (Hg.), Frankfurt am Main: CampusVerlag, 1991, 25-34.

Bourdieu, Pierre und Loic Wacquant. »Die Ziele der reflexiven Soziologie. Chicago-Seminar 1987 «, in: Reflexive Anthropologie, dies. (Hg.), Frankfurt am Main: Suhrkamp, 1996, 95-249.

Büttner, Nils. Geschichte der Landschaftsmalerei, München: Hirmer, 2006.

Bruns, Diedrich. "Landschaft, ein internationaler Begriff?«, in: Landschaften: Theorie, Praxis und internationale Bezüge, Diedrich Bruns und Olaf Kühne (Hg.), Schwerin: Oceano Verlag, 2013, 153-170.

Carol, Hans. »Grundsätzliches zum Landschaftsbegriff«, in: Das Wesen der Landschaft, Karlheinz Paffen (Hg.), Darmstadt: Wissenschaftliche Buchgesellschaft, 1973 [Erstdruck 1957], 142-155.

Cosgrove, Denis E. Social Formation and Symbolic Landscape, London u. a.: Croom Helm, 1984.

Ders. The Palladian Landscape: Geographical Change and Its Representation in SixteenthCentury Italy, Leicester: Leicester University Press, 1993.

Davies, Douglas. "The Evocative Symbolism of Trees ", in: The Iconography of Landscape. Essays on the Symbolic Representation, Design and Use of Environments, Dennis Cosgrove (Hg.), Cambridge u. a.: Cambridge University Press, 1988, 32-42.

Drexler, Dóra. Landschaft und Landschaftswahrnehmung: Untersuchung des kulturhistorischen Bedeutungswandels von Landschaft anhand eines Vergleichs von England, Frankreich, Deutschland und Ungarn, Saarbrücken: Südwestdeutscher Verlag für Hochschulschriften, 2010.

Egner, Heike. Theoretische Geographie, Darmstadt: Wissenschaftliche Buchgesellschaft, 2010.

Elias, Norbert. Über die Zeit. Arbeiten zur Wissenssoziologie II, Frankfurt am Main: Suhrkamp, 1994.

Haber, Wolfgang. "Kulturlandschaft zwischen Bild und Wirklichkeit«, in: Die Zukunft der Kulturlandschaft zwischen Verlust, Bewahrung und Gestaltung, Forschungs- und Sitzungsberichte der ARL, Band 215, Karolina Begusch-Pfefferkorn (Hg.), Hannover: ARL, 2001, 6-29.

Hard, Gerhard. "Das Wort Landschaft und sein semantischer Hof. Zur Methode und Ergebnis eines linguistischen Tests «, in: Wirkendes Wort 19, 1969, 3-14.

Ders. »Zu den Landschaftsbegriffen der Geographie«, in: »Landschaft« als interdisziplinäres Forschungsproblem, Alfred Hartlieb von Wallthor (Hg.), Münster: Aschendorff, 1977, 13-24.

Ders. «Zu Begriff und Geschichte von `Natur` und `Landschaft` in der Geographie des 19. und 20. Jahrhunderts", in: Landschaft und Raum. Aufsätze zur Theorie der Geographie, ders. (Hg.), Osnabrück: Rasch, 2002 [Erstdruck 1983], 171-210.

Heiland, Stefan. »Zwischen Wandel und Bewahrung, zwischen Sein und Sollen: Kulturlandschaft als Thema und Schutzgut in Naturschutz und Landschaftsplanung", in: Kulturlandschaften als Herausforderung für die Raumplanung. Verständnisse - Erfahrungen - Perspektiven, Ulf Matthiesen (Hg.), Hannover: ARL, 2006, 43-70. 
Hernik, Józef und Robert Dixon-Gough. »The concept and importance of landscape in Polish language and in Poland", in: Landschaften: Theorie, Praxis und internationale Bezüge, Diedrich Bruns und Olaf Kühne (Hg.), Schwerin: Oceano Verlag, 2013, 83-98.

Hoskins, William G. The Making of the English Landscape, London: Hodder \& Stoughton, 2006 [Erstdruck 1956].

Hunziker, Marcel. »Die Bedeutungen der Landschaft für den Menschen: objektive Eigenschaft der Landschaft oder individuelle Wahrnehmung des Menschen?«, in: Forum für Wissen 21 (2010), 33-41.

Jones, Michael und Karoline Daugstad. "Usages of the >cultural landscaper concept in Norwegian and Nordic landscape administration«, in: Landscape Research 22, 3 (1997), 267-281.

Jorgenson, Anna und Marian Tylecote. "Ambivalent landscapes - wilderness in the urban interstices", in: Landscape Research 32, 4 (2007), 443-462.

Klüter, Helmut. Raum als Element sozialer Kommunikation, Gießen: Selbstverlag des Geographischen Instituts der Justus-Liebig-Universität Gießen, 1986.

Köck, Helmut. »Raumkonzepte in der Geographie - methodologisch analysiert«, in: Geographie und Schule 36, 209 (2014), 3-14.

Körner, Stefan. »Landschaft und Raum im Heimat- und Naturschutz«, in: Strukturierung von Raum und Landschaft. Konzepte in Ökologie und der Theorie gesellschaftlicher Naturverhältnisse, Michael Weingarten (Hg.), Münster: Westfälisches Dampfboot, 2005, 107-117.

Ders. „Die neue Debatte über Kulturlandschaft in Naturschutz und Stadtplanung «, 2006, www.bfn.de/fileadmin/MDB/documents/service/perspektivekultur_koerner.pdf, zuletzt geprüft am 03. April 2019.

Köstlin, Konrad. »Kultur als Natur - des Menschen«, in: Natur - Kultur. Volkskundliche Perspektiven auf Mensch und Umwelt, Rolf Wilhelm Brednich (Hg.), Münster/New York/ München/ Berlin: Waxmann, 2001, 1-10.

Küchler, Johannes und Xinhai Wang. »Vielfältig und vieldeutig. Natur und Landschaft im Chinesischen «, in: Vieldeutige Natur. Landschaft, Wildnis, Ökosystem als kulturgeschichtliche Phänomene, Thomas Kirchhoff (Hg.), Bielefeld: transcript, 2009, 201-220.

Kühne, Olaf. Landschaft in der Postmoderne. Das Beispiel des Saarlandes, Wiesbaden: VS Verlag, 2006.

Ders. Distinktion - Macht - Landschaft. Zur sozialen Definition von Landschaft, Wiesbaden: VS Verlag, 2008.

Ders. Stadt - Landschaft - Hybridität. Ästhetische Bezüge im postmodernen Los Angeles mit seinen modernen Persistenzen, Wiesbaden: Springer VS, 2012.

Ders. Landschaftstheorie und Landschaftspraxis. Eine Einführung aus sozialkonstruktivistischer Perspektive, Wiesbaden: Springer VS, 2013.

Ders. »Weltanschauungen in regionalentwickelndem Handeln - die Beispiele liberaler und konservativer Ideensysteme«, in: Bausteine der Regionalentwicklung, Olaf Kühne und Florian Weber (Hg.), Wiesbaden: Springer VS, 2015.

Läpple, Dieter. »Gesellschaftszentriertes Raumkonzept«, in: Stadt-Räume, Martin Wentz (Hg.), Frankfurt am Main, New York: Suhrkamp, 1991, 35-46.

Lehmann, Herbert. Formen landschaftlicher Raumerfahrung im Spiegel der bildenden Kunst, Erlangen: Palm und Enke, 1968.

Löw, Martina. Raumsoziologie, Frankfurt am Main: Suhrkamp, 2001. 
Lorber, Frank. Metaphern und Metamorphosen der Landschaft. Die Funktion von Leitbildern in der Landespflege, Dissertation, Universität Kassel, 2006.

Mitchell, Don. „Cultural Landscapes: Just Landscapes or Landscapes of Justice?», in: Progress in Human Geography 27, 6 (2003), 787-796.

Müller, Gunter. »Zur Geschichte des Wortes Landschaft«, in: »Landschaft « als interdisziplinäres Forschungsproblem, Alfred Hartlieb von Wallthor (Hg.), Münster: Aschendorff, 1977, 3-13.

Münker, Stefan. Emergenz digitaler Öffentlichkeiten. Die Sozialen Medien im Web 2.0, Frankfurt am Main: Suhrkamp, 2009.

Paasi, Anssi. »Finnish Landscape as Social Practice. Mapping Identity and Scale«, in: Nordic Landscapes. Region and Belonging on the Northern Edge of Europe, Michael Jones (Hg.), Minneapolis/London: University of Minnesota Press, 2008, 511-539.

Schenk, Winfried. Historische Geographie, Darmstadt: Wissenschaftliche Buchgesellschaft, 2011.

Schmithüsen, Josef. »Was ist eine Landschaft?«, in: Das Wesen der Landschaft, Karlheinz Paffen (Hg.), Darmstadt: Wissenschaftliche Buchgesellschaft, 1973, 156-174.

Spanier, Heinrich. »Natur und Kultur«, in: ANL 25, 2001, 69-86.

Ders. »Mensch und Natur - Reflexionen über unseren Platz in der Natur«, in: Naturschutz im Kontext einer nachhaltigen Entwicklung. Ansätze, Konzepte, Strategien, Karl-Heinz Erdmann (Hg.), Bonn-Bad Godesberg: Bundesamt für Naturschutz, 2008, 269-292.

Spirn, Anne Whiston. »The Poetics of City and Nature. Towards a New Aesthetic for Urban Design«, in: Landscape Journal 7 (1988), 108-126.

Stöber, Georg. »Kulturraumkonzepte in Curricula, Schulbüchern und Unterricht», in: Geographie und Schule 33, 199 (2011), 15-31.

Türer Baskaya und Fatma Aycim. "Landscape Concepts in Istanbul, Turkey«, in: Landschaften: Theorie, Praxis und internationale Bezüge, Diedrich Bruns und Olaf Kühne (Hg.), Schwerin: Oceano Verlag, 2013, 101-113.

Ueda, Hirofumi. »The Concept of Landscape in Japan", in: Landschaften: Theorie, Praxis und internationale Bezüge, Diedrich Bruns und Olaf Kühne (Hg.), Schwerin: Oceano Verlag, 2013, 115-132.

Warnke, Martin. Politische Landschaft. Zur Kunstgeschichte der Natur, München/Wien: Hanser, 1992.

Weichhart, Peter. Entwicklungslinien der Sozialgeographie. Von Hans Bobek bis Benno Werlen, Stuttgart: Steiner, 2008.

Werlen, Benno. Sozialgeographie alltäglicher Regionalisierungen. Band 1: Zur Ontologie von Gesellschaft und Raum, Stuttgart: Steiner, 1995.

Ders. Sozialgeographie alltäglicher Regionalisierungen. Band 2: Globalisierung, Region und Regionalisierung, Stuttgart: Steiner, 1997.

Zhang, Zhao und Diedrich Bruns, "Landschaftsbegriffe in China", in: Landschaften: Theorie, Praxis und internationale Bezüge, Diedrich Bruns und Olaf Kühne (Hg.), Schwerin: Oceano Verlag, 2013, 133-152.

Zierhofer, Wolfgang. »Natur - das Andere der Kultur? Konturen einer nicht-essentialistischen Geographie«, in: Kulturgeographie. Aktuelle Ansätze und Entwicklungen, Hans Gebhardt und Harald Bathelt (Hg.), Heidelberg/Berlin: Spektrum Akademischer Verlag, 2003, 193-212. 


\section{Violetta Julkowska}

\section{Kulturlandschaft als erkenntnisleitende Begriffskategorie der Geschichtsdidaktik}

\section{Einleitung}

Wir alle leben in Kulturräumen, die vorausgegangene Generationen gestaltet und geprägt haben. Dabei begleitet uns Vergangenes auf Schritt und Tritt. Und dennoch: Selbst wenn wir an einem Ort heimisch sind, erkennen wir nicht immer die dortigen Spuren der Vergangenheit. Das Alte erscheint uns so gewohnt und selbstverständlich, dass es uns gar nicht mehr auffällt. Selbst wenn wir historische Relikte identifizieren, sind wir nicht immer in der Lage, ihre ursprüngliche Funktion und Bedeutung einzuordnen. Es ist offenbar so, dass für ein fundiertes Verständnis ihrer historisch-kulturellen Semantik kognitive Anstrengung erforderlich ist. Erst ästhetische Sensibilität und grundlegendes Interesse an materiellen Zeugnissen der Vergangenheit setzen Arbeit am historischen Bewusstsein in Gang. Dabei ist eine gewisse kognitive Distanz unverzichtbar, um die Vielfalt und Komplexität von Kulturlandschaften wahrnehmen und verstehen zu können. Wichtig ist, bereits in der Schule die Kompetenz zu vermitteln, Kulturlandschaften als solche zu erkennen und zu deuten, um ein positives Verhältnis zu eigenem wie fremdem Kulturerbe zu schaffen.

"Kulturlandschaft« ist ein in der Geschichtsdidaktik bisher wenig beachteter Begriff, was keineswegs heißt, dass er in der Bildungspraxis nicht präsent wäre. Dies belegen aktuelle Schulgeschichtsbücher ebenso wie schulische Bildungsprojekte. In den Lehrbüchern finden wir didaktischen Zwecken dienende Bilder, die Kulturlandschaften repräsentieren, ohne dass dies ausdrücklich intendiert wäre. Bei regionalen Bildungsprojekten oder auf historischen Exkursionen werden Informationen zu Artefakten oder räumlichen Anordnungen in Kulturlandschaften vermittelt. Dabei wird weder der Begriff der "Landschaft « in herkömmlicher Bedeutung verwendet, noch werden die Potentiale von »Kulturlandschaft « didaktisch genutzt. Selbst wenn Geschichtslehrende Beispiele für Kulturlandschaften verwenden, setzten sie diesen Begriff in der Regel nicht zu erkenntnisleitenden Zwecken ein. 
Daher glaube ich, dass Kulturlandschaft als weit gefasste, interdisziplinäre und um eine historische Dimension zu erweiternde Begriffskategorie die Chance bietet, die Geschichtsdidaktik für neue Erkenntnisse und Anwendungsansätze zu öffnen. Außerdem ermöglicht das Konzept in der praktischen Bildungsarbeit, historische und ästhetische Sensibilität für Landschaften zu entwickeln.

Dieser Beitrag soll Landschaft als eine für die Geschichtsdidaktik wichtige offene Begriffskategorie definieren und Bezüge zu anderen Schlüsselkategorien sichtbar machen. ${ }^{1}$ Besonders wichtig erscheint dabei, durch die ästhetische, topografische und kulturelle Konzipierung von Landschaft ihre geschichtlichen Bezüge zu Zeit und Raum sowie die historischen Veränderungen im Raum zu erkennen. In diesen Kontext gehören ebenso Überlegungen zu Erinnerung und Gedächtnis für die Schaffung imaginierter Landschaften.

\section{Landschaft als komplexe Konzeption}

Zwei antike Traditionen, die jüdisch-christliche und die griechische, prägten mittelalterliche Vorstellungen von der Natur. Die biblische Überlieferung gebot ihre Kultivierung und Bewirtschaftung, während die klassische Antike die Kultur um die Sensibilität für ihre Schönheit bereicherte. Im Mittelalter sehen wir die Benediktiner und Zisterzienser mit ihrer hochentwickelten Agrarkultur, später die Franziskaner mit ihrer Bejahung der Natur. ${ }^{2}$ Zeugnisse vielfältigen Interesses an der natürlichen Umgebung und Topografie sind von Reisenden, Kreuzfahrern, Kaufleuten, Gartenarchitekten, Dichtern und Künstlern überliefert; sie bieten anregendes Quellenmaterial.

Die Konzeption der Landschaft kam in der Renaissance zur vollen Blüte, Anfänge sind jedoch bereits in spätmittelalterlichen Miniaturen und Genrebildern zu erkennen; Beispiele dieser Entwicklung sind das Stundenbuch des Jean de Berry und die Genremalerei Pieter Bruegels, Schlüsselwerke für die frühe

1 Violetta Julkowska, "O paradygmatycznej zmienności myślenia historycznego« [Die paradigmatische Wandelbarkeit historischen Denkens], in: Justyna Budzińska und Justyna Strykowska (Hg.), Wspótczesna edukacja historyczna: Doświadczenia, oczekiwania [Moderne Geschichtserziehung: Erfahrungen, Erwartungen], Poznań: Instytut Historii UAM, 2015, 147-157; dies., »Refleksje dydaktyka historii na kanwie `O myśleniu historycznym〈 Wojciecha Wrzoska« [Geschichtsdidaktische Überlegungen anhand von Wojciech Wrzoseks >Vom historischen Denken`], in: Sensus Historiae. Studia interdyscyplinarne 1 (2010), 107-118.

2 Beata Frydryczak, Krajobraz. Od estetyki the picturesque do doświadczenia topograficznego [Landschaft. Von der Ästhetik des Pittoresken zur topografischen Erfahrung], Poznań: Poznańskie Towarzystwo Przyjaciół Nau, 2013, 8. 
Landschaftsmalerei in Westeuropa. ${ }^{3}$ Die Brüder von Limburg, die im Auftrag des Herzogs von Berry arbeiteten, machten die Umgebung des herzoglichen Schlosses zur Szenerie: die farbenfrohe und im Rhythmus der Jahreszeiten schillernde Landschaft bildet den Hintergrund für die Präsentation einer elitären Hofkultur. Bruegels Bilder dagegen bringen Ausschnitte aus dem in die Kulturlandschaft eingebetteten Alltagsleben des einfachen Volkes. ${ }^{4}$

Der Geograf John Brinckerhoff Jackson befasst sich in seinen toponymischen Studien mit dem Sinn der Landschaft im Bewusstsein des mittelalterlichen Menschen. Der altenglische Begriff landscape besaß demnach ein reichhaltiges Bedeutungsspektrum. Er bezog sich auf ein abgetrenntes und als Ganzes begriffenes Territorium, das sich vertikal und horizontal erstreckt, visuell wahrnehmbar ist und stets menschliche Präsenz impliziert. ${ }^{5}$ Noch konkretere Bedeutungen besaß der französische Ausdruck champagne, der ein als Nutzfläche kultiviertes Terrain bezeichnet. Das Kompositum landscape ist semantisch komplex: land bedeutet einen von Menschen abgegrenzten Raum, während sich scape auf die Methode der Raumorganisation bezieht. Das alte, umgangssprachliche Verständnis von landscape zeigt, dass der so bezeichnete Raum eher als ländlich begriffen wurde.

Kulturell fremde Landschaften finden sich in topografischen und anthropologischen Texten wieder, die einst die einzige Wissensquelle über andere Kulturräume waren. Sie stammen von Kaufleuten, Pilgern oder Kreuzfahrern, Kolonisatoren und Entdeckungsreisenden. Sie alle hatten Gelegenheit zur Beobachtung einer fremden Kultur aus der Distanz oder durch direkte Teilnahme.

Die Landschaftsforschung wählt gern die Renaissance zum Ausgangspunkt. Erst diese, so das vielfach bemühte Argument, habe die Menschen für die ästhetische Qualität der Natur sensibilisiert und Landschaft zum Thema für Künstler und Philosophen gemacht. Damals wurde die Umgebung von Florenz und Siena zur Ideallandschaft stilisiert, in der der Mensch vermeintlich in Harmonie mit der Natur lebe. Die toskanische Landschaft, wie sie von Leonardo da Vinci, Fra Angelico, Ambrogio Lorenzetti und Benozzo Gozzoli im Bildhintergrund dargestellt wurde, begründete den Mythos der italienischen Landschaft schlechthin. ${ }^{6}$ Diese Darstellungen stellen ein harmonisches Gleichgewicht zwi-

3 Kenneth Clark, Landscape into Art, London: John Murray, 1952, 12; Jan Białostocki, Refleksje i syntezy ze świata sztuki [Überlegungen und Synthesen aus der Welt der Kunst], Warschau: PWN, 1978, 70.

4 Franco de Poli und Edi Baccheschi, Geniusze sztuki. Bruegel [Genies der Kunst. B.], übersetzt von Wojciech Jekiel, Warschau: Krajowa agencja wydawnicza KAW, 1985, 82.

5 J. B. Jackson, "Krajobraz lokalny» [Lokale Landschaft], in: Beata Frydryczak und Dorota Angutek (Hg.), Krajobrazy. Antologia tekstów, [Landschaften. Eine Textantologie], Band 3, Poznań: PTPN, 2014, 285-298, hier 288.

6 Franco Cardini, Toskania. Pejzaż, historia, sztuka [Die Toskana. Landschaftsmalerei, Geschichte, Kunst], übersetzt von Bożena Mierzejewska, Warschau: Arkady, 2005, 15-19. 
schen der Stadt und ihrer grünen Umgebung aus Weinstöcken, Olivengärten, Feldern und Faktoreien auf Hügelspitzen her. Dabei waren es nicht in erster Linie neue Perspektiven und Topografien von Interesse, vielmehr ging es den Meistern um die Bereicherung des Raumes durch kulturelle Zeugnisse seiner Bewohntheit. Daher nannte Fernand Braudel die toskanische Kulturlandschaft »die ergreifendste Landschaft der Welt «. ${ }^{7}$ Besonders Leonardo da Vinci sorgte für eine innovative Wahrnehmung der Topografie durch synoptische Darstellung und Vogelperspektive. In seiner malerischen Interpretation der Landschaft kommen seine botanischen, physikalischen und optischen Studien zum Tragen; seine Bilder sind ebenso Zeugnisse des wissenschaftlichen Fortschritts wie der neuentdeckten ästhetischen Faszination durch die Natur. ${ }^{8}$

Auch eine erst in der Neuzeit aufgekommene philosophische Konnotation des Begriffs weist auf diese neuentdeckte ästhetische Qualität von Landschaft hin. Sie rührt aus dem Entwurf des Subjekts, das die äußere Welt aus einer individuellen Perspektive wahrnimmt, wodurch die Natur erst zur ästhetisch und emotional erlebten Landschaft wird. Die kontemplative Dimension der Landschaftserfahrung verbindet sich mit der klassischen Kantschen Idee des distanzierten Blicks; dieser ist unbedingte Voraussetzung, um Ausschnitte von Raum und Natur wahrnehmen und darüber in einer Weise reflektieren zu können, wie sie an die Rezeption eines Kunstwerkes erinnert. Kontemplative Landschaften werden in Gemälden dargestellt; seit dem 19. Jahrhundert kommen dann auch fotografische und schließlich filmische Abbildungen ins Spiel. ${ }^{9}$

Die kontemplative und ästhetisierende Haltung lässt außer Acht, dass der Mensch aktiv an der Gestaltung von Landschaft beteiligt ist. Geografie, Ethnologie, Anthropologie und Geschichtswissenschaften betonen genau diesen Umstand. Das Handeln des Menschen orientiert sich an den für den jeweiligen Raum vorgegebenen historischen und kulturellen Mustern.

7 Zit. nach ebd., 15.

8 Leonardo da Vinci, "Traktat o malarstwie« [Traktat über die Malerei], in: Jan Białostocki (Hg.), Teoretycy, pisarze i artyści o sztuce 1500-1600 [Theoretiker, Schriftsteller und Künstler über die Kunst 1500-1600], Warschau: PWN, 1985, 456-490, 456.

9 Hans Belting, Antropologia obrazu. Szkice do nauki o obrazie [Anthropologie des Bildes. Skizzen zur Bildwissenschaft], übersetzt von Mariusz Bryl, Kraków: Universitas, 2012, 76-86; Andre Rouillé, Fotografia. Między dokumentem a sztuką współczesną [Fotografie. Zwischen Zeitzeugnis und moderner Kunst], übersetzt von Oskar Hedermann, Kraków: Universitas, 2007, $286 \mathrm{f}$. 


\section{Sozial- und geisteswissenschaftliche Definitionen von Kulturlandschaft}

Die kulturelle Aktivität des Menschen im Raum ist eine Konstante der geisteswissenschaftlichen und humangeografischen Definitionen von Kulturlandschaft, und zwar ungeachtet ihrer jeweils unterschiedlich gesetzten Schwerpunkte.

Für die Geografen entsteht eine Kulturlandschaft in Folge von anthropogenen Veränderungen im Raum, die dauerhaft sind, wenn sie durch ständige Eingriffe aufrechterhalten werden. Danach sind harmonische und degradierte Landschaften zu unterscheiden, je nach Art und Ausmaß der Eingriffe. Hier dominiert ein interdisziplinärer Ansatz, der unterscheidet zwischen einem mit den natürlichen Bedingungen übereinstimmenden oder aber das Gleichgewicht der Natur verletzenden Handeln. Letzteres verursacht dauerhafte und fortschreitend negative Veränderungen. ${ }^{10}$

1927 definierte der Geograf Alfred Hettner Kulturlandschaft als harmonische Gesamtheit von Ort, Klima, Flora, Fauna und menschlicher Kultur. ${ }^{11}$ Diese Definition betont Sinn und Ergebnis menschlichen Handelns in Natur und Gesellschaft, sie verbindet also sozial- und naturwissenschaftliche Kategorien. Nach dem Zweiten Weltkrieg entwickelte sich diese Denkrichtung weiter in der US-amerikanischen Schule der Kulturlandschaft, parallel dazu in der französischen, auf Emile Durkheims Soziologismus (1947) zurückgehenden Humangeografie. Die französische Schule überwand naturdeterministisches Denken und inspiriert bis heute viele Ansätze der Kulturlandschaftsforschung. ${ }^{12}$ Einer ihrer Begründer, Paul Vidal de La Blache, entwickelte den Ansatz, in der Kulturlandschaft Geschichte und Kultur zu verbinden und so den Akzent weiter in die geisteswissenschaftliche Richtung zu verschieben. Dieser Ansatz wurde in Polen unter anderem von Maria Dobrowolska aufgenommen, einer wichtigen Vertreterin der polnischen Landschaftsschule, die auch Methoden zur Kulturlandschaftsforschung entwickelte. Sie wies auf Historizität und gesellschaftliche Dimension der in der Landschaft vor sich gehenden Wandlungen hin. Indem sie Kulturlandschaft als Synthese sozialen Handelns im geografischen Umfeld definierte, betonte sie die Interdependenz zwischen Natur und Gesellschaft; Kul-

10 Józef Partyka, Mijające krajobrazy Polski [Passierende Landschaften Polens], Kraków: Centralny Ośrodek Turystyki Górskiej PTTK, 2012, 7.

11 Alfred Hettner, Geographie, ihre Geschichte, ihr Wesen und ihre Methoden, Breslau: Hirt, 1927; Urszula Myga-Piątek, Krajobrazy kulturowe. Aspekty ewolucyjne i typologiczne [Kulturlandschaften. Aspekte ihrer Evolution und Typologie], Katowice: Uniwersytet Śląski, $2012,35 \mathrm{f}$.

12 Ebd., $45 f$. 
turlandschaft ist die Summe der Wandlungen, die im Laufe der historischen Entwicklung vor sich gehen. ${ }^{13}$

Der Perspektivwechsel der Geografie hin zum aktuellen Zustand der Kulturlandschaft erfordert es, den historischen Moment der Veränderung in den Blick zu nehmen, um kulturelle Schichten aus verschiedenen Epochen zu erfassen. Die Humangeografie sieht kulturelle Veränderungen im Raum als räumliche Stratifikation.

Dieser Ansatz der Humangeografie steht der Kulturgeschichte, der Archäologie und der Kulturanthropologie nahe, für welche die Landschaft eine Form des kulturellen Erbes und ein historischer Ort ist, über den die Identität einer Gemeinschaft bestimmt werden kann. Geschichtswissenschaft und Geografie gemeinsam ist auch die Siedlungsforschung, die weitere Begriffe wie die Heideggersche »Gegend « in die Diskussion einführt.

Die Kategorie der Kulturlandschaft offenbart das unterschiedliche Verständnis verschiedener geisteswissenschaftlicher Disziplinen vom Verhältnis des Subjekts zur Landschaft. Dabei geht es um zwei semantisch verschiedene Begriffe: "Anblick« und "Gegend» bzw. »Umgebung». »Anblick « meint Landschaft in ästhetischer Sicht als Hintergrund und Beobachtungsgegenstand des distanzierten Subjekts. »Umgebung» dagegen meint den vom Subjekt bewohnten Ort und seinen Handlungsraum.

Die Anthropologisierung der Landschaft führte daher zur Neukonzipierung der klassischen Kategorie, denn sie erweiterte die kontemplative Auffassung um das zivilisatorische Handeln des Menschen in wirtschaftlicher, gesellschaftlicher und kulturell-symbolischer Hinsicht. In dieser Bedeutung steht Kulturlandschaft dem Raum als Begriff von Umgebung nah, die der Mensch sich aneignet und bewirtschaftet. Umgebung ist ein Raum voller Spuren und Zeichen, entstanden aus den Zwecken und kulturellen Aktivitäten von Generationen von Einwohnern.

Historisch-anthropologische Definitionen von Kulturlandschaft befreien den Landschaftsbegriff von der Konnotation des statischen Bilds. Dieser Ansatz zieht eine veränderte Ästhetik der Landschaft nach sich. Die traditionelle Ästhetik hat ein distanziertes und reflektiertes Verhältnis zur als Kunstwerk betrachteten Landschaft. Deren aus der distanzierten Haltung des Subjekts resultierende Fremdheit ist Voraussetzung ihrer reflektierenden Rezeption. Dies ändert sich, wenn Präsenz und Perspektive der Urheber der Kulturlandschaft einbezogen werden. Der aus einer anthropologisch-kulturellen Perspektive Beobachtende widmet sich dem Raum alltäglicher Kontakte und erkennt eine alternative Ästhetik des Alltags.

13 Maria Dobrowolska, "Dynamika krajobrazu kulturalnego« [Die Dynamik der Kulturlandschaft], in: Przegląd Geograficzny 21, 1 (1948), 151-203. 
Um die konstitutiven Eigenschaften einer solchen Alltagsästhetik zu definieren, wendet sich der Philosoph Arto Haapala der Heideggerschen existenziellen Ontologie des Daseins zu. Haapala führt die Kulturlandschaft auf die Dimension des Alltagsortes zurück. Die Perspektive des nahen Ortes und des Alltags zwingt den Forscher dazu, seine Aufmerksamkeit auf alltägliche, intime Dinge und Ereignisse zu richten. Intimität und Alltäglichkeit sind das Wesen des Ortes. Haapala schlägt zur Erforschung der Kulturlandschaft eine neue, auf den Existenzialismus zurückgehende anthropologisch-kulturelle Perspektive und eine Verminderung der klassischen kognitiven Distanz vor. So schafft die Veränderung der Forschungsperspektive einen neuen Ansatz und neue Methoden der teilnehmenden Beobachtung, die charakteristisch für die anthropologische Forschung sind. Die Verminderung der kognitiven Distanz verändert die Ästhetik und den Maßstab der Landschaft. Als würde man auf Vermeers Panoramen verzichten, um sich stattdessen in Bruegels Detailausschnitte zu vertiefen.

Der Wechsel der Perspektive bietet die Chance der Annäherung an den Alltag. Mikrohistorische Studien müssen nichtklassische Quellen einbeziehen, zu denen subjektive Zeugnisse wie persönliche Gegenstände, Fotos, Erinnerungen und mündliche Überlieferung gehören. So wie das Lesen der Kulturlandschaft aus der Distanz, ermöglicht das der Forschung und Didaktik, sich in sie hineinzubegeben.

Haapala exemplifiziert seine Überlegungen an einem künstlerischen Experiment, das die Erkenntnisperspektive verändert, die klassische Distanz aufgibt und Bildgrenzen überschreitet, um neuen Sinn zu erschließen: ${ }^{14}$ Lech Majewskis Film »Die Mühle und das Kreuz« (2011), die Verfilmung eines Essays des Kunstkritikers Michael Gibson über Pieter Bruegels »Die Kreuztragung Christi ${ }^{15}$ Der Film experimentiert mit der Belebung der ins Bild gesetzten Kulturlandschaft. Er erzielt einen Effekt teilnehmender Beobachtung, indem er Szenen computertechnisch übereinanderlegt und so auf die historische, kulturelle und ethische Aussagekraft des Bildes verweist. Durch Lenkung der maximalen Aufmerksamkeit auf das Bild macht der Film deutlich, dass die Entschlüsselung von Kultur viele Zeichenebenen erfordert.

Die angeführten Definitionen betonen den menschlichen Anteil an der Schaffung von Kulturlandschaft und verweisen bei der Forschung zu Landschaftsdarstellungen in der Kunst auf den kulturell vermittelten Kontakt des Menschen mit der Natur.

14 Arto Happala, »Estetyka codzienności«.

15 Michael Francis Gibson, The Mill and the Cross, Lausanne: Acatos, 2001. 


\section{Das Lesen der Kulturlandschaft}

Die kulturellen Artefakte, die wir in einer Landschaft wahrnehmen, sind Zeugnis einer bestimmten Gemeinschaft und enthalten auch Informationen über deren Identität. Doch alle bedeutsamen Elemente der Kulturlandschaft, alles, was in ihr präsent ist und Bedeutungen enthält, erfordert eine Interpretation, also ein "Lesen", genauer gesagt, das verborgene Sinngebungen eruierende Lesen eines Verstehenden. Dieses "Lesen« des Raumes als Sammlung von Zeichen schlägt Karl Schlögel vor. Von Kant ausgehend, spricht er von einem reflektierten Schauen, das erlernbar sei. Dieses sei jedoch nicht möglich ohne eine Verbindung zwischen sinnlicher Erfahrung (Unmittelbarkeit) und intellektueller Arbeit. ${ }^{16}$ Reflektierend die kulturelle Wirklichkeit zu betrachten, bezieht den Intellekt in die Interpretation des auf der Grundlage historisch-kulturellen Wissens Wahrgenommenen ein. Mit kognitiver Distanz zu schauen, weckt überdies Sensibilität für die ästhetische Dimension des Geschauten. Werke der Literatur und Kunst sind Spuren der Rezeption des kulturellen Raums und kulturelle Texte, die das kulturelle Gedächtnis um eine zusätzliche symbolische Dimension bereichern. Man kann sie analysieren und interpretieren, ähnlich wie übliche historische Schriftquellen.

Die beste Art der Erfahrung einer Kulturlandschaft ist, in einen realen Raum einzutauchen. Der direkte Kontakt mit der Landschaft bei einer von kenntnisreichen Kommentaren begleiteten Begehung regt die geschichtliche Phantasie an und lehrt, beim Schauen zu verstehen. In der Verkehrung der bekannten Redensart, dass Reisen bildet, allerdings nur die Gebildeten, klingt die Erkenntnis an, auf die sich auch Schlögel bezieht: Nur wer etwas wisse, schreibt Schlögel, könne etwas erkennen. Man müsse etwas über Künstler, Architektur, Handwerk und Stile in Erfahrung bringen. Allerdings sei das alles nutzlos, wenn wir unseren eigenen Augen nicht vertrauen, wenn wir der Form nicht die ihr eigene Bedeutung einräumen.

Die vom Wanderer erfahrene Unmittelbarkeit der Landschaft kann in einen aspektreichen Diskurs eingehen, der an die Kulturlandschaft anknüpft. Für die Forschung wird diese Kategorie damit zum theoretischen Rahmen, der den Sinn des Geschauten erklären kann. Die Inspirationen aus dem Diskurs über die historische und multikulturelle Komplexität der masurischen Landschaft zu

16 Karl Schlögel, Im Raume lesen wir die Zeit. Über Zivilisationsgeschichte und Geopolitik, München: Hanser, 2003; hier nach der poln. Ausgabe W przestrzeni czas czytamy. O historii cywilizacji i geopolityce, übersetzt von Izabela Drozdowska und Łukasz Musiał, Nachwort Hubert Orłowski, Poznań: Wydawn. Poznańskie, 2009, 270. 
nutzen, ist seit den neunziger Jahren ein wichtiger Ansatz regionaler Bildungspraxis, der Grenzen nationalstaatlicher Perspektivierung überschreitet. ${ }^{17}$

Das erste Projekt wurde 1993 mit polnischen Gymnasiasten und deutschen Freiwilligen in dem masurischen Dorf Drwęcko realisiert. Es umfasste die Restaurierung eines Friedhofs aus dem Ersten Weltkrieg und Begegnungen mit Dorfbewohnern und Zeitzeugen und hatte zum Ziel, Geschichte kennenzulernen und ihre Multidimensionalität zu begreifen. ${ }^{18}$ Diese Aktivitäten wurden in den Jahren 1994 bis 1998 fortgesetzt und ausgeweitet. So kristallisierte sich ein als "Lesen von Kulturlandschaft « bezeichnetes Programm heraus. Dabei wurde eine neue Methodik der Regionalbildung erarbeitet, die auf europäische landeskundliche, bis zur Wende vom 19. zum 20. Jahrhundert reichende Vorbilder zurückgreift. Diese Arbeit mündete in ein weiteres, von Elżbieta Traba, Robert Traba und Jörg Hackmann geleitetes Projekt, durchgeführt von der Kulturgemeinschaft »Borussia» unter dem Titel »Entdeckung europäischer Kulturlandschaften. Regionalgeschichte in Deutschland, Polen, Russland und Litauen am Beispiel von Ostpreußen $«{ }^{19}$ Es zielte darauf ab, Barrieren zwischen Menschen verschiedener Kulturen und Ethnien zu überwinden und Möglichkeiten zum Aufbau neuer Beziehungen auszuloten. Das Projekt sollte Interpretationsmuster für das kulturelle Erbe von Regionen schaffen, welche die Geschichten einst verfeindeter Nationen sowie der heutigen Bewohner des ehemals multikulturellen Grenzlands reflektieren. Das Projekt stützte sich auf die Architektur, die eine Mittlerrolle in der Geschichte Ostpreußens spielt, nämlich Schloss, Friedhof, Denkmal, Kirche, Gutshof, Herrenhaus und Bahnhof. Diese Objekte dienten dazu, der Vergangenheit und ihrer Rezeption nachzugehen und die Frage zu beantworten, wie eine jahrzehntelang verdrängte und ungewollte Tradition dennoch in das kulturelle Gedächtnis integriert werden kann. Eines der Ergebnisse legte die Erkenntnis nahe, dass es für den Aufbau einer offenen Bürgergesellschaft erforderlich sei, das vielfältige Kulturerbe zu erschließen und dabei gerade auch Fremdes zu würdigen.

17 Robert Traba, Przeszłość w teraźniejszości. Polskie spory o historie na początku XXI wieku [Vergangenheit und Gegenwart. Polnische Auseinandersetzungen über Geschichte am Anfang des 21. Jahrhunderts], Poznań: Wydawnictwo Poznańskie, 2009, 138.

18 Ebd., 140.

19 Ebd., 142. 


\section{Der didaktisch-geschichtswissenschaftliche Diskurs rund um Kulturlandschaft}

Das oben erläuterte Konzept von Kulturlandschaft fügt sich in die Grundkategorien der Geschichtswissenschaft ein, die auch von der Geschichtsdidaktik verwendet werden und das historische Denken mitprägen. Dessen Ausbildung im Geschichtsunterricht folgt wechselnden Einflüssen: der jeweiligen Interpretation der gesellschaftlichen Funktion von Geschichte, den Moden der Geschichtsschreibung, dem Geschichtsbewusstsein der Gesellschaft sowie den didaktischen Mitteln. ${ }^{20}$ Axiome des historischen Denkens wie Raum, Zeit und Veränderung sind zugleich methodische Kategorien des Vergangenheitsbildes, das für den Geschichtsunterricht konstruiert wird. ${ }^{21}$ In der schulischen Praxis wird das historische Denken über das Narrativ der Lehrbücher herausgebildet, welches das Vergangenheitsbild entscheidend mitbeeinflusst. Dieses Narrativ prägt die spezifischen Eigenschaften der Konstruktion und damit das Verständnis von Vergangenheit. Je nach Lehrbuch kann sich das Narrativ unterscheiden; die unterschiedlichen Narrative bilden einen Bezugsrahmen, der die Interpretation der Kulturlandschaft unterstützen kann, und zwar ausgehend sowohl von der Tradition der Geschichtsschreibung als auch vom durch eine Meistererzählung geprägten Vergangenheitsbild, das in den Schulbüchern in der Regel überwiegt. Die humangeografische und kulturanthropologische Definition von Kulturlandschaft ist auch geschichtsdidaktisch einer der möglichen Ansätze, erfordert jedoch zusätzlich die Betonung der historischen Perspektive sowie eine für den Bildungsansatz wesentliche Ergänzung.

Der historische Ansatz ergänzt den geisteswissenschaftlichen Diskurs zur Kulturlandschaft um ein konstitutives Element, nämlich den »historischen Menschen«, auf den etwa Joachim Lelewel in seiner Forschung immer wieder gern zurückkam. ${ }^{22}$ Der historische Mensch ist das handelnde Subjekt im Kontext von Raum und Zeit. Abhängig von der methodischen Grundlage des Vergangenheitsbilds kann der historische Mensch in der Kulturlandschaft in einem breiten Spektrum seiner Rollen untersucht werden: als Herrscher, Bauer, Verteidiger, Forscher, Priester, Künstler, Dichter. Die historische Raumforschung arbeitet also aus einer anderen Perspektive als die Geografie: Der Raum ist eine

20 Jan Pomorski, „Edukacja historyczna u progu XXI wieku« [Historische Erziehung an der Schwelle zum 21. Jahrhundert], in: Czesław Majorek (Hg.), Po co uczyć historii? [Wozu Geschichte unterrichten?], Warschau: COM SNP, 1988, 239-253, $242 \mathrm{f}$.

21 Violetta Julkowska, „Szkolna narracja historyczna» [Geschichtsnarrative in der Schulpraxis], in: Współczesna dydaktyka historii. Zarys encyklopedyczny [Moderne Geschichtsdidaktik. Ein enzyklopädischer Abriss], Warschau: Wydawn. Juka, 2001, 360-362.

22 Joachim Lelewel, Historyka tudzież o łatwem i pożytecznem nauczaniu historyi [Historica sowie über das leichte und nützliche Lehren der Geschichte], Wilno: A. Żółkowski, 1815. 
historische und anthropologische Handlungsbühne, auf der politische, wirtschaftliche, soziale, künstlerische, religiöse, wissenschaftliche oder kulturelle Aspekte beleuchtet werden können. Die Aktivitäten des Menschen legen sich als Schichten übereinander und bilden ein Netz wechselseitiger Abhängigkeiten, die weiteres Handeln auslösen oder verhindern. Aus dieser Perspektive werden sich historisch verändernde Vorgänge im Kulturraum untersucht: die politische oder wirtschaftliche Aufteilung, Besiedlung, Verstädterung, Industrialisierung und Kolonisierung, die Erschließung neuer und Wiederbelebung alter Räume. Der Raum ist eine von menschlicher Aktivität angetriebene, dynamische Größe. Dabei werden qualitative Veränderungen sowie ihre Intensität in der Zeit berücksichtigt, die z.B. anders sind beim Ackerbau und bei der Gewinnung von Rohstoffen und ihren Konsequenzen für die Umwelt. Für die Geschichtswissenschaften spiegelt der Raum das Handeln vieler Generationen. Er wird als Synthese sich überlagernder kultureller Schichten verstanden, die ein Palimpsest bilden. Das bewusste Handeln zum Schutz der Kulturlandschaft als historisches und kulturelles Erbe ist ein Ausdruck des Geschichtsbewusstseins.

Die historische Perspektive auf die Kulturlandschaft besitzt eine unverzichtbare zeitliche Dimension, die nicht physikalisch, sondern kulturell gemessen wird. Daher wurde die Historizität der Landschaft von der Humangeografie als Parameter angenommen. Die historische Zeit ist an den Generationen zu messen, die bleibende, einander überlagernde Spuren ihres Handelns hinterlassen haben. Sie sind Belege der kulturellen Identität der den Ort bewohnenden sozialen Gruppen. Der Palimpsestcharakter von Kulturlandschaften begründet deren Reichtum, liefert aber auch Vorwände für ethno-nationalistische Auseinandersetzungen über territoriale Zugehörigkeit und daraus abgeleitete Besitzansprüche.

Zeit und Raum sind aus historischer Perspektive konstitutive Eigenschaften einer jeden Kulturlandschaft. Sie sind um einen weiteren Begriff zu ergänzen, nämlich den der kulturellen Kontinuität. Manche Bestandteile der Kultur überdauern erstaunlich lange, und zwar nicht nur materielle Artefakte. Andere verändern sich und verlieren ihre frühere Bedeutung. Antike Denkmäler sind Beispiele dafür, dass einzelne Artefakte oder ganze städtische Komplexe in einem Zustand überdauern können, der die Erforschung ihrer kulturellen Sinngebungen ermöglicht. Ähnlich verhält es sich bei mittelalterlichen Denkmälern; bis heute haben sich in Europa deutliche Spuren früherer städtischer und ländlicher Raumstrukturen erhalten. Ihre Kontinuität und Lesbarkeit machen es möglich, dauerhafte Überreste der Vergangenheit zu erkennen. Doch meist erscheinen alte Kulturphänomene nicht als homogene Sequenzen, sondern treten als einzelne Denkmäler auf oder zeigen sich in tieferen kulturellen Schichten. 
Die Kulturlandschaft ist aus historischer Perspektive ein aus chronologisch und stilistisch heterogenen Objekten zusammengesetztes Mosaik. Je nach ihrer Dauerhaftigkeit, können die Bestandteile dieses Mosaiks bis heute ihre Funktionalität bewahrt haben oder aber bloße Überreste vergangener Epochen sein.

Es tritt ein wesentlicher Unterschied zwischen Kulturgeschichte und Archäologie zur Erforschung zeitgenössischer Kulturen zutage; denn erstere müssen zu den Relikten vorstoßen, um diese als historische Quellen zu interpretieren. Eine alte und fremde Gesellschaft muss mitsamt ihrer Normen und Werte erkundet werden, um ihre Entscheidungen verstehen und deren langfristige Folgen nachzeichnen zu können. Eine weitere Domäne der Kulturgeschichte ist die Erforschung der Kulturlandschaft in ihren historischen künstlerischen Darstellungen.

\section{Kulturlandschaft im Geschichtsunterricht}

Der Geschichtsdidaktik stehen verschiedene Möglichkeiten zur Verfügung, das Thema Kulturlandschaft in den Geschichtsunterricht einzubringen. Ich möchte im Folgenden exemplarische Lösungen vorstellen und auf deren Erkenntnis-, Kompetenz- und Bildungspotenziale eingehen. Neben der traditionellen Arbeit mit Lehrbuchmaterialien verweise ich auch auf die multimediale Visualisierung bei der Arbeit mit ikonografischen Materialien. Damit knüpfe ich an Bildungsprojekte an, bei denen Exkursionen an Orte gemacht werden, die als kulturelles Erbe gelten. Diese Projekte sollen Feldforschung mit der Interpretation der Quellen verbinden.

Die im Folgenden skizzierten Lösungen gehen davon aus, dass Kulturlandschaften Zeugnisse der Tätigkeit ihrer früheren Bewohner bewahrt haben und Zeichen der regionalen Identität darstellen. Daher besteht eine Aufgabe der Forschung darin, den Sinn im kulturellen Handeln von Menschen zu erkennen. Es ist von didaktischer Bedeutung, Werte des Kulturerbes in den Fokus zu rücken, um Geschichtsbewusstsein und geschichtswissenschaftliche Kompetenzen zu entwickeln, die beim eigenständigen Erforschen der Vergangenheit helfen, etwa durch das »Lesen der Kulturlandschaft«.

a) Kulturlandschaft und Vergangenheitsbild in polnischen Geschichtsbüchern

Der spezifische Ansatz der Geschichte zu Zeit und Raum ermöglicht in der Geschichtsdidaktik drei Varianten der Darstellung von Kulturlandschaft, je nach dem vom jeweiligen Lehrbuch vorgegebenen Narrativ. 
Ich gehe vereinfachend davon aus, dass sich analog zu den Typen der Historiografie in den Geschichtsbüchern die Modelle der schulischen Geschichtsnarrative wiederfinden. Zur Beschreibung des schulischen Geschichtsnarrativs bediene ich mich der Kategorien Zeit, Raum, Wandel und Kontinuität, außerdem achte ich auf ein ganzheitliches Vergangenheitsbild im Narrativ der Lehrbücher. Die einzelnen Narrative lassen sich auf folgende Eigenschaften zurückführen: - im klassischen ereignisgeschichtlichen Modell sind dies direkte Anthropomorphisierung; handelndes Subjekt; faktografische (klassische) Konzeption von Wahrheit; deskriptives Narrativ; temps court/événement (Ereigniszeit); Dominanz der politischen Geschichte;

- im modernen Modell sind dies indirekte Anthropomorphisierung; prozessuale Wirklichkeit; klassische Wahrheitskonzeption; Dominanz von Theorie über Erfahrung; erklärendes, objektivierendes Narrativ; longue durée; funktionale Determinierung; Dominanz der Sozialgeschichte;

- im postmodernen Modell in der anthropologisch-kulturellen Variante sind dies makrohistorische Perspektive; Kultur in anthropologischer Interpretation; nichtklassische Wahrheitskonzeption; verstehendes, subjektivierendes Narrativ; Lebenszeit des Individuums oder der Mikrostruktur; Dominanz der Kulturgeschichte.

Diese Geschichtsnarrative beeinflussen entscheidend die Repräsentation von Kulturlandschaft. In Lehrbüchern mit klassischem ereignisgeschichtlichen Narrativ erscheint Kulturlandschaft zumeist als Resonanzraum politischer Macht. Beispiele dafür sind Betonung der politischen Territorialzugehörigkeit; Gründung einer Ortschaft nach deutschem Recht und ihre politischen Bedingungen; durch Verträge bestimmte politische Grenzen, die alte lokale und regionale Bindungen zerreißen; Zwangsmigration der Bevölkerung, die die kulturelle Kontinuität einer Region zerstört.

In der klassischen Geschichtsinterpretation verflachen die Kategorien. Ihre metaphorische Bedeutung erscheint erst im Kontext nichtklassischer Interpretationen, welche die bisherigen Kriterien der geschichtlichen Welt (Spezifik und Zeitgebundenheit, Wandel und Kontinuität) um die soziale und kulturelle Dimension des Raumes sowie die identitätsstiftende und kulturelle Dimension der Zeit ergänzen. Diese neue soziokulturelle Dimension verleiht dem historischen Bild Tiefe, anders als die Malerei, denn sie tut dies nicht auf illusionistische, sondern metaphorische Weise.

Daher erscheint in Lehrbüchern mit einem strukturellen und prozessualen Narrativ Kulturlandschaft als Raum sozioökonomischen und kulturellen Handelns. Beispiele dafür sind Darstellungen, die Raum komplex nach Kriterien wie Besiedlung, Urbanisierung und Industrialisierung organisieren und deren 
langfristige soziale, ökonomische und kulturelle Folgen für Gesellschaft und lokale Gemeinschaften einbeziehen.

In Lehrbüchern mit einem anthropologisch-kulturellen Narrativ in mikrohistorischer Perspektive erscheint die Kulturlandschaft kulturell subjektiviert, da ihrer eigenen Identität bewusst. Ein Beispiel für dieses Narrativ ist eine Darstellung des Alltags einer lokalen Gemeinschaft, die ins Innere der Kulturlandschaft führt. Entscheidend für die Subjektivierung ist eine verringerte kognitive, ästhetische und ethische Distanz. Alles geschieht aus der Nahsicht, weshalb die klassische Ästhetik ersetzt wird durch eine Ästhetik der Nähe, die eine aktive Teilnahme an der Erforschung der Welt erfordert.

\section{b) Multimediale Visualisierung von Kulturlandschaft}

Künstlerische Landschaftsdarstellungen sind Ausdruck von Betrachtung, Erleben oder nostalgischer Erinnerung. Das bedeutet nicht, dass im Unterricht ausschließlich die illustrative Funktion visueller Quellen berücksichtigt wird. Ganz im Gegenteil: Künstlerisch verarbeitete Landschaften können indirekt zur Eruierung mentaler Prozesse bei Künstlern und Autoren herangezogen werden. Das quellenkritische Lesen gehört zu den Kompetenzen, die durch die Verwendung neuer Medien ausgebildet werden. Die Sensibilisierung für die Aneignung von Kulturlandschaften durch Texte ist ein richtungsweisendes Bildungsziel. Die Massenkultur ist durch Audiovisualität und Interaktivität, Verminderung kommunikativer Distanz und Dynamisierung geprägt. ${ }^{23} \mathrm{Mul}-$ timedialität und Einsatz neuer Technologien sind daher zukunftsweisende Formen der Geschichtsvermittlung.

Natürlich sind auch multimediale Darstellungen von Kulturlandschaft Konstruktionen. Doch die neuen Technologien ermöglichen es, die Grenzen zwischen der forschungsnahen Simulation »möglicher Welten« und einer Simulation im Sinne der "erweiterten Realität" zu verwischen. Es geht hier um zwei alternative Visualisierungsformen:

1. Virtuelle Welten (Virtual Reality Modelling Language, VRML) oder dreidimensionale Simulationen sind suggestive Visualisierungen, die umfangreiche Informationen über die materielle Kultur bereitstellen, jedoch die symbolische Dimension der Kultur vereinfachen. Man begegnet ihnen in modern eingerichteten multimedialen Museen, in Touristenführern und im Begleitmaterial zu Geschichtsbüchern.

23 Violetta Julkowska, »Multimedialne iluzje jako reprezentacje przeszłości« [Multimediale Illusionen als Repräsentationen von Vergangenheit], in: Rocznik Antropologii Historii 1 (2013), 80-83. 
2. Visualisierungen rekonstruierter Objekte präsentieren auch deren heutigen Zustand. Sie sind eine Art von Vor-Ort-Rekonstruktion, die mittels erweiterter Realität (Augmented Reality, AR) stattfindet. ${ }^{24}$ Diese Methode verbindet die reale Welt mit computergrafisch generierten Elementen. Dies ermöglicht eine spektakuläre Darstellung vergangener Kulturlandschaften, die sich in der Realität fragmentiert oder vollkommen zerstört darbieten. Die erweiterte Realität ist nicht identisch mit VRML, bei der eine neue Welt am Computer generiert wird; sie zeigt keine virtuellen Welten, sondern erforscht reale Objekte und versieht diese mit zusätzlichen Informationen und virtuellen Bildern, die das reale Bild ergänzen. ${ }^{25}$ Die Methode macht eine aktive Beteiligung am Erkenntnisprozess zur Voraussetzung für eine Vorstellung über den historischen Zustand. Eine andere Möglichkeit besteht darin, eine Kamera auf ein Objekt zu richten, das mit weiteren Informationen angereichert wird; dadurch entsteht ein Bild als Verbindung von Realität und virtuellem Gewebe. Die AR-Methode verlangt eine aktive Beteiligung an der Rezeption des materiellen Kulturerbes und ist komplementär zum Schutz des immateriellen Kulturerbes. ${ }^{26}$ Durch diese Methode können fragmentarische oder nicht mehr existierende Landschaften visuell wieder hergestellt werden. Das hilft, den Erhalt von Denkmalsobjekten als gesellschaftlichen Wert zu verstehen.

\section{c) Historische Exkursionen in die Tiefe der Kulturlandschaft}

In Polen wird die Didaktik sehr weit gefasst, darunter versteht man sowohl die Auswahl des Lehrstoffes als auch die Art der Vermittlung. Die didaktische Methode der direkten Teilnahme, die diesem breit gefassten Konzept der Didaktik folgt, kommt im mikrohistorischen Ansatz am besten zum Tragen. Sie ermöglicht das Studium von Kulturlandschaft bei landeskundlichen Exkursionen und im Gespräch mit Zeitzeugen. Derartige Begegnungen mit der Vergangenheit sollten einhergehen mit organisatorisch-methodischen Überlegungen und in-

24 Agnieszka Dejnaka, »Rzeczywistość rozszerzona i jej zastosowanie w edukacji« [Erweiterte Realität und ihre Anwendung in der Erziehung], in: E-mentor 44, 2 (2012), 30-36.

25 Rafał Zapłata, "Zabytkowa architektura we współczesnym mieście - krajobraz miejski zmysłowo doświadczany. Wybrane zagadnienia prezentacji in situ historycznej zabudowy" [Denkmalsarchitektur in der modernen Stadt - gedanklich erfahrene Stadtlandschaft. Ausgewählte Probleme der in situ-Präsentation von historischer Bebauung], in: Beata Frydryczak und Mieszko Ciesielski (Hg.), Krajobraz kulturowy [Die Kulturlandschaft], Poznań: PTPN, 2014, 226-228.

26 Marek Barański, "Pomiędzy materialnym zabytkiem i pozamaterialnym dziedzictwem kultury« [Zwischen materiellem Denkmal und immateriellem Kulturerbe], in: Andrzej Kadłuczka (Hg.), Karta Krakowska 2000 dziesięć lat później, Kraków: Wydaw. Politechniki Krakowskiej, 2011, 13. 
haltlichen Vorbereitungen auf die anthropologisch-kulturelle und ästhetische Interpretation des Ortes, die unverzichtbar ist für das Verständnis der mikrohistorischen Ebene der Kulturlandschaft.

Eine Methodik der Ortsbegehung umfasst folgende Schritte, über die sich die Lernenden den Ort aneignen, die aber auch im Gespräch mit Menschen zu berücksichtigen sind, die den Ort bewohnen: ${ }^{27}$

1. Wir sehen uns den fremden Ort aus der Distanz an.

2. Wir machen ihn uns auf sinnlicher Ebene vertraut: Wir sehen, hören, tasten, riechen ihn.

3. Wir erforschen die Funktion und Bedeutung von Orten: Geschäfte, Kirche, Schule, Friedhof, Weg, Marktplatz, Allee.

4. Wir konzentrieren uns auf die ästhetische Qualität von Objekten.

5. Wir lassen uns nieder, um mit dem Ort vertraut zu werden.

6. Die emotionale Beziehung zu unserem Wohnort ist der Schlüssel zum Verständnis der Ästhetik des Ortes.

7. Wir stellen Beziehungen und Bindungen her, um uns am Ort zu verankern.

Vor der Begegnung sollten Methoden der oral history bekannt sein.

Die hier beschriebene Art von Reflexion sollte zur historischen Kultur der Geschichtslehrkräfte gehören, damit die didaktische Vermittlung von Geschichte kritisch ist und ein Bewusstsein für die sich verändernden Vorstellungen von kultureller Ordnung besteht.

In der Didaktik hat die Relation wissen/sehen eine kulturell-psychologische Dimension und ist an die individuelle Entwicklung des Denkens gekoppelt, das sich von einem bildhaften zu einem begriffsmäßigen und semantischen wandelt. Bei diesem Prozess geht eine jedem Kind eigene, bei Erwachsenen dagegen nur noch marginal vorhandene Erfahrung der Welterschließung verloren. Diese Veränderung geht einher mit dem Übergang vom Bild zum Text. Die Relation sehen/wissen ist transitiv und wirkt kognitiv auf beide Seiten, wie Praktiken der Gedenkstättenarbeit belegen. ${ }^{28}$ Diese basieren auf einer Visualisierung dessen, was nicht mehr da ist, von dem man aber weiß, dass es da gewesen ist. Derartige Visualisierungen entstehen aus dem Bedürfnis, die Erinnerung durch Visualisierung zu bewahren, etwa in Form lebender Bilder, Rekonstruktionen und Installationen. Die Reflexion, die das ursprüngliche Bedürfnis des Sehens begleitet, ist in Wirklichkeit keine sekundäre, sondern eine primäre und bildet die Quelle der Visualisierung.

27 Zitiert nach: Arto Happala, »Estetyka codzienności« [Die Ästhetik des Alltags], übersetzt von Beata Frydryczak, in: Frydryczak und Ciesielski (Hg.), Krajobraz kulturowy [Kulturlandschaft], Poznań: PTPN, 2014, 27-42, 35.

28 Julkowska, »Refleksje dydaktyka historii«, 110; vgl. Wojciech Wrzosek, O myśleniu historycznym [Das historische Denken], Poznań: Oficyna Wydawnicza Epigram, 2009, $87 \mathrm{f}$. 
Es entsteht eine neue Art der Relation: Vom Wissen über das Sehen zum Verstehen.

\section{Schlussbemerkungen}

Die Wahrnehmung der Kulturlandschaft und ihres Kulturerbes stellt an didaktische Arbeit besondere Anforderungen und macht eine interdisziplinäre Herangehensweise geradezu unerlässlich. Ich glaube, dass die Einführung der Begriffskategorie »Kulturlandschaft « in die Geschichtsdidaktik es möglich machen wird, im Geschichtsunterricht eine neue Erkenntnis- und Interpretationsperspektive zu gewinnen.

Diese neue Perspektive regt dazu an, bisher ungewohnte Methoden bei der Ausbildung des historischen Denkens auszuloten und anzuwenden. Didaktische Unterrichtsstrategien, die emotionales Engagement und Kontakt mit alten Kulturlandschaften und Zeugnissen der Geschichte einbeziehen, regen zum Nachdenken über die Flüchtigkeit von Identitäten an und lenken die Aufmerksamkeit auf den beschleunigten Wandel der Kultur, der uns alle als Beteiligte erfasst und uns einmal mehr vor Augen führt, dass unsere Identität sich in einem bisher nicht gekannten Ausmaß verändert.

Aus dem Polnischen übersetzt von Ulrich Heiße

\section{Literatur}

Barański, Marek. »Pomiędzy materialnym zabytkiem i pozamaterialnym dziedzictwem kultury« [Zwischen materiellem Denkmal und immateriellem Kulturerbe], in: Karta Krakowska 2000 dziesięć lat później, Andrzej Kadłuczka (Hg.), Kraków: Wydaw. Politechniki Krakowskiej, 2011, 13-17.

Belting, Hans. Antropologia obrazu. Szkice do nauki o obrazie [Anthropologie des Bildes. Skizzen zur Bildwissenschaft], übersetzt von Mariusz Bryl, Kraków: Universitas, 2012, 76-86.

Białostocki, Jan. Refleksje i syntezy ze świata sztuki [Überlegungen und Synthesen aus der Welt der Kunst], Warschau: PWN, 1978.

Cardini, Franco. Toskania. Pejzaż, historia, sztuka [Die Toskana. Landschaftsmalerei, Geschichte, Kunst], übersetzt von Bożena Mierzejewska, Warschau: Arkady, 2005.

Clark, Kenneth. Landscape into Art, London: John Murray, 1952.

Da Vinci, Leonardo. "Traktat o malarstwie« [Traktat über die Malerei], in: Teoretycy, pisarze i artyści o sztuce. Od starożytności do 1500 [Theoretiker, Schriftsteller und Künstler über die Kunst. Von der Antike bis 1500], Jan Białostocki (Hg.), Warschau: Państwowe Wydawnictwo Naukowe (PWN), 1985, Bd. 1, 456-490. 
Dejnaka, Agnieszka. »Rzeczywistość rozszerzona i jej zastosowanie w edukacji« [Erweiterte Realität und ihre Anwendung in der Erziehung], in: E-mentor 44, 2 (2012), 30-36.

De Poli, Franco und Edi Baccheschi. Geniusze sztuki. Bruegel [Genies der Kunst. Bruegel], übersetzt von Wojciech Jekiel, Warschau: Krajowa agencja wydawnicza KAW, 1985.

Dobrowolska, Maria. "Dynamika krajobrazu kulturalnego« [Die Dynamik der Kulturlandschaft], in: Przegląd Geograficzny 21, 1 (1948), 151-203.

Frydryczak, Beata. Krajobraz. Od estetyki the picturesque do doświadczenia topograficznego [Landschaft. Von der Ästhetik des Pittoresken zur topografischen Erfahrung], Poznań: Poznańskie Towarzystwo Przyjaciół Nauk, 2013.

Haapala, Arto. »Estetyka codzienności« [Die Ästhetik des Alltags], übersetzt von Beata Frydryczak, in: Krajobraz kulturowy, Beata Frydryczak und Dorota Angutek (Hg.), Poznań: PTPN, 2014, 27-42.

Hettner, Alfred. Geographie, ihre Geschichte, ihr Wesen und ihre Methoden, Breslau: Hirt, 1927.

Jackson, J[ohn] B[rinckerhoff]. »Krajobraz lokalny« [Lokale Landschaft], in: Krajobrazy. Antologia tekstów [Landschaften. Eine Textantologie], Band 3, Beata Frydryczak und Dorota Angutek (Hg.), Poznań: PTPN, 2014, 285-298.

Julkowska, Violetta. »Szkolna narracja historyczna" [Geschichtsnarrative in der Schulpraxis], in: Wspótczesna dydaktyka historii. Zarys encyklopedyczny [Moderne Geschichtsdidaktik. Ein enzyklopädischer Abriss], Jerzy Maternicki (Hg.), Warschau: Wydawn. Juka, 2001, 360-362.

Dies. "Refleksje dydaktyka historii na kanwie `O myśleniu historycznym` Wojciecha Wrzoska« [Geschichtsdidaktische Überlegungen anhand von Wojciech Wrzoseks ,Vom historischen Denken`], in: Sensus Historiae. Studia interdyscyplinarne 1 (2010), 107-118.

Dies. »Multimedialne iluzje jako reprezentacje przeszłości« [Multimediale Illusionen als Repräsentationen von Vergangenheit], in: Rocznik Antropologii Historii 1 (2013), 80-83.

Dies. "O paradygmatycznej zmienności myślenia historycznego« [Die paradigmatische Wandelbarkeit historischen Denkens], in: Współczesna edukacja historyczna: Doświadczenia, oczekiwania [Moderne Geschichtserziehung: Erfahrungen, Erwartungen], Justyna Budzińska und Justyna Strykowska (Hg.), Poznań: Instytut Historii UAM, 2015, 147-157.

Lelewel, Joachim. Historyka tudzież o łatwem i pożytecznem nauczaniu historyi [Historik sowie über das leichte und nützliche Lehren der Geschichte], Wilno: A. Żółkowski, 1815.

Myga-Piątek, Urszula. Krajobrazy kulturowe. Aspekty ewolucyjne i typologiczne [Kulturlandschaften. Aspekte ihrer Evolution und Typologie], Katowice: Uniwersytet Śląski, 2012.

Partyka, Józef. Mijające krajobrazy Polski [Passierende Landschaften Polens], Kraków: Centralny Ośrodek Turystyki Górskiej PTTK, 2012.

Pomorski, Jan. »Edukacja historyczna u progu XXI wieku« [Historische Erziehung an der Schwelle zum 21. Jahrhundert], in: Po co uczyć historii? [Wozu Geschichte unterrichten], Czesław Majorek (Hg.), Warschau: COM SNP, 1988, 239-253. 
Rouillé, Andre. Fotografia. Między dokumentem a sztuką wspótczesną [Fotografie. Zwischen Zeitzeugnis und moderner Kunst], übersetzt von Oskar Hedermann, Kraków: Universitas, 2007.

Schlögel, Karl. Im Raume lesen wir die Zeit. Über Zivilisationsgeschichte und Geopolitik, München: Hanser, 2003.

Ders. W przestrzeni czas czytamy. O historii cywilizacji i geopolityce [Im Raume lesen wir die Zeit. Über Zivilisationsgeschichte und Geopolitik], übersetzt von Izabela Drozdowska und Łukasz Musiał, Nachwort Hubert Orłowski, Poznań: Wydawnictwo Poznańskie, 2009.

Traba, Robert. Przeszłość w teraźniejszości. Polskie spory o historie na początku XXI wieku [Vergangenheit und Gegenwart. Polnische Auseinandersetzungen über Geschichte am Anfang des 21. Jahrhunderts], Poznań: Wydawnictwo Poznańskie, 2009.

Wrzosek, Wojciech. O myśleniu historycznym [Das historische Denken], Poznań: Oficyna Wydawnicza Epigram, 2009.

Zapłata, Rafał. „Zabytkowa architektura we współczesnym mieście - krajobraz miejski zmysłowo doświadczany. Wybrane zagadnienia prezentacji in situ historycznej zabudowy « [Denkmalsarchitektur in der modernen Stadt - sinnlich erfahrbare Stadtlandschaft. Ausgewählte Probleme der in situ-Präsentation von historischer Bebauung], in: Krajobraz kulturowy [Die Kulturlandschaft], Beata Frydryczak und Mieszko Ciesielski (Hg.), Poznań: PTPN, 2014, 226-228. 
Open-Access-Publikation im Sinne der CC-Lizenz BY 4.0

(c) 2020, Vandenhoeck \& Ruprecht GmbH \& Co. KG, Göttingen ISBN Print: 9783847107507 - ISBN E-Lib: 9783737007504 


\section{Der Wert von Kulturlandschaften für die Umweltbildung in Deutschland aus kulturgeografischer und ideengeschichtlicher Perspektive}

Will man über den Wert von »Kulturlandschaften« für die Bildung in Deutschland schreiben, so sind die beiden Komponenten des Wortes kultur- und ideengeschichtlich zu analysieren, denn die aus der Vergangenheit überkommenen Verständnisse von "Kultur" und »Landschaft« bestimmen bis heute die Wertzuweisungen an "Kulturlandschaft" und beeinflussen mithin die Formen der Kulturlandschaftsbildung mit. Da es keinen expliziten schulischen Ort für "Kulturlandschaftsbildung" gibt, ist das für gewöhnlich eingebunden in den Erdkunde- oder Biologieunterricht als Teil der Umweltbildung, die allgemein auf einen verantwortungsbewussten Umgang mit der Umwelt und den natürlichen Ressourcen zielt. Außerschulisch und in der Erwachsenbildung sind die zahlreichen Initiativen und Publikationen des Bundes für Heimat und Umwelt (BHU) zur Vermittlung von Kulturlandschaft zu nennen.

\section{Zur Verbindung von Kultur und Landschaft im Deutschen in Kulturlandschaft}

Es wurde wiederholt empirisch belegt, dass »Kultur» im Zusammenhang mit "Landschaft« im deutschen Sprachraum mehrheitlich in einem agrarischen Sinne verstanden wird: einer Sache bäuerliche Pflege angedeihen lassen $!^{1}$ In einer nicht mehr agrarisch geprägten Gesellschaft wie der deutschen (weniger als knapp 2,5 \% der Erwerbstätigen arbeiten 2019 in der Forst- und Landwirtschaft sowie der Fischerei) greift dieses Kulturverständnis allerdings nicht mehr recht, denn es trifft weder das Denken noch das Handeln der Mehrheit. Auch wenn

1 Wolfgang Haber, »Kulturlandschaft zwischen Bild und Wirklichkeit«, in: Akademie für Raumforschung und Landesplanung (Hg.), Die Zukunft der Kulturlandschaft zwischen Verlust, Bewahrung und Gestaltung, Forschungs- und Sitzungsberichte der Akademie für Raumforschung und Landesplanung 215, Hannover: ARL, 2001, 6-29; Olaf Kühne, Landschaft in der Postmoderne. Das Beispiel des Saarlandes, Wiesbaden: Deutscher Universitätsverlag, 2006. 
derzeit noch gut $50 \%$ der Fläche der Bundesrepublik Deutschland agrarisch genutzt werden, wird damit ein stetig kleiner werdender Teil charakterisiert, denn im Durchschnitt der Jahre 2009/10 wurden täglich 77 ha in Verkehrs- und Siedlungsflächen umgewidmet. In einer pluralistischen und offenen Gesellschaft kommen folglich weitere, nicht selten konfligierende Kulturbegriffe zum Tragen. Man muss daher heute von einem erweiterten, offenen Verständnis von Kultur ausgehen, was sich in einem flexiblen Verständnis von »Kulturlandschaft« niederschlägt. $^{2}$

Auch »Landschaft« als zweites Element des Kompositums »Kulturlandschaft» hat im Deutschen vielfache Wandlungen durchlaufen. Sprachgeschichtlich ist "Landschaft« im Deutschen eine zweifache sekundäre Bildung ${ }^{3}$ :

1. Im Mittelalter (der Erstbeleg stammt von 830) erfolgte eine Übertragung von den einheimischen, politisch handlungsfähigen Bewohnern eines definierten Landstrichs auf den von diesen Personengruppen besiedelten politischen oder natürlichen Raum. Aspekte der Regionalisierung verbinden sich seither mit »Landschaft «.

2. Ab der Frühen Neuzeit setzte, befördert durch die Malerei, ein Prozess der Vergegenständlichung eines in ästhetischer Einstellung gemalten Raumausschnitts ein. Seitdem ist der Begriff auch philosophisch-ästhetisch belegt.

Im Zuge der Industrialisierung wird "Landschaft» schließlich durch das Bürgertum in antistädtischer Attitude zu einem positiven Gegenentwurf zur Stadt überhöht. Wie die genannten empirischen Untersuchungen ebenfalls zeigen, meint "Landschaft« im Deutschen deshalb umgangssprachlich vor allem den ländlichen, "schönen« Raum außerhalb der der Stadt. Der Aphoristiker Werner Mitsch fasst das pointiert so zusammen: „Gegenden ohne Landschaft nennt man Städte. « ${ }^{4}$

Der agrarisch geprägte Raum wurde zudem immer wieder verbunden mit einer Gleichsetzung von "Land und Leuten ${ }^{5}$ und damit dem Versuch, Charakterzüge von Menschen aus der »Landschaft« zu erklären. Positiv formuliert trägt

2 Dorothea Hokema, »Die Landschaft der Regionalentwicklung: Wie flexibel ist der Landschaftsbegriff?«, in: Raumforschung und Raumordnung 3 (2009), 239-249.

3 Winfried Schenk, "Landschaft als zweifache sekundäre Bildung. Historische Aspekte im aktuellen Gebrauch von Landschaft im deutschsprachigen Raum, namentlich in der Geographie«, in: Diedrich Bruns und Olaf Kühne (Hg.), Landschaften: Theorie, Praxis und internationale Bezüge, Schwerin: Oceano Verlag, 2013, 23-34.

4 Werner Mitsch, Hin- und Widersprüche, Rosenheim: Rosenheimer Verlagshaus, 1986, zitiert nach Herbert Haas und Walter Haub: Die Sechziger Jahre und das mainfränkische Dorf, Würzburg: VSG, 1997, 11. Zusammenfassend jüngst Karsten Berr und Winfried Schenk: »Begriffsgeschichte (Landschaft)«, in: Olaf Kühne et al. (Hg.), Handbuch Landschaft, RaumFragen: Stadt - Region - Landschaft, Wiesbaden: Springer Nature, 2019, 23-38.

5 Im Sinne des Begründers der deutschen Volkskunde Wilhelm Heinrich Riehl, Naturgeschichte des deutschen Volkes als Grundlage einer deutschen Socialpolitik. Land und Leute, Band 1, Stuttgart/Tübingen: J. G. Cotta'sche Verlagsbuchhandlung, 1854. 
"Landschaft " damit in sich auch Vorstellungen einer »Antizipation einer humanisierten inneren und äußeren Natur « und einer »gelungene[n] Vermittlung von Gesellschaft und Territorium...«. ${ }^{6}$ Bei unkritischer Verwendung trägt "Landschaft " unweigerlich die Hauptklischees einer trivialen pessimistischen Zivilisations-, Technik- und Vernunftkritik in sich, also »Ideen von völkischer Verwurzelung, von Geborgenheit in der Gemeinschaft, vom Untergang der Erde am Geist und von ihrer Rettung durch Landschafts(schutz), Landschaftserleben, Heimat, Seele, Gemüt, Ganzheit und Synthese, Tradition und Werte. ${ }^{7}$

Wenn man nun diese beiden, mehrfach umgedeuteten und zunehmend flexibel gewordenen, zudem kultur- und ideengeschichtlich vielfach aufgeladenen Begriffe zu »Kulturlandschaft« zusammenbindet, ergibt sich eine große Breite von Verständnissen von »Kulturlandschaft«. Obgleich Markus Leibenath und Ludger Gailing es vor diesem Hintergrund für unmöglich halten, zu einer verlässlichen universalen und konsistenten Definition von (Kultur-)Landschaft zu gelangen, ${ }^{8}$ bieten sie in einer anderen Publikation aus dem selben Jahr auf der Basis von Diskursanalysen einen Orientierungsrahmen dazu an, was "(Kultur-)Landschaft « im Deutschen alles heißen kann (Abb. 1). ${ }^{9}$ Er kann als Angebot zur Selbstverortung als Wissenschaftlerin/Wissenschaftler, Planerin/Planer oder Lehrende/Lehrender verstanden werden. Mit der gewählten Schreibweise mit Klammern soll angezeigt werden, dass »Landschaft « und »Kulturlandschaft « im Deutschen bisweilen synonym verwendet werden, denn in Mitteleuropa ist jede Landschaft kulturell überprägt, also »Kulturlandschaft«. »Kulturlandschaft « wird als strategischer Pleonasmus vor allem dann verwendet, wenn die Rolle des Menschen bei der Gestaltung von Räumen in einer historischen Perspektive hervorgehoben werden soll.

6 Gerhard Hard und Adelheid Gliedner, "Wort und Begriff Landschaft anno 1976«, in: Friedrich Achleitner (Hg.), Die Ware Landschaft, Salzburg: Residenz Verlag, 1978, 16-24.

7 Gerhard Hard, „Die `Natur` der Geographen«, in: Ute Luig und Hans-Dietrich Schultz (Hg.), Natur in der Moderne, Berlin: Berliner Geographische Arbeiten, 2002, 67-85.

8 Ludger Gailing und Markus Leibenath, »Von der Schwierigkeit, >Landschaft oder $>$ Kulturlandschaft` allgemeingültig zu definieren«, in: Raumforschung und Raumordnung 2 (2012), 95-106.

9 Markus Leibenath und Ludger Gailing, »Semantische Annäherung an `Landschaft` und 〉Kulturlandschaft ««, in: Winfried Schenk, Manfred Kühn, Markus Leibenath und Sabine Tzschaschel (Hg.), Suburbane Räume als Kulturlandschaften, Forschungs- und Sitzungsberichte des ARL 236, Hannover: ARL, 2012, 58-79, hier 62. 


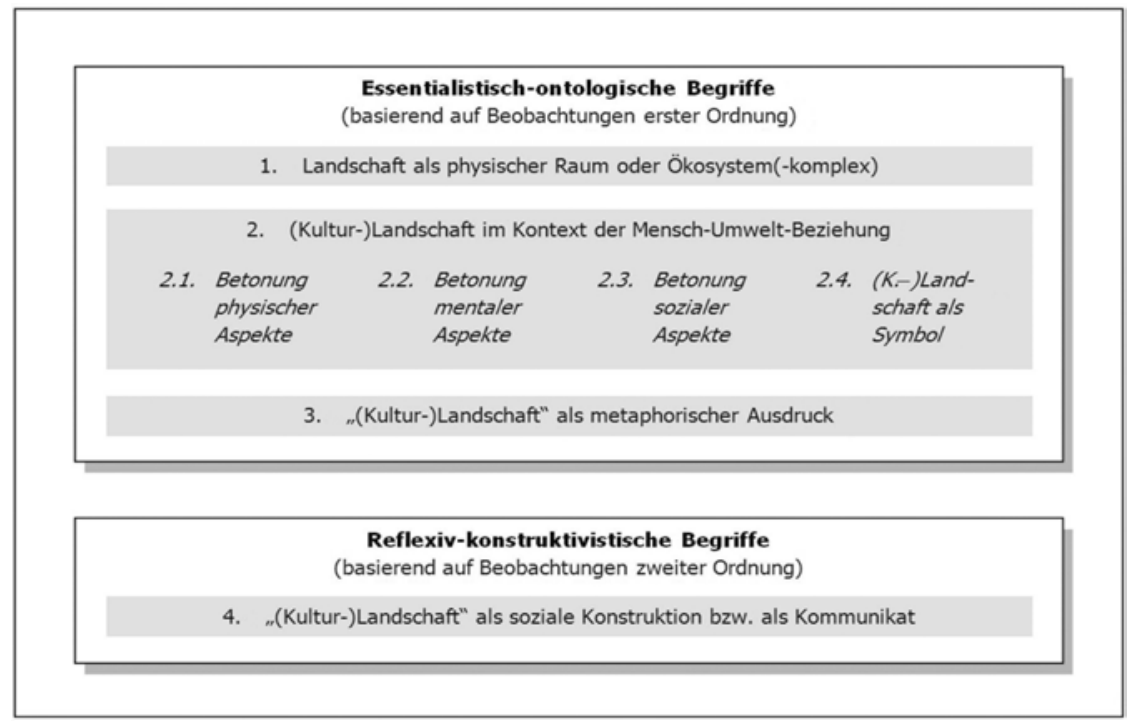

Abb. 1: (Kultur-)Landschaftsbegriffe im Deutschen ${ }^{10}$

Danach finden sich Verständnisse von (Kultur-)Landschaft in einer Breite von essentialistischen, das meint an materiellen Strukturen und Ideen der Bewahrung sich orientierenden Verständnissen, bis hin $\mathrm{zu}$ partizipatorischkonstruktivistischen Konzepten, die »Kulturlandschaft» als Ergebnis von Diskursen und Akteurshandeln verstehen. ${ }^{11}$ Indem Menschen über Räume als "Kulturlandschaften" sprechen, konstruieren sie diese diskursiv. Zudem wird deutlich, dass »Kulturlandschaft « zunehmend auf alle Räume angewandt wird; nach den Leitbildern der Raumordnung von 2006 sind $100 \%$ der Fläche Deutschlands »Kulturlandschaften $« !^{12}$

10 Gailing und Leibenath, »Von der Schwierigkeit, `Landschaft $८$ oder $>$ Kulturlandschaft allgemeingültig zu definieren «, 95-106.

11 Ludger Gailing und Andreas Röhring, "Kulturlandschaften als Handlungsräume der Regionalentwicklung. Implikationen des neuen Leitbildes zur Kulturlandschaftsgestaltung", in: RaumPlanung 136, 2 (2008), 5-10; Dietrich Fürst, Ludger Gailing, Kim Pollermann und Andreas Röhring, (Hg.), Kulturlandschaft als Handlungsraum. Institutionen und Governance im Umgang mit dem regionalen Gemeinschaftsgut Kulturlandschaft, Dortmund: Rohn, 2008.

12 Winfried Schenk, "Aktuelle Verständnisse von Kulturlandschaft in der deutschen Raumplanung", in: Informationen zur Raumentwicklung 5 (2008), 271-277; sowie Winfried Schenk, »Was meint `Kulturlandschaft $\$ in der Raumplanung und Regionalentwicklung?«, in: Verband Deutscher Schulgeographen und Akademie für Raumforschung und Landesplanung (Hg.), Kulturlandschaften in Geographie und Raumplanung, Bretten: VDSG, 2009, $12-15$. 


\section{Wertzuweisungen an Kulturlandschaft}

Gemeinsam ist den vorab skizzierten Verständnissen von Kulturlandschaft eine milieu- und altersspezifische ${ }^{13}$ normative Aufladung bezüglich des kulturellen Wertes von Kulturlandschaften, was daran innerhalb der jeweiligen Gruppen als identitätsstiftend angesehen wird. Diese spezifischen Kulturlandschaftsverständnisse unterscheiden sich zudem grundlegend in ihrer institutionellen Rückbindung an Fachpolitiken und wissenschaftliche Disziplinen (Abb. 2), aus denen rechtliche und fachliche Begründungen für den »kulturlandschaftlichen Wert « und planerisch-methodische Zugänge $\mathrm{zu}$ »Kulturlandschaften « abgeleitet werden. So werden essentialistisch-konservierende Verständnisse von Kulturlandschaft vor allem von auf Schutz gerichteten Planungen wie etwa der Bau- und Bodendenkmalpflege $^{14}$ vertreten, auch das Kulturlandschaftsverständnis in weiten Teilen der Heimatbünde ist hierzu zu rechnen. Sie entnehmen ihre Begründungen für den Wert von Kulturlandschaften vor allem historisch-kulturwissenschaftlichen Disziplinen wie der Archäologie, der Kunstgeschichte, der Agrargeschichte oder der Historischen Geografie. Der geschichtliche Zeugniswert, das Alter und der Erhaltungszustand, die historische Funktion oder die regionale Spezifik von Kulturlandschaftsstrukturen und -elementen sind daher wichtige Kriterien. Sofern sich das mit den nach Bundesländern differenzierten Denkmalschutzgesetzen in Deckung bringen lässt, werden mehr oder minder umfassend kulturlandschaftliche Phänomene etwa in Denkmallisten dokumentiert und einem länderspezifischen Schutzstatus unterstellt. Dabei bleibt allerdings eine Vielzahl von Elementen und Strukturen, die »Kulturlandschaft « in einem erweiterten Verständnis konstituieren, unberücksichtigt.

Den explizit konstruktivistischen Verständnissen von Kulturlandschaft mangelt es dagegen bislang an einer institutionalisierten Rückbindung an korrespondierende Wissenschaften. Eine Operationalisierung eines konstruktivistischen Kulturlandschaftsverständnisses im Kontext von Projekten der Bildung findet bislang erst in Ansätzen statt.

13 Olaf Kühne, »Der doppelte Landschaftswandel, Physische Räume, soziale Deutungen, Bewertungen «, in: Nachrichten der ARL, 1, 2018, 14-17.

14 Thomas Gunzelmann und Winfried Schenk, »Kulturlandschaftspflege im Spannungsfeld von Denkmalpflege, Naturschutz und Raumordnung «, in: Informationen zur Raumentwicklung 5/6 (1999), 347-360. 


\section{Kulturlandschaft}

in Politik und Praxis

Verständnisse von Kulturlandschaft

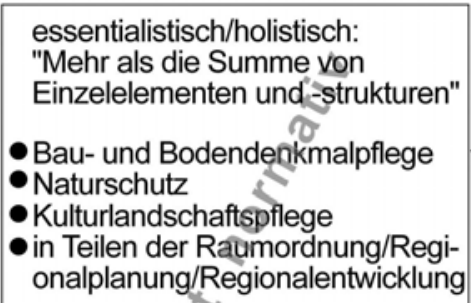

tendentiell konstruktivistisch in der Raumordnung/Regionalplanung: Identitäts-, Wahrnehmungsund Hấdlungsräume in der Wissenschaft

Analytisch-methodische Zugänge

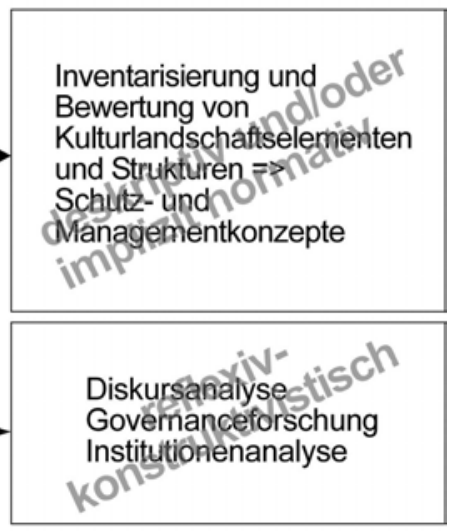

Abb. 2: Zum Verhältnis von Kulturlandschaftsverständnissen in Wissenschaft sowie Politik und Praxis $^{15}$

\section{Kulturlandschaftsbildung in der Praxis und zukünftige Anforderungen}

Als Folge dieses beschriebenen Missverhältnisses ist die Mehrzahl der Projekte, die »Kulturlandschaft « in der Bildung verwenden, einem eher essentialistischen, objektorientierten, meist agrarisch-historischen Verständnis von Kulturlandschaft zuzuordnen. Ein Bespiel dafür ist das sehr erfolgreiche Archäologische Spessartprojekt. Unterstützt von einer Geschäftsstelle wurden zwischenzeitlich gut 100 Kulturwege im Spessart, Odenwald, der Fränkischen Platte und dem Taubertal von Bürgerinnen und Bürgern entwickelt und ausgebaut. ${ }^{16}$ Im Mittelpunkt stehen historische Strukturen und Elemente, die gesichert und mittels Tafeln oder Flyern erklärt werden. Das dient gleichermaßen der regionalen Identitätsbildung und touristischen Zwecken.

Einen vermittelnden Zugang zwischen essentialistisch-schutzorientierten und reflexiv-diskursiven Kulturlandschaftsverständnissen bietet das von der

15 Winfried Schenk, Historische Geographie, Darmstadt: Wissenschaftliche Buchgesellschaft, $2011,113$.

16 Zum aktuellen Stand siehe http://www.spessartprojekt.de/, zuletzt geprüft am 17. April 2020. 
Geografie forcierte Konzept der Kulturlandschaftspflege. ${ }^{17}$ Es setzt wie die Bauund Bodendenkmalpflege an den sichtbaren Elementen und Strukturen der Kulturlandschaft an, erfasst aber in Ergänzung dazu auch und gerade eine Vielzahl nichtdenkmalwürdiger Elemente und Strukturen als ebenso konstitutiv für die Ausprägung von Kulturlandschaften. Der methodische Zugang erfolgt dabei in einem ersten Schritt (Abb. 3) über die systematische Erfassung linearer, flächiger und punkthafter Elemente und Strukturen der Kulturlandschaft in sog. Kulturlandschaftsinventaren oder -katastern ${ }^{18}$; beispielhaft entwickelte dazu der Landschaftsverband Rheinland das internetbasierte Planungs- und zugleich Informationsinstrument KuLaDig (Kultur. Landschaft. Digital.) zu Kulturlandschaften. ${ }^{19}$ In einem zweiten Schritt werden die erfassten Elemente und Strukturen in größere regionale Bezüge eingeordnet und gewichtet, wobei Kriterien wie Alter, Erhaltungszustand, regionale Spezifik je nach administrativ-rechtlichem Hintergrund fallbezogen modifiziert werden können. Darauf fußend werden schließlich in einem dritten Schritt Schutz- und Managementkonzepte abgeleitet und die Ergebnisse wiederholt evaluiert.

Kulturlandschaftspflege versteht sich also als ein diskursiver und zirkulärer Prozess, in dem die Wirksamkeit von Maßnahmen immer wieder in neuem Licht bewertet werden muss. Letztlich bedeutet das einen beständigen bürgerschaftlichen Diskurs um Werte, die der Kulturlandschaft zugewiesen werden. Veränderungen sind dabei prinzipiell möglich, sofern die Ablesbarkeit historischer Prozesse an Strukturen und Elementen noch gegeben ist.

Da nur das, was bekannt ist und womit man sich identifiziert, erhaltend weiterentwickelt und z.B. für regionale Entwicklungen oder die Identitätsbildung genutzt werden kann, bildet die "Kulturlandschaftsbildung" einen zentralen Aspekt des Konzepts. Häufig verwendete Medien sind z. B. Kulturlandschaftsführer in Form von Büchern, geführte Exkursionen oder erklärte Wanderwege. Bei der »Geschichtsstraße« in der Eifel kommen alle diese Ansätze zum Tragen. $^{20}$

17 Winfried Schenk, Klaus Fehn und Dietrich Denecke (Hg.), Kulturlandschaftspflege. Beiträge der Geographie zur räumlichen Planung, Stuttgart und Berlin: Borntraeger, 1997.

18 Schenk, Historische Geographie, 115-116.

19 http://www.kuladig.de, zuletzt geprüft am 09. April 2019.

20 »Geschichtsstraße«, Eifel.de, http://www.eifel.de/go/sehenswertes-detail/geschichtsstrasse kelberg.html, zuletzt geprüft am 17. April 2020. 


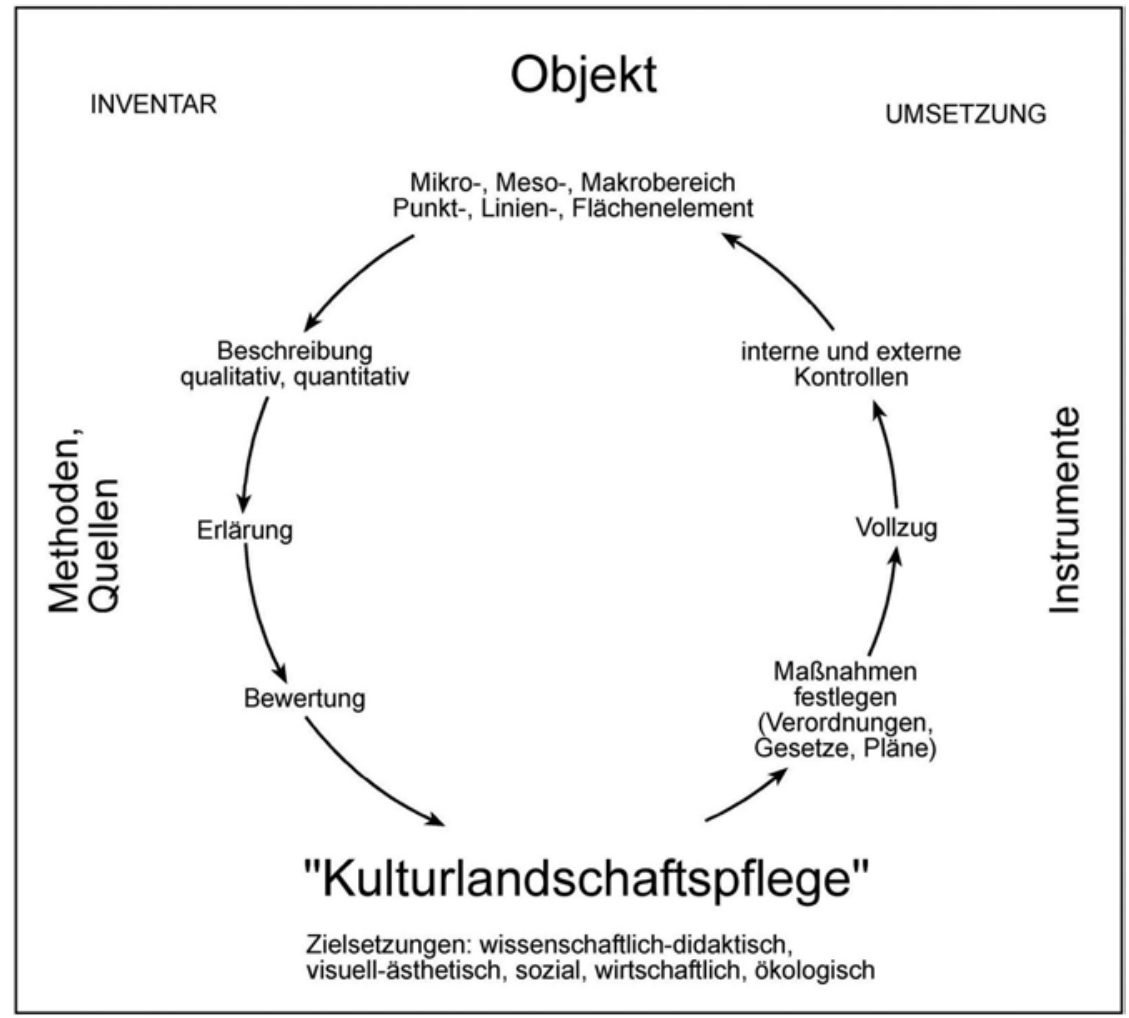

Abb. 3: Kulturlandschaftspflege als diskursiver Prozess ${ }^{21}$

Da die unmittelbare Begegnung die stärksten Lerneffekte zeitigt, bemüht man sich bei der didaktischen Erschließung von Kulturlandschaft, als Einstieg möglichst die emotionale bzw. eine ästhetische ${ }^{22}$ Seite von Kulturlandschaft anzusprechen, um über das Erklären und Verstehen von Kulturlandschaft zu einem Kulturlandschaftsbewusstsein zu kommen, welches hoffentlich Handeln für die Kulturlandschaft und Akzeptanz für Maßnahmen der Kulturlandschaftspflege hervorbringt.

Kulturlandschaftsbildung heißt also, zuvörderst Kulturlandschaft erlebbar zu machen, um dann über räumliche Qualitäten zu sprechen, was zu einem bewussten Umgang mit dem kulturellen Erbe in unseren Landschaften führen soll. Kulturlandschaften sind in diesem Sinne Erlebnis-, Diskurs- und Handlungs-

21 Schenk, Historische Geographie, 116.

22 Siehe dazu Detlev Ipsen, Ort und Landschaft, Wiesbaden: Springer, 2006 und Detlev Ipsen, Uli Reichhardt, Steffi Schuster, Astrid Wehrle und Holger Weichler, Zukunft Landschaft. Bürgerszenarien zur Landschaftsentwicklung, Kassel: kassel university press, 2003. 
räume der Bürgergesellschaft gemäß der Europäischen Landschaftskonvention. Entsprechend der Formulierung in Artikel 1 " Landscape perceived by people, whose character is the result of the action and interaction of natural and/or human factors" ist die Konvention von einem explizit partizipatorischen und konstruktivistischen Ansatz geprägt; nebenbei sei angemerkt, dass »Kulturlandschaft « als die adäquate Übersetzung von landscape ins Deutsche erscheint, ${ }^{23}$ da die anthropogene Perspektive in einer GesellschaftNaturrelation hervorgehoben wird.

Da sich aber das Verständnis von Kultur und auch unsere Kulturlandschaften in ihrem Gefüge und ihrer materiellen Substanz stetig ändern, wird es eine der Aufgaben der zukünftigen Kulturlandschaftsbildung sein, Wege der Erschließung von Kulturlandschaften in einem weiteren Verständnis zu suchen.

Die im Folgenden vorgestellte Idee der »Heimatkisten« für den suburbanen Raum westlich von Köln ist als ein assoziativ-kommunikativer Ansatz in diesem Sinne zu verstehen. Da sich aufgrund unseres tradierten Verständnisses von Kulturlandschaft und der in der Folge eintrainierten Sichtweisen in suburbanen Räumen die kulturellen Konventionen zu den räumlich verortbaren Werten morphogenetisch nicht sofort erschließen, muss das mit einer assoziativ-diskursiven Wahrnehmungsebene ergänzt werden. Dieser Zwischenschritt hilft bei der nachfolgenden Entscheidung der zu erfassenden Strukturen und Elemente weiter. Damit wird ein wahrnehmungsbasierter Ansatz zur Erfassung von kulturellen Werten im suburbanen Raum notwendig. Anstelle von Interviews mit Schlüsselpersonen und regionalen Bewohnern wurde in einer Lehrveranstaltung unter der Leitung des Autors ein kommunikativ-diskursiver Ansatz gewählt, das heißt, Studierende haben sich Teilgebiete des suburbanen Raumes um Köln in Arbeitsgruppen ergebnisoffen genähert. ${ }^{24}$ In Exkursionen und Seminarsitzungen sollte der Frage nachgegangen werden, was die kulturelle Dimension dieses suburbanen Raumes ist. Um dieses zu konkretisieren, sollten Gegenstände erworben und hergestellt werden, die symbolhaft für das kulturelle Erbe stehen und dann in entsprechende "Planungskisten " gelegt werden. Die assoziative Ebene erfolgt mit dem Begriff »Heimat" als alltagssprachlichem Synonym für regionale Identität. Diese Kisten wurden daher »Heimatkisten« genannt. Obgleich es aus organisatorischen Gründen nicht gelang, durch die Ausstellung dieser »Heimatkisten« in öffentlichen Einrichtungen einen breiten regionalen

23 Dazu Winfried Schenk, "Landscape«, in: Ludger Kühnhardt und Tilman Meyer (Hg.): The Bonn Handbook of Globality, Vol. 1, Wiesbaden: VS Springer, 2019, 621-633.

24 Klaus-Dieter Kleefeld und Winfried Schenk, ")Heimatkisten « - Ein kommunikativ-assoziativer Zugang zum kulturellen Erbe in der suburbanen Kulturlandschaft westlich von Köln«, in: Winfried Schenk, Manfred Kühn, Markus Leibenath und Sabine Tzschaschel (Hg.), Suburbane Räume als Kulturlandschaften, Forschungs- und Sitzungsberichte des ARL 236, Hannover: ARL, 2012, 286-302. 
Diskurs um kulturelle Werte im suburbanen Raum westlich von Köln auslösen, zeigte sich doch, dass der Ansatz, auch solche Räume als (Kultur-)Landschaften zu denken, zur Verbreiterung der Perspektiven auf solche Räume führt. Die Geschichtlichkeit auch solcher Räume, ihre identitätsbildende Kraft und ihr überraschender Strukturreichtum werden dann sichtbar.

\section{Literatur}

Karsten Berr und Winfried Schenk. »Begriffsgeschichte (Landschaft)«, in: Handbuch Landschaft, RaumFragen: Stadt - Region - Landschaft, Olaf Kühne et al. (Hg.), Wiesbaden: Springer Nature, 2019, 23-38.

Fürst, Dietrich, Ludger Gailing, Kim Pollermann und Andreas Röhring (Hg.). Kulturlandschaft als Handlungsraum. Institutionen und Governance im Umgang mit dem regionalen Gemeinschaftsgut Kulturlandschaft, Dortmund: Rohn, 2008.

Gailing, Ludger und Andreas Röhring. «Kulturlandschaften als Handlungsräume der Regionalentwicklung. Implikationen des neuen Leitbildes zur Kulturlandschaftsgestaltung ", in: RaumPlanung 136, 2 (2008), 5-10.

Gunzelmann, Thomas und Winfried Schenk. »Kulturlandschaftspflege im Spannungsfeld von Denkmalpflege, Naturschutz und Raumordnung", in: Informationen zur Raumentwicklung 5/6 (1999), 347-360.

Haber, Wolfgang. »Kulturlandschaft zwischen Bild und Wirklichkeit, Hannover«, in: Die Zukunft der Kulturlandschaft zwischen Verlust, Bewahrung und Gestaltung, Akademie für Raumforschung und Landesplanung (Hg.), Hannover: ARL, 2001, 6-29.

Hard, Gerhard. Die "Landschaft» der Sprache und die "Landschaft« der Geographen, Colloqium Geographicum 11, Bonn: Kommission bei F. Dümmler, 1970.

Ders. »Die `Natur der Geographen«, in: Natur in der Moderne. Interdisziplinäre Ansichten, Uli Luig und Hans-Dietrich Schultz (Hg.), Berlin: Berliner Geographische Arbeiten, 2002, 67-85.

Hard, Gerhard und Adelheid Gliedner. »Wort und Begriff Landschaft anno 1976«, in: Die Ware Landschaft, Friedrich Achleitner (Hg.), Salzburg: Residenz Verlag, 1978, 16-24.

Haas, Herbert und Walter Haub: Die Sechziger Jahre und das mainfränkische Dorf, Würzburg: VSG, 1997.

Ipsen, Detlev. Ort und Landschaft, Wiesbaden: VS Verlag, 2006.

Ipsen, Detlev, Uli Reichhardt, Steffi Schuster, Astrid Wehrle und Holger Weichler. Zukunft Landschaft. Bürgerszenarien zur Landschaftsentwicklung, Kassel: kassel university press, 2003.

Gailing, Ludger und Markus Leibenath. »Von der Schwierigkeit, >Landschaft` oder `Kulturlandschaft « allgemeingültig zu definieren «, in: Raumforschung und Raumordnung 70, 2 (2012), 95-106.

Hokema, Dorothea. »Die Landschaft der Regionalentwicklung: Wie flexibel ist der Landschaftsbegriff?", in: Raumforschung und Raumordnung 67, 3 (2009), 239-249.

Kleefeld, Klaus-Dieter und Winfried Schenk. »Heimatkisten - Ein kommunikativ-assoziativer Zugang zum kulturellen Erbe in der suburbanen Kulturlandschaft westlich von 
Köln«, in: Suburbane Räume als Kulturlandschaften, Winfried Schenk, Manfred Kühn, Markus Leibenath und Sabine Tzschaschel (Hg.), Hannover: ARL, 2012, 286-302.

Kühne, Olaf. Landschaft in der Postmoderne. Das Beispiel des Saarlandes, Wiesbaden: VS Verlag, 2006.

Ders. «Der doppelte Landschaftswandel, Physische Räume, soziale Deutungen, Bewertungen «, in: Nachrichten der ARL, 1, 2018, 14-17.

Leibenath, Markus und Ludger Gailing. "Semantische Annäherung an `Landschaft` und 'Kulturlandschaft‘«, in: Suburbane Räume als Kulturlandschaften, Winfried Schenk, Manfred Kühn, Markus Leibenath und Sabine Tzschaschel (Hg.), Hannover: ARL, 2012, 58-79.

Riehl, Wilhelm Heinrich. Naturgeschichte des deutschen Volkes als Grundlage einer deutschen Socialpolitik. Land und Leute, Band 1, Stuttgart/Tübingen: J. G. Cotta'sche Verlagsbuchhandlung, 1854.

Schenk, Winfried. "Aktuelle Verständnisse von Kulturlandschaft in der deutschen Raumplanung ", in: Informationen zur Raumentwicklung 5 (2008), 271-277.

Ders. »Was meint `Kulturlandschaft in der Raumplanung und Regionalentwicklung?«, in: Kulturlandschaften in Geografie und Raumplanung, Verband Deutscher Schulgeographen und Akademie für Raumforschung und Landesplanung (Hg.), Bretten: VDSG, 2009, 12-15.

Ders. Historische Geographie, Darmstadt: Wissenschaftliche Buchgesellschaft, 2011.

Ders. »Landschaft als zweifache sekundäre Bildung. Historische Aspekte im aktuellen Gebrauch von Landschaft im deutschsprachigen Raum, namentlich in der Geographie» in: Landschaften: Theorie, Praxis und internationale Bezüge, Diedrich Bruns und Olaf Kühne (Hg.), Schwerin: Oceano Verlag, 2013, 23-34.

Schenk, Winfried, Klaus Fehn und Dietrich Denecke (Hg.). Kulturlandschaftspflege. Beiträge der Geografie zur räumlichen Planung, Stuttgart/Berlin: Borntraeger, 1997.

Schenk, Winfried, Manfred Kühn, Markus Leibenath und Sabine Tzschaschel (Hg.). Suburbane Räume als Kulturlandschaften, Hannover: ARL, 2012.

Schenk, Winfried: »Landscape«, in: Ludger Kühnhardt und Tilman Meyer (Hg.): The Bonn Handbook of Globality, Vol. 1, Wiesbaden: VS Springer, 2019, 621-633. 
Open-Access-Publikation im Sinne der CC-Lizenz BY 4.0

(c) 2020, Vandenhoeck \& Ruprecht GmbH \& Co. KG, Göttingen ISBN Print: 9783847107507 - ISBN E-Lib: 9783737007504 


\section{Landschaften Lesen - Variable Identitäten von}

Kulturlandschaft 
Open-Access-Publikation im Sinne der CC-Lizenz BY 4.0

(c) 2020, Vandenhoeck \& Ruprecht GmbH \& Co. KG, Göttingen ISBN Print: 9783847107507 - ISBN E-Lib: 9783737007504 


\section{Gabi Dolff-Bonekämper}

\section{In anderer Leute Vergangenheit gehen}

\section{Vorbemerkung}

Dass vergangene Ereignisse in topografisch und sozial fassbaren Rahmen verortet und erinnert werden, und dass sie, wenn Personen oder Gruppen in Bewegung geraten und soziale und politischen Rahmen sich verschieben, gegebenenfalls neu verortet und anders erinnert werden, gehört zu den wesentlichen Erkenntnissen des Soziologen Maurice Halbwachs. ${ }^{1}$ Die raumbezogen argumentierende Geschichtswissenschaft, die von Fernand Baudel ${ }^{2}$ und, in jüngerer Zeit, von Pierre Nora und anderen Autoren das Konzept der lieux de mémoirel Erinnerungsorte übernommen und abgewandelt hat, führt ihre Leserinnen und Leser aus den Büchern hinaus zu den Orten, wo dingliche und nicht dingliche Zeugnisse bewahrt sind und Vergangenheiten vergegenwärtigt und in jeweils persönlichen Lernerlebnissen erkannt werden. ${ }^{3}$ Betrachtet man die Orte in thematischen Verbünden, die chronologisch, politisch, wirtschaftlich oder infrastrukturell begründet sein können, dann ergeben sich komplexe Verflechtungen von Räumen, Wegen und Zielen, die im städtischen und, vorzugsweise, im kultur-landschaftlichen Raum erkannt, historisiert und im jeweils angemessenen Maßstab erforscht und weitergegeben werden können.

Überlagerungen und mögliche Verschiebungen sozialer und topografischer Rahmen erzeugen Spannungen im Verhältnis von Bevölkerungen zu eigenen oder sagen wir als »eigen« empfundenen sowie zu benachbarten gegebenenfalls

1 Vgl. Maurice Halbwachs, Les cadres sociaux de la mémoire, Paris: Librairie Félix Alcan, 1925 und ders.: La topographie légendaire des evangiles en Terre sainte, Paris: Presses Univ. de France, 1941.

2 Fernand Braudel, La Méditerranée et le monde méditeranéen à l'epoque de Philippe II, Paris: Armand Colin, 1949.

3 Pierre Nora, Les Lieux de mémoire, 3 Bde., Paris: Gallimard, 1984-1994; Etienne Francois und Hagen Schulze, Deutsche Erinnerungsorte, München: C.H. Beck, 2001; Hans Henning Hahn, Robert Traba, Oliver Loew, Deutsch-Polnische Erinnerungsorte, 5 Bde., Paderborn: Schöningh, 2012-2019. 
als »fremd « empfundenen Orten und Vergangenheiten. Die Frage, ob und gegebenenfalls wie lange zugewanderte Personen die Vergangenheiten ihres Herkunftsortes weitertragen oder ob und wann sie als neue Akteure in die cadres locaux und damit möglichweise auch die cadres sociaux ihres Ankunftsortes in Stadt und/oder Landschaft eintreten oder ob sie neue, eigene, möglicherweise hybride und doch durchaus örtlich fassbare Rahmen ausbilden, Räume besetzen und Vergangenheit produzieren, hängt von vielen Faktoren ab, die ich im konzeptuellen ersten Teil des Aufsatzes erläutere.

Wer, so wie ich es in meinem Aufsatz schildere, forschend in anderer Leute Gegenwartsräume eintritt und dort materielle Relikte und Zeichen sowie medial fassbare Narrative erfasst, die von vergangenen Ereignissen zeugen, forscht und geht also gewissermaßen »in anderer Leute Vergangenheit«. Das kann in einem anderen Land geschehen aber ebenso hinter der nächsten Straßenkreuzung. Da an einem Ort gewöhnlich nicht nur eine Vergangenheitsspur zu verzeichnen ist, und da nicht alle Forschenden dieselben Ereignisse verfolgen, ergeben sich in der Anlage von Forschungswegen Begegnungen, Überlagerungen, Schnittpunkte und überraschende, ganz ungeplante Zugänge, vielleicht zu einem Abseits, das auf lange Zeit keiner betreten hat. Auch die Wege selber können zum Forschungsgegenstand werden, wenn durch die Begehung oder Befahrung sozialräumliche Bezüge, Distanzen, Reisedauer und Transportmodalitäten in größeren topografischen und historischen Konstellationen, die wiederum vorzugsweise kulturlandschaftlich zu fassen sind, nachvollzogen werden können. Dies ist vor allem für meinen Bericht über die Erkundung der Stadt und der Umgebung von Konin maßgebend. Die Orte der Verfolgung, Deportation und Ermordung der jüdischen Bewohnerinnen und Bewohner Konins sind nur im Maßstab der im Raum und Umraum der Stadt anzutreffenden Fluß-, und Waldlandschaft und der auf weite Räume in ganz Europa ausgreifenden Beherrschung und Steuerung von Transportwegen und -medien durch die deutsche Besatzungsarmee begreifbar. In all dem liegt eine starke Bezugnahme auf den Maßstab und die Eigenart von Kulturlandschaft(en).

Die Selbstverortung der Forscherin, die Offenlegung des eigenen Weges, der gegangen und gedacht sein wollte, also das Ich in meinem Text, ist für die Perspektivierung der Ergebnisse unverzichtbar. In der diskutierten Sache gibt es keinen neutralen Standpunkt.

\section{Aktuelle Zeugenschaft}

Oradour sur Glane, August 1967, ich bin 15 Jahre alt. In Oradour sur Glane im Limousin, in der Südhälfte Frankreichs, hat eine Kompanie des SS-Panzergrenadier-Regiments »Der Führer« am 10. Juni 1944, als Vergeltung für eine Aktion 
der Résistence, die gesamte Bevölkerung getötet. Die Frauen und Kinder wurden in der Kirche zusammengetrieben, dann das Dorf und die Kirche in Brand gesteckt. Die Männer wurden erschossen. 642 Menschen starben, nur sechs überlebten. Ich gehe, 23 Jahre später, durch Oradour sur Glane, bewege mich vorwärts und sehe im Gehen die konservierten und für die Besichtigung stabilisierten Ruinen, die Hinweisschilder, die Indizien und Zeugnisse des Massakers und des Brandes und verstumme vor Schrecken und Anteilnahme. Werde, gehend, zur Zeugin, nicht des Geschehens von damals - es liegt in der Vergangenheit des Ortes - sondern meines eigenen Erlebens und meines Wissenserwerbs. Der Ort hält eine Vergangenheit für mich bereit, der ich anderswo so nicht begegnen kann.

Diese Vergangenheit gehört zu den heutigen Bewohnern des Landstriches im Limousin. Es ist die Vergangenheit der Franzosen, die die Vernichtung des Dorfes und seiner Einwohner als national wichtiges Kriegsereignis kennen. Sie entschieden sich, den Ort zu bewahren, die Ruinen dauerhaft $\mathrm{zu}$ sichern und damit die Möglichkeit, das Wissen über das Ereignis fortwährend weiterzugeben.

Ich treffe hier aber auch auf die Vergangenheit meines Vaters: Er war als Soldat in Frankreich, er liebte das Land und die Sprache. Im Juli 1944 war er im Norden des Landes stationiert, weit weg von Oradour, hatte aber, wie er berichtete, schon damals von dem Massaker gehört. Als Angehöriger der Wehrmacht musste er sich, auch aus der Entfernung, zum Kreis der Verantwortlichen rechnen. Mit dem Besuch im Jahre 1967 strebt er, wie ich denke, eine direkte, aktuelle Zeugenschaft an und damit wohl auch eine Art von Entschuldung. Und selbst ich begegne in Oradour auch meiner eigenen Vergangenheit, insofern, als ich spüre, dass ich als Deutsche in der Gegenwart von 1967 dem äußeren Kreis derer zugehöre, die sich für mitverantwortlich halten können. Ob wir damals den Franzosen in Oradour willkommen waren, ist nicht mehr zu klären.

In meiner Erinnerung an den Besuch in Oradour ist auch das Gehen wichtig, meine eigene physische Präsenz und meine Bewegung durch den Ereignisraum. Ich hätte wohl über das Geschehen in einem Buch lesen können, still und aufmerksam, an einem anderen Ort. Auch dies hätte sich einprägen können, ich hätte mich später vermutlich erinnert, wo und wann ich das Buch las. Da ich aber selber durch den Ereignisraum gegangen bin, hat sich mein Erleben des Ortes auf besondere Weise eingeprägt. Gesehene Bilder, persönliche Empfindungen und Körpergefühl sind gemeinsam mit dem erworbenen Wissen als Gesamtheit in meinem Gedächtnis nachhaltig bewahrt. 


\section{Leitfragen}

Welches Material liefert dieser Bericht für ein Modell zur konzeptuellen Verknüpfung von Gehen, Schauen, Raumerleben, Wissenserwerb, Zeugenschaft und Erinnerung? Wenn eine Person in einen vorher nicht gekannten Raum hineingehen kann und dort die Relikte und Indizien einer Vergangenheit erkennt und interpretiert, die nicht die ihre ist, welche Folgen hat dies für die Person, die ja selber stets eine eigene Vergangenheit mit sich trägt? Wie erleben die angestammten Bewohner das Eintreten fremder Personen in ihren gegenwärtigen Raum und deren Anteilnahme an ihrer Vergangenheit? Wie wichtig ist es für die Besucher, am Ort willkommen zu sein? Wie wichtig sind, für Besucher und Besuchte gleichermaßen, Herkunft und Gruppenzugehörigkeit? Wie bestimmt sich das Spannungsfeld zwischen individuellen Herkunftsbindungen und persönlichen Optionen des Hinzutretens ${ }^{4}$ - oder auch des »Hinwegtretens «, wenn man einräumt, dass es auch Personen geben kann, die nicht an ihrem Ort und nicht in ihrer kulturellen Referenzgruppe bleiben und sich von ihrer "eigenen« Vergangenheit absetzen wollen.

\section{Vergangenheiten}

»Vergangenheit ist abstrakt, bis sie zu jemandem gehört.« (Julian Bonekämper)

Jan Assmann schreibt im Maurice Halbwachs gewidmeten Kapitel seines Buches Das kulturelle Gedächtnis: »Was P.L. Berger und Th. Luckmann für die Wirklichkeit im Ganzen gezeigt haben, hat Halbwachs, 40 Jahre vorher, für die Vergangenheit behauptet: sie ist eine soziale Konstruktion, deren Beschaffenheit sich aus den Sinnbedürfnissen und Bezugsrahmen der jeweiligen Gegenwart ergibt. Vergangenheit steht nicht naturwüchsig an, sie ist eine kulturelle Schöpfung. “ ${ }^{5}$ Dem will ich hier folgen und werde daher das Wort Vergangenheit in den Plural setzen, da in jeder neuen Gegenwart neue Vergangenheiten und

4 Hinzutreten ist eine einseitige Annäherung, mit dem Risiko behaftet, nicht willkommen zu sein. »Hinzutreten« schafft, im Gegensatz zu »Eintreten« oder »Beitreten« keine Verbindlichkeiten, es müssen keine Satzungen oder Regeln anerkannt werden. »Momente des Hinzutretens" sind Momente, präzise in Zeit und Raum, in denen eine Person sich von ihrer angestammten Gruppe, ihrem Ort, ihrer kulturellen Referenzgruppe entfernt, um einer anderen, bis dahin nicht gekannten oder nicht geschätzten Gruppe näher zu treten. Solche Momente, in denen Individuen ihre Bewegungsmöglichkeit wahrnehmen, erweisen sich als Gelenkstellen im System der bereits organisierten europäischen Gedächtniskollektive.

5 Jan Assmann, Das kulturelle Gedächtnis. Schrift, Erinnerung und politische Identität in frühen Hochkulturen, München: C.H. Beck, 2007, 48. 
selbst in ein und derselben Gegenwart, von unterschiedlichen Interessen geleitet, verschiedene Vergangenheiten konstruiert werden können. Die Beschaffenheit der Vergangenheiten ergibt sich aus Sinnbedürfnissen und Bezugsrahmen der jeweiligen Gegenwart.

Wie soll man das verstehen? Hinter der Sachlichkeit und Abstraktheit dieser beiden Begriffe tut sich ein weites Feld möglicher Auffassungen, Dissense und Konflikte auf. Es ist mit verschiedenen Lesarten, Deutungshoheiten und Machtansprüchen von Regierenden und anderen Akteuren zu rechnen, mit Mehrheiten und Minderheiten, die in ihrer Gegenwart (mit-)bestimmen wollen, was heute oder in Zukunft über die eigene Vergangenheit gesagt werden soll bzw. darf und was nicht. In anderem Zusammenhang wurde dies als »Geschichtswollen « bezeichnet. $^{6}$ Was erwähnt und was vergessen wird, was beschönigt, was erfunden, was weitergegeben und was aktiv beschwiegen, ergibt sich, je nach Regierungsform, durch autoritäre Setzung oder durch komplexe Aushandlungsprozesse, die jederzeit neu beginnen können, wenn neue Fakten aufgeworfen werden oder andere Akteure die Bühne betreten.

Das bringt mich zu der Frage, was genau eine »soziale Konstruktion" sein soll und wie man sich ihre Entstehung vorstellen kann. Der Ausdruck wird heute vielfach verwendet, um klarzustellen, dass Wert und Sinn gesellschaftlich zugewiesen - also »konstruiert « werden und nicht dem Gegenstand innewohnen. ${ }^{7}$ Das klärt aber noch nicht, wie solch ein sozialer Konstruktionsvorgang abläuft. Man kann davon ausgehen, dass mindestens zu Beginn das Wissen und Wollen der Beteiligten ungleich ist, dass ihre Perspektiven und ihre Urteile verschieden sind und ihre Ziele divergieren. Es kommt also sehr drauf an, wer in welchem Falle den Aushandlungsprozess organisiert und moderiert, wer das Wort hat, wer es ergreift, wer wem zuhört und wer das Ergebnis formuliert und weitergibt. Und damit ist noch nicht entschieden, wer sich wie lange an das einmal Ausgehandelte gebunden fühlt und ob nicht ein Minderheitenvotum wieder aufge-

6 Gabi Dolff-Bonekämper, „Wahr oder falsch. Denkmalpflege als Medium nationaler Identitätskonstruktionen «, in: Otto Gerhard Oexle (Hg.), Bilder gedeuteter Geschichte. Das Mittelalter in der Kunst und Architektur der Moderne [Kolloquium »Bilder Gedeuteter Geschichte Das Mittelalter in der Kunst und Architektur der Moderne«, das am 20. und 21. Juni 2003 im Max-Planck-Institut für Geschichte in Göttingen stattfand], Göttingen: Wallstein, 2004, 231-285. Hier besonders: »Ich will damit keinesfalls auf die Konstruktion eines jeweils epochenspezifischen Gesamtwollens hinaus, sondern im Gegenteil auf die Berücksichtigung von Divergenzen und Dissensen zwischen gesellschaftlichen Gruppen und Interessenträgern, die sich nicht nur, aber auch, in unterschiedlichem Geschichtswollen artikuliert.«, ebd., 277.

7 Ich habe über die Vorgänge der sozialen Wertzumessung für Denkmäler an anderer Stelle ausführlich geschrieben: Gabi Dolff-Bonekämper, »Gegenwartswerte. Für eine Erneuerung von Alois Riegls Denkmalwerttheorie«, in: Hans-Rudolf Meier und Ingrid Scheurmann (Hg.), DENKmalWERTE. Beiträge zur Theorie und Aktualität der Denkmalpflege. Georg Mörsch zum 70. Geburtstag, Berlin/München: Deutscher Kunstverlag, 2010, 27-40. 
griffen wird und am Ende die Partei gewinnt, die am Anfang die wenigsten Chancen zu haben schien.

Es steht außer Frage, dass Vergangenheitsbeherrschung sowohl ein Feld als auch ein Mittel der staatlichen und nichtstaatlichen Gegenwartspolitik ist. Hierzu schreibt Robert Traba, Mitherausgeber der Buchreihe »Deutsch-Polnische Erinnerungsorte«:

The sights in terms of creating images of the past are set by current dominant trends and the political and cultural climate. The past in the present is always a response to the ideological needs of contemporaneity, not to an intellectual challenge to reconstruct historical phenomena and processes. ${ }^{8}$

Das Verhandeln über Vergangenheiten ist daher nicht umsonst, insbesondere unter Nachbarn, die voneinander wissen und ähnliche oder gar zeitgleiche und gegebenenfalls ortsgleiche Ereignisse verschieden erlebt haben und aus unterschiedlicher Perspektive bewerten - ein langwieriger, konfliktdurchsetzter Vorgang, der allerdings unverzichtbar ist, will man eine politische und kulturelle Nähe erzeugen oder behalten. Dafür stehen die jahrelangen Debatten diverser bilateraler Schulbuchkommissionen, die darüber zu verhandeln haben, was in deutschen und französischen, polnischen oder tschechischen Geschichtsbüchern über die jeweils eigene und die jeweils andere Seite stehen soll. Die Herausforderung besteht darin, eine Verständigung darüber herbeizuführen, wie Unterschiede zwischen den jeweiligen Vergangenheiten in der Gegenwart ins gemeinsame Denken einbezogen werden können, nicht darin, wie man diese beseitigt.

Was für benachbarte Nationalstaaten gilt, gilt gleichermaßen für Regionen, Städte, Quartiere und ebenso für Gemeinschaften, die am selben Ort leben, aber aufgrund ihres Standes, ihres Berufes, ihrer Herkunft oder ihrer kulturellen Zugehörigkeit jeweils andere Ereignisse erwähnen und weitergeben bzw. weglassen. Man kann damit rechnen, auch hier mit Vergangenheits-Nachbarschaften konfrontiert zu werden, die alte Feindschaften weitertragen, aber auch neue Freundschaften begründen können. Ich schlage daher vor, auf allen räumlichen und sozialen Maßstabsebenen von »benachbarten Vergangenheiten« zu sprechen, die sich von jeweils »eigenen Vergangenheiten« unterscheiden. Dazu will ich noch die Kategorie der »fremden Vergangenheiten« stellen.

Die »eigene« Vergangenheit wird aus Selber-Erfahrenem und -Gelerntem gespeist, das allerdings immer schon im Bezugsrahmen einer sozialen und kulturellen Referenzgruppe gedeutet ist. Die »eigene Vergangenheit« einer Gruppe bildet sodann, unter Einbeziehung anderer als »eigenen« apostrophierter Merk-

8 Robert Traba, » It was Only a Film!،. Three Images of Conflict and Dialogues of Memory«, in: Międzynarodowe Centrum Kultury (Kraków) (Hg.), Pamiec Rejestry i terytoria /Memory, Registers and Territories, Kraków: Międzynarodowe Centrum Kultury, 2014, 15-22, 16. 
male wie Ethnie, Sprache oder Religion, die Basis für identitätspolitische Setzungen und Bestimmungen, die die Gemeinschaft stärken sollen. Diese werden gewissermaßen von einer höheren Warte aus formuliert und erhalten ihre Allgemeingültigkeit, Verbindlichkeit und Autorität durch Abstraktion vom Einzelschicksal. Was als »eigene Vergangenheit » verinnerlicht wird, unterliegt also in hohem Maße äußeren Bestimmungen, die paradoxerweise die Empfindung des Eigenen nicht schwächen, sondern verstärken. In diesem Modell fehlt aber noch ein für viele Zeitgenossinnen und -genossen essentieller Gesichtspunkt: der der Mobilität. Immer weniger Menschen leben heutzutage dort, wo sie - oder gar ihre Eltern und Vorfahren - geboren wurden, die sozialen und lokalen Bestimmungen von Personen sind selten tatsächlich kongruent, verlässlich und konstant. Dennoch wird dies oft behauptet, als Heimatverbundenheit gepriesen und als Druckmittel, als großes WIR aufgebaut. Damit entfaltet es Bindungen, denen schwer zu entrinnen ist: Zum großen WIR gehört logischerweise ein großes NICHT WIR, das den Zugang zum Eigenen eng hält und die Grenzen zum Nachbarn verfestigt.

Mit »benachbart« will ich die Vergangenheiten bezeichnen, die dicht neben der jeweils eigenen liegen und sich doch merkbar unterscheiden. Ihre Hauptund Nebenereignisse werden aus verschiedenen Perspektiven gesehen und erhalten durch unterschiedliche Erfahrungshorizonte eine spürbar andere Wendung. Die Rolle der jeweils Anderen im eigenen Vergangenheitsnarrativ kann sowohl Freundschaften als auch Feindschaften fortschreiben, gegebenenfalls über Jahrhunderte. Als »fremd « bezeichne ich hier einstweilen Vergangenheiten, die räumlich oder kulturell in größerer Ferne liegen und zu denen nur wenige Personen über Wissen und Deutungen verfügen, die aber jederzeit, durch Ortsveränderung oder persönliche Kontakte, ganz nahe rücken können - ohne indes die vertrauten Motive früher gelebter Nachbarschaft zu enthalten.

Die konkrete Bestimmung des jeweils Eigenen, Benachbarten oder des Fremden kann logischerweise nur in Abhängigkeit von der konkreten Perspektive einer Person oder einer Gruppe erfolgen. Sie muss sich verändern, wenn eine Person an einen anderen Ort übersiedelt oder in eine andere Bezugsgruppe wechselt, die am selben Ort einen anderen sozialen Rahmen absteckt. Das »Eigene" kann sich unversehens in die Ferne verlagern und das "Fremde» kann dicht neben dem »Eigenen« beginnen. So entstehen fortwährend neue Nachbarschaften. $\mathrm{Ob}$, wie und wann damit auch neue Optionen der individuellen Zugehörigkeit entstehen, ob, wie und wann Personen mit eigenen, angestammten Vergangenheitsbindungen an einem anderen Ort einer anderen Vergangenheit nähertreten können, hängt nicht nur von ihrem eigenen Wollen, sondern auch von ihrem Handlungsrahmen im örtlichen Gemeinwesen ab.

In der rückblickenden Rekonstruktion meiner Reise nach Oradour sur Glane wird mir deutlich, dass ich dort im Gehen durch den Raum mehreren Vergan- 
genheiten zugleich nähergetreten bin, die ich heute anteilig als eigene, benachbarte und fremde identifizieren kann. Und ebendiese, mir damals nicht in ihrer vollen Reichweite begreifbare Erfahrung ist nun Teil meiner persönlichen, eigenen Vergangenheit, an die ich mich gebunden fühle. Ich bin nicht an den Ort zurückgekehrt.

\section{Ortszugehörigkeit, Ortsbindung und Ortsansässigkeit}

Ortszugehörigkeit kann als behördlich definierter, legaler Status einer Person aufgefasst werden, der Ortsansässigkeit (also eine beim Einwohnermeldeamt bekannte Adresse) erfordert und staatsbürgerliche Rechte und Pflichten untermauert. Oder als soziale Zuschreibung durch Dritte, die eine Person als zu einer örtlichen Gemeinschaft/Kommune zugehörig oder nicht zugehörig einschließt oder ausschließt. Ortszugehörigkeit ist aber auch eine persönliche Empfindung, die sich aus Herkunft und eventuell langjähriger Ortsansässigkeit der Familie, Vertrautheit mit der Umgebung, Wissen über die Geschichte und vielfältigen Alltagserfahrungen nähren kann. Dies alles mag eine starke Ortsbindung erzeugen, die wir als Heimatgefühl bezeichnen.

Die Frage ist nun, welche Bedeutung in diesem Zusammenhang der Zeit zukommt. Wie und wann wird aus Ortszugehörigkeit Ortsbindung und ist das überhaupt ein erstrebenswerter Zustand? Wie nachhaltig bewahren sich Ortsbindungen? Kann man sie im Bedarfsfall auch loswerden? Wie lange muss etwa eine Person an einem Ort ansässig sein, um als ortszugehörig zu gelten oder sich zumindest so zu fühlen? »How much time do you need to become local?«, so formulierte es die in England lebende chinesische Künstlerin Judy Ling Wong. ${ }^{9}$ Und ab wann werden Personen das Wort ergreifen, wenn es um die Konstruktion lokaler Vergangenheiten geht? Es scheint mir nicht angemessen, die Verweildauer zum einzigen Gradmesser zu machen, auch die mögliche Verweilabsicht und die persönlich empfundene Zugehörigkeit sollte beachtet werden. Daher schlage ich vor, alle drei Parameter zu berücksichtigen und folgende Varianten persönlicher lokaler Zugehörigkeit zu unterscheiden:

9 Judy Ling Wong ist Präsidentin des Black Environment Networks (BEN) London, das für die Beteiligung von Einwanderern an Debatten um die natürliche und gebaute Umwelt eintritt. Sie sagte diesen Satz auf einer den "European Heritage Days « gewidmeten Tagung des Europarates 2008 in Brüssel. http://ec.europa.eu/culture/news/ne0035-launch-of-the-2008-euro pean-heritage-days_en.htm, Artikel ist nicht mehr verfügbar. Vgl. auch François Matarasso, "Open Doors and open minds«, First European Heritage Forum on »Heritage and Dialogue«, Brüssel, 23.-24. Oktober 2008, Report DGIV/PAT/JEP(2008)20rev, CDPATEP(2008)32rev, 14. Januar 2009. 
- die Alteingesessenen (old locals),

- die neu Hinzugezogenen (new locals),

- die ehemals Ansässigen (former locals),

- und die Besucher, egal, wie lange sie bleiben (non-locals). ${ }^{10}$

Die englischen Begriffe haben den Vorteil, dass sie lokale und soziale Zugehörigkeit in zwei Worten zusammenfassen, daher werde ich sie im Weiteren verwenden.

Mit old locals sind Personen gemeint, deren Familien schon lange Zeit an einem Ort leben, die, mit Begriffen wie »alteingesessen «, »angestammt « oder »de souche (frz.: mit der Scholle verbunden) bezeichnet, als quasi naturwüchsig mit dem Ort verwachsen gelten und das auch selber so empfinden. Mit diesem Status verbinden sie eine Art Urheberrecht in Bezug auf lokale Vergangenheiten, das auch das Verbergen oder aktive Beschweigen von Ereignissen und Sachverhalten einschließen kann.

New locals bezeichnet Personen, die in jüngerer Zeit hinzugekommen sind und als "zugezogene" Neubürger, egal welcher Herkunft, noch im Wartestand für die Aufnahme in den inneren Kreis der Ortsansässigen verharren. Die Wartezeit kann einige Jahre betragen, kann sich aber auch über einen Generationswechsel ausdehnen. New locals haben am neuen Ort (noch) keine Vergangenheit.

Former locals sind Personen, die früher einmal am Ort lebten, ihn aber freiwillig oder gezwungen, aus politischen oder wirtschaftlichen Gründen verlassen haben: Weggezogene, Auswanderer, Vertriebene, Exilierte oder Migranten, die ihre Verbundenheit mit ihrer alten Vergangenheit in ihrer alten Heimat noch über Jahrzehnte, gegebenenfalls über Jahrhunderte, weitertragen.

Non-locals bezeichnet Besucher, Reisende oder Forschende, die sich nur vorübergehend am Ort aufhalten und nicht ansässig werden. Sie können dort die Zeichen fremder oder benachbarter Vergangenheiten erkennen, sie besichtigen und bearbeiten. Sie können sich, obwohl sie nicht bleiben, als ortszugehörig empfinden.

Es liegt nahe zu vermuten, dass der Mitsprachewunsch und das Mitspracherecht bei der Konstruktion lokaler Vergangenheiten mit der Dauer der Orts-

10 Die englischen Begriffe habe ich anlässlich des »Meetings on the `European Dimension` of Heritage Days Events - Strasbourg (France)«, 11. bis 12. Dezember 2011, http://www.coe.int/ t/dg4/cultureheritage/heritage/ehd/2011/EDimension_en.asp, Artikel ist nicht mehr verfügbar, zuletzt geprüft am 22. Februar 2018, in Straßburg eingebracht und seitdem vielfach verwendet. Den Ausdruck und das Konzept der former locals hat der belgische Referent Piet Jaspaert beigesteuert. Jelena Mocevic, »Meeting on the Theme of $>$ The European Dimension of Heritage Days Events« Strasbourg (France)«, 11-12 December 2011, Meeting Report DGIV/PAT/JEP(2011)14 2012. 
zugehörigkeit ansteigt, diese also voraussetzt. Es kann indes beobachtet werden, dass die Auseinandersetzung mit lokalen Vergangenheiten selbst ein Medium der Annäherung sein kann, zum Beispiel in durchaus konfliktuellen Auseinandersetzungen um die Deutung von Ereignissen der jüngeren und älteren Geschichte. Diese werfen zwar Dissense auf, sie bringen aber auch Akteure zusammen, die einander in einer Debatte um eine »dritte Sache« näher kommen können, egal wie lange sie schon am Ort wohnen oder woher sie gekommen sind. Dies kann den Vorgang der Beheimatung positiv beeinflussen. Ortsansässigkeit, Ortszugehörigkeit und Ortsbindung werden in Fallbeispielen im zweiten Teil des Aufsatzes eine wichtige Rolle spielen, dort werden die vier Varianten des »Local«-Seins wieder aufgegriffen.

\section{Materielle und soziale Topografien und Beheimatung}

Wer an einen vorher nicht gekannten Ort, in eine Stadt kommt, um sich dort dauerhaft oder auch nur vorübergehend aufzuhalten, wird auf Raumstrukturen, Straßen und Plätze, Bauwerke und Bildwerke, Zeichen und Relikte treffen, die ortsfest sind und, in vielfacher Überlagerung, vom Gewesenen, Gewollten und Gewordenen in einer Stadt, einem Dorf, einer Landschaft zeugen. Je nach fachlicher Kompetenz und aufgewandter Mühe können solche materiellen Spuren auch von new locals und non-locals gelesen und gedeutet werden. Sie sind indes nicht das Gedächtnis oder die Träger von Erinnerung, wie gern behauptet wird. Sie sind materielle Ressourcen, schon vielfach angeeignet und gedeutet, die verschiedene Vergangenheiten evozieren können und in immer neuen Gegenwarten von immer anderen Personengruppen stets aufs Neue angeeignet werden können - vorausgesetzt, sie werden nicht beseitigt. Die niederländische Denkmalpflegerin Marieke Kuipers hat dies »Multichronologizität « genannt. ${ }^{11}$

$\mathrm{Zu}$ dieser materiell-räumlichen Topografie kommt die Ereignistopografie, die in lange bestehenden und von verschiedenen Bevölkerungsgruppen dicht bewohnten Städten mehrschichtig und komplex ausfallen kann, da sich an ein und demselben Ort zahlreiche verschiedene Ereignisse zugetragen haben können. Wer diese Orte in welches Vergangenheitsnarrativ einbaut, hängt wiederum von den von Assmann genannten Bezugsrahmen und Sinnbedürfnissen ab. Orte werden somit mehrfach codiert, oft auch mehrfach benannt; im cadre local

11 Marieke Kuipers, „Conserveren in de wegwerpmaatschappij. Pleidooi voor een polychrone cultuur«, Habilitationsvortrag vom 30. März 2001 an der Universität Maastricht, Maastricht 2001. Kuipers spricht dort von »chrono-diversiteit« und von »polychrone cultuur«, ebd., 27. 
stoßen sich verschiedene cadres sociaux..$^{12}$ Wer hier hinzutritt, hat die Wahl, dem einen oder dem anderen näherzutreten oder selbst eine neuen Rahmen aufzuspannen. Dies setzt aber voraus, dass er oder sie den lokalen Narrativen nachgeht, Akteuren zuhört, selber Fragen stellt und sich nicht nur dem Raum, sondern auch den Erzählungen aussetzt. Mit anderen Worten: wer hinzutritt, muss sich bewegen, durch den physischen Raum der Bauten und Zeichen, wie durch den sozialen Raum der Codierungen und Narrative. So schreibt Karsten Drohsel in seiner Arbeit über das Gehen als Entdeckungs- und Mnemotechnik:

Es kann also festgestellt werden, dass es beim »Sehen« von Geschichte primär um Sichtbarkeit und Unsichtbarkeit von historischen Prozessen und Ereignissen geht, die in ihrer Raumwirksamkeit Spuren hinterlassen haben. Durch deren Kenntnis und die Fähigkeit, diese zu lesen, ist es möglich, Strukturen und Verhältnisse zu entziffern und Fragen an die Geschichte des Ortes zustellen. Im Grunde wird durch diese Fähigkeit ein objekt- oder zeitgebundener Diskurs erst möglich. ${ }^{13}$

Hier wird klar, warum es wichtig ist zu gehen; denn nur im Gehen, in der stetigen Veränderung der eigenen Position und Perspektive erfährt man den Ereignisraum in allen seinen Dimensionen, das Gesuchte und das Unerwartete, die Fassaden und die Rückseiten, die Bauten und die Menschen, die Rhythmen und die Choreografien des öffentlichen Lebens in einer Stadt. Den Weg, den man gegangen sein wird, kann man später als persönlichen Lernweg bezeugen und memorieren.

\section{Orte des Geschehens - Orte der Weitergabe}

Wer ein Ereignis wirklich verstehen und im buchstäblichen Sinne begreifen will, wird sich also aufmachen, um den Ort des Geschehens aufzusuchen, der das Vergangene so viel wirkmächtiger evoziert, als es ein Text, ein Bild oder ein Relikt in einem Museum je könnte. Die Präsenz des Vergangenen wird im Gegenwartsraum erlebt. Sagen zu können »hier ist es geschehen « und »ich war dort" bekräftigt die persönliche Gewissheit des Besuchers/der Besucherin, zum Zeugen geworden zu sein - so, wie es mir in Oradour sur Glane erging. Für ge-

12 Ich habe Maurice Halbwachs' Konzept von den »cadres sociaux de la mémoire« um die "cadres spatiaux « erweitert, in älteren Schriften die Bestimmung von Kulturerbe und hier auf die Bestimmung von Vergangenheiten übertragen. Vgl. engl. Übersetzung: dies., »The social and spatial frameworks of heritage - What is new in the Faro Convention?«, in: Council of Europe (Hg.), Heritage and beyond, Straßburg: Council of Europe Publishing, 2009, 69-74. Vgl. auch Maurice Halbwachs, Les cadres sociaux de la mémoire, Reprint der Ausgabe von 1935, Paris: A. Michel, 2004.

13 Karsten Michael Drohsel, Das Erbe des Flanierens. Der Souveneur - ein handlungsbezogenes Konzept für urbane Erinnerungsdiskurse, Bielefeld: transcript, 2016, 164. 
wöhnlich sind allerdings solche Orte nicht »einfach so" erhalten, sondern durch Maßnahmen der Erhaltung und Pflege, der Vermittlung und gelegentlich der Inszenierung verändert - Maßnahmen, die von früheren Sinnbedürfnissen, Bezugs- und Handlungsrahmen der ortsansässigen bzw. der lokal zuständigen Akteure zeugen. Wer hier hinzutritt, trifft auf eine bereits konsolidierte Auffassung vom Geschehen, auf eine Vergangenheitskonstruktion, die andere errichtet haben. Betritt er damit anderer Leute Vergangenheit?

Komplizierter wird die Sache in einer großen, dicht bebauten und dicht bevölkerten Stadt, wo Orte gewöhnlich von zahlreichen unterschiedlichen Ereignissen zeugen, die wiederum von unterschiedlichen Gemeinschaften für wichtig gehalten und als Bausteine ihrer eigenen Vergangenheit weitergegeben werden sollen. Vielfältige Bezugsrahmen, Sinnzuschreibungen und Sinnbedürfnisse überkreuzen einander, die Ereignistopografien einzelner Gruppen erzeugen unterschiedliche Codierungen derselben Orte, die sich nur dann erschließen, wenn die Möglichkeit der Weitergabe und die Bereitschaft zur Aufnahme gegeben sind. Wo man dann genau in wessen Vergangenheit umherwandert und welche Grenzen man gerade überschreitet, lässt sich nur annäherungsweise bestimmen. Wer sich in Zukunft wo in Gemeinschaft mit wem an was erinnern und möglicherweise eine neue gemeinsame Vergangenheitskonstruktion errichten wird, lässt sich durch die Bewahrung und Erklärung von Orten beeinflussen, aber nicht planen.

Die Beziehung zwischen Orten und Erinnerungen ist durch die Arbeiten von Pierre Nora, Hagen Schulze und Etienne François sowie Robert Traba und Hans Henning Hahn ${ }^{14}$ eingehend beschrieben worden und ist in dem Ausdruck lieux de mémoire - »Erinnerungsorte« im Diskurs über Vergangenheiten seit geraumer Zeit zu Recht allgegenwärtig. Der konkrete örtliche Rahmen der Erinnerung wird dem sozialen Bezugsrahmen gewissermaßen begrifflich vorangestellt, man könnte von der Priorität des Topos sprechen. ${ }^{15}$ Der Ort wird zum Träger und Auslöser der "mémoire«, ein Wort, das im Französischen - je nach Kontext sowohl Erinnerung als auch Gedächtnis bedeuten kann.

Das ursprünglich auf eine klassenübergreifende soziale und kulturelle Konsensbildung über Vergangenheit in Frankreich zielende Konzept der lieux de mémoire hat indes eine Tendenz zur Harmonisierung der Akteurskonstellatio-

14 Pierre Nora, Les lieux de mémoire, Band 1, Paris: Gallimard, 2004; ders., Les lieux de mémoire, Band 2, Paris: Gallimard, 2003; ders., Les lieux de mémoire, Band 3, Paris: Gallimard, 2004; Etienne François und Hagen Schulze (Hg.), Deutsche Erinnerungsorte, München: C.H. Beck, 2001; Hans Henning Hahn und Robert Traba (Hg.), Deutsch-Polnische Erinnerungsorte / Polsko-Niemieckie Miejsca Pamiesci, Paderborn u. a.: Schöningh, 2012.

15 Es ist mir bewusst, dass der Ausdruck »lieux « in Französisch zweideutig ist und nicht nur auf Orte, sondern auch auf Anlässe zielt. »Lieux de mémoire « müssen also nicht notwendig Orte bezeichnen. In den deutschsprachigen Buchtiteln zum Thema wird dies stark verunklärt. 
nen vor Ort. Es kann dazu verleiten, den Besuch als ein Eintreten in eine Gemeinschaft von Wissenden zu konzipieren und das Ringen um die Wege der Weitergabe und die Anstrengung des Lernens gedanklich zu überspringen. ${ }^{16}$ Diese sind aber wesentlich zu beachten, denn hier begegnen sich die lokalen Akteure und die Besucher, direkt oder medial vermittelt; hier entscheidet sich, an was Besucher sich in Zukunft erinnern werden, ob sie, wie ich in Oradour, zu Zeugen, nicht des historischen Geschehens, sondern ihres eigenen Erlebens und Wissenserwerbs werden. Hier eröffnen sich Möglichkeiten des Hinzutretens oder der Distanzierung. Dies führt zurück zu der grundsätzlichen Frage, wie individuelle Herkunftsbindungen die persönlichen Optionen des Eintretens in anderer Leute Vergangenheit beeinflussen.

\section{Fallbeispiel Nr. 1: Konin, Abwesenheit und Beteiligung}

Auf einer aktuellen Straßenkarte wie der des ADAC »Polen" im Maßstab 1:700 000 die Grenz- und Demarkationslinien zu verorten, die in den letzten drei Jahrhunderten das polnische Staatsterritorium umrissen oder genauer: zerrissen und schließlich wieder neu definiert haben, ist eine echte Herausforderung. Die Flüsse oder Gebirgszüge, die in der Vergangenheit bevorzugt genutzt wurden, um Grenzen topografisch und kartografisch deutlich erkennbar ziehen zu können, sind für eine Straßenkarte verständlicherweise nebensächlich. Die thematischen und didaktischen Karten hingegen, die farbig und klar erkennbar die drei Teilungen Polens im 18. Jahrhundert (1772, 1793, 1795) und die zweimalige Neukonstituierung des polnischen Territoriums nach 1918 und nach 1945 vor Augen führen, sind summarisch und in ihrem Maßstab mit dem meiner Straßenkarte nur schwer kommensurabel.

Ich habe die Straßenkarte erworben, um die Grenzen früherer Herrschaftsund Verantwortungszonen markieren zu können, Ereignisse zu verorten, zu sehen, wie weit die Wege zwischen den oft genannten Ereignisorten vor allem der jüngeren Geschichte in Polen sind, und um neben den dominierenden Autobahntrassen die historischen Verkehrswege, vor allem die Eisenbahntrassen, zu identifizieren. So hoffe ich, nach einer Reise nach Polen im Juni 2014, im Rückblick ermessen zu können, in welche und in wessen Vergangenheiten ich dort eigentlich gegangen bin.

16 Vgl. Gabi Dolff-Bonekämper, "Memorable moments - chosen cultural affiliations«, in: Muriel Blaive, Christian Lindenberger und Thomas Gerbel (Hg.), Clashes in European memory. The case of communist repression and the Holocaust, Band 2, Innsbruck: StudienVerlag, 2011, 143-153. 
Konin, eine kleine, im Kern auf eine mittelalterliche Gründung zurückgehende Stadt, die heute von Braunkohletagebau und Leichtmetallindustrie lebt, liegt an der Bahnstrecke zwischen Berlin und Warschau. Von der früheren Bedeutung des Ortes für die Verkehrswege des Landes am Übergang über die Warthe zeugt der laut Inschrift 1151 gestiftete große Meilenstein, bis heute der Stolz der Gemeinde. ${ }^{17}$ Konin fiel bei der zweiten Teilung Polens (1793) in die bis 1807 bestehende Provinz Südpreußen. In dieser Zeit wurde das neue Rathaus an der Straße des 13. Mai errichtet, das mit seiner klassizistischen Formsprache klar erkennbar dem Stil der preußischen Staatsbaukunst um 1800, also der Zeit David Gillys, vor Karl Friedrich Schinkel, nahesteht. Nach der Niederlage Preußens und dem von Napoleon oktroyierten Frieden von Tilsit fiel Konin 1807 ins Territorium des neu gebildeten Herzogtums Warschau und danach ins 1815 neu zugeschnittene Kongresspolen, ein dem russischen Zaren unterstelltes, unselbständiges Königreich Polen. In dessen Anfangszeit fällt die Errichtung der neuen, stattlichen Koniner Synagoge (1825-28), die einen Vorgängerbau aus Holz ersetzte. ${ }^{18}$ Von der russischen Eingliederungspolitik begünstigt, wuchs die jüdische Gemeinde Konins im Laufe des 19. Jahrhunderts stark an.

Die polnisch-russische Judenpolitik wollte die Juden aus ihrer wirtschaftlich-sozialen Sonderstellung und kulturellen Abgeschiedenheit herausholen und zu "nützlichen" Bürgern erziehen. ( ...) Die rechtliche Gleichstellung der Juden erfolgte im Jahre 1862. Polen hatte damit unter russischer Herrschaft eine weit fortschrittlichere Judengesetzgebung als Russland selbst. ${ }^{19}$

Die direkte Zugverbindung zwischen Berlin und Warschau besteht seit 1921, sie konnte erst nach der Neukonstituierung des polnischen Staatsterritoriums am Ende des Ersten Weltkrieges und der landesweiten Vereinheitlichung der Spurbreite der Eisenbahn erfolgen. Meine Karte zeigt mir, dass etwa $30 \mathrm{~km}$ weiter östlich auf derselben Bahnlinie das Städtchen Kolo liegt, in dessen Süden, im Dorf Chełmno, während der deutschen Besatzung in »Kulmhof « umbenannt, im Herbst 1941 auf einem ehemaligen Gutshof das erste und das am weitesten im Westen liegende Vernichtungslager in Polen eingerichtet wurde.

Das wusste ich nicht, als ich im Juni 2014 in Konin aus dem Berlin-WarschauExpress ausstieg. Mein Ziel war Ciążeń, das gut $30 \mathrm{~km}$ weiter westlich am Rande der Warthe-Niederung liegt. Dort fand, im früheren Sommerschloss des Posener

17 Stadt Konin, »Willkommen bei Konin. Die Zusammenarbeit mit dem Ausland«, http://www. konin.pl/index.php/die-zusammenarbeit-mit-dem-ausland.html, zuletzt geprüft am 18. September 2015.

18 Stadt Konin, »Willkommen bei Konin. Denkmale«, http://www.konin.pl/index.php/denkma le.html, zuletzt geprüft am 18. September 2015.

19 Monica Rüthers, "Ostjüdische Vielfalt in einer multikulturellen Umgebung", in: Ost-West Europäische Perspektiven, 3 (2008), 163-174, https://www.owep.de/artikel/67/ostjuedischevielfalt-in-einer-multikulturellen-umgebung, zuletzt geprüft am 22. September 2015. 
Bischofs, die Konferenz der Gemeinsamen Deutsch-Polnischen Schulbuchkommission zum Thema "Historische Kulturlandschaften« statt. Zum Programm gehörte eine Exkursion, auf der wir unter anderem die noch immer in der Kulturlandschaft sichtbaren strukturellen Unterschiede zwischen dem ehemaligen russischen und dem ehemaligen preußischen Teilungsgebiet entdecken sollten. Konin war eine Station auf dieser Tour.

Zunächst das Bezirksmuseum: Es ist seit 1986 in und auf der 1978-86 restaurierten spätmittelalterlichen Burg, einem stattlichen Backsteinbau, im Dorf Gosławice im Norden der Stadt eingerichtet. Im äußeren Burghof, in den Nischen der gründlich erneuerten Umfassungsmauer, sind jüdische Grabsteine gegen die Mauer gelehnt, viele sind zerbrochen, aber alle sind erkennbar. Das Museum verfügt über eine sehr große Sammlung von Grabsteinen aus den zerstörten jüdischen Friedhöfen des Koniner Umlandes, allein 500 Steine stammen aus Turek. ${ }^{20}$ Turek liegt $26 \mathrm{~km}$ südöstlich von Konin. Wir Besucher werden von unserem Fremdenführer zunächst in die Judaica-Abteilung geleitet, die in zwei recht niedrigen, fensterlosen Räumen mit Ziegelgewölbe und kostbarem Rotmarmor-Bodenbelag im ersten Geschoss der Burg eingerichtet ist. Die Ausstellung kombiniert großformatige Reproduktionen von Bildern traditionell gekleideter bärtiger Männer und Tafeln, auf denen Originaldokumente und Fotos aus der jüngeren Geschichte der jüdischen Gemeinde angeordnet sind. An einer Wand sind Bruchstücke besonders kunstvoll gearbeiteter, farbig gefasster Grabsteine ausgestellt. Einige gerahmte Bauzeichnungen zeigen die Entwürfe für die Koniner Mikwe und für die Erweiterung der Synagoge. Im Raum und an der Wand stehen Vitrinen mit bestürzend schönen, offensichtlich sehr kostbaren Kultgeräten für den jüdischen Gottesdienst.

Der Website des Museums ist zu entnehmen, dass die Kultgeräte als "Schatz von Sompolno« bezeichnet werden. Sompolno liegt $32 \mathrm{~km}$ entfernt im Nordosten von Konin. Im Jahre 1931 lebten dort 1125 Juden. ${ }^{21}$ Die Liste der Herkunftsorte der im Vernichtungslager Kulmhof Ermordeten enthält den Eintrag: »Sompolno, Vernichtungsdatum 2. Februar $1942 \lll{ }^{22}$ Für Turek finden sich in der

20 Instytucja Kultury Samorządu Województwa Wielkopolskiego, »Muzeum Okręgowe w Koninie« [Das Bezirksmuseum in Konin], 2007, http://www.muzeum.com.pl/en/historyczny. htm, zuletzt geprüft am 20. September 2015.

21 Albert Breyer, »Zur Geschichte von Sompolno und Umgebung«, 2010, http://www.upstream vistula.org/Documents/ABreyer_Sompolno.pdf, zuletzt geprüft am 18.09.2015, 11 [Erstveröffentlichung in: Unsere Heimat. Volkstümliche Schriftenreihe zur Förderung der deutschen Heimatbildung und Familienüberlieferung in Polen, 4 (1938) Posen.

$22 »$ The List of Places from which Jewish People were Murdered in the Chełmno-on-Ner Extermination Center, on the basis of the study by Krzysztof Gorczyca and Zdzisław Lorek, Kalendarium Chetmna«, 2005, http://www.zchor.org/chelmno/list.htm, zuletzt geprüft am 21. September 2015. 
Liste Einträge von 1941 und 1942. ${ }^{23}$ Unser Fremdenführer trägt allgemeine Fakten über den Gebrauch der ausgestellten Geräte und über die relative Größe der jüdischen Gemeinde von Konin im 18., 19. und 20. Jahrhundert vor und spricht auch über die Deportation und Ermordung der Koniner Juden. Er bleibt seltsam wortkarg, als wir ihn nach der Geschichte und der Herbringung der Exponate und nach dem Leben der jüdischen Koniner befragen. Das ist nicht sein Wissensgebiet.

Später am Tag, nach einem Abstecher in die Braunkohletagebau-Nachfolgelandschaft, fahren wir in die Stadt, nicht in das moderne Konin mit seinen steilen Plattenbauten und dem D-Zug Bahnhof aus der sozialistischen Zeit, sondern, über Viadukte und Schleifen durch die Warthe-Niederung, zum alten Konin. Wir sehen den Meilenstein, die Kirche, das Rathaus, an der Straße des 3. Mai die aufgereihten zweigeschossigen Häuser mit ihren schmucken schmiedeeisernen Balkonen, den großen Platz. Der polnische Schriftsteller Jarosław Iwaszkiewicz hat das Städtchen im Sommer 1945 besucht. Nach den Erfahrungen des Krieges in der Warschauer Gegend, dem Anblick des zerstörten Landes, erschien ihm das wenig zerstörte Konin vor allem als Enklave der Ruhe und wohlwollender, offener Menschen, die in der außergewöhnlichen Fauna des Warthelandes lebten. An diesem und an vielen anderen Orten, die er während seiner Sommerreise im Jahr 1945 besuchte, wollte er vor allem das neu erwachende Leben sehen. Der Krieg und seine Grausamkeiten waren nur ein ferner Hintergrund. Auf diesen Reisen gab es keinen Platz für die Tragödie der Juden und ihre verlorene Welt. ${ }^{24}$

Unser Fremdenführer geleitet uns im Jahr 2014 zu einem kleineren Platz, wo sich, wie er sagt, das jüdische »Schtetl« befunden hat. In der Ulica Mickiewicza die vom Platz zum Park führt, sehen wir die Synagoge, mit hohen, orientalisch anmutenden Schlüssellochfenstern. Wenn sie, wie mitgeteilt wird, schon 1825 konzipiert wurde, ist sie ein sehr frühes und sehr beachtliches Beispiel des maurischen Synagogenstiles, der im Laufe des 19. Jahrhunderts weit verbreitet

23 Ebd.

24 Jarosław Iwaszkiewicz (1894-1980) war einer der herausragenden polnischen Schriftsteller des 20. Jahrhunderts. Er wurde in Kiew geboren, in der Zeit, als es den polnischen Staat nicht gab. Das nicht existente Vaterland beschäftige ihn weit über die Wiedererlangung der Unabhängigkeit Polens (1918) hinaus. Auch nach 1918 reiste er noch »nach Polen « und nicht »innerhalb Polens«. Er wollte in die Welt eintreten, die es in seiner Jugend nicht gegeben hatte: „Obgleich ich in Polen lange Jahre meines Lebens verbracht habe, wurde es für mich nie zu etwas Gewöhnlichem und begeisterte mich immer aufs Neue. Und dies wird wohl der Gegenstand meiner Erzählungen sein.« In: Podróże do Polski, Warschau: Wydawnictwo "Alfa», 1987, 11. Eine seiner Reisen "nach Polen« nach dem Zweiten Weltkrieg führte Iwaszkiewicz nach Konin (vgl. 139-146). Den Hinweis auf den Autor und seine Geschichte verdanke ich Robert Traba. 
war. ${ }^{25}$ Rechts daneben das ehemalige Schulhaus (Besmedresch) und links eine Filiale der Supermarktkette Lewiathan, in bzw. unter der die Mikwe noch erhalten sein soll. Die Synagoge wurde im Krieg beschädigt, später zunächst als Lager benutzt und nach Jahren der Vernachlässigung instandgesetzt, um dort die städtische Bibliothek unterzubringen. ${ }^{26}$ Sie steht leer.

Aber wo ist das Schtetl? Wo war es? Und wenn es nicht mehr existiert, gibt es materielle oder räumliche Spuren? Ich habe keine gesehen. Ich erinnere mich auch nicht an eine signifikant aussehende Leerstelle, wo man seine Abwesenheit hätte spüren können. Ich frage mich, was eigentlich von wem genau als »Schtetl« bezeichnet wird und wie man es erkennt? Ganz offenbar nicht an einer spezifischen städtebaulichen Form oder Architektur, die geplant oder ungeplant entstünde, sondern, wie vielfach nachzulesen steht, an einer charakteristischen sozialen Dichte und Betriebsamkeit, am Rhythmus der Woche, am Verhalten der Bewohner. ${ }^{27}$ In Abwesenheit der Juden gibt es demnach kein sichtbares Schtetl, auch wenn noch Häuser stehen, die früher von Juden bewohnt waren. Und die Juden sind für mich in Konin derart abwesend, dass ich Mühe habe, sie überhaupt zu vermissen. ${ }^{28}$

Warum erfuhren wir auf unserer Exkursion so wenig über die Koniner Juden? Mehrere gewichtige Gründe sind zu benennen: Der erste ist ganz grundsätzlicher

25 Zum Orientalismus im Synagogenbau vgl. Harold Hammer-Schenk, Synagogen in Deutschland. Geschichte einer Baugattung im 19. und 20. Jh. (1780-1933), zwei Teilbände, Hamburg: Hans Christians; und Dominique Jarrassé, Une histoire des synagogues françaises. Entre Occident et Orient: Essai, Arles: Hébraïca 1997.

26 Theo Richmond schildert den Bibliotheksbetrieb und den zur Zeit seines Besuches gegenwärtigen, restaurierten Zustand des Inneren der Synagoge. Theo Richmond, Konin. Auf der Suche nach der Stadt meiner Eltern, übersetzt von Elke Hosfeld, München: Bertelsmann, 1997, 491.

$27 »$ Das Herz des Schtetlech war der Marktplatz, der von den großen Häusern der reichen Juden umgeben war. Hier herrschte wochentags unvorstellbarer Trubel, denn der Markt war zugleich auch Hauptberührungspunkt zwischen Juden und Nichtjuden, und die Bauern der Umgebung brachten ihre Waren zum Verkauf. In den weniger wohlhabenden Straßen des Schtetlech waren die Häuser häßlich und schmutzig, oft direkt aneinandergebaut, um eine Wand zu sparen, dadurch aber schief und krumm. Im Sommer wie im Winter versank man im Schlamm der Straßen. Oft mußten sich mehrere Familien eine einzige Stube teilen. Die Armut war im äußeren Anschein des Schtetlech nicht zu übersehen. Für die Bewohner des Schtetlech waren solche Äußerlichkeiten nicht wichtig, denn: ২Mein Schtetl, das sind die Leute, die darin wohnen, nicht der Ort, die Gebäude oder die Straße. « Andrea Ehrlich, „Das Schtetl. Wirtschaftliche und soziale Strukturen der ostjüdischen Lebensweise«, Teil 3, 1996, http://www.hagalil.com/galluth/shtetl/au3.htm, zuletzt geprüft am 27. August 2015.

28 Heute gibt es das - auf der ganzen Welt bisher einzige - Schtetl-Museum in der Wojewodschaft Świętokrzyskie in der Ortschaft Chmielnik, 30 Kilometer südlich von Kielce. Es beschreibt die Geschichte von 90 Schtetln in der Wojewodschaft Świętokrzyskie, die sich nicht im Osten, sondern genau in der Mitte Polens befanden. In den Schtetln stellte die jüdische Minderheit mit 60-80\% die Mehrheit der Einwohner dar. Diesen Hinweis verdanke ich Robert Traba. 
Art: Wenn alle Angehörigen einer Bevölkerungsgruppe ermordet wurden, ist keiner mehr da, der ihre Geschichte erzählen könnte. Die sozialen Referenzrahmen der Erinnerung und der Weitergabe, les cadres sociaux de la mémoire (Halbwachs) sind zertrümmert, und der lokale Rahmen, der Raum, in dem das jüdische Leben stattfand, von dem zu berichten wäre, ist verwaist. Vorhandene materielle Spuren können nicht gelesen werden, werden missachtet, schriftliche Zeugnisse, wenn sie nicht auch vernichtet sind, müssten erst einmal bekannt werden, bevor sich jemand daran machen könnte, sie zu lesen und zu deuten.

Der zweite Grund ist historisch und politisch, konkreter: Die staatliche Geschichtspolitik im Polen der Nachkriegszeit, dicht an die Sinnsetzungen der Sowjetunion angelehnt, wollte das polnische Volk auf der Seite der Sieger und der Opfer sehen; die Erwähnung der jüdischen Opfer hatte darin, so berichtet der französische Historiker und Politikwissenschaftler Jean-Yves Potel in seinem für mich grundlegenden Werk über das komplizierte Verhältnis Polens zu seiner jüdischen Vergangenheit, über Jahre hinweg keinen Platz:

Über lange Zeit hat das Regime, wie überall, die spezifisch jüdische Seite dieser Vergangenheit verdunkelt. Zuerst haben die Kommunisten sie unter einem antifaschistischen und patriotischen Opferdiskurs begraben, dann haben sie im Namen eines Pseudo-Universalismus das Schweigen angeordnet, vor allem während der 1950er Jahre und nach der antisemitischen Kampagne der Staatsführung im Jahre 1968 und der Ausreise der letzten Juden aus Polen. ${ }^{29}$

Es wurde nicht nur die Überlieferung unterbrochen, die das Leben der jüdischen Polen im Bewusstsein der neuen Generationen bewahrt hätte, sondern auch ihr Sterben blieb lange Zeit unerwähnt und ungewürdigt.

Der dritte Grund ist vor allem sozial konkreter und von besonderer Schwere, weil er das persönliche Erleben eines jeden polnischen Zeitzeugen ins Spiel bringt. Potel schreibt dazu: «Diese Massaker brachten die Polen, selber Opfer roher Unterdrückung, in eine ganz eigene Position in Europa, in die des >Zeugenvolks` der Shoah. Neben den Tötungen in den Ghettos - es gab fast 400 auf dem Territorium der II. Republik - sahen sie, hörten sie, und rochen sie den Geruch der Todeslager monatelang. ॥ $^{30}$

Das ganz gewiss unvergessliche Mit-Erleben der Shoah zu beschweigen, wie von der erwähnten Geschichtspolitik gefördert, machte es indes, wie ich denke, für die Angehörigen des »Zeugenvolkes« nicht leichter, sondern noch schwerer, diese Zeugenschaft auszuhalten.

Das Beschweigen und das Nichtsehen der Spuren und Leerstellen haben über Jahre die Wissensüberlieferung unterbrochen und dann, auf paradoxe Weise,

29 Jean-Yves Potel, La fin de l’innocence. La Pologne face à son passé juif, Paris: Autrement Frontières, 2009, 26-27, Übersetzung der Autorin.

30 Ebd., 21, Übersetzung der Autorin. 
neue, besondere Aufmerksamkeit auf die Orte gelenkt: Jean-Yves Potel schreibt über zahlreiche Initiativen zur Erforschung, Veröffentlichung, künstlerischen Bearbeitung und dauerhaften Weitergabe von Wissen über Orte und Ereignisse der Shoah. Die Initiativen, die in der überwiegenden Zahl der Fälle von nichtjüdischen Polen der jüngeren Generation ausgehen, begannen in den späten 1970er Jahren und nehmen seit dem Ende der sozialistischen Volksrepublik Polen stetig zu. Und immer wieder berichten die Akteure, dass sie in ihrer Jugend und manchmal über Jahrzehnte nicht gewusst haben, dass in ihrer Stadt überhaupt einmal Juden gelebt hatten, die ermordet worden waren.

Die jungen Leute begannen, die vormals von Juden bewohnten Quartiere zu erkunden, Spuren zu suchen, Fotos, Pläne und Dokumente aufzutreiben, um schließlich das jüdische Leben an seinem früheren Ort erzählerisch oder bildnerisch zu vergegenwärtigen. So in Lublin, wo im Stadttor »Brama Grodzka«, das einst zwischen der christlichen Stadt und dem jüdischen Viertel stand, ein Theater gegründet wurde. Lublin liegt im Osten Polens, in der ehemaligen österreichischen Teilungszone, ca. $120 \mathrm{~km}$ westlich vom Grenzfluss Bug, der Westgrenze der 1939 von der Sowjetunion besetzten Zone, die mit der heutigen polnischen Ostgrenze zusammenfällt. Am südlichen Stadtrand von Lublin lag das Konzentrations- und Vernichtungslager Majdanek. Das jüdische Viertel, das 1941/42 als Ghetto für den Zwischenaufenthalt deportierter Juden vor dem Transport in die Vernichtungslager eingerichtet worden war, wurde in der Nachkriegszeit nahezu vollständig abgerissen.

Die Theatermacher erforschten die Geschichte seiner Bauten und Bewohner und übertrugen sie in die Stadträume der Gegenwart:

Plötzlich ist eine andere Stadt erschienen, mit ihren jüdischen Quartieren an der Stelle eines Parks, der großen Jeschiwa (orthodoxe jüdische Hochschule) an der Stelle einer medizinischen Fakultät. Es erscheint die Szeroka-Straße und kein Parkplatz, eine Synagoge und nicht eine Schnellstraße. (...) In dieser Zeit stieg in uns eine Wut gegen das Vergessen auf, sagt mir Tomasz. Hier wohnten Juden und die Polen haben sie vollkommen vergessen. ${ }^{31}$

Die jüdische Vergangenheit von Lublin war zwar durch Abriss und Überplanung des jüdischen Quartiers für eine Zeit unsichtbar und unerwähnt geblieben, aber doch nicht ortlos geworden. So war eine räumliche Annäherung möglich und danach eine Verräumlichung der anderweitig ermittelten Orte und Ereignisse. Die Theatermacher im alten Stadttor agieren als Übersetzer und Übermittler. Sie laden die Menschen im Publikum ein, nicht nur in das Theater, sondern auch in den Stadtraum zu gehen und das, was sie sehen, und auch das, was sie nicht sehen - Evokationen einer Vergangenheit, die nicht die eigene ist -, in ihrer Gegenwart

31 Ebd., 66, Übersetzung der Autorin. Potels Gesprächspartner »Tomasz« ist Tomasz Pietrasiewicz, Theater-Regisseur und Initiator des Theaters im Stadttor. 
zu erleben und zu bezeugen. Jean-Yves Potel wiederum übermittelt die jüdische Vergangenheit Lublins, in ihrer Bearbeitung durch die heutigen, in der Mehrzahl nicht jüdischen Lubliner, für sein Lesepublikum in Europa. So entsteht ein neuer sozialer Referenzrahmen der Weitergabe und Erinnerung, der vom alten lokalen Rahmen ausgeht, aber eine weit darüber hinausgehende räumliche Reichweite entwickelt.

Vergleichbare Initiativen gibt es auch in Konin. Die Sammlung der jüdischen Grabsteine, die Ausstellung im Bezirksmuseum, das auch für die Gedenkstätte in Chełmno zuständig ist, die in den 1980er Jahren erfolgte Restaurierung der Synagoge, die Informationen auf der Website der Stadt und des Museums - all dies zeugt davon, dass die in Konin anwesenden nichtjüdischen Bewohner sich seit geraumer Zeit der Vergangenheit der abwesenden Koniner Juden angenommen haben, die der ihren benachbart ist. Daran hat ganz sicher ein Autor mitgewirkt, dessen Buch ich nach meiner Rückkehr aus Polen als ersten Literaturverweis im Wikipedia-Artikel über Konin fand und umgehend erwarb: Theo Richmonds Konin. A Quest, das 1995 auf Englisch, 1997 auf Deutsch und 2001 auf Polnisch erschien. ${ }^{32}$

Theo Richmonds Eltern wuchsen beide im Schtetl von Konin auf und wanderten vor dem Ersten Weltkrieg nach England aus. Der Familienname war Ryczke, bevor der Vater ihn anglisierte. Die Mitglieder der Familie Ryczke, die nicht ausgewandert waren, wurden, wie die allermeisten der wohl 3.000 Koniner Juden, während der deutschen Besatzungszeit verschleppt und ermordet. Theo Richmond wurde in England geboren und hatte in seinem Leben schon oft den Ortsnamen Konin gehört, bevor er sich 1987 entschloss, das Leben und auch das Sterben der Koniner Juden $\mathrm{zu}$ erforschen. Er verbrachte Jahre damit, die Überlebenden in England, den USA und Israel ausfindig $\mathrm{zu}$ machen und $\mathrm{zu}$ befragen, und immer wieder die Angaben, die sie über Orte, Personen und Ereignisse machen konnten, in seinem immer dichter beschriebenen Stadtplan von Konin zu notieren. So entstand eine Art Bewohner- und Ereigniskataster, das eindrucksvoll vor Augen führt, wie das Leben der jüdischen Koniner in den dicht bebauten und bewohnten Straßen rund um den »Tepper Marik « organisiert war. Das war dann also das Schtetl, das heute nicht existieren kann, weil keine Juden da sind.

32 Theo Richmond, Konin. A Quest, London: Random House, 1995; Theo Richmond, Konin. One Man's Quest for a Vanished Jewish Community, New York: Pantheon Books, 1996; Theo Richmond, Konin. Een zoektocht, übersetzt von Josephine Ruitenberg, Amsterdam: Wereldbibliotheek, 1996; Theo Richmond, Konin. Auf der Suche nach der Stadt meiner Eltern, übersetzt von Elke Hosfeld, München: Bertelsmann, 1997; Theo Richmond, Konin. La città che vive altrove, übersetzt von Elena Loewenthal, Turin: Instar Libri, 1998; Theo Richmond, Uporczywe echo. Sztetl Konin: poszukiwanie, übersetzt von Piotr Szymczak, Poznań: Media Rodzina, 2001. 


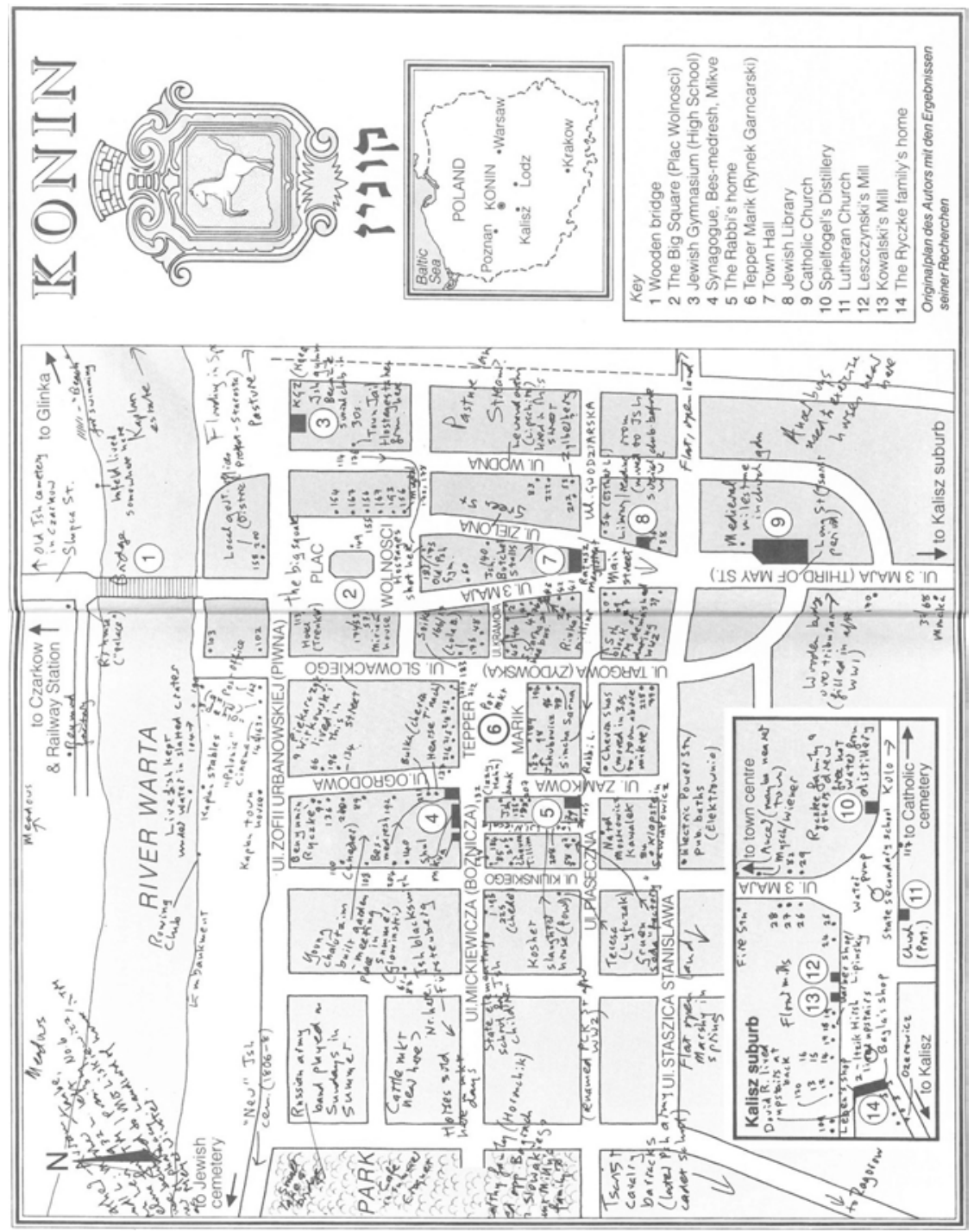

Abb. 1: Das historische Stadtzentrum von Konin, Arbeitsdokument von Theo Richmond. Die handschriftlichen Vermerke verweisen auf Ereignisse sowie auf Lebens- und Arbeitsorte der Koniner Juden. ${ }^{33}$

33 Theo Richmond, Konin. Auf der Suche nach der Stadt meiner Eltern, Abbildung im hinteren Buchdeckel. 
Für Theo Richmond war nicht, wie für die Lubliner Theatermacher, der noch vorhandene, wenn auch vielleicht unkenntliche Ort der Ausgangspunkt, sondern die Erzählungen der Überlebenden, die als former locals fern von Konin lebten. Für ihn war der Ort der Endpunkt. Er schreibt:

Es kam mir einfach unwirklich vor, wie im Traum, durch die Straßen zu gehen, in denen ich so oft in meiner Vorstellung umhergewandert war. Ich brauchte kaum auf meinen alten Stadtplan zu sehen, denn ich wusste, welche Straße wohin führte, welche Szenerie mich an jeder Ecke erwartete, welche Biegung mich zum Fluß, zum Tepper Marik oder zum Park bringen würde. Als ich das Rathaus, die katholische Kirche und den mittelalterlichen Meilenstein erblickte, fühlte ich mich wie eine wiedergeborene Seele, die sich aus einem früheren Leben an etwas erinnerte. ${ }^{34}$

Für mich war wiederum der Ort Ausgangspunkt. Wäre ich nicht, ohne Vorwissen und mit nur wenig Informationen vor Ort, in der Stadt herumgewandert, hätte ich nicht die Irritation erlebt, dass man mir etwas zeigte - das Schtetl -, das ich nur als abwesend wahrnehmen konnte, dann hätte ich niemals weiter nachgeforscht. Die Lektüre von Theo Richmonds Buch, sein beschrifteter Stadtplan und weitere Recherchen machten mir nachhaltig klar, was es war, das ich dort vermisst hatte - das Leben und die Spuren der jüdischen Koniner. In dem weiter oben entwickelten Modell der Weitergabe ist Theo Richmond für mich der Übersetzer. Die Momente der Weitergabe sind die unzählbaren Momente der persönlichen Lektüre, an die ich mich als Leserin - wie auch alle anderen Leserinnen und Leser - in Zukunft erinnern werde.

Welcher ist nun heute und in näherer Zukunft der soziale und der lokale Rahmen der Erinnerung an dieses untergegangene Koniner Schtetl? Wem gehört die Vergangenheit dieses Ortes, wer kann ihr zugehörig sein oder werden? Legen wir das Diktum von Jan Assmann zu Grunde, nach dem die Vergangenheit »eine soziale Konstruktion (ist), deren Beschaffenheit sich aus den Sinnbedürfnissen und Bezugsrahmen der jeweiligen Gegenwarten her ergibt « ${ }^{35}$, dann können es nur die gegenwärtig Lebenden sein. Sind es also die Nachfahren der inzwischen in der Diaspora gestorbenen jüdischen former locals, die die Nachfolge antreten? Dann wäre der soziale Bezugsrahmen endgültig vom lokalen abgespalten, die Deutungshoheit und die Verantwortung für die Weitergabe des Wissens über das Schtetl lägen in der Ferne. Oder sind es die heutigen polnischen Koniner, die, ausgehend vom bestehenden lokalen Bezugsrahmen, in dem sie die Räume und Bauwerke des Schtetls sehen, in ihrer Stadt einen

34 Richmond, Konin. Auf der Suche nach der Stadt meiner Eltern, 477. Die deutsche Übersetzung ist am Ende des Absatzes recht frei formuliert. Im englischen Original heißt es: »I felt a jolt of recognition, like a reincarnated soul returning from a previous life.« Richmond gefällt auch die deutsche Fassung dieses Absatzes (persönliche Mitteilung am 9. Mai 2015).

35 Assmann, Das kulturelle Gedächtnis, 48. 
neuen sozialen Referenzrahmen konstruieren, in dem die benachbarten jüdischen und polnischen Vergangenheiten in einem komplexeren Narrativ integriert und verflochten werden? Genau dies ist wohl gegenwärtig der Fall, und daran hat das Buch Theo Richmonds einen wesentlichen Anteil: Richmond berichtet, dass er und auch sein Buch - die polnische Ausgabe erschien 2001 - in Konin sehr freundlich aufgenommen wurden. Der Bürgermeister empfing ihn, man trug ihm eine Ehrenbürgerschaft an, und der Stadtrat erwarb 200 Exemplare seines Buches, um sie an die örtlichen Schulen und Bildungsreinrichtungen zu verteilen. ${ }^{36}$ Das Letztere wurde nachhaltig umgesetzt und ebenso nachhaltig wirksam: Eine im September 2015 durchgeführte Umfrage in der Koniner Stadtbibliothek und ihren acht Zweigstellen ergab, dass das Buch in allen Zweigstellen vorhanden ist, in manchen mehrfach, und dass die Bücher seit 2001 viele hundert Mal ausgeliehen wurden. ${ }^{37}$ Offenbar wollen zahlreiche heutige Koniner die Geschichte der jüdischen Koniner kennenlernen und Theo Richmonds Sozial- und Ereigniskataster des Schtetls ist inzwischen vielen bekannt. So erklärt sich auch, warum für unseren Fremdenführer das Schtetl selbstverständlich existierte.

Ich bin also im Juni 2014 in Konin in eine Vergangenheit geraten, die sich gewissermaßen noch im Aufbau befindet. Ich bin als Fremde hinzugetreten und empfinde mich nunmehr als Beteiligte - nicht an den Ereignissen der Kriegszeiten, auf die hier alles zurückverweist, sondern an ihrer Bearbeitung.

\section{Fallbeispiel Nr. 2: Ost- und Westberlin - untrennbar geteilt}

Nach dem Fall der Mauer und nach der im Herbst 1990 erfolgten Zusammenlegung der Berliner Behörden hatte ich in den denkmalpolitischen Kontroversen der Nachwendezeit, die sich auf die Schutzwürdigkeit der programmatischen Denkmäler der untergegangenen DDR bezogen, von Amts wegen Partei zu ergreifen. Das Argument, mit dem damals die sonst in der Denkmalkunde übliche Zeitgrenze, die für die Objekte ein Mindestalter von 30 Jahren vorschreibt, außer Kraft gesetzt wurde, war, dass die Bauten und Denkmäler der DDR-Zeit nunmehr einer abgeschlossenen Kulturepoche angehörten und daher die zur Beurteilung ihres möglichen Denkmalwertes erforderliche Distanz bestand. Das klang gut und tat auch seine Wirkung im Rahmen der Administration und der Rechtsprechung.

36 Theo Richmond, E-Mail an die Autorin vom 2. September 2015.

37 Diese Informationen verdanke ich Frau Małgorzata Popiołek; E-Mail an die Autorin vom 11. September 2015. Es wurden 19 Bücher gezählt, die insgesamt mindestens $842 \mathrm{Mal}$ ausgeliehen wurden. 
Die behauptete Distanz war allerdings nicht ohne Anstrengung zu haben, sie musste erst erzeugt werden; und dies erlebten die Akteure aus dem Osten notwendigerweise anders als die aus dem Westen. Schließlich war es ihre Vergangenheit, die von einem Tag auf den anderen einer abgeschlossenen Kulturepoche zugerechnet werden sollte. Nicht nur die Gebäudebestände, sondern auch die ihnen mitgegebenen Sinnsetzungen, ihre mit der Zeit gewachsenen kulturellen und sozialen Werte sollten auf einen Schlag der Vergangenheit angehören. Aber wessen Vergangenheit? Und wer formulierte hier das Sinnbedürfnis und wer konstruierte den Bezugsrahmen?

Ich, zum Beispiel, und ich brachte dafür, wie ich dachte, gute Voraussetzungen mit. Ich arbeitete erst seit 1988 in der Stadt und war, was die Berliner Teilungsgeschichte anging, nicht von eigenen leidvollen Erfahrungen belastet, war eine Hinzugezogene, eine new local. Als westdeutsche Kunsthistorikerin der Marburger Schule, die für ihre gesellschaftsbezogene, politische Orientierung gerühmt wurde, fand ich mich geeignet, die Zeugnisse des Sozialismus mit dem gehörigen dialektischen Sinn für widersprüchliche Setzungen und Gegensetzungen gegen voreilige Abrisswünsche zu verteidigen. Ich wanderte also nach Ost-Berlin hinüber, das auf meinem westlichen Vorwende-Falkplan grau gefärbt war, erkundete die Stadträume, sah die gründerzeitlichen Quartiere und die Neubauten der DDR-Moderne und wurde rasch zur amtlichen Spezialistin für die Grenzbauten und die Relikte der Berliner Mauer. ${ }^{38}$

Was ich verkannt hatte, war, dass ich in Ost-Berlin nicht nur einem anderen Raum, sondern auch einer anderen Vergangenheit nähertrat, die ungleich schwieriger zu erkennen war als die Bauten selber, die ich in Form und Typologie durchaus einzuordnen und zu bewerten verstand. Wonach ich nicht genug fragte, war, welche Bedeutung die Bauten und Orte für die Ost-Berliner gehabt hatten und welche Ereignisse und Werte und durchaus ambivalenten Gefühle mit ihnen noch immer assoziiert wurden. Es macht einen Unterschied, ob man ein Bauwerk wie das Staatsratsgebäude quasi bis gestern als Ort der Macht und des eigenen Beherrschtseins erfahren hat oder ob man es erst nach dem Sturz der Macht erlebt und ohne weitere Umstände als Geschichtszeugnis und als Werk der Baukunst sehen kann. Was ich nicht verstand, war, warum mein Eintreten für die

38 Vgl. hierzu die jüngeren Publikationen: Deutsches Nationalkomitee für Denkmalschutz (Hg.), Tagung Mauer und Grenze - Denkmal und Gedenken, Berlin: DNK, 2009; Gabi DolffBonekämper, Hartmut Dorgerloh, Peter Goralczyk u. a., "Gesprächsrunde: `Gefunden und verloren: Metamorphose von der Sperranlage zum (fast verschwundenen) Denkmal«, in: DNK (Hg.), Tagung Mauer und Grenze - Denkmal und Gedenken, [Dokumentation der Tagung des Deutschen Nationalkomitees für Denkmalschutz vom 10. bis 12. Mai 2009 in Berlin] Berlin: DNK, 2009, 51-64, hier 55-57, 63; Axel Klausmeier und Günter Schlusche (Hg.), Denkmalpflege für die Berliner Mauer. Die Konservierung eines unbequemen Bauwerks, Berlin: Links, 2011. 
Erhaltung etwa des Palastes der Republik, der Reste der Mauer, der monumentalen Denkmäler für Lenin und Thälmann und der DDR-Fassung der Neuen Wache Unter den Linden von den in gleicher Sache engagierten Ostberliner Akteuren vorerst nicht mit Freude und Beifall aufgenommen wurde, sondern mit Skepsis und Reserve. Sie erlebten meine Arbeit als Übergriff auf ihre eigene Vergangenheit. ${ }^{39}$ Wie das Ende der DDR als Verlust des eigenen Bezugsrahmens erlebt werden konnte, hat die französische Autorin Cécile Wajsbrot ihrer literarischen Figur eines Ostberliner Lyrikers in den Mund gelegt, der nach der Wende vorübergehend zu großem Ansehen gelangt:

Doch als draußen wieder Ruhe einkehrte, hatte sich in mir nichts verändert, ich empfand dieselbe Unruhe, dasselbe Chaos wie zuvor, mein Leben war plötzlich eingestürzt, und das Glück, die Mauer verschwinden zu sehen, war getrübt von der Sorge, zugleich auch alles andere verschwinden zu sehen, die Bezugspunkte und Werte, die wir entwickelt hatten, alles musste neu betrachtet werden, von einem Tag auf den anderen hatten die Briefmarken und die Geldscheine andere Gesichter, änderten sich die Straßennamen, wir wohnten noch im selben Land, in derselben Stadt, sprachen noch dieselbe Sprache, und trotzdem waren wir im Exil. Aber ich wollte vom Schweigen sprechen. ${ }^{40}$

Treffender kann man wohl das Fremdwerden der eigenen Gegenwart nicht beschreiben. Im Rückblick erkenne ich, dass die politische und territoriale Teilung der Stadt auf beiden Seiten der Sektorengrenze und später der Mauer zunächst verschiedene Lebenswelten und in der Folge die Konstruktion verschiedener, im Sinne des weiter oben vorgeschlagenen Begriffs, »benachbarter« Vergangenheiten zur Folge hatte. Benachbart, aber nicht parallel, weil zwar die gründerzeitliche Stadtstruktur, die ältere Stadtgeschichte, die Kriegszerstörung und die Anstrengungen des Wiederaufbaus beiden gemeinsam waren, die politische und die Kulturgeschichte aber von anderen Rhythmen bestimmt und mit anderen Wertsetzungen assoziiert. Daher nahmen Ost- und Westberliner nicht nur die Grenzbauten und die Spuren der Teilung verschieden wahr, sondern vor allem die programmatischen Bauten und Denkmäler des politischen Aufbruchs und der Phasen der Konsolidierung auf der jeweils eigenen und der jeweils anderen Seite.

Die materiellen Zeugnisse der benachbarten Vergangenheiten von Ost- und West-Berlin sind im Raum bis heute lesbar, man kann sie - mit oder ohne Anleitung - ungehindert besuchen und wieder verlassen. Alteingesessene und langjährige Neubürger wie ich bewahren weiterhin die Topografie der Teilung in

39 Wichtige Einsichten in dieser Sache verdanke ich meinen früheren Kollegen Hubert Staroste und Sibylle Schulz, die im Jahre 1990 vom Institut für Denkmalpflege der DDR ans Berliner Landesdenkmalamt kamen.

40 Cécile Wajsbrot, Mann und Frau den Mond betrachtend, übersetzt von Holger Fock und Sabine Müller, München: Liebeskind, 2006, 63-64. 
ihrem Bewusstsein und ihrem Körpergedächtnis. Aber über diese geteilte Topografie hat sich inzwischen eine ganz andere gebreitet, andere Raumbezüge und -hierarchien überlagern die Ost-West-Ordnung und die Nachwendegegenwart bietet seit geraumer Zeit die Gelegenheit, die zwei Vergangenheiten der Stadt neu zu bearbeiten. Mit anderen Worten: Wir sollten uns auf eine neue Vergangenheit gefasst machen. ${ }^{41}$

\section{Fallbeispiel Nr. 3: Kreuzberger Ortsgespräche}

Als zu Anfang der 1960er Jahre die ersten türkischen Gastarbeiter und Gastarbeiterinnen in Berlin eintrafen, rechneten die Berliner Wirtschaft, die Politik und die betroffenen Personen selber nicht entfernt damit, dass sie länger als für ihre maximale Vertragszeit - zwei Jahre - bleiben würden, keiner der Beteiligten dachte an Einwanderung. Man brachte die Arbeiterinnen und Arbeiter zunächst in werksbetriebenen Wohnheimen unter, die Unternehmen transportierten sie mit Bussen zum Arbeitsplatz und hielten sie damit in Abhängigkeit und Unselbständigkeit, auch was die Erkundung des Stadtraumes anging. Die Autorin Emine Sevgi Özdamar, die selber Mitte der 1960er Jahre als Arbeiterin nach Berlin kam, schildert in ihrem autobiografisch fundierten Roman Die Brücke vom Goldenen Horn die Orientierungsprobleme der Arbeiterinnen bei der Ankunft nach einer langen Bahnreise von Istanbul:

In den ersten Tagen war die Stadt für mich wie ein endloses Gebäude. Sogar zwischen München und Berlin war das Land wie ein einziges Gebäude. In München aus der Zugtür raus mit den anderen Frauen, rein in die Bahnhofsmissionstür. Brötchen Kaffee - Milch - Nonnen - Neonlampen, dann raus aus der Missionstür, dann rein in die Tür des Flugzeugs, raus in Berlin aus der Flugzeugtür, rein in die Bustür, raus aus der Bustür, rein in die türkische Frauenwonaymtür, raus aus der Wonaymtür, rein in die Kaufhaus-Hertietür am Halleschen Tor. Von der Wonaymtür gingen wir zur Hertietür, man musste unter einer U-Bahnbrücke laufen. Bei Hertie im letzten Stock gab es Lebensmittel. ${ }^{42}$

Eine Reise und dann eine Stadt voller Türen, ganz ohne Raum. Dies ist, wohlgemerkt, ein literarischer Text, der, im Rückblick verfasst, einen Erinnerungsstrang der Autorin artikuliert hervorhebt. Dennoch kann er für das stehen, was ich hier verdeutlichen will: Die türkischen Arbeiterinnen und Arbeiter wären

41 Dazu hat u.a. die Publikation der Vortragsreihe "Stadtentwicklung im doppelten Berlin« beigetragen, die das Dokumentationszentrum Gedenkstätte Berliner Mauer und die TU Berlin gemeinsam in den Jahren 2012 und 2013 veranstaltet haben. Vgl. Günter Schlusche, Verena Pfeiffer-Kloss, Gabi Dolff-Bonekämper und Axel Klausmeier (Hg.), Stadtentwicklung im doppelten Berlin: Zeitgenossenschaft und Erinnerungsorte, Berlin: Links, 2014.

42 Emine Sevgi Özdamar, Die Brücke vom Goldenen Horn, Köln: KiWi, 2. Auflage 2005, 18. 
damals, was ihren Ortsbezug angeht, als non locals einzustufen gewesen, als zwar vorübergehend ortsansässig, aber nicht ortszugehörig und ganz gewiss nicht ortsgebunden - Bindungen und Zugehörigkeit galten dem vorübergehend verlassenen Heimatland, wo auch die eigene Vergangenheit zu Hause blieb. Dennoch kann man selbst in der Geschichte Sevgi Özdamars Anzeichen eines »becoming local« im Sinne von Judy Ling Wong beobachten, denn wer herausgefunden hat, wo man in einer Umgebung Lebensmittel einkauft, ist nicht mehr vollständig ohne Orientierung in einer Stadt.

Bekanntlich blieben die türkischen Arbeiter und Arbeiterinnen länger als zwei Jahre, ihre Zahl stieg, ihre Familien kamen nach und in der zweiten und mittlerweile dritten Generation wurden und werden neue Familien in Berlin gegründet. Der Begriff »Migrant/Migrantin« ersetzte den des »Gastarbeiters«/ der "Gastarbeiterin « und für die in Berlin bzw. in Deutschland geborenen Kinder und Enkel wurde in jüngerer Zeit der Begriff »Mensch mit Familienhintergrund aus der Türkei« vorgeschlagen, der keine ethnische Herkunft benennt sondern ein Herkunftsterritorium. Wenn nun der Vorgang der lokalen Beheimatung ausschließlich von der Dauer des Aufenthaltes bestimmt wäre, wären die seit Langem ortansässigen Migrantinnen und Migranten, egal welcher Generation, in der Stadtgesellschaft aufgegangen. Ortszugehörigkeit ist aber, wie weiter oben ausgeführt, kein objektiver Sachverhalt oder gesetzmäßig ablaufender Vorgang, sondern eine subjektive Empfindung.

Wie schnell und wo sich eine Person ortszugehörig fühlt, hängt von vielen Faktoren ab: von Beziehungen am Arbeitsplatz, am Wohnort, im privaten Umfeld, von persönlicher Bewegungsfreiheit, von Bildungschancen und Aufstiegsmöglichkeiten, von Sicherheit und Orientierung im öffentlichen Raum und, so behaupte ich, ganz wesentlich von der Einlassung auf lokale Vergangenheiten. Aber auf welche, wessen und wo genau? Und warum sollten sich new locals, egal woher sie kommen, überhaupt für Ereignisse interessieren, die sich zugetragen hatten, lange bevor sie die Stadt betraten? Weil die Räume, in denen sie leben und umhergehen, von diesen Ereignissen geprägt sind, weil Strukturen, Zeichen, Relikte, Straßennamen, Ortsbezeichnungen erst verständlich werden, wenn sie Ursachen und Zusammenhänge erkennen. Weil die Ereignisse das Leben der älteren locals geprägt haben, denen sie in der Stadt begegnen. Weil Vergangenheiten Gegenstand aktueller städtischer Debatten sind, an denen Anteil zu nehmen den Weg zu einer lokalen Beheimatung bereiten kann.

Nun sind die vorgefundenen Räume im Zuge ihrer Besiedlung und Aneignung durch Einwanderer aus der Türkei Schauplätze anderer Ereignisse geworden, andere Zeichen, Schriften, Namen, Markierungen sind hinzugekommen, die gelesen und gedeutet werden können. Orte wurden neu und möglicherweise ganz anders codiert. Eine andere, jüngere, benachbarte Berliner Vergangenheit kann erzählt werden, die Vergangenheit der Berliner Türken. Aber wer erzählt sie 
wem? Und warum sollten sich die old locals, womit in diesem Falle die deutschstämmige Berliner Mehrheitsgesellschaft gemeint sein soll, für Ereignisse interessieren, die sich zwar in ihrer Stadt, aber nicht in ihrer sozialen Bezugsgruppe zugetragen haben? Warum habe ich angefangen, mich dafür zu interessieren? Weil sich mir die Frage stellte, ob und wie die türkischen Ladenschilder und Reklameschriften, die Laden- und Restauranteinrichtungen einen eigenen Denkmalwert haben oder zumindest als Teil eines denkmalwerten Gebäudes ins Schutzgut aufzunehmen sind. Dies zu behaupten, würde die Bezugnahme auf Erzählungen von Betreibern und Bewohnern voraussetzen, denn sonst könnte man nichts über die Bedeutung sagen.

Wie die Bezugnahme auf Vergangenheiten mit Raumerkundung zusammenhängt, welche Bedeutung Vergangenheit und Erbe für die mittlerweile seit mehreren Jahrzehnten in Berlin lebenden Migrantinnen und Migranten haben nicht nur für türkische - , und ob es richtig ist, eigene und benachbarte oder fremde Vergangenheiten, eignes oder fremden Erbe zu unterscheiden, wird seit einigen Jahren am Lehrstuhl für Denkmalpflege der TU in Berlin erforscht. ${ }^{43}$ Zunächst wurde das Konzept der Erinnerungsorte, das Pierre Nora, Hagen Schulze und Etienne François sowie Robert Traba so überzeugend für den jeweiligen nationalen bzw. bi-nationalen Bezugsrahmen ausführen, auf kleinere soziale Gruppen und auf den städtischen Bezugsrahmen übertragen. Ziel war es, die lieux de mémoire der türkischen Einwanderer in Berlin zu identifizieren und ihre persönliche, gruppenbezogene und gesamtstädtische Bindungskraft zu erkunden. Dann wurden Einzelstudien angefertigt.

Die Arbeit konzentrierte sich auf die Bezirke Kreuzberg und Nord-Neukölln. Denn hier, im von Großplanungen des Berliner Senats befangenen Gebiet, wo zahlreiche Altbauten, teils in sehr schlechtem baulichen Zustand, teils bereits leerstehend, verfügbar waren, nahmen die türkischen Arbeiterinnen und Arbeiter Wohnung. Sie zogen, wie seinerzeit die umgesiedelten Polen, in Häuser, die nicht von ihnen und nicht für sie gebaut worden waren, in ein Gebiet, das seit dem Mauerbau von den Ostberliner Nachbarbezirken abgeschnitten und durch stillgelegte Bahngelände von Westberlin weitgehend abgehängt war. Fragen nach prägenden Ereignissen und besonderen Orten der Migrationsgeschichte in Berlin setzten bei den befragten Personen Erinnerungen frei, die sie selber zuvor

43 »Stadt Mensch Geheimnis. Ausstellung und Projektbericht des Studienprojektes Fremdes Erbe«, Berlin 2006, unveröff. Manuskript; Zeinab Hijazi, »Das Neue Kreuzberg Zentrum. Von der Utopie der Planung zum Zentrum der Migration«, BA-Arbeit, 2012, unveröff. Manuskript; Pinar Boga, »Die Topographie der Anderen. Berliner Orte in literarischen Texten von türkischen Migranten«, BA-Arbeit, 2012, unveröff. Manuskript; Khalib Salem Ben Muftah, "Stadtteil alte Heimat - Konzentration außereuropäischer Minoritäten in Berlin und Paris", BA-Arbeit, 2012, unveröff. Manuskript; Gülsah Stapel, »Recht auf Erbe in der Migrationsgesellschaft «, Dissertation im DFG-Graduiertenkolleg »Identität und Erbe«, TU Berlin, 2020. 
nicht als bedeutsam erkannt hatten. Dass sie in Berlin längst eine eigene Vergangenheit und auch ein eigenes Erbe hatten, war ihnen bis dahin nicht bewusst gewesen. Das erste türkische Kulturzentrum in der Neuköllner Schinkestraße, die Namik-Kemal-Bibliothek, das von türkischen Arbeiterinnen besetzte Wohnhaus an der Kottbusser Straße, das Denkmal für den von Anhängern der politisch rechts orientierten Grauen Wölfe ermordeten Lehrer und Gewerkschafter Celalettin Kesim am Kottbusser Tor, der Gemüsegarten von Remzi Karatas im Vorhof des Friedrichshain-Kreuzberg Museums, das Gecekondu (»über Nacht gebautes« Nothaus) und das Zwiebelbeet von Osman Kalin am Bethaniendamm dicht an der Mauer, dessen Entstehung und bisherige Erhaltung eng mit der Berliner Teilungsgeschichte und Teilungsnachgeschichte verschränkt ist - es gibt sie, die "eigenen « türkischen lieux de mémoire in Berlin. ${ }^{44}$

Nehmen wir etwa das ehemalige Krankenhaus Bethanien am Mariannenplatz, auf dessen Treppe zum 1. Mai 1975 der deutsch-türkische Arbeiterchor, geleitet von dem türkischen Musiker Tahsin İncirci, die Internationale sang. Es wurde 1847 von zwei berühmten Architekten - Ludwig Persius und Friedrich August Stüler - errichtet. Hier führte Theodor Fontane eine Apotheke, bevor er sich entschloss, sich nur noch dem Schreiben zu widmen. Nicht einmal 100 Meter nördlich verlief die Berliner Mauer. Nach erfolgreichen Protesten gegen den 1968 geplanten Abriss wurde im Hauptgebäude das legendäre Künstlerhaus Bethanien eingerichtet, das mit seinen Ausstellungen weit über die Landesgrenzen hinaus bekannt wurde. Der Auftrittsort des deutsch-türkischen Arbeiterchores ist für andere Publika aus anderen Gründen ebenfalls wichtig. Der Erinnerungsort erweist sich als Teil mehrerer thematisch unterscheidbarer, persönlicher und gruppenbezogener Erinnerungstopografien, die einander vielfach überschneiden, in denen zahlreiche Orte mehrfach codiert sind. Wer hier umherwandert, wird buchstäblich auf Schritt und Tritt anderen Vergangenheiten begegnen; manche sind offensichtlich, im Baubestand, an Zeichen und Relikten ablesbar, andere müssen erzählt und weitererzählt werden. Die Orte der Weitergabe können die bereits codierten Ereignisorte sein, aber auch andere Orte der Vermittlung sind denkbar.

Zum Beispiel das Friedrichshain-Kreuzberg Museum in der Adalbertstraße, mitten in dem Quartier, in dem sich seit den 1960er Jahren die türkischen Gastarbeiter und seitdem auch viele andere nicht deutschstämmigen Bewohner dauerhaft oder vorübergehend ansiedelten. Von 2010 bis 2012 wurde dort die ständige Ausstellung zur Bezirksgeschichte neu konzipiert, sie trägt den pro-

44 Gülsah Stapel, »Identität und Erbe«, Vortragsmanuskript zur Tagung »Das Erbe der Anderen «, an der Universität Bamberg, 14. bis 15. November 2013, in: Gerhard Vinken (Hg.), Das Erbe der Anderen. Denkmalpflegerisches Handeln im Zeichen der Globalisierung, Bamberg: University of Bamberg Press, 2015, 69-76. 
grammatischen Titel »Ortsgespräche«. Ein vergrößerter Plan des Doppelbezirks Kreuzberg/Friedrichshain vergegenwärtigt den Stadtraum im Museum, er bedeckt den Fußboden eines großen Ausstellungsraums. Auf ihm sind Ereignissorte markiert, die in den Erzählungen befragter Bewohner Erwähnung fanden. Für die Aufnahme weiterer Berichte steht ein Aufnahmegerät bereit, die neu eingelieferten Erzählungen werden regelmäßig eingepflegt. Die Berichte der Bewohner sind auf Tonträgern gespeichert, die die Besucher selber anhalten und umschalten können. Sie werden durch die Erzählungen $\mathrm{zu}$ den markierten Punkten im Stadtplan am Boden geführt, können dann an jedem Knotenpunkt, der in mehreren Erzählungen vorkommt, entscheiden, ob sie der erzählenden Person weiter zu einem anderen Ort im Stadtplan folgen wollen oder von einem anderen Sprecher eine weitere Geschichte zum selben Ort hören wollen und diesem weiter folgen. So werden die Vergangenheiten und Orte in der Gegenwart des Zuhörenden miteinander verflochten, immer neu, immer anders. Auf die Art wird die Vielfachcodierung von Orten zugleich hörbar und sichtbar. Die Besucher wandern ganz buchstäblich in mehreren benachbarten Vergangenheiten zugleich umher, die Migrantengeschichte ist hier eine unter mehreren. ${ }^{45}$

Das Museum lädt dazu ein, allein oder geführt in den Stadtraum zu gehen und selber Orte, Zeichen und Spuren zu erkunden und damit zum Zeugen zu werden - nicht der Ereignisse und ihrer Ursachen und Anlässe, denn die liegen, wie die in Oradour, in Polen und im west-östlichen Berlin in den diversen benachbarten Vergangenheiten der erzählenden Personen -, sondern zum Zeugen des eigenen Gehens und Lernens in der Gegenwart. Für diese Übung muss niemand seine Herkunftsbindung aufgeben. Was sich auftut, sind Optionen für mögliche Distanzierungen und neue, zusätzliche Bindungen - Optionen des Hinzutretens zu Vergangenheiten, die nicht die eigenen sind.

Am vorläufigen Ende meiner Überlegungen angekommen, stelle ich fest, dass ich, wenn man es genau nimmt, doch nicht in anderer Leute Vergangenheit hineingegangen bin, sondern in anderer Leute Gegenwart, die sich im Gehen und Schreiben mit meiner eigenen Gegenwart verflochten hat und somit Teil meiner zukünftigen Vergangenheit sein wird.

45 »Ortsgespäche. stadt - migration - geschichte: vom halleschen zum frankfurter tor«. Das Konzept für diese Ausstellungsinstallation wurde im Auftrag des Museumsleiters Martin Düspohl von Lorraine Bluche, Frauke Miera und Gülsah Stapel erarbeitet. Die Ausstellung wurde gezeigt vom 29. Januar 2012 bis zum 31. Dezember 2014. 


\section{Literatur}

Assmann, Jan. Das kulturelle Gedächtnis. Schrift, Erinnerung und politische Identität in frühen Hochkulturen, München: Beck, 2007.

Braudel, Fernand. La Méditerranée et le monde méditeranéen à l'epoque de Philippe II, Paris: Armand Colin, 1949.

Ben Muftah, Khalib Salem. »Stadtteil als Heimat. Konzentration außereuropäischer Minoritäten in Berlin und Paris«, unveröffentlichte Bachelorarbeit, Berlin, 2012.

Boga, Pinar. »Die Topographie der Anderen. Berliner Orte in literarischen Texten von türkischen Migranten«, unveröffentlichte Bachelorarbeit, Berlin, 2012.

Albert Breyer, »Zur Geschichte von Sompolno und Umgebung«, 2010, 11, http://www.up streamvistula.org/Documents/ABreyer_Sompolno.pdf, zuletzt geprüft am 18.09.2015 [Erstveröffentlichung in: Unsere Heimat. Volkstümliche Schriftenreihe zur Förderung der deutschen Heimatbildung und Familienüberlieferung in Polen, 4 (1938) Posen.

Deutsches Nationalkomitee für Denkmalschutz (Hg.). "Tagung Mauer und Grenze Denkmal und Gedenken«, Dokumentation der Tagung des Deutschen Nationalkomitees für Denkmalschutz in Berlin vom 10. bis 12. Mai 2009.

Dolff-Bonekämper, Gabi. »Wahr oder falsch. Denkmalpflege als Medium nationaler Identitätskonstruktionen", in: Bilder gedeuteter Geschichte. Das Mittelalter in der Kunst und Architektur der Moderne, Otto Gerhard Oexle (Hg.), Göttingen: Wallstein, 2004, 231-285.

Dies. »Les cadres sociaux et spatiaux du patrimoine - Quoi de neuf dans la Convention de Faro?«, in: Le patrimoine et au delà, Conseil de l'Europe (Hg.), Straßburg: Editions du Conseil de l'Europe, 2009, 75-81.

Dies. »The social and spatial frameworks of heritage - What is new in the Faro Convention? «, in: Heritage and beyond, Council of Europe (Hg.), Straßburg: Council of Europe Publishing, 2009, 69-74.

Dies. »Gegenwartswerte. Für eine Erneuerung von Alois Riegls Denkmalwerttheorie«, in: DENKmalWERTE. Beiträge zur Theorie und Aktualität der Denkmalpflege. Georg Mörsch zum 70. Geburtstag, Hans-Rudolf Meier und Ingrid Scheurmann (Hg.), Berlin/ München: Deutscher Kunstverlag, 2010, 27-40.

Dies. "Memorable moments - chosen cultural affiliations«, in: Clashes in European memory. The case of communist repression and the Holocaust, Band 2, Muriel Blaive, Christian Lindenberger und Thomas Gerbel (Hg.), Innsbruck: Studienverlag, 2011, 143-153.

Dolff-Bonekämper, Gabi, Hartmut Dorgerloh, Peter Goralczyk, Rainer Klemke, Helmut Trotnow und Anke Kuhrmann [Moderatorin]. „Gesprächsrunde: `Gefunden und verloren: Metamorphose von der Sperranlage zum (fast verschwundenen) Denkmal«, in: Schriftenreihe des Deutschen Nationalkomitees für Denkmalschutz, 76/2 Tagung Mauer und Grenze - Denkmal und Gedenken [Dokumentation der Tagung des Deutschen Nationalkomitees für Denkmalschutz vom 10. bis 12. Mai 2009 in Berlin], Deutsches Nationalkomitee für Denkmalschutz (Hg.), Berlin: DNK, 2009, 51-64.

Drohsel, Karsten Michael. Das Erbe des Flanierens. Der Souveneur - ein handlungsbezogenes Konzept für urbane Erinnerungsdiskurse, Bielefeld: transcript, 2016.

Ehrlich, Andrea. "Das Schtetl. Wirtschaftliche und soziale Strukturen der ostjüdischen Lebensweise«, Teil 3, 1996, http://www.hagalil.com/galluth/shtetl/au3.htm, zuletzt geprüft am 12. Februar 2020. 
François, Etienne und Hagen Schulz. Deutsche Erinnerungsorte, München: C.H. Beck, 2001.

Hahn, Hans Henning und Robert Traba (Hg.). Deutsch-polnische Erinnerungsorte / PolskoNiemieckie Miejsca Pamięci, Paderborn u. a.: Schöningh, 2012.

Halbwachs, Maurice. Les cadres sociaux de la mémoire, Reprint der Ausgabe von 1925, Paris: A. Michel, 2004.

Ders. La topographie légendaire des evangiles en Terre sainte, Paris: Presses Univ. de France, 1941.

Hammer-Schenk, Harold. Synagogen in Deutschland. Geschichte einer Baugattung im 19. und 20. Jh. (1780-1933), zwei Teilbände, Hamburger Beiträge zur Geschichte der deutschen Juden, Bd. 8., Hamburg: Hans Christians, 1981.

Hijazi, Zeinab. »Das Neue Kreuzberg Zentrum. Von der Utopie der Planung zum Zentrum der Migration«, unveröffentlichte Bachelorarbeit, Berlin, 2012.

Instytucja Kultury Samorządu Województwa Wielkopolskiego, "Muzeum Okręgowe w Koninie« [Das Bezirksmuseum in Konin], 2007, http://www.muzeum.com.pl/en/histo ryczny.htm, zuletzt geprüft am 20. September 2015.

Iwaszkiewicz, Jarosław. Podróże do Polski, Warschau: Wydawnictwo »Alfa«, 1987.

Jarrassé, Dominique. Une histoire des synagogues françaises. Entre Occident et Orient: Essai, Arles: Hébraïca, 1997.

Klausmeier, Axel und Günter Schlusche. Denkmalpflege für die Berliner Mauer. Die Konservierung eines unbequemen Bauwerks, Berlin: Links, 2011.

Kuipers, Marieke. »Conserveren in de wegwerpmaatschappij. Pleidooi voor een polychrone cultuur«, Habilitationsvortrag vom 30. März 2001 an der Universität Maastricht, Maastricht, 2001, https://cris.maastrichtuniversity.nl/portal/en/publications/ conserveren-in-de-wegwerpmaatschappij-pleidooi-voor-een-polychrone-cultuur(2b5 3366f-5b1d-4de8-abb6-8323b9c14916).html, zuletzt geprüft am 12. Juni 2019.

Matarasso, François. »Open Doors and open minds«, First European Heritage Forum on »Heritage and Dialogue«, Brüssel, 23.-24. Oktober 2008, Report DGIV/PAT/JEP (2008)20rev, CDPATEP(2008)32rev, 14. Januar 2009.

"Meeting on the `European Dimension` of Heritage Days Events - Strasbourg (France), 11-12 December 2011 «, http://www.coe.int/t/dg4/cultureheritage/heritage/ehd/2011/ EDimension_en.asp, Artikel ist nicht mehr verfügbar, zuletzt geprüft am 05. April 2014.

Michnik, Adam. "Laudatio auf die Kulturgemeinschaft Borussia anlässlich der Verleihung des Lew Kopelew Preises (2004)«, in: Borussia. Wspólnota Kulturowa, Konstantin M. Azadovskij und Robert Traba (Hg.), Olsztyn: Stowarzyszenie Wspólnata Kulturowa »Borussia«, 2006, 14-17.

Mocevic, Jelena. »Meeting on the Theme of `The European Dimension of Heritage Days Events«", Strasbourg (Frankreich), 11. - 12. Dezember 2011, Meeting Report - DGIV/ PAT/JEP(2011)14 2012.

Nora, Pierre (Hg.). Les lieux de mémoire, Band 1, Paris: Gallimard, 2004.

Ders. Les lieux de mémoire. Band 2, Paris: Gallimard, 2003.

Ders. Les lieux de mémoire. Band 3, Paris: Gallimard, 2004.

Özdamer, Emine Sevgi. Die Brücke vom Goldenen Horn, Köln: KiWi, 2005.

Potel, Jean-Yves. La fin de l'innocence. La Pologne face à son passé juif, Paris: Autrement Frontières, 2009.

Richmond, Theo. Konin. A Quest, London: Random House, 1995. 
Ders. Konin. Een zoektocht, übers. von Josephine Ruitenberg, Amsterdam: Wereldbibliotheek, 1996.

Ders. Konin. One Man's Quest for a Vanished Jewish Community, New York: Pantheon Books, 1996.

Ders. Konin. Auf der Suche nach der Stadt meiner Eltern, übers. von Elke Hosfeld, München: Bertelsmann, 1997.

Ders. Konin. La città che vive altrove, übers. von Elena Löwenthal, Turin: Instar Libri, 1998.

Ders. Uporczywe echo. Sztetl Konin: poszukiwanie, übers. von Piotr Szymczak, Poznań: Media Rodzina, 2001.

Rüthers, Monica. »Ostjüdische Vielfalt in einer multikulturellen Umgebung«, in: Ost-West Europäische Perspektiven, 3 (2008), 163-174, https://www.owep.de/artikel/67/ostjuedi sche-vielfalt-in-einer-multikulturellen-umgebung, zuletzt geprüft am 22. September 2015.

Schlusche, Günter, Verena Pfeiffer-Kloss, Gabi Dolff-Bonekämper und Axel Klausmeier (Hg.). Stadtentwicklung im doppelten Berlin: Zeitgenossenschaft und Erinnerungsorte, Berlin: Links, 2014.

Stadt Konin. »Willkommen bei Konin. Denkmale«, http://www.konin.pl/index.php/denk male.html, zuletzt geprüft am 18. September 2015.

Dies. »Willkommen bei Konin. Die Zusammenarbeit mit dem Ausland», http://www. konin.pl/index.php/die-zusammenarbeit-mit-dem-ausland.html, zuletzt geprüft am 18. September 2015.

»Stadt Mensch Geheimnis. Ausstellung und Projektbericht des Studienprojektes $>$ Fremdes Erbe«", unveröffentlichter Projektbericht zur Ausstellung, Berlin, 2006.

Stapel, Gülsah. »Identität und Erbe: Der Mariannenplatz - ein Erinnerungsort türkischer Berliner. Identity and Heritage: The Mariannenplatz - a site of memory for Turkish residents of Berlin«, in: Das Erbe der Anderen. Denkmalpflegerisches Handeln im Zeichen der Globalisierung. The Heritage of the Other. Conservation Considerations in an Age of Globalization, Gerhard Vinken (Hg.), Bd. 2, Bamberg: University of Bamberg Press, 2015, 69-76.

Dies. »Recht auf Erbe in der Migrationsgesellschaft«, Dissertation, TU Berlin, 2020.

"The List of Places from which Jewish People were Murdered in the Chełmno-on-Ner Extermination Center, on the basis of the study by Krzysztof Gorczyca and Zdzisław Lorek, Kalendarium Chetmna«, 2005, http://www.zchor.org/chelmno/list.htm, zuletzt geprüft am 21. September 2015.

Thum, Gregor. Die fremde Stadt. Breslau nach 1945, München: Pantheon Verlag, 2006.

Traba, Robert. »It was Only a Film! ‘ Three Images of Conflict and Dialogues of memory«, in: Pamiec Rejestry i terytoria / Memory, Registers and Territories, Międzynarodowe Centrum Kultury (Hg.), Kraków: Międzynarodowe Centrum Kultury, 2014, 15-22.

Wajsbrot, Cécile. Mann und Frau den Mond betrachtend, übersetzt von Holger Fock und Sabine Müller, München: Liebeskind, 2006. 
Open-Access-Publikation im Sinne der CC-Lizenz BY 4.0

(c) 2020, Vandenhoeck \& Ruprecht GmbH \& Co. KG, Göttingen ISBN Print: 9783847107507 - ISBN E-Lib: 9783737007504 


\section{(Re-)konstruierter Raum als Ausdruck gesellschaftlichen Wandels - die Beispiele Elbing/Elbląg und Glogau/Głogów}

\section{Einführung}

Die in den letzten Jahren entstandenen postmodernen Altstadtlandschaften im Kern der in der Wojewodschaft Ermland-Masuren gelegenen Stadt Elbing/Elbląg mit knapp 124.000 Einwohnern wie dem der niederschlesischen 70.000-Einwohner-Stadt Glogau/Głogów stellen Ergebnisse eines Prozesses dar, in dessen Rahmen in einer ganzen Reihe west- und nordpolnischer Städte nach Kriegszerstörungen und Enttrümmerung jahrzehntelang brachliegende Altstadtareale im postmodernen Kostüm wieder bebaut worden sind. Dieses Phänomen ist wiederholt Gegenstand wissenschaftlicher Abhandlungen geworden, dabei jedoch stets aus der mit einem »Wiederaufbau historischer Altstädte« begrifflich gefassten Perspektive betrachtet worden. ${ }^{1}$ Entsprechend stand dabei vor allem die Sichtbarmachung historischer Spuren im Rahmen der Neubebauung im

1 In der Literatur geht es begrifflich um den Wiederaufbau bzw. die Wiederherstellung von Altstädten bzw. historischen Stadtzentren, im Polnischen mit »odbudowa starych/historycznych miast« bezeichnet. Vgl. Arnold Bartetzky, »Zwischen Denkmalpflege und Stadtverhübschung. Der Wiederaufbau historischer Stadtzentren in Nordpolen seit 1980«, in: Bernfried Lichtnau (Hg.), Architektur und Städtebau im südlichen Ostseeraum zwischen 1936 und 1980, Berlin: Lukas, 2002, 434-446; Lorenz Frank, "Die Wiederherstellung historischer Altstädte in Polen seit 1985«, in: Andrea Langer (Hg.), Der Umgang mit dem kulturellen Erbe in Deutschland und Polen im 20. Jahrhundert, Warschau: Instytut Sztuki PAN, 2004, 191-208; Maria Lubocka-Hoffmann, "Die neue Altstadt von Elbing", in: Michał Woźniak (Hg.), Kunstgeschichte und Denkmalpflege. Beiträge des Arbeitskreises deutscher und polnischer Kunsthistoriker, Toruń: Wydawnictwo UMK, 2002, 225-240; Agnieszka Zabłocka-Kos, »Städte in Schlesien: Von der ssozialistischen Stadt ‘ der Arbeiterklasse zur bürgerlichen neuen `Altstadtı. Legnica und Głogów nach 1945«, in: Thomas Bohn (Hg.), Von der reuropäischen Stadt zur ssozialistischen Stadt und zurück? Urbane Transformationen im östlichen Europa des 20. Jahrhunderts, München: Oldenbourg, 2009, 155-174; sowie die Beiträge in Andreas Billert (Hg.), Wiederaufbau und Stadterneuerung in historischen Altstadtkernen. Głogów, Lubań, Polkowice, Frankfurt (Oder), Görlitz und Kamenz, Lubań: Gmina Miejska Lubań, 2007, und in Maria Lubocka-Hoffmann (Hg.), Odbudowa miast historycznych. Dokonania przeszłości Potrzeby i możliwości wspótczesne - Wyzwania przyszłości, Elbląg: PKN ICOMOS, 1998, 148-160. 
Vordergrund, diskutiert als Spannungsfeld zwischen Denkmalschutz und Rekonstruktion, zwischen archäologisch-stadthistorischen Forschungen und Geschichtsinterpretation und -selektion sowie zwischen historische Bezüge herstellender Architektur und einer Produktion von Pseudo-Altstädten. Gesellschaftliche Kontexte blieben so im Hintergrund oder gar ausgeblendet. Problematisch erscheint zudem, dass der Blickwinkel des "Wiederaufbaus« des in Folge eines Kataklysmus zerstörten Kerns einer Stadt impliziert, dass dessen Fehlen als Verlust in identitätsstiftender wie funktionaler Hinsicht empfunden wird. Natürlich lässt sich grundsätzlich nicht bestreiten, dass die materiellen Strukturen einer Stadt »Kristallisationspunkte für biographische Erinnerungen ebenso wie für das kollektive Gedächtnis der Gesellschaft « ${ }^{2}$ sind, jedoch ist diese Voraussetzung im spezifischen Fall der Städte in Nord- und Westpolen, bei denen 1945 die Verschiebung der deutsch-polnischen Grenze an Oder und Neiße mit einem vollständigen Bevölkerungsaustausch verbunden war, gerade nicht gegeben. Somit kann es offensichtlich nicht um den Wiederaufbau einer Altstadt im genannten implizierten Verständnis gehen, da die heutige Stadtgesellschaft deren Verlust kollektiv gar nicht empfinden kann, sondern um die erneute Bebauung des Altstadtareals im komplexen ökonomischen, politischen und kulturellen Geflecht aktueller gesellschaftlicher Vorstellungen und Bedürfnisse. Als Betrachtungsgegenstand wird daher im vorliegenden Beitrag die Realisierung einer städtebaulichen Quartiersentwicklung auf einem Gebiet von gesamtstädtisch zentraler Bedeutung verstanden. Die stattfindende Raumkonstruktion wird aus der Perspektive des baulichen Ausdrucks des gesellschaftlichen Wandels betrachtet, der mit dem politischen Umbruch von der sozialistischen Planzur demokratischen Marktwirtschaft eingesetzt hat. Am Beispiel der Städte Elbing/Elbląg und Glogau/Głogów wird gezeigt, von welcher Vorstellung von städtischer postsozialistischer Gesellschaft die entstandenen Stadtareale zeugen, bzw. welche in der postsozialistischen Gesellschaft vorherrschende Vorstellung von Stadt in diesen Arealen zum Ausdruck kommt.

\section{Merkmale postsozialistischer Stadtlandschaften}

Gesellschaftlicher Wandel findet stets seinen Ausdruck in Veränderungen städtebaulicher und stadtfunktionaler Strukturen. "Realisierte Stadtkonzeptionen, deren Entwürfe einzelnen Personen oder Gruppen zuzuschreiben sind, stellen in dieser Sichtweise Vehikel der Umsetzung von neuen gesellschaftlichen

2 Walter Siebel, "Einleitung: Die europäische Stadt», in: ders. (Hg.), Die europäische Stadt, Frankfurt am Main: Suhrkamp, 2004, 43. 
Problemlagen in Möglichkeiten der baulich-räumlichen Stadtentwicklung dar. ${ }^{3}$ Entsprechend hat der tiefgreifende politische und sozioökonomische Wandel, der mit dem Kollaps des sozialistischen planwirtschaftlichen Systems und der anschließenden Errichtung von demokratischen und marktwirtschaftlichen Strukturen in Polen verbunden war, seine unübersehbaren Spuren in den polnischen Stadtlandschaften hinterlassen. Dazu gehören die Kommerzialisierung innerstädtischer Nutzungsstrukturen ebenso wie die Revitalisierung lang vernachlässigter zentraler Quartiere, der schleichende Verfall innerstädtischer Wohnviertel mit komplizierten Eigentums- und Sozialverhältnissen ebenso wie die Entstehung ausgedehnter Siedlungsgebiete in Stadtrandbereichen und der Niedergang funktionslos gewordener Industriebausubstanz ebenso wie der Bau von glitzernden Einkaufszentren und gläsernen Bürotürmen. ${ }^{4}$

Ein prägendes Element ist dabei die mit dem Niedergang des sozialistischen planwirtschaftlichen Systems einhergehende Entwertung seiner Symbole verbunden; zugleich entwickelte sich die Frage nach der adäquaten räumlichen Repräsentierung des neuen, sich herausbildenden Systems. Diese manifestierte sich zuvörderst durch eine ostentative Abkehr von den Hinterlassenschaften des sozialistischen Systems, wofür etwa die Umbenennung von Straßen und das Schleifen von Denkmälern stehen. Verbunden war damit eine Integration von "westlichen" oder "internationalisierenden « Ensembles in den Stadtraum in Form von Emblemen des Kapitals und des Konsums. ${ }^{5}$ Diese Phänomene beruhen auf einer tendenziell starken gesellschaftlichen Akzeptanz nicht mehr von obrigkeitsstaatlicher Ideologie und Baupolitik bestimmter, sondern dem jeweiligen Geschmack und der finanzieller Potenz individueller Bauherren entsprechenden Baustrukturen. Im Zusammenspiel mit einem schwachen stadtplanerischen Instrumentarium führt dies - in den an das dahinterstehende neoliberale Konzept der ökonomischen Schock-Therapie anspielenden Worten von Czepczyński - zur Entstehung »eher `schockierender Landschaften`, welche

3 Marianne Rodenstein, »Städtebaukonzepte - Bilder für den baulich-räumlichen Wandel der Stadt«, in: Hartmut Häußermann, Detlev Ipsen, Thomas Krämer-Badoni, Dieter Läpple, Marianne Rodenstein und Walter Siebel, Stadt und Raum. Soziologische Analysen, Pfaffenweiler: Centaurus, 2. Auflage 1992, 31.

4 Vgl. Mariusz Czepczyński, Cultural Landscapes of Post-Socialist Cities. Representation of Powers and Needs, Aldershot \& Burlington: Ashgate, 2008; Jerzy Parysek, Miasta polskie na przełomie XX i XXI wieku. Rozwój i przekształcenia strukturalne, Poznań: Bogucki, 2005; Sasha Tsenkova, »Beyond transitions: Understanding urban change in post-socialist cities«, in: Sasha Tsenkova und Zorica Nedović-Budić (Hg.), The Urban Mosaic of Post-Socialist Europe. Space, Institutions and Policy, Heidelberg/New York: Physica, 2006, 21-50.

5 Gregory Andrusz, »From socialist to post-socialist city: a journey from wall to mall and from security to risk", in: Adelheid Pichler und Gertraud Marinelli-König (Hg.), Kultur - Erbe Stadt. Stadtentwicklung und UNESCO-Mandat in post- und spätsozialistischen Städten, Innsbruck/Wien/Bozen: StudienVerlag, 2008, 11-31. 
Befreiung von Wirtschafts- wie Gestaltungshemmnissen repräsentieren. « ${ }^{6}$ Diese Stadträume zeichneten sich durch eine Konsequenz in der architektonischen Zurschaustellung der kommerziellen Philosophie ihrer Erbauer aus, die so - insbesondere in Form einer Kontrasthaftigkeit aufgrund der häufig fehlenden Einbettung in den gestalterischen und funktionalen Kontext - in den vermeintlichen Vorbildstädten des »Westens « zumindest in Europa durchaus nicht dominiert. Bei der Entstehung von europäischen Stadtlandschaften, die sich bewusst von der sozialistisch gewollten Einförmigkeit absetzen, stellte die Produktion "westlicher « moderner und kapitalistischer Bilder jedoch nur einen Aspekt dar, der durch die bewusste gestalterisch-funktionale Herstellung von Bezügen zu einem »Goldenen Zeitalter« der Stadtentwicklung komplementiert wurde. ${ }^{7}$ Im Sinne eines »Zurück in die Zukunft « steht dieses »Goldene Zeitalter» für eine prosperierende Epoche in der Geschichte der Stadt, an welche mit dem Ende der - den vermeintlich "normalen « Entwicklungspfad unterbrechenden Episode des Sozialismus wieder angeknüpft werden kann. Bei der Herausbildung einer neuen Stadtidentität - verstanden als eine Identifizierung sowohl von als auch mit einer Stadt - und in der Folge eines postsozialistischen Stadtimages spielen bauliches Erbe und Symbole einer gewählten Epoche einschließlich ihrer Wiederherstellung und zeitangepassten Umdeutung eine zentrale Rolle. Das genannte Spannungsfeld zwischen im dargelegten Sinne europäischer und an Vergangenheit orientierter Identitätskonstruktion scheint, wie in der Folge gezeigt werden wird, auch maßgeblich den gesellschaftlichen Prozess der postsozialistischen Stadtkonzipierung auf den Altstadtarealen in Elbing/Elbląg und Glogau/Głogów zu bestimmen.

\section{Stadtkonzeptionen als Gesellschaftsentwürfe einer Umbruchzeit}

Eine bemerkenswerte Besonderheit ist im Falle beider Städte der Fakt, dass postsozialistische Stadtkonzeptionen bereits lange vor dem Vorhandensein postsozialistischer Städte entstehen. Die schwindende Autorität der staatlichen Machthaber nach der durch Streiks erzwungenen Zulassung der Solidarność und der folgenden Verhängung des Kriegsrechts mit seinen Auswirkungen eröffnete

6 Czepczyński, Cultural Landscapes, 152 (Übersetzung des Verfassers).

7 Vgl. Agata Anna Lisiak, Urban Cultures in (Post)Colonial Central Europe, West Lafayette: Purdue University Press, 2010; Alexander Tölle, »Urban identity policies in Berlin: From critical reconstruction to reconstructing the Wall«, in: Cities 27 (2010), 348-357; Craig Young und Duncan Light, "»Communist heritage tourism`: between economic development and European integration«, in: Dieter Hassenpflug, Burkhardt Kolbmüller und Sebastian Schröder-Esch (Hg.), Heritage and Media in Europe - Contributing towards Integration and Regional Development, Weimar: Bauhaus-Universität, 2006, 249-263. 
in den frühen 1980er Jahren den Freiraum zur Erstellung von städtischen Konzepten jenseits ideologischer Vorgaben. Dies äußerte sich allein schon in der Beschäftigung mit einem Areal, welches jahrzehntelang übergangen worden war und somit mit Ausnahme weniger Solitäre »eine große, begrünte Freifläche in der Mitte der Stadt ${ }^{8}$ darstellte. Weder das Fehlen eines städtischen Zentrums sowohl für Elbing/Elbląg wie für Glogau/Głogów (gesamtstädtische Funktionen hatten sich in Stadtgebiete außerhalb des jeweiligen Altstadtbereiches verlagert, ohne dass dort funktional oder stadträumlich urbane Zentren entstanden wären) noch die historische Bedeutung der Altstadtareale begründeten aus Sicht sozialistischer Baupolitik ein Handlungserfordernis. Allein mit dem allmählichen Anstieg der Bevölkerung - in Elbing/Elbląg wurde in den 1960er Jahren wieder die Vorkriegs-Bevölkerungszahl erreicht, in Glogau/Głogów etwa ein Jahrzehnt später - entstanden Konzepte zur Einbeziehung der Altstadtareale in die wachsende Wohnbautätigkeit - freilich ohne Berücksichtigung deren stadträumlicher und historischer Bedeutung. ${ }^{9}$

In scharfen Kontrast zu solchen Ansätzen werden zunächst in Elbing/Elbląg umfangreiche archäologische Forschungen auf dem Gebiet der ehemaligen Altstadt durch das Büro der Denkmalkonservatorin der Wojewodschaft Maria Lubocka-Hoffmann durchgeführt, welche den Ausgangspunkt für ein sehr stark durch eine Auseinandersetzung mit Fragen des Denkmalschutzes geprägtes Bebauungskonzept bilden. Dessen Grundstruktur bildet der freigelegte Stadtgrundriss, d.h. die historische kleinteilige Parzellenstruktur der bürgerlichen Stadt. Zudem sollten neue, in moderner Architektur errichtete Gebäude in ihrer Kubatur, Giebel- und Dachform sowie in architektonischen Details und Fassadenmaterialien auf ihren jeweiligen historischen Vorgängerbau verweisen; Grundlage dafür waren denkmalpflegerische Untersuchungen insbesondere unter Auswertungen von erhaltenen Bauunterlagen und -beschreibungen sowie Abbildungen. Dabei sollten entsprechend denkmalpflegerischen Grundsätzen die »Hinzufügungen unserer Zeit den erhalten gebliebenen urbanistischen und architektonischen Werten strikt untergeordnet ${ }^{10}{ }^{10}$ werden, und auch eine vorgesehene Rekonstruktion weniger ausgewählter Gebäude von hohem architek-

8 Frank, »Die Wiederherstellung historischer Altstädte«, 192.

9 Davon zeugen beispielsweise die im Rahmen eines in den 1970er Jahren vom Verband der polnischen Architekten (SARP) ausgelobten städtebaulichen Wettbewerbs entstandenen Entwürfe für eine Bebauung des Altstadtareals von Glogau/Głogów mit Wohnhochhäusern. Vgl. Edyta Wojtowicz, »Der Wiederaufbau der Altstadt in Głogów«, in: Andreas Billert (Hg.), Wiederaufbau und Stadterneuerung in historischen Altstadtkernen. Głogów, Lubań, Polkowice, Frankfurt (Oder), Görlitz und Kamenz, Lubań: Gmina Miejska Lubań, 2007, 31 f. Vgl. zur Stadtentwicklung auch: Edyta Wojtowicz und Dariusz Wojtowicz, »Die städtebauliche Entwicklung von Głogów in den Jahren 1945-1997«, in: Hanna Nogossek (Hg.), Annäherungen - Ansichten von Glogau, Marburg: Herder-Institut, 1997, $67 \mathrm{f}$.

10 Lubocka-Hoffmann, »Die neue Altstadt von Elbing«, 229. 
tonischen oder historischen Wert sollte den Hintergrund für die authentischen Gebäude und Strukturen bilden.

Für das Verfahren zur Bebauung der Altstadtareale von Elbing/Elbląg wurde von Maria Lubocka-Hoffmann der Begriff der »Retroversion « geschaffen, bei der es um »eine Rückkehr zum `Geist` und nicht zum `Buchstaben` des Urmusters» der alten Stadt geht, d.h. um eine Rückkehr »zum alten Bilde der Stadt ${ }^{11}$. Bescheidener in seinem wissenschaftlich-denkmalpflegerischen Ansatz, jedoch ganz ähnlich in seiner inhaltlichen Ausrichtung, ist die Anfang der 1980er Jahre von jungen Mitgliedern einer Ortsgruppe des Verbands der polnischen Architekten (SARP) erstellte Studie für eine die historischen Raumstrukturen und Funktionen berücksichtigende Bebauung des Altstadtareals von Glogau/Głogów, welche die Grundlage für den 1983 beschlossenen Bebauungsplan bildet. ${ }^{12}$ Auch hier sollten auf der Grundlage archäologischer Ausgrabungen und Bauforschungen historische Stadträume, Bebauungslinien und Parzellenstrukturen durch Neubauten, die in ihrer architektonischen Gestaltung und Kubatur an ihre zerstörten Vorgängerbauten erinnern, wieder sichtbar gemacht werden. Eine Rekonstruktion einzelner zerstörter Gebäude war anders als in Elbing/Elbląg zwar nicht vorgesehen, hingegen wie dort »der Erhalt bestehender Denkmalbauten von hoher kultureller Bedeutung und anderer Gebäude von kulturellem Wert ${ }^{13}$. In beiden Städten stellen die erstellten Konzepte jedoch nicht nur Entwürfe für eine anderen städtebaulichen Umgang mit Altstadtarealen dar, ihnen ist in gesellschaftlicher Hinsicht ein Bruch mit ideologisch vorgegebenen Konventionen immanent. In der Folge lässt sich behaupten, dass die Konzepte bezüglich ihrer Bezugnahme auf lokale Identitätskonstruktion und auf eine Tradition individuellen Bauherrentums für eine postsozialistische Gesellschaft geplant waren, deren Konturen zum Entstehungszeitpunkt noch gar nicht abzusehen waren.

Der erstgenannte Aspekt wird vor dem Hintergrund verständlich, dass der Umgang mit Altbausubstanz in der Volksrepublik Polen nahezu ausschließlich an dem Verständnis solcher Ensembles als Träger polnischer nationaler Identität orientiert war. Angesichts der Dezimierung der polnischen Kulturlandschaften durch Kriegszerstörungen ebenso wie durch den Verlust der polnischen Ostgebiete wurde die Wiedererrichtung verlorener historischer Bauten und Stadtlandschaften als nationale identitätstragende Symbole $\mathrm{zu}$ einer zentralen Aufgabe, im Übrigen durchaus in Anknüpfung an Traditionen der Zwischen-

11 Ebd., 230.

12 Vgl. Grzegorz Grajewski, »Poglądy na odbudowę Głogowa w mijajacym półwieczu«, in: Maria Lubocka-Hoffmann (Hg.), Odbudowa miast historycznych. Dokonania przeszłości Potrzeby i możliwości współczesne - Wyzwania przyszłości, Elbłąg: PKN ICOMOS, 1998, $228 \mathrm{f}$.

13 Ebd., 228 (Übersetzung des Verfassers). 
kriegszeit. ${ }^{14}$ In diesem Geiste entstand die 1946 veröffentlichte Programmschrift zum Wiederaufbau zerstörter historischer Bausubstanz des polnischen Generalkonservators Jan Zachwatowicz, welcher der sog. Polnischen Schule der Denkmalpflege zugrunde liegt, ${ }^{15}$ und welche zur Rekonstruktion von zerstörten Stadtbildensembles u. a. in den Stadtkernen von Warschau/Warszawa, Posen/ Poznań, Danzig/Gdańsk und Breslau/Wrocław unter Federführung von Denkmalpflegern und Kunsthistorikern geführt hat. Die Hervorhebung des "polnischen « Charakters eines Bauwerks, etwa durch Bezugnahme auf einen mit der Piasten-Zeit verbundenen Bauzustand, lässt sich aber auch in den seit Mitte der 1950er Jahre nach neuen Vorgaben erarbeiteten Aufbaukonzeptionen bei den Solitärbauten weiter beobachten, welche als im genannten Sinne bedeutende bauliche Zeugen rekonstruiert wurden - freilich jetzt in Altstadtarealen, die ansonsten überwiegend in modernistischer Zeilenbauweise neu bebaut wurden. Der hinter diesem nationalbezogenen Ansatz stehende, zur Machtlegitimierung geschaffene Mythos des kommunistischen Regimes als Hüter nationaler Identität und - im Bündnis mit der Sowjetunion - territorialer Integrität bedingte ein oktroyiertes Verständnis der nach 1945 polnisch gewordenen ehemaligen ostdeutschen Gebiete allein als »urpolnisch". Geplant wurde so für eine lokale Gesellschaft, die sich allein über ihre polnische Identität definieren sollte, und deren Aneignung der neuen Heimat allein in deren polnischem Charakter einen Ausdruck finden sollte. Jegliche Herausbildung eines Lokalbewusstseins über eine Auseinandersetzung mit örtlicher Geschichte oder ihren baulichen Hinterlassenschaften wurde so unterbunden. Diesbezüglich stellten die jenseits einer $»$ Polonisierung dieser Städte ${ }^{16}$ auf archäologischen Untersuchungen und stadthistorischen Forschungen beruhenden Altstadtbebauungskonzepte für Glogau/Głogów und Elbing/Elbląg einen Umbruch dar, da ihnen ein ideologisch unvoreingenommener, gerade auf Wissen um die lokale Stadtentwicklungsgeschichte beruhender Ansatz zugrunde lag. Das »neue Konzept einer in der Geschichte verwurzelten Stadt ${ }^{17}$ stellte den ernsthaften Versuch der Altstadtentwicklung auf Grundlage historischer Stadtstrukturen und -spuren dar, wenn auch in Glogau/Głogów wie Elbing/Elbląg eine Auseinandersetzung vor allem mit der mittelalterlichen Stadt unter Vernachlässigung späterer Epochen - insbesondere der in beiden Fällen für die Stadtgestalt vor der Zerstörung prägenden Gründerzeit - zu konstatieren ist. ${ }^{18}$ Dies spiegelt jedoch wohl vor

14 Vgl. Andreas Billert, „Denkmalpflege in Polen. Nationale Identität, Schönheitstraum und Verlust der Mitte«, in: Informationen zur Raumentwicklung 6 (2005), 410.

15 Bohdan Rymaszewski, Polska ochrona zabytków, Warschau: Scholar, 2005, 102 (Übersetzung des Verfassers).

16 Zabłocka-Kos, »Städte in Schlesien«, 155.

17 Ebd., 169.

18 Vgl. ebd., 171 bzw. Franz, »Wiederherstellung historischer Altstädte«, 193. 
allem den Stand der gesellschaftlichen Wertschätzung für bauliche Zeugen dieser Epoche wider, welche sich auch in westlichen Ländern um diese Zeit erst zu entwickeln begann.

Der zweite Aspekt bezieht sich darauf, dass die Überwindung der durch Grundstücksgrenzen und Bodenpreise determinierten Entwicklung der kapitalistischen Stadt ein Grundpostulat des sozialistischen Städtebaus darstellte. Dies war auch an den genannten Wiederaufbaukonzepten für Altstadtareale in der Volksrepublik Polen ablesbar. Bereits bei den der Polnischen Schule der Denkmalpflege entsprechenden Konzepten waren mit der Ausnahme weniger restaurierter Solitäre über historische Parzellengrenzen hinweg moderne Gebäude mit dem historischen Vorbild nachgestalteten vorgesetzten Straßenfassaden errichtet worden. Dabei wurden historische Baulinien entlang der Straßen eingehalten, während die Bebauungstiefe reduziert und auf eine Wiederbebauung der Blockinnenbereiche zugunsten von großzügigen halböffentlichen Wohnhöfen weitgehend verzichtet wurde. Spätere Konzepte entsprachen bereits einem sozialistischen Städtebau in modernistischer Form, demzufolge alte Parzellengrenzen - und zunehmend auch Straßenverläufe - ignoriert wurden zugunsten eines aufgelockerten und autogerechten Städtebaus mit Wohnscheiben, Pavillons und Punkthochhäusern inmitten ausgedehnter Grün- und Freiflächenbereiche. Die Anfang der 1980er Jahre für die Wiederbebauung der Altstadtareale in Glogau/Głogów und Elbing/Elbląg entstandenen Konzeptionen nahmen jedoch die - gemäß sozialistischer Ideologie zu überwindende - bürgerliche Stadt mit ihrer Parzellenstruktur zur Ausgangslage. Dies stellte zugleich indirekt eine Abkehr von den Vorgaben einer planwirtschaftlichen Baupolitik dar, mit der Wohnbebauungsformen auf historischen Parzellengrößen mit integrierten kleinteiligen Handels- und Dienstleistungsstrukturen schlicht kaum realisierbar waren. Zudem war damit eine Zurückweisung einer kollektivistischen, angesichts eines in die Millionen gehenden Fehlbestands an Wohneinheiten allein auf die quantitative Befriedigung von Bedürfnissen durch gesichtslosen Massenwohnungsbau in Großtafelbauweise gerichtete Stadtentwicklungspolitik verbunden. Die für die Altstadtareale von Glogau/Głogów und Elbing/Elbląg entstandenen städtebaulichen Konzeptionen mit ihren Parzellengrößen der bürgerlichen Stadt und einem Konzept von individueller Bauherrentätigkeit drückten so nicht nur eine gesellschaftliche Sehnsucht nach "bunter « Individualität statt "grauem" Kollektivismus aus, sondern sie setzten dabei eine Gesellschaftsform voraus, die zum Zeitpunkt der Entwürfe kaum existieren und mit Sicherheit keine raumprägende Aktivität entfalten konnte. 


\section{(»Alt«-)Stadtentwicklung lokaler postsozialistischer Gesellschaften}

Die Umsetzung der für die Altstadtareale von Elbing/Elbląg und Glogau/Głogów beschlossenen komplexen städtebaulichen Konzepte erfolgte den gegebenen Realien einer sozialistischen Bauwirtschaft (und der Unangepasstheit der Entwürfe an diese) entsprechend schleppend. Symbolhaft steht dafür die bis 1989 von einer Wohnungsbaugenossenschaft realisierte Bebauung an der östlichen Marktplatzseite in Glogau/Głogów, welche in Großtafelbauweise erfolgte. Die entstandene Blockrandbebauung mit ihrer Straßenfassadengestaltung imitierte zwar lediglich kleinteilige Strukturen, integrierte dabei jedoch traditionelle Bauformen, war an altstadtgerechten Baumaßen und -linien orientiert und bot den im damaligen Zeitkontext sehr ungewöhnlichen Komfort einer Tiefgarage. Handels- und Dienstleistungsflächen im Erdgeschoss zeugten zudem von dem Willen, das Altstadtareal funktional als Stadtzentrum zu entwickeln. Für diesen Ansatz »innerstädtischen Bauens auf der Grundlage produktiver industrieller Bauweisen ${ }^{19}{ }^{9}$ in den 1980er Jahren lassen sich auch zahlreiche Beispiele in Städten der DDR und anderer Staaten hinter dem Eisernen Vorhang finden. Die entstandenen Ensembles sind in der Retrospektive als eher hilflose und auch wenig ökonomische Versuche anzusehen, auf das in Fach- wie bestimmten Gesellschaftskreisen zunehmend lauter artikulierte Bedürfnis nach dem Erhalt und der Entwicklung historischer Stadtbereiche und nach dem Bau von Siedlungsstrukturen in menschlichem Maßstab mit der Projektierung kleinteiliger Stadtstrukturen zu reagieren, welche aber mit auf die Anlage von Großsiedlungen ausgerichteter Technologie zu realisieren waren.

Jedoch änderten sich mit dem Beginn von Demokratie und Marktwirtschaft in Polen, insbesondere verbunden mit der Einführung der kommunalen Selbstverwaltung, die Rahmenbedingungen für die Umsetzung der für die Altstadtareale von Elbing/Elbląg und Glogau/Głogów verabschiedeten Bebauungskonzeptionen grundlegend. Natürlich sollten sich die meisten der zur Zeit der Volksrepublik in den polnischen Städten und Gemeinden entstandenen städtebaulichen Pläne schnell als völlig unzulänglich erweisen, entsprachen sie doch weder in ihren inhaltlichen Festlegungen den neuen Anforderungen, noch bildeten sie eine geeignete Grundlage für die jetzt erforderliche gemeindliche Regulierung privater Bauinvestitionen. Ganz im Gegenteil dazu bedeutete jedoch der Systemwechsel die Möglichkeit der tatsächlichen Umsetzung der Bebauungskonzepte für die Altstadtareale, da sich ganz offensichtlich die im spezifischen gesellschaftlichen Kontext der Spätphase der Volksrepublik geschaffenen

19 Werner Rietdorf, Stadterneuerung. Innerstädtisches Bauen als Einheit von Erhaltung und Umgestaltung, Berlin: VEB Verlag für Bauwesen, 1989, 15. 
Planungsinhalte als kompatibel mit den sozioökonomischen Rahmenbedingungen nach dem politischen Umbruch erwiesen haben. Das Phänomen, dass aus bestimmten gesellschaftlichen Gründen heraus Stadtkonzeptionen entstehen, jedoch in einer ganz anderen gesellschaftlichen Situation "die in ihnen enthaltenen Lösungen für Probleme der Stadtentwicklung politisch durchgesetzt werden $«,{ }^{20}$ soll im Folgenden anhand von vier Gründen dafür erörtert werden.

\section{Gesellschaftliche Diskreditierung von planerischen Eingriffen in Eigentumsrechte}

Generell spiegelt das polnische räumliche Planungssystem bis heute eine geringe gesellschaftliche Akzeptanz von Eingriffen in private Eigentumsrechte wider, was sicher nicht zuletzt als eine Reaktion auf staatliche Willkürakte unter planwirtschaftlichem Deckmantel zu Zeiten der Volksrepublik angesehen werden kann und sich auch in anderen postsozialistischen Ländern beobachten lässt. Verbunden ist damit die Ausformung eines planerischen Instrumentariums, mit welchem Flächennutzungsvorgaben, städtebauliche Konzepte oder Leitlinien gegen individuelle Grundeigentümerinteressen nur unzureichend durchsetzbar sind. ${ }^{21}$ Paradoxerweise stellte diese frappante Unterordnung öffentlicher Interessen unter diejenigen privaten Grundeigentums, welche insbesondere Anfang der 1990er Jahre zu oft chaotischen räumlichen Entwicklungsprozessen geführt hat, ${ }^{22}$ im Falle der Wiederbebauung der Altstadtareale einen Vorteil dar. Der Grund dafür war die spezifische Eigentumssituation in den Städten der polnischen Nord- und Westgebiete: Hier war nach der Vertreibung der deutschen Bevölkerung nahezu das gesamte Grundeigentum verstaatlicht und nach dem Ende der Volksrepublik an die kommunalen Selbstverwaltungen übertragen worden. Somit konnten diese im Falle der Altstadtareale die Parzellierung entsprechend der gewünschten Grundstücksstruktur vornehmen und in den Ausschreibungsverfahren den Verkauf an Bauherren von vornherein an die Einhaltung städtebaulich-architektonischer Vorgaben verbinden, welche angesichts fehlender Instrumentarien so über Baugenehmigungsverfahren nicht durchsetzbar gewesen wären. Gleichzeitig waren für Interessierte damit die denkmalpflegerischen Auflagen von vornherein überschaubar. Der Standort in einem als Flächendenkmal eingetragenen Stadtareal stellte so für Investoren kein potentielles Hindernis im Sinne etwaig zu befürchtender mühseliger Abstim-

20 Rodenstein, »Städtebaukonzepte«, 32.

21 Vgl. Alexander Tölle, »Raumbewirtschaftung in Polen. Grenzen eines gesellschaftlichen Planungsverständnisses «, in: PlanerIn 1 (2014), $49 \mathrm{f}$.

22 Vgl. Parysek, Miasta polskie, 2005. 
mungsprozesse mit den Denkmalschutzbehörden mehr dar. Zudem gaben die umfassenden und dokumentierten Untersuchungen den städtebaulichen Vorgaben grundsätzlich legitimierende wie auch rechtliche Autorität, womit deren gesellschaftliche Akzeptanz erhöht wurde.

\section{Gesellschaftliches Bedürfnis nach Individualität}

Den Konzepten zur Wiederbebauung der Altstadtgebiete liegt in beiden Städten die Vorstellung einer lokalen Gesellschaft zugrunde, die ihren Stadtraum durch die Bauten individueller Bauherren gestaltet. Damit wird, wie bereits ausgeführt, an das klassische Modell der Entwicklung der bürgerlichen Stadt angeknüpft, deren Hinterlassenschaft in Form der durch archäologische Arbeiten wieder erkennbar gemachten Parzellenstruktur das Rückgrat der rekonstruierten Stadtlandschaft bildet (Abb. 1). Dieser Ansatz soll sich in der Vielgestaltigkeit der einzelnen architektonischer Projekte, welche den jeweiligen Vorstellungen ihrer Entwerfer bzw. deren Auftraggebern entsprechen, widerspiegeln; zugleich soll der vorgegebene, am historischen Stadtbild orientierte Gestaltungsrahmen die Entstehung eines harmonischen Ganzen sicherstellen. Die entstandenen Stadtlandschaften drücken zweifellos einen gesellschaftlichen Wunsch nach Buntheit und Individualität aus.

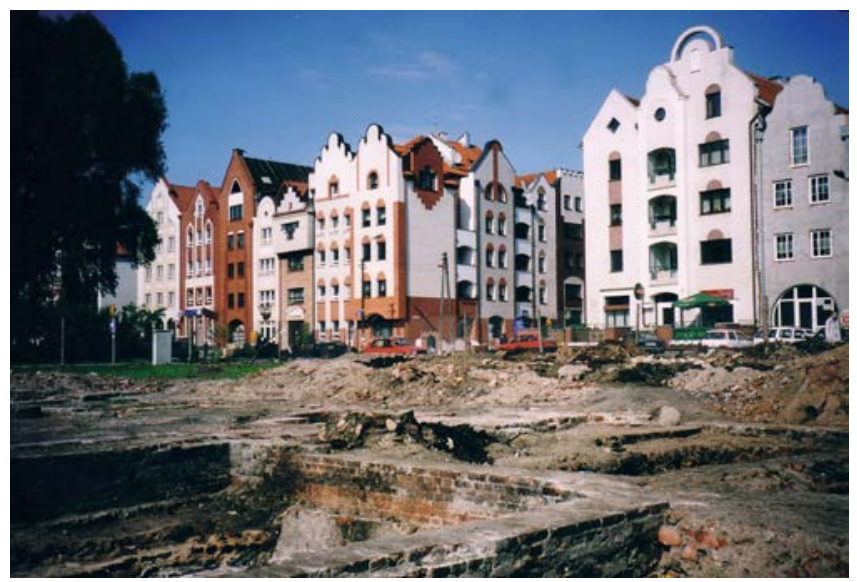

Abb. 1: Freilegung historischer Parzellenstrukturen auf dem Altstadtareal in Elbing/Elbląg; Foto: A. Tölle, 2003

Insbesondere die zum Teil knalligen Farben der auf dem Altstadtareal von Glogau/Głogów errichteten Ensembles hat polenweit über Fachkreise hinaus Bekanntheit erlangt und Kontroversen provoziert, wovon exemplarisch der in 
einer der führenden polnischen Tageszeitungen veröffentlichte Artikel unter der polemischen Schlagzeile »United Colors of Głogów « ${ }^{23}$ zeugt. Aus ästhetisch-stadtgestalterischer wie denkmalpflegerischer Perspektive mögen die baulichen Endergebnisse kritikwürdig erscheinen. Diese fällt freilich durchaus nicht eindeutig aus: während die einen in Glogau/Głogów »gekünstelte, bunte Fassaden, an denen mit pseudohistorischen Dekorationselementen nicht gespart wurde «, ${ }^{24}$ bemängeln, stört andere in Elbing/Elbląg an der anfangs vergleichsweise mehr zurückhaltenden und stringenter an historischen Vorgängerbauten orientierten Architektur gerade, dass »die Bauten bei allem Bemühen um Vielfalt bislang recht steril und seriell wirken . $^{25}$

Von manchen mögen die geschaffenen Stadtbilder vielleicht als die oben genannten "schockierenden Landschaften" empfunden werden; diese sind jedoch nicht einfach das Produkt ungesteuerten Investorenverhaltens, sondern drücken zweifellos Vorstellungen von Stadtbildern postsozialistischer lokaler Gesellschaften aus. Darauf verweisen auch die nicht unbedingt repräsentativen, jedoch zweifellos indikativen Ergebnisse einer Befragung, die im Rahmen der Erstellung einer vom Autor dieses Textes betreuten raumwirtschaftlichen Magisterarbeit von deren Verfasser im Herbst 2009 in der Umgebung des Marktes von Glogau/Głogów durchgeführt wurde. ${ }^{26}$ Von den knapp 100 befragten Passantinnen und Passanten haben zwei Drittel die architektonische Form und Farbgebung der neuen Altstadtbebauung positiv beurteilt, nur etwa ein Viertel bzw. Drittel negativ. Bei den angegebenen Gründen für den Aufenthalt auf dem Altstadtareal überwog im Übrigen deutlich das Ziel des Einkaufens; trotz eines fehlenden Einkaufszentrums lädt die entstandene (mit einem größeren Supermarkt ergänzte) kleinteilige Einzelhandelsstruktur offenbar dazu ein. Andererseits wurden mit einem lebendigen Stadtzentrum verbundene sonstige gesellschaftliche Aktivitäten - Nutzung gastronomischer Angebote, Kneipenbummel, Spaziergang - deutlich seltener als Aufenthaltsgrund genannt, und der des touristischen Besuchs fast gar nicht. Ein interessantes Licht auf die Bedürfnisse postsozialistischer Stadtgesellschaften wirft auch die Frage danach, welche Motive für eine Wohnortentscheidung für das Altstadtareal ausschlaggebend sein könnten. Letztlich stehen dabei - jeweils von über der Hälfte der Befragten angeführte - praktische Gründe wie Immobilienpreis bzw. Mietbedingungen, Vertrauenswürdigkeit des Anbieters oder bauliche Qualität im Vordergrund, während nur für zwei Fünftel ein interessantes Wohnumfeld und für etwa ein

23 Vgl. Gazeta Wyborcza vom 09. August 2000, Beilage »Dom« Nr. 32, 1.

24 Zabłocka-Kos, "Städte in Schlesien«, 172.

25 Bartetzky, »Zwischen Denkmalpflege und Stadtverhübschung«, 438.

26 Henryk Gorący, »Analiza przestrzenno-funkcjonalna odbudowanej dzielnicy staromiejskiej w Głogowie«, Magisterarbeit, Studienrichtung Raumwirtschaft, Adam-Mickiewicz-Universität zu Poznań, Collegium Polonicum in Słubice, 2010 (unveröffentlicht). 
Drittel Prestige bzw. Renommee eines Wohnens im Stadtzentrum von Bedeutung sind. Das gesellschaftliche Bedürfnis nach Repräsentation von Individualität im postsozialistischen Kontext bewegt sich eindeutig in einem engen sozioökonomischen Rahmen. Dazu gehört zweifellos auch die Verbindung von Charakter und Komfort zeitgenössischer Vorort-Wohnsiedlungen, in Glogau/Głogów z. T. einschließlich Einfamilienhäusern mit Garten und Garage, mit einem inner- wie altstädtischen Wohnambiente.

\section{Gesellschaftliches Bedürfnis nach identitätsstiftenden Stadtlandschaften}

Aus Sicht eines privaten Immobilienmarktes müssen "Produkte« konform zu gesellschaftlichen Erwartungen und Anforderungen konzipiert werden, damit potentielle Nutzer, d.h. Käufer, Mieter oder Konsumenten, sich mit diesen identifizieren können. Die auf den Altstadtarealen von Elbing/Elbląg und Glogau/Głogów errichteten Ensembles entsprechen dem an der großen Zahl an postmodernen Neubauten mit historisierenden Stilelementen in polnischen Städten ablesbaren hohen gesellschaftlichen Identifikationsgrad mit einem »historischen « Ambiente; generell wird »die Rückkehr des Historischen als das Schöne und Stimmungsvolle begrüßt, als etwas, was die Standorte bereichert und für die Stadt wirbt. ${ }^{27}$ Postmoderne Städtebauformen können grundsätzlich als »Spiegel enttäuschter Hoffnungen auf eine neue fortschrittliche Gesellschaft, wie sie sich in den Konzeptionen Le Corbusiers, Mays u. a. ausgedrückt hatte ${ }^{28}$, interpretiert werden - und im postsozialistischen Kontext bezieht sich diese Enttäuschung zusätzlich noch auf das reale Antlitz einer vermeintlich ein ideales Gesellschaftssystem anstrebenden Ideologie. Zugleich geht es in der spezifischen Situation der vormals deutschen west- und nordpolnischen Regionen um die Abkehr von nationalen zugunsten lokaler Identitätskonstruktionen als Teil der gesellschaftlichen Aneignung der Gebiete. Mit der gewählten Bebauungsform wird gerade eine Sichtbarmachung von Stadtgeschichte und -tradition angestrebt, womit deren Integration in lokale räumliche Identitätsbildungsprozesse ermöglicht wird. Die Fokussierung auf ein "goldenes Zeitalter« dient dabei der Schaffung eines auf vergangener Bedeutung und Reichtum basierenden Images einer geschichtsbewussten Stadtgesellschaft. Der Fokus auf die spätmittelalterliche Epoche, im Falle von Elbing/Elbląg zugleich hanseatische Blütezeit, kann dabei nicht mehr im Zusammenhang mit einer nationalistisch motivierten Bezugnahme auf das Piastentum gesehen werden, ${ }^{29}$ nicht zuletzt da multiethnische

27 Billert, »Denkmalpflege in Polen«, 412.

28 Rodenstein, »Städtebaukonzepte«, 63.

29 Vgl. Bartetzky, "Zwischen Denkmalpflege und Stadtverhübschung«, $445 \mathrm{f}$. 
und -religiöse Aspekte dieser Epoche in lokalen Narrationen mittlerweile enthalten sind - ein Beispiel dafür sind die in Glogau/Głogów am Ort der Fundamente der ehemaligen Synagoge wie der der ehemaligen evangelischen Kirche "Schifflein Christi« angelegten Lapidarien. Somit lässt sich auch schwerlich eine Interpretation der entstandenen Stadtlandschaften aus der Perspektive einer Wiederentdeckung oder Negierung deutscher Spuren rechtfertigen. Die Bezugnahme auf ein "goldenes Zeitalter" scheint sich vielmehr in einen entsprechenden generellen Trend der Entwicklung postsozialistischer Städte einzuordnen, wobei jedoch mittlerweile in Elbing/Elbląg wie vor allem in Glogau/ Głogów die Stilpalette erkennbar um gründerzeitliche Architekturformen erweitert worden ist, die unvermeidbar mit der deutschen Vergangenheit der Städte in Verbindung stehen (Abb. 1).

Zudem erlauben die entstehenden neuen Stadtlandschaften auf altstädtischen Terrains eine Vermeidung des Phänomens, welches die Attraktivität zahlreicher Innenstädte in Polen nachdrücklich einschränkt: der Verfall der tatsächlich historischen Bausubstanz. Bereits der an sich neutrale Begriff »kamienica " für Wohnaltbauten aus der Zeit der Industrialisierung oder früheren Epochen ist in Polen seit Jahren stark stigmatisiert und wird mit niedrigem Wohnkomfort und einer sozial schwierigen Wohnbevölkerung gleichgesetzt. ${ }^{30}$ Die Instandsetzung und Modernisierung dieser Bestände scheitert zum einen am völligen Fehlen von Instrumentarien und Förderpolitiken für eine soziale Bestandsentwicklung. Zum anderen hat eine unkoordinierte Privatisierungspolitik, im Rahmen derer massenhaft Einzelwohnungen in Kommunalbeständen an Bestandsmietparteien zu geringen Vorzugspreisen verkauft wurden, dazu geführt, dass die betroffenen Wohngebäude nicht mehr im Rahmen öffentlicher Investitionen saniert werden können und sie zugleich uninteressant für private Investoren geworden sind. Die Errichtung postmoderner Neubauten mit historisierenden Fassaden, deren Wohnungen und Ladenlokale an Gutbetuchte veräußert werden, direkt neben verfallenden Altbauten mit stigmatisierter Wohnbevölkerung sind ein in polnischen Städten alltägliches Bild. Selbst in den neugebauten Altstädten von Elbing/Elbląg und Glogau/Głogów drohen so entsprechend den gesellschaftlichen Vorstellungen von Altstadt gestaltete Neubauten die wenigen authentischen und zum Teil im schlechten Zustand befindlichen historischen Objekte in den Hintergrund der Wahrnehmung zu drängen, zumal im Falle von Elbing/Elbląg noch einige nach historischem Vorbild exakt rekonstruierte Objekte »beginnen, mit den wenigen erhaltenen historischen Bauten in Konkurrenz zu treten ${ }^{31}{ }^{31}$ Die

30 Vgl. Alexander Tölle, »Aktuelle Prozesse und Tendenzen in der polnischen Stadterneuerung am Beispiel der Stadt Posen", in: Jahrbuch Stadterneuerung des Arbeitskreises Stadterneuerung an deutschsprachigen Hochschulen 6/7 (2007), 339-356.

31 Frank, »Die Wiederherstellung historischer Altstädte«, 193. 
»Sehnsucht nach der verlorenen Altstadt ${ }^{32}$ ist somit in bemerkenswerter Weise nicht an ein gesellschaftliches Interesse an authentischen baulichen Zeugnissen gekoppelt.

\section{Europäische Stadt als gesellschaftliche Konstruktion}

Die Altstadtareale von Elbing/Elbląg und Glogau/Głogów lassen sich zweifellos in den Zusammenhang des Strebens einer postsozialistischen lokalen Gesellschaft nach »europäischer« Stadtlandschaft einordnen, da sie sich durch das traditionelle Bild von der europäischen Stadt determinierende städtebauliche Merkmale wie Zentralität, verdichtete Blockrandbebauung, kleinkörnige Nutzungsmischung, Kompaktheit und kleinteilige Parzellen auszeichnen. Bemerkenswert ist jedoch, dass die realisierten Konzepte nicht nur einfach postmodernen Architekturvorstellungen nacheifern, welche wie die in den 1980er Jahren in den USA entstandene Bewegung des "Neuen Urbanismus" auf die Errichtung von kompakten Siedlungen in traditionellen Städtebauformen abzielen. Solche Versuche, »lokale Identität ästhetisch zu inszenieren ${ }^{33}$, scheitern letztlich an einer fehlenden Einbindung in lokale gesellschaftliche Verhandlungen. Bezüglich der Altstadtareale in Elbing/Elbląg und Glogau/Głogów kann hingegen die These gewagt werden, dass diese von einem Verständnis von europäischer Stadt als kollektivem Akteur und lokaler Gesellschaft zeugen im Sinne eines neo-weberianischen Ansatzes, wie er seit einigen Jahren den fachlichen Diskurs $^{34}$ und die auf europäischer Ebene definierten Leitlinien zur Entwicklung der Städte Europas ${ }^{35}$ bestimmt. Der Kern des Prozesses »liegt darin, den Bürger als städtischen Bauherrn zu gewinnen durch den Rückgriff auf das [...] Konzept der Parzelle. Eine Vielzahl von Einzeleigentümern [...] soll ein neues produktives Rechtsverhältnis der Bürger zu ihrer Stadt begründen, um so zumindest einen Teil der Stadtproduktion den großen Entwicklungsträgern und Woh-

32 Bartetzky, "Zwischen Denkmalpflege und Stadtverhübschung«, 436.

33 Albrecht Göschel, „Lokale und regionale Identitätspolitik «, in: Siebel (Hg.), Die europäische Stadt, 165.

34 Vgl. dazu grundlegend: Arnaldo Bagnasco und Patrick Le Galès, »Les villes européennes comme société et comme acteur«, in: dies. (Hg.), Villes en Europe, Paris: La Découverte, 1997, 7-45. Vgl. auch: Florian Koch, Die europäische Stadt in Transformation. Stadtplanung und Stadtentwicklungspolitik im postsozialistischen Warschau, Wiesbaden: VS Verlag, 2010; Hartmut Häußermann und Anne Haila, »The European City: a conceptual framework and normative project«, in: Yuri Kazepov (Hg.), Cities of Europe: Changing Contexts, Local Arrangement and the Challenge to Urban Cohesion, Oxford: Blackwell, 2005, 43-63.

35 Dazu zählen vor allem die von den Fachministern aller damaligen EU-Mitgliedstaaten 2007 verabschiedete "Leipzig-Charta zur nachhaltigen europäischen Stadt" sowie die vom Europäischen Rat der Stadtplaner 1998 in Form der "Neuen Charta von Athen« beschlossenen Richtlinien zur Planung von Städten. 
nungsbaugesellschaften zu entreißen ${ }^{36}$ - so könnte eine Bewertung der neuen Altstadtbebauungen durchaus lauten. Das Zitat bezieht sich jedoch auf eines der bekanntesten deutschen Mustervorhaben zum Neubau von Stadtquartieren in einer Neuinterpretation der Tradition der europäischen Stadt, und zwar des städtebaulichen Projektes »Südstadt/Französisches Viertel« in Tübingen. Die Konversion einer Militärbrache in ein innerstädtisches Quartier wurde dort durch "parzelliertes Bauen ${ }^{37}$ auf kleinen Baugrundstücken durch individuelle Bauherren oder Bauherrengruppen durchgeführt. Auch das dort entstandene Stadtbild ist ob seiner großen gestalterischen wie farblichen Heterogenität aus ästhetischer Perspektive oft kritisiert worden, wird von seinen Befürwortern jedoch als Ausdruck von »Individualität, Eigenständigkeit und Identifikation ${ }^{38}$ der lokalen Gesellschaft interpretiert. Der Bezug zur historischen Genese-Form europäischer Städte ist dabei auch für die beiden Altstadtareale zu konstatieren, wenn etwa in Glogau/Głogów die "Art der Wiederherstellung der früheren Bebauung [...] an den Entstehungsprozess der Stadt im Mittelalter ${ }^{39}$ erinnert und in der Konsequenz zu einer Stadtstruktur führt, die »sehr typisch für die frühmittelalterlichen Städte in Schlesien ${ }^{40}$ ist.

Eine weitere Parallele der Wiederbebauung der Altstadtareale von Elbing/ Elbląg und Glogau/Głogów zu Konzepten für Quartiersentwicklungen in der Tradition der europäischen Stadt - im Gegensatz zu einer rein "marktförmig organisierten Stadtentwicklung ${ }^{41}$ - ist der hohe Stellenwert der Gestaltung des öffentlichen Raumes als kommunale Aufgabe. In beiden Städten funktioniert die Zusammenarbeit zwischen öffentlichem und privatem Sektor bemerkenswert gut: Die von der kommunalen Selbstverwaltung für die Bebauung vorbereiteten Parzellen werden im Rahmen definierter Zielrichtungen durch private Bauherren bebaut, während öffentliche Investitionen - mittlerweile häufig gestützt auf EU-Fördermittel - ein attraktives Umfeld durch Straßen- und Platzgestaltung, Anlage von Stellplätzen und insbesondere auch die Restaurierung oder Rekonstruktion historischer Objekte schafft. Mit dieser im öffentlichen Raum sichtbaren Handschrift kommunalen Gestaltungswillens heben sich beide Altstadtgebiete deutlich von einer in Polen vorherrschenden postsozialistischen Stadtentwicklungspraxis ab, welche die Gestaltung des öffentlichen Raumes zum

36 Johann Jessen, »Europäische Stadt als Bausteinkasten für die Städtebaupraxis - die neuen Stadtteile«, in: Siebel (Hg.), Die europäische Stadt, 102.

37 Matthias Schuster, „Das Tübinger Modell«, in: Gudrun Theresia de Maddalena und Matthias Schuster (Hg.), Go south. Das Tübinger Modell, Tübingen und Berlin: Ernst Wasmuth, 2005, $12-29,23$.

38 Ebd., 14.

39 Zabłocka-Kos, »Städte in Schlesien«, 172.

40 Ebd., 173.

41 Siebel, »Die europäische Stadt«, 35. 
einen als mit EU-Geldern finanzierbare technische Aufgabe ohne Einbeziehung sozioökonomischer und funktionaler Ziele bezüglich des diesen Raum bildenden Baubestands sowie zum anderen als Angelegenheit privater Investoren bei der Entwicklung von Neubauvorhaben begreift. ${ }^{22}$ Natürlich stellen dabei weder Elbing/Elbląg noch Glogau/Głogów einen aus dem gesellschaftlichen Kontext der Entwicklung der postsozialistischen Stadt herausgelösten Idealfall dar. Ein deutliches Beispiel dafür in Glogau/Głogów ist die 2005 erfolgte Ansiedlung der Filiale einer Discounter-Lebensmittelkette als übliches eingeschossiges großflächiges Objekt mit ausgedehnten Kundenstellplatzflächen unweit des Marktplatzes; der eher hilflose Versuch, diesen Klotz entlang der zum Markt führenden Straße mit einer Attrappe von Altstadt-Häuschen ohne Fenster und Türen zu kaschieren (Abb. 2), ist in der polnischen Fachwelt zu unrühmlicher Bekanntheit gelangt.

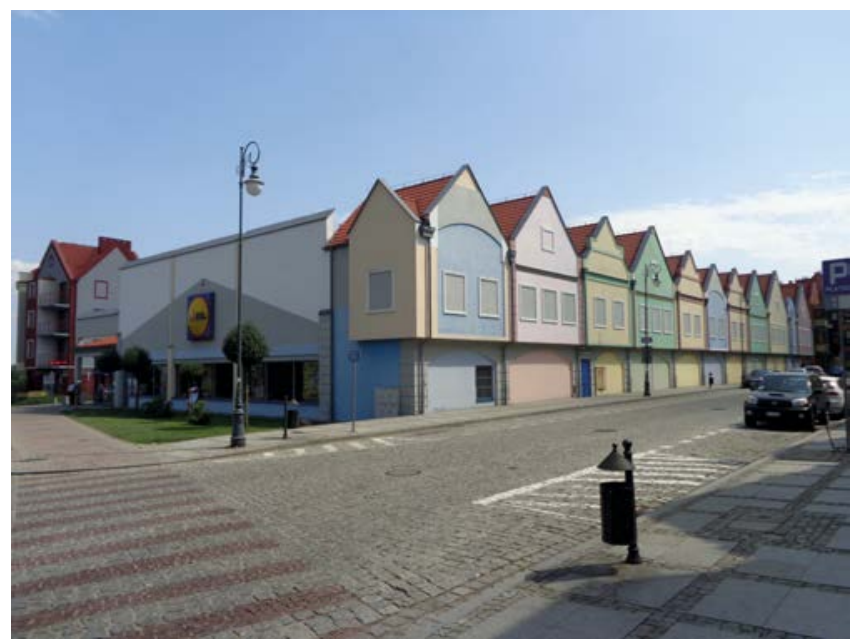

Abb. 2: Mälzstraße (ul. Słodowa) in Glogau/Głogów; Foto: A. Tölle, 2014

Ein in ganz anderer Hinsicht zweifelhaftes bauliches Resultat ist der in Elbing/ Elbląg 2011 als städtisches Ausstellungs- und Konferenzobjekt fertiggestellte Neubau des Altstädter Rathauses (Abb. 3) mit seiner an einen bereits im 18. Jahrhundert zerstörten Vorgängerbau angelehnten Architektur. Der stilistisch umstrittene städtische "Rathaus«-Bau mit seiner EU-geförderten Zielstellung einer Erhöhung der touristischen Attraktivität steht von seiner gesell-

42 Vgl. Adam Radzimski, »Probleme der Stadtplanung in Polen am Beispiel des Wohnungsbaus in Posen", in: Rainer Wehrhahn und Alexander Tölle (Hg.), Aktuelle Entwicklungen in norddeutschen und westpolnischen Stadtregionen, Kieler Arbeitspapiere zur Landeskunde und Raumordnung 53, Kiel: Geographisches Institut der Christian-Albrechts-Universität, 2012, 139-154. 
schaftlichen Anlage her in merklichem Kontrast zum Prozess der Rekonstruktion des Rathauses von Glogau/Głogów, welche 2002 abgeschlossen worden ist (Abb. 4). Die lokalgesellschaftliche Bedeutung dieses bereits 1984 begonnenen und später u. a. von Mitteln aus dem deutsch-polnischen Fonds unterstützten Vorhabens bewegte sich nicht nur im Rahmen eines eingeleiteten Begegnungsprozesses zwischen polnischen und ehemaligen deutschen Bewohnern der Stadt ${ }^{43}$ sondern beinhaltete auch die erneute Nutzung des zentralen Gebäudes der Stadt als Mittelpunkt städtischer Selbstverwaltung. Damit hat das Altstadtareal als funktionales Zentrum der Stadt eine entscheidende Stärkung von auch symbolischer Ausstrahlung erfahren.

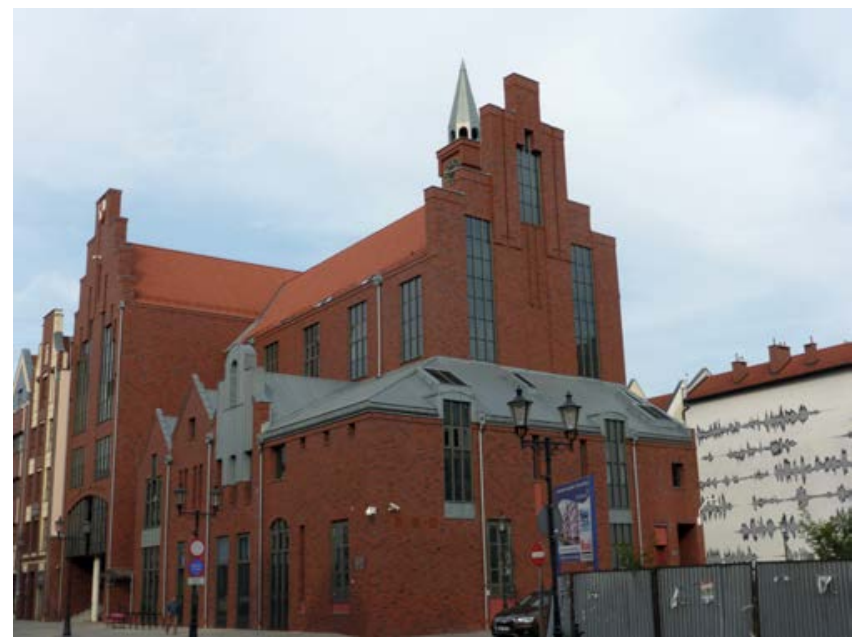

Abb. 3: Altstädter Rathaus (Ratusz Staromiejski) in Elbing/Elbląg; Foto: A. Tölle, 2017

\section{Abschließende Betrachtung}

Die Wiederbebauung der Altstadtareale in Elbing/Elbląg und Glogau/Głogów integriert in bemerkenswerter Weise die Ziele, zum einen zeitgenössischen Städtebau an einem historischen städtischen Ort zu ermöglichen, und zum anderen eine Stadtlandschaft entstehen zu lassen, in der authentischer historischer Bestand und auch das Ausmaß der Verluste an diesem ablesbar bleiben. Dieser Ansatz grenzt sich dabei sowohl von Projekten ab, welche vergangene Stadt-

43 Vgl. Christian Schmidt-Häuer, "Die Weisen von Glogau. In der schlesischen Stadt setzten Deutsche und Polen den Opfern der Vertreibung ein gemeinsames Denkmal«, in: Die Zeit, 3. November 2003, http://www.zeit.de/2003/45/Glogau, nicht frei zugänglich, zuletzt geprüft am 16. Oktober 2014. 


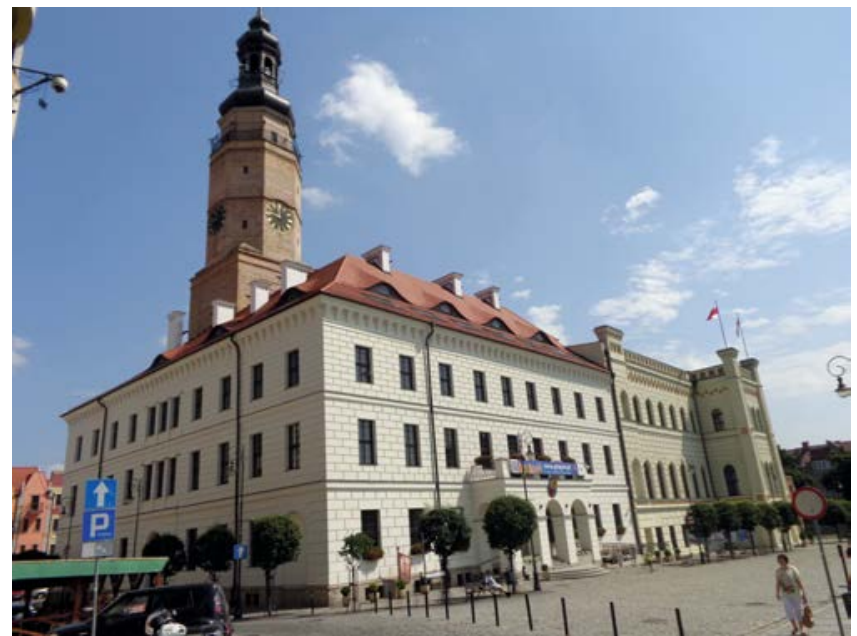

Abb. 4: Rathaus von Glogau/Głogów; Foto: A. Tölle, 2014

landschaften im Rahmen einer Geschichtskorrektur im imaginierten »alten Glanz« eines vergangenen goldenen Zeitalters zu rekonstruieren suchen, als auch von Bauvorhaben in postmoderner Architektur, die unreflektierte RetroBilder als Katalysatoren einer profitablen Projektentwicklung produzieren. In postsozialistischen Städten entstehende "[n]eue Landschaften haben vielen unterschiedlichen Verhandlungen rekonstruierter Zivilgesellschaft, ihren Aspirationen und Komplexen, $\mathrm{zu}$ entsprechen ${ }^{44}$, und im Falle der auf den Altstadtgebieten neu errichteten Ensembles verbinden sich in ungewöhnlicher Weise die resultierenden typischen Elemente - die demonstrative Abkehr von mit dem sozialistischen System verbundenen Städtebauformen, die Adaption »westlicher« Trends und Vorbilder, deren Ausführung in einer aus westlicher Sicht wenn nicht unbedingt "schockierenden«, so aber doch »verblüffenden" Konsequenz sowie die Suche nach baulichem Ausdruck einer lokalen Identität und Historizität. Untypisch für den postsozialistischen Kontext eines schwachen Planungsinstrumentariums und einer geringen gesellschaftlichen Akzeptanz von planerischen Eingriffen in individuelle Bauherrenrechte ist dabei die gegebene Ablesbarkeit einer klaren Entwicklungsphilosophie und einheitlicher Gestaltungsmerkmale in den realisierten Stadtensembles, die von einer hohen Akzeptanz auf Ebene der Stadtgesellschaft, der städtischen Entscheidungsträger und der Bauherren, von denen viele der Stadtgesellschaft angehört, zeugen. In beiden Fällen liegt den noch zu »sozialistischen Zeiten « entstandenen Konzepten die Vorstellung einer postsozialistischen Stadtgesellschaft zugrunde, die sich als

44 Czepczyński, Cultural Landscapes, 160 (Übersetzung des Verfassers). 
Bürgergesellschaft in der Tradition der europäischen Stadt organisiert und innerhalb eines durch historische Überlieferung vorgegebenen Rahmens eine Stadtlandschaft entstehen lässt, welche diese Gesellschaft insgesamt wie ihre individuellen Mitglieder repräsentiert. Entsprechend dem soziologischen Grundverständnis, dass gebaute Substanz einer Stadt "materialisiertes gesellschaftliches Verhältnis (ist), und ein entscheidendes gesellschaftliches Verhältnis insbesondere für die Städte (...) die Eigentumsverhältnisse ${ }^{45}$ sind, bildet der Rückgriff auf die Parzellenstruktur der bürgerlichen Stadt eine Schlüsselkomponente des Entwicklungsansatzes. Dieser ist im Gegenzug offenbar geeignet gewesen, der postsozialistischen lokalen Gesellschaft einen akzeptierbaren Rahmen zur Verwirklichung ihrer Vorstellung einer postmodernen Stadtentwicklung in Form eines schönen "Altstadt«-Ambientes in einer Symbiose von Innenstadt- und Vorstadtwohnqualität zu bieten. Zu konstatieren ist dabei aber zweifellos auch der "Ausdruck des gesellschaftlichen Verlangens nach einer urbanen und historisch bestimmten Stadtidentität, auf deren Grundlage eine neue sozial-kulturelle Identität der Bewohner heute aufbaut und von ihnen in der Zukunft weiter entwickelt wird. ${ }^{46}$ Ob ihrer gesellschaftlichen Akzeptanz können die Altstadtareale von Elbing/Elbląg und Glogau/Głogów somit ebenso identitätsstiftend wirken, wie sie im Gegenzug auch ein Produkt der Suche nach geschichtlich verankerter lokaler Identität sind.

\section{Literatur}

Andrusz, Gregory. »From socialist to post-socialist city: a journey from wall to mall and from security to risk«, in: Kultur - Erbe - Stadt. Stadtentwicklung und UNESCOMandat in post- und spätsozialistischen Städten, Adelheid Pichler und Gertraud Marinelli-König (Hg.), Innsbruck/Wien/Bozen: StudienVerlag, 2008, 11-31.

Bagnasco, Arnaldo und Patrick Le Galès. »Les villes européennes comme société et comme acteur «, in: Villes en Europe, dies. (Hg.), Paris: La Découverte, 1997, 7-45.

Bartetzky, Arnold. »Zwischen Denkmalpflege und Stadtverhübschung. Der Wiederaufbau historischer Stadtzentren in Nordpolen seit 1980«, in: Architektur und Städtebau im südlichen Ostseeraum zwischen 1936 und 1980, Bernfried Lichtnau (Hg.), Berlin: Lukas, 2002, 434-446.

Billert, Andreas. "Denkmalpflege in Polen. Nationale Identität, Schönheitstraum und Verlust der Mitte«, in: Informationen zur Raumentwicklung 6 (2005), 409-415.

45 Siebel, "Die europäische Stadt«, 43.

46 Andreas Billert, »Wiederaufbau der Altstädte in Polen und die Erfahrungen deutscher Stadterneuerung", in: ders. (Hg.), Wiederaufbau und Stadterneuerung in historischen Altstadtkernen. Głogów, Lubań, Polkowice, Frankfurt (Oder), Görlitz und Kamenz, Lubań: Gmina Miejska, 2007, 23. 
Ders. (Hg.). Wiederaufbau und Stadterneuerung in historischen Altstadtkernen. Głogów, Lubań, Polkowice, Frankfurt (Oder), Görlitz und Kamenz, Lubań: Gmina Miejska Lubań, 2007.

Czepczyński, Mariusz. Cultural Landscapes of Post-Socialist Cities. Representation of Powers and Needs, Aldershot \& Burlington: Ashgate, 2008.

Frank, Lorenz. »Die Wiederherstellung historischer Altstädte in Polen seit 1985«, in: Der Umgang mit dem kulturellen Erbe in Deutschland und Polen im 20. Jahrhundert, Andrea Langer (Hg.), Warschau: Instytut Sztuki PAN, 2004, 191-208.

Göschel, Albrecht. »Lokale und regionale Identitätspolitik«, in: Die europäische Stadt, Walter Siebel (Hg.), Frankfurt am Main: Suhrkamp, 2004, 158-168.

Gorący, Henryk. »Analiza przestrzenno-funkcjonalna odbudowanej dzielnicy staromiejskiej w Głogowie«, Magisterarbeit, Studienrichtung Raumwirtschaft, AdamMickiewicz-Universität zu Poznań, Collegium Polonicum in Słubice, 2010 (unveröffentlicht).

Grajewski, Grzegorz. "Poglądy na odbudowę Głogowa w mijajacym półwieczu«, in: Odbudowa miast historycznych. Dokonania przeszłości - Potrzeby i możliwości wspótczesne - Wyzwania przyszłości, Maria Lubocka-Hoffmann (Hg.), Elbłąg: PKN ICOMOS, 1998, 224-232.

Häußermann, Hartmut und Anne Haila.»The European City: a conceptual framework and normative project «, in: Cities of Europe: Changing Contexts, Local Arrangement and the Challenge to Urban Cohesion, Yuri Kazepov (Hg.), Oxford: Blackwell, 2005, 43-63.

Jessen, Johann. »Europäische Stadt als Bausteinkasten für die Städtebaupraxis - die neuen Stadtteile«, in: Die europäische Stadt, Walter Siebel (Hg.), Frankfurt am Main: Suhrkamp, 2004, 92-104.

Koch, Florian. Die europäische Stadt in Transformation. Stadtplanung und Stadtentwicklungspolitik im postsozialistischen Warschau, Wiesbaden: VS Verlag, 2010.

Lisiak, Agata Anna. Urban Cultures in (Post)Colonial Central Europe, West Lafayette: Purdue University Press, 2010.

Lubocka-Hoffmann, Maria (Hg.). Odbudowa miast historycznych. Dokonania przeszłościPotrzeby i możliwości współczesne - Wyzwania przyszłości, Elbłąg: PKN ICOMOS, 1998.

Dies. »Die neue Altstadt von Elbing", in: Kunstgeschichte und Denkmalpflege. Beiträge des Arbeitskreises deutscher und polnischer Kunsthistoriker, Michał Woźniak (Hg.), Torun: Wydawnictwo UMK, 2002, 225-240.

Parysek, Jerzy. Miasta polskie na przełomie XX i XXI wieku. Rozwój i przekształcenia strukturalne, Poznań: Bogucki, 2005.

Radzimski, Adam. »Probleme der Stadtplanung in Polen am Beispiel des Wohnungsbaus in Posen «, in: Aktuelle Entwicklungen in norddeutschen und westpolnischen Stadtregionen, Kieler Arbeitspapiere zur Landeskunde und Raumordnung 53, Rainer Wehrhahn und Alexander Tölle (Hg.), Kiel: Geographisches Institut der Christian-Albrechts-Universität, 2012, 139-154.

Rietdorf, Werner. Stadterneuerung. Innerstädtisches Bauen als Einheit von Erhaltung und Umgestaltung, Berlin: VEB Verlag für Bauwesen, 1989.

Rodenstein, Marianne. „Städtebaukonzepte - Bilder für den baulich-räumlichen Wandel der Stadt «, in: Stadt und Raum. Soziologische Analysen, Hartmut Häußermann, Detlev Ipsen, Thomas Krämer-Badoni, Dieter Läpple, Marianne Rodenstein und Walter Siebel (Hg.), Pfaffenweiler: Centaurus, 2. Auflage 1992, 31-67. 
Rymaszewski, Bohdan. Polska ochrona zabytków, Warschau: Scholar, 2005.

Schmidt-Häuer, Christian. »Die Weisen von Glogau. In der schlesischen Stadt setzten Deutsche und Polen den Opfern der Vertreibung ein gemeinsames Denkmal«, in: Die Zeit, 3. November 2003, http://www.zeit.de/2003/45/Glogau, nicht frei zugänglich, zuletzt geprüft am 16. Oktober 2014.

Schuster, Matthias. »Das Tübinger Modell«, in: Go south. Das Tübinger Modell, Gudrun Theresia de Maddalena und Matthias Schuster (Hg.), Tübingen und Berlin: Ernst Wasmuth, 2005, 12-29.

Siebel, Walter. »Einleitung: Die europäische Stadt«, in: Die europäische Stadt, ders. (Hg.), Frankfurt am Main: Suhrkamp, 2004, 11-48.

Tsenkova, Sasha. »Beyond transitions: Understanding urban change in post-socialist cities", in: The Urban Mosaic of Post-Socialist Europe. Space, Institutions and Policy, Sasha Tsenkova und Zorica Nedović-Budić (Hg.), Heidelberg/New York: Physica, 2006, 21-50.

Tölle, Alexander. »Aktuelle Prozesse und Tendenzen in der polnischen Stadterneuerung am Beispiel der Stadt Posen «, in: Jahrbuch Stadterneuerung des Arbeitskreises Stadterneuerung an deutschsprachigen Hochschulen 6/7 (2007), 339-356.

Ders. »Urban identity policies in Berlin: From critical reconstruction to reconstructing the Wall«, in: Cities 27 (2010), 348-357.

Ders. "Raumbewirtschaftung in Polen. Grenzen eines gesellschaftlichen Planungsverständnisse, in: PlanerIn 1 (2014), 49-50.

Wojtowicz, Edyta. »Der Wiederaufbau der Altstadt in Głogów«, in: Wiederaufbau und Stadterneuerung in historischen Altstadtkernen. Głogów, Lubań, Polkowice, Frankfurt (Oder), Görlitz und Kamenz, Andreas Billert (Hg.), Lubań: Gmina Miejska Lubań, 2007, $31 \mathrm{f}$.

Wojtowicz, Edyta und Dariusz Wojtowicz. »Die städtebauliche Entwicklung von Głogów in den Jahren 1945-1997«, in: Annäherungen - Ansichten von Glogau, Hanna Nogossek (Hg.), Marburg: Herder-Institut, 1997, 67-72.

Young, Craig und Duncan Light. "»Communist heritage tourism`: between economic development and European integration «, in: Heritage and Media in Europe - Contributing towards Integration and Regional Development, Dieter Hassenpflug, Burkhardt Kolbmüller und Sebastian Schröder-Esch (Hg.), Weimar: Bauhaus-Universität, 2006, 249-263.

Zabłocka-Kos, Agnieszka. »Städte in Schlesien: Von der `sozialistischen Stadt` der Arbeiterklasse zur bürgerlichen neuen >Altstadt‘. Legnica und Głogów nach 1945«, in: Von der >europäischen Stadt zur >sozialistischen Stadt und zurück? Urbane Transformationen im östlichen Europa des 20. Jahrhunderts, Thomas Bohn (Hg.), München: Oldenbourg, 2009, 155-174. 


\section{Historische Landschaften aus der Perspektive der Fernerkundung}

\section{Einführung}

Der Begriff der "Landschaft» findet im aktuellen wissenschaftlichen Diskurs viele unterschiedliche Anwendungen. Das gilt für Naturwissenschaften wie Biologie, für die Gesellschafts- und Geschichtswissenschaften wie Soziologie, Geschichte und Archäologie und für die Geografie an der Schnittstelle von Natur- und Gesellschaftswissenschaften. Diese Disziplinen konzeptualisieren den Begriff jeweils anders, ihre Untersuchungsmethoden unterscheiden sich. Daher sind mit dem Begriff verschiedene Dinge gemeint, so dass ein und dasselbe physische Objekt im Raum Bestandteil ganz unterschiedlich konzipierter Landschaften sein kann. ${ }^{1}$

$\mathrm{Zu}$ einem Findling können die verschiedensten Narrative entworfen werden, wenn es um seinen Ort in der Landschaft oder die Konstituierung der Landschaft durch ihn geht. Während seiner Entstehung infolge von geologischen Prozessen oder während seiner Fortbewegung durch einen Gletscher war der Findling kein Landschaftselement, weil niemand ihn beobachtete und sich ein Narrativ für ihn ausdachte. Zum Landschaftselement wurde er erst, indem ein urzeitlicher Mensch ihn mit einer mythischen Erzählung verband, ihn zum Bau eines Grabmals benutzte oder wenn er den Ort eines gesellschaftlichen Ereignisses markierte. Der Findling wurde damit in eine kulturelle Erzählung integriert und erhielt eine bestimmte Bedeutung. Für den Bauern, dem er die Feldarbeit erschwert, ist der Findling etwas anderes als für den Geologen, der ihn als Gegenstand seiner erdgeschichtlichen Studien betrachtet. Aktuell wird derselbe Findling womöglich in ein öffentliches Gedenkritual integriert oder zum Naturdenkmal erklärt. Der Findling gehört in diesen Kontexten jeweils einer an-

1 Denis Cosgrove und Stephen Daniels (Hg.), The Iconography of Landscape, Cambridge: Cambridge University Press, 1988; Christopher Tilley, Phenomenology of Landscape: Places, Paths and Monuments, Oxford/Providence: Berg, 1994; John Wylie, Landscape, London/New York: Routledge, 2007. 
deren Landschaft an: derjenigen eines Menschen des Neolithikums, eines Bauern, eines Wissenschaftlers oder eines Politikers. Demnach haben wir es mit jeweils unterschiedlichen Landschaften $\mathrm{zu}$ tun, selbst wenn deren physische Bestandteile dieselben sind.

Das führt zu dem Schluss, dass unser Weltbild ein ganz anderes ist als das von Menschen in der Vergangenheit. Die historischen Wissenschaften stehen vor der Herausforderung, Landschaften zu erforschen, die verschwunden und in Vergessenheit geraten sind. Der Palimpsest als Metapher von Landschaft spielt in diesem Zusammenhang eine wichtige Rolle. Von O.G.S. Crawford in den wissenschaftlichen Diskurs eingebracht, ${ }^{2}$ stellt er eine Analogie zu mehrfach genutztem Beschreibmaterial her, auf dem früherer Text gelöscht und durch neuen Text ersetzt wurde. Diese Metapher legt nahe, die Landschaft als Prozess zu sehen: Sie ist nicht starr, sondern verändert sich dynamisch. Die menschliche Geschichte hat verschiedenste Landschaften entstehen lassen, die mit der Zeit verändert, von nachfolgenden Generationen ausgelöscht und durch neue Landschaften ersetzt wurden. Die historischen Wissenschaften haben die Aufgabe, zu diesen vergangenen Landschaften vorzudringen.

Mein Ausgangspunkt aus der Sicht meines Faches ist, das Verhältnis von Archäologie zu Raum und Landschaft als Forschungskategorien zu bestimmen (Abb. 1). Im Kontext dessen, wie Vorstellungen über vergangene Landschaften kreiert werden, möchte ich Verbindungen zwischen archäologischen Theorien und Methoden der Fernerkundung vorstellen. Allerdings sollen die im Folgenden gegebenen Beispiele nicht zur Rekonstruktion vergangener Landschaften beitragen, sondern bedürfen selbst der Interpretation, um in den akademischen wie öffentlichen Diskurs aufgenommen zu werden.

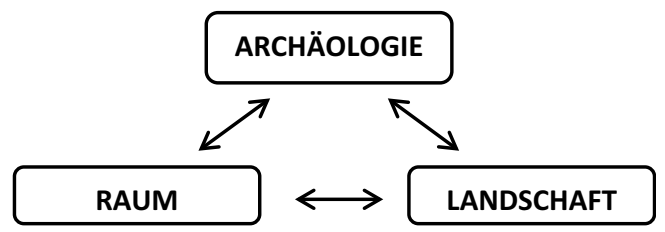

Abb. 1: Schema: Die Landschaft und ihre Verbindungen zu den Raumkonzepten in der Archäologie

2 Osbert Guy Stanhope Crawford, Archaeology in the Field, London: Dent, 1953. 


\section{Archäologie und vergangene Landschaften}

Die Archäologie bildete sich seit Mitte des 19. Jahrhunderts als eigenständige Wissenschaft heraus. Sie konzentrierte sich zunächst besonders darauf, die untersuchten Sachverhalte in eine chronologische Ordnung zu bringen. Erst Friedrich Ratzels Anthropogeographie führte den Raum als geschichtswissenschaftliche Kategorie ein. ${ }^{3}$ Diese Konzeption betonte die Abhängigkeit des Menschen von seiner Umwelt und erklärte, wie sich menschliche Kulturen nach den jeweiligen Umweltbedingungen verändern. ${ }^{4}$ Der Raum im geografischen Verständnis als Summe seiner physischen Bestandteile natürlichen Ursprungs wurde damit zu einem wesentlichen kulturschaffenden Faktor. Ratzels Konzeption war deswegen so erfolgreich, weil sie die Veränderlichkeit von Kulturen überzeugend erklärte und die damals vorherrschende Evolutionstheorie ausstach; so fand sie schnell Eingang in die Geschichtswissenschaften. Die Anthropogeografie brachte deskriptive Begriffe wie Diffusion und Migration sowie die Landkarte als analytisches Instrument ein. In der Archäologie nennt sich die von Ratzel inspirierte Strömung »Diffusionismus«. Dieser fand einen wesentlichen Platz in der mitteleuropäischen (Fritz Graebner, Bernhard Ankermann, Wilhelm Schmidt, Gustaf Kossinna) wie in der angelsächsischen Archäologie (Elliot Smith, William Perry). Es bildeten sich stark differierende Varianten bis hin zum Hyperdiffusionismus aus, der einen einzigen Ausgangspunkt aller menschlichen Kulturen annimmt, bevor diese sich in verschiedene Richtungen ausdehnten und je nach Umwelt unterschiedlich ausprägten. Gustaf Kossinna war mit seiner siedlungsarchäologischen Methode und seiner Verbindung von Kulturprovinzen mit bestimmten Völkern (Ethnizität) ähnlich einflussreich. ${ }^{5}$

Der Geodeterminismus verleitete dazu, gleich alle anthropologische und kulturelle Diversität auf disparate Umweltbedingungen zurückzuführen. Doch solche Auffassungen wurden bald vor allem von französischen Geografen wie Paul Vidal de La Blache infrage gestellt. Dieser verneinte zwar nicht den Einfluss der Umwelt auf die kulturelle Entwicklung, schrieb jedoch dem menschlichen Handeln eine weit bedeutendere Rolle zu, besonders beim Wandel der Kultur und dabei, wie sich diese wiederum in der Landschaft manifestiert. Zur Abgrenzung gegen Ratzels Determinismus wurde die von Vidal de La Blache inspirierte Denkrichtung »Possibilismus« genannt. Ein Anhänger des Possibilis-

3 Friedrich Ratzel, Anthropogeographie, Bd. I, Stuttgart: J. Engethorn, 1882; ders., Anthropogeographie, Vol. II, Stuttgart: J. Engethorn, 1891; ders., Politische Geographie, München: Oldenburg, 1897.

4 Józef Babicz, Nauka o ludziach Fryderyka Ratzla [Friedrich Ratzels Lehre von den Menschen], Wrocław: Polskie Towarzystwo Ludoznawcze, 1962.

5 Gustav Kossinna, Die Herkunft der Germanen: Zur Methode der Siedlungsarchäologie, Würzburg: Mannus-Bibliothek, 1911. 
mus war der deutsche Geograf Otto Schlüter, der Studien zur »Kulturlandschaft» initiierte. ${ }^{6}$ Die französische und deutsche historische Geografie hatte wesentlichen Einfluss auf die historische und archäologische Forschung in Mitteleuropa. Beispiele hierfür sind der polnische Historiker Karol Potkański und der deutsche Archäologe Herbert Jankuhn. Potkański gab in Polen den Anstoß für die historisch-archäologische Siedlungsforschung. ${ }^{7}$ Jankuhn erarbeitete eine darauf abgestellte Forschungsmethode, Besiedlung im Hinblick auf die Einwirkung der geografischen Umgebung zu betrachten. ${ }^{8}$ Für die Besiedlung relevante Faktoren sind demnach natürliche Umgebung, Bevölkerungsgröße und -struktur, Bewirtschaftung und technisches Niveau (Abb. 2).

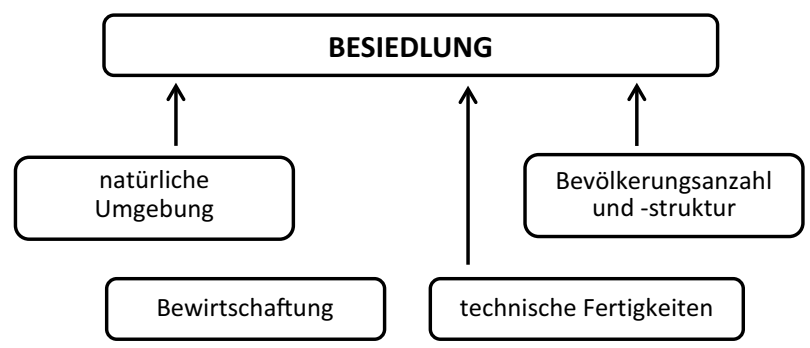

Abb. 2: Die Entwicklungsfaktoren der historischen Ansiedlung nach H. Jankuhn (1977)

Bei der Erarbeitung ihres Forschungsfeldes berücksichtigte die Archäologie Theoreme des Evolutionismus wie des Diffusionismus, jedoch in weniger orthodoxer Form. Gerade Einflüsse des Possibilismus spielten zumindest programmatisch eine wichtige Rolle bei Untersuchungen zum Verhältnis zwischen Mensch und geografischem Umfeld. Diese Strömung wird als kulturelle und historische Archäologie bezeichnet.

Die kulturgeschichtliche Archäologie schöpft aus Evolutionismus und Diffusionismus; sie beruft sich in ihren Grundannahmen auf Positivismus und Empirismus und wendet die induktive Schlussfolgerung an. ${ }^{9}$ Forschungen zu Elementen des Raumes basieren damit auf der Konzeption einer archäologischen Stätte, also eines begrenzten Gebietes mit materiellen Relikten menschlicher Handlungen. Die räumliche Identifizierung kleiner Enklaven von Spuren

6 Preston Everett James und Geoffrey J. Martin, All Possible Worlds: A History of Geographical Ideas, New York: John Wiley \& Sons, 1981.

7 Karol Potkański, Pisma pośmiertne [Posthume Schriften], Band 1, Kraków: Polska Akademia Umiejętności, 1922.

8 Herbert Jankuhn, «Methoden und Probleme siedlungsarchäologischer Forschung«, in: Archaeologia Geographica 4 (1952-55), 73-84; ders., Einführung in die Siedlungsarchäologie, Berlin/New York: De Gruyter, 1977.

9 Bruce Trigger, A History of Archaeological Thought, Cambridge: Cambridge University Press, 2007. 
menschlicher Handlungen und deren Kartierung lassen den Raum der Vergangenheit diskontinuierlich werden. Eine Erkundung unterschiedlicher Tiefe, die sich aus topografisch ungleich verteilten archäologischen Grabungen und den Forschungsmethoden der Disziplin ergab, führte zu der Schlussfolgerung, es gebe »Siedlungskonzentrationen « und "Siedlungsleere«. Deren Verteilung und Veränderung wurden im Kontext der natürlichen Umgebung analysiert, was gewöhnlich zu der Behauptung führte, die Eigenschaften des Raums seien die Ursache für eine bestimmte Verteilung menschlicher Aktivität in der Vergangenheit (Geodeterminismus). Solche Schlussfolgerungen über historische Siedlungsaktivitäten sind intuitiv, zufällig und können keine dauerhaften Theorien begründen. ${ }^{10}$ Diese Praxis der Archäologie und anderer Disziplinen provozierte substantielle Kritik an ihren positivistischen Grundlagen und die Formulierung von antipositivistischen Methoden. ${ }^{11}$

Das führte zur Herausbildung zahlreicher archäologischer Richtungen, die sich auf ganz unterschiedliche Theorien berufen: die auf der Systemtheorie basierende prozessuale Archäologie; die auf dem historischen Materialismus beruhende marxistische Archäologie; die sich auf den Strukturalismus stützende strukturelle Archäologie; die funktionale Archäologie, die an funktionalistische Ideen der Kulturanthropologie anknüpft. ${ }^{12}$ Diese Strömungen stellen die induktive Schlussfolgerung infrage; in ihrer Gesamtheit begreifen sie kulturelle Phänomene auf universalistische Weise.

Die Kategorie des Raums ist besonders für die prozessuale Archäologie wesentlich, weil diese die Auffassung vertritt, dass Relikte von Wirtschaftsformen in einer bestimmten geografischen Umgebung Rückschlüsse auf das Kultursystem erlauben. ${ }^{13}$ Dieser Ansatz verlangt die Untersuchung von Siedlungen und Lagerstätten oder des Siedlungssystems insgesamt unter Berücksichtigung von Umweltressourcen. Untersuchungen $\mathrm{zu}$ diesen sowie $\mathrm{zu}$ den ökonomischen Grundlagen soziokultureller Systeme gehen über die einzelne archäologische Stätte hinaus. Damit sind die Voraussetzungen zur Untersuchung größerer

10 Timothy Champion, »Theoretical Archaeology in Britain«, in: Ian Hodder (Hg.), Archaeological Theory in Europe: The last three decades, London: Routledge, 1991, 129-160.

11 Reinhard Bernbeck, Theorien in der Archäologie, Tübingen: A. Francke Verlag, 1997; Gabriele Mante, Die deutschsprachige Prähistorische Archäologie, Münster: Waxmann, 2007; Alexander Gramsch und Ulrike Sommer (Hg.), A History of Central European Archaeology. Theory, Methods, and Politics, Budapest: Archaeolingua Alapítvány, 2011; Manfred K. H. Eggert und Ulrich Veit (Hg.), Theorie in der Archäologie: zur jüngeren Diskussion in Deutschland, Münster: Waxmann, 2013.

12 Z. B. Arkadiusz Marciniak, »Teoria w archeologii« [Theorie in der Archäologie], in: Stanisław Tabaczyński, Arkadiusz Marciniak, Dorota Cyngot und Anna Zalewska (Hg.), Przeszłość społeczna: Próba konceptualizacji [Die gesellschaftliche Vergangenheit: Versuch einer Konzeptualisierung], Poznań: Wydawnictwo Poznańskie, 2012, 84-116.

13 Lewis R. Binford, "The Archaeology of Place«, in: Journal of Anthropological Archaeology 1 (1982), 5-31. 
Räume erfüllt, die der Gegenstand von Raumanalysen ist. ${ }^{14}$ Das setzt zudem messbare Daten räumlicher Phänomene voraus; dazu wird die historische Landschaft in ihren physischen Eigenschaften vermessen. ${ }^{15}$ Die Rekonstruktion einer historischen Landschaft geht überdies von der ökonomischen Rationalität der Besiedlung aus und benutzt sozioökonomische Modelle, um die räumliche Verteilung der archäologischen Stätten in der Landschaft zu erklären. ${ }^{16}$

Die prozessuale Archäologie bezieht den Menschen im Raum als Systembestandteil ein. In diesem Modell ist der Mensch nicht in der Lage, völlig selbstbestimmte Entscheidungen zu treffen, vielmehr unterliegt er systemimmanenten Mechanismen und damit kulturunabhängigen Gesetzmäßigkeiten. Der Marxismus sieht das Problem anders. Er betont menschliche Aktivität und Entscheidungsfindung, was den Akzent von der natürlichen Umwelt auf die Kultur verschiebt. ${ }^{17}$ Demnach trifft der Mensch bewusste und rationale Entscheidungen zu Wohnsitz und Nutzung natürlicher Ressourcen, indem er seine Situation analysiert und sein Weltwissen einsetzt. Damit eröffnet der Marxismus die Möglichkeit, das Verhältnis zwischen Mensch und natürlicher Umwelt neu zu fassen und die theoretischen Schemata des ausgehenden 19. Jahrhunderts zu durchbrechen.

Eine andere Auffassung von Raum knüpft an den linguistic turn an und betrachtet Raum als gesellschaftlich konstituiert. Soziale Gemeinschaften oder Individuen handeln in bestimmten Räumen, die nicht ohne die in ihnen wirkenden Menschen existieren. Erst durch menschliches Wirken wird der Raum im Verhältnis zum Menschen konstitutiv, wobei er ständig kulturell reproduziert und verändert wird. ${ }^{18}$ Ein solcher Raum ist somit Mittel wie Resultat menschlichen Handelns. So verstanden umfasst der Raum ein komplexes System von Verbindungen zwischen menschlichem Körper, Erkenntnis und Repräsentation sowie kultureller und natürlicher Umgebung. Die soziale Erschaffung des Raums unterliegt der kulturellen Reproduktion, doch vollzieht sich dabei auch ein Wandel in Wahrnehmung und Verständnis des Raumes oder einzelner seiner

14 Ian Hodder und Clive Orton, Spatial Analysis in Archaeology, Cambridge: Cambridge University Press, 1976.

15 Timothy Darvill, "Landscapes and the archaeologists", in: Katherine Baker und Timothy Darvill (Hg.), Making English Landscapes: Changing Perspectives, Oxford: Oxbow, 1997, 70-91.

16 Z. B. Johann Heinrich von Thünens Modell des isolierten Staates, Alfred Webers Modell der optimierten Standortwahl oder Walter Christallers Modell des zentralen Ortes. David L. Clarke, "Spatial Information in Archaeology«, in: ders. (Hg.), Spatial Archaeology, London u. a.: Academic Press, 1977, 1-32.

17 Henryk Łowmiański, Początki Polski [Die Anfänge Polens], Band III, Warschau: PWN, 1967; Jerzy Topolski, Wolnosś́ i przymus w tworzeniu historii [Freiheit und Zwang beim Schaffen von Geschichte], Warschau: Państwowy Instytut Wydawniczy, 1990.

18 Marcos Llobera, »Exploring the topography of mind: GIS, social space and archaeology«, in: Antiquity 70 (1996), 612-622. 
Bestandteile. Daraus folgt, dass der Raum immer auch eine subjektive Bedeutung aufweist und nicht losgelöst von der symbolisch konstruierten sozialen und kulturellen Welt betrachtet werden kann. Der Raum hat keine Bedeutung an sich, sondern einzig im durch die Beziehung zwischen Mensch und Ort geschaffenen Verständnis. Das verbindet ihn auch mit der Kategorie der Zeit. Raum wird im Verhältnis zu den zuvor geschaffenen Räumen fortwährend neu kreiert, reproduziert und transformiert. Raum ist also eng mit der Geschichte von Menschen und Gesellschaften verknüpft. ${ }^{19}$ Die Außenwelt liefert den Rohstoff für den im Raum aktiven Menschen. Doch dieser Rohstoff in Form von physischen Objekten ist nicht geordnet und besitzt keine Bedeutungen. Die Elemente müssen zunächst wahrgenommen und benannt werden, damit sie Eingang in die geordnete Welt der Kultur finden. Die Wahrnehmung der Welt gestattet deren Konstituierung, und das geht unter den Bedingungen eines historisch geformten Erlebens der Welt vonstatten. Daraus entsteht eine komplexe Struktur von Elementen und Relationen, die man "Kulturlandschaft « nennen kann. ${ }^{20}$

Zusammenfassend lässt sich sagen, dass die Archäologie unterschiedliche Auffassungen von Raum und historischer Landschaft konstruiert, die von den jeweiligen Forschungstraditionen und gängigen Theorien abhängen. Was diese Ansätze voneinander abgrenzt, ist, inwieweit sie die Erkundung historischer Landschaften vermittels physischer Objekte für möglichen halten (vgl. die kulturgeschichtliche, die prozessuale, die marxistische Archäologie u.a.). Davon setzt sich die Auffassung ab, die Erkundung der vergangenen Welt sei nicht möglich; diese plädiert, den wissenschaftlichen Diskurs für die Konstruktion historischer Landschaften und die Ermittlung von Bedeutungen vergangener, dynamischer Landschaften zu öffnen.

\section{Archäologische Fernerkundung in der Forschung zur Kulturlandschaft}

Archäologen sind sich weitgehend darin einig, die Fernerkundung bei der Erforschung historischer Landschaften als wichtige Methode zur Generierung empirischer Daten zu sehen. Der Begriff der Fernerkundung kam 1960 auf: Diese ist definiert als Beobachtung und Vermessung eines Objekts ohne direkten Kontakt zum Objekt. ${ }^{21}$ Heute werden bei der Fernerkundung zur Erkennung und Vermessung von Objekten in einer gewissen Entfernung Detektoren für

19 Tilley, Phenomenology of Landscape.

20 Ebd.; Alexander Gramsch, »Landscape Archaeology: Of Making and Seeing«, in: Journal of European Archaeology 4 (2013), 19-38.

21 Paul J. Curran, Principles of Remote Sensing, London: Longman, 1985. 
elektromagnetische Strahlung angewendet. ${ }^{22}$ Dem liegt zugrunde, dass alle physischen Objekte mit einer Temperatur über null K (dem absoluten Nullpunkt) durch die Bewegung von Atomen und Molekülen elektromagnetische Energie erzeugen. Die Fernerkundung registriert also zunächst diese Strahlung. Jedes physische Objekt zeichnet sich durch eine nur ihm eigene Verteilung reflektierter, absorbierter und emittierter Strahlung aus. Diese Strahlungsspezifik kann genutzt werden, um Daten zu Form, Größe und weiteren physikalischen und chemischen Eigenschaften von Objekten oder Phänomenen sowie über deren Veränderung in der Zeit zu erhalten. ${ }^{23}$ Die Fernerkundung erfolgt mithilfe von sogenannten aktiven oder passiven Systemen. Beim aktiven System sendet das Gerät ein elektromagnetisches Signal aus und empfängt eine reflektierte Welle, die aufgezeichnet und weiter analysiert wird. Beim passiven System wird hingegen lediglich die Strahlung registriert, die von einer bestehenden Energiequelle wie einem Objekt oder einer Schicht ausgeht. Die Registrierung der Strahlung kann als Analogbild oder in digitaler Form erfolgen. ${ }^{24}$

$\mathrm{Zu}$ den ältesten Fernerkundungsmethoden gehört die Luftaufnahme, die seit Ende des 19. Jahrhunderts genutzt wird. Die Luftaufnahme ist ein Verfahren aus der Gruppe der passiven Methoden; sie arbeitet hauptsächlich mit elektromagnetischer Strahlung aus dem Bereich des sichtbaren Lichts, manchmal auch aus dem nahen Infrarotbereich. Zu den passiven Methoden gehört auch die Nutzung von Satellitenbildern; hier ist jedoch der registrierte Bereich der elektromagnetischen Strahlung um einiges breiter und reicht bis zur Radarstrahlung. Die jüngste Methode ist das Airborne Laserscanning (ALS, LiDAR), ein aktives Verfahren, bei dem ein starker hochfrequenter Lichtstrahl ausgesendet, von Hindernissen wie z.B. der Erdoberfläche reflektiert wird und zum Sensor zurückkehrt. ${ }^{25}$ Die ermittelten Daten erlauben, in der Landschaft befindliche Objekte zu identifizieren, zu messen und zu beschreiben.

22 James I. Ebert, »Remote Sensing Applications in Archaeology«, in: Michael B. Schiffer (Hg.), Advances in Archaeological Method and Theory, Vol. 7, New York: Academic Press, 1984, 293-362; Roy Estess, »Remote Sensing Fundamentals», in: Robert K. Holz (Hg.), The Surveillant Science: Remote Sensing of the Environment, New York: John Wiley \& Sons, 1985, 12-27.

23 John Estes und Robert K. Holz, »Remote Sensing: Coming of Age in the 800 s «, in: Robert K. Holz (Hg.), The Surveillant Science: Remote Sensing of the Environment, New York: John Wiley \& Sons, 1985, 30-52.

24 Andrzej Ciołkosz, Jerzy Miszalski und Jan R. Olędzki, Interpretacja zdjęć lotniczych [Die Interpretation von Luftbildern], Warschau: Wydawnictwo Naukowe PWN, 1999; Estess, "Remote Sensing Fundamentals«, 12-27.

25 Włodzimierz Rączkowski, »Metody w archeologii« [Methoden in der Archäologie], in: Stanisław Tabaczyński, Arkadiusz Marciniak, Dorota Cyngot und Anna Zalewska (Hg.), Przeszłość społeczna: Próba konceptualizacji [Die soziale Vergangenheit: Versuch einer Konzeptualisierung], Poznań: Wydawnictwo Poznańskie, 2012, 367-408. 
Die Erkenntnis, dass die Fernerkundung eine präzise und ökonomische Registrierung von Spuren der Vergangenheit ermöglicht, entschied über ihren Erfolg in der Archäologie, auch wenn sie nicht in allen Ländern und Forschungsrichtungen gleichermaßen angewendet wird. Die verschiedenen Nutzungsweisen der Fernerkundung liefern ein gutes Beispiel für die Abhängigkeit einer Methode von den theoretischen Grundlagen. ${ }^{26}$ Die ersten bekannten Luftaufnahmen archäologischer Stätten datieren aus dem ausgehenden 19. Jahrhundert: Giacomo Bonis Untersuchung des Forum Romanum von 1899. In der Archäologiegeschichte gilt daneben Osbert Guy Stanhope Crawford als Pionier der Luftaufnahme. Seine Erkenntnis ihres Nutzens für die archäologische Forschung geht darauf zurück, dass er Anfang des 20. Jahrhunderts zum Anhänger des Diffusionismus wurde; auch hier ging also die Theoriebildung der Forschungsmethode voraus.

Die Fotografie war eine Erfindung des 19. Jahrhunderts; Fotografien erfreuten sich von Anfang an großen Interesses, förderten sie doch die Erkundung der Welt und die Erweiterung des Wissens. Nach allgemeiner Auffassung bildeten sie die Welt auf präzise und unverzerrte Weise $a b .^{27}$ Die Archäologen jener Zeit - später auch die kulturgeschichtliche Archäologie - schätzten Luftaufnahmen vor allem als empirisches Werkzeug zur Erforschung und Registrierung archäologischer Stätten. ${ }^{28}$ Sie wurden ausschließlich angefertigt, um Daten über kulturelle Artefakte in einer Landschaft zu erheben. Die positivistische Archäologie schränkte damit den Anwendungsbereich von Luftaufnahmen stark ein.

Als in den 1960er Jahren die prozessuale Archäologie aufkam, wurden in den Humanwissenschaften verstärkt neue technische Entwicklungen adaptiert. Standardisierte Methoden und wiederholbare Prozeduren passten hervorragend zum Glauben an die Objektivität von Forschung, an universale Gesetze und Theorien. Von den Naturwissenschaften entlehnte Methoden suggerierten Objektivität. Fernerkundungsmethoden, also Luftaufnahmen und die damals noch ganz neuen Satellitenbilder, erlaubten die präzise Vermessung kultureller und natürlicher Phänomene und machten die Forschung anscheinend von subjek-

26 Włodzimierz Rączkowski, Archeologia lotnicza - metoda wobec teorii [Die Archäologie aus der Luft - Methode und Theorien], Poznań: Wydawnictwo Naukowe UAM, 2002; ders., "Theoretical dialogues - is there any theory in aerial archaeology?", in: AARGnews, Supplement 1 (2005), 12-22.

27 Chris Jenks, »The Centrality of the Eye in Western Culture: an Introduction«, in: ders. (Hg.), Visual Culture, London: Routledge, 1995, 1-25; Don Slater, »Photography and modern vision: the spectacle of 'natural magic «, in: Jenks, Visual Culture, 218-237.

28 Rainer Christlein und Otto Braasch, Das unterirdische Bayern, Stuttgart: Theiss, 1982; Otto Braasch, Luftbildarchäologie in Südwestdeutschland: Spuren aus römischer Zeit, Stuttgart: Württ. Landesmuseum, 1983; Walter Sölter (Hg.), Das römische Germanien aus der Luft, Bergisch-Gladbach: Lübbe, 1987; Ralf Schwarz, Pilotstudien: 12 Jahre Luftbildarchäologie in Sachsen-Anhalt, Halle/Saale: Landesamt für Archäologie Sachsen-Anhalt, 2003. 
tiven Einschätzungen unabhängig. Die neue Technologie sollte einer neuen Art von Archäologie dienen. ${ }^{29}$

Der linguistic turn brachte einschneidende Veränderungen im Umgang mit Luftaufnahmen und Satellitenbildern. Unsere Wahrnehmung gilt seither nicht mehr als natürliche, angeborene Fähigkeit - sie hänge vielmehr davon ab, wie in der Gesellschaft Wissensformen, Machtstrategien oder Bedürfnissysteme angelegt seien. In der Konsequenz sollen Luftaufnahmen und andere räumliche Visualisierungen dazu dienen zu verstehen, wie sich der Mensch auf die Landschaft auswirkt. Alle Abbildungen des Raumes unterliegen der Interpretation und sind wichtig bei der Konstruktion überzeugender Narrative über historische Landschaften. ${ }^{30}$

Bis heute nutzt die kulturgeschichtliche Archäologie die Fernerkundung zur Entdeckung neuer Fakten. Die prozessuale Archäologie legt besonderen Wert darauf, detaillierte und objektivierte Vermessungen von räumlich beschreibbaren kulturellen Phänomenen durchzuführen. Die postprozessuale Archäologie stellt in den Vordergrund, welche Rolle die Fernerkundung bei der Erforschung von landschaftlichen Bedeutungen spielt und wie diese nachvollziehend zu erfassen seien (Abb. 3).

\section{METHODEN DER FERNERKUNDUNG $\longrightarrow$ LANDSCHAFT}

kulturgeschichtliche Archäologie $\longrightarrow$ Entdeckung neuer Fakten

prozessuale Archäologie

postprozessuale Archäologie

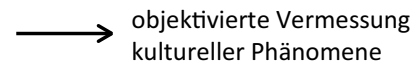

Erforschung von Bedeutung, Verständnis, Empathie

Abb. 3: Die Rolle von Fernerkundungsmethoden in Landschaftsstudien in verschiedenen Auffassungen in der Archäologie

\section{Darstellung historischer Landschaften mit Methoden der Fernerkundung}

Die besonderen Eigenschaften der Luftaufnahme passen gut zu dem Ansatz, Raum und Landschaft als diskontinuierliche Phänomene zu sehen. Der Bildausschnitt zeigt nur ein bestimmtes Raumfragment und isoliert es von seiner

29 Rączkowski, Archeologia lotnicza.

30 Rączkowski, "Metody w archeologii«, 367-408. 
Umgebung. Die Fotografie der Spur eines historischen Geschehens trennt die Spur zwangsläufig von ihrer Umgebung. Während das in der auf Entdeckung und Identifikation einzelner Spuren ausgerichteten kulturgeschichtlichen Archäologie unproblematisch ist, haben die prozessuale wie die postprozessuale Archäologie damit ein methodologisches Problem. Für die prozessuale Archäologie lautet die Lösung, sämtliche registrierten Spuren historischer Aktivität auf eine Karte zu übertragen und so zusammenfassend zu repräsentieren, um sie weiter untersuchen zu können. ${ }^{31}$ Die postprozessuale Archäologie versucht, mit 3D-Visualisierungen und virtuellen Spaziergängen durch die »Landschaften der Vergangenheit« die Beschränkungen älterer Visualisierungsmethoden zu überwinden. Dabei sind neue Technologien wie das Airborne Laserscanning oder Structure from Motion hilfreich. ${ }^{32}$ Einer ihrer Vorteile liegt darin, dass sie einen schnellen Wechsel zwischen den Skalen der Raumpräsentation ermöglichen, also von der Detailbetrachtung zum weiten Raumausschnitt und umgekehrt.

Für die Zwecke dieses Beitrags sollen eher Einzelbestandteile einer Landschaft als deren Gesamtheit abgebildet werden. Somit können die ausgewählten Beispiele nur Ausgangspunkt für weitergehende Landschaftsanalysen sein. ${ }^{33}$

31 Roger Palmer, Danebury. An Iron Age Hillfort in Hampshire: An Aerial Photographic Interpretation of Its Environs, London: RCHME, 1984. Vgl. auch das National Mapping Programme: Robert H. Bewley, »A National Mapping Programme for England«, in: Jürgen Kunow, Luftbildarchäologie in Ost- und Mitteleuropa, Potsdam: Brandenburgisches Landesmuseum für Ur- und Frühgeschichte, 1995, 83-92.

32 Geert Verhoeven, "Taking computer vision aloft - archaeological three-dimensional reconstructions from aerial photographs with PhotoScan«, in: Archaeological Prospection 18, 1 (2011), 67-73; Geert Verhoeven, Michael Doneus, Christian Briese und Frank Vermeulen, "Mapping by matching: a computer vision-based approach to fast and accurate georeferencing of archaeological aerial photographs«, in: Journal of Archaeological Science 39 (2012), 2060-2070; Rachel Opitz und Dave Cowley (Hg.), Interpreting Archaeological Topography. 3 Data, Visualisation and Observation, Oxford: Oxbow Books, 2013; Žiga Kokalj und Ralf Hesse, Airborne laser scanning raster data visualization: A Guide to Good Practice, Ljubljana: Založba ZR., 2017.

33 Die in diesem Text verwendeten Fernerkundungsdaten stammen aus einer Zusammenarbeit zwischen dem Institut für Urgeschichte der Adam-Mickiewicz-Universität Posen und dem Wojewodschafts-Denkmalkonservator in Leszno 1999 sowie den folgenden Projekten: European Landscapes: Past, Present \& Future (2004-2007), ArchaeoLandscapes Europe (2010-2015), Przeszłe krajobrazy w kontekście danych przestrzennych. Współczesne technologie $i$ możliwości interpretacyjne archeologii $w$ studiach mikroregionu wczesnośredniowiecznego grodziska we Wrześnicy [Vergangene Landschaften im Kontext räumlicher Daten. Moderne Technologien und Interpretationsmöglichkeiten der Archäologie bei Studien zur Mikroregion der frühmittelalterlichen Burg in Wrześnica] (2011-2014) und ArchEO - archaeological applications of Earth Observation techniques (2014-2016). 


\subsection{Frühe bäuerliche Landschaften}

Die von Bauern im 6. und 5. Jahrtausend v. Chr. mitgeprägten mitteleuropäischen Landschaften sind längst vergangen. Doch sind Spuren davon unter der Erdoberfläche verborgen und die Methoden der Fernerkundung erlauben es, sie sichtbar werden zu lassen. ${ }^{34}$ Am besten auf Luftaufnahmen oder Satellitenbildern lesbar sind Spuren von Siedlungen ${ }^{35}$ mit einer charakteristischen Trapezform der Häuser, die sich leicht identifizieren und interpretieren lässt (Abb. 4).

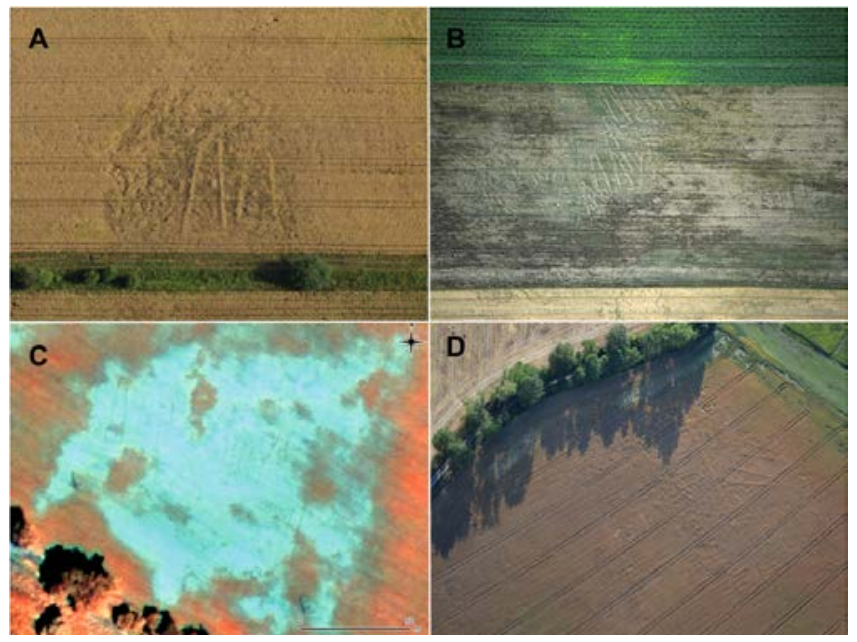

Abb. 4: Hütten von länglicher Form in der Landschaft früher Bauern. A - Wróble (Luftaufnahme), B - Kaczkowo (Luftaufnahme), C - Kaczkowo (Satellitenbild), D - Tarnowo (Luftaufnahme)

Bei der Analyse von Siedlungsrelikten ist zu bedenken, dass eine Siedlungsumgebung vielfältig genutzt wurde: Bäume wurden gerodet, Tiere weideten, Lehm wurde abgetragen; es gab Kontakte mit Nachbargemeinschaften. So entstand eine spezifische Landschaft, die womöglich rotierend besiedelt wurde, das heißt, Siedlungsorte wurden zeitweilig verlassen und nach Jahren erneut bezogen. Dies lässt sich an der Bebauung der Siedlungen und an sich überschneidenden Spuren von Behausungen erkennen (Abb. 4B).

34 Michael Shanks, Experiencing the Past: On the Character of Archaeology, London: Routledge, 1992.

35 Alasdair Whittle, Europe in the Neolithic: The Creation of New Worlds, Cambridge: Cambridge University Press, 1996. 


\subsection{Landschaften an der Wende von der Bronze- zur Eisenzeit}

In der Archäologie Mitteleuropas ist der Übergang von der Bronze- zur Eisenzeit eine besonders wichtige Phase. ${ }^{36}$ Festzustellen sind nicht nur technologische Veränderungen wie die einsetzende Herstellung von Eisenerzeugnissen, sondern auch neue Gesellschaftsstrukturen und Hierarchisierung. Das ist an der zunehmend rund um Wehrsiedlungen konzentrierten Ansiedlung erkennbar, für die das prähistorische Dorf Biskupin in der heutigen Wojewodschaft KujawienPommern exemplarisch ist. Aufgrund ihrer spezifischen Eigenschaften sind nur wenige Spuren menschlicher Aktivität ohne weiteres mithilfe der Fernerkundung identifizierbar (Abb. 5). Die Identifizierung von Wehrsiedlungen ist problemlos, doch fällt sie im Falle von Dörfern schwer, die aus verstreuten Höhlen und Erdhütten ohne spezifische Eigenschaften bestehen oder bei Begräbnisstätten, bei denen Gräberfelder mit kleinen Urnengräbern überwiegen. So generierten vielfältige ökonomische und kultische Aktivität komplexe Landschaften, die sich heute nur schwer rekonstruieren lassen.

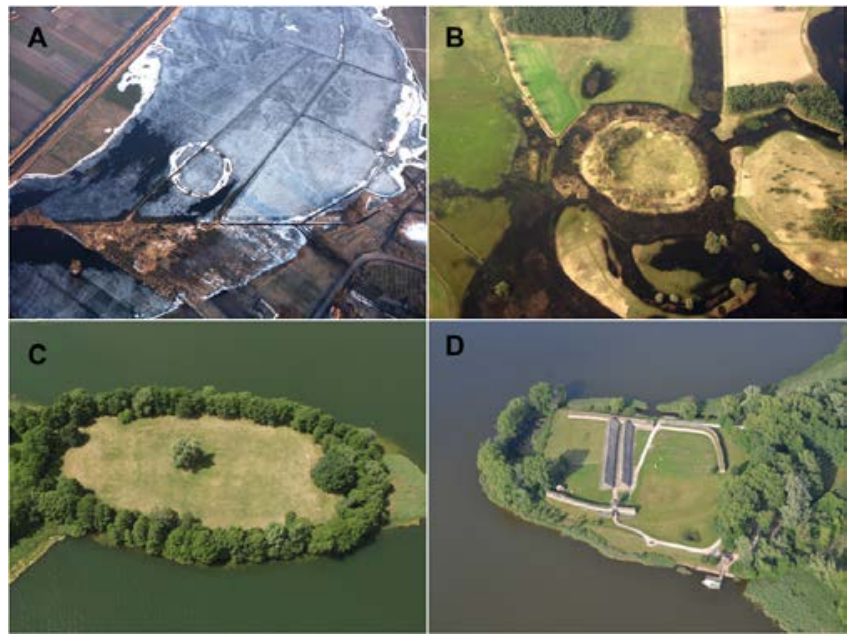

Abb. 5: Wehrsiedlungen aus dem Übergang von Bronze- zu Eisenzeit. A - Jurkowo (Luftaufnahme), B - Tarnowo (Luftaufnahme), C - Izdebno (Luftaufnahme), D - Biskupin (Luftaufnahme)

36 Anthony Harding und Harry Fokkens, Oxford Handbook of the European Bronze Age, Oxford: Oxford University Press, 2013. 


\subsection{Landschaften des frühen Mittelalters}

Das Frühmittelalter sah eine dynamische Umgestaltung der mitteleuropäischen Kultur. Unter den materiellen Relikten nehmen häufig noch sichtbare Burganlagen eine Sonderposition ein (Abb.6). Sie waren vermutlich sozioökonomische und politische Zentren von Stammesgesellschaften, ${ }^{37}$ die in der Landschaft räumliche Bezugspunkte für die Bewohner darstellten. In der Nachbarschaft der Burgen befanden sich Dörfer, Äcker, Viehweiden und Verkehrswege. Bewegung im Raum schuf Vorstellungen über die Landschaft und verlieh bestimmten Orten besondere Bedeutungen. Durch die gesellschaftliche und generationenübergreifende Überlieferung dieser Bedeutungen wurden Identität und Zusammenhalt der Gruppe gefestigt.

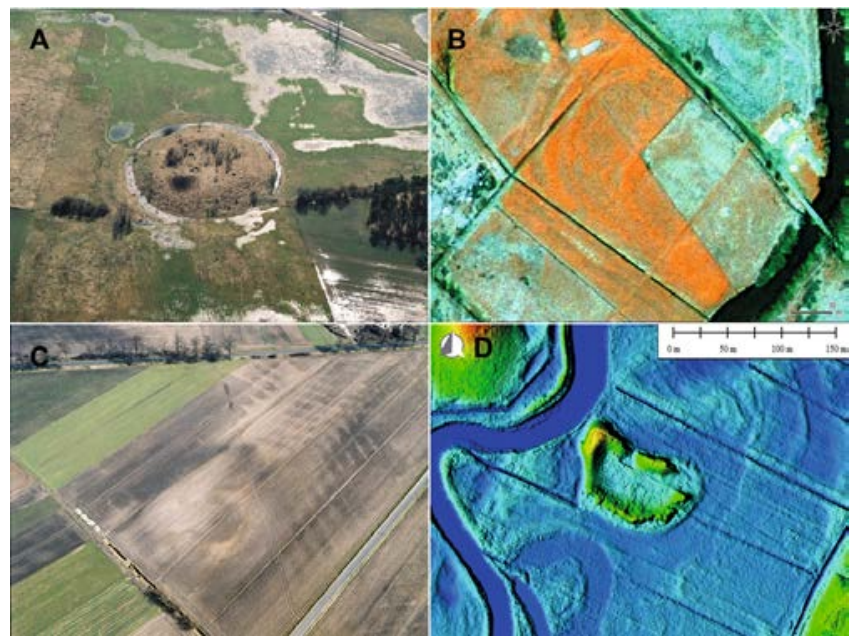

Abb. 6: Burganlagen waren in der frühmittelalterlichen Landschaft wichtige Orte. A - Karzec (Luftaufnahme), B - Sławsko (Satellitenbild), C - Rębowo (Luftaufnahme), D - Wrześnica (numerisches Landschaftsmodell, angelegt nach Laserscandaten)

37 Andrzej Buko, The Archaeology of Early Medieval Poland: Discoveries - Hypotheses - Interpretations, Leiden, Boston: Brill, 2008; Karol Modzelewski, Organizacja gospodarcza państwa piastowskiego (X-XIII wiek) [Die wirtschaftliche Organisation des Piastenstaates (10.-13. Jahrhundert)], Poznań: Wydawnictwo Poznańskie, 2000. 


\subsection{Dörfliche Landschaften}

Dörfer waren von der Zeit der ersten Bauern an zentrale Orte in der Landschaft. Dort spielte sich das Leben ab, sie waren Orte von Aktivität und Begegnung. Sie besaßen eine dynamische, räumliche wenig geordnete Struktur. Erst seit dem Mittelalter nahmen sie vorab geplante Formen an, so bei der Kolonisation nach deutschem Recht. Die Anordnung der Bebauung, aber auch die Aufteilung von Feldern, Wiesen und Weiden war festgelegt. Viele Dörfer haben bis heute diesen Plan beibehalten (Abb. 7). Und obwohl die Überbauung im 19. und 20. Jahrhundert Spuren der früheren Bebauung löschte, lassen sich wesentliche räumliche Strukturen noch identifizieren. Dies gilt für die Felder direkt an Bauernhöfen, aber auch in größeren Gebieten, beispielsweise in den Landschaften der Hauländer. Die Erweiterung der Dörfer und neue Besiedlung brachten neue Elemente in die dörflichen Landschaften. Diese Landschaften repräsentieren heute wohl am besten den kulturellen Wandel früherer Jahrhunderte.

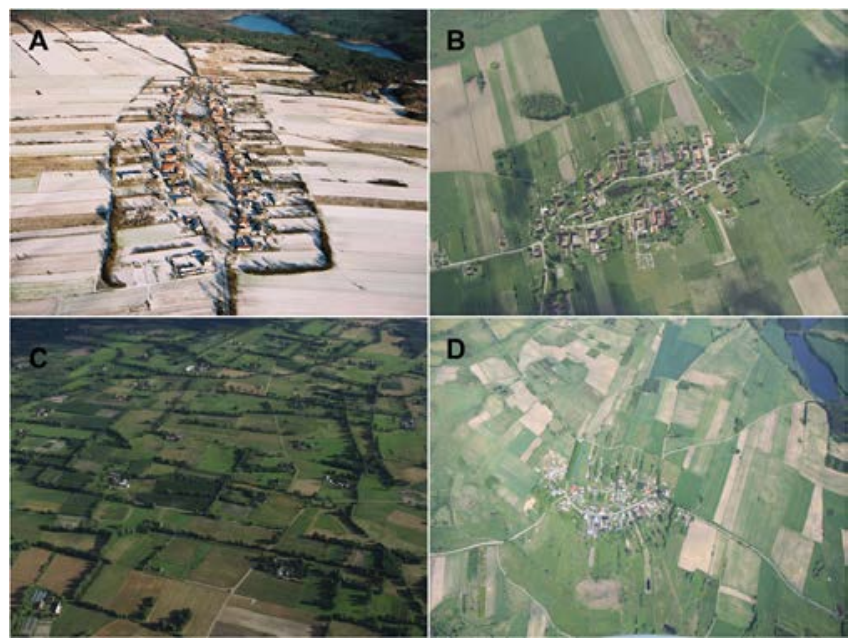

Abb. 7: Beispiele für Dörfer, welche die Landschaft wesentlich modifizierten. A - Jemiołów (Luftaufnahme), B - Swołowo (Luftaufnahme), C - Landschaft einer Hauländer-Siedlung bei Boruja Kościelna, D - Tągowie (Luftaufnahme)

\subsection{Militärische Landschaften}

Unvermeidbar hat auch die menschliche Konfliktgeschichte ihre Spuren in der Landschaft hinterlassen. Dazu gehören Burganlagen, Schlösser, Wehrmauern, Gräben, Verteidigungslinien, Schlachtfelder u. a. Manche davon fungieren als historische Denkmäler zur Wahrung ethnischer oder nationaler Identität, an- 
dere werden nicht beachtet, werden vergessen und verschwinden (Abb. 8). Ihre Geschichte ist ein gutes Beispiel für die Landschaft als Palimpsest. Diskurse der Gegenwart verändern Bedeutung und Präsenz solcher Objekte. Das gilt zum Beispiel für die Festungslinie Oder-Warthe-Bogen, die in den 1930er Jahren von den Deutschen errichtet wurde und in Polen jahrelang in Vergessenheit geraten, ja geradezu aus dem Gedächtnis getilgt war. Heute kehrt sie auf dem Umweg über den Schutz von Fledermäusen in den kulturellen Diskurs zurück, aber auch als Touristenattraktion, während nationalistische Konnotationen ganz in den Hintergrund getreten sind.

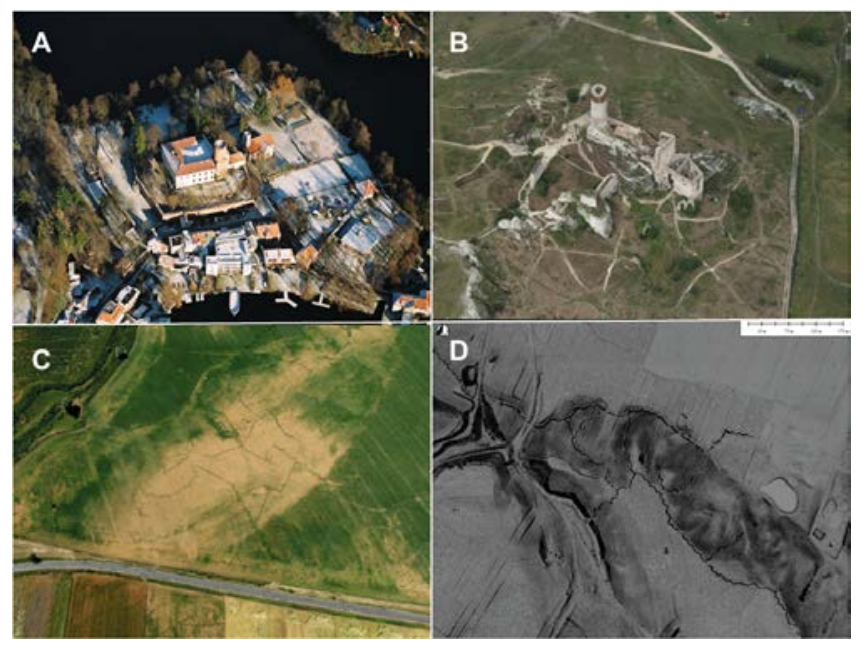

Abb. 8: Noch erkennbare oder aus der Landschaft getilgte militärgeschichtliche Orte. A - Łagów (Luftaufnahme), B - Olsztyn (Luftaufnahme), C - Graby - Schützengäben (Luftaufnahme), D Umgebung von Polanów (numerisches Modell der Landschaft, angelegt nach LaserscanningDaten)

\section{Zusammenfassung}

"Landschaft « ist als soziales Konstrukt in die Kulturentwicklung eingebunden. Daher lässt sich nicht von einer einzigen Landschaft sprechen, vielmehr gibt es viele Landschaften, die so unterschiedlich wie die Weltanschauungen verschiedener Kulturen sind. Historische Landschaften sind abhängig vom jeweiligen theoretischen und methodologischen Ansatz und der entsprechenden Fragestellung. Für ihre Untersuchung ist die Fernerkundung besonders wichtig. Durch den Einsatz dieser Methoden eröffnen sich neue Forschungsperspektiven und -felder und damit erschließen sie auch zuvor übersehene historische Landschaften. Eine wesentliche Eigenschaft der Fernerkundung liegt darin, eine 
Landschaft wie ein Palimpsest erkunden und zu den nicht mehr sichtbaren Schichten vordringen zu können. Dadurch erweckt die Fernerkundung vergangene Landschaften für die Forschung wieder zum Leben.

Aus dem Polnischen von Lisa Palmes

\section{Literatur}

Babicz, Józef. Nauka o ludziach Fryderyka Ratzla [Friedrich Ratzels Lehre von den Menschen], Wrocław: Polskie Towarzystwo Ludoznawcze, 1962.

Bernbeck, Reinhard. Theorien in der Archäologie, Tübingen: A. Francke Verlag, 1997.

Bewley, Robert H. »A National Mapping Programme for England «, in: Luftbildarchäologie in Ost- und Mitteleuropa, Jürgen Kunow (Hg.), Potsdam: Brandenburgisches Landesmuseum für Ur- und Frühgeschichte, 1995, 83-92.

Binford, Lewis R. »The Archaeology of Place«, in: Journal of Anthropological Archaeology 1 (1982), 5-31.

Braasch, Otto. Luftbildarchäologie in Südwestdeutschland: Spuren aus römischer Zeit, Stuttgart: Württ. Landesmuseum, 1983.

Buko, Andrzej. The Archaeology of Early Medieval Poland. Discoveries - Hypotheses Interpretations, Leiden/Boston: Brill, 2008.

Champion, Timothy. »Theoretical Archaeology in Britain«, in: Archaeological Theory in Europe. The last three decades, Ian Hodder (Hg.), London: Routledge, 1991, 129-160.

Christlein, Rainer und Otto Braasch. Das unterirdische Bayern, Stuttgart: Theiss, 1982.

Ciołkosz, Andrzej, Jerzy Miszalski und Jan R. Olędzki. Interpretacja zdjęć lotniczych [Die Interpretation von Luftbildern], Warschau: Wydawnictwo Naukowe PWN, 1999.

Clarke, David L. "Spatial Information in Archaeology«, in: Spatial Archaeology, ders. (Hg.), London u. a.: Academic Press, 1977, 1-32.

Cosgrove, Denis und Stephen Daniels (Hg.). The Iconography of Landscape, Cambridge: Cambridge University Press, 1988.

Crawford, Osbert Guy Stanhope. Archaeology in the Field, London: Dent, 1953.

Curran, Paul J. Principles of Remote Sensing, London: Longman, 1985.

Darvill, Timothy. "Landscapes and the archaeologists«, in: Making English Landscapes: Changing Perspectives, Katherine Baker und Timothy Darvill (Hg.), Oxford: Oxbow, 1997, 70-91.

Ebert, James I. "Remote Sensing Applications in Archaeology", in: Advances in Archaeological Method and Theory, Band 7, Michael B. Schiffer (Hg.), New York: Academic Press, 1984, 293-362.

Eggert, Manfred K. H. und Ulrich Veit (Hg.). Theorie in der Archäologie: zur jüngeren Diskussion in Deutschland, Münster: Waxmann, 2013.

Estes, John und Robert K. Holz. "Remote Sensing: Coming of Age in the $>80$ s «, in: The Surveillant Science: Remote Sensing of the Environment, Robert K. Holz (Hg.), New York: John Wiley \& Sons, 1985, 30-52.

Estess, Roy. »Remote Sensing Fundamentals«, in: The Surveillant Science: Remote Sensing of the Environment, Robert K. Holz (Hg.), New York: John Wiley \& Sons, 1985, 12-27. 
Gramsch, Alexander. »Landscape Archaeology: Of Making and Seeing «, in: Journal of European Archaeology 4 (2013), 19-38.

Gramsch, Alexander und Ulrike Sommer (Hg.). A History of Central European Archaeology. Theory, Methods, and Politics, Budapest: Archaeolingua Alapítvány, 2011.

Harding, Anthony und Harry Fokkens. Oxford Handbook of the European Bronze Age, Oxford: Oxford University Press, 2013.

Hodder, Ian und Clive Orton. Spatial Analysis in Archaeology, Cambridge: Cambridge University Press, 1976.

James, Preston Everett und Geoffrey J. Martin. All Possible Worlds: A History of Geographical Ideas, New York: John Wiley \& Sons, 1981.

Jankuhn, Herbert. "Methoden und Probleme siedlungsarchäologischer Forschung", in: Archaeologia Geographica 4 (1952-1955), 73-84.

Ders. Einführung in die Siedlungsarchäologie, Berlin/New York: De Gruyter, 1977.

Jenks, Chris. »The Centrality of the Eye in Western Culture: An Introduction«, in: Visual Culture, ders. (Hg.), London: Routledge, 1995, 1-25.

Kokalj, Žiga und Ralf Hesse. Airborne laser scanning raster data visualization: A Guide to Good Practice, Ljubljana: Založba ZR., 2017.

Kossinna, Gustav. Die Herkunft der Germanen: Zur Methode der Siedlungsarchäologie, Würzburg: Mannus-Bibliothek, 1911.

Llobera, Marcos. »Exploring the topography of mind: GIS, social space and archaeology«, in: Antiquity 70 (1996), 612-622.

Łowmiański, Henryk. Początki Polski [Die Anfänge Polens], Band III, Warschau: PWN, 1967.

Mante, Gabriele. Die deutschsprachige Prähistorische Archäologie, Münster: Waxmann, 2007.

Marciniak, Arkadiusz. »Teoria w archeologii« [Die Theorie in der Archäologie], in: Przeszłość społeczna. Próba konceptualizacji [Die gesellschaftliche Vergangenheit. Versuch einer Konzeptualisierung], Stanisław Tabaczyński, Arkadiusz Marciniak, Dorota Cyngot und Anna Zalewska (Hg.), Poznań: Wydawnictwo Poznańskie, 2012, 84-116.

Modzelewski, Karol. Organizacja gospodarcza państwa piastowskiego (X-XIII wiek) [Die wirtschaftliche Organisation des Piastenstaates (10.-13. Jahrhundert)], Poznań: Wydawnictwo Poznańskie, 2000.

Opitz, Rachel und Dave Cowley (Hg.). Interpreting Archaeological Topography. 3D Data, Visualisation and Observation, Oxford: Oxbow Books, 2013.

Palmer, Roger. Danebury. An Iron Age Hillfort in Hampshire: An Aerial Photographic Interpretation of Its Environs, London: RCHME, 1984.

Potkański, Karol. Pisma pośmiertne [Posthume Schriften], Band 1, Kraków: Polska Akademia Umiejętności, 1922.

Rączkowski, Włodzimierz. Archeologia lotnicza - metoda wobec teorii [Die Archäologie aus der Luft - eine Methode und Theorie], Poznań: Wydawnictwo Naukowe UAM, 2002.

Ders. "Theoretical dialogues - is there any theory in aerial archaeology? «, in: AARGnews, Supplement 1 (2005), 12-22.

Ders. »Metody w archeologii« [Methoden in der Archäologie], in: Przeszłość społeczna. Próba konceptualizacji [Die soziale Vergangenheit. Versuch einer Konzeptualisierung], 
Stanisław Tabaczyński, Arkadiusz Marciniak, Dorota Cyngot und Anna Zalewska (Hg.), Poznań: Wydawnictwo Poznańskie, 2012, 367-408.

Ratzel, Friedrich. Anthropogeographie, Band I, Stuttgart: J. Engethorn, 1882.

Ders. Anthropogeographie, Band II, Stuttgart: J. Engethorn, 1891.

Ders. Politische Geographie, München: Oldenburg, 1897.

Schwarz, Ralf. Pilotstudien: 12 Jahre Luftbildarchäologie in Sachsen-Anhalt, Halle/Saale: Landesamt für Archäologie Sachsen-Anhalt, 2003.

Shanks, Michael. Experiencing the Past: On the Character of Archaeology, London: Routledge, 1992.

Slater, Don. »Photography and modern vision: the spectacle of `natural magic «, in: Visual Culture, Chris Jenks (Hg.), London: Routledge, 1995, 218-237.

Sölter, Walter (Hg.). Das römische Germanien aus der Luft, Bergisch-Gladbach: Lübbe, 1987.

Tilley, Christopher. Phenomenology of Landscape: Places, Paths and Monuments, Oxford/ Providence: Berg, 1994.

Trigger, Bruce. A History of Archaeological Thought, Cambridge: Cambridge University Press, 2007.

Topolski, Jerzy. Wolność i przymus w tworzeniu historii [Freiheit und Zwang beim Schaffen von Geschichte], Warschau: Państwowy Instytut Wydawniczy, 1990.

Verhoeven, Geert. »Taking computer vision aloft - archaeological three-dimensional reconstructions from aerial photographs with PhotoScan«, in: Archaeological Prospection 18, 1 (2011), 67-73.

Verhoeven, Geert, Michael Doneus, Christian Briese und Frank Vermeulen. »Mapping by matching: a computer vision-based approach to fast and accurate georeferencing of archaeological aerial photographs", in: Journal of Archaeological Science 39 (2012), 2060-2070.

Whittle, Alasdair. Europe in the Neolithic: The Creation of New Worlds, Cambridge: Cambridge University Press, 1996.

Wylie, John. Landscape, London/New York: Routledge, 2007. 
Open-Access-Publikation im Sinne der CC-Lizenz BY 4.0

(c) 2020, Vandenhoeck \& Ruprecht GmbH \& Co. KG, Göttingen ISBN Print: 9783847107507 - ISBN E-Lib: 9783737007504 


\title{
Tadeusz Stryjakiewicz
}

\section{Kulturlandschaft in Veränderung: Konin und Umgebung}

\author{
Bauen heißt, mit der Erde zusammenzuarbeiten, \\ der Landschaft den Stempel des Menschen aufzudrücken, \\ die dadurch für immer verändert wird. \\ Vita Hadriani
}

\section{Einleitung und Terminologie}

Das Zitat aus dem 2. Jahrhundert n. Chr. zeigt, dass Veränderungen der Landschaft durch den Menschen schon im Altertum von Interesse waren. Nachdem sich die Geografie als selbständige wissenschaftliche Disziplin herausgebildet hatte, wurde der Zusammenhang zwischen menschlichem Handeln und Landschaft für die geografische Forschung zentral. Alfred Hettner war der wichtigste Proponent einer landschaftsorientierten Forschung, ${ }^{1}$ aber bereits im 19. Jahrhundert gab es mit Alexander von Humboldt und anderen, vorwiegend deutschen Gelehrten Vorläufer dieser Richtung. ${ }^{2}$

1 Alfred Hettner, Geographie, ihre Geschichte, ihr Wesen und ihre Methoden, Breslau: Hirt, 1927.

2 Zur jüngsten Diskussion zum Thema Katarzyna Ostaszewska, Geografia krajobrazu [Landschaftsgeografie], Warschau: Wydawnictwo Naukowe PWN, 2002; Alan R. H. Baker, Geography and History. Bridging the Divide, Cambridge: Cambridge University Press, 2003, 109-155; Maciej Pietrzak, "Ewolucja poglądów geograficznych na krajobraz« [Die Entwicklung geografischer Sichtweisen der Landschaft], in: Wiesław Maik, Krystyna Rembowska und Andrzej Suliborski (Hg.), Geografia jako nauka o przestrzeni, środowisku i krajobrazie. Band 1: Podstawowe idee i koncepcje $w$ geografii [Geografie als Wissenschaft von Raum, Umwelt und Landschaft. Band 1: Grundideen und Konzeptionen in der Geografie], Łódź: Łódzkie Towarzystwo Naukowe, 2005, 151-162; V. N. Kaluzkov, "Landšaft v kulturno-geografičeskich issledovanijach « [Landschaft in der kulturgeografischen Forschung], in: Izvestija RAN, Seria Geografičeskaja 4 (2008), 11-19; Florian Plit, Krajobraz kulturowy - czym jest? [Kulturlandschaft - was ist das?], Warschau: Uniwersytet Warszawski, Wydział Geografii i Studiów Regionalnych, 2011; Andrzej Richling und Jerzy Solon, Ekologia krajobrazu [Ökologie der Landschaft], Warschau: PWN, 5. Auflage 2011; Peter J. Howard, An Introduction to Landscape, Ashgate/Abingdon/Oxon/Williston, VT: Routledge, 2011; Urszula Myga-Piątek, Krajobrazy kulturowe. Aspekty ewolucyjne i typologiczne [Kulturlandschaften. Aspekte der Evolution und Typologie], Katowice: Uniwersytet Śląski, 2012; Ken Taylor und Jane Lennon, Managing Cultural Landscapes, London: Routledge, 2012; IRS Aktuell. Newsletter for Social Science-Based Spacial Research, Heft: Historical Research in the Context of Spatial Social 
Die räumliche und wirtschaftliche Expansion des Menschen führt dazu, dass immer größere Gebiete anthropogene Landschaften sind, die wir als Kulturlandschaften bezeichnen. Gegenstand dieses Artikels ist nicht, den geografischen Kulturlandschaftsbegriff, seine Operationalisierung, Forschungskonzepte und Analysemethoden zur Diskussion zu stellen. Um Missverständnisse zu vermeiden, möchte ich im Folgenden dennoch für diesen Beitrag wichtige Begriffe definieren.

Anknüpfend an Lev Simonovič Berg $(1947)^{3}$ bezeichne ich Landschaft als die Summe der typischen Merkmale eines Ausschnitts der Erdoberfläche, dessen Einzelbestandteile sich zu einem interdependenten Ganzen fügen und der sich von den umliegenden Gebieten unterscheidet. ${ }^{4}$ Kulturlandschaft wiederum ist eine "vom Menschen infolge der zivilisatorischen Entwicklung umgestaltete Landschaft ${ }^{5}{ }^{5}$

Auf für diesen Beitrag wesentliche Eigenschaften von Landschaft weisen zwei normative Akte hin. Die 2004 in Kraft getretene Europäische Landschaftskonvention definiert Landschaft als "vom Menschen als solches wahrgenommenes Gebiet, dessen Charakter das Ergebnis des Wirkens und Zusammenwirkens natürlicher und/oder anthropogener Faktoren ist « (meine Hervorhebung). ${ }^{6}$ Neben einem materiellen Verständnis von Landschaft ist also auch ein solches der subjektiven Wahrnehmung möglich. Dieses weist nichtmateriellen, semiotischen Bestandteilen der Landschaft besondere Bedeutung zu. Wie Florian Plit spreche ich von einer Richtung in der Geografie, die Kulturlandschaften real und semiotisch versteht. ${ }^{7}$ Im Unterschied zur allgemeinen Geografie befasst sich diese

Sciences, 7, December 2014), https://leibniz-irs.de/en/knowledge-transfer/transfer-publicati ons/irs-aktuell-en/historical-research-in-the-context-of-spatial-social-sciences/, zuletzt geprüft 8. September 2019; Marek Degórski, Katarzyna Ostaszewska, Andrzej Richling und Jerzy Solon, »Współczesne kierunki badań krajobrazowych w kontekście wdrażania Europejskiej Konwencji Krajobrazowej« [Zeitgenössische Richtungen der Landschaftsforschung bei der Umsetzung der Europäischen Landschaftskonvention], in: Przegląd Geograficzny 86, 3 (2014), 295-316. Ferner zahlreiche Nummern der Prace Komisji Krajobrazu Kulturwego Polskiego Towarzystwa Geograficznego [Arbeiten der Kommission für Kulturlandschaft der Polnischen Geographischen Gesellschaft].

3 Lev Semenovič Berg, Geografičeskie zony Sovetskogo Sojuza [Geografische Zonen der Sowjetunion], Moskau: Katalog Agrar, 1947.

4 Dazu auch Tadeusz Bartkowski, Metody badań geografii fizycznej [Forschungsmethoden der physischen Geografie], Warschau/Poznań: PWN, 1977; Tadeusz Stryjakiewicz, »Krajobraz antropogeniczny, przestrzenie kreatywne a turystyka« [Anthropogene Landschaft, kreativer Raum und Touristik], in: Krajobraz a turystyka. Prace Komisji Krajobrazu Kulturowego PTG 14 (2010), 52-62.

5 Myga-Piątek, Krajobrazy kulturowe, 17.

6 Council of Europe, »Europäisches Landschaftsübereinkommen. Florence. 20.X.2000«, Nichtamtliche Übersetzung, in: Sammlung europäischer Verträge- Nr. 176, https://www.coe.int/en/ web/conventions/full-list/-/conventions/rms/0900001680080630, zuletzt geprüft am 8. September 2019.

7 Plit, Krajobraz kulturowy, 48-56. 
Richtung mit den Bedeutungen von Landschaftsformen, nicht mit deren Beschreibung. ${ }^{8}$

Das polnische Gesetz über Denkmalschutz und Denkmalpflege von 2003 definiert Kulturlandschaft als einen »durch menschliches Handeln historisch gestalteten Raum, der Gebilde der Zivilisation sowie natürliche Bestandteile umfasst. $"{ }^{9}$ Diese Definition stellt eine Verbindung zu dem heute populären evolutionären Ansatz der Humangeografie her, Landschaft sozial konstituiert und in ständiger dynamischer Veränderung zu sehen. ${ }^{10}$ Theoretisch ist dieser Ansatz von der Konzeption der Pfadabhängigkeit (path dependence) inspiriert.

Diese Konzeption wird in ihren unterschiedlichen Varianten von James Mahoney ${ }^{11}$ und Krzysztof Gwosdz ${ }^{12}$ genauer beschrieben. In diesem Beitrag wird Entwicklungspfad im Anschluss an James Mahoney als Sequenz zeitlich geordneter und kausal verbundener Ereignisse verstanden, von denen jedes eine Reaktion auf frühere Ereignisse und Ursache späterer Ereignisse ist. Der Entwicklungspfad ist vielschichtig und sorgt dafür, dass sich Landschaft aus in verschiedenen Etappen gebildeten Schichten zusammensetzt. Jede dieser Schichten hat Einfluss darauf, in welchem Grade neue Schichten den alten hinzugefügt werden können. Bei Veränderungen der Kulturlandschaft spielen allerdings Wendepunkte (critical junctures) eine besondere Rolle, die bei einschneidenden Ereignissen wie Kriegen, politischen Entscheidungen wie der Änderung von Staatsgrenzen oder standortbezogenen Entscheidungen wie dem Bau von Verkehrslinien oder Industrieanlagen eintreten. Sämtliche Faktoren, die Veränderungen der Kulturlandschaft auslösen, sind in der Region Konin zu beobachten, die Gegenstand dieser Fallstudien ist.

8 Steve Hinchliffe, ")Inhabiting Landscapes and Natures«, in: Kay Anderson, Mona Domosh, Steve Pile und Nigel Thrift (Hg.), Handbook of Cultural Geography, London/Thousand Oaks/ New Delhi: Sage Publ., 2003, 207-225.

9 »Ustawa z dnia 23 lipca 2003 r. o ochronie zabytków i opiece nad zabytkami« [Gesetz vom 23. Juli 2013 über Denkmalschutz und -pflege], in: Dziennik Ustaw [Gesetzblatt] 2003, Nr. 182, Position 1568; Hervorhebung des Verfassers.

10 Dieser Ansatz eignet sich für die interdisziplinäre geografische und historische Forschung.

11 James Mahoney, »Path dependence in historical sociology«, in: Theory and Society 29 (2000), 507-548.

12 Krzysztof Gwosdz, »Koncepcja zależności od ścieżki (path dependence) w geografii społeczno-ekonomicznej « [Die Konzeption der Pfadabhängigkeit in der sozioökonomischen Geografie], in: Przegląd Geograficzny 76, 4 (2004), 433-456. 


\section{Die Region}

Konin: eine adrette, angenehme Kleinstadt nahe der deutschen Grenze. Gelegen an einem Fluss mit einer Holzbrücke. In der Nähe Wiesen, Gärten und Wälder. Im Winter liefen die Einwohner Schlittschuh auf dem zugefrorenen Fluss. Im Sommer spazierten sie durch den Stadtpark, wo sonntagnachmittags manchmal das Feuerwehrorchester spielte. In der Stadt waren russische Soldaten kaserniert, die schicken Rittmeister der Kavallerie erhöhten die Umsätze der jüdischen Läden.

So stellt Theo Richmond die Stadt am Anfang seines Buches Konin. A Quest dar. ${ }^{13}$ Dieses Buch beschreibt die Kulturlandschaft von Konin aus der Sicht eines jüdischen Beobachters, dessen Familie die Stadt unmittelbar vor dem Ersten Weltkrieg verließ und der aus Neugier und motiviert von Erinnerungen seiner Vorfahren drei Generationen danach zurückkehrt, um »die Flussufer, Wiesen, Gärten und Wälder zu erkunden [...], jede Straße kennenzulernen, jede Ecke, jedes Haus [...], sich auf die Stadt, wie sie einst war, zu konzentrieren, ihre Bewohner, auf die Prinzipien und Werte, die ihr Leben bestimmten [...], vor allem aber auf den Geschmack und das Kolorit ihres alltäglichen Lebens. ${ }^{14}$ Dieses Buch werde ich nutzen, um Ausmaß und Art der Veränderungen der Kulturlandschaft nachzuzeichnen und eine Landschaft zu zeigen, die es nicht

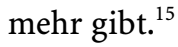

Um 1800 war Konin eine am linken Wartheufer gelegene Grenzstadt mit etwa 8.000 Einwohnern, von denen fast die Hälfte Juden waren. Heute ist Konin eine Stadt mit 75.000 Einwohnern, die für ihre Braunkohlegruben und -kraftwerke bekannt ist. Die Großindustrie prägt die Kulturlandschaft der ganzen Region. Die Grenze zwischen dem preußischen und dem russischen Teilungsgebiet verschwand vor einhundert Jahren, dennoch sind ihre Spuren nach wie vor im Raum sichtbar. Daher ist Konin mit seiner Umgebung ein gutes Beispiel für die Veränderung der Kulturlandschaft auf verschiedenen Ebenen. In diesem Text will ich mich auf zwei Aspekte konzentrieren: erstens Veränderungen der städtebaulichen Struktur und der Stadtlandschaft sowie zweitens Veränderungen der Industrielandschaft und der Industriebrachen in der Umgebung von Konin.

13 Auf polnisch unter dem Titel Uporczywe echo. Sztetl Konin. Poszukiwanie [Das hartnäckige Echo. Das Shtetl Konin. Eine Suche], Poznań: Media Rodzina, 2001, 21.

14 Ebd., 13.

15 Ein anderes literarisches Werk, in dem Konin einen wichtigen Platz einnimmt, ist Jarosław Iwaszkiewicz' Podróże do Polski [Polenreisen], Poznań: Zysk i S-ka, 2009. Richmonds Buch bietet jedoch ein besseres Bezugssystem, um die Veränderungen der Kulturlandschaft aufzuzeigen. 


\section{Veränderungen der städtebaulichen Struktur und der Stadtlandschaft}

Die Anfänge Konins und seine heutige Physiognomie sind eng mit der Warthe verbunden. Sehr wahrscheinlich gab es hier bereits im 1. Jahrhundert n. Chr. eine Siedlung an der Bernsteinroute von Kalisch nach Kruschwitz. ${ }^{16}$ Aus dem Mittelalter ist ein Objekt des historischen Konin erhalten: eine zweieinhalb Meter hohe Säule aus Sandstein mit der lateinischen Majuskelinschrift, dass diese Säule im Jahre 1151 auf der Hälfte des Weges zwischen Kalisch und Kruschwitz aufgestellt wurde, etwa 52 Kilometer von beiden Ortschaften entfernt. Es ist dies das älteste Verkehrszeichen in Polen; seine Herkunft ist nach wie vor ungeklärt.

Die Stadtgründung erfolgte nach Magdeburger Stadtrecht wahrscheinlich 1293. Die stadtgeschichtlichen Anfänge beruhen auf einer Siedlung, die etwa vier Kilometer südlich der heutigen Stadt am linken Wartheufer lag. Jedoch erfolgte sehr bald eine räumliche Verschiebung (Translokation) hin zu einer alten Marktsiedlung. ${ }^{17}$ Dieser Teil der Stadt, das heutige Alt-Konin, hat seinen mittelalterlichen Grundriss bewahrt. Das Schloss und die Stadtmauern aus der Zeit Kasimirs des Großen, die über viele Jahre eine landschaftliche Dominante darstellten, blieben jedoch nicht erhalten. Der Umriss der heutigen städtebaulichen Struktur von Alt-Konin geht auf das Regulierungsprojekt Karol Ziółkowskis aus dem 19. Jahrhundert zurück, aufgrund dessen beschädigte Gebäude abgerissen, die Bebauungslinie ausgeglichen, ein neues Straßennetz entworfen und die alten Straßen begradigt und verbreitert wurden. Trotz dieser Bebauungsmaßnahmen wurde die mittelalterliche Raumordnung nicht nur belassen, sondern in ihren Umrissen sogar gefestigt, sodass diese bis heute bewahrt werden konnte. ${ }^{18}$

Der Stadtteil am rechten Wartheufer, der heute Neu-Konin genannt wird, entwickelte sich nach dem Zweiten Weltkrieg. Der den Entwicklungspfad völlig neu ausrichtende Wendepunkt war der Beschluss, die Braunkohlevorkommen in der Region industriell zu nutzen, getroffen vom Wirtschaftskomitee des Ministerrats der Volksrepublik Polen 1949. Die diesem Beschluss folgenden Entscheidungen über den Beginn des Braunkohletagebaus, den Bau eines Kraftwerks, einer Aluminiumhütte und der begleitenden Investitionen verän-

16 Piotr Rybczyński, Spacerkiem w przeszłość. Szkice z dziejów Konina [Zu Fuß in die Vergangenheit. Skizzen zur Geschichte von Konin], Konin: Apeks, 1997; Piotr Maluśkiewicz, Województwo Konińskie. Szkic Monograficzny [Die Wojewodschaft Konin. Monografische Skizze], Warschau/Poznań: PWN, 1983; Anna Plenzler, "Konin i ziemia konińska« [Konin und das Koniner Land], in: dies., Wielkopolska, [Großpolen], Olszanica: Bosz, 2008.

17 Plenzler, »Konin i ziemia konińska« [Konin und das Koniner Land], VII.

18 Piotr Rybczyński, „Nowe oblicze konińskiej Starówki« [Das neue Antlitz der Altstadt von Konin], in: Józef Orczyk (Hg.), Rocznik koniński, Band 14, Konin: PWSZ, 2003, 267-273. 
derten sowohl das sozioökonomische Profil als auch die Kulturlandschaft von Stadt und Region. Der nächste Entwicklungsimpuls war die Schaffung einer Wojewodschaft mit Sitz in Konin im Jahre 1975. Infolgedessen wuchs die Einwohnerzahl der Stadt von 12.000 im Jahre 1959 auf fast 84.000 im Jahre 1998; Ende 2017 lag sie bei 75.000. Zwischen 1945 und 1986 wurden einige Male die Verwaltungsgrenzen der Stadt verändert, wodurch sich ihre Fläche von etwa $20 \mathrm{~km}^{2}$ im Jahre 1960 auf über $80 \mathrm{~km}^{2}$ heute vervierfachte. Folge dieser Entwicklung war die Entstehung mindestens dreier voneinander getrennter Siedlungszentren, die sich in Physiognomie und Funktion unterscheiden. Es sind dies Alt-Konin, Neu-Konin und der nördliche industrielle Teil mit dem Dorf Gosławice. Das heutige Konin ist daher eine schwach integrierte Stadt auf relativ großer Fläche. ${ }^{19}$

Derart radikale Veränderungen brachten selbstverständlich eine vollständig neue Kulturlandschaft hervor. Ich möchte diese Veränderungen hier auf zweifache Weise skizzieren: zum einen mit einer kontrastiven Methode, die reale Landschaftsveränderungen anhand von Grafiken und Fotos vorstellt; zum anderen gestützt auf Berichte von Zeitzeugen aus Theo Richmonds Buch, also mittels einer semiotischen Analyse. Hierbei richte ich das Augenmerk auf Veränderungen der Kulturlandschaft durch Stadtplanung und Bebauungsformen.

Während die städtebauliche Struktur von Alt-Konin durch Regelmäßigkeit und Harmonie geprägt ist, herrscht im neuen Stadtteil städtebauliches Chaos. Über diese Unterschiede sagt Izzy Hahn, der vor dem Krieg in Konin lebte und 1988 als Besucher zurückkehrte:

Die Bandbreite der Architektur des Marktplatzes ${ }^{20}$ spiegelt das Gedeihen Konins in der ersten Hälfte des 19. Jahrhunderts wider. Das Kopfsteinpflaster ist verschwunden. Wo einst in der Mitte des Platzes die Pumpen standen, befinden sich jetzt von der Stadt angelegte Rosenbeete. Aber im Grunde hat sich der Marktplatz nicht verändert. Die neoklassizistischen Fassaden blieben unangetastet, in einem der Giebel ist die Jahreszahl 1840 eingemeißelt, bei einer anderen Fassade führen Steintreppen von zwei Seiten zu einem hübschen Portikus. Statt kalter architektonischer Einheitlichkeit gibt es hier eine Mischung von Bauweisen, eine Anhäufung von Stilen, wie man ihr manchmal in englischen Kleinstädten begegnet. ${ }^{21}$

Andererseits verzeichnen Izzy Hahn wie auch Theo Richmond einen immensen Wertverlust der Kulturlandschaft im ehemaligen Judenviertel:

19 Marek Ciesielski, »Koniński Zespół Produkcyjno-Osadniczy. Relikt okresu intensywnej industrializacji czy realny szkielet regionu?» [Der Produktions- und Siedlungskomplex von Konin. Relikt der Zeit intensiver Industrialisierung oder realer Rückhalt der Region?], unveröffentlichte Magisterarbeit am Institut für Sozioökonomische Geografie und Raumwirtschaft der Adam-Mickiewicz-Universität Poznań, 2009.

20 Gemeint ist der Große Markt, heute Plac Wolności.

21 Richmond, Uporczywe echo, $448 \mathrm{f}$. 
Das stärkste Gefühl von Verlust erfasste mich auf dem Tepper Markt, dem heutigen Schlossplatz, auf dem die jüdische Besiedlung in Konin begonnen hatte. Ich werde hier den alten Namen verwenden: Er ist Teil meiner Kindheit, und ich kenne keinen Einwohner von Konin, der sich beim Hören dieser beiden Worte nicht voller Schmerz an die vergangenen Zeiten erinnern würde.

Jene Koniner würden den Tepper Markt nicht wiedererkennen, auf den ich geschaut habe. Die eine Seite des Platzes wurde abgerissen, wodurch die Piaseczna-Straße, einstmals separat, heute die Südseite des auf das Doppelte vergrößerten Marktplatzes bildet. Es gibt kein menschliches Maß mehr. Dutzende Häuser haben das Schicksal ihrer Bewohner geteilt und sind von der Erdoberfläche verschwunden. Der Vandalismus der Nazis, Jahre der Vernachlässigung, unklare Eigentumsverhältnisse, löchrige Dächer - all das hat zu Verfall, Degeneration und Abbruch beigetragen.

Die verbliebenen drei Seiten des alten Markts bieten einen trübseligen Anblick: ein mit Brettern vernageltes, rußgeschwärztes Haus, ein Büdchen aus Fertigteilen, leere Grundstücke, wo einst die abgerissenen Häuser standen und keine neuen entstanden sind. Ein neues Gebäude, dessen Stil nicht zu den Nachbarhäusern passt, ist anstelle des Hauses der Familie Gluba errichtet worden, das früher das prächtigste Gebäude am Marktplatz war. Alles zusammen bietet einen unzusammenhängenden, zerrissenen Anblick, als ob der Rest des alten Tepper Markts nur darauf warte, dass der nächste Bautrupp den Abriss zu Ende bringt. ${ }^{22}$

Für Neu-Konin bleibt vollends nur harsche Kritik übrig; es sei ein »Geschöpf bürokratischer Planung, entworfen ohne Gefühl«:

Von einem Fenster im siebten Stock schaute ich auf Neu-Konin. Die internationale architektonische Sprache des Banalen hat die Stadt jeglicher Individualität beraubt [...] Die anonymen Straßen unter mir, die Betonblocks und die Aluminiumhütte haben mit meinem Konin nichts gemeinsam. ${ }^{23}$

Die größten Kontraste in der Koniner Kulturlandschaft tun sich beim Wohnungsbau auf. Innerhalb der Stadtgrenzen haben sich noch Enklaven der alten Gehöftbauten erhalten, andererseits entstanden ausgedehnte, standardisierte Siedlungen mit mehrstöckigen Blocks, so z. B. die Siedlung Va an dem Ort, an dem sich früher das Dorf Czarków befand. Die Funktionen der Warthe und ihrer Brücken in der Stadtlandschaft haben sich ebenfalls verändert; wiederum in den Worten von Theo Richmond:

Wir gingen nach oben, und vor uns erstreckte sich der Fluss, sich nach Westen durch eine unberührte Landschaft flacher Wiesen schlängelnd. Dunkle Büschel von Schilfrohr und wilden Blumen glätteten die Uferlinien. Ein einsamer Angler neigte sich nach vorne und starrte auf ein Floß. [...] Im Osten verlor die Landschaft ihren zeitlosen Charakter. Anstelle der alten Holzbrücke [...] gab es einen modernen, stählernen Steg; ein Stück dahinter die Straßenbrücke, über welche die Hauptstraße von Posen nach

22 Ebd., $452 \mathrm{f}$.

23 Ebd., $441 \mathrm{f}$. 
Warschau verläuft, und noch weiter, Richtung Glinka, die Masten der Überlandleitung und andere Merkmale der Industrie. ${ }^{24}$

In jüngster Zeit sind Eingriffe in die Kulturlandschaft durch Versuche geprägt, alte und neue Stadtteile stärker zu integrieren und eine Revitalisierung in Gang zu setzten, wofür Subventionen der Europäischen Union eine starke Stimulanz bilden. 2007 verabschiedete der Stadtrat das »Integrierte Lokale Revitalisierungsprogramm für die Jahre 2007 bis 2015 « mit dem Ziel, »die Schaffung neuer gesellschaftlicher, wirtschaftlicher, touristischer, kultureller und ökologischer Funktionen durch Regeneration des degradierten Stadtgebiets sowie Revitalisierung der ehemaligen Industrie- und Militärflächen zu unterstützen. « ${ }^{25}$

Die Revitalisierungsmaßnahmen gelten einzelnen Objekten und ausgewählten Flächen. So wurde beispielsweise ein Warthe-Boulevard geschaffen. Über lange Zeit war das Flussufer praktisch ungenutzt, vernachlässigt und vergessen. Die 2010 durchgeführte Revitalisierung schuf einen neuen öffentlichen Raum in Gestalt einer Promenade, wie es in Konin nicht viele gibt. 2012 zeichnete die Gesellschaft Polnischer Stadtplaner die Koniner Boulevards als besten neugeschaffenen öffentlichen Raum in Polen aus. ${ }^{26}$

Die Belebung des Wartheufers war Ansporn für weitere Revitalisierungsunternehmungen, die teilweise auch von Privatpersonen verwirklicht wurden. Ein Beispiel hierfür ist das Koniner Zollhaus, an dem im frühen 20. Jahrhundert der Brückenzoll entrichtet wurde. Im Laufe der Zeit wechselte das Gebäude mehrfach Besitzer und Bestimmung, bis es in den 1990er Jahren verfallen war; seither wurde es zu einem Restaurant umgebaut. So wie sich die Kulturlandschaft und ihre Funktionen verändern, verändern sich einzelne Objekte und ganze Stadtflächen. Das Beispiel zeigt, dass durch die Orientierung hin zum Fluss in jüngster Zeit auch naturnahe Landschaften wie die Wartheauen in eine anthropogene Form verwandelt werden. Wie solche Entwicklungen zu bewerten sind, hängt stark von der jeweiligen Perspektive ab.

24 Ebd., 445.

25 »Zintegrowany Lokalny Program Rewitalizacji Miasta Konina na lata 2007-2015« [Integriertes Lokales Programm zur Revitalisierung von Konin 2007-2015], Konin: Urząd Miejski w Koninie, 2011, https://docplayer.pl/4109680-Zintegrowany-lokalny-program-rewitali zacji-miasta-konina-na-lata-2007-2015.html, 99, zuletzt geprüft am 8. September 2019.

26 Justyna Błaszczyńska, »Obiekty i tereny niewykorzystane w przestrzeni Starego Konina“ [Ungenutzte Objekte und Gelände im Areal von Alt Konin], unveröffentlichte Magisterarbeit am Institut für Sozioökonomische Geografie und Raumwirtschaft der Adam-MickiewiczUniversität Poznań, 2015. 


\section{Veränderungen von Industrielandschaft und Industriebrachen nach dem Ende des Braunkohlentagebaus bei Konin}

Der Abbau von Braunkohle und ihre Verstromung in grubennahen Kraftwerken ist ein außergewöhnlich heftiger Eingriff in die Landschaft. Hier ist der Zusammenhang zwischen Veränderungen der Naturlandschaft besonders augenfällig, insbesondere in Bezug auf Geländerelief und Grundwasserspiegel und Entwicklung der Kulturlandschaft. Diese Veränderungen wurden anhand verschiedener Beispiele vielfach beschrieben. ${ }^{27}$ In diesem Abschnitt soll eine Synthese der wichtigsten Landschaftsveränderungen im Koniner Industrierevier folgen. Dabei wird zu beantworten sein, ob es sich um einen neuen Entwicklungspfad der Kulturlandschaft handelt oder aber um eine »Reproduktion des Entwicklungspfads « (path reproduction). ${ }^{28}$

Die Region Konin ist seit den 1950er Jahren mit Industrie assoziiert, doch reicht der Koniner Bergbau bis ins Mittelalter zurück. Damals wurden hier Sandund Kalkstein abgebaut. ${ }^{29}$ Bei der Ortschaft Brzeźno bestand bis ins 19. Jahrhundert ein großer Sandsteinbruch. Aus diesem Sandstein wurde die erwähnte Koniner Wegsäule gefertigt, ebenso wie viele Schmuckelemente von Sakralbauten in der gesamten Region. ${ }^{30}$

Die zweite Etappe des Koniner Bergbaus begann mit der Erschließung von Braunkohlevorkommen. Eine Braunkohlegrube in Brzeźno bestand offenbar bereits seit $1871 .^{31}$ Ihre wenig umfangreiche Förderung deckte den Bedarf der lokalen Ziegelei und Brennerei. 1916 entstand in Konin ein kleines Kraftwerk.

27 Tadeusz Stryjakiewicz, »Recycling przestrzeni w kontekście procesu przemian przemysłu i nowych teorii lokalizacji« [Raumrecycling im Kontext industriellen Wandels und neuer Lokalisierungstheorien], in: Jörg Gleisenstein u.a. (Hg.), Recykling przestrzeni, zagospodarowanie terenów poprzemysłowych i pomilitarnych, [Raumrecycling, Bewirtschaftung von Industrie- und Militärbrachen], Słubice: Collegium Polonicum, 2002, 14-19; Zbigniew Kasztelewicz und Maciej Zajączkowski, »Wpływ działalności górnictwa węgla brunatnego na otoczenie« [Der Einfluss der Braunkohlenförderung auf die Umgebung], in: Polityka Energetyczna 13, 2 (2010), 227-243. Siehe auch den Beitrag von Markus Schwarzer »Wandel von Kulturlandschaften durch den Braunkohletagebau" in diesem Band.

28 Robert Kloosterman und Eva Stegmeijer, "Cultural industries in the Netherlands. Pathdependent patterns and institutional context: The case of architecture in Rotterdam«, in: Petermanns Geographische Mitteilungen 148, 4 (2004), 68-75.

29 Zygmunt Kowalczykiewicz, Zaczęło się w Brzeźnie. Dzieje Kopalni Węgla Brunatnego »Konin« 1945-1995 [Es begann in Brzeźno. Geschichte des Braunkohlenbergwerks Konin 1945-1995], Konin: Kopalnia Węgla Brunatnego »Konin«, 1995.

30 Janusz Skoczylas und Marek Żyromski, Symbolika kamienia jako element procesu legitymizacji władzy w cywilizacji europejskiej [Die Symbolik des Steins bei der Herrschaftslegitimierung in der europäischen Zivilisation], Poznań: Wydawnictwo Naukowe UAM, 2005.

31 Kowalczykiewicz, Zaczęło się w Brzeźnie. 
Nach dem Ersten Weltkrieg setzten die Polen den Braunkohleabbau nicht fort, obwohl 1926 in Arnold Sariusz Makowskis geologischem Erkundungsbericht zwölf große Kohlefelder benannt wurden, deren Ausbeutung sich lohnen würde. 1934 wurde bei der Tongewinnung für die lokale Ziegelei auf dem Landgut Glinka (heute auf dem rechten Wartheufer von Konin) zufällig ein Kohlevorkommen mit einer Mächtigkeit von zwölf Metern entdeckt. Einige Jahre später wurde auf diesem Gelände der erste Tagebau für das Deutsche Reich eröffnet. Nach der Besetzung Polens untersuchten die Deutschen 1941/42 die Kohlevorkommen genauer, wozu über 1.500 Bohrungen ausgeführt wurden, zu denen Polen aus Arbeitslagern herangezogen wurden. ${ }^{32} 1942$ gründeten die Deutschen die "Braunkohlenwerke Wartheland « und nahmen einen Tagebau bei Morzysław (heute ein Stadtteil von Konin) in Betrieb. Das Gerät dazu holte man aus einem geschlossenen Tagebau bei Klettwitz in der Lausitz. Das Abbaugebiet wurde enteignet, die polnische Bevölkerung ausgesiedelt. 1944 entstanden die Braunkohlenwerke Brawag, die mit der Entwicklung eines Treibstoff- und Energiezentrums in Konin beginnen sollten. Damals entstand auch eine Brikettfabrik in Marantów; zuvor war die Brikettherstellung in Deutschland erfolgt. ${ }^{33}$

Das Ende des Zweiten Weltkriegs durchkreuzte die deutschen Pläne für den weiteren Ausbau des Treibstoff- und Energiekomplexes. Nach der Übernahme von Bergwerk, Brikettfabrik und Ziegelei Glinka durch den polnischen Staat folgte eine mehrjährige Übergangsphase vor dem wichtigsten Wendepunkt in der Entwicklung des Koniner Industriegebiets. ${ }^{34}$ Die Entwicklung dieses Bezirks war eine der zentralen Aufgaben des »Sechsjahresplans der wirtschaftlichen Entwicklung und der Errichtung der Grundlagen des Sozialismus in Polen« (1950-1955). Zu seiner Umsetzung wurden 1950 das Unternehmen Braunkohlegrube Konin sowie das Braunkohleverarbeitungswerk Konin gegründet. So wurden die großflächigen Veränderungen der Kulturlandschaft der Region eingeleitet. In den Folgejahren wurden weitere Braunkohlegruben in Betrieb genommen: Niesłusz (1953), Gosławice (1957), Pątnów (1962), Kazimierz (1965), Jóżwin (1971), Lubstów (1983), Drzewce (2005) und Tomisławie (2010). Die nicht mehr genutzten Gebiete umfassen eine Fläche von einigen Tausend Hektar. Das Ausmaß dieser Umwandlungen veranschaulicht am besten die

32 Ewa Galantkiewicz (Hg.), Wyimki: kronika 65-lecia Kopalni Węgla Brunatnego »Konin« [Exzerpte: Chronik des 65. Jahrestags des Braunkohlenbergwerks Konin], Bydgoszcz: Qax Manufaktura Artystyczna Katarzyna Janikowska, 2010.

33 Kowalczykiewicz, Zaczęło się w Brzeźnie.

34 Die Hauptprobleme dieser Zeit waren, dass die geologische Dokumentation von den Deutschen verschleppt worden war, polnische Kader keine Erfahrung mit Braunkohle hatten sowie das gesellschaftspolitische System gewaltsam verändert wurde; dazu gehörte die Unvereinbarkeit des Gesetzes zur Nationalisierung der Bergwerke von 1946 mit den Ansprüchen im Krieg enteigneter Besitzer. 
Größe des Abraums, also der Erdschicht über dem Kohlevorkommen, die seit Beginn des Tagebaus weggeschafft werden musste: über drei Milliarden $\mathrm{Ku}$ bikmeter. Dabei fiel fünfmal so viel Abraum an, wie Kohle abgebaut wurde. ${ }^{35}$ Es ist charakteristisch, dass mit sich verschlechternden Abbaubedingungen und dem Fortschritt der Fördertechnologie das Ausmaß der landschaftlichen Umgestaltungen immer stärker zunahm. Nur einige Beispiele: In Niesłusz (seit 1953 in Betrieb) entstanden $8.500 \mathrm{~m}^{3}$ Abraum, in der vier Jahre später in Betrieb genommenen Grube Gosławice $77.600 \mathrm{~m}^{3}$, in Kazimierz Południe und Jóźwin IIA (seit 1965 bzw. 1971) etwa $740.000 \mathrm{~m}^{3}$. Sichtbarste landschaftliche Effekte dieser Erdumwälzungen sind die Veränderungen des Geländereliefs (Halden, Gruben) sowie der Flora (die Halden sind oft mit Birkenwäldern bewachsen) und der Wasserverhältnisse durch die Absenkungstrichter. ${ }^{36}$

Bagger, Förderanlagen und Absetzer sind typische Bestandteile der Kulturlandschaft von Konin geworden. Dazu kommen die Schornsteine und Kühltürme der Kraftwerke Konin (seit 1958) und Pątnów (seit 1969). Diese Landschaft löste die traditionelle Agrarlandschaft und die dörfliche Besiedlung ab. Das hatte seinen Preis. Beispielsweise mussten für den Tagebau von Pątnów 110 ha Ackerland und 75 ha Wald aufgekauft und 220 Familien umgesiedelt werden. Für den Tagebau Kazimierz Południe wurden über 156 ha Land gekauft und 24 ha Gehöfte abgerissen. Zum Glück fiel wegen des hohen Denkmalwertes zweier Sakralkomplexe in der Ortschaft Kazimierz Biskupi, nämlich eine von Piotr Dunin gestiftete romanische Kirche aus dem 12. Jahrhundert sowie eine von Bischof Jan Lubrański gestiftete Kirche und ein Franziskanerkloster, die Entscheidung, auf die Ausbeutung der Hälfte des Vorkommens zu verzichten. ${ }^{37}$ Andererseits wurden beim Abbau viele archäologische Entdeckungen gemacht, die spektakulärste beim Tagebau Drzewce, wo im Zuge der weiteren Erkundung in den Jahren 1999 bis 2001 vom Bezirksmuseum Konin über 100 frühmittelalterliche Gräber und die Reste einer mittelalterlichen Siedlung in Pąchów gefunden wurden. ${ }^{38}$

Ein großes Problem der landschaftlichen Eingriffe in den Braunkohlegebieten sind die großen Abbauareale, die Rekultivierungsmaßnahmen erfordern. Hinzu kommt eine vielfältige industrielle Infrastruktur. Eine Wiederherstellung der

35 Zbigniew Kasztelewicz, Jarosław Czyż und Elżbieta Dwornik, »Sztuka górnicza w sześćdziesięcioleciu KWB `Konin «" [Die Bergbaukunst beim 60. Jahrestag des Braunkohlenbergwerks Konin], in: Wegiel Brunatny 53, 4 (2005), 23-29.

36 Seit Eröffnung des Bergwerks Konin wurden daraus 4,5 Mrd. $\mathrm{m}^{3}$ Wasser abgepumpt; Kasztelewicz und Zajączkowski, »Wpływ«.

37 Krzysztof Kubajewski, »Odkrywka `Kazimierz` przechodzi do historii« [Tagebau »Kazimierz« wird Geschichte], in: Wegiel Brunatny 76, 3 (2011), 23-28, siehe auch http://www.ppwb. org.pl/Static/upload/File/wegiel_76_3_2011.pdf, zuletzt geprüft am 11. September 2019.

38 Krzystof Gorczyca und Lucyna Mazurek, »Prace archeologiczne na terenie odkrywki >Drzewce«" [Archäologische Arbeiten auf dem Erschließungsgelände "Drzewce«], in: Węgiel Brunatny 53, 4 (2005), 30-32. 
ursprünglichen Landschaft ist meist nicht möglich. Die Rekultivierung bietet ein neues Tätigkeitsfeld: das Landschaftsmanagement, dazu gehörig das Kulturlandschaftsmanagement. ${ }^{39}$

Die Braunkohlegrube Konin ist in Polen ein Pilotprojekt für die Rekultivierung von Tagebauflächen, denn noch bevor die ersten Gesetze zur Rekultivierung und Nutzung von Industriebrachen in Kraft traten, begann hier die Arbeit. In der Reihenfolge der Flächengröße wird durch Aufforstung, Schaffung von Wasserflächen sowie Schaffung von Ackerland rekultiviert. Auch die Nutzung für Erholung und Sport nimmt zu. Allerdings mangelt es der in Konin vom Menschen geschaffenen Kulturlandschaft an Kulturelementen wie Bühnen für künstlerische Events oder Ausstellungsorte für Kunst.

\section{Veränderungen der Kulturlandschaft von Konin und Umgebung: Synthese und Ausblick}

Der folgende Versuch einer Synthese der Entwicklung der Kulturlandschaft von Konin und Umgebung bedient sich der Begriffe der Pfadabhängigkeit und des landschaftsbildenden Zyklus, der vor allem in der physischen Geografie und besonders der Geomorphologie verwendet wird. ${ }^{40}$ Bei den Veränderungen der Kulturlandschaft können vier Gestaltungsbereiche der untersuchten Landschaft unterschieden werden, von denen jeder eine Spezifik aufweist, die ich landschaftsbildende Zyklen nenne. Diese Zyklen und ihre wichtigsten Merkmale sind in Tabelle 1 dargestellt.

Tabelle 1. Landschaftsbildende Zyklen von Konin und Umgebung

\begin{tabular}{|c|c|c|}
\hline Zeitraum & Stadt Konin & Region Konin \\
\hline Mittelalter & $\begin{array}{l}\text { regelmäßige Raumordnung, ge- } \\
\text { schlossene Holzbebauung, } \\
\text { gemauerte Burg, Übergang über die } \\
\text { Warthe an wichtigem Handelsweg }\end{array}$ & $\begin{array}{l}\text { Agrarregion, Wälder, Feucht- } \\
\text { wiesen, Förderung des Sandsteins } \\
\text { von Brzeźce für Bauzwecke; erste } \\
\text { Klöster (Benediktiner in Kazimierz) }\end{array}$ \\
\hline $\begin{array}{l}\text { 17.-18. Jahr- } \\
\text { hundert }\end{array}$ & $\begin{array}{l}\text { Entwicklungsrückschritte und } \\
\text { Zerstörung durch Pestwellen und } \\
\text { Bevölkerungsverlust, Brände sowie } \\
\text { Kriegshandlungen während der } \\
\text { schwedischen Invasion } \\
\text { (1655-1660), des Nordischen Kriegs } \\
\text { (1700-1721) und des } \\
\text { Siebenjährigen Kriegs (1756-1763) }\end{array}$ & $\begin{array}{l}\text { Entwicklungsrückschritte und } \\
\text { Zerstörung durch Pestwellen und } \\
\text { Bevölkerungsverlust, Brände sowie } \\
\text { Kriegshandlungen in der Zeit der } \\
\text { schwedischen Invasion } \\
\text { (1655-1660), des Nordischen Kriegs } \\
\text { (1700-1721) und des } \\
\text { Siebenjährigen Kriegs (1756-1763) }\end{array}$ \\
\hline
\end{tabular}

39 Ken Taylor und Jane Lennon, Managing Cultural Landscape, London: Routledge, 2012.

40 Diese Synthese bezieht sich vor allem auf die reale (materielle) Schicht von Landschaft, in geringerem Maße betrifft sie ihre semiotische Schicht. 


(Fortsetzung)
\begin{tabular}{|l|l|l|}
\hline Zeitraum & Stadt Konin & Region Konin \\
\hline $\begin{array}{l}\text { 19. und erste } \\
\text { Hälfte des } \\
\text { 20. Jahrhun- } \\
\text { derts }\end{array}$ & $\begin{array}{l}\text { Umsetzung des Regulierungs- } \\
\text { plans; Entstehung zahlreicher } \\
\text { Handwerksbetriebe und Klein- } \\
\text { industrie; Garnisonsbebauung; } \\
\text { jüdisches Viertel }\end{array}$ & $\begin{array}{l}\text { Entstehung zahlreicher Betriebe } \\
\text { der Agrar- und Lebensmittel- } \\
\text { industrie (Zuckerfabrik } \\
\text { Gosławice, Brennereien, Getreide- } \\
\text { und Windmühlen) sowie einer } \\
\text { Ziegelei }\end{array}$ \\
\hline $\begin{array}{l}\text { 1950er Jahre } \\
\text { bis heute }\end{array}$ & $\begin{array}{l}\text { Entstehung des neuen Konin am } \\
\text { rechten Wartheufer mit typischer } \\
\text { sozialistischer Bebauung; Zer- } \\
\text { siedlung in nördlicher Richtung; } \\
\text { neues Profil als Industriestadt }\end{array}$ & $\begin{array}{l}\text { Umwandlung großer Flächen durch } \\
\text { Tagebau und Energiewirtschaft; } \\
\text { Rekultivierung von Tagebau- } \\
\text { brachen; u. a. Hochspannungs- } \\
\text { leitungen und Verkehrslinien } \\
\text { werden prägend }\end{array}$ \\
\hline
\end{tabular}

Die Entwicklungspfade der Kulturlandschaft von Konin und Umgebung legen einige Schlussfolgerungen nahe:

1. Die 1950er Jahre brachten den wichtigsten Wendepunkt auf diesem Entwicklungspfad. Die damaligen Entscheidungen zum Bau eines großen Treibstoffund Energiekomplexes veränderten den Landschaftstyp und den Grad ihrer Umgestaltung durch den Menschen. Diese Veränderungen sind sowohl auf materieller wie auf semiotischer Ebene (z. B. Bestandteile der bergmännischen Kultur und Tradition) sichtbar. Hauptakteure der Gestaltung oder vielmehr Schaffung der Kulturlandschaft waren die Bergbau- und Energieunternehmen.

2. Die heutige Kulturlandschaft von Konin und Umgebung ist eine solche der Kontraste. Einerseits gibt es noch Relikte der alten landschaftsbildenden Zyklen wie die Koniner Altstadt, das Schloss in Gosławice oder die Kirchen in der Altstadt, in Kazimierz Biskupi und in Bieniszew, andererseits existieren neue industrielle Dominanten in der Kulturlandschaft. Auch auch hier gibt es ein modernes Gegengewicht. So sind die neue Basilika und das Sanktuarium der Gottesmutter von Licheń in Stary Licheń prägende Veränderungen der Kulturlandschaft. Diese Konstruktion mit einem 156 Meter hohen Turm - eines der größten Sakralobjekte weltweit - konkurriert in ihrer Realdimension mit den sich unweit befindenden Baggern und Absetzern. In der symbolischen Dimension kontrastieren die Massen der Pilger und ihre Wallfahrtsinfrastruktur mit der Stille und der »kulturellen Entfremdung « des Kamaldulenserklosters im nahen Bieniszew. Kontraste sieht man auch auf den Dörfern, wo sich die Höfe der Menschen, die ihren Lebensunterhalt durch Arbeit in der Industrie verdienen, oft von denen unterscheiden, für die Landwirtschaft noch immer die Haupteinkommensquelle ist.

3. Die Rekultivierung der Bergwerksbrachen trägt zur Verbesserung einer Landschaft bei, die als durch die industrielle Nutzung entwertet gilt. Andererseits tauchen dadurch neue Landschaftmerkmale auf, z.B. Wälder und 
Seen mit ausgedehnten Erholungszonen, sowie dem Flachland fremde Elemente wie Skihänge, die jedoch die Attraktivität der Gegend für Einheimische wie Touristen erhöhen. Eine eindeutige Bewertung dieser Veränderungen ist schwierig. Was aber ist mit dem genius loci von Konin? Inwiefern unterscheidet sich Konin heute etwa von vergleichbaren Zentren der Braunkohleförderung und der Energieindustrie wie Bełchatów oder Bogatynia?

Wie gezeigt, vollzieht die Kulturlandschaft von Konin und Umgebung eine dynamische Entwicklung. Somit stellt sich die nächste Frage: Welche Veränderungen sind in der nächsten Zukunft zu erwarten? Ein in der letzten Zeit vieldiskutiertes Problem ist der abnehmende Wasserspiegel. Der Wasserstand im See von Wilczyn ist in den letzten zehn Jahren um vier Meter gesunken, der Wasserspiegel hat sich in derselben Zeit um etwa 100 Hektar verkleinert. Die Nutzung von Grubenwasser zur Versorgung des Sees soll der weiteren Absenkung des Wasserspiegels dieses Gewässers im Powidz-Landschaftspark entgegenwirken. Eine große Rohrleitung soll Wasser aus dem Bergwerk von Konin in den See leiten. ${ }^{41}$ Dies ist nicht der erste solche Fall, ähnliche Probleme hat z. B. Ościsłów. Große Rohrleitungen werden also schon bald stärker als bisher die Landschaft prägen.

Um Wasser geht es auch bei den Plänen für eine Neuausrichtung von Konin und Umgebung nach Erschöpfung der Braunkohlevorkommen. Diese sehen die Nutzung geothermaler Wasservorkommen vor, die in diesem Gebiet entdeckt wurden. Sie befinden sich in einer Tiefe von $2.500 \mathrm{~m}$ und haben eine Temperatur von $95^{\circ} \mathrm{C}$; die Quellen stoßen $400 \mathrm{~m}^{3}$ in der Stunde aus. Zu der geplanten Kulturlandschaft würden sowohl ein Heizkraftwerk als auch Heil- und Erholungseinrichtungen mit Thermalbecken gehören, wie es sie etwa am Posener Maltasee oder im nahegelegenen Uniejów gibt. Die Kulturlandschaft eines Kurortes würde hier besonders scharf mit der bisherigen Industrielandschaft kontrastieren.

Es ist zudem nicht auszuschließen, dass Konin zukünftig gerade aufgrund solcher neuen Attraktionen Schriftsteller und Künstler anlocken kann. Die Relikte der Industrielandschaft, wie etwa die gigantischen Bagger, könnten für sie zur Inspirationsquelle werden. ${ }^{42}$ Diese Vorstellung scheint gegenwärtig noch fantastisch. Es besteht aber kein Zweifel, dass nach dem Ende des Braunkohletagebaus auf dem Entwicklungspfad der Kulturlandschaft von Konin und Umgebung ein weiterer Wendepunkt folgen wird, sollte nicht die Energiepolitik der

41 »Wielka rura na ratunek« [Große Rohrleitung soll aus der Not helfen], in: Monitor Wielkopolski 167, 4 (2015), 6, http://www.monitorwielkopolski.pl/pl/download/upload/articles/ numery/pdf/2013_od_06/2015_pdf_4.pdf, zuletzt geprüft am 9. September 2019).

42 Vor einigen Jahren habe ich im ehemaligen deutschen Braunkohlerevier von Lichterfeld in Brandenburg eine Vorstellung von Verdis Oper »Aida" gesehen, in der ein wichtiges Element des Bühnenbilds ein ebensolcher Bagger war. 
Europäischen Union diesen schon früher erzwingen. Daher sollte schon heute die Diskussion über mögliche Zukunftsszenarien beginnen.

Aus dem Polnischen von Markus Krzoska

\section{Literatur}

Baker, Alan R. H. Geography and History. Bridging the Divide, Cambridge: Cambridge University Press, 2003.

Bartkowski, Tadeusz. Metody badań geografii fizycznej [Forschungsmethoden der physischen Geografie], Warschau/ Poznań: PWN, 1977.

Berg, Lev Semenovič. Geografičeskie zony Sovetskogo Sojuza [Geografische Zonen der Sowjetunion], Moskau: Katalog Agrar, 1947.

Błaszczyński, Jerzy. "Obiekty i tereny niewykorzystane w przestrzeni Starego Konina" [Ungenutzte Objekte und Gelände im Areal von Alt Konin], unveröffentlichte Magisterarbeit am Institut für Sozioökonomische Geografie und Raumwirtschaft der AdamMickiewicz-Universität Poznań, 2015.

Ciesielski, Marek. »Koniński Zespół Produkcyjno-Osadniczy. Relikt okresu intensywnej industrializacji czy realny szkielet regionu? [Der Produktions- und Siedlungskomplex von Konin. Relikt der Zeit intensiver Industrialisierung oder realer Rückhalt der Region?], unveröffentlichte Magisterarbeit am Institut für Sozioökonomische Geografie und Raumwirtschaft der Adam-Mickiewicz-Universität, 2009.

Council of Europe. "Europäisches Landschaftsübereinkommen. Florence. 20.X. 2000«, Nichtamtliche Übersetzung, in: Sammlung europäischer Verträge - Nr. 176, https:// www.coe.int/en/web/conventions/full-list/-/conventions/rms/0900001680080630, zuletzt geprüft am 8. September 2019.

Degórski, Marek, Katarzyna Ostaszewska, Andrzej Richling und Jerzy Solon. »Współczesne kierunki badań krajobrazowych w kontekście wdrażania Europejskiej Konwencji Krajobrazowej« [Zeitgenössische Richtungen der Landschaftsforschung bei der Umsetzung der Europäischen Landschaftskonvention], in: Przegląd Geograficzny 86, 3 (2014), 295-316.

Galantkiewicz, Ewa (Hg.). Wyimki: kronika 65-lecia Kopalni Wegla Brunatnego "Konin" [Exzerpte: Chronik des 65. Jahrestags des Braunkohlenbergwerks Konin], Bydgoszcz: Qax Manufaktura Artystyczna Katarzyna Janikowska, 2010.

Gorczyca, Krzysztof und Lucyna Mazurek. "Prace archeologiczne na terenie odkrywki >Drzewce« [Archäologische Arbeiten auf dem Erschließungsgelände »Drzewce«], in: Wegiel Brunatny 53, 4 (2005), 30-32.

Gwosdz, Krzysztof. »Koncepcja zależności od ścieżki (path dependence) w geografii społeczno-ekonomicznej “ [Die Konzeption der Pfadabhängigkeit in der sozioökonomischen Geografie], in: Przegląd Geograficzny 76, 4 (2004), 433-456.

Hettner, Alfred. Geographie, ihre Geschichte, ihr Wesen und ihre Methoden, Breslau: Hirt, 1927. 
Hinchcliffe, Steve. ")Inhabiting Landscapes and Natures«, in: Handbook of Cultural Geography, Kay Anderson, Mona Domosh, Steve Pile und Nigel Thrift (Hg.), London/ Thousand Oaks/New Delhi: Sage, 2003, 207-225.

IRS Aktuell. Newsletter for Social Science-Based Spatial Research, Heft: Historical Research in the Context of Spatial Social Sciences, 7, December 2014, https://leibniz-irs.de/en/ knowledge-transfer/transfer-publications/irs-aktuell-en/historical-research-in-thecontext-of-spatial-social-sciences/, zuletzt geprüft am 17. September 2019.

Howard, Peter J. An Introduction to Landscape, Ashgate/Abingdon/Oxon/Williston, VT: Routledge, 2011.

Iwaszkiewicz, Jarosław. Podróże do Polski [Polenreisen], Poznań: Zysk i S-ka, 2009.

Kaluzkov, V. N. »Landšaft v kulturno-geografičeskich issledovanijach « [Landschaft in der kulturgeografischen Forschung], in: Izvestija RAN, Seria Geografičeskaja 4 (2008), 11-19.

Kasztelewicz, Zbigniew, Jarosław Czyż und Elżbieta Dwornik. „Sztuka górnicza w sześćdziesięcioleciu KWB Konin« [Die Bergbaukunst beim 60. Jahrestag des Braunkohlenbergwerks Konin], in: Węgiel Brunatny 53, 4 (2005), 23-29.

Kasztelewicz, Zbigniew und Maciej Zajączkowski. »Wpływ działalności górnictwa węgla brunatnego na otoczenie« [Der Einfluss der Braunkohlenförderung auf die Umgebung], in: Polityka Energetyczna 13, 2 (2010), 227-243.

Kloosterman, Robert und Eva Stegmeijer. „Cultural industries in the Netherlands. Pathdependent patterns and institutional context: The case of architecture in Rotterdam", in: Petermanns Geographische Mitteilungen 148, 4 (2004), 68-75.

Kowalczykiewicz, Zygmunt. Zaczęło się w Brzeźnie. Dzieje Kopalni Węgla Brunatnego "Konin« 1945-1995 [Es begann in Brzeźno. Geschichte des Braunkohlenbergwerks Konin 1945-1995], Konin: Kopalnia Węgla Brunatnego »Konin«, 1995.

Kubajewski, Krzysztof. »Odkrywka >Kazimierz` przechodzi do historii« [Tagebau »Kazimierz« wird Geschichte], in: Wegiel Brunatny, 76, 3 (2011), 23-28.

Mahoney, James. »Path dependence in historical sociology«, in: Theory and Society 29 (2000), 507-548.

Maluśkiewicz, Piotr. Województwo Konińskie. Szkic Monograficzny [Die Wojewodschaft Konin. Monografische Skizze], Warschau/Poznań: PWN, 1983.

Myga-Piątek, Urszula. Krajobrazy kulturowe. Aspekty ewolucyjne i typologiczne [Kulturlandschaften. Aspekte von Evolution und Typologie], Katowice: Uniwersytet Śląski, 2012.

Ostaszewska, Katarzyna. Geografia krajobrazu [Landschaftsgeografie], Warschau: Wydawnictwo Naukowe PWN, 2002.

Pietrzak, Maciej. »Ewolucja poglądów geograficznych na krajobraz« [Die Entwicklung geografischer Sichtweisen der Landschaft], in: Geografia jako nauka o przestrzeni, środowisku i krajobrazie. Band 1: Podstawowe idee i koncepcje w geografii [Geografie als Wissenschaft von Raum, Umwelt und Landschaft. Band 1: Grundideen und Konzeptionen in der Geografie], Wiesław Maik, Krystyna Rembowska und Andrzej Suliborski (Hg.), Łódź: Łódzkie Towarzystwo Naukowe 2005, 151-162.

Plenzler, Anna. Wielkopolska [Großpolen], Olszanica: Bosz, 2008.

Plit, Florian. Krajobraz kulturowy - czym jest? [Kulturlandschaft - was ist das?], Warschau: Uniwersytet Warszawski, Wydział Geografii i Studiów Regionalnych, 2011. 
Richling, Andrzej und Jerzy Solon. Ekologia krajobrazu [Ökologie der Landschaft], Warszawa: PWN, 5. Auflage 2011.

Richmond, Theo. Uporczywe echo. Sztetl Konin. Poszukiwanie [Das hartnäckige Echo. Das Shtetl Konin. Eine Suche], Poznań: Media Rodzina, 2001.

Rybczyński, Piotr. Spacerkiem w przeszłość. Szkice z dziejów Konina [Zu Fuß in die Vergangenheit. Skizzen aus der Geschichte Konins], Konin: Apeks, 1997.

Ders. »Nowe oblicze konińskiej Starówki« [Ein neues Antlitz der Koniner Altstadt], in: Rocznik koniński, Band 14, Józef Orczyk (Hg.), Konin: PWSZ, 2003, 267-273.

Skoczylas, Janusz und Marek Żyromski. Symbolika kamienia jako element procesu legitymizacji władzy w cywilizacji europejskiej, [Die Symbolik des Steins bei der Herrschaftslegitimierung in der europäischen Zivilisation], Poznań: Wydawnictwo Naukowe UAM, 2005.

Stryjakiewicz, Tadeusz. »Krajobraz antropogeniczny, przestrzenie kreatywne a turystyka" [Die anthropogene Landschaft, kreativer Raum und Touristik], in: Krajobraz a turystyka. Prace Komisji Krajobrazu Kulturowego PTG 14, 2010, 52-62.

Ders. »Recykling przestrzeni w kontekście procesu przemian przemysłu i nowych teorii lokalizacji« [Raumrecycling im Kontext industriellen Wandels und neuer Lokalisierungstheorien], in: Recykling przestrzeni, zagospodarowanie terenów poprzemysłowych i pomilitarnych [Raumrecycling, Bewirtschaftung von Industrie- und Militärbrachen], Jörg Gleisenstein u. a. (Hg.), Słubice: Collegium Polonicum, 2002, 14-19.

Taylor, Ken und Jane Lennon. Managing Cultural Landscape, London: Routledge, 2012. »Ustawa z dnia 23 lipca 2003 r. o ochronie zabytków i opiece nad zabytkami« [Gesetz vom 23. Juli 2013 über Denkmalschutz und -pflege], in: Dziennik Ustaw [Gesetzblatt] 2003, Nr. 182, Position 1568.

»Wielka rura na ratunek" [Große Rohrleitung soll aus der Not helfen], in: Monitor Wielkopolski, 167, 4 (2015), 6, http://www.monitorwielkopolski.pl/pl/download/upload/ar ticles/numery/pdf/2013_od_06/2015_pdf_4.pdf, zuletzt geprüft am 9. September 2019.

"Zintegrowany Lokalny Program Rewitalizacji Miasta Konina na lata 2007-2015 « [Integriertes Lokales Programm zur Revitalisierung von Konin 2007-2015], Konin: Urząd Miejski w Koninie, 2011, https://docplayer.pl/4109680-Zintegrowany-lokalny-pro gram-rewitalizacji-miasta-konina-na-lata-2007-2015.html, zuletzt geprüft am 8. September 2019. 
Open-Access-Publikation im Sinne der CC-Lizenz BY 4.0

(c) 2020, Vandenhoeck \& Ruprecht GmbH \& Co. KG, Göttingen ISBN Print: 9783847107507 - ISBN E-Lib: 9783737007504 


\section{Wandel von Kulturlandschaften durch den Braunkohletagebau}

\section{Einleitung}

Die Landschaftsveränderungen durch den Abbau von Braunkohle sind gravierend. Weil die jüngste aller Kohlesorten, die aus untergegangenen fossilen Wäldern entstand, relativ nah an der Erdoberfläche lagert, wird Braunkohle überwiegend im Tagebau gefördert. Der Braunkohletagebau, der ein weitreichendes Absenken von Grundwasser erfordert, findet regelmäßig so großflächig statt, dass mit ihm eine Umsiedlung der ansässigen Bevölkerung, ein Überbaggern von Ortschaften, Feldern und Wäldern und ein Verlegen von Fließgewässern und Infrastrukturen verbunden ist. Diese enormen Auswirkungen des Tagebaus führen aber nicht nur zu physischen Veränderungen der Landschaft, sondern betreffen gesellschaftlich-kulturelle Vorstellungen von Landschaft. Dies zeigt sich etwa daran, dass die Gewinnung von Braunkohle im Tagebau als "Verlust der Heimat « und der "gewachsenen Kulturlandschaft ${ }^{1}$ gedeutet wird, ihre Brachen aber auch als besonders faszinierende Wüstenlandschaft thematisiert werden (vgl. Abb. 1). ${ }^{2}$

Nach dem jahrzehntelangen Abbau können durch Rekultivierung, Renaturierung und Gestaltung der Tagebaugebiete wieder land- und forstwirtschaftliche Nutzflächen, neue, für Erholung und Tourismus gestaltete Seen und für den Naturschutz wertvolle Bereiche entstehen. Solche transformierten Landschaften werden mittlerweile überwiegend positiv wahrgenommen und gedeutet. Im Diskurs über die Sanierung, Rekultivierung und Gestaltung der Braunkohletagebaugebiete in Ostdeutschland von 1990 bis etwa 2010, der im Mittelpunkt dieses Beitrags steht, gab es allerdings heftige Kontroversen zwischen den ver-

1 So der Herausgeber des Standardwerks: Wolfram Pflug (Hg.), Braunkohlentagebau und Rekultivierung. Landschaftsökologie, Folgenutzung, Naturschutz, Berlin und Heidelberg: Springer, 1998, 1.

2 Rolf Toyka (Hg.), Bitterfeld. Braunkohlebrachen: Probleme - Chancen - Visionen, München: Prestel, 1993. 


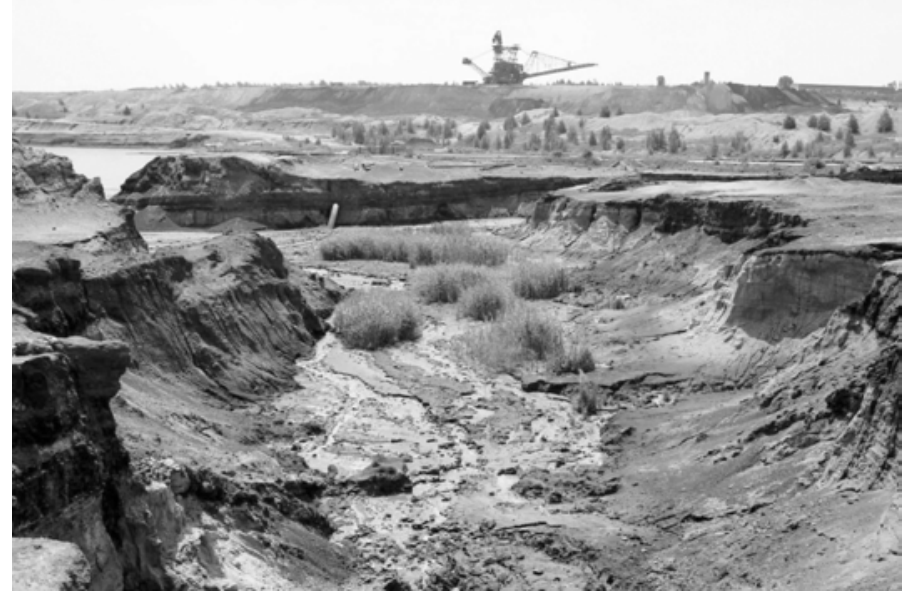

Abb. 1: Tagebau Goitzsche bei Bitterfeld; Foto: Marion Wenzel, 1992

schiedenen Positionen und Konzepten, die nachfolgend analysiert werden. ${ }^{3}$ Dem Ansatz der Untersuchung liegt eine gemäßigt-konstruktivistische, soziokulturell verstehende Perspektive auf Landschaft zugrunde. Die Arbeit bezieht sich vor allem auf die intensiven Debatten, die nach der Zäsur 1989/90 über die Gestaltung der großräumigen Braunkohlegebiete der DDR geführt wurden, die als "Mondlandschaften « verschrien waren. An diesem speziellen Diskurs lässt sich der Wandel von Kulturlandschaften durch den Braunkohletagebau in besonderer Weise veranschaulichen. Denn in ihm ging es nach dem politischen Umbruch besonders auch darum, ein neues positives "Image«, eine neue »Identität« der vom Tagebau gezeichneten Regionen und Landschaften zu erzeugen und Möglichkeiten dafür zu schaffen, die Tagebaulandschaften, deren Betreten jahrelang verboten war, überhaupt erleben und wahrnehmen zu können.

Zur Untersuchung werden Landschaftskonzepte aus drei großen zusammenhängenden Bergbauregionen, dem »Südraum Leipzig «, der Region »DessauBitterfeld-Wittenberg“ (die zusammen einen Großteil des Mitteldeutschen Braunkohlereviers ausmachen) und aus der Lausitz, insbesondere dem neuen »Lausitzer Seenland «, analysiert. ${ }^{4}$ Die dabei leitende Frage lautet: Welche Ideen

3 In den jüngeren Protesten gegen und Debatten über die Braunkohle in Deutschland geht es - im Unterschied zum untersuchten Diskurs - zwar auch um die gravierenden Landschaftsveränderungen, insbesondere jedoch um den Kohleausstieg aufgrund der negativen Klimabilanz der Kohleindustrie und um Hilfen im Kontext des Strukturwandels der betroffenen Regionen.

4 Siehe dazu die Übersichtskarte (Abb. 2), die dem deutsch-polnischen Ansatz des Bandes entsprechend angefertigt wurde. Zu Beispielen der Rekultivierung polnischer Tagebaugebiete, die nachfolgend nicht untersucht werden, siehe: Arkadiusz Niewiadomski, »Tagebau in polnischer Landschaft - Rekultivierungsmöglichkeiten bei Braunkohlen- und Schwefelbergwerken«, in: 
von Landschaft sind in diesem Diskurs wirksam und auf welche soziokulturell verankerten Werte und Symboliken wird in den planerisch-gestalterischen Konzepten rekurriert? ${ }^{5}$

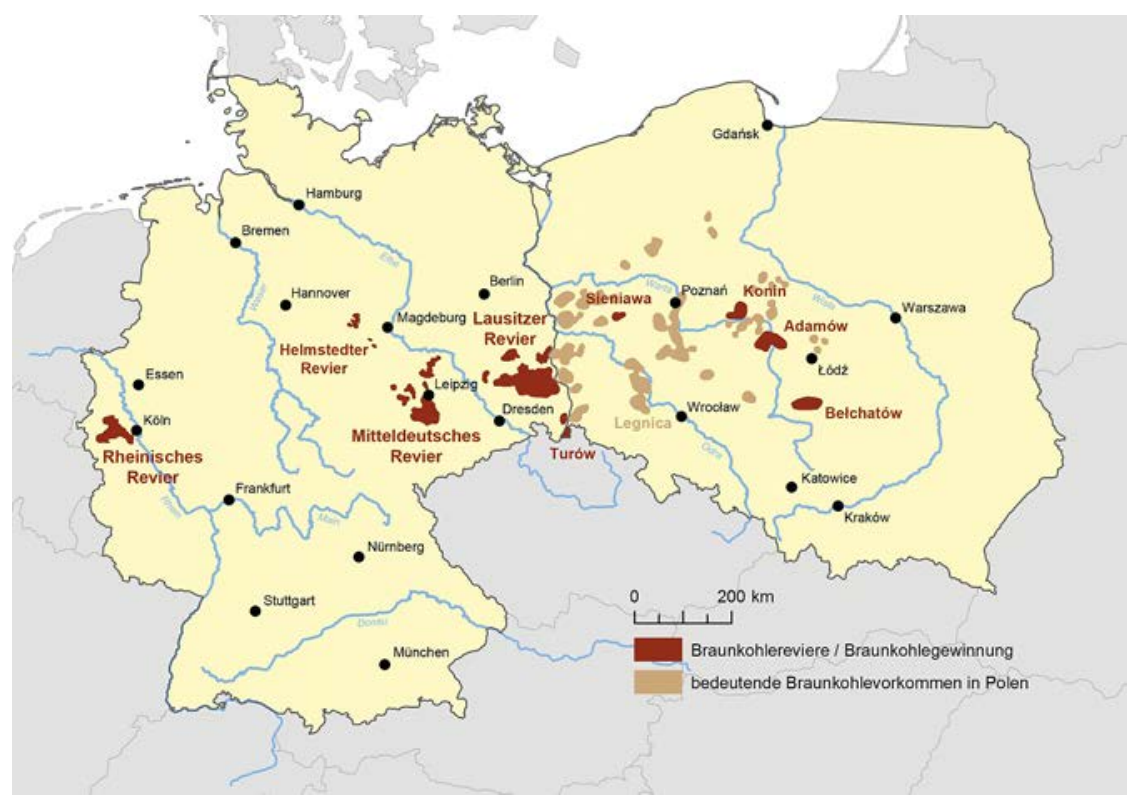

Abb. 2: Braunkohlebergbau in Deutschland und Polen: Braunkohlereviere in Deutschland Abbaugebiete und bedeutende Braunkohlevorkommen in Polen ${ }^{6}$

\section{Braunkohleförderung und -tagebau im Überblick}

Viele Jahre lang war die DDR weltweit mit Abstand Spitzenreiter in der Braunkohleförderung, die nach den Ölkrisen ausgedehnt wurde und im Jahr 1984 rund 375 Millionen Tonnen betrug. Zum Vergleich: In der Bundesrepublik Deutsch-

Georg Stöber (Hg.), Zwischen Ökonomie und Ökologie? Raumstruktureller Wandel, Raumplanung und Nutzungskonflikte in Deutschland und Polen, Göttingen: V\&R unipress, 2012, 27-41.

5 Siehe ausführlich dazu: Markus Schwarzer, Von Mondlandschaften zur Vision eines neuen Seenlandes. Der Diskurs über die Gestaltung von Tagebaubrachen in Ostdeutschland, Wiesbaden: Springer VS, 2014.

6 Kartografie: Maria Löber, Kartengrundlagen: Ländergrenzen: »Natural Earth, Free vector and raster map data, admin countries«, 2013; Flüsse und Städte: Openstreetmap Lizenz CCBY-SA; Braunkohlegebiete: Bundesverband Braunkohle DEBRIV, "Braunkohlenreviere in Deutschland « (Wandkarte), 2012; Antoni Tajduś, Wiesław Kozioł und Paweł Kawalec, "Present state and prospects of lignite extraction in Poland ", in: World of Mining - Surface \& Underground 59, 1 (2007), 36-41, hier 36. 
land waren es damals ca. 110 Millionen, in Polen etwa 52 Millionen Tonnen Braunkohle. ${ }^{7}$ Nachdem die Förderung von Braunkohle weltweit in den 1980er Jahren anstieg, verringerte sie sich nach den Revolutionen in Ostmitteleuropa und der Transformation der Sowjetunion im folgenden Jahrzehnt. Parallel dazu kam es in Indonesien, Thailand, Indien, China und Australien zu einer Ausweitung der Braunkohleförderung. ${ }^{8}$ Auf Europa - insbesondere auf Deutschland und Polen - entfällt, nach leichten Anstiegen in den Nuller-Jahren und einer Reduzierung im vergangenen Jahrzehnt, aktuell immer noch deutlich mehr als die Hälfte der weltweiten Förderung von Braunkohle, die vor allem in Mittel- und Südosteuropa abgebaut wird. ${ }^{9}$

Die Förderung von Braunkohle im Tagebau lässt sich mit Hilfe eines Schemas veranschaulichen, das aus einem populären DDR-Fachbuch stammt (siehe Abb. 3). Es zeigt auf zwei Doppelseiten einen Tagebau, der mit einer Förderbrücke betrieben wird, wie es im Lausitzer Revier typisch ist und auch im Mitteldeutschen Revier verbreitet war. Das Schema stellt den Tagebau in der Manier eines Kinderbuchs dar: Links werden der Abriss von Häusern und die Rodung von Wald - bergbausprachlich die "Vorfeldberäumung" - gezeigt. Damit der Tagebau trocken erfolgen kann, findet zu Beginn eine tiefgreifende Entwässerung des Gebiets statt, die sich weit in die Umgebung auswirkt. In mehreren Stufen wird mit Schaufelrad- und Eimerkettenbaggern der Abraum über der Kohle entfernt. Bei Tagebauaufschluss wird der Abraum auf eine Halde aufgeschüttet; später wird er, wie im Bild, über Bänder und die Abraumförderbrücke in den bereits abgebauten Bereich transportiert. Ganz unten in der Mitte des Bildes wird die Kohle gebaggert und in Industrieanlagen abtransportiert, deren rauchende Schlote als "Fahnen des Fortschritts« den Horizont markieren. Rechts zeigt das Bild, dass nach dem Abbau der Boden planiert und wieder urbar gemacht wird und schließlich - nur ein Stück weiter - die rekultivierten Flächen als Feld und Forst bereits in frischem Grün erscheinen.

7 Le Monde diplomatique (Hg.), Atlas der Globalisierung, spezial. Das 20. Jahrhundert, Berlin: TAZ, 2011, 53.

8 Bundesanstalt für Geowissenschaften und Rohstoffe, Energierohstoffe 2009. Reserven, Ressourcen, Verfügbarkeit, Hannover: Schweizerbart'sche E., 2009, $150 \mathrm{f}$.

9 Die Braunkohleförderung in Europa (ohne Russland) betrug 2018 etwa 433 Millionen Tonnen und entfiel jeweils gerundet auf folgende Länder: Deutschland (166), Polen (59), Tschechien (39), Serbien (38), Griechenland (36), Bulgarien (30), Rumänien (24), Bosnien-Herzegowina (14), Ungarn (8), Kosovo (7), Mazedonien (5), Slowenien (3), Montenegro (2) und die Slowakei (2) [Statistik der Kohlenwirtschaft (Hg.), Der Kohlenbergbau in der Energiewirtschaft der Bundesrepublik Deutschland im Jahre 2018, Essen/Bergheim, 2019, 83]. Vgl. Hartmut Ernst, Helmut Wolff und Sven-Uwe Schulz, "Die europäischen Braunkohlenreviere«, in: Rolf Dieter Stoll, Christian Niemann-Delius, Carsten Drebenstedt und Klaus Müllensiefen (Hg.), Der Braunkohlentagebau. Bedeutung, Planung, Betrieb, Technik, Umwelt, Berlin/ Heidelberg: Springer, 2009, 13-33. 


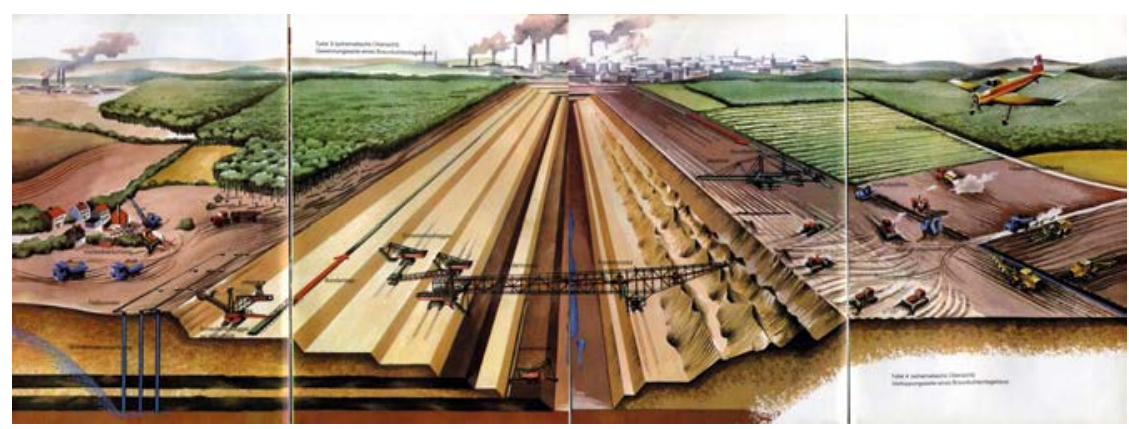

Abb. 3: Schematische Übersicht eines Braunkohletagebaus ${ }^{10}$

Das Schema ist, was die Zwangsumsiedlungen betrifft, verharmlosend. Denn solche Umsiedlungen, die vielfach als Heimatverlust gedeutet wurden, zählen zu den prägenden Negativerfahrungen der Betroffenen, und zwar selbst dann, wenn sich die Wohn- und Lebenssituation verbesserte. ${ }^{11}$ Bis zum Jahr 2000 waren im Mitteldeutschen Revier etwa 51.200 Menschen von einer Bergbau-Umsiedlung betroffen (vor allem in den 1950er/1960er Jahren), im Lausitzer Revier waren es ca. 27.500 Betroffene (insbesondere in den 1980er Jahren) und im Rheinischen Revier waren es rund 28.400 Bergbau-Umsiedler. ${ }^{12}$

Fern der Realität ist das Schema insbesondere hinsichtlich der schnellen Rekultivierung in der DDR um 1980. Der für Betrachter oft prägende Eindruck der weiten, nahezu unermesslich erscheinenden Ausdehnung einer Grube mit ihren wüst erscheinenden Abraummassen ist für einen aktiven Großtagebau kennzeichnend. Die ausgedehnten Tagebaubrachen werden in dem Fachbuch jedoch keinesfalls geleugnet, sondern erfahren folgende prägnante Deutung im Kontext der energiewirtschaftlichen Zwangslage der DDR:

Jeder [...] empfindet die weite Öde eines Tagebaus, die nackten, von jeder Pflanzendecke entblößten Halden, als ein zutiefst niederdrückendes Erlebnis. Erschüttert steht der Besucher inmitten der zerstörten Landschaft, an die sich die Bewohner längst gewöhnt haben. Erst hier begreift man das ganze Ausmaß der Landschaftsveränderung, die wir vornehmen müssen, um ausreichend Kohle für Industrie und Bevölkerung zu gewinnen. ${ }^{13}$

10 Tafel $3 \mathrm{f}$ von Wolfgang Parschau (Illustrationen) in: Albrecht Krummsdorf und Gerhard Grümmer, Landschaft vom Reißbrett. Die Zukunft unserer Kippen, Halden und Restlöcher, Leipzig/Jena/Berlin: Urania, 1981.

11 Frank Förster, Bergbau-Umsiedler. Erfahrungsberichte aus dem Lausitzer Braunkohlenrevier, Bautzen: Domowina, 1998, 172.

12 Akademie für Raumforschung und Landesplanung (Hg.), Braunkohlenplanung und Umsiedlungsproblematik in der Raumordnungsplanung Brandenburgs, Nordrhein-Westfalens, Sachsens und Sachsen-Anhalts, Hannover: ARL, 2000, 48.

13 Krummsdorf und Grümmer, Landschaft vom Reißbrett, 5; vgl. zur Interpretation: Schwarzer, Von Mondlandschaften zur Vision eines neuen Seenlandes, $135 \mathrm{f}$. 
Weil seit den 1970er Jahren in der DDR der Tagebau ausgeweitet und die Rekultivierung vernachlässigt wurde, blieben zahlreiche solcher großflächigen "Mondlandschaften« zurück, die den Ausgangspunkt des untersuchten Diskurses bilden. Dieser muss vor dem Hintergrund des politisch-ökonomischen Umbruchs nach 1989/90 gesehen werden, der zu einer Deindustrialisierung weiter Teile Ostdeutschlands und damit verbunden zu einem großen Verlust von Arbeitsplätzen führte. ${ }^{14}$

\section{Theoretischer Ansatz: Diskursanalyse und weltanschauliche Idealtypen von Landschaft}

Die kulturwissenschaftlich ausgerichtete Analyse orientiert sich an dem von Foucault geprägten Diskursverständnis und erfolgt mit Hilfe von Idealtypen im Sinne Max Webers. ${ }^{15}$ Entscheidend für die Formation des Diskurses ist demnach, von welchem sozialen und institutionellen Ort, $d$. h. von welcher »Diskursebene» die Konzepte hervorgebracht werden. ${ }^{16}$ Als wesentliche soziale und institutionelle Ebenen des untersuchten Diskurses werden (1) »staatliche Planung«, (2) "anwendungsorientierte Wissenschaften «, (3) "zivilgesellschaftliche Gruppen " und (4) »Öffentlich-Private Partnerschaften« unterschieden. Diese Auswahl lässt sich unter Rekurs auf die Entwicklung des westlichen Planungsverständnisses nach 1945 begründen. ${ }^{17}$

Zur Analyse der normativen Gehalte der Landschaftskonzepte bedarf es einer Grundlage. Als solche werden unter Bezug auf bestehende Typologien wesentliche Deutungen von Landschaft als Idealtypen formuliert. Dazu rekurriere ich auf die für das heutige politische Denken wesentlichen Weltanschauungen des Liberalismus, des Konservatismus und der demokratischen Aufklärung (aus der

14 Die Zahl der Beschäftigten in der ostdeutschen Braunkohleindustrie nahm von $138.000 \mathrm{im}$ Jahr 1989 drastisch ab auf 11.000 im Jahr 2000, zugleich wurde die Anzahl der Tagebaugebiete von 39 auf acht und die der Veredelungsanlagen von 94 auf sechs reduziert (Günter Bayerl, "Die Niederlausitz. Industrialisierung und De-Industrialisierung einer Kulturlandschaft", in: Blätter für Technikgeschichte 65 (2003), 89-163, hier 139).

15 Max Weber, "Die `Objektivität` sozialwissenschaftlicher und sozialpolitischer Erkenntnis«, in: Johannes Winckelmann (Hg.), Gesammelte Aufsätze zur Wissenschaftslehre von Max Weber, Tübingen: J.C.B. Mohr, 1988 [Erstdruck 1904], 146-214, insbes. 190; vgl. zur Bedeutung der idealtypischen Begriffsbildung in den Kulturwissenschaften: Gertrude Hirsch Hadorn, "Webers Idealtypus als Methode zur Bestimmung des Begriffsinhalts theoretischer Begriffe in den Kulturwissenschaften«, in: Journal for General Philosophy of Science 28 (1997), 275-296.

16 Achim Landwehr, Historische Diskursanalyse, Frankfurt und New York: Campus, 2008, 70, vgl. Michel Foucault, Archäologie des Wissens (französisches Original: L'archéologie du savoir, Paris: Gallimard, 1969), Frankfurt am Main: Suhrkamp, 1997, 178.

17 Siehe dazu: Schwarzer, Von Mondlandschaften zur Vision eines neuen Seenlandes, 54-57. 
später der Sozialismus hervorging). Diese wurden entscheidend in der »Sattelzeit« (Koselleck) der Moderne zwischen 1750 und 1850 geprägt. Die romantische Weltanschauung, die in dieser Zeit eine für die Moderne grundlegende Landschaftsidee ausbildete, ergänzt die Typologie. Auf diese Weise wird ein Deutungsrepertoire gebildet, mit dem die Landschaftskonzepte des Diskurses auf ihre wesentlichen normativen Gehalte analysiert werden können. ${ }^{18}$

\section{Überblick über das weltanschauliche Deutungsrepertoire von Landschaft $^{19}$}

In der Weltanschauung des Liberalismus wird Landschaft vor allem positiv bewertet, wenn es gelingt, sie als nutzbare Ressource zu sehen oder wenn sie Freiheit von gesellschaftlichen Zwängen symbolisiert. Sie soll rationell nach Bedürfnissen und Interessen geplant werden, aber im Gegensatz zur demokratischen Weltsicht nach Maßgabe der Privateigentümer.

Im Konservatismus ist Landschaft konkreter Ort, prägnanter Ausdruck und Ideal einer gelungenen kulturellen Entwicklung. Ihre Eigenart gründet in der unverwechselbaren, organischen Einheit von "Land und Leuten" (Riehl). Die Schönheit der Landschaft ist Ausdruck und Maß der konkreten, historisch gewachsenen Vollkommenheit. Das konservative Ideal der Kulturlandschaft avancierte zum wirkmächtigen Gegenbild gegen die im klassisch-konservativen Denken abgelehnte Industrialisierung. ${ }^{20}$

In der Weltanschauung der demokratischen Aufklärung, in dessen Tradition der Sozialismus steht, geht es nicht um ein "Zurück zur Natur", sondern Landschaft ist analog zur demokratischen Gesellschaft erst nach Prinzipien der Vernunft herzustellen. Der Maßstab dafür ist die Orientierung am Gemeinwohl. Als demokratische Ideallandschaft kann die arkadisch-pastorale Landschaft des "goldenen Zeitalters« im Sinne Rousseaus fungieren. Sie symbolisiert Genügsamkeit und Schönheit und kann emanzipatorischer Referenzpunkt für die Befreiung aus natürlichen und gesellschaftlichen Abhängigkeiten sein. Aber ins

18 Ebd., 75-79. Die Typologie bezieht sich insbesondere auf: Vera Vicenzotti, Der »Zwischenstadt«-Diskurs. Eine Analyse zwischen Wildnis, Kulturlandschaft und Stadt, Bielefeld: transcript, 2011.

19 Die in diesem Abschnitt angesprochenen Weltanschauungen und Landschaftsvorstellungen können hier nur sehr verkürzt dargestellt werden, siehe ausführlich dazu: Schwarzer, Von Mondlandschaften zur Vision eines neuen Seenlandes, 79-100.

20 Siehe zu historischen Deutungen industrieller Landschaft: Markus Schwarzer, "Landschaft und Industrie. Zur Geschichte und Theorie eines ambivalenten Verhältnisses«, in: Sven Petersen, Dominik Collet und Marian Füssel (Hg.), Umwelten. Ereignisse, Räume und Erfahrungen in der Frühen Neuzeit. Festschrift für Manfred Jakubowski-Tiessen, Göttingen: V\&R unipress, 2015, 101-125. 
demokratische Ideal passen auch gar nicht so arkadische Landschaften: Es können auch Landschaften als charaktervoll anerkannt werden, in denen rationale Planung und Technik auf die Spitze getrieben wurde, wie in Industrielandschaften.

Die Romantik reagiert auf die »Entzauberung « der Welt durch die Aufklärung und den empfundenen Verlust der althergebrachten Religion, indem sie Natur, insbesondere Landschaft, künstlerisch beseelt. Die Sehnsucht nach der Verschmelzung des künstlerischen Subjektes mit der quasi-religiös als göttliches Ganzes aufgefassten Natur richtet sich auf die gerade nicht der Vernunft unterworfene bzw. nicht harmonische Natur. So wird Landschaft in der romantischen Weltsicht insbesondere als unerreichbare Ferne (Horizont) oder als bedrohliche Nähe (Abgrund) zum ausgezeichneten Medium der Sinnvermittlung. ${ }^{21}$

\section{Die leitenden Konzepte für die vom Braunkohletagebau überformte Landschaft}

\section{Landschaftskonzepte der staatlichen Sanierung}

Auf der Ebene staatlicher Planung wurde nach 1990 eine Bestandsaufnahme der Umweltsituation in Ostdeutschland durchgeführt, die auch die Tagebaugebiete betraf. Parallel dazu wurde mit der Sanierung und Rekultivierung dieser Gebiete im Rahmen von sogenannten Arbeitsbeschaffungsmaßnahmen begonnen. In »Braunkohleausschüssen « wurden ab den frühen 1990er Jahren Sanierungspläne gemäß den in der alten Bundesrepublik etablierten gesetzlichen und administrativen Strukturen erarbeitet. Die politisch beschlossenen Sanierungspläne hatten eine hohe Verbindlichkeit für die staatliche Landes- und die Regionalplanung und enthielten in der Regel implizite Landschaftsvorstellungen. Sie orientierten sich an typischen Mustern der Landnutzung und sahen vor allem Flächen für Land- und Forstwirtschaft, Seen besonders zur "Freizeitnutzung» und sonstige Flächen vor. Dieses Schema zeigt sich bis heute in einschlägigen Statistiken, in denen die enorme Landinanspruchnahme und das Ausmaß des

$21 \mathrm{Zu}$ diesem Abschnitt wurde eine Fülle an Literatur herangezogen (vgl. Schwarzer, Von Mondlandschaften zur Vision eines neuen Seenlandes, 75-100), die hier in der knappen Darstellung nicht angemessen angegeben werden kann. Neben der grundlegenden Arbeit von Vicenzotti sind folgende einschlägig: Bernhard Gill, Streitfall Natur: Weltbilder in Technik- und Umweltkonflikten, Wiesbaden: Westdeutscher Verlag, 2003; Ludwig Trepl, Die Idee der Landschaft. Eine Kulturgeschichte von der Aufklärung bis zur Ökologiebewegung, Bielefeld: transcript, 2012; Bernd Heidenreich (Hg.), Politische Theorien des 19. Jahrhunderts. Konservatismus, Liberalismus, Sozialismus, Berlin: Akademie Verlag, 2002. 
neuen Landschaftselements, der Wasserflächen, vor allem in den beiden ostdeutschen Revieren deutlich werden (vgl. Tabelle 1).

Tabelle 1: Betriebsflächen und wieder nutzbar gemachte Flächen in den drei großen Braunkohlerevieren in Deutschland, Stand: Ende Dezember 2018 (Zahlen gerundet). ${ }^{22}$

\begin{tabular}{|c|c|c|c|c|c|c|c|c|}
\hline \multirow[b]{3}{*}{ Revier } & \multirow[b]{3}{*}{ Einheit } & \multirow{3}{*}{$\begin{array}{l}\text { Landin- } \\
\text { an- } \\
\text { spruch- } \\
\text { nahme } \\
\text { insge- } \\
\text { samt }\end{array}$} & \multirow{3}{*}{$\begin{array}{l}\text { Be- } \\
\text { triebs- } \\
\text { flächen } \\
\text { (Ab- } \\
\text { raum, } \\
\text { Kohle, } \\
\text { Kippe) } \\
\text { 1) }\end{array}$} & \multicolumn{5}{|c|}{ wieder nutzbar gemachte Flächen } \\
\hline & & & & \multirow[b]{2}{*}{$\begin{array}{l}\text { Insge- } \\
\text { samt }\end{array}$} & \multicolumn{4}{|l|}{ davon } \\
\hline & & & & & $\begin{array}{l}\text { Land- } \\
\text { wirt- } \\
\text { schaft }\end{array}$ & $\begin{array}{l}\text { Forst- } \\
\text { wirt- } \\
\text { schaft }\end{array}$ & $\begin{array}{l}\text { Was- } \\
\text { serflä- } \\
\text { chen }\end{array}$ & $\begin{array}{l}\text { Sonsti- } \\
\text { ges 2) }\end{array}$ \\
\hline $\begin{array}{l}\text { Rhein- } \\
\text { land }\end{array}$ & $\begin{array}{l}\text { ha } \\
\%\end{array}$ & $\begin{array}{l}33.238 \\
100\end{array}$ & $\begin{array}{l}9.747 \\
29\end{array}$ & $\begin{array}{l}23.491 \\
71\end{array}$ & $\begin{array}{l}12.732 \\
38\end{array}$ & $\begin{array}{l}8.726 \\
26\end{array}$ & $\begin{array}{l}820 \\
2,5\end{array}$ & $\begin{array}{l}1.213 \\
3,6\end{array}$ \\
\hline Lausitz & $\begin{array}{l}\text { ha } \\
\%\end{array}$ & $\begin{array}{l}88.911 \\
100\end{array}$ & $\begin{array}{l}30.648 \\
35\end{array}$ & $\begin{array}{l}58.263 \\
66\end{array}$ & $\begin{array}{l}10.606 \\
12\end{array}$ & $\begin{array}{l}31.417 \\
35\end{array}$ & $\begin{array}{l}8.977 \\
10\end{array}$ & $\begin{array}{l}7.263 \\
8,2\end{array}$ \\
\hline $\begin{array}{l}\text { Mittel- } \\
\text { deutsch- } \\
\text { land }\end{array}$ & $\begin{array}{l}\text { ha } \\
\%\end{array}$ & $\begin{array}{l}48.123 \\
100\end{array}$ & $\begin{array}{l}12.365 \\
25\end{array}$ & $\begin{array}{l}36.448 \\
75\end{array}$ & $\begin{array}{l}9.391 \\
19\end{array}$ & $\begin{array}{l}11.501 \\
24\end{array}$ & $\begin{array}{l}12.420 \\
25\end{array}$ & $\begin{array}{l}3.137 \\
6,4\end{array}$ \\
\hline
\end{tabular}

1) einschließlich Rekultivierungsrückstände und Risikoflächen - 2) Wohnsiedlungen, fremde Betriebe, Verkehrswege etc.

In der staatlichen Sanierung sollten vor allem rein technisch Gefahren - insbesondere an vielen instabilen Böschungen - reduziert, die sogenannte Wiedernutzbarmachung der Flächen erreicht und ein möglichst ausgeglichener Wasserhaushalt »wiederhergestellt« werden. ${ }^{23}$ Die Ausrichtung auf die Nutzbarkeit und die beabsichtigte anschließende Privatisierung der Flächen deuten auf eine liberale Landschaftsvorstellung hin. Dennoch beinhalten die Sanierungspläne ein regionales Leitbild. Weil dies anfangs am "vorbergbaulichen Zustand « der Landschaft orientiert war, ohne jedoch den historischen Bezugspunkt zu klären, lässt sich die Sanierungskonzeption als Kombination einer liberalen und zugleich unreflektierten konservativen Landschaftsvorstellung interpretieren.

22 Statistik der Kohlenwirtschaft (Hg.), Der Kohlenbergbau in Deutschland, 50.

23 Friedrich von Bismarck, »Programm der Braunkohlesanierung: Weichenstellung für Regionen?«, in: Cornelia Gläßer (Hg.), Nachhaltige Entwicklung von Folgelandschaften des Braunkohlebergbaus. Stand und Perspektiven in Wissenschaft und Praxis, Berlin: Analytica, 2004, 12-19. Für die Sanierung wurden enorme öffentliche Mittel bereitgestellt, die sich im Zeitraum von 1991 bis Ende 2012 auf insgesamt rund 9,6 Milliarden Euro beliefen, vgl. BundLänder-Geschäftsstelle für die Braunkohlesanierung (Hg.), 20 Jahre Verwaltungsabkommen Braunkohlesanierung. Gesichter und Geschichten der Braunkohlesanierung, Berlin: BundLänder-Geschäftsstelle für die Braunkohlesanierung, 2012, 14. 
(2) Landschaftskonzepte im anwendungsorientierten

Forschungsprogramm

Auf der Ebene anwendungsorientierter Forschung waren mehrere wissenschaftliche Fächer und zahlreiche Institute am Forschungsprogramm zur Sanierung, Rekultivierung und Gestaltung der Tagebaugebiete beteiligt, schwerpunktmäßig von 1994/95 bis etwa 2000. In zahlreichen natur- und ingenieurwissenschaftlichen Studien zur Rekultivierung und zu Naturschutz erforschte man vor allem Möglichkeiten zur Verbesserung der künftigen Nutzung oder zum Schutz der Landschaft. In wenigen sozialwissenschaftlichen Arbeiten ging es z. B. um Revitalisierungsprozesse in Tagebauregionen. Die Ergebnisse und Empfehlungen des umfangreichen Forschungsprogramms enthalten im Wesentlichen folgende, teils grundlegend verschiedene Landschaftsvorstellungen.

\section{Forstwirtschaftliche Rekultivierungsforschung}

Durch intensive Rekultivierungsforschung und -praxis gelang in den 1960er Jahren der entscheidende Erfolg bei der Rekultivierung »kulturfeindlicher" tertiärer Substrate in der DDR. Dabei wurden wesentliche praktische Grundlagen, etwa zur Klassifizierung der Kippen nach pflanzenverfügbarem Nährstoffund Wasserangebot, gelegt und eine Theorie standörtlich differenzierter »Bestandeszieltypen« entwickelt. In der Praxis kam es jedoch zur großflächigen Rekultivierung weniger Arten (vor allem Kiefer, Roteiche, Pappel). Seit 1970 wurde diese Forschung jedoch weitgehend eingestellt, und es war ein zunehmendes Rekultivierungsdefizit zu verzeichnen. Nach 1990 kam es zu einer Neuorientierung am »naturnahen Waldbau« und zur Erforschung von früher rekultivierten Flächen. In diesem Kontext wurden große Monokulturen, insbesondere aus Kiefer und Pappel, als »schädlingsdisponiert« eingestuft. Zudem avancierte der »Aufbau stabiler, multifunktionaler und regionaltypischer Waldökosysteme« zum Ziel der forstlichen Rekultivierung. ${ }^{24}$ Der Anwendung standortkundlicher Grundlagen liegt ein konstruktivistisches Moment zugrunde, wie es der demokratischen und sozialistischen Landschaftsvorstellung entspricht. Die Zielvorstellung potentieller natürlicher und regionaltypischer Waldgesellschaften folgt demgegenüber tendenziell konservativen Mustern des populären »ökologisierten« Waldbilds.

24 Dirk Knoche, »Forstliche Rekultivierung «, in: Lausitzer und Mitteldeutsche Bergbau-Verwaltungsgesellschaft (LMBV) (Hg.), Wissenschaftliche Begleitung der ostdeutschen Braunkohlesanierung. Forschungsprojekte 1994 bis 2000, Berlin: LMBV, 2001, 105-131, hier 106, 131. 


\section{Landwirtschaftliche Rekultivierungsforschung}

Das Ziel der auf Ackerbau ausgerichteten Rekultivierungsforschung, die ebenfalls an wegweisende Ergebnisse aus den 1960er Jahren anknüpfte, ist eine bodenschonende, langfristig die Bodenfruchtbarkeit fördernde Landnutzung. Sofern eine offene Landschaft erwünscht, Ackerbau aber nicht mehr rentabel ist, wird eine extensive Weidelandschaft empfohlen. Besonders Schafe eigneten sich zur Beweidung der rekultivierten Gebiete einschließlich der Sukzessionsflächen. ${ }^{25}$ Anders als bei der konservativen Pflege traditioneller Heiden wird aufgrund von Standorteigenschaften die gezielte Herstellung einer Weidelandschaft empfohlen. Diese konstruktivistische Auffassung erinnert an die in der demokratischen Aufklärung (aber nicht nur dort) idealisierte arkadisch-pastorale Landschaft.

\section{Naturschutzforschung}

Naturschutz spielte in den Braunkohlegebieten der DDR nur eine marginale Rolle. Weil große Areale dort jedoch teils über Jahrzehnte sich selbst überlassen blieben, konnten diese von Tieren und Pflanzen besiedelt werden. Seit den 1990er Jahren ging es darum, diese Gebiete vor allem hinsichtlich der Vegetation und deren Sukzession zu untersuchen und Möglichkeiten zur Initiierung und Erhaltung wertvoller Biotope zu erforschen. ${ }^{26}$ In dieser Forschung ging es im Grunde darum, die einflussreiche These zu widerlegen, die Tagebaubrachen seien bloß »devastierte« oder »zerstörte Mondlandschaften«, die der Sanierung und Rekultivierung bedürften. Die weithin negativ codierten Brachen mit ihren Rohböden und ihrer "spontanen « Vegetation wurden im Naturschutzdiskurs als "urwüchsig«, "pionierartig« oder »wild « symbolisch aufgeladen. Die mit dieser Symbolik verbundene Wertschätzung förderte die Entwicklung von »Wildnis« und von »bergbauspezifischen Biotopen« als Leitvorstellungen im Naturschutz. Die genannte Symbolik, die gewissermaßen »dem Gemeinen einen hohen Sinn« (Novalis) gibt, weist deutlich auf eine romantische Vorstellung von Landschaft und Wildnis, die als solche im Diskurs aber nicht reflektiert wurde. Weil es galt, solche Ausprägungen der Brachennatur vor dem Verlust durch Sanierungs- oder

25 Michael Haubold-Rosar, »Landwirtschaft«, in: LMBV (Hg.), Wissenschaftliche Begleitung der ostdeutschen Braunkohlesanierung. Forschungsprojekte 1994 bis 2000, Berlin: LMBV, 2001, 132-154, hier 146, 152.

26 Uwe-Volkmar Köck, »Naturschutz«, in: LMBV (Hg.), Wissenschaftliche Begleitung der ostdeutschen Braunkohlesanierung. Forschungsprojekte 1994 bis 2000, Berlin: LMBV, 2001, 155-192; vgl. Gerhard Wiegleb, Udo Bröring, Jadranka Mrzljak und Friederike Schulz (Hg.), Naturschutz in Bergbaufolgelandschaften. Landschaftsanalyse und Leitbildentwicklung, Heidelberg: Physica, 2000 und Sabine Tischew (Hg.), Renaturierung nach dem Braunkohleabbau, Stuttgart/Leipzig/Wiesbaden: Teubner, 2004. 
Rekultivierungsmaßnahmen zu bewahren, mischen sich mit dieser Vorstellung konservative Muster.

Im staatlich geförderten Forschungsprogramm wurde insgesamt weitgehend instrumentelles Wissen erzeugt. Obwohl es um die »Gestaltung der Landschaften" gehen sollte, spielte die eigentlich wesentliche Frage nach der kulturellen Orientierung, nach Gestaltungsideen, dafür - wenn überhaupt - nur eine marginale Rolle.

Insbesondere im Verlauf der 1990er Jahre beteiligten sich zivilgesellschaftliche Initiativen am planerisch-gestalterischen Diskurs, von denen sich zahlreiche lokale und regionale Gruppen zum Dachverband Bergbaufolgelandschaft zusammenschlossen. Im Unterschied zum Dachverband, der regionenübergreifende Foren etablierte und eine Plattform für kontroverse Debatten bot, waren das Reformprojekt »Industrielles Gartenreich" vom Bauhaus Dessau und die "Mitteldeutsche Straße der Braunkohle» stärker auf die Verwirklichung von Alternativen zu den bisherigen Planungen angelegt.

\section{Dachverband Bergbaufolgelandschaft}

Wenngleich die Positionen im Verband vielgestaltig und kontrovers waren, so einte sie doch die Kritik an bestehenden Sanierungs- und Rekultivierungskonzepten, am eingeschränkten Zugang zu Informationen und an geringen Einflussmöglichkeiten bei Entscheidungen. Um die Defizite bisheriger Planung zu beheben, wurden vor allem eine gestalterische Qualifizierung der Sanierungs- und Rekultivierungskonzepte, die verstärkte Berücksichtigung von Naturschutzanliegen und die Erhaltung von industriekulturell bedeutsamen Sachzeugen der Braunkohleindustrie gefordert. ${ }^{27}$ In dieser Lage gewann die Sichtweise an Bedeutung, die ungeliebten technisch massiv überformten Gebiete als solche wahrzunehmen und auch als besondere Landschaft anzuerkennen. Insofern gerade die technisch-industriell geformten Hinterlassenschaften der Industrie als charaktervolle Merkmale der Landschaft eine Wertschätzung fanden, liegt hier eine demokratische Landschaftsvorstellung zugrunde. Indem diese Gebiete als erst noch zu »entdecken «, als »wüst « und eigentümlich reizvoll bezeichnet wurden, mischen sich mit dieser Landschaftsvorstellung romantische Motive.

27 Siehe dazu die vier Jahrbücher, insbesondere das erste: Dachverband Bergbaufolgelandschaft u. a. (Hg.), Jahrbuch Bergbaufolgelandschaft, Leipzig: Pro Leipzig, 1996-1999. 
Besonderen Anklang im Dachverband fanden geführte Spaziergänge durch eine Tagebaubrache. Diese Orte waren eigentlich tabu, denn ihr Betreten war grundsätzlich verboten. Nach Genehmigung der Bergbausanierung wurde durch die Wegeführung und die Installationen die Brache als bildwürdiger Ort und besondere Landschaft sichtbar gemacht. Diese positive Faszination wird im Diskurs gebrochen oder ergänzt, wenn die Brachen, wie um Bitterfeld, als »kontaminiert« eingestuft und ambivalent als schrecklich-schöne Landschaft gedeutet werden. $^{28}$

»Industrielles Gartenreich« (Bauhaus Dessau)

Das Reformprojekt »Industrielles Gartenreich« des Bauhauses Dessau setzte sich in der Region Dessau-Bitterfeld-Wittenberg von 1989 bis 1999 für die Wahrnehmung und symbolische Umgestaltung der überkommenen Industrielandschaft ein. Diese steht im Bauhaus-Projekt für die Verheißungen der industriellen Moderne, für die Verbindung von Kunst und Technik, und zugleich für die Schattenseiten, für Raubbau und Verwüstung. ${ }^{29}$ Diese ambivalente, im Kern demokratische Vorstellung von Industrielandschaft wird dem Terminus »Industrielles Gartenreich" entsprechend mit der aufklärerischen Idee des als Landschaft gestalteten Gartens verbunden. Weil der verkannten Industrielandschaft der Verlust drohte, galt es, deren Zeugnisse und Spuren zu bewahren. An dieser Stelle greift die industriekulturell reflektierte Vorstellung die konservative Idee des Bewahrens auf und bindet sie in die leitende demokratische Landschaftsidee ein. Dies manifestiert sich in der symbolischen Umgestaltung der industriellen Zeugnisse zu Zeichen einer neuen, postindustriellen Landschaft, wie dies in der Baggerstadt "Ferropolis« - einem außergewöhnlichen Denkmal und Veranstaltungsort - beispielhaft vorgenommen wurde. Diese Deutung enthält außerdem, der Tradition der Aufklärung entsprechend, eine erzieherische Aufgabe, nämlich die Erinnerung an das ambivalente Erbe des Industriezeitalters wachzuhalten.

»Mitteldeutsche Straße der Braunkohle«

Mit diesem Projekt »soll länder- und revierübergreifend der Versuch unternommen werden, sowohl für Einheimische als auch für Gäste in der Region markante bergbaubedingte Sachzeugen zu erhalten, zu erläutern und in einen Zusammenhang zu stellen. Damit soll die Erinnerung an eine über 150 Jahre

28 Vgl. Abb. 1 und Toyka (Hg.), Bitterfeld. Braunkohlebrachen.

29 Siehe dazu die zwei Bände: Stiftung Bauhaus Dessau (Hg.), Industrielles Gartenreich. Dessau - Bitterfeld - Wittenberg, Berlin: ex pose, 1996 und 1999. 
Industriegeschichte entstandene, zweifellos streitbare Kulturlandschaft bewahrt und eine Brücke in die Zukunft geschlagen werden. $\aleph^{30}$ Die "Straße der Braunkohle« umfasst explizit auch die entstehende Seenlandschaft (die im "Industriellen Gartenreich « keine nennenswerte Rolle spielte, aber mittlerweile die ehemaligen Tagebauregionen bestimmt). Diese Ausrichtung wurde mit dem Wunsch der Bevölkerung nach einer attraktiven Seenlandschaft begründet. Wenig später wurde dieser Wunsch auch als ein Ergebnis sozialwissenschaftlicher Befragungen übereinstimmend festgestellt. Die Einbeziehung der erst entstehenden Seenlandschaft enthält eine progressive, wesentlich demokratische Landschaftsvorstellung. Insofern diese mit dem Ziel der »Erhaltung und Wiederbelebung regionaler Identität« (Berkner) verbunden wird, findet zwar eine Anknüpfung an die konservative Idee der Eigenart statt, die traditionell in lokal-regional "gewachsenen « Einheiten von »Land und Leuten « zum Ausdruck kam. Doch diese Vorstellung von Eigenart wird insofern umgedeutet, als gerade die wesentlich "gemachte« industrielle Prägung der Landschaft ihren Charakter bestimmt.

\section{Landschaftskonzepte Öffentlich-Privater Partnerschaften}

Öffentlich-Private Partnerschaften, die im Rahmen der Deregulierung und Privatisierung staatlicher Aufgaben in Westeuropa seit den späten 1980er Jahren vermehrt aufkamen, wurden auch im Bereich der regionalen räumlichen Planung eingesetzt. Als solche werden die Expo-Korrespondenzregion SachsenAnhalt GmbH (1995-2000) und die Internationale Bauausstellung (IBA) FürstPückler-Land (2000-2010), denen im Diskurs eine besondere Bedeutung zukommt, untersucht. Beide griffen Ideen zivilgesellschaftlicher Gruppen und wissenschaftlicher Institutionen auf und verfolgten die Strategie einer gestalterischen Qualifizierung der Tagebaugebiete. Diese sollte möglichst durch internationale Wettbewerbe vorbereitet und in Kooperation mit der staatlichen Sanierungsgesellschaft geschehen.

\section{Expo-Korrespondenzregion Sachsen-Anhalt}

Im Zuge der Vorbereitung auf die Weltausstellung Expo 2000 entstanden unter anderem im ehemaligen Tagebau Goitzsche bei Bitterfeld besondere Land-

30 Andreas Berkner, »Der Südraum Leipzig - Rückblick und Entwicklungslinien seit 1960 und Ausblick auf den Beginn des neuen Jahrtausends«, in: Sächsische Heimatblätter 43, 5 (1997), 353-361, hier 361; vgl. Dachverein Mitteldeutsche Straße der Braunkohle (Hg.), Auf der Straße der Braunkohle. Eine Entdeckungsreise durch Mitteldeutschland, Leipzig: Pro Leipzig, 2009. 


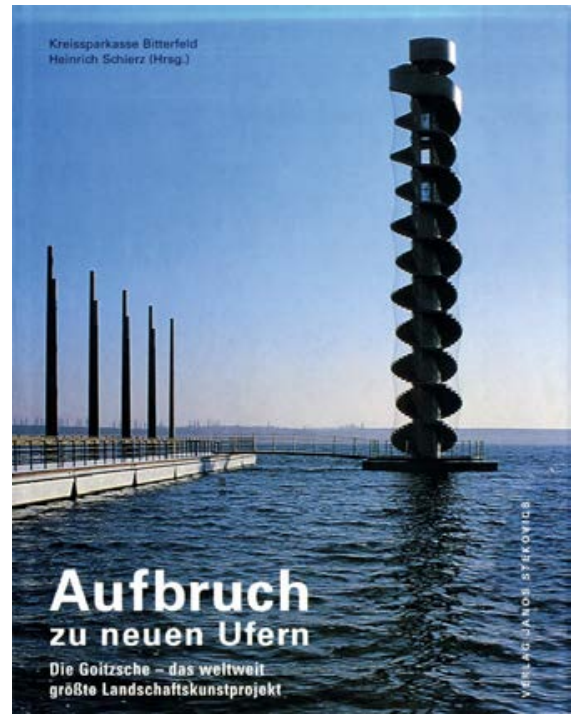

Abb. 4: „Seebrücke und Pegelturm«, Teilansicht der Arbeit von Wolfgang Christ und Klaus Bollinger am Goitzschesee, Bitterfeld; Foto: Thomas Kläber

schaftskunstwerke. Am Planungsprozess wirkten dort außer Planern und Politikern auch Teile der Bevölkerung und Künstler mit. Man einigte sich darauf, die bergbaulich-industrielle Prägung des Gebiets als kulturlandschaftlich bedeutsam anzuerkennen. ${ }^{31}$ In Anlehnung an das konservative Landschaftsideal sollte sich die Goitzsche durch ihre historische Eigenart auszeichnen. Sie wird aber entgegen diesem Ideal nicht ausschließlich als harmonisch und schön gedeutet, sondern die industriell bedingten Brüche und Widersprüche dieser Landschaft sollten künstlerisch in der Landschaft zum Thema gemacht werden. Diese demokratische Vorstellung wurde grundlegend, wenngleich die Kunstwerke mehrdeutig erscheinen und z. B. in konservativer oder romantischer Lesart betrachtet werden können. Das großräumige Landschaftskunstwerk »8 Hügel \& 49 Haldenkegel« wurde von den Künstlern Marc Babarit und Gilles Bruni mit Personen aus der Bevölkerung aus Restmaterialien geformt und erinnert explizit an die damals im Vergehen begriffene Brachenlandschaft. Beim Werk »Seebrücke mit Pegelturm« sollte die Brücke mit dem ansteigenden Wasser in der ehemaligen Tagebaugrube soweit aufschwimmen, wie die Führungsstäbe anzeigen (siehe Abb. 4). Der begehbare Turm gilt als Reminiszenz an den Bergbau und die

31 Expo 2000, Sachsen-Anhalt und Heinrich Schierz (Hg.), Land gewinnen. Die Goitzsche - das weltweit größte Landschaftskunstprojekt. Katalog zum Projekt und zur Ausstellung Kulturlandschaft Goitzsche, Halle: Mitteldeutscher Verlag, 2000. 
Ingenieurskunst. Er verweist somit zugleich auf die bergbauliche Vergangenheit und Zukunft der künstlichen Seenlandschaft.

Internationale Bauausstellung (IBA) Fürst-Pückler-Land

Die planerische Organisation IBA Fürst-Pückler-Land, die von 2000 bis 2010 in der Lausitz wirkte, trat als »Werkstatt für neue Landschaften« an. Sie kritisierte zu Beginn die Sanierungskonzepte, durch welche die riesige entstehende Seenlandschaft in der Lausitz "schnell zu einer der eintönigsten Landschaften in Europa « zu werden drohte. Vielmehr sollte die neu entstehende Landschaft insbesondere »ihren widersprüchlichen Charakter als Industrie- und Kulturlandschaft nicht verleugnen «; sie benötige moderne Industrie- und Freizeitanlagen sowie "neue städtebauliche und architektonisch-künstlerische Akzente «. ${ }^{32}$ Die von der IBA verfolgten programmatischen Ideen verdichten sich in ihrem Mottobild (siehe Abb. 5).

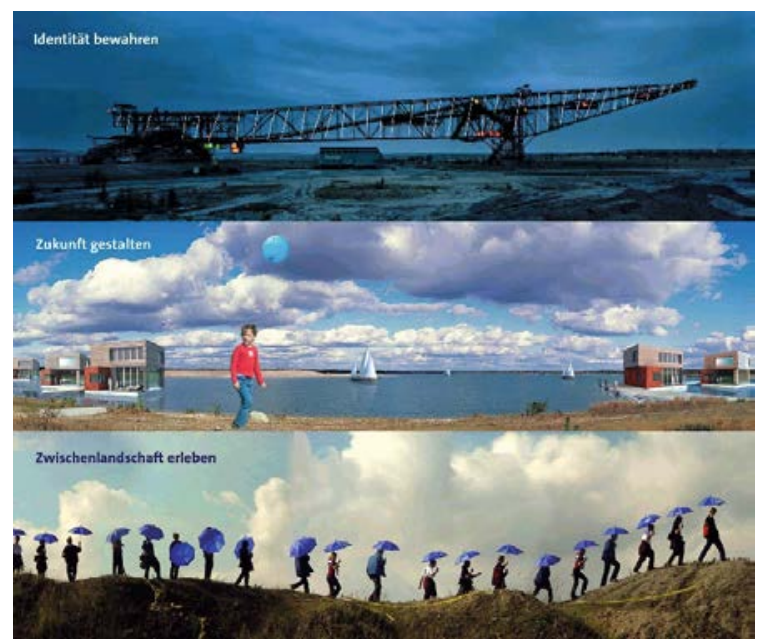

Abb. 5: Mottobild der »IBA Fürst-Pückler-Land» (2000-2010); Montage IBA

Die IBA setzte sich z. B. für die Erhaltung der oben abgebildeten Abraumförderbrücke F60, ihre Umgestaltung und Einbindung in die touristische "ENERGIE-Route Lausitzer Industriekultur« ein. Dabei war eine industriekulturell reflektierte Vorstellung leitend, welche die IBA auch explizit in die Debatten um

32 IBA Vorbereitungsgesellschaft (Hg.), Internationale Bauausstellung (IBA) Fürst-PücklerLand 2000 bis 2010. Projektkatalog, 2. verb. Aufl., Großräschen, 1999, 8; vgl. zum Abschluss der IBA: Internationale Bauausstellung (IBA) Fürst-Pückler-Land, Katalog: Neue Landschaft Lausitz/New Landscape Lusatia, Berlin: Jovis, 2010. 
das neue "Lausitzer Seenland « einbrachte. Wie das mittlere Bild zeigt, sollen »schwimmende Häuser « die junge Seenlandschaft auszeichnen. Der wesentlich demokratischen Landschaftsidee der IBA entsprechend wird das "Lausitzer Seenland ", in dem zahlreiche Seen über Kanäle schiffbar verbunden werden, als eine neu entstehende, künstliche Seenlandschaft gedeutet, die durch die bergbaulich-industrielle Geschichte bedingt ist. Diese industriegeschichtliche Prägung sollte in der Landschaft »lesbar« bleiben. Wie das untere Bild der Abbildung veranschaulicht, ging es der IBA schließlich darum, auf Touren auch ungewöhnliche oder bis dahin wenig bekannte Seiten dieser "Zwischenlandschaften« erlebbar zu machen, wie dies zuvor bereits bei den Tagebauspaziergängen im zivilgesellschaftlichen Kontext praktiziert wurde.

\section{Fazit}

Die eingangs geschilderten Auswirkungen des Tagebaus - Überbaggern von Ortschaften, Feldern und Wäldern, Umsiedlungen der Bevölkerung, weitreichendes Absenken von Grundwasser, Verlegung von Fließgewässern und Infrastrukturen - gehören $\mathrm{zu}$ den gravierendsten Landschaftsveränderungen überhaupt. Diese prägen besonders dann die Identität einer Landschaft, wenn in ihr großräumig und über eine lange Zeit, z. B. über 70 Jahre, Bergbau betrieben wurde und sich große Braunkohlereviere herausgebildet haben, die Komplexe zur industriellen Verarbeitung der Kohle umfassen. Dass sich das Gesicht der Landschaft durch die Sanierung, Rekultivierung und Umgestaltung nach dem Abbau nochmals grundlegend wandeln kann, wurde an zahlreichen Beispielen herausgearbeitet. Den gravierenden langfristigen, durch Abbau und Umgestaltung bedingten Wandel der Landschaft durch den Tagebau verdeutlichen exemplarisch die Karten des Gebiets südlich von Leipzig (siehe Abb. 6).

Links wird die Situation vor dem Bergbau um 1850 gezeigt, die sich durch ein System gewerblich genutzter Fließgewässer und Mühlgräben auszeichnet. In der Mitte wird die maximale Ausdehnung des Tagebaus um 1990 dargestellt, die zeigt, dass der »Südraum Leipzig« vollkommen vom Bergbau überformt wurde. Rechts ist der neue Gewässerverbund im »Leipziger Neuseenland " um 2015 abgebildet, in dem zahlreiche neue Seen - für die wohl ein langfristiger Steuerungsbedarf bestehen bleiben wird - mit Kanälen für Boote, teils auch Schiffe, verbunden sind. 

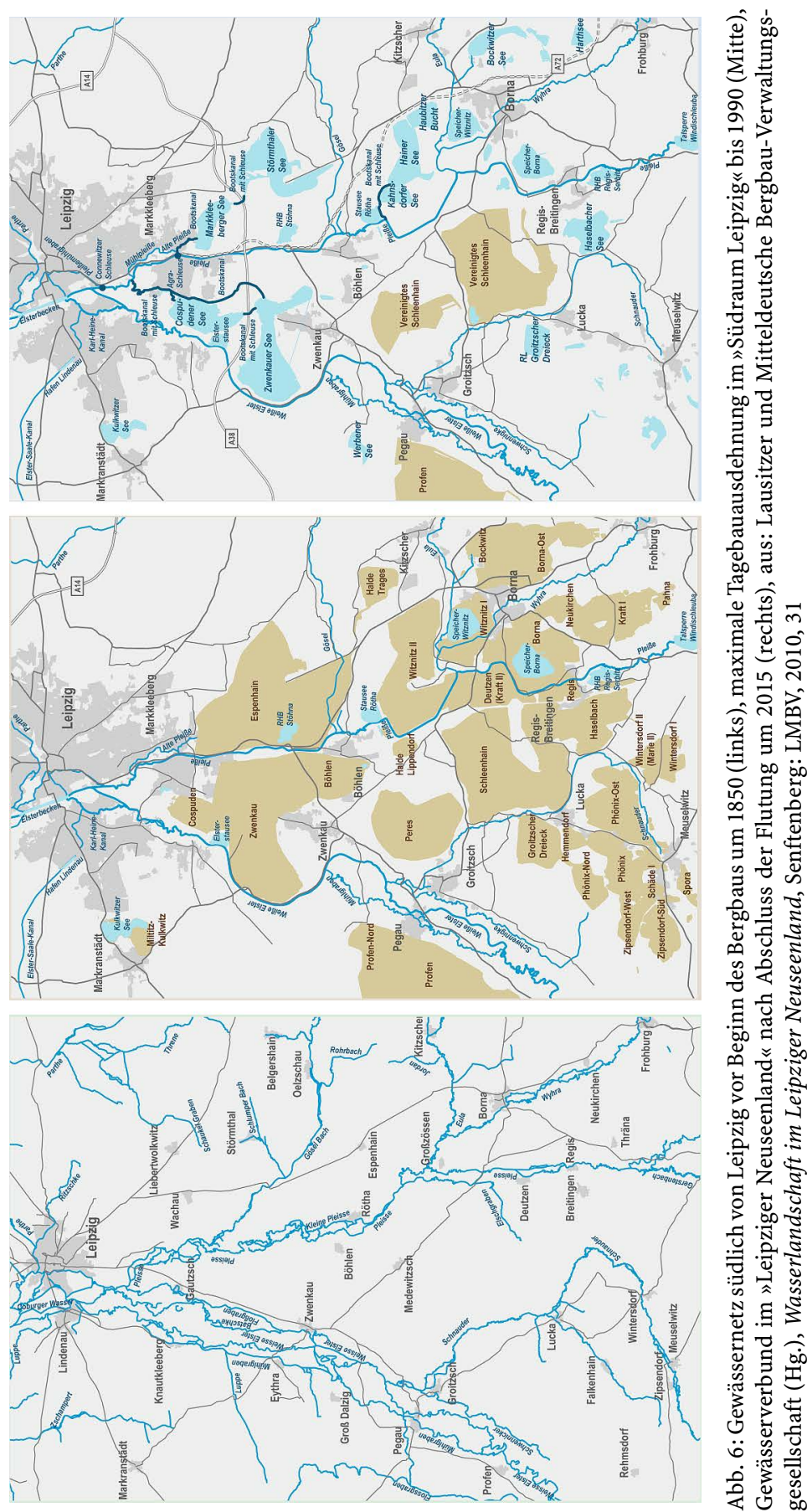

Open-Access-Publikation im Sinne der CC-Lizenz BY 4.0 
Mit dem gravierenden physischen Wandel der Landschaft korrespondiert in Bezug auf die letzte Phase der umfassenden Umgestaltung nach dem Abbau ein grundlegender Wandel des Diskurses über die Bergbaufolgelandschaft in Ostdeutschland von 1990 bis etwa 2010, der sich in folgenden Schritten charakterisieren lässt: ${ }^{33}$

(1) Zu Beginn des Diskurses hatte die rein technische Problembewältigung durch Sanierung und Rekultivierung die klare Deutungshoheit.

(2) Zwei grundlegende Umdeutungen der Tagebaubrachen gewannen an Einfluss: Die erste basierte darauf, dass die Brachen explizit ästhetisch als ungewöhnlich-faszinierende Landschaft z. B. als Wüste wahrgenommen und gedeutet wurden. Die zweite Umdeutung gründet in der besonderen symbolischen Aufladung der Brachen als »urwüchsige«, "wilde» Natur. Für beide Umdeutungen, die auf demokratischen und romantischen Sichtweisen beruhen, ist die weltanschauliche Gegnerschaft zu den in der Sanierung kombinierten liberalen und konservativen Landschaftsvorstellungen wesentlich.

(3) Die symbolische Gestaltung postindustrieller Landschaft durch eine partielle industriekulturelle und landschaftskünstlerische Ausweitung der Sanierung gelang zunächst in Einzelfällen. In diesen wurde von üblichen Abrissund Sanierungskonzepten abgewichen, wie besonders in "Ferropolis « und in der Goitzsche im Rahmen der Expo-Vorbereitung.

(4) Für die Verstetigung der Landschaftsgestaltung im Rahmen der Sanierung waren die sichtbaren und anerkannten Gestaltungen mit Modellcharakter entscheidend, wie um den Cospudener See bei Leipzig oder um den Goitzschesee bei Bitterfeld. Diese Verstetigung manifestiert sich darin, dass die Durchführung besonderer landschaftsgestalterischer Maßnahmen nach 2002 institutionalisiert und regelmäßig im Kontext der Sanierung durchgeführt wurden, wenn auch in unterschiedlicher Qualität.

(5) Die Profilierung der vom Tagebau vollkommen überformten Regionen basiert auf Artefakten der historischen Industrielandschaft und insbesondere der neu entstehenden Seen mit ihren Häfen, Kanälen, Stränden und Promenaden. Diese regionale Profilierung impliziert eine weite Deutung von Landschaft, die in der Regel positiv auf ihre künftige Nutzbarkeit und auf den bergbaulichindustriellen Charakter rekurriert, der in unterschiedlichem Ausmaß reflektiert wird.

Die naturnahe Entwicklung der Tagebaubrachen, ihre Sanierung, Rekultivierung und Umgestaltung führte dazu, dass zum Teil Landschaften mit einer eigenen Charakteristik entstanden sind. Einige von ihnen, in denen kein Abbau mehr stattfindet und die sich durch besondere Naturausprägungen und industriekulturelle Relikte oder Gestaltungen auszeichnen wie die Goitzsche, die

33 Schwarzer, Von Mondlandschaften zur Vision eines neuen Seenlandes, 381-385. 
Industriekulturlandschaft »Ferropolis«, das Leipziger Neuseenland oder das Lausitzer Seenland, gehören mittlerweile zu den »Bedeutsamen Landschaften in Deutschland « und wurden im gleichnamigen Konzept aufgenommen. ${ }^{34}$

\section{Literatur}

Akademie für Raumforschung und Landesplanung (Hg.). Braunkohlenplanung und Umsiedlungsproblematik in der Raumordnungsplanung Brandenburgs, NordrheinWestfalens, Sachsens und Sachsen-Anhalts, Hannover: ARL, 2000.

Bayerl, Günter. «Die Niederlausitz. Industrialisierung und De-Industrialisierung einer Kulturlandschaft«, in: Blätter für Technikgeschichte 65 (2003), 89-163.

Berkner, Andreas. »Der Südraum Leipzig - Rückblick und Entwicklungslinien seit 1960 und Ausblick auf den Beginn des neuen Jahrtausends«, in: Sächsische Heimatblätter 43, 5 (1997), 353-361.

Bismarck, Friedrich von. »Programm der Braunkohlesanierung: Weichenstellung für Regionen?«, in: Nachhaltige Entwicklung von Folgelandschaften des Braunkohlebergbaus. Stand und Perspektiven in Wissenschaft und Praxis, Cornelia Gläßer (Hg.), Berlin: Analytica, 2004, 12-19.

Bundesanstalt für Geowissenschaften und Rohstoffe. Energierohstoffe 2009. Reserven, Ressourcen, Verfügbarkeit, Hannover: BGR, 2009.

Bund-Länder-Geschäftsstelle für die Braunkohlesanierung (Hg.). 20 Jahre Verwaltungsabkommen Braunkohlesanierung. Gesichter und Geschichten der Braunkohlesanierung, Berlin: Bund-Länder-Geschäftsstelle für die Braunkohlesanierung, 2012.

Dachverband Bergbaufolgelandschaft u. a. (Hg.). Jahrbuch Bergbaufolgelandschaft. Leipzig: Pro Leipzig, 1996.

Ders. (Hg.). Jahrbuch Bergbaufolgelandschaft. Leipzig: Pro Leipzig, 1997.

Ders. (Hg.). Jahrbuch Bergbaufolgelandschaft. Leipzig: Pro Leipzig, 1998.

Ders. (Hg.). Jahrbuch Bergbaufolgelandschaft. Leipzig: Pro Leipzig, 1999.

Dachverein Mitteldeutsche Straße der Braunkohle (Hg.). Auf der Straße der Braunkohle. Eine Entdeckungsreise durch Mitteldeutschland, Leipzig: Pro Leipzig, 2009.

Ernst, Hartmut, Helmut Wolff und Sven-Uwe Schulz. »Die europäischen Braunkohlenreviere«, in: Der Braunkohlentagebau. Bedeutung, Planung, Betrieb, Technik, Umwelt, Rolf Dieter Stoll, Christian Niemann-Delius, Carsten Drebenstedt und Klaus Müllensiefen (Hg.), Berlin/Heidelberg: Springer, 2009, 13-33.

Expo 2000, Sachsen-Anhalt und Heinrich Schierz (Hg.). Land gewinnen. Die Goitzsche das weltweit größte Landschaftskunstprojekt. Katalog zum Projekt und zur Ausstellung Kulturlandschaft Goitzsche, Halle: Mitteldeutscher Verlag, 2000.

Förster, Frank. Bergbau-Umsiedler. Erfahrungsberichte aus dem Lausitzer Braunkohlenrevier, Bautzen: Domowina, 1998.

34 Markus Schwarzer, Andreas Mengel, Werner Konold, Nicole Reppin, Linda Mertelmeyer, Manuel Jansen, Karl-Heinz Gaudry und Manuel Oelke, Bedeutsame Landschaften in Deutschland. Gutachtliche Empfehlungen für eine Raumauswahl, Band 1 und 2, BfN-Skripten 516 und 517, Bonn-Bad Godesberg, 2018. 
Foucault, Michel. Archäologie des Wissens (französisches Origiginal: L'archéologie du savoir, Paris: Gallimard, 1969), Frankfurt am Main: Suhrkamp, 1997.

Gill, Bernhard. Streitfall Natur: Weltbilder in Technik- und Umweltkonflikten, Wiesbaden: Westdeutscher Verlag, 2003.

Haubold-Rosar, Michael. "Landwirtschaft«, in: Wissenschaftliche Begleitung der ostdeutschen Braunkohlesanierung. Forschungsprojekte 1994 bis 2000, Lausitzer und Mitteldeutsche Bergbau-Verwaltungsgesellschaft (LMBV) (Hg.), Berlin: LMBV, 2001, 132-154.

Heidenreich, Bernd (Hg.). Politische Theorien des 19. Jahrhunderts. Konservatismus, Liberalismus, Sozialismus, Berlin: Akademie Verlag, 2002.

Hirsch Hadorn, Gertrude. "Webers Idealtypus als Methode zur Bestimmung des Begriffsinhalts theoretischer Begriffe in den Kulturwissenschaften ", in: Journal for General Philosophy of Science 28 (1997), 275-296.

IBA Vorbereitungsgesellschaft (Hg.). Internationale Bauausstellung (IBA) Fürst-PücklerLand 2000 bis 2010. Projektkatalog, Großräschen, 2. verbesserte Auflage 1999.

Internationale Bauausstellung (IBA) Fürst-Pückler-Land. Katalog: Neue Landschaft Lausitz/ New Landscape Lusatia, Berlin: Jovis, 2010.

Knoche, Dirk. "Forstliche Rekultivierung", in: Wissenschaftliche Begleitung der ostdeutschen Braunkohlesanierung. Forschungsprojekte 1994 bis 2000, Lausitzer und Mitteldeutsche Bergbau-Verwaltungsgesellschaft (LMBV) (Hg.), Berlin: LMBV, 2001, 105-131.

Köck, Uwe-Volkmar, »Naturschutz«, in: Wissenschaftliche Begleitung der ostdeutschen Braunkohlesanierung. Forschungsprojekte 1994 bis 2000, Lausitzer und Mitteldeutsche Bergbau-Verwaltungsgesellschaft (LMBV) (Hg.), Berlin: LMBV, 2001, 155-192.

Krummsdorf, Albrecht und Gerhard Grümmer. Landschaft vom Reißbrett. Die Zukunft unserer Kippen, Halden und Restlöcher, Leipzig/Jena/Berlin: Urania, 1981.

Landwehr, Achim. Historische Diskursanalyse, Frankfurt/New York: Campus, 2008.

Lausitzer und Mitteldeutsche Bergbau-Verwaltungsgesellschaft (LMBV) (Hg.). Wasserlandschaft im Leipziger Neuseenland, Senftenberg: LMBV, 2010.

Le Monde diplomatique (Hg.). Atlas der Globalisierung, spezial. Das 20. Jahrhundert, Berlin: TAZ, 2011.

Niewiadomski, Arkadiusz. "Tagebau in polnischer Landschaft - Rekultivierungsmöglichkeiten bei Braunkohlen- und Schwefelbergwerken", in: Zwischen Ökonomie und Ökologie? Raumstruktureller Wandel, Raumplanung und Nutzungskonflikte in Deutschland und Polen, Georg Stöber (Hg.), Göttingen: V\&R unipress, 2012, 27-41.

Pflug, Wolfram (Hg.). Braunkohlentagebau und Rekultivierung. Landschaftsökologie, Folgenutzung, Naturschutz, Berlin/Heidelberg: Springer, 1998.

Schwarzer, Markus. Von Mondlandschaften zur Vision eines neuen Seenlandes. Der Diskurs über die Gestaltung von Tagebaubrachen in Ostdeutschland, Wiesbaden: Springer VS, 2014.

Ders. »Landschaft und Industrie. Zur Geschichte und Theorie eines ambivalenten Verhältnisses", in: Umwelten. Ereignisse, Räume und Erfahrungen in der Frühen Neuzeit. Festschrift für Manfred Jakubowski-Tiessen, Sven Petersen, Dominik Collet und Marian Füssel (Hg.), Göttingen: V\&R unipress, 2015, 101-125.

Schwarzer, Markus, Andreas Mengel, Werner Konold, Nicole Reppin, Linda Mertelmeyer, Manuel Jansen, Karl-Heinz Gaudry und Manuel Oelke. Bedeutsame Landschaften in 
Deutschland. Gutachtliche Empfehlungen für eine Raumauswahl, Band 1 und 2, BfNSkripten 516 und 517, Bonn-Bad Godesberg, 2018.

Statistik der Kohlenwirtschaft (Hg.). Der Kohlenbergbau in der Energiewirtschaft der Bundesrepublik Deutschland im Jahre 2018, Essen/Bergheim: Statistik der Kohlenwirtschaft, 2019.

Stiftung Bauhaus Dessau (Hg.). Industrielles Gartenreich. Dessau - Bitterfeld - Wittenberg, 2 Bände, Berlin: ex pose, 1996 und 1999.

Tajduś, Antoni, Wiesław Kozioł und Paweł Kawalec. »Present state and prospects of lignite extraction in Poland «, in: World of Mining - Surface \& Underground 59, 1 (2007), 36-41.

Tischew, Sabine (Hg.). Renaturierung nach dem Braunkohleabbau, Stuttgart/Leipzig/ Wiesbaden: Teubner, 2004.

Toyka, Rolf (Hg.). Bitterfeld. Braunkohlebrachen: Probleme - Chancen - Visionen, München: Prestel, 1993.

Trepl, Ludwig. Die Idee der Landschaft. Eine Kulturgeschichte von der Aufklärung bis zur Ökologiebewegung, Bielefeld: transcript, 2012.

Vicenzotti, Vera. Der "Zwischenstadt«-Diskurs. Eine Analyse zwischen Wildnis, Kulturlandschaft und Stadt, Bielefeld: transcript, 2011.

Weber, Max. »Die `Objektivität`sozialwissenschaftlicher und sozialpolitischer Erkenntnis«, in: Gesammelte Aufsätze zur Wissenschaftslehre von Max Weber, Johannes Winckelmann (Hg.), Tübingen: J.C.B. Mohr, 1988 [Erstdruck 1904], 146-214.

Wiegleb, Gerhard, Udo Bröring, Jadranka Mrzljak und Friederike Schulz (Hg.). Naturschutz in Bergbaufolgelandschaften. Landschaftsanalyse und Leitbildentwicklung, Heidelberg: Physica, 2000. 


\section{Windenergienutzung und Landschaftsdebatten - Erfahrungen aus Polen und Deutschland}

\section{Windenergienutzung und Landschaftsdebatten in Polen und Deutschland: Eine Annäherung}

Die Entwicklung erneuerbarer Energien ist in den Nachbarstaaten Polen und Deutschland bislang sehr unterschiedlich verlaufen. Während Deutschland die Energiewende und damit $u$. a. den Ausbau der erneuerbaren Energien ausgerufen hat, setzt Polen weiterhin vor allem auf die Versorgung durch Braun- und Steinkohle und den Bau von zwei Atomkraftwerkens, wobei über deren Standort noch nicht entschieden wurde. Beide Staaten haben sich in der EU-Richtlinie 2009/28/ EG dazu verpflichtet, im Jahr 2020 einen bestimmten Anteil ihrer Energie aus erneuerbaren Quellen zu gewinnen: $15 \%$ in Polen und $18 \%$ in Deutschland. Da diese Ziele vor allem im Transportsektor schwer zu erfüllen sind, müssen im Stromsektor höhere Ziele erreicht werden. Die Umsetzung wird in beiden Staaten mit sehr unterschiedlichen Anreizsystemen angestrebt - in Deutschland durch festgelegte Verpflichtungen zur Abnahme und zur Vergütung von Strom und in Polen durch ein System von Zertifikaten. ${ }^{1}$ In Deutschland entwickelte sich die Windenergienutzung ${ }^{2}$ relativ schnell, so dass sich Ende 2018 an Land 29.213 Windenergieanlagen (WEA) ${ }^{3}$ mit einer installierten Leistung von fast $53 \mathrm{GW}$ drehten. ${ }^{4}$ Allerdings sank die Neubaurate 2018 und 2019 erheblich. ${ }^{5}$ Die Ent-

1 Wolfram Distler, »Vergleich einzelner Regulierungssysteme - Deutschland, Frankreich, Italien und Polen«, in: Jörg Böttcher (Hg.), Handbuch Windenergie. Onshore-Projekte: Realisierung, Finanzierung, Recht und Technik, München: Oldenbourg Wissenschaftsverlag, 2012, 67-98.

2 Auch wenn die Windenergienutzung vor der Küste eine zunehmende Rolle spielt, steht in diesem Artikel nur die Onshore-Windkraft im Fokus.

3 Statista, »Anzahl der Onshore-Windenergieanlagen in Deutschland in den Jahren 2000 bis 2018«, https://de.statista.com/statistik/daten/studie/20116/umfrage/anzahl-der-windkraftan lagen-in-deutschland-seit-1993/, zuletzt geprüft am 25. November 2019.

4 Deutsche WindGuard GmbH, „Status des Windenergieausbaus an Land in Deutschland. Jahr 2018«, https://www.wind-energie.de/fileadmin/redaktion/dokumente/pressemitteilungen/ 2019/20190129_Factsheet_Status_des_Windenergieausbaus-Jahr_2018.pdf, zuletzt geprüft am 25. November 2019. 
wicklung in Polen verlief bisher schleppender: mit 2.300 Anlagen und einer installierten Leistung von 3,7 GW erreichte Polen nur etwa ein Zehntel der in Deutschland installierten Kapazität. ${ }^{6}$ Auf der lokalen Ebene zeigen sich in beiden Staaten sehr unterschiedliche Reaktionen auf konkrete Windenergieplanungen, die von engagierter Unterstützung bis zur offenen Ablehnung reichen. Neben vielen anderen Diskussionspunkten hinsichtlich der Befürwortung oder Ablehnung von Windenergieprojekten - wie beispielsweise ökonomische Vor- und Nachteile, ökologische Ziele und Gefahren, Gesundheitsrisiken oder Misstrauen gegenüber Investoren und Planern - wird die Veränderung der Landschaft häufig als ein wesentliches Argument in lokalen Windkraftdiskussionen beschrieben.

Windkraftanlagen verändern mit ihrer steigenden Anzahl und Größe vielerorts den physischen Raum und lassen dabei in einem rasanten Tempo "new landscapes ${ }^{7}$ entstehen. In diesen Energielandschaften oder »landscapes of carbon neutrality ${ }^{8}$ materialisieren sich Debatten um Energiesicherheit, Klimaschutz und den Ausbau erneuerbarer Energien und es werden neue gesellschaftliche Anforderungen an den Raum sichtbar. Landschaft und deren Veränderungen werden in diesem Beitrag aus einer konstruktivistischen Perspektive betrachtet. Es wird also davon ausgegangen, dass es nicht natürlich oder festgelegt ist, was unter "Landschaft « verstanden wird und wie deren Veränderungen wahrgenommen werden, sondern dass Landschaftsverständnisse jeweils sozial ausgehandelt werden beispielsweise in Diskussionen um die Nutzung der Windenergie. ${ }^{9}$ In diesem Beitrag soll zum einen aufgezeigt werden, wie sich die Windenergienutzung in Deutschland und Polen entwickelt hat. Zum anderen soll der Frage nachgegangen werden, ob und wenn ja, welche Landschaftsdebatten mit dieser Entwicklung in Deutschland und Polen verknüpft waren und sind.

5 Deutsche WindGuard GmbH, "Status des Windenergieausbaus an Land in Deutschland. Erstes Halbjahr 2019«, https://www.wind-energie.de/fileadmin/redaktion/dokumente/publi kationen-oeffentlich/themen/06-zahlen-und-fakten/20190725_Factsheet_Status_des_Wind energieausbaus_an_Land_-_Halbjahr_2019.pdf, zuletzt geprüft am 25. November 2019.

6 »Ile mamy w Polsce wiatraków? Zainstalowana moc elektrowni wiatrowych w 2014 r« [Wie viele Windmühlen haben wir in Polen? Installierte Kapazität im Jahr 2014], http://wiatrowa. blox.pl/2014/07/Ile-mamy-w-Polsce-wiatrakow-Zainstalowana-moc.html, zuletzt geprüft am 22. Februar 2018.

7 Robert Thayler und Carla Freeman, «Altamont: Public Perceptions of a Wind Energy Landscape«, in: Landscape and Urban Planning 14 (1987), 379-398, 396.

8 Paul Selman, "Learning to Love the Landscapes of Carbon-Neutrality«, in: Landscape Research 35, 2 (2010), 157-171.

9 Detaillierte Darstellungen zu einer konstruktivistischen Sichtweise auf Landschaft finden sich u. a. in Ludger Gailing und Markus Leibenath, "Von der Schwierigkeit, 'Landschaft ‘ oder ,Kulturlandschaft` allgemeingültig zu definieren«, in: Raumforschung und Raumordnung 70, 4 (2012), 95-106 sowie in Olaf Kühne, „Grundzüge einer konstruktivistischen Landschaftstheorie und ihre Konsequenzen für die räumliche Planung", in: Raumforschung und Raumordnung 67, 5-6 (2009), 395-404. 
Um diese Fragen zu beantworten werden zunächst die Entwicklungen der Windenergienutzung und verbundene lokale Auseinandersetzungen in Deutschland und Polen aufgezeigt. Daran schließt sich ein Kapitel an, in dem Literatur zitiert wird, die zum Teil über beide Staaten hinausgeht und die Rolle von Landschaft in lokalen Konflikten um Windräder beleuchtet. Anschließend wird je ein Fallbeispiel zu einem Windenergiekonflikt aus Deutschland und Polen vorgestellt, bevor ein Fazit gezogen wird.

\section{Deutschland: Entwicklung der Windenergienutzung und lokale Konflikte}

Seit Mitte der 1960er gab es zahlreiche lokale Proteste in Deutschland, die mit der zunehmend wachsenden Umweltbewegung ${ }^{10}$ verknüpft waren. Die Ablehnung der Atomenergie spielte dabei eine entscheidende Rolle. ${ }^{11}$ Erste Anfänge der modernen Nutzung der Windenergie wurden in der wachsenden Umweltbewegung als zukunftsweisende, nicht-endliche Alternative zur Atomenergie verstanden und in den 1980er Jahre zudem als eine Antwort auf den vieldiskutierten "sauren Regen« gesehen. In den 1990ern unterstützten die Debatten um Klimawandel und Nachhaltigkeit sowie das neu eingeführte Stromeinspeisungsgesetz den Ausbau der Windenergienutzung weiter. $\mathrm{Zu}$ dieser Zeit setzte eine Institutionalisierung der Windenergiebranche ein. Während die vereinzelt stehenden, kleinen Anlagen von Idealisten und Bauern betrieben wurden, stiegen nun große Investoren in das Windgeschäft ein und die Anzahl der Windkraftanlagen nahm insbesondere in Norddeutschland rasant $\mathrm{zu}^{12}{ }^{12}$ Zusammenfassend fand seitdem eine Konsolidierung und eine weitere Zunahme des Windenergieausbaus statt, wobei das Erneuerbare-Energien-Gesetz seit 2000 ein stabiles Anreizsystem durch festgelegte Anschluss-, Abnahme- und Vergütungsverpflichtungen bietet. ${ }^{13}$ Diese Verstetigung der Windenergienutzung wurde durch

10 Die Umweltbewegung erstarkt zwar ab den 1960ern, geht aber auf die mehr als 100 Jahre alte Naturschutzbewegung zurück. Siehe z. B. Frank Uekötter, „Sieger der Geschichte? Überlegungen zum merkwürdigen Verhältnis des Naturschutzes zu seinem eigenen Erfolg", in: Schriftenreihe des Deutschen Rates für Landespflege 75 (2003), 34-38.

11 Joseph Huber, "Umweltbewegung. Vom Outsider-Protest zur Assimilation«, in: Joseph Huber (Hg.), Allgemeine Umweltsoziologie, Wiesbaden: VS, 2011, 120-126.

12 Rüdiger Mautz, »Konflikte um die Offshore-Windkraftnutzung - eine neue Konstellation der gesellschaftlichen Auseinandersetzung um Ökologie« in: Peter Feindt und Thomas Saretzki (Hg.), Umwelt- und Technikkonflikte, Wiesbaden: VS, 2010, 181-186; Ion Bogdan Vasi, Winds of Change. The Environmental Movement and the Global Development of the Wind Energy Industry, Oxford: Oxford University Press, 2011, 55-68.

13 Rüdiger Mautz, Andreas Byzio und Wolf Rosenbaum, Auf dem Weg zur Energiewende. Die Entwicklung der Stromproduktion aus erneuerbaren Energien in Deutschland, Göttingen: 
den sogenannten Ausstieg aus der Atomenergie, der vor dem Hintergrund des Tsunamis und dessen Folgen für das Atomkraftwerk in Fukushima (Japan) 2011 von der Bundesregierung erneut beschlossen wurde, weiter bestärkt. Grundlage des Ausbaus erneuerbarer Energien in Deutschland ist das sogenannte energiepolitische Zieldreieck, das aus Bezahlbarkeit, Versorgungssicherheit und Umweltverträglichkeit besteht. ${ }^{14}$ Allerdings erfolgte seit 2018 der Zubau sehr gebremst. ${ }^{15}$ Der Anteil der Windenergie am Stromverbrauch lag 2018 bei über $14 \%$ und der Anteil aller erneuerbaren Energien bei 35,2 \%. ${ }^{16}$ Bis 2025 soll der Beitrag der erneuerbaren Energien am Stromverbrauch von 25,3 \% 2013 auf 40 bis $45 \%$ erhöht werden und hierfür soll auch die Windenergienutzung weiter gestärkt werden. ${ }^{17}$ Dies soll zu Teilen dadurch erreicht werden, dass alte WEA durch neuere, effizientere Anlagen ersetzt werden (Repowering), die in der Regel deutlich höher sind als ältere Anlagen.

Auf der lokalen Ebene zeigt sich derzeit ein sehr diverses Bild, das von Bürgerenergiegenossenschaften als Betreibern von Windparks bis hin zu Initiativen reicht, die gegen Windenergieprojekte kämpfen. ${ }^{18}$ Lokale Konflikte um Windparks zeigten sich in einigen Regionen bereits in den 1990er Jahren. ${ }^{19}$ Dies ging einher mit einer Zunahme und Konzentration von WEA, die zu größeren Windparks führte. ${ }^{20}$ In diesen Konflikten spielen Anwohnerinteressen und Nutzungskonkurrenzen eine entscheidende Rolle. Neben der Kritik an einer Beeinträchtigung der Lebensqualität durch Lärm oder visuelle Störungen, der Angst um Wertverlust von Immobilien und der Gefährdung von Vögeln und

Universitätsverlag Göttingen, 2008, 83-135; Distler, »Vergleich einzelner Regulierungssysteme - Deutschland, Frankreich, Italien und Polen«, $69 \mathrm{f}$.

14 Bundesministerium für Wirtschaft und Energie, »Zweiter Monitoring-Bericht $>$ Energie der Zukunft«", http://www.bmwi.de/BMWi/Redaktion/PDF/Publikationen/zweiter-monitoringbericht-energie-der-zukunft,property $=$ pdf,bereich $=$ bmwi2012, sprache $=$ de, $r w b=$ true.pdf, zuletzt geprüft am 22. Februar 2018.

15 Deutsche WindGuard GmbH, "Status des Windenergieausbaus an Land in Deutschland. Erstes Halbjahr 2019«.

16 Agentur für Erneuerbare Energien, »Grafik-Dossier: Der Strommix in Deutschland 2014-2018«, https://www.unendlich-viel-energie.de/mediathek/grafiken/der-strommix-indeutschland-2018, zuletzt geprüft am 22. November 2019.

17 Bundesministerium für Wirtschaft und Energie, "Gesetz für den Ausbau erneuerbarer Energien (Erneuerbare-Energien-Gesetz - EEG 2014)«, http://www.bmwi.de/BMWi/Redakti on/PDF/G/gesetz-fuer-den-ausbau-erneuerbarer-energien,property $=$ pdf,bereich $=$ bmwi 2012, sprache $=$ de, $r w b=$ true.pdf, zuletzt geprüft am 22. Februar 2018.

18 Für Brandenburg z. B.: Sören Becker, Ludger Gailing und Matthias Naumann, "Neue Akteurslandschaften der Energiewende. Aktuelle Entwicklungen in Brandenburg«, in: RaumPlanung 162, 3 (2012), 42-46.

19 Dörte Ohlhorst und Susanne Schön, "Windenergienutzung in Deutschland im dynamischen Wandel von Konfliktkonstellationen und Konflikttypen« in: Peter H. Feindt und Thomas Saretzki (Hg.), Umwelt- und Technikkonflikte, Wiesbaden: Verlag für Sozialwissenschaften, 2010, 198-218, 200.

20 Mautz, Byzio und Rosenbaum, Auf dem Weg zur Energiewende, 104-106. 
Fledermäusen wurde die "Verspargelung« der Landschaft seit Mitte der 1990er Jahre als ein Hauptargument gegen geplante Windparks vorgebracht. ${ }^{21}$ In den letzten Jahren hat sich der Protest über einzelne Bürgerinitiativen hinweg institutionalisiert. So gibt es seit 2013 beispielsweise die Initiative Vernunftkraft ${ }^{22}$, die sich gegen den "subventionierten Ausbau« der Windenergie engagiert und seit 2017 mit der AfD eine Partei im Bundestag, die sich zum Ziel gesetzt hat, den "Ausbau der Windenergie [zu] stoppen ${ }^{23}$

Die Raumplanung ist dafür zuständig, zwischen divergierenden Interessen abzuwägen und Standorte als Vorrang-, Vorbehalts- oder Ausschlussgebiete für die Windenergienutzung auszuweisen. ${ }^{24}$ Das Vorgehen ist dabei entsprechend der föderalen Struktur Deutschlands nicht einheitlich. Die erarbeiteten Pläne müssen laut Raumordnungsgesetz der Öffentlichkeit zur Information und Stellungnahme ausgelegt werden. ${ }^{25}$ Bei der konkreten Standortplanung regelt das Bundesimmissionsschutzgesetz, ab welcher Windparkgröße eine Umweltverträglichkeitsprüfung mit einer Öffentlichkeitsbeteiligung notwendig ist (bspw. bei mehr als 20 Anlagen). Negative Auswirkungen von Windparks auf Natur und Landschaft müssen laut Bundesnaturschutzgesetz kompensiert werden. ${ }^{26}$

\section{Polen: Entwicklung der Windenergienutzung und lokale Konflikte}

Im Gegensatz zu Deutschland weist Polen keine starke Opposition gegen Atomenergie auf. Zwar wurde der Bau des Atomreaktors in Żarnowiec Anfang der 1990er Jahre u. a. aufgrund sozialer Proteste aufgegeben, ${ }^{27}$ aber die Protestbewegung war zu schwach um eine radikale Transformation des Energiesektors,

21 Elke Bruns und Dörte Ohlhorst, »Wind Power Generation in Germany«, in: The Journal of Transdisciplinary Environmental Studies 10, 1 (2011), 44-67.

22 Bundesinitiative Vernunftkraft e. V., »Unser Antrieb«, https://www.vernunftkraft.de/missi on/, zuletzt geprüft am 25. November 2019.

23 AfD (Alternative für Deutschland), »Programm für Deutschland. Wahlprogramm der Alternative für Deutschland für die Wahl zum Deutschen Bundestag am 24. September 2017«, https://www.afd.de/wp-content/uploads/sites/111/2017/06/2017-06-01_AfD-Bundestagswahl programm_Onlinefassung.pdf, zuletzt zugegriffen am 25. November 2019.

24 Daniel Schneider und Nils Boenigk, Themenheft »Planungsrecht \& Erneuerbare Energien«, Renews Spezial. Hintergrundinformation der Agentur für Erneuerbare Energien 62 (2012), $15-17$.

25 Jörn Birkmann, Maike Vollmer und Jochen Schanze, Raumentwicklung im Klimawandel. Herausforderungen für die räumliche Planung, Forschungsberichte der ARL 2, Hannover: ARL, 2013, 101.

26 Schneider und Boenigk, »Planungsrecht \& Erneuerbare Energien«, 15-17 und $27 \mathrm{f}$.

27 Ilona Kordulska, Zanim wejdziesz na drzewo. Poradnik prawny obrońcy środowiska [Bevor du auf den Baum steigst. Juristisches Fachbuch für Umweltschützer], http://www.zb.eco.pl/ BZB/34/rozdz4.htm, zuletzt geprüft am 22. Februar 2018. 
ähnlich der deutschen »Energiewende«, zu initiieren. Vielmehr führte Polens Mitgliedschaft in der Europäischen Union zur Einführung eines Fördermechanismus im Jahre 2005 und zum Ausbau erneuerbarer Energien. Der Anteil der Windenergie am Stromverbrauch in Polen nahm seitdem stetig zu und lag 2012 bei knapp drei $\%{ }^{28} 2013$ stand Polen bei der neu installierten Kapazität von Windenergie nach Deutschland und Großbritannien sogar europaweit auf dem dritten Platz. ${ }^{29}$

Allerdings erwies sich das in Polen eingeführte System der "Grünen Zertifikate" (zielone certyfikaty) im Vergleich zum deutschen System als kompliziert und aufwendig. In diesem System erhalten Windenergieinvestoren neben dem durchschnittlichen Börsenstrompreis aus dem vorherigen Jahr Zertifikate, die sie an der Börse verkaufen können, um zusätzliche Gewinne zu erzielen. Damit ist aber ein hohes Risiko verbunden, denn die Preise dieser Zertifikate können sich sehr schnell ändern und dadurch die Wirtschaftlichkeit der Projekte beeinflussen. Aus diesem Grund wurden Windenergieinvestitionen hauptsächlich von großen, ausländischen Investoren getätigt. Zwar können sich Gemeinden mit WEA über zusätzliche Steuereinnahmen freuen, aber insbesondere die strukturschwächeren von ihnen verlieren mit den steigenden Einnahmen ihren Anspruch auf staatliche Subventionen. ${ }^{30}$ Dadurch entsteht vor Ort oft der Eindruck einer ungleichmäßigen Verteilung der (visuellen) Kosten und (finanziellen) Vorteile eines Windparks, was zu Protesten gegen solche Planungen führt.

Die Gegner der Windenergie in Polen sind gut vernetzt und organisiert. Eine Initiative "Stopp den Windmühlen" (Stop wiatrakom) unterstützt die Gemeinden, in denen Windenergieinvestitionen geplant werden. Die Argumente von Windenergiegegnern sind vielfältig und beziehen sich auf Naturschutzaspekte, finanzielle Beteiligung, rechtliche und gesundheitliche Aspekte sowie Landschaftsbeeinträchtigungen. Diese Argumente fanden Unterstützung in der größten Oppositionspartei im polnischen Parlament, der Partei Recht und Gerechtigkeit (Prawo i Sprawiedliwość - PiS). Im Juni 2012 legten Mitglieder dieser Partei einen Entwurf zur Novellierung des Baugesetzes vor, welcher einen Abstand zu Wohnsiedlungen von mindestens $3 \mathrm{~km}$ für WEA, die größer als $500 \mathrm{~kW}$

28 International Energy Agency, »Statistics. Poland: Energy and Heat for 2012«, http://www.iea. org/statistics/statisticssearch/report/?country=POLAND\& product=electricityandheat $\&$ year $=201$, Seite ist nicht mehr aktiv.

29 The European Wind Energy Association, »Wind in power 2013. European statistics, February 2014«, 5, http://www.ewea.org/fileadmin/files/library/publications/statistics/EWEA_Annu al_Statistics_2013.pdf, zuletzt geprüft am 22. Februar 2018.

30 »Sejm RP. Obwieszczenie Marszałka Sejmu Rzeczypospolitej Polskiej z dnia 28 kwietnia 2010 r. w sprawie ogłoszenia jednolitego tekstu ustawy o dochodach jednostek samorządu terytorialnego « [Bekanntmachung des Vorsitzenden des polnischen Parlaments vom 28. April 2010 über die Veröffentlichung des einheitlichen Textes des Gesetzes zum Erträge der lokalen Gemeinden], Dziennik Ustaw 2010, Nr. 80, Position 526, Art. 19. 
sind, vorschreibt. ${ }^{31}$ Zwar wurde dieser Vorschlag durch das Parlament abgelehnt, doch kurz danach brachte der polnische Präsident einen Entwurf des sogenannten "Landschaftsgesetzes« ein, das eigentlich gegen die allgegenwärtige Werbung gerichtet ist, aber nun auch Windräder als landschaftsdominierende Elemente betrachtet. Das Gesetz wurde 2015 verabschiedet. Damit wurde es für Investoren schwieriger, neue WEA zu bauen, selbst wenn die Gemeinde zustimmt, denn neue Planungen können auch von den Wojewoden blockiert werden.

In einer steigenden Anzahl von Gemeinden nimmt die Unterstützung für erneuerbare Energien dennoch als eine Alternative zum Braunkohleabbau zu. Im Jahr 2009 hat sich die Initiative »Stopp dem Tagebau (Stop odkrywce) gegründet - mit dem Ziel, weitere von der Regierung geplante Tagebaustätten zu verhindern und stattdessen Unterstützung für erneuerbare Energien, insbesondere als Bürgerprojekte, $\mathrm{zu}$ fordern. Im Jahre 2011 wurde eine polenweite Koalition »Entwicklung JA - Tagebaue NEIN« (Ogólnopolska Koalicja »Rozwój TAK Odkrywki NIE«) mit dem gleichen Ziel gegründet, der Gemeinden, lokale Vereine und Umweltverbände angehören. ${ }^{32}$ Zudem gibt es zahlreiche Gemeinden, in denen WEA nicht als Beeinträchtigung der Landschaft, sondern als Touristenattraktion angesehen werden. In Karlino wurde beispielsweise in direkter Nachbarschaft zu Windturbinen ein Fahrradweg gebaut. ${ }^{33}$ Viele Gemeinden stellen die WEAs auf ihrer Internetseite als ein Symbol für wirtschaftliche Entwicklung dar. ${ }^{34}$

In einer Ende 2013 unter Gemeindeverwaltungen durchgeführten Umfrage sahen fast $70 \%$ der Befragten den Ausbau der erneuerbaren Energien als Chance für die wirtschaftliche Entwicklung und $61 \%$ als eine Investition in die Zukunft. Andererseits stuften $20 \%$ der lokalen Behörden erneuerbare Energien als für die Nachbarschaft beeinträchtigend ein und $7 \%$ sogar als eine »Bedrohung ${ }^{35}{ }^{35}$ In

31 »Sejm RP. Projekt Ustawy o zmianie ustawy Prawo Budowlane i ustawy o planowaniu i zagospodarowaniu przestrzennym«[Gesetzentwurf über Änderung des Baugesetzes und Gesetz über räumliche Planung und Bewirtschaftung], Druk 758, 2012.

32 Website »Rowój TAK - Odkrywki NIE« [Entwicklung JA - Tagebaue NEIN], https://rozwoj tak-odkrywkinie.pl/, zuletzt geprüft am 25. November 2019.

33 »Ścieżka rowerowa po nasypie kolejki wąskotorowej« [Fahrradweg auf dem Bahndamm], http://www.karlino.pl/strona-555-sciezka_rowerowa_po_nasypie_kolejki.html, zuletzt geprüft am 22. Februar 2018.

34 Z. B. die Websites von Będzino (http://bedzino.pl/ ), Kobylnica (http://www.kobylnica.pl/), Karlino (http://www.karlino.pl/ ) und Płużnica (http://www.pluznica.pl/), alle zuletzt geprüft am 22. Februar 2018.

35 Andrzej Ancygier und Kacper Szulecki, »Does Local Energy Mean Renewable? Report from a survey of the acceptance for renewable energy sources development among Polish local authorities« [Bedeutet hiesig auch erneuerbarer? Ergebnisse einer Umfrage über die Akzeptanz für die Entwicklung erneurbarer Energien unter den lokalen Behörden], in: ESPR $i$ Report 1 (2013/2014), 1-17. 
einigen Gemeinden wird behauptet, dass Windräder Ratten anziehen, zu Rissen in Gebäuden führen und gesundheitliche Probleme wie Depressionen und Unruhe verursachen. ${ }^{36}$

$\mathrm{Zu}$ einer Öffentlichkeitsbeteiligung hat sich Polen mit der europäischen Richtlinie über die Beteiligung der Öffentlichkeit bei der Ausarbeitung bestimmter umweltbezogener Pläne und Programme (2003/3/EG) und mit dem Inkrafttreten der Europäischen Landschaftskonvention ${ }^{37} 2005$ verpflichtet. Ein Gesetz, das den Zugang zu Informationen, die Öffentlichkeitsbeteiligung im Umweltschutz und die Umweltverträglichkeitsprüfung regelt, ist 2008 in Kraft getreten. ${ }^{38}$ Eine Verordnung auf Grundlage dieses Gesetzes von 2010 klärt, für welche Investitionen eine Umweltverträglichkeitsprüfung mit einer Öffentlichkeitsbeteiligung durchgeführt werden muss. Darunter fallen WEA mit einer Gesamtleistung von mehr als $100 \mathrm{MW}$ sowie Anlagen mit einer Gesamthöhe von mehr als $30 \mathrm{~m}$, die in Naturschutzgebieten errichtet werden sollen.

\section{Windenergienutzung und Landschaftsdebatten in genereller Perspektive}

In der Literatur werden Landschaftsveränderungen häufig als ein wesentliches Argument, in einigen Publikationen sogar als der zentrale Kritikpunkt von Windkraftgegnern benannt. ${ }^{39}$ Einige Autoren kommen zu dem Ergebnis, dass nicht nur bei Gegnern, sondern auch bei Unterstützern der Windenergienutzung der Landschaftseinfluss das entscheidende Kriterium für die Befürwortung oder

36 Akademia Wiatru, »Wietrzne Wojny?« [Windige Kriege?], Report von einer Feldforschung über die Akzeptanz für Windenergie in Polen, https://docplayer.pl/8567575-Wietrznewojny-1.html, zuletzt geprüft am 3. Dezember 2019.

37 Für mehr Informationen zur europäischen Landschaftskonvention siehe: http://conven tions.coe.int/Treaty/GER/Treaties/Html/176.htm, zuletzt geprüft am 22. Februar 2018; Deutschland hat das Abkommen bisher nicht unterzeichnet.

38 »Ustawa $\mathrm{z}$ dnia 3 października 2008 r. o udostępnianiu informacji o środowisku i jego ochronie, udziale społeczeństwa w ochronie środowiska oraz o ocenach oddziaływania na środowisko« [Gesetz vom 3. Oktober 2009 über den Zugang zu Informationen über der Umwelt und deren Schutz, der Öffentlichkeitsbeteiligung in Umweltschutz und der Umweltverträglichkeitsprüfung], 48, http://isap.sejm.gov.pl/DetailsServlet?id=WDU20081991 227, zuletzt geprüft am 22. Februar 2018.

39 Z.B. Charles Warren und Richard Birnie, "Re-powering Scotland: Wind Farms and the 'Energy or Environment? Debate«, in: Scottish Geographical Journal 125, 2 (2009), 97-126, 110; Maarten Wolsink, »Planning of renewables schemes: Deliberative and fair decisionmaking on landscape issues instead of reproachful accusations of non-cooperation ", in: Energy Policy 35 (2007), 2692-2704, 2696. 
Ablehnung ist. ${ }^{40}$ Bei einer repräsentativen Umfrage im Jahr 2013 in Deutschland stimmte etwa die Hälfte der Befragten der Aussage »durch die Energiewende wird die Landschaft durch Windräder und andere Anlagen verschandelt « (eher) zu. Die andere Hälfte lehnte diese Äußerung (eher) ab. ${ }^{41}$ Wie Landschaft und deren Veränderungen in Windenergiedebatten konzeptualisiert werden, ist also gar nicht eindeutig - nämlich nicht nur negativ und ablehnend. Die Fragen, die daher relevant werden, sind $»$ What kind of landscape do we want, and what do we want our landscape to remind us of? ${ }^{42}$ Um diese Fragen zu beantworten, reicht es nicht aus, nur die Argumente der Windkraftgegner zu betrachten, wie es in vielen Studien üblich ist. ${ }^{43}$ Erst der Blick auf Argumente sowohl der Befürworter wie der Gegner legt kontroverse Ansichten zu Landschaft und WEA frei.

In einer Untersuchung zu deutschlandweiten Debatten um Landschaft und Windkraftanlagen ermitteln Leibenath und Otto drei Landschaftskonzepte, die mittels Argumentationsmuster mit Positionen zur Windenergienutzung verbunden werden. Im ersten Landschaftskonzept werden Landschaften als schön, wertvoll, natürlich und der Erholung dienend angesehen. Allerdings gibt es weit mehr Gebiete, die diese Kriterien nicht erfüllen und daher keine Landschaften (mehr) darstellen. Ausgehend von dieser Landschaftsbetrachtung werden Windparks abgelehnt, um die schöne Landschaft vor der Zerstörung zu schützen. ${ }^{44}$ Diese Argumentation findet sich in zahlreichen Studien zu Windkraftgegnern wieder. ${ }^{45}$

40 Charles Warren, Carolyne Lumsden, Simone O’Dowd und Richard Birnie, ") Green on Green: Public Perceptions of Wind Power in Scotland and Ireland «, in: Journal of Environmental Planning and Management 48, 6 (2005), 854; Maarten Wolsink, »Wind power and the NIMBY-myth: institutional capacity and the limited significance of public support«, in: Renewable Energy 21 (2000), 835-875, 851.

41 Verbraucherzentrale Bundesverband, "Verbraucherinteressen in der Energiewende«, 2013, http://www.vzbv.de/cps/rde/xbcr/vzbv/Energiewende_Studie_lang_vzbv_2013.pdf, zuletzt geprüft am 22. Februar 2018.

42 Alain Nadaï und Dan van der Horst, »Wind power planning, landscape and publics», in: Land Use Policy 27 (2010), 181-184, 182.

43 Wolsink, »Planning of renewables schemes: Deliberative and fair decision-making on landscape issues instead of reproachful accusations of non-cooperation«, 2699; Rolf Wüstenhagen, Maarten Wolsink und Mary Jean Bürer, »Social acceptance of renewable energy innovation: An introduction to the concept«, in: Energy Policy 35 (2007), 2683-2691, 2686.

44 Markus Leibenath und Antje Otto, "Diskursive Konstituierung von Kulturlandschaft am Beispiel politischer Windenergiediskurse in Deutschland«, in: Raumforschung und Raumordnung 70, 2 (2012), 119-131, $126 \mathrm{f}$.

45 Z.B. in: John Barry, Geraint Ellis und Clive Robinson, "Cool Rationalities and Hot Air: A Rhetorical Approach to Understanding Debates on Renewable Energy«, in: Global Environmental Politics 8, 2 (2008), 67-98, 71-73; Brad Jessup, »Plural and hybrid environmental values: a discourse analysis of the wind energy conflict in Australia and the United Kingdom«, in: Environmental Politics 19, 1 (2010), 32-38; Michael Woods, "Conflicting Environmental Visions of the Rural: Windfarm Development in Mid Wales«, in: Sociologia Ruralis 43,3 (2003), 271-288, $280 \mathrm{f}$. 
Allerdings gibt es auch Zustimmung zu Windenergieprojekten vor dem Hintergrund der Konzeption einer schönen und wertvollen Landschaft. Diese zunächst widersprüchlich erscheinende Verknüpfung wird mittels zwei verschiedener Argumentationsmuster hergestellt, die beide davon ausgehen, dass WEA die Landschaft beeinträchtigen. Einmal lässt sich diese Beeinträchtigung jedoch durch die richtige Planung abmildern und zum anderen ist dies im Gegensatz zu Landschaftsveränderungen durch den Klimawandel oder durch andere Energieformen das kleinere und daher zu akzeptierende Übel. ${ }^{46}$ Hinweise auf diese zwei Argumentationsmuster liefern auch andere Autoren. ${ }^{47}$

In dem zweiten Landschaftskonzept wird Landschaft als ein ständig von Menschen verändertes Gebiet konstruiert. Somit gelten auch industriell genutzte oder städtisch-geprägte Gebiete als Landschaften. Windräder sind in der hier verankerten Argumentation neue Elemente in der Landschaft, die qualitätsvoll gestaltet werden müssten, um bereichernd zu wirken. ${ }^{48}$ Diese Argumentation wurde in anderen Arbeiten anscheinend seltener ermittelt. ${ }^{49}$

Das dritte Konzept trat nur am Rande auf. Es beinhaltet, dass Landschaft und die Einschätzung von Landschaftsveränderungen Teil der subjektiven Wahrnehmung sind. Hinsichtlich der Windenergienutzung wird angenommen, dass eine Gewöhnung an die Windräder stattfinden wird. ${ }^{50}$ Auch diese Argumentation kann vereinzelt in anderen Studien gelesen werden. ${ }^{51}$

Die zahlreichen hier zitierten Belege lassen den Eindruck entstehen, als ob die Kontroverse um Landschaftsveränderungen im Zuge der Windenergienutzung geradezu ubiquitär wäre. ${ }^{52}$ Dabei ist zu beachten, dass das Wort »Landschaft»

46 Leibenath und Otto, »Diskursive Konstituierung von Kulturlandschaft am Beispiel politischer Windenergiediskurse in Deutschland«, $126 \mathrm{f}$.

47 Z. B. in: Barry, Ellis und Robinson, "Cool Rationalities and Hot Air: A Rhetorical Approach to Understanding Debates on Renewable Energy«, 80-81; Jessup, "Plural and hybrid environmental values: a discourse analysis of the wind energy conflict in Australia and the United Kingdom", 30; Kelvin Mason und Paul Milbourne, »Constructing a >landscape justice for windfarm development: The case of Nant Y Moch, Wales«, in: Geoforum 53 (2014), 104-115, 112; Warren, Lumsden, O'Dowd und Birnie, »)Green on Green «: Public Perceptions of Wind Power in Scotland and Ireland«, 865.

48 Leibenath und Otto, "Diskursive Konstituierung von Kulturlandschaft am Beispiel politischer Windenergiediskurse in Deutschland «, $126 \mathrm{f}$.

49 Z. B. in: Warren, Lumsden, O’Dowd und Birnie, »'Green on Greens: Public Perceptions of Wind Power in Scotland and Ireland «, 863.

50 Leibenath und Otto, "Diskursive Konstituierung von Kulturlandschaft am Beispiel politischer Windenergiediskurse in Deutschland«, $126 \mathrm{f}$.

51 Z. B. in: Soren Krohn und Steffen Damborg, "On Public Attitudes Towards Wind Power«, in: Renewable Energy 16 (1999), 956; Frode B. Nielsen, »A formula for success in Denmark «, in: Martin Pasqualetti, Paul Gipe und Robert W. Righter (Hg.), Wind Power in View: Energy Landscapes in a Crowded World, San Diego, CA: Academic Press, 2002, 115-132, 130.

52 Phadke unterstützt diese Ansicht, wenn sie schreibt: "In several countries, including the United Kingdom, the Netherlands, France, New Zealand and Australia, contestations over 
bzw. seine Entsprechungen in unterschiedlichen Sprachen ganz verschiedene semantische Konnotationen tragen und damit in unterschiedlichen Sprachen und Kulturen andere inhaltliche Bezüge in den Mittelpunkt treten. ${ }^{53}$ Die Annahme, dass in allen Regionen und Sprachen überhaupt ein vergleichbares Landschaftsverständnis verwendet wird, weist Corner mit den Worten zurück: "To assume that every society shares an American, English, or French view of landscape, or even that other societies possess any version of landscape at all, is to wrongly impose on other cultures one's own image. ${ }^{54}$

Angesichts dessen stellt sich die Frage nach den Konnotationen von $»$ Landschaft im Deutschen und »krajobraz« im Polnischen. ${ }^{55}$ Das im Deutschen verbreitete Landschaftsverständnis verknüpft »sächliche und ästhetische Bedeutungen $\aleph^{56}$, denn es beinhaltet sowohl ein Gebiet mit dessen speziellem Charakter, spezifischen Eigenschaften und Größe als auch dessen Erscheinungsbild. Zudem wird mit dem Wort »Landschaft« ein Gefühl der Zugehörigkeit und der Identität verbunden. ${ }^{57}$ Das Landschaftsverständnis im Polnischen vereinigt die Wörter »kraj«, welches sich auf das Land bezieht, in dem wir leben, und »obraz«, welches eine größere Bedeutungsvielfalt aufweist und "picture, image, painting, [...] observation, view and even the pattern and movie« enthält. ${ }^{58}$ Diesen beiden

wind energy have been >largely due to its visual impact on landscapesı.", Roopali Phadke, "Steel forests or smoke stacks: the politics of visualisation in the Cape Wind controversy", in: Environmental Politics 19, 1 (2010), 1-20, 1.

53 Siehe die verschiedenen Beiträge in Diedrich Bruns und Olaf Kühne (Hg.), Landschaften: Theorie, Praxis und Internationale Bezüge. Impulse zum Landschaftsbegriff mit seinen ästhetischen, ökonomischen, sozialen und philosophischen Bezügen mit dem Ziel, die Verbindung von Theorie und Landschaftspraxis zu stärken, Schwerin: Oceano Verlag, 2013.

54 James Corner, »Introduction: Recovering Landscape as a Critical Cultural Pracitice«, in: James Corner (Hg.), Recovering Landscape. Essays in Contemporary Landscape Architecture, Hudson, NY: Princeton Architectural Press, 1999, 1-28, 5. Ähnlich auch der Hinweis von Bruns: "Viele Kulturkreise besitzen weder ein `Landschaftswort`, noch sonstige Wörter mit denen sich >westlicher Landschaftskonnotationen ausrücken [sic] ließen.", Diedrich Bruns, "Landschaft, ein internationaler Begriff?«, in: Bruns und Kühne (Hg.), Landschaften: Theorie, Praxis und Internationale Bezüge, 153-170, 153.

55 Allerdings sollte nicht in die Falle getappt werden, Landschaftsbegriffe als konstruiert zu betrachten, aber Nationen, Sprachen oder Kulturen essentialistisch zu behandeln. Auch wenn hier ein bestimmtes Verständnis in den jeweiligen Sprachen benannt wird, finden sich jeweils verschiedene, konkurrierende Landschaftsbegriffe.

56 Dóra Drexler, »Kulturelle Differenzen der Landschaftswahrnehmung in England, Frankreich, Deutschland und Ungarn«, in: Thomas Kirchhoff und Ludwig Trepl (Hg.), Vieldeutige Natur. Landschaft, Wildnis und Ökosystem als kulturgeschichtliche Phänomene, Bielefeld: transcript, 2009, 119-136, 121.

57 Ebd., 121 f. Dóra Drexler, »Die Wahrnehmung der Landschaft - Ein Blick auf das englische, französische und ungarische Landschaftsverständnis«, in: Bruns und Kühne (Hg.), Landschaften: Theorie, Praxis und Internationale Bezüge, 38.

58 Józef Hernik und Robert Dixon-Gough, »The Concept and Importance of Landscape in the Polish Language and in Poland «, in: Bruns und Kühne (Hg.), Landschaften: Theorie, Praxis und Internationale Bezüge, 83-98, 85. 
Beschreibungen folgend, scheint das polnische Verständnis stärker ästhetisch geprägt zu sein als im Deutschen.

Viele der Studien zu Windenergiekonflikten und Landschaft beziehen sich nur auf einige wenige europäische Länder wie Großbritannien, die Niederlande oder Deutschland. Studien, die mehrere Länder hinsichtlich Argumentationen um Landschaft und Windenergie analysieren, sind rar. ${ }^{59}$ Ein Vergleich zwischen Großbritannien, Spanien, Dänemark, den Niederlanden und Deutschland stützt sich in seiner Untersuchung auf die Anzahl von Landschaftsschutzverbänden als Anhaltspunkt dafür, ob und wie Landschaftsveränderungen akzeptiert werden. Die Studie kommt zu dem Ergebnis, dass die Landschaftsschutzverbände in Großbritannien eine sehr starke Position innehaben und Landschaftsbeeinträchtigungen daher ein wichtiges Argument in Windenergiedebatten sind. In Spanien hingegen spielt die Landschaftsveränderung durch WEA keine große Rolle, was mit fehlenden Landschaftsschutzverbänden sowie einer geringeren Wertschätzung des ländlichen Raums als Wohnort begründet wird. Die anderen drei untersuchten Staaten weisen zwar eine Beschäftigung mit Landschaftsveränderungen im Rahmen der Windenergienutzung auf, das Argument ist aber wohl nicht so zentral wie in Großbritannien. ${ }^{60}$ Auf unterschiedliche Konnotationen des Wortes "Landschaft", "landscape«, "paisaje» usw. wird in dem Artikel nicht eingegangen.

In Deutschland wird etwa seit dem Jahr 2000 eine gesteigerte Aufmerksamkeit für Landschaftsthemen in Windenergiekonflikten festgestell $t^{61}$ und seit einigen Jahren gewinnt auch die wissenschaftliche Beschäftigung mit diesem Thema an Relevanz. ${ }^{62}$ Die Bedenken bezüglich Landschaftsbeeinträchtigungen in Windenergiekonflikten sind auch in Polen wichtig, ${ }^{63}$ aber waren bisher nicht Ausgangspunkt für wissenschaftliche Untersuchungen.

Im Folgenden wird je ein Fallbeispiel für einen Windenergiekonflikt aus Deutschland und aus Polen vorgestellt. In dem Fallbeispiel aus Deutschland werden insbesondere die kontroversen Landschaftszuschreibungen herausge-

59 David Toke, Sylvia Breukers und Maarten Wolsink, »Wind power deployment outcomes: How can we account for the differences?", in: Renewable and Sustainable Energy Reviews 12 (2008), 1129-1147, 1136.

60 Ebd., 1137.

61 Ebd.

62 Markus Leibenath, „Landschaften unter Strom«, in: Ludger Gailing und Markus Leibenath (Hg.), Neue Energielandschaften - Neue Perspektiven der Landschaftsforschung, Reihe Raum Fragen: Stadt - Region - Landschaft, Wiesbaden: Springer VS, 2013, 7-15, $7 \mathrm{f}$.

63 Z.B. »Duże farmy wiatrowe zniszczą krajobraz?« [Werden die großen Windfarmen die Landschaft zerstören?], in: Portal Samorządowy, 13. März 2013, http://www.portalsamorza dowy.pl/gospodarka-komunalna/duze-farmy-wiatrowe-zniszcza-krajobraz,46022.html, zuletzt geprüft am 20. Februar 2018. 
arbeitet. In Polen werden hingegen Landschaftsbeeinträchtigungen als ein Gegenargument neben anderen Aspekten in der Auseinandersetzung verortet.

\section{Deutschland: Ein Fallbeispiel zur Windenergienutzung und Landschaftsdebatten}

In Deutschland drehen sich zahlreiche lokale Debatten, in denen Landschaft eine große Rolle spielt, um Windenergiepläne. ${ }^{64}$ In vielen Fällen wird nur eine starke Opposition sichtbar, während sich Unterstützer eher selten zu Wort melden (ähnlich wie im polnischen Fallbeispiel). Für die Betrachtung umstrittener Landschaftskonzeptionen sind aber die Sichtweisen beider Seiten bedeutsam. Daher wurde eine Fallstudie gewählt, in der es zahlreiche landschaftsbezogene Aussagen sowohl von Gegnern als auch von Befürwortern gibt: die Debatte um den Plan, vier Bürgerwindräder auf dem bewaldeten Rödeser Berg in Wolfhagen (Hessen) $\mathrm{zu}$ installieren. ${ }^{65}$

Wolfhagen ist eine Gemeinde von rund 14.000 Einwohnern, ${ }^{66}$ dessen Stadtverordnete 2008 einstimmig den Beschluss gefasst haben, bis 2015 den gesamten Stromverbrauch der Stadt vor Ort aus erneuerbaren Quellen zu gewinnen. Für diesen Vorsatz gab es in der Gemeinde einen breiten Konsens, doch als nach einiger Abwägung Ende 2008 der bewaldete Rödeser Berg als Standort festgelegt wurde, zerbrach die Einigkeit. Es gründeten sich verschiedene Initiativen für und gegen den Standort. Ein Mediationsversuch scheiterte 2009, woraufhin sich der Konflikt verfestigte. Bei der Kommunalwahl im März 2011 erhielten die

64 Markus Leibenath und Antje Otto, "Local debates about `landscaper as viewed by German regional planners: Results of a representative survey in a discourse-analytical framework", in: Land Use Policy 32 (2013), 366-374, 368.

65 Bei der Betrachtung der Fallstudie wurde eine diskursanalytische, post-strukturelle Perspektive eingenommen. Vor diesem Hintergrund ging es in der Analyse der etwa 500 Dokumente sowie der acht Interviewtranskripte um die Wörter "Landschaft» und »Rödeser Berg" und deren Verknüpfung mit anderen Wörtern, Objekten oder Praktiken. Theorie und Methodik der Fallstudie wurde an anderer Stelle detailliert dargelegt. Markus Leibenath und Antje Otto, »Windräder in Wolfhagen - eine Fallstudie zur diskursiven Konstituierung von Landschaften", in: Markus Leibenath, Stefan Heiland, Heiderose Kilper und Sabine Tzschaschel (Hg.), Wie werden Landschaften gemacht? Sozialwissenschaftliche Perspektiven aufdie Konstituierung von Kulturlandschaften, Bielefeld: transcript, 2013, 205-236, 206-219; Antje Otto und Markus Leibenath, »The interrelation between collective identities and place concepts in local wind energy conflicts", in: Local Environment 19, 6 (2014), 660-676, 662-666.

66 Siehe http://www.wolfhagen.de/de/rathaus/die_stadt.php?navanchor=1110041, zuletzt geprüft am 20. Februar 2018. 
Gegner etwa ein Drittel der Stimmen und die Befürworter zwei Drittel. ${ }^{67}$ Ende 2014 gingen die vier Windräder in Betrieb, während die Debatte noch immer nicht vollends ruhte.

Auf der Seite der Standortbefürworter und -gegner existieren verschiedene Gruppierungen mit zum Teil diversen Meinungen. Aufgrund der Kürze werden hier lediglich zwei Positionen - zugespitzt und vereinfachend - dargestellt.

Den Befürwortern geht es mit ihrem Energiekonzept um wirtschaftliche Entwicklung und Arbeitsplätze, aber auch um eine »klimaneutrale Zukunft «, das Ablösen von großen Energieversorgern und von konventionellen Energieträgern sowie um mehr Mitspracherecht bei lokalen energiepolitischen Entscheidungen. WEA werden dabei überaus positiv bewertet. Äußerungen, die im Zusammenhang mit dem Standort stehen, spielen eine wichtige Rolle. Der Rödeser Berg wird als »Kulturlandschaft« bewachsen mit »Wirtschaftswald « bezeichnet, der eben keine »Naturlandschaft « mit »Urwald « darstelle. Der Wald auf dem Rödeser Berg sei ohnehin bereits durch Stürme geschädigt und weise »keine besondere Bedeutung für Arten« auf. Zudem sei er anderen Standorten mit seiner hohen Windhöffigkeit und bereits vorhandener Infrastruktur überlegen. Der Rödeser Berg sei damit ein idealer »Ort des Klimaschutzes «. ${ }^{68}$

Die Gegner sehen in den Windenergieplänen ein »überaus fragwürdiges Industrieprojekt «, das mit »Volksverdummung", "Profitgier « und wirtschaftlichen Risiken verknüpft wird. Es werden andere Lösungen gefordert. Die WEA werden ausschließlich negativ dargestellt, auch wenn häufig betont wird, dass es um die Ablehnung des Standorts und nicht der Windenergienutzung allgemein gehe. Der Rödeser Berg spielt dementsprechend eine grundlegende Rolle in den Aussagen der Gegner. Er wird als mit "Buchen- und Eichenmischwald « bewachsen dargestellt, in dem bedrohte Arten lebten, weshalb eine Zerstörung sowie Windräder im Wald abgelehnt werden. Der Wald trage ohnehin zum Klimaschutz bei, da er $\mathrm{CO}_{2}$ speichere. Es werden Alternativen gefordert, da zu befürchten sei, dass wenn dieser bewaldete Berg mit Windrädern bebaut werde, weitere Berge folgen werden. Insgesamt sei der Rödeser Berg ein Teil »unserer schönen Landschaft« und eine Bebauung wäre eine »Katastrophe für die Landschaft «. ${ }^{69}$

67 Leibenath und Otto, »Windräder in Wolfhagen - eine Fallstudie zur diskursiven Konstituierung von Landschaften«, 213-216; Otto und Leibenath, »The interrelation between collective identities and place concepts in local wind energy conflicts «, 666-669.

68 Leibenath und Otto, "Windräder in Wolfhagen - eine Fallstudie zur diskursiven Konstituierung von Landschaften«, 221-227; Otto und Leibenath, "The interrelation between collective identities and place concepts in local wind energy conflicts «, 669-670.

69 Leibenath und Otto, »Windräder in Wolfhagen - eine Fallstudie zur diskursiven Konstituierung von Landschaften ", 227-230; Otto und Leibenath, "The interrelation between collective identities and place concepts in local wind energy conflicts«, 670-672. 
In diesem Fallbeispiel zum Rödeser Berg zeigen sich also diametrale $\mathrm{Zu}$ schreibungen für ein und denselben Standort. Die Landschaft ist mit vieldeutigen Sinngehalten belegt.

\section{Polen: Ein Fallbeispiel zur Windenergienutzung und Landschaftsveränderungen}

Es wurde bereits darauf hingewiesen, dass auch in Polen Bedenken bezüglich Landschaftsbeeinträchtigungen in Windenergiekonflikten eine wichtig Rolle spielen und damit häufig neben einer großen Zahl an naturschutzbezogenen, ökonomischen, rechtlichen und gesundheitlichen Befürchtungen stehen. ${ }^{70}$ Dies soll für die Auseinandersetzung in Dębki (dt. Dembeck) nachvollzogen werden.

Im Jahre 2008 hatte die Initiative "Stopp den Windmühlen« zu einer der größten Proteste gegen Windenergie in Polen aufgerufen und eine große Medienresonanz erhalten. Der Protest fand in dem Erholungsdorf Dębki in der Wojewodschaft Pommern an der Ostseeküste statt, in dem außerhalb der Urlaubssaison lediglich einige Dutzend Einwohner leben. Dębki ist ein sehr kleiner, aber wegen seines breiten Strands - zweitbreitester Strand in Polen nach Świnoujście (dt. Swinemünde) - und der ruhigen Lage ein sehr beliebter Ort. ${ }^{71}$ Dort plante ein Unternehmen mit einem dänischen Kapitalgeber, Wiatropol International, den Bau des ersten Offshore-Windparks in Polen. Der Windpark sollte aus 33 Windturbinen in 4-7 km Entfernung vom Strand und mit einer Höhe von 120 m entstehen und wäre damit direkt vom Strand in Dębki sichtbar gewesen. ${ }^{72}$

Diese Planung stieß auf ungewöhnlich breiten Widerstand, der die Einwohner des Ortes, Touristen, die lokale Verwaltung, vier Umweltschutzorganisationen sowie wichtige und bekannte Prominente umfasste. ${ }^{73}$ Sie riefen eine Aktion namens "Dębki nie są odnawialne» (dt.: Dębki ist nicht erneuerbar) ins Leben, aus der später ein Verein entstand. Die Gegner des Windparks in Dębki sammelten dreitausend Unterschriften für eine Petition an den Wojewoden, der für

70 Karolina Jankowska, „Die Kräfte des Wandels. Die Wandlung Polens von einer auf Kohle basierenden zu einer an erneuerbaren Energien orientierten Gesellschaft«, Dissertation FU Berlin, 2012, 197, http://www.diss.fu-berlin.de/diss/receive/FUDISS_thesis_000000037268, zuletzt geprüft am 20. Februar 2018.

71 Debki.pl, »Dębki ogólnie«, http://www.debki.pl/o-debkach, zuletzt geprüft am 20. März 2019.

72 Baltyckie.pl, »Walka o krajobraz bez wiatraków«, http://www.baltyckie.pl/page/city/debki/ aktualnosci/aktualnosci/walka-o-krajobraz-bez-wiatrakow.html, zuletzt geprüft am 30. September 2014; Seite nicht mehr aktiv.

73 Ebd.; Mikołaj Chrzan, »Dębki bez wiatraków«, in: Gazeta Wyborcza, 16. Juni 2009, http:// www.portalmorski.pl/morze-inne/turystyka-morska/12925-debki-bez-wiatrakow, zuletzt geprüft am 20. Februar 2018. 
die Umweltverträglichkeitsprüfung zuständig war. Es wurden Proteste am Strand organisiert, spezielle T-Shirts hergestellt und eine Internetseite eingerichtet (www.chronmydebki.pl - allerdings ist die Seite nicht mehr abrufbar). ${ }^{74}$

Die Proteste richteten sich v.a. gegen die von den Gegnern befürchteten "Zerstörung" der Ostsee-Landschaft, ${ }^{75}$ u. a. ihrer Schönheit und ihrer klaren Horizontlinie. ${ }^{76}$ Weitere Argumente der Gegner bezogen sich auf die Auswirkungen des Windparks auf die Umwelt, da die WEA auf einem Natura 2000Gebiet $^{77}$ gebaut werden sollten. Insbesondere die Folgen für Vögel und Fische sowie Lärm durch den Bau und Betrieb der Windturbinen wurden negativ gesehen. Die Einwohner und die lokale Verwaltung befürchteten, dass Dębki durch die Einrichtung des Windparks seine Attraktivität für Touristen verlieren und dies zu finanziellen Verlusten für den Ort führen könne, in dem der Tourismus die wichtigste Einkommensquelle ist. Die Protestierenden betonten jedoch, dass sie nicht generell gegen Windenergie seien und ihre Hauptforderungen an den Investor und den Wojewoden waren, den Windpark nicht auf einem Natura 2000-Gebiet und weiter entfernt von der Küste zu bauen. Als eine geeignete Entfernung vom Strand wurden ca. $20 \mathrm{~km}$ vorgeschlagen. ${ }^{78}$

Letztendlich folgte die zuständige Behörde den Argumenten der Protestierenden ${ }^{79}$ und die Umweltverträglichkeitsprüfung fiel negativ aus. Die Entscheidung wurde damit begründet, dass der Standort in einem Natura 2000-Gebiet liege und der Investor keine solide Untersuchung des Einflusses der Investition auf geschützte Arten sowie über einen alternativen Standort vorgelegt habe. Die Organisatoren der lokalen Proteste gegen den Windpark in Dębki haben diese Entscheidung zum eigenen Erfolg erklärt, weil sie bestätigt habe, dass der durch den Investor vorgeschlagene Standort besonders ungeeignet und mit dem Prinzip der nachhaltigen Entwicklung nicht vereinbar sei. ${ }^{80}$

Dieser Fall zeigt, dass in Polen, in dem die Einführung erneuerbarer Energien erst seit Kurzem verstärkt betrieben wird, noch nicht alle Aspekte rechtlich geregelt sind. ${ }^{81}$ Von daher ist es möglich, dass Forderungen der lokalen Bevölkerung auf wichtige, erst noch zu lösende Probleme bei der Nutzung erneuerbarer Energien hinweisen. ${ }^{82}$ Eine frühere Beteiligung der Bevölkerung hätte die

74 Baltyckie.pl, »Walka o krajobraz bez wiatraków«.

75 Ebd.; Chrzan, "Dębki bez wiatraków«.

76 Gazeta Wyborcza Trójmiasto, »Dębki walczą z wiatrakami«, http://www.skalar.pomorze.pl/ index.php/pl/17/755/sitemap, zuletzt geprüft am 20. Februar 2018.

77 Natura 2000 ist ein zusammenhängendes Netz von Schutzgebieten innerhalb der EU mit dem Ziel, gefährdete wildlebende Pflanzen- und Tierarten in ihren Lebensräumen zu schützen.

78 Baltyckie.pl, »Walka o krajobraz bez wiatraków«.

79 Chrzan, »Dębki bez wiatraków«.

80 Ebd.

81 Jankowska, Die Kräfte des Wandels, 197.

82 Ebd. 
Proteste in Dębki eventuell verhindern und gleichzeitig die notwendigen Investitionen in erneuerbare Energien ermöglichen können.

\section{Fazit}

Zusammenfassend lässt sich feststellen, dass sich die Windenergie in Deutschland und Polen vor dem Hintergrund verschiedener Energieversorgung, Protestkulturen und politischer Fördermechanismen sehr unterschiedlich entwickelt hat. In beiden Staaten traten allerdings mit einer steigenden Anzahl an Windturbinen auch zunehmend lokale Konflikte auf. Landschaftsveränderungen spielen in lokalen Auseinandersetzungen um die Windenergienutzung sowohl in Deutschland als auch in Polen eine wesentliche Rolle. Es wird angenommen, dass mit zunehmender Anzahl von WEA in Polen die Anzahl der Konflikte, in denen Landschaftskontroversen relevant sind, noch zunehmen könnten. ${ }^{83}$ Wie Toke, Breukers und Wolsink feststellen: »It does seem that as the proportion of wind power increases there is a tendency for landscape issues to become more important. ${ }^{84}$ Folglich könnte auch in Polen das wissenschaftliche Interesse an Landschaftsthemen in Windenergiekonflikten in Zukunft steigen.

In den Ausführungen wird deutlich, dass gewisse Kontinuitäten und Übereinstimmungen zwischen den Äußerungen zur Windenergie und deren Einfluss auf die Landschaft bestehen. Häufig wird argumentiert, dass Windkraftanlagen die Landschaft beeinträchtigen - wie in den Fallbeispielen dargestellt. Eine gewisse Persistenz in der Landschaftswahrnehmung scheint dabei zwischen unterschiedlichen lokalen Windenergiekonflikten innerhalb eines Staates aber auch über Ländergrenzen hinweg zu bestehen. Dies ist hinsichtlich der unterschiedlichen Konnotationen von »Landschaft", "krajobraz« und entsprechenden Wörtern in diversen anderen Sprachen bemerkenswert.

Die Darstellungen zur Windenergie in Deutschland und Polen zeigen, dass es in beiden Staaten nicht nur die Windkraftgegner sind, die Landschaftszuschreibungen äußern. Im zitierten Fallbeispiel für Deutschland wird dies sehr deutlich, aber auch in den Ausführungen dazu, dass einige polnische Gemeinden Windturbinen als Touristenattraktion vermarkten. Damit treten in einigen Debatten sowohl in Deutschland als auch in Polen kontroverse Landschaftszuschreibungen ans Licht, was zeigt, dass "Landschaft « und ihre Bewertung nicht feststehend, beständig oder selbstverständlich ist. Dies wird nicht zuletzt in Konflikten um die Windenergienutzung ständig neu ausgehandelt.

83 Ebd., 93.

84 Toke, Breukers und Wolsink, Wind power deployment outcomes: How can we account for the differences?, 1143. 
Demzufolge ist es problematisch, die »richtige« bzw. eine konfliktfreie Landschaft als Standort für Windturbinen auszuwählen - auch wenn dies von Planern angestrebt wird - denn allerorts und stets akzeptierte Kriterien kann es gar nicht geben. Nicht nur unberührte Landschaften können als schützenswert angesehen werden, sondern auch die "heimatliche Normallandschaft", die vertraut aber nicht unbedingt stereotyp schön ist. ${ }^{85}$ Folglich ist eine generelle ideale Lösung für Standortfindungen und Landschaftsveränderungen gar nicht möglich. Stattdessen sollte jeweils ein Diskussionsprozess mit der Bevölkerung vor Ort geführt werden, um Kompromisse zu finden. Die Umsetzung von Öffentlichkeitsbeteiligung wird dabei in Deutschland und in Polen aber zum Teil kritisch gesehen, und es wird dabei beklagt, dass sie zu selten, zu spät und zu formalistisch erfolge. ${ }^{86}$

In der Literatur wird eine Gewöhnung an Windräder in Landschaften angenommen, ${ }^{87}$ doch in welcher Geschwindigkeit und ob sich diese in verschiedenen Regionen und für unterschiedliche Milieus, Altersgruppen, Geschlechter etc. ähnlich vollzieht, bleibt derzeit noch offen. Sowohl in Bezug auf bestehende Persistenz als auch mögliche Verschiebungen der Debatten um Landschaft stellen sich zudem die Fragen, inwieweit und in welcher Form ein Austausch und Lernprozess bezüglich verschiedener Konfliktfällen vorhanden ist und ob dieser vielleicht sogar über Landesgrenzen hinausgeht.

Auf der Grundlage unserer Untersuchung kann nicht abgeschätzt werden, ob die Windenergienutzung in Polen oder in Deutschland konfliktreicher diskutiert wird und welche Rolle Landschaftsbeeinträchtigungen als Argument im Vergleich zu anderen Bedenken spielen. Hierzu wären weitere Studien notwendig, die eine größere Fallzahl an Konflikten detailliert betrachten und diese u. a. hinsichtlich der verwendeten (landschaftsbezogenen) Argumente vergleicht. Eine Vermutung von uns ist allerdings, dass die Anzahl der Konflikte bezogen auf die Anzahl der Windenergieprojekte in Polen höher ist als in Deutschland. Dies könnte mit der vergleichsweisen kurzen Nutzungsgeschichte zusammenhängen,

85 Ebd., 109 und 118.

86 Für mehr Informationen hierzu zu Deutschland siehe beispielsweise die verschiedenen Beiträge in: Klaus Töpfer, Dolores Volkert und Ulrich Mans (Hg.), Verändern durch Wissen. Chancen und Herausforderungen demokratischer Beteiligung: von "Stuttgart 21" bis zur Energiewende, München: oekom, 2013. Für mehr Informationen zu diesem Thema zu Polen siehe: »Polskie Towarzystwo Socjologiczne, Raport końcowy. Ewaluacja konsultacji społecznych realizowanych przy budowie elektrowni wiatrowych w Polsce» [Polnische Soziologische Gesellschaft, Endbericht. Eine Evaluierung der gesellschaftlichen Konsultationen in Bezug auf den Bau von Windkraftanlagen in Polen], 2011, http://stopwiatrakom.eu/wts/ pliki/25_kd_20012012a.pdf, zuletzt geprüft am 20. Februar 2018.

87 Olaf Kühne, »Landschaftsästhetik und regenerative Energien - Grundüberlegungen zu Deund Re-Sensualisierungen und inversen Landschaften", in: Ludger Gailing und Markus Leibenath (Hg.), Neue Energielandschaften - Neue Perspektiven der Landschaftsforschung, Reihe RaumFragen: Stadt - Region - Landschaft, Wiesbaden: Springer VS, 2013, 118. 
weswegen Themen wie beispielsweise die Bürgerbeteiligung noch nicht ausreichend geregelt sind. Ein möglicherweise größeres Konfliktpotenzial von Windenergienutzungen in Polen könnte zudem durch die stärker auf Ästhetik ausgerichtete Konnotation von »krajobraz« im Vergleich zu Bedeutungen von "Landschaft« beeinflusst sein. Diese Überlegungen bieten Ansatzpunkte für weitere Forschungen. Des Weiteren sind landestypische Pfadabhängigkeiten möglich und es wäre daher interessant zu untersuchen, ob charakteristische Argumente aus den Windenergiedebatten auch in anderen Standortdiskussionen eine Rolle spielen.

\section{Literatur}

AfD (Alternative für Deutschland), »Programm für Deutschland. Wahlprogramm der Alternative für Deutschland für die Wahl zum Deutschen Bundestag am 24. September 2017«, https://www.afd.de/wp-content/uploads/sites/111/2017/06/2017-06-01_AfDBundestagswahlprogramm_Onlinefassung.pdf, zuletzt geprüft am 25. November 2019. Agentur für Erneuerbare Energien, „Grafik-Dossier: Der Strommix in Deutschland 2014-2018«, https://www.unendlich-viel-energie.de/mediathek/grafiken/der-strom mix-in-deutschland-2018, zuletzt geprüft am 22. November 2019.

Ancygier, Andrzej und Kacper Szulecki, »Does Local Energy Mean Renewable? Report from a survey of the acceptance for renewable energy sources development among Polish local authorities « [Bedeutet hiesig auch erneuerbarer? Ergebnisse einer Umfrage über die Akzeptanz für die Entwicklung erneurbarer Energien unter den lokalen Behörden], in: ESPRi Report 1 (2013/2014), 2-17.

Baltyckie.pl. „Walka o krajobraz bez wiatraków«, http://www.baltyckie.pl/page/city/ debki/aktualnosci/aktualnosci/walka-o-krajobraz-bez-wiatrakow.html, Seite ist nicht mehr aktiv, zuletzt geprüft am 30. September 2014.

Barry, John, Geraint Ellis und Clive Robinson. »Cool Rationalities and Hot Air: A Rhetorical Approach to Understanding Debates on Renewable Energy“, in: Global Environmental Politics 8, 2 (2008), 67-98.

Becker, Sören, Ludger Gailing und Matthias Naumann. »Neue Akteurslandschaften der Energiewende. Aktuelle Entwicklungen in Brandenburg", in: RaumPlanung 162, 3 (2012), 42-46.

Birkmann, Jörn, Maike Vollmer und Jochen Schanze (Hg.). Raumentwicklung im Klimawandel. Herausforderungen für die räumliche Planung, Forschungsberichte der ARL 2, Hannover: ARL, 2013.

Bruns, Diedrich. "Landschaft, ein internationaler Begriff?", in: Landschaften: Theorie, Praxis und Internationale Bezüge. Impulse zum Landschaftsbegriff mit seinen ästhetischen, ökonomischen, sozialen und philosophischen Bezügen mit dem Ziel, die Verbindung von Theorie und Landschaftspraxis zu stärken, Diedrich Bruns und Olaf Kühne (Hg.), Schwerin: Oceano Verlag, 2013, 153-170.

Bruns, Diedrich und Olaf Kühne (Hg.). Landschaften: Theorie, Praxis und Internationale Bezüge. Impulse zum Landschaftsbegriff mit seinen ästhetischen, ökonomischen, so- 
zialen und philosophischen Bezügen mit dem Ziel, die Verbindung von Theorie und Landschaftspraxis zu stärken, Schwerin: Oceano Verlag, 2013.

Bruns, Elke und Dörte Ohlhorst. »Wind Power Generation in Germany«, in: The Journal of Transdisciplinary Environmental Studies 10, 1 (2011), 44-67.

Bundesinitiative Vernunftkraft e. V., Unser Antrieb, https://www.vernunftkraft.de/missi on/, zuletzt geprüft am 25. November 2019.

Bundesministerium für Wirtschaft und Energie. »Zweiter Monitoring-Bericht $>$ Energie der Zukunft «, http://www.bmwi.de/BMWi/Redaktion/PDF/Publikationen/zweiter-moni toring-bericht-energie-der-zukunft,property $=$ pdf,bereich $=$ bmwi2012, sprache $=$ de, $r$ $\mathrm{wb}=$ true.pdf, zuletzt geprüft am 18. Juni 2019.

Bundesministerium für Wirtschaft und Energie. »Gesetz für den Ausbau erneuerbarer Energien (Erneuerbare-Energien-Gesetz - EEG 2014)«, http://www.bmwi.de/BMWi/Re daktion/PDF/G/gesetz-fuer-den-ausbau-erneuerbarer-energien, property=pdf,bereich $=$ bmwi2012,sprache $=$ de, $r w b=$ true.pdf, zuletzt geprüft am 18. Juli 2019.

Chrzan, Mikołaj. „Dębki bez wiatraków«, in: Gazeta Wyborcza, 16. Juni 2009, http://www. portalmorski.pl/morze-inne/turystyka-morska/12925-debki-bez-wiatrakow, zuletzt geprüft am 20. Februar 2018.

Corner, James. »Introduction: Recovering Landscape as a Critical Cultural Pracitice«, in: Recovering Landscape. Essays in Contemporary Landscape Architecture, James Corner (Hg.), Hudson, NY: Princeton Architectural Press, 1999, 1-28.

Debki.pl. »Dębki ogólnie«, http://www.debki.pl/o-debkach, zuletzt geprüft am 20. März 2019.

Deutsche WindGuard GmbH, »Status des Windenergieausbaus an Land in Deutschland. Jahr 2018«, https://www.wind-energie.de/fileadmin/redaktion/dokumente/pressemit teilungen/2019/20190129_Factsheet_Status_des_Windenergieausbaus-Jahr_2018.pdf, zuletzt geprüft am 25. November 2019.

Deutsche WindGuard GmbH, »Status des Windenergieausbaus an Land in Deutschland. Erstes Halbjahr 2019«, https://www.wind-energie.de/fileadmin/redaktion/dokumente/ publikationen-oeffentlich/themen/06-zahlen-und-fakten/20190725_Factsheet_Status_ des_Windenergieausbaus_an_Land_-_Halbjahr_2019.pdf, zuletzt geprüft am 25. November 2019.

Distler, Wolfram. »Vergleich einzelner Regulierungssysteme - Deutschland, Frankreich, Italien und Polen«, in: Handbuch Windenergie. Onshore-Projekte: Realisierung, Finanzierung, Recht und Technik, Jörg Böttcher (Hg.), München: Oldenbourg Wissenschaftsverlag, 2012, 67-99.

Drexler, Dóra. »Kulturelle Differenzen der Landschaftswahrnehmung in England, Frankreich, Deutschland und Ungarn«, in: Vieldeutige Natur. Landschaft, Wildnis und Ökosystem als kulturgeschichtliche Phänomene, Thomas Kirchhoff und Ludwig Trepl (Hg.), Bielfeld: transcript, 2009, 119-136.

Dies. »Die Wahrnehmung der Landschaft - Ein Blick auf das englische, französische und ungarische Landschaftsverständnis", in: Landschaften: Theorie, Praxis und Internationale Bezüge. Impulse zum Landschaftsbegriff mit seinen ästhetischen, ökonomischen, sozialen und philosophischen Bezügen mit dem Ziel, die Verbindung von Theorie und Landschaftspraxis zu stärken, Diedrich Bruns und Olaf Kühne (Hg.), Schwerin: Oceano Verlag, 2013, 37-52. 
Gailing, Ludger und Markus Leibenath. »Von der Schwierigkeit, >Landschaft oder `Kulturlandschaft allgemeingültig zu definieren«, in: Raumforschung und Raumordnung 70, 4 (2012), 95-106.

Gazeta Wyborcza Trójmiasto. »Dębki walczą z wiatrakami«, http://www.skalar.pomorze. pl/index.php/pl/17/755/sitemap, zuletzt geprüft am 05. Juni 2019.

Hernik, Józef und Robert Dixon-Gough. »The Concept and Importance of Landscape in the Polish Language and in Poland", in: Landschaften: Theorie, Praxis und Internationale Bezüge. Impulse zum Landschaftsbegriff mit seinen ästhetischen, ökonomischen, sozialen und philosophischen Bezügen mit dem Ziel, die Verbindung von Theorie und Landschaftspraxis zu stärken, Diedrich Bruns und Olaf Kühne (Hg.), Schwerin: Oceano Verlag, 2013, 83-98.

Huber, Joseph. "Umweltbewegung. Vom Outsider-Protest zur Assimilation", in: Allgemeine Umweltsoziologie, Joseph Huber (Hg.), Wiesbaden: VS, 2011, 109-133.

Jankowska, Karolina. »Die Kräfte des Wandels. Die Wandlung Polens von einer auf Kohle basierenden zu einer an erneuerbaren Energien orientierten Gesellschaft«, Dissertation FU Berlin, 2012, https://refubium.fu-berlin.de/bitstream/handle/fub188/609 3/Dissertation_Karolina_Jankowska.pdf?sequence $=1 \&$ isAllowed $=y$, zuletzt geprüft am 18. Juni 2019.

Jessup, Brad. »Plural and hybrid environmental values: a discourse analysis of the wind energy conflict in Australia and the United Kingdom«, in: Environmental Politics 19, 1 (2010), 21-44.

Krohn, Soren und Steffen Damborg. »On Public Attitudes Towards Wind Power«, in: Renewable Energy 16 (1999), 954-960.

Kühne, Olaf. „Grundzüge einer konstruktivistischen Landschaftstheorie und ihre Konsequenzen für die räumliche Planung ", in: Raumforschung und Raumordnung 67, 5/6 (2009), 395-404.

Ders. »Landschaftsästhetik und regenerative Energien - Grundüberlegungen zu De- und Re-Sensualisierungen und inversen Landschaften", in: Neue Energielandschaften Neue Perspektiven der Landschaftsforschung, Reihe RaumFragen: Stadt - Region Landschaft, Ludger Gailing und Markus Leibenath (Hg.), Wiesbaden: Springer VS, 2013, 101-120.

Leibenath, Markus. "Landschaften unter Strom», in: Neue Energielandschaften - Neue Perspektiven der Landschaftsforschung, RaumFragen: Stadt - Region - Landschaft, Ludger Gailing und Markus Leibenath (Hg.), Wiesbaden: Springer VS, 2013, 7-15.

Leibenath, Markus und Antje Otto. »Diskursive Konstituierung von Kulturlandschaft am Beispiel politischer Windenergiediskurse in Deutschland«, in: Raumforschung und Raumordnung 70, 2 (2012), 119-131.

Dies. »Local debates about `landscape « as viewed by German regional planners: Results of a representative survey in a discourse-analytical framework", in: Land Use Policy 32 (2013), 366-374.

Dies. "Windräder in Wolfhagen - eine Fallstudie zur diskursiven Konstituierung von Landschaften", in: Wie werden Landschaften gemacht? Sozialwissenschaftliche Perspektiven auf die Konstituierung von Kulturlandschaften, Markus Leibenath, Stefan Heiland, Heiderose Kilper und Sabine Tzschaschel (Hg.), Bielefeld: transcript, 2013, 205-236. 
Mason, Kelvin und Paul Milbourne. »Constructing a >landscape justice development: The case of Nant Y Moch, Wales«, in: Geoforum 53 (2014), 104-115.

Mautz, Rüdiger. "Konflikte um die Offshore-Windkraftnutzung - eine neue Konstellation der gesellschaftlichen Auseinandersetzung um Ökologie« in: Umwelt- und Technikkonflikte, Peter Feindt und Thomas Saretzki (Hg.), Wiesbaden: VS, 2010, 181-197.

Mautz, Rüdiger, Andreas Byzio und Wolf Rosenbaum. Aufdem Weg zur Energiewende. Die Entwicklung der Stromproduktion aus erneuerbaren Energien in Deutschland, Göttingen: Universitätsverlag Göttingen, 2008.

Nadaï, Alain und Dan van der Horst. »Editorial. Wind power planning, landscape and publics«, in: Land Use Policy 27 (2010), 181-184.

Nielsen, Frode. "A formula for success in Denmark«, in: Wind Power in View: Energy Landscapes in a Crowded World, Martin Pasqualetti, Paul Gipe und Robert W. Righter (Hg.), San Diego, CA: Academic Press, 2002, 115-132.

Ohlhorst, Dörte und Susanne Schön. »Windenergienutzung in Deutschland im dynamischen Wandel von Konfliktkonstellationen und Konflikttypen « in: Umwelt- und Technikkonflikte, Peter Feindt und Thomas Saretzki (Hg.), Wiesbaden: VS, 2010, 198-218.

Otto, Antje und Markus Leibenath. "The interrelation between collective identities and place concepts in local wind energy conflicts«, in: Local Environment 19, 6 (2014), 660-676.

Phadke, Roopali. "Steel forests or smoke stacks: the politics of visualisation in the Cape Wind controversy«, in: Environmental Politics 19, 1 (2010), 1-20.

Polskie Towarzystwo Socjologiczne. »Raport końcowy. Ewaluacja konsultacji społecznych realizowanych przy budowie elektrowni wiatrowych w Polsce« [Polnische Soziologische Gesellschaft, Endbericht. Eine Evaluierung der gesellschaftlichen Konsultationen beim Bau der Windenergieanlagen in Polen], 2011, http://stopwiatrakom.eu/wts/pliki/ 25_kd_20012012a.pdf, zuletzt geprüft am 20. März 2019.

Schneider, Daniel und Nils Boenigk. Themenheft »Planungsrecht \& Erneuerbare Energien «, Renews Spezial, Hintergrundinformation der Agentur für Erneuerbare Energien 62 (2012).

Selman, Paul. "Learning to Love the Landscapes of Carbon-Neutrality", in: Landscape Research 35, 2 (2010), 157-171.

Statista, Anzahl der Onshore-Windenergieanlagen in Deutschland in den Jahren 2000 bis 2018, https:/de.statista.com/statistik/daten/studie/20116/umfrage/anzahl-der-windkraftanlagen-in-deutschland-seit-1993/, zuletzt geprüft am 25. November 2019.

Thayler, Robert und Carla Freeman. "Altamont: Public Perceptions of a Wind Energy Landscape«, in: Landscape and Urban Planning 14 (1987), 379-398.

Toke, David, Sylvia Breukers und Maarten Wolsink. »Wind power deployment outcomes: How can we account for the differences?", in: Renewable and Sustainable Energy Reviews 12 (2008), 1129-1147.

Uekötter, Frank. „Sieger der Geschichte? Überlegungen zum merkwürdigen Verhältnis des Naturschutzes zu seinem eigenen Erfolg", in: Schriftenreihe des Deutschen Rates für Landespflege 75 (2003), 34-38.

Vasi, Ion Bogdan. Winds of Change. The Environmental Movement and the Global Development of the Wind Energy Industry, Oxford: Oxford University Press, 2011. 
Verbraucherzentrale Bundesverband. "Verbraucherinteressen in der Energiewende«, 2013, https://www.vzbv.de/sites/default/files/downloads/Energiewende_Studie_lang_ vzbv_2013.pdf, zuletzt geprüft am 20. März 2019.

Warren, Charles und Richard Birnie. »Re-powering Scotland: Wind Farms and the $>$ Energy or Environment?» Debate«, in: Scottish Geographical Journal 125, 2 (2009), 97-126.

Warren, Charles, Carolyne Lumsden, Simone O'Dowd und Richard Birnie. "'Green on Green : Public Perceptions of Wind Power in Scotland and Ireland «, in: Journal of Environmental Planning and Management 48, 6 (2005), 854.

Wolsink, Maarten. »Wind power and the NIMBY-myth: institutional capacity and the limited significance of public support «, in: Renewable Energy 21 (2000), 835-875.

Ders. "Planning of renewables schemes: Deliberative and fair decision-making on landscape issues instead of reproachful accusations of non-cooperation «, in: Energy Policy 35 (2007), 2692-2704.

Woods, Michael. „Conflicting Environmental Visions of the Rural: Windfarm Development in Mid Wales«, in: Sociologia Ruralis 43, 3 (2003), 271-288.

Wüstenhagen, Rolf, Maarten Wolsink und Mary Jean Bürer. »Social acceptance of renewable energy innovation: An introduction to the concept«, in: Energy Policy 35 (2007), 2683-26. 
Open-Access-Publikation im Sinne der CC-Lizenz BY 4.0

(c) 2020, Vandenhoeck \& Ruprecht GmbH \& Co. KG, Göttingen ISBN Print: 9783847107507 - ISBN E-Lib: 9783737007504 


\title{
Vergangene Arbeitswelten. Sosnowiec und die Umgestaltung der postindustriellen Landschaft
}

\begin{abstract}
Die zivilisatorische Entwicklung wird durch den Lebensraum des Menschen und seine Nutzung determiniert. Der menschliche Drang, natürliche Ressourcen zu nutzen, verändert die Umwelt irreversibel. In der Kulturlandschaft sind urbanisierte, industrielle, vernachlässigte oder verlassene Räume am stärksten durch menschliche Aktivität geprägt. Die degradierte und vergessene Landschaft verliert ihren kulturellen Existenzsinn, sie ist vermeintlich tot. Sie sich als Beleg menschlicher Tätigkeit ins Bewusstsein zu rufen, erfordert die Reinterpretation der Bedeutungen und die Wiederherstellung für künftige Generationen. Es ist also nicht nur zu bedenken, wie ein Gebiet technisch zu rekultivieren ist, sondern auch nach Möglichkeiten zu suchen, vorgefundene Werte zu erkennen und in einer scheinbar ausdruckslosen Landschaft neue Werte zu schaffen. ${ }^{1}$
\end{abstract}

\section{Definitionen}

»Landschaft « ist ein mehrdeutiger Begriff, der in verschiedenen Wissenschaftsdisziplinen verwendet und unterschiedlich definiert wird. Ganz allgemein ist Landschaft die Summe natürlicher und anthropogener Merkmale, die ein bestimmtes Areal repräsentieren, das typische Eigenschaften aufweist.

In Abhängigkeit vom Grad der anthropogenen Veränderung sind fünf Landschaftstypen zu unterscheiden:

1. ursprüngliche Landschaften (Abwesenheit menschlicher Eingriffe);

2. natürliche Landschaften (ohne wesentliche Eingriffe);

3. Kulturlandschaften (intensive Eingriffe);

1 Aleksandra Idziak und Krzysztof Herman, »Między kopalnią a krajobrazem. Transformacje sztuki krajobrazu. Instalacje, rzeźba, performance jako formy rekultywacji krajobrazów postindustrialnych« [Zwischen Bergwerk und Landschaft. Transformationen der Landschaftskunst. Installationen, Skulptur, Performances als Formen der Rekultivierung postindustrieller Landschaften], in: Prace Komisji Krajobrazu Kulturowego 10 (2008), 386-394, hier 386. 
4. verwüstete Landschaften (starke Industrialisierung und Urbanisierung);

5. künstliche Landschaften (Umgestaltung für Erholung und Entspannung). ${ }^{2}$

Nach dem polnischen Gesetz über Denkmalschutz und Denkmalpflege von 2003 ist »Landschaft « ein durch menschliche Tätigkeit gestalteter Raum, der Artefakte der Zivilisation und natürliche Elemente umfasst, also eine Kulturlandschaft. Die Stadtlandschaft ist von der Landschaft ihrer Umgebung, die oft in ihre Beurteilung eingeht, nicht zu trennen.

Wir leben in einer Epoche des »Gedenkens«: Die Eruption der Erinnerung bringt Menschen dazu, Fragen nach der Vergangenheit zu stellen und damit nach der eigenen Identität. ${ }^{3}$ Was war und den Lebensrhythmus der Gemeinschaft formte, hat materielle Spuren in Raum und Landschaft hinterlassen. In der Wojewodschaft Schlesien finden wir viele Artefakte der industriellen Vergangenheit: Fördertürme aus Stahl oder Stahlbeton, Wassertürme und Fabrikschornsteine, die noch vor Kurzem die Landschaft dominierten, jetzt aber langsam verschwinden. Das einzige, was bleibt, ist das Gezähe (kupla), das Bergbauemblem, das oft in den Wappen der alten Bergbaustädte zu sehen ist. ${ }^{4}$ Man findet es auch an Grubengebäuden, in der Symbolik von Sportvereinen der Bergbauregionen, ${ }^{5}$ manchmal auch auf Grabsteinen von Bergleuten.

\section{Die Wojewodschaft Schlesien}

Die Wojewodschaft Schlesien besitzt ein beeindruckendes industrielles Erbe. Sie kann sich wohl mit Abstand der größten Dichte großer Industriestädte in Polen rühmen. ${ }^{6}$ Die Entwicklung der meisten Städte der Wojewodschaft ging mit der

2 Die Systematik nach Anna Nitkiewicz-Jankowska und Grzegorz Jankowski, »Krajobraz kulturowy jako walor turystyczny« [Kulturlandschaft als touristischer Wert], in: Prace Komisji Krajobrazu Kulturowego 14 (2009), 185-194.

3 Dorota Świtała-Trybek, »Lokomotywy i wagoniki górnicze jako pamiątki historii oraz atrakcje turystyczne" [Bergbaulokomotiven und -loren als historische Erinnerungsstücke und Touristenattraktion], in: Turystyka kulturowa 8 (2014), 33-50, 33.

4 Zwanzig Städte der Wojewodschaft Schlesien führen in ihren Wappen Hinweise auf Bergbau oder Industrie: Katowice, Sosnowitz, Zabrze, Beuthen, Dąbrowa Górnicza, Jastrzębie Zdrój, Jaworzno, Tarnowitz, Schwientochlowitz, Zawiercie, Knurów, Myszków, Czerwionka-Leszczyny, Ustroń, Poręba, Kalety, Sławków, Ruda Śląśka und Strumien.

5 U. a. Górnik Zabrze, GKS Katowice, Concordia Knurów, GKS Tychy, Ruch Radzionków, Górnik Mysłowice, Zagłębie Sosnowiec, oder auch Vereine außerhalb der Region wie Górnik Łęczna, Górnik Konin, GKS Bełchatów oder Czarni Wałbrzych.

6 Der Urbanisierungskoeffizient der Wojewodschaft Schlesien ist mit 78 \% im Jahre 2008 der höchste in Polen. Es gibt hier 71 Städte mit einer Gesamtfläche von 379.017 ha; dazu im Vergleich die Gesamtfläche der Wojewodschaft 1.233.309 ha. Ministerstwa Rozwoju Regionalnego (Hg.), Rozwój miast w Polsce: raport wprowadzający Ministerstwa Rozwoju Regio- 
Entwicklung der Industrie einher. Ein Teil entstand während der Industriellen Revolution im frühen 19. Jahrhundert. Die Kattowitzer Agglomeration ${ }^{7}$ ist eine Folge der Bodenschätze der Region. Montanindustrie (Gruben und Hütten) und Leichtindustrie (Textil) bildeten die Grundlage für Zuwanderung aus verschiedenen Teilen des heutigen Polen und anderen Ländern. Dieser quantitativ bedeutende Zuzug in ein verhältnismäßig kleines Gebiet gestaltete die Landschaft in radikaler Weise um. Ähnlich wie bei anderen großen Industrierevieren verlief die Urbanisierung dynamisch und war ganz auf die Förderung und Verarbeitung der Bodenschätze ausgerichtet. Es war dies also ein temporärer, auf eine kurze Zeitspanne angelegter Prozess, begleitet von der Entstehung minimaler sozialer und kultureller Infrastruktur.

In der Entwicklung des Ballungsgebiets sind bei der Herausbildung der Raumstruktur vier Phasen zu unterscheiden:

1. 1750-1850: langsames Aufkommen kleiner Siedlungseinheiten;

2. 1850-1950: Konsolidierung der Siedlungen und Bildung von Städten;

3. 1950 bis heute: sich verstärkende räumliche Konflikte;

4. Beginn in naher Zukunft: Änderung des Entwicklungsparadigmas. ${ }^{8}$

Die Wojewodschaft Schlesien umfasst $12.333 \mathrm{~km}^{2}$, das sind fast vier Prozent der Fläche Polens. Zur Wojewodschaft gehören 167 Gemeinden in 36 Kreisen, davon 17 Land- und 19 Stadtkreise. Das Siedlungssystem der Wojewodschaft besteht aus 1.369 Orten, darunter 71 Städten, was eine Dichte von 58 Städten auf $10.000 \mathrm{~km}^{2}$ bedeutet (doppelt so hoch wie im Landesdurchschnitt). $2011 \mathrm{nahm}$ die Wojewodschaft landesweit den dritten Rang bei den rekultivierungsbedürftigen Flächen ein, darunter 3.715 ha verwüstete Flächen sowie 1.206 ha irreparabel zerstörte Flächen. Die Region ist von 4,63 Mio. Menschen (zwölf Prozent der Gesamtbevölkerung Polens) bewohnt. Die Wojewodschaft Schlesien ist die am stärksten urbanisierte Region des Landes (77,7 \% städtische Bevölkerung) und besitzt mit 375 Personen pro $\mathrm{km}^{2}$ oder dem Dreifachen des Landesdurchschnitts die höchste Bevölkerungsdichte.

nalnego [Stadtentwicklung in Polen: einführender Bericht des Ministeriums für Regionalentwicklung], Warszawa: MRR, 2010.

7 In der Literatur auch folgende gleichberechtigte Bezeichnungen: oberschlesische Konurbation, Kattowitzer Städteverbund, Kattowitzer oder oberschlesischer Metropolenverbund. Dazu gehören die Städte Gleiwitz, Zabrze, Ruda Śląska, Beuthen, Schwientochlowitz, Königshütte, Deutsch Piekar, Czeladź, Będzin, Siemianowitz, Katowice, Sosnowitz, Myslowitz, Dąbrowa.

8 Krzysztof Gasidło, »Kierunki przemian struktury aglomeracji śląskiej« [Veränderungsrichtungen der Struktur der oberschlesischen Agglomeration], in: Janusz Słodczyk (Hg.), Przemiany struktury przestrzennej miast $w$ sferze funkcjonalnej $i$ społecznej [Funktionale und soziale Veränderungen der Raumstruktur von Städten], Opole: Uniwersytet Opolski, 2004, 63-78, hier 64. 
In den Jahren 2002-2011 wurde in der Wojewodschaft Schlesien eine vom landesweiten Trend abweichende Veränderung der Bevölkerungszahl beobachtet. Denn sie von 4,732 Mio. auf 4,626 Mio. oder um 2,2\% zurück, während sie in Polen insgesamt von 38,219 Mio. auf 38,538 Mio. oder um 0,8 \% anstieg. ${ }^{9}$ Die seit 1989 wirtschaftlichen und politischen Veränderungen hatten sozioökonomische Folgen in Gestalt von Deindustrialisierung, Deurbanisierung und der damit einhergehenden Abwertung großer Teile des Ballungszentrums und der gesamten Wojewodschaft. Der Niedergang von Industrieunternehmen reißt von diesen abhängige Wohnsiedlungen und Dienstleistungszentren mit in den Abwärtstrend. Dazu gehören zurückgehende Bevölkerungszahlen, Änderung der Sozialstruktur, Anstieg der Arbeitslosigkeit und der Außenmigration, Niedergang vieler Dienstleistungsbranchen, die bisher von den großen Industriebetrieben finanziert worden waren, darunter Gesundheitszentren, Kulturhäuser und Sportvereine, sowie Verschlechterung der Wohnsubstanz.

In kurzer Zeit wurden die meisten großen Industriebetriebe in der Wojewodschaft Schlesien abgewickelt oder gingen Bankrott, was hohe Arbeitslosigkeit verursachte. Die Lage der Arbeitslosen war deshalb schwierig, weil die oft nur in einem Bereich wie Bergbau oder Hüttenwesen Qualifizierten in ihrer Branche keine neue Arbeit fanden. Das führte zu einer Änderung der traditionellen Rollenverteilung in den Familien, da Frauen nun ebenfalls Arbeit außer Haus suchten, um zum Lebensunterhalt beizutragen.

Für den durchschnittlichen Polen ist die Wojewodschaft Schlesien, genauer das Ballungszentrum um Katowice, ein kohärenter und einheitlicher Organismus. Doch muss man die kulturellen und historischen Unterschiede zwischen den Städten Oberschlesiens und des Dąbrowa-Beckens ${ }^{10}$ auf beiden Seiten des Flusses Brynica beachten, obwohl beide Gebiete von der Industrie geprägt sind. In der Wojewodschaft befindet sich die Dreikaiserreichsecke, an der bis 1918 die Grenzen Russlands, Deutschlands und Österreich-Ungarns aufeinandertrafen. Sie ist ein Symbol der kulturellen Vielfalt der Region. Bis heute ist die Teilung in

9 Województwo Śląskie (Hg.), Strategia Rozwoju Województwa Śląskiego »Śląskie 2020+« [Entwicklungsstrategie der Schlesischen Wojewodschaft "Schlesische 2020+«], Katowice 2013.

10 Der Begriff Dąbrowa-Becken bzw. -Revier kam im 19. Jahrhundert für das Gebiet der Steinkohleförderung im Königreich Polen in Gebrauch. Das jetzige Revier war seit dem Mittelalter ein breiter Grenzstreifen zwischen Kleinpolen und Schlesien. Im Laufe der Jahrhunderte änderte sich seine regionale und staatliche Zugehörigkeit mehrfach. Die territoriale Bezeichnung "Dąbrowa-Becken« bürgerte sich als Name des Gebiets rund um die Städte Będzin, Sosnowitz, Dąbrowa Górnicza, Czeladź, Zawiercie und Ząbkowice ein. Er ist eher die Bezeichnung eines Wirtschaftsgebiets, denn die Bestimmung seiner Verwaltungsgrenzen bereitet eine Reihe von Schwierigkeiten, weil es sich nicht mit einer Region im ethnographischen oder historischen Sinne deckt. Jan Przemsza-Zieliński, Historia Zagłębia Dąbrowskiego [Geschichte des Dąbrowa-Reviers], Sosnowiec: Związek Zagłębiowski, 2006, 239. 
Städte sichtbar, die wie Oberschlesien von Berlin aus regiert wurden, und denen, die unter russländischer Herrschaft standen wie das Dąbrowa-Becken. Die unterschiedliche Geschichte spiegelt sich in der Alltagskultur wider, wurde aber in der Zeit der Volksrepublik Polen gezielt übergangen. Nach 1989 konnte sie wieder öffentlich werden. Es gab eine Renaissance der oberschlesischen Kultur, die sich häufig antagonistisch zu der des Dąbrowa-Beckens verhält. Vielleicht war das negative Verhältnis der hanysy, also der alteingesessenen Bewohner des ehemals preußischen Teils Oberschlesiens, zu den sogenannten gorole, also den Einwohnern des Dąbrowa-Beckens und der übrigen Teile Polens, ein Grund für die Unterdrückung der oberschlesischen Identität durch politisch Verantwortliche aus dem Dąbrowa-Revier, die die Wojewodschaft zwischen 1957 und 1980 regierten. $^{11}$

Nach 1989 setzten in den Städten des Ballungszentrums infolge der Umstrukturierung der Wirtschaft heftige soziale und kulturelle Veränderungen ein. Diese verliefen in Oberschlesien und Dąbrowa-Revier unterschiedlich. In Oberschlesien löste die Schließung von Gruben und anderen Betrieben Proteste aus, was manchmal Unternehmen rettete oder zum Zusammenschluss mehrerer Unternehmen führte. Dagegen verlief der Prozess im Dąbrowa-Becken reibungsloser, während die Gesellschaft sich eher apathisch verhielt. Das gibt einen Einblick in die Probleme der Städte östlich der Brynica, die plötzlich auf die Industriekultur als zentralen Identitätsfaktor verzichten mussten und zudem ihre Haupteinnahmequelle verloren. Die Kommunen mussten Lösungen für die sozialen Folgen dieses kulturellen und sozioökonomischen Kahlschlags finden. ${ }^{12}$

Das Dąbrowa-Becken wurde lange fast ausschließlich mit fälschlich als kommunistisch identifizierten Arbeitertraditionen assoziiert. Dabei gerieten zwei weitere wichtige Aspekte der kulturellen Identität dieses Gebiets völlig in Vergessenheit: das jüdische Erbe einer einst sehr großen jüdischen Gemeinde sowie die von der bürgerlichen inteligencja geprägte städtische Kultur, zu der in der Zwischenkriegszeit ein hohes Bildungsniveau gehörte. Natürlich prägte die bergmännische oder, allgemeiner gefasst, industrielle Tradition und Identität die Region ebenso, aber die Stilllegung der Industriebetriebe hinterließ im Dą-

11 Erste Sekretäre des Wojewodschaftskomitees der Polnischen Vereinigten Arbeiterpartei (PZPR) in Katowice waren im erwähnten Zeitraum der aus dem Dąbrowa-Becken stammende Edward Gierek und anschließend Zdzisław Grudzień.

12 Jacek und Kazimiera Wódz, »Restrukturyzacja ekonomiczna województwa śląskiego a przekształcenia społeczno-kulturowe miast. W poszukiwaniu nowej tożsamości« [Wirtschaftliche Restrukturierung der Schlesischen Wojewodschaft und die soziokulturelle Umgestaltung der Städte. Auf der Suche nach einer neuen Identität], in: Grzegorz Gorzelak, Marek S. Szczepański und Weronika Ślęzak-Tazbir (Hg.), Człowiek-miasto-region. Związki i interakcje. Ksiega jubileuszowa profesora Bohdana Jałowieckiego [Mensch - Stadt - Region: Verbindungen und Interaktion. Festschrift für Prof. Bohdan Jałowiecki], Warschau: Wydawnictwo Naukowe Scholar, 2009, hier $208 \mathrm{f}$. 
browa-Becken schwerwiegendere Probleme als in Oberschlesien. Hier hatte die Umstrukturierung des ausgehenden 20. Jahrhunderts vor allem besonders schmerzhafte soziale Verwerfungen zur Folge. ${ }^{13}$

Die Rolle der Industrie im Dąbrowa-Becken bis 1989 zeigt sich an der Zahl der Arbeitsplätze: in Sosnowiec (Sosnowitz) waren 44.000 Personen in der Industrie beschäftigt, in Dąbrowa Górnicza 36.000, in Będzin 16.400 und in Zawiercie knapp 15.000. Die Schwerindustrie (Steinkohlebergbau, Hüttenwesen, Energiewirtschaft) hatte die führende Rolle. Im Hüttenwesen waren 198924.600 Personen beschäftigt (Katowicka- und Bankowa-Hütte in Dąbrowa Górnicza, Buczek- und Cedler-Hütte in Sosnowitz); darüber hinaus gab es eine Eisenhütte in Zawiercie und eine Hütte für Nichteisenmetalle in Będzin. Im Dąbrowa-Revier gab es zahlreiche, für den lokalen Markt produzierende, mit der Montanindustrie verzahnte Elektromaschinenbetriebe. Daneben gab es noch andere produzierende Industrie: Textilindustrie in Sosnowiec und Zawiercie, Schuhherstellung in Będzin sowie Mineralindustrie in Dąbrowa Górnicza, Zawiercie, Łazy, Ogrodzieniec, Czeladź und Sosnowiec. Nach 1989 wurden marktwirtschaftliche Mechanismen eingeleitet, es kam zu Privatisierungen und ausländischen Investitionen. Das wirkte sich dahingehend aus, dass sich die Städte von monofunktionalen Bergbau- und Hüttenzentren zu diversifizierten Produktions- und Dienstleistungsstandorten verwandelten.

\section{Die Stadtlandschaft von Sosnowiec}

Sosnowiec entstand im ausgehenden 19. und frühen 20. Jahrhunderts durch Eingemeindung dörflicher Siedlungen und Arbeiterkolonien. Lange entwickelte es sich daher auf stadtplanerisch ungeordnete Weise. Zahlreiche Fabriken und Industriebetriebe, vor allem im Stadtzentrum angesiedelt, verliehen der Stadt ein besonderes Gepräge. Auch wenn die ersten Kohlengruben des Gebiets bereits im frühen 19. Jahrhundert entstanden, datieren dessen wahren Anfänge auf das Jahr 1859, als eine Abzweigung der Bahnlinie Warschau-Wien gebaut wurde, für die eine Bahnstation in Granica (heute Maczki) und dann der Hauptbahnhof von Sosnowiec gebaut wurden. ${ }^{14}$ In der Nähe der Bahnstationen begannen sich Groß-

131977 waren im Dąbrowa-Revier noch neun Bergwerke aktiv (Grodziec in Będzin, Jowisz in Wojkowice, Kazimierz-Juliusz, Czerwone Zagłębie [später Sosnowiec], Niwka-Modrzejów, Mortimer-Porąbka in Sosnowitz, Paryż in Dąbrowa Górnicza, Saturn in Czeladź). Zudem gehörte auch die Grube Siemianowice zum Bestand der Dąbrowaer Vereinigung der Kohleindustrie, Nowe Zagłębie 5 (2010), 30.

14 Eine zweite Bahnlinie entstand auf dem Gebiet des heutigen Sosnowitz um das Jahr 1885, nämlich die Eisenbahn von Iwanogród (Dęblin) nach Dąbrowa Górnicza. Von dieser Linie zeugt das stark verfallene Bahnhofsgebäude von Sosnowitz-Süd. 
und Einzelhandel zu entwickeln. Dort entstanden auch Zollämter, Eisenbahnerwohnungen und katholische wie orthodoxe Kirchen. Rund um dieses Verkehrs-, Handels- und Dienstleistungszentrum wuchs die Stadt, die mit der Zeit die ringsum errichteten Arbeitersiedlungen und Industriebetriebe in sich aufnahm. So waren Eisenbahn und Handel für Sosnowiec stadtbildende Faktoren. ${ }^{15}$ Sosnowiec bemühte sich seit 1898 um die Stadtrechte und erhielt sie im Juni 1902. Die neu geschaffene Stadt umfasste 1.875 ha und zählte 60.000 Einwohner. Die größte Bevölkerungszahl erreichte Sosnowiec mit 259.000 Einwohnern im Jahre 1990; 2016 waren es nur noch 205.000. ${ }^{16}$

Von dieser Stadtentwicklung sind nur noch wenige Spuren erhalten. In den 1970er Jahren wurden die alten Arbeitersiedlungen nach und nach abgerissen oder um Plattenbauten erweitert. Diese Maßnahmen kamen nach 1989 zum Ende, als die Betriebe stillgelegt wurden, die die Visitenkarte der Stadt waren und heute dem Verfall preisgegeben sind. Territorial erweiterte sich Sosnowiec in den 1970er Jahren um vier weitere Orte (Kazimierz Górniczy, Klimontów, Porąbka, Zagórze) sowie zwei Stadtsiedlungen (Maczki und Ostrowy Górnicze). Das Ergebnis war untypisch für die Urbanisierung in Polen, denn in Sosnowiec befand sich auf zehn Quadratkilometer je eine Stadt oder städtische Siedlung, um die herum sich in 1,5 bis $2 \mathrm{~km}$ Entfernung weitere Siedlungskerne bildeten. ${ }^{17}$

Die Stadt hat infolgedessen eine städtebauliche Struktur, die funktional und morphologisch dem polyzentrischen, mosaikartigen Mehrkernmodell von Harris und Ullman entspricht. Im Stadtgebiet von Sosnowiec befinden sich geschlossene Hochbebauungen aus den Jahren um 1900 (Innenstadt, Pogoń, AltSosnowiec) ebenso wie Arbeiter- und Betriebssiedlungen (Niwka, Dańdówka, Ostrowy Górnicze, Dębowa Góra) oder urbanisierte Dörfer und Viertel mit Flachbebauung (Porąbka, Klimontów, Bór, Milowice). ${ }^{18}$

Die Stadt durchlief in den 1970er und 1980er Jahren mit der Erneuerung der Wohnungsinfrastruktur, dem Ausbau von Straßen und Straßenbahnlinien und der Eingliederung neuer städtischer Zentren eine dynamische Entwicklung, bevor sie in den 1990er Jahren von der Krise erfasst wurde. Trotz des erwähnten Verlustes an Bausubstanz war der Stadtausbau eine Begleiterscheinung der Modernisierung von Sosnowiec im Rahmen der zeitgegebenen Möglichkeiten.

15 Robert Krzysztofik, »Proces umiastowienia obszaru współczesnego Sosnowca i jego efekty« [Die Urbanisierung des Gebiets des modernen Sosnowitz und ihre Effekte], in: Andrzej T. Jankowski (Hg.), Rocznik Sosnowiecki, Band 15, Sosnowiec: Muzeum w Sosnowcu, 2007, 89-95.

16 Daten aus Publikationen des Statistischen Hauptamtes (GUS).

17 Krzysztofik, »Proces«, $102 \mathrm{f}$.

18 Edmund Czarski (Hg.), Procesy i struktury demograficzno-społeczne na obszarze województwa śląskiego $w$ latach 1988-2008 [Demographische und soziale Prozesse und Strukturen in der Schlesischen Wojewodschaft 1988-2008], Katowice: Urząd Statystyczny w Katowicach, 2010, 101. 
Am schwierigsten war die Lage der Schwerindustrie. 1989 bis 2005 verlor die Stadt etwa $80 \%$ der Arbeitsplätze in der Schwerindustrie. ${ }^{19}$ Dies war nach den beiden Weltkriegen das größte Entwicklungstrauma, das Sosnowiec je erlebte. ${ }^{20}$ Bis 2008 wurden drei von vier Steinkohlegruben der Stadt geschlossen, ${ }^{21}$ die Eisenhüttenindustrie umstrukturiert, die Textil- und Bekleidungsindustrie kam praktisch zum Erliegen; ähnlich verhielt es sich mit Maschinenbau und Elektrotechnik. Der Arbeitsmarkt schrumpfte, bedingt durch die Entwicklung in den Nachbarstädten wie Dąbrowa Górnicza und Katowice, in die viele Einwohnerinnen und Einwohner von Sosnowiec zur Arbeit pendelten. Das alles wirkte sich verheerend auf die städtischen Finanzen aus, was Investitionen und Modernisierung auf das bare Minimum schrumpfen ließ.

Wie sich die Stadt im Hinblick auf demografische Entwicklung, Arbeitslosigkeit und Beschäftigung in der Wojewodschaft und den beiden Nachbarstädten veränderte, fassen die beiden folgenden Tabellen zusammen.

$\mathrm{Zu}$ Beginn des 21. Jahrhunderts gründete die Firma Heraeus Electro-Nite eine Fabrik auf dem Gelände der alten Steinkohlengrube Sosnowiec. Dies brachte die Wende. Seither ließen sich viele weitere Firmen auf Industriebrachen nieder. $\mathrm{Zu}$ den ersten und wichtigsten gehören das Messe- und Ausstellungszentrum ExpoSilesia in Zagórze sowie die Firma Polskapresse mit der Redaktion des Dziennik Zachodni und der Druckerei in Milowice. ${ }^{22}$

19 Czarski (Hg.), Procesy, 104.

20 Iwona Kantor-Pietraga und Robert Krzysztofik, »Uwarunkowania przemian Sosnowca w sytuacji transformacji społeczno-ekonomicznej przełomu XX i XXI wieku« [Bedingungen des Wandels von Sosnowitz bei der sozioökonomischen Transformation im 20. und 21. Jahrhundert], in: Kazimierz Gołosz (Hg.), Rocznik Sosnowiecki, Band 19, Sosnowiec: Muzeum w Sosnowcu, 2011, 39-58.

21 Ebd., 46.

22 Ebd., 57. 


\begin{tabular}{|c|c|c|c|c|c|}
\hline & $\begin{array}{l}\infty \\
0 \\
1 \\
2 \\
2 \\
2 \\
2\end{array}$ & $\begin{array}{l}\vec{n} \\
\text { ڤू } \\
o \\
1\end{array}$ & 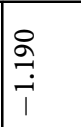 & 章 & $\frac{8}{9}$ \\
\hline & $\begin{array}{l}\infty \\
2 \\
1 \\
\alpha \\
o \\
2 \\
1\end{array}$ & 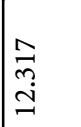 & $\underset{\infty}{0}$ & $\begin{array}{l}n \\
i n \\
i \\
i \\
i\end{array}$ & in \\
\hline 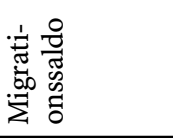 & \begin{tabular}{l}
$\infty$ \\
$\infty$ \\
1 \\
$\infty$ \\
\multirow{2}{2}{} \\
-1
\end{tabular} & 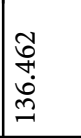 & \begin{tabular}{l}
\multirow{2}{*}{} \\
$\stackrel{2}{-}$
\end{tabular} & 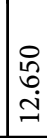 & $\begin{array}{l}\vec{\delta} \\
\infty \\
\stackrel{+}{\sim}\end{array}$ \\
\hline & $\begin{array}{l}\infty \\
0 \\
1 \\
2 \\
2 \\
2 \\
2\end{array}$ & 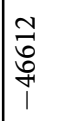 & 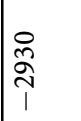 & $\begin{array}{l}\hat{\Upsilon} \\
\hat{n} \\
0 \\
0 \\
0\end{array}$ & $\underset{1}{ت}$ \\
\hline & $\begin{array}{l}\infty \\
a \\
1 \\
2 \\
2 \\
2 \\
-1\end{array}$ & 帝 & 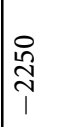 & $\begin{array}{l}0 \\
0 \\
0 \\
0 \\
0 \\
1\end{array}$ & 离 \\
\hline 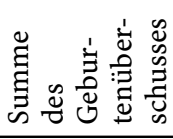 & 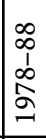 & $\begin{array}{l}\infty \\
0 \\
\hat{L} \\
\infty \\
\infty \\
m \\
m\end{array}$ & 离 & $\overrightarrow{\widetilde{\sigma}}$ & $\begin{array}{l}\stackrel{2}{+} \\
\stackrel{+}{1}\end{array}$ \\
\hline & 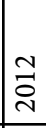 & 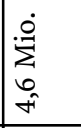 & $\begin{array}{l}\vec{D} \\
\stackrel{+}{+} \\
\stackrel{-}{J}\end{array}$ & ڤñ & 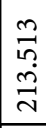 \\
\hline & ळ & \begin{tabular}{l}
2 \\
\multirow{+}{*}{$\dot{2}$}
\end{tabular} & $\begin{array}{l}\vec{\theta} \\
\ddot{m} \\
\ddot{n}\end{array}$ & 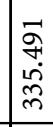 & กิ \\
\hline & $\begin{array}{l}\infty \\
\infty \\
\stackrel{2}{2}\end{array}$ & 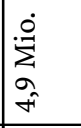 & $\begin{array}{l}\stackrel{0}{\sim} \\
\sim \\
\ddot{m} \\
\end{array}$ & $\mid \begin{array}{l}\infty \\
0 \\
\infty \\
i \\
0 \\
\infty\end{array}$ & 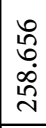 \\
\hline 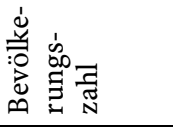 & $\stackrel{\infty}{\stackrel{\infty}{2}}$ & $\stackrel{n}{2} \dot{f}$ & 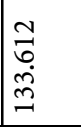 & $\begin{array}{l}\hat{a} \\
\text { o. } \\
\text { aे } \\
\text { m. }\end{array}$ & $\begin{array}{l}\text { ก} \\
\text { n̊. } \\
\text { సิ }\end{array}$ \\
\hline 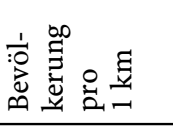 & $\stackrel{n}{\stackrel{2}{2}}$ & $\stackrel{m}{\sim}$ & $\hat{2}$ & 帝 & ָ̊ \\
\hline & 营 & 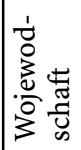 & 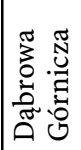 & 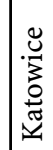 & 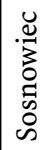 \\
\hline
\end{tabular}


Tabelle 2: Zahl der Beschäftigten, Arbeitslosen, staatliche Betriebe (eigene Darstellung auf der Grundlage von Daten des Statistischen Amtes in Katowice)

\begin{tabular}{|l|l|l|l|l|l|l|}
\hline Auflistung & \multicolumn{2}{|l|}{ Beschäftigte (pro Einwohner) } & $\begin{array}{l}\text { Insgesamt } \\
\text { Beschäf- } \\
\text { tigte }\end{array}$ & $\begin{array}{l}\text { Regis- } \\
\text { trierte } \\
\text { Arbeits- } \\
\text { lose }\end{array}$ & $\begin{array}{l}\text { Staatliche } \\
\text { Betriebe } \\
\text { im } \\
\text { Register } \\
\text { REGON }\end{array}$ \\
\hline Jahr & 1978 & 1988 & 2006 & 2012 & 2012 & 2012 \\
\hline $\begin{array}{l}\text { Wojewod- } \\
\text { schaft }\end{array}$ & 0,424 & 0,375 & 0,240 & & $208.300^{23}$ & \\
\hline $\begin{array}{l}\text { Dąbrowa } \\
\text { Górnicza }\end{array}$ & 0,627 & 0,544 & 0,306 & 39.117 & 7.166 & 12.140 \\
\hline Katowice & 0,688 & 0,594 & 0,473 & 156.954 & 10.834 & 44.050 \\
\hline Sosnowiec & 0,408 & 0,348 & 0,215 & 47.128 & 11.555 & 23.776 \\
\hline
\end{tabular}

\section{Die Industriebrachen in Sosnowiec}

Für Geschichte und Identität der Stadt sind die Bahnhöfe Sosnowiec Główny (Hbf.) und Maczki wichtig. Sie waren die Schweißnähte und Schwungräder der Stadtentwicklung. Ihre aktuelle Nutzung könnte unterschiedlicher nicht sein: Der Hauptbahnhof wurde anlässlich der Hundertjahrfeiern der Stadtrechte renoviert, ist Teil der oberschlesischen $»$ Route der Industriekultur ${ }^{24}$ und eine Visitenkarte der Stadt, aber es gibt kein Nutzungskonzept; die meisten Räume stehen leer. Der Bahnhof in Maczki dagegen, der in den 1960er Jahren ins Denkmalregister eingetragen wurde, verfällt mitsamt seiner Umgebung und ist nur noch ein Schatten seiner früheren Pracht. Von ihren ursprünglichen Plänen, gemeinsam mit den Staatsbahnen (PKP) im alten Bahnhof ein WissenschaftlichDidaktisches Zentrum für Eisenbahntransport anzusiedeln, in dem bereits ab 1. Oktober 2016 Eisenbahningenieure ausgebildet werden sollten, ist die Schlesische Technische Hochschule im September 2017 abgerückt. ${ }^{25}$

23 Ende 2013.

24 Szlak Zabytków Techniki [Route der Technikdenkmäler], http://www.zabytkitechniki.pl, zuletzt geprüft am 9. September 2019.

25 Piotr Purzyński, "Politechnika Śląska się wycofała, PKP przerywa przebudowę dworca w Maczkach« [Schlesisches Politechnikum hat sich zurückgezogen, Polnische Staatseisenbahnen unterbrechen Umbau des Bahnhofs Maczki], in: wyborcza.pl Sosnowiec, 13. September 2017, http://sosnowiec.wyborcza.pl/sosnowiec/7,93867,22364975,politechnika-slas ka-sie-wycofala-pkp-przerywa-przebudowe-dworca.html, zuletzt geprüft am 9. September 2019. 
Die von Heinrich Dietel aus Sachsen gegründete größte Kammgarnspinnerei des ehemaligen Königreichs Polen verfällt ebenso zusehends. Der nach dem Zweiten Weltkrieg verstaatlichte und unter dem Namen POLITEX bekannte Betrieb meldete 1993 Konkurs an. Die Liegenschaften der Spinnerei gingen in Privatbesitz über, lediglich das Verwaltungsgebäude wurde renoviert und für die Polizei hergerichtet; es ist in das Denkmalregister eingetragen. Außerdem wurde noch ein weiteres auf Dietel zurückgehendes Bauwerk gerettet: der frühere Familiensitz, ein neobarocker Palast, dessen Renovierung vor kurzem abgeschlossen wurde. ${ }^{26}$

Auch die beiden anderen großen Textilfabriken wurden geschlossen. INTERTEX in der Chemiczna-Straße wurde 2007 dem Insolvenzverwalter übergeben. Heute befinden sich auf dem Fabrikgelände viele kleinere Firmen mit unterschiedlichem Profil. Ein Teil der Gebäude verfällt. Die ehemalige Wirkwarenfabrik Wanda ging ebenfalls den typischen Weg eines Industriebetriebs in den 1990er Jahren: Zusammenbruch der Produktion, Entlassungen, Verkauf des Grundstücks. ${ }^{27}$

Ein für die Entwicklung von Sosnowiec noch wichtigeres Unternehmen, nämlich die Steinkohlegrube Sosnowiec (vorher unter dem Namen Fanny- oder Graf Renard-Grube) wurde nach 140 Jahren 1997 stillgelegt. Heute ist von dem einstigen Betrieb nur der Annaschacht übriggeblieben, der Teil eines Ende 2012 eröffneten Kletterzentrums ist. Auf dem Turm gibt es eine Aussichtsplattform, in der Hängebank befinden sich Kletterwände, Fitnessstudio, Trainingsräume, ein Café sowie ein Konferenzsaal. ${ }^{28}$

Dagegen entstehen in einem anderen Gebäude, nämlich im Renard-Kraftwerk auf der gegenüberliegenden Straßenseite, die Hotels Mercure und Ibis Styles. Sie sollen das Neue mit dem Alten verbinden. Das Gebäude wird sechs Stockwerke, mehrere Restaurants sowie ein Spa haben. Das Objekt soll 2022 in Betrieb genommen werden. ${ }^{29}$

$26 »$ Mercure Sosnowiec, hotel grupy Orbis, ma być otwarty w 2022 roku« [Das Mercure Sosnowitz, ein Hotel der Orbis-Gruppe, soll 2022 eröffnet werden], in: Wiadomości Sosnowiec, naszemiasto.pl, 22. Januar 2019, https://sosnowiec.naszemiasto.pl/mercure-sosnowiec-ho tel-grupy-orbis-ma-byc-otwarty-w-2022/ar/c3-4965186, zuletzt geprüft am 9. September 2019.

27 http://sosnowiec.gazeta.pl/gazetasosnowiec/56,93867,14181965,Wanda_piekarnia_i_szkie letor_Widma_Sosnowca_FOTO_.html, Seite ist nicht mehr aktiv.

28 »Ściana wspinaczkowa [Kletterwand] Fitness Club«, http://poziom450.pl/, zuletzt geprüft am 9. September 2019.

29 "Nowe hotele w Sosnowcu: W dawnej elektrowni Renard będzie Mercure i ibis Styles« [Neue Hotels in Sosnowitz: Im alten Renard-Kraftwerk wird es ein Mercure und ein Ibis Styles geben], in: Dziennik Zachodni, 24. Oktober 2014, http://www.dziennikzachodni.pl/artykul/ 1025045, nowe-hotele-w-sosnowcu-w-dawnej-elektrowni-renard-bedzie-mercure-i-ibis-sty les-zdjecia,id,t.html, zuletzt geprüft am 19. September 2019. 
Auf dem Gelände der zweiten stillgelegten Steinkohlegrube Niwka-Modrzejów wird die Stadt einen Wissenschafts- und Technologiepark (SPNT) errichten. ${ }^{30}$ Dadurch sollen günstige Bedingungen für wirtschaftlich innovative Unternehmen geschaffen werden, die moderne Technologien einführen und Arbeitsplätze schaffen. Hierzu wurden zwei Gebäude des alten Bergwerks umgebaut: die Schaltzentrale für Produktions- und Forschungszwecke sowie der ehemalige Arbeitsschutzkomplex, um diesen für fünf Unternehmen herzurichten. Beide Maßnahmen wurden aus Mitteln des Europäischen Regionalen Entwicklungsfonds im Rahmen des Regionalen Operationsprogramms der Wojewodschaft Schlesien für die Jahre 2007-2013 finanziert. Für das Gelände der ehemaligen Steinkohlegrube Niwka-Modrzejów wurde ein neues Verkehrskonzept erarbeitet; es wurden auch Spazierwege geschaffen, um früher geschlossene Werkteile für die Stadtbevölkerung zugänglich zu machen. 2012 zogen erste Firmen auf dem Gelände des SPNT ein.

Diese wenigen Beispiele veranschaulichen die Problematik der vielfach dem Verfall preisgegebenen Industrieflächen. Auch das letzte noch im Betrieb befindliche Bergwerk im ganzen Dąbrowa-Becken, die Grube Kazimierz-Juliusz im Stadtgebiet von Sosnowiec, wurde bis Ende 2018 endgültig liquidiert. ${ }^{31}$ Die Flächen zweier weiterer geschlossener Steinkohlengruben, Porąbka-Klimontów und Milowice (Saturn III), haben bereits neue Funktionen erhalten oder es ist bereits eine Neubebauung geplant.

Die Bergwerke und Hütten organisierten den umliegenden Stadtraum für die Zwecke ihrer Belegschaften, wovon aber auch die übrigen Einwohner profitierten. So entstanden Kulturhäuser, Bibliotheken, Sportvereine; dies waren in Sosnowiec u. a. das Schwimmbad im Sielecki-Park und die Kunsteishalle im Żeromski-Park. ${ }^{32}$ Die Bergwerke errichteten aus eigenen Mitteln ganze Wohnsiedlungen und veranstalteten Ferienlager für Kinder und Beschäftigte. Von einem Tag auf den anderen war das alles Vergangenheit. Zudem wurden zur gleichen Zeit die Textilbetriebe geschlossen, in denen viele Frauen aus der Stadt und der Umgebung angestellt waren. Mit einem Schlag lag die traditionelle Familienstruktur in Sosnowiec mit dem Mann als Kumpel und der Frau als Textilarbeiterin in Trümmern.

30 Sosnowiecki Park Naukowo-Technologiczny, http://www.spnt.sosnowiec.pl/index.php?pa ge=misja-i-wizja, zuletzt geprüft am 9. September 2019.

31 »Kopalnia Węgla Kamiennego Kazimierz-Juliusz « [Steinkohlengrube Kazimierz-Juliusz], in: Wikipedia. Wolna encyklopedia, https://pl.wikipedia.org/wiki/Kopalnia_W\%C4 \%99gla_Ka miennego_Kazimierz-Juliusz, zuletzt geprüft am 9. September 2019.

32 Andrzej Sawicki, "Zmierzch gigantów« [Dämmerung der Giganten], in: Nowe Zagłębie 1 (2009), 30f., hier 31. 


\section{Ausblick}

Die Identitätskrise, welche die alten Industriestädte seit dem ausgehenden 20. Jahrhundert erfasst hat, ist zugleich als Auftakt zu sehen, sich neu zu erfinden. Nicht jede Stadt des Ballungsgebiets um Katowice hat eine eigene Vision für sich gefunden, aber alle Pläne sollten auf sozialen und kulturellen Merkmalen der Region und auf Einwohnerinitiative aufbauen. Deshalb sollen Hochschulwesen und gesellschaftliche wie kulturelle Initiativen gestärkt werden. ${ }^{33}$ Eine Herausforderung bleibt die alte Industrielandschaft, die nach wie vor verfällt und vielfach schließlich verschwinden wird. Teilweise wird sie aber für neue Zwecke genutzt werden. Die Lösung der architektonischen und städtebaulichen Fragen erfordern jedoch langfristige finanzielle Anstrengungen. Angesichts der für die Revitalisierung in Polen vorgesehenen Mittel besteht hierfür allerdings kein großer Spielraum.

Die Transformation in den alten Industrierevieren hat kulturelle Verschiebungen mit sich gebracht. In vielen Teilen Europas ließen Deindustrialisierung und wirtschaftliche Umstrukturierung kulturelle Traditionen zusammenbrechen, wie sie die regionale Industriegeschichte hervorgebracht hatte. Die Industrie, die den Rhythmus des Alltags bestimmte, war ein wichtiger Bezugspunkt des Ballungsraums um Katowice. Während im Kommunismus die Arbeiterklasse auf ein Podest gehoben wurde, begann nach 1989 eine Zeit der Denkmalstürze. ${ }^{34}$ Die Transformation war eine Phase des Zusammenbruchs der etablierten gesellschaftlichen Ordnung, aber auch der Ordnung des industriell geprägten städtischen Raums.

Die einst identitätsprägenden Industriebetriebe werden heute oft ungeschickt verwaltet und bieten einen Anblick, der besonders für die ehemaligen Beschäftigten schmerzlich sein muss. Die Stadtzentren verlieren Einwohner, es fehlt an geeigneten Begegnungsräumen, stattdessen entstehen Banken, Parkplätze und Einkaufszentren. Diese Plätze entsprechen nicht den Bedürfnissen der Menschen. Im Ergebnis schreitet eine Art "Ghettoisierung « der Betriebssiedlungen voran; Sozialwohnungen lockern die sozialen Beziehungen und lassen das Gemeinschaftsgefühl schwinden, wie es zuvor in den Stadtvierteln bestand. Der Ort verliert seine Seele, das Arbeitsethos schwindet. Der gesellschaftliche Kontext geht verloren und mit ihm die identitätsstiftenden materiellen und mentalen Dominanten der Landschaft.

33 Wódz und Wódz, »Restrukturyzacja«, $212 \mathrm{f}$.

34 Kazimiera Wódz (Hg.), Zapomniane miejsca, zapomniani ludzie: restrukturyzacja ekonomiczna a zmiana kulturowa [Vergessene Orte, vergessene Menschen: Wirtschaftliche Restrukturierung und kultureller Wandel], Katowice: Śląsk, 2013, $151 \mathrm{f}$. 
Im Dąbrowa-Becken hatte die Industrie, anders als in Oberschlesien, eine geringere Bedeutung für die kulturelle Identität. Diese rührte eher aus der spezifischen Tätigkeit, war also weniger ein Bestandteil der regionalen Kultur. Jetzt ändert dies sich langsam, der Kultur- und Industrietourismus wird populärer, und zwar im Sinne der Erkundung der Industriekultur als ein erinnerungswürdiges Kulturerbe. Für diesen neuen Tourismuszweig müssen alte Industrieobjekte erhalten werden. Dazu ist es wichtig, sie mit neuen Funktionen zu versehen, ohne ihre ursprüngliche Bedeutung in Vergessenheit geraten zu lassen. Diese Orte waren für viele Menschen ein wichtiger Teil ihres Lebens, sie definieren weiterhin die Identität der Region und formen ihren Charakter. Bei der Revitalisierung der Industriebrachen muss außer dem rein wirtschaftlichen auch der räumlich-städtebauliche Faktor berücksichtigt werden.

Der Erhalt des industriellen Erbes ist eine Voraussetzung dafür, die historische Identität der Region zu wahren. Natürlich ist das nicht leicht, da sich die Problemzonen in den Stadtzentren häufen. Doch bietet sich in den Stadtzentren die Chance, Investoren und neue Nutzungsmöglichkeiten zu finden. Andererseits weckt eine attraktive Lage auch Anreize für Immobilienspekulation. Die Umnutzung von Industriebrachen ist zudem für die Ästhetik der Städte wichtig, denn die meisten Flächen sind stark vernachlässigt und wirken wenig einladend. Der historische und architektonische Wert vieler alter Industrieobjekte kann jedoch umgekehrt zur touristischen Attraktivität der Stadtzentren beitragen.

Die privaten wie öffentlichen Initiativen zur Rettung der Industriebrachen sind mit Blick auf ihre Wirksamkeit nur schwer einzuschätzen. So ist nicht nachzuvollziehen, warum historisch wertvolle Objekte verfallen oder verunstaltet werden. Für die ständige Umnutzung und Modernisierung von Industrieobjekten scheint jedoch stillschweigende Zustimmung zu bestehen. Daher fällt es schwer, bestimmte Maßnahmen wie den Bau von Einkaufszentren oder Sportstätten pauschal positiv oder negativ zu bewerten.

Blickt man vom historischen Standpunkt auf die Umgestaltung von Industrielandschaften, ist ihre historische Identität und Tradition zu wahren. Am wichtigsten sind dabei die Bedürfnisse der Einwohner. Als Kulturlandschaft ist die Region durch Menschen geprägt, was ebenso umgekehrt gilt. Die Landschaft ihrer Industriedenkmäler zu berauben, würde eine Lücke in der Regionalgeschichte reißen, die Region ihrer Geschichte berauben. Die hier lebenden Menschen würden damit einen wichtigen Teil ihrer Identität verlieren.

Aus dem Polnischen von Markus Krzoska 


\section{Literatur}

Czarski, Edmund (Hg.). Procesy i struktury demograficzno-społeczne na obszarze województwa śląskiego w latach 1988-2008 [Demographische und soziale Prozesse und Strukturen in der Schlesischen Wojewodschaft 1988-2008], Katowice: Urząd Statystyczny w Katowicach, 2010.

Fabiańska, Patrycja. »Problematyka terenów poeksploatacyjnych na obszarach miejskich i podmiejskich" [Aufgelassene Abbauareale auf städtischem und vorstädtischem Gebiet], in: Przemiany struktury przestrzennej miast $w$ sferze funkcjonalnej $i$ społecznej [Funktionale und soziale Veränderungen der Raumstruktur von Städten], Janusz Słodczyk (Hg.), Opole: Uniwersytet Opolski, 2004, 165-182.

Gasidło, Krzysztof. »Kierunki przemian struktury aglomeracji górnośląskiej« [Veränderungsrichtungen der Struktur der oberschlesischen Agglomeration], in: Przemiany struktury przestrzennej miast $w$ sferze funkcjonalnej i społecznej [Funktionale und soziale Veränderungen der Raumstruktur von Städten], Janusz Słodczyk (Hg.), Opole: Uniwersytet Opolski, 2004, 63-78.

Idziak, Aleksandra und Krzysztof Herman. »Między kopalnią a krajobrazem. Transformacje sztuki krajobrazu. Instalacje, rzeźba, performance jako formy rekultywacji krajobrazów postindustrialnych « [Zwischen Bergwerk und Landschaft. Transformationen der Landschaftskunst. Installationen, Skulptur, Performances als Formen der Rekultivierung postindustrieller Landschaften], in: Prace Komisji Krajobrazu Kulturowego PTG 10 (2008), 386-394.

Kantor-Pietraga, Iwona und Robert Krzysztofik. »Uwarunkowania przemian Sosnowca w sytuacji transformacji społeczno-ekonomicznej przełomu XX i XXI wieku« [Bedingungen von Sosnowiec bei der sozioökonomischen Transformation im 20. und 21. Jahrhundert], in: Rocznik Sosnowiecki, Band 19, Kazimierz Gołosz (Hg.), Sosnowiec: Muzeum w Sosnowcu, 2011, 39-58.

»Kopalnia Węgla Kamiennego Kazimierz-Juliusz« [Steinkohlengrube Kazimierz-Juliusz], in: Wikipedia. Wolna encyklopedia, https://pl.wikipedia.org/wiki/Kopalnia_W\%C4\%9 9gla_Kamiennego_Kazimierz-Juliusz, zuletzt geprüft am 9. September 2019.

Krzysztofik, Robert. »Proces umiastowienia obszaru współczesnego Sosnowca i jego efekty« [Die Urbanisierung des Gebiets des modernen Sosnowiec und ihre Effekte], in: Rocznik Sosnowiecki, Band 15, Andrzej T. Jankowski (Hg.), Sosnowiec: Muzeum Sosnowca, 2007, 83-106.

Lewandowski, Jan F. »Kręcone nad Przemszą" [Kręcone an der Przemsa], in: Nowe Zagłębie 1 (2009), $53 \mathrm{f}$.

Libor, Grzegorz und Dorota Nowalska-Kapuścik. »Regiony poprzemysłowe jako trend i atrakcja turystyczna na przykładzie województwa śląskiego i Południowej Walii« [Postindustrielle Regionen als Trend und Touristenattraktion am Beispiel der Schlesischen Wojewodschaft und von Südwales], in: Turystyka Kulturowa 8 (2014), 20-32.

Ludnossć, ruch naturalny $i$ migracje $w$ województwie śląskim w 2013 r. [Bevölkerung, natürliche Bewegung und Migrationen in der Schlesischen Wojewodschaft 2013], Katowice: Urząd Statystyczny, 2014.

"Mercure Sosnowiec, hotel grupy Orbis, ma być otwarty w 2022 roku“ [Das Mercure Sosnowiec, eine Hotel der Orbis-Gruppe, soll 2022 eröffnet werden], in: Wiadomości Sosnowiec, naszemiasto.pl, 22. Januar 2019, https://sosnowiec.naszemiasto.pl/merc 
ure-sosnowiec-hotel-grupy-orbis-ma-byc-otwarty-w-2022/ar/c3-4965186, zuletzt geprüft am 9. September 2019.

Ministerstwa Rozwoju Regionalnego (Hg.). Rozwój miast w Polsce: raport wprowadzający Ministerstwa Rozwoju Regionalnego [Stadtentwicklung in Polen: einführender Bericht des Ministeriums für Regionalentwicklung], Warschau: MRR, 2010.

Narodowy Spis Powszechny Ludzi i Mieszkań 2011: Ludność w województwie ślaskim. Stan i struktura demograficzno-społeczna [Allgemeines Nationalverzeichnung von Menschen und Wohnungen 2011: Die Bevölkerung in der Schlesischen Wojewodschaft. Stand und demographisch-soziale Struktur], Katowice: Urząd Statystyczny, 2014.

Nitkiewicz-Jankowska, Anna und Grzegorz Jankowski. »Krajobraz kulturowy jako walor turystyczny « [Kulturlandschaft als touristischer Wert], in: Prace Komisji Krajobrazu Kulturowego PTG 14 (2009), 185-193.

"Nowe hotele w Sosnowcu: W dawnej elektrowni Renard będzie Mercure i ibis Styles" [Neue Hotels in Sosnowiec: Im alten Renard-Kraftwerk wird es ein Mercure und ein Ibis Styles geben], in: Dziennik Zachodni, 24. Oktober 2014, http://www.dziennikzachodni. pl/artykul/1025045, nowe-hotele-w-sosnowcu-w-dawnej-elektrowni-renard-bedziemercure-i-ibis-styles-zdjecia,id,t.html, zuletzt geprüft am 19. September 2019.

Powiaty w województwie śląskim w 2012 [Die Kreise in der Schlesischen Wojewodschaft 2012], Katowice: Urząd Statystyczny, 2013.

Przemsza-Zieliński, Jan. Historia Zagłębia Dąbrowskiego [Geschichte des Dąbrowa-Reviers], Sosnowiec: Związek Zagłębiowski, 2006.

Purzyński, Piotr. »Politechnika Śląska się wycofała, PKP przerywa przebudowę dworca w Maczkach« [Schlesisches Politechnikum hat sich zurückgezogen, Polnische Staatseisenbahnen unterbrechen Umbau des Bahnhofs Maczki], in: wyborcza.pl Sosnowiec, 13. September 2017, http://sosnowiec.wyborcza.pl/sosnowiec/7,93867,22364975,poli technika-slaska-sie-wycofala-pkp-przerywa-przebudowe-dworca.html, zuletzt geprüft 9. September 2019.

Raport o sytuacji społeczno-gospodarczej w województwie śląskim w 2013 [Bericht über die sozioökonomische Lage in der Wojewodschaft Schlesien 2013], Katowice: Urząd Statystyczny, 2014.

Rocznik Statystyczny Województwa Śląskiego 2013 [Statistisches Jahrbuch der Wojewodschaft Schlesien 2013], Katowice: Urząd Statystyczny, 2014.

Sawicki, Andrzej. »Zmierzch gigantów« [Dämmerung der Giganten], in: Nowe Zagłębie 1 (2009), $30 \mathrm{f}$.

"Ściana wspinaczkowa [Kletterwand] Fitness Club«, http://poziom450.pl/, zuletzt geprüft am 9. September 2019.

Świtała-Trybek, Dorota. »Lokomotywy i wagoniki górnicze jako pamiątki historii oraz atrakcje turystyczne« [Bergbaulokomotiven und -loren als historische Erinnerungsstücke und Touristenattraktion], in: Turystyka Kulturowa 8 (2014), 33-50.

"Szlak Zabytków Techniki« [Route der Technikdenkmäler], http://www.zabytkitechniki. pl, zuletzt geprüft am 9. September 2019.

Tkocz, Maria. »Przemysł miast zagłębiowskich w XXI wieku« [Die Industrie der Revierstädte im 21. Jahrhundert], in: Nowe Zagłębie 1 (2010), 4-7.

Wódz, Jacek und Kazimiera Wódz. »Restrukturyzacja ekonomiczna województwa śląskiego a przekształcenia społeczno-kulturowe miast. W poszukiwaniu nowej tożsamości« [Wirtschaftliche Restrukturierung der Schlesischen Wojewodschaft und die 
soziokulturelle Umgestaltung der Städte. Auf der Suche nach einer neuen Identität], in: Człowiek - miasto - region: związki i interakcje. Księga jubileuszowa profesora Bohdana Jałowieckiego [Mensch - Stadt - Region: Verbindungen und Interaktion. Festschrift für Prof. Bohdan Jałowiecki], Grzegorz Gorzelak, Marek S. Szczepański und Weronika Ślęzak-Tazbir (Hg.), Warschau: Wydawnictwo Naukowe Scholar, 2009.

Wódz, Kazimiera (Hg.). Zapomniane miejsca, zapomniani ludzie: restrukturyzacja ekonomiczna a zmiana kulturowa [Vergessene Orte, vergessene Menschen: Wirtschaftliche Restrukturierung und kultureller Wandel], Katowice: Śląsk, 2013.

Województwo Śląskie (Hg.), Strategia Rozwoju Województwa Śląskiego »Śląskie 2020+« [Entwicklungsstrategie der Schlesischen Wojewodschaft »Schlesien 2020+«], Katowice 2013, https://www.slaskie.pl/content/1372921202_2013-07-04, zuletzt geprüft am 11. September 2019.

Województwo Śląskie w liczbach 2014 [Die Schlesische Wojewodschaft in Zahlen 2014], Katowice: Urząd Statystyczny, 2014. 
Open-Access-Publikation im Sinne der CC-Lizenz BY 4.0

(c) 2020, Vandenhoeck \& Ruprecht GmbH \& Co. KG, Göttingen ISBN Print: 9783847107507 - ISBN E-Lib: 9783737007504 


\section{Dekolonisierung der Berge. Zwei Abstiege nach Schelmenart}

Dieser Text handelt vom - überraschend schwierigen - Vorgang, die Folgen der Kolonialisierung von Podhale - dem polnischen Karpatenvorland - abzubauen. Dabei geht es nicht etwa um die Kolonisierung durch die österreichische Teilungsmacht, die Ende des 18. Jahrhunderts die Karpaten besetzte, und auch nicht um die deutsche Besatzung zur Zeit des Zweiten Weltkrieges. Die Kolonisierung und Dekolonisierung, die Gegenstand dieser Überlegungen sind, sind ein polnisch-polnisches Phänomen. Somit beziehe ich mich hier nur auf die Konzepte aus der äußerst umfassenden postkolonialen Methodologie, die den ungewöhnlichen Prozess der Selbstkolonisierung berücksichtigen. ${ }^{1}$ Diese Selbstkolonisierung ist eine kulturelle, aber auch politische und wirtschaftliche Eroberung, die durch jene erfolgt, die die gleiche Sprache wie die Eroberten sprechen.

Unter diesem Blickwinkel will ich zwei Bücher besprechen: Sklep potrzeb kulturalnych [Der Laden des kulturellen Bedarfs] von Antoni Kroh und Spiski [Verschwörungen] von Wojciech Kuczok. Dabei soll anhand beider Werke sowohl den Kolonisierungsprozess untersucht werden wie auch der Prozess der Dekolonisierung. Ein gewichtiges Erbe der (Selbst-)Kolonisierung aufseiten der kolonisierten Bevölkerung ist das, was ich hier "verschwommene Verantwortung" nennen will. Die Bewohner des jeweiligen Gebietes betrachten die ehemalige Unterdrückung als Rechtfertigung für gegenwärtiges sträfliches Verhalten, sodass sie nicht mal dann Abhilfemaßnahmen ergreifen, wenn sie ihr eigenes Land zerstören. Dieser besondere Zustand bringt den Forscher in eine merkwürdige Lage: Er kann seine Protagonisten (die Opfer der Eroberung) nicht eindeutig verurteilen, zugleich aber sollte er sie nicht entschuldigen (denn sie sind Verursacher vieler Übel). Eine Lösung dieses Dilemmas, die in beiden analysierten Büchern vorgeschlagen wird, ist die solidarische Kritik - eine Mischung aus kompromisslos-ehrlichem Urteil und Nachbarschaftssolidarität.

1 Als Inspiration (aber auch negativer Bezugspunkt) dient mir der Text von Aleksander Kiosew, "Uwagi o samo-kolonizujących się kulturach « [Anmerkungen zur Selbst-Kolonisierung der Kulturen], in: Dekada Literacka, 2000, Nr. 9/10, $14 \mathrm{f}$. 


\section{Abstieg Eins: Eine ethnografische Schelmenplauderei}

Antoni Krohs Buch erschien im Jahr 1999. ${ }^{2}$ Nach der Veröffentlichung konnte der Autor sich angeblich längere Zeit nicht im Podhale, dem polnischen Karpatenvorland, blicken lassen. Die Goralen können nachtragend sein, und von nachtragend zu impulsiv ist es bei ihnen nicht weit - wehe also jedem, der in die Reichweite ihrer Fäuste gerät.

Zum Glück passierte gar nichts. Vielleicht braute sich nicht einmal etwas zusammen, aber das Gerücht rollte von Berg zu Tal und traf dort auf fruchtbaren Boden. Allein aber, dass es jemand in die Welt gesetzt hatte, will schon etwas heißen - denn der Autor kritisierte eindeutig nicht die Goralen, sondern die Zugereisten.

Kroh wurde 1942 in Warschau geboren. Als Kind war er viel krank, deswegen brachte seine Mutter ihn zur Genesung und Kräftigung in die Berge. Mit sechs Jahren kam er also nach Bukowina, ein nahe Zakopane gelegenes Dorf, wo er mit Unterbrechungen lebte, bis er 14 war. Und weil Kindheit und Jugend die Zeit im Leben sind, in der »der Mensch am meisten aufnimmt und alles, was wichtig ist, tief in ihn einsinkt $^{3}$, prägten sich ihm die Berge für immer ein. Später befasste er sich in Studium und Beruf mit dem Podhale. Er wurde Ethnograf, lernte Tschechisch und Slowakisch, arbeitete im Tatra-Museum in Zakopane (19671970) und im Bezirksmuseum in Nowy Sącz. Immer war er dabei mehr als ein Forscher: Er organisierte Wettbewerbe für die volkstümliche Kunst der Karpaten, war Kurator manch wichtiger Ausstellung wie »Łemkowie» (Die Lemken), "Duchy epoki, czyli pierwsza wojna światowa trwa do dziś» (Die Geister der Epoche oder Der Erste Weltkrieg dauert fort), "Spisz« (Die Zips). Seit Mitte der Siebzigerjahre ist er außerdem ein angesehener Literaturübersetzer und überträgt ausgewählte tschechische (Vladimír Neff, Josef Toman, Miroslava Tomanová, Stanislav Rudolf, Jan Ryska) und slowakische Autorinnen und Autoren (Jozef Cíger-Hronský, Ján Lenčo, Štefan Žáry, Ladislav Paule) ins Polnische. 2009 erschien seine lang angekündigte Übersetzung von Der Brave Soldat Schwejk, die Krönung seiner bisherigen Arbeit als Übersetzer.

Vielleicht ist dieses spezielle Konglomerat aus ethnografischen Interessen, einer feinen Antenne für das heikle Thema kultureller Differenzen und einer Vorliebe für tschechischen Humor der Grund, warum Kroh stets den Narrationen von festgelegten lokalen und gesellschaftlichen Identitäten misstraute. Als er Ende der Neunzigerjahre seinen Erzählband Sklep potrzeb kulturalnych (Laden des kulturellen Bedarfs) verfasste, gingen bereits eine Monografie über volks-

2 Antoni Kroh, Sklep potrzeb kulturalnych [Laden des kulturellen Bedarfs], Warszawa: Prószyński i S-ka, 1999.

3 Ebd., 7. 
tümliche Skulpturen der polnischen Karpaten (1979), eine zweite über die Kriegsfriedhöfe in den Niederen Beskiden (1991) sowie ein Buch mit dem Titel O Szwejku i o nas (Über Schwejk und über uns; 1992) auf sein Konto. Aus seiner langjährigen Arbeit zog er vor allem einen Schluss: dass die Geschichte des Podhale eine einzige Verkettung gewaltsamer Ereignisse gewesen sei, wirtschaftlich, administrativ und kulturell.

Die Anfänge reichen weit zurück. Im 13. Jahrhundert wurden mit gesetzlicher Erlaubnis Kolonien deutscher Siedler im Podhale gegründet. Koloniale Aneignung in anderen Formen fand dort auch in den nächsten Jahrhunderten noch statt: Im Podhale gab es keine Schulen, also wurden sämtliche Fachleute und selbst Arbeiter aus den Tälern geholt. Die Abneigung gegen sie ist bis heute in dem abschätzigen regionalen Ausdruck ceper erhalten geblieben, mit dem Schienen- und Straßenarbeiter und Steinmetze, die zum Arbeiten herkommen, bezeichnet werden. Die Leibeigenschaft wurde in einem großen Teil des Podhale erst 1848 abgeschafft. Doch Reste davon hatten selbst noch im unabhängigen Polen Bestand: „Łapsze Niżne, Niedzica und das nahegelegene Falsztyn sind die Dörfer in Polen, in denen am längsten Fronarbeit geleistet wurde. Die letzten Fronpflichten wurden dort erst im Jahr 1931 durch ein Gesetz des Sejm der Zweiten Polnischen Republik aufgehoben. « ${ }^{4}$ Infolge dieser späten Entwicklung war das Podhale ein Gebiet, in dem noch lange Armut und Unterdrückung herrschten. Von hier stammten die meisten Menschen, die Ende des 19. Jahrhunderts in die Erwerbsemigration nach Übersee gingen.

Der polnische Nationalschriftsteller Henryk Sienkiewicz mythologisierte die Goralen. In "Sintflut«, dem mittleren Teil seiner Trilogie, beschreibt er einen seltsamen Partisanentrupp, der 1655 König Johann II. Kasimir rettet, als er mit einer bescheidenen Eskorte aus der Verbannung zurückkehrt und von schwedischen Truppen angegriffen wird. Die Heroisierung des Volkes aus dem Podhale übernahmen später einige Schriftsteller des Jungen Polen: Władysław Orkan, Kazimierz Przerwa-Tetmajer, Stanisław Witkiewicz. Wie auch andere Vertreter des Jungen Europa waren sie auf der Suche nach kraftvollen Vorbildern. Je stärker die Kultur des ausgehenden 19. Jahrhunderts vom Schopenhauerschen Dekadenzgedanken durchdrungen war, desto verzweifelter sehnte sie sich nach Charakteren, die Stärke verkörperten. Daher erging sich ein Teil der polnischen Literatur in Bewunderung für die Bauern, der andere schwärmte für das Volk des Podhale. Das äußerte sich in einer romantischen Bergmythologie, in der von den Bergen eine erhabene Macht ausging. Die Phantasie prallte gegen hoch aufragende Gipfel, stolperte über den recht nebulösen Sinn all dieser Gewaltigkeit und förderte ein nagendes Gefühl menschlicher Nichtigkeit. Den stolzen Goralen dichtete die polnische Literatur des ausgehenden 19. Jahrhunderts noch einen

4 Ebd., 77. 
Sienkiewiczschen Patriotismus an. Damit waren die Goralen unversehens die »reinen«, nicht durch fremde Einflüsse verdorbenen Polen; Menschen, die niemals mit dem Feind paktiert hätten und in einer zu unwegsamen Gegend lebten, als dass die Teilungsmächte sie sich hätten untertan machen können.

Drei vermeintliche Identitätsmerkmale der Goralen - die aus ihrem einfachen Leben erwachsene Sittlichkeit, die wegen des rauen Klimas erforderliche Zähigkeit und bedingungsloser Patriotismus - bildeten die Grundlage für eine publizistische Operation, die an der Wende vom 19. zum 20. Jahrhundert vollzogen wurde: Ethnografen und Dichter ersannen eine komplette Kultur des Podhale: einen Persönlichkeitstypus der Goralen, eine bestimmte Architektur, Kleidung, Tänze und Bräuche. Zur ökonomischen Ausbeutung gesellte sich eine von den Meinungsbildnern betriebene kulturelle Aneignung einer regionalen Gemeinschaft.

Diese Aneignung bestand darin, einzelne Bestandteile der Kultur aus ihrem lokalen Kontext zu reißen oder ihr erdachte Muster überzustülpen. So wurden die Merkmale des podhalischen Stils von den Ethnografen nicht in ihrer ursprünglichen Form bewahrt, sondern künstlich umgestaltet oder frei erfunden. Das Ergebnis war ein maßgeschneidertes Image, das den Teufelskreis der Aneignung schloss: Die dominierende Kultur setzte alles daran, die Schönheit des Podhale zu beschwören und zugänglich zu machen - verbreitete diese allerdings in einer selbstkreierten Interpretation. Das Podhalische bleibt "schön« innerhalb einer sich »natürlich« gebenden Konvention. Es ist

[s]chön, weil es goralisch ist, und damit uralt, archaisch, homerisch, wie durch ein Wunder bis in unsere Zeit erhalten geblieben. Schön, denn das befanden die größten polnischen Künstler. Schön, weil es als schön gilt, seit Generationen geliebt. Schön, weil es Ausländer begeistert. Schön, weil es sich gehört, es »schön « zu nennen. Diese Ansicht herrscht in Polen seit über hundert Jahren, und das ist gut so, soll diese Ansicht noch viel länger leben, denn sie brachte und bringt viel Segen. $\mathrm{Na}$, aber von Nahem ansehen darf man sie sich wohl trotzdem. ${ }^{5}$

"Von Nahem " sieht Kroh sich das Allgemeinwissen an. Dieses seit hundert Jahren etablierte Wissen behauptet, jeder Gorale trage kierpce, Bundschuhe aus einem zusammenhängenden Lederstück, an den Füßen, seine Hose sei mit bunten parzenice-Stickereien verziert, er pflege über dem Hemd einen kubrak, eine Schaffellweste, zu tragen, er stütze sich auf eine ciupaga, einen Wanderstock mit massiver Axtklinge, - und auf seinem Kopf sitze stets ein runder Federhut. Als zbójnik, als Wegelagerer und Gesetzloser (welcher Gorale ist das nicht?), trage er eine Art Tschako auf dem Kopf, tanze am Lagerfeuer den passenden taniec zbójnicki (Räubertanz) und sei mocarny, also kräftig und muskulös. Ist

5 Ebd., 123. 
das wahr? Nach Józef Tischners denkwürdiger Klassifikation kennt das Polnische drei Kategorien von Wahrheit: die "heilige Wahrheit (święta prawda), die "Auch-wohl-wahr-Wahrheit" (też prawda) und die "Scheiß-Wahrheit" (gówno prawda). Die erste ist unanfechtbar, um die zweite handelt es sich dann, wenn zwei Interpretationen einander nicht ausschließen, und die dritte hat nicht viel mit der Realität zu tun. Bedauerlicherweise oszillieren die meisten Elemente, die dem Podhale zugerechnet werden, zwischen Kategorien zwei und drei. Kierpce, also Lederbundschuhe, trugen im Podhale nur die armen Schlucker, die zwar von richtigen Schuhen träumten, sich aber keine leisten konnten; herzförmige parzenice-Stickereien an besonders leicht verschleißenden Stellen zieren zwar tatsächlich die Goralenhosen, jedoch kamen sie erst Mitte des 19. Jahrhunderts von Ungarn ins Podhale (ähnlich wie die berühmte podhalische Glasmalerei); die Feder am Hut kennzeichnete Junggesellen, kann also nicht am Hut eines jeden Mannes gesteckt haben; der Tschako war noch nie ein Kleidungsstück von Wegelagerern und Straßenräubern. „Das Attribut mocarny [kräftig, muskelbepackt] ist in den kleinpolnischen Mundarten eine Beleidigung, so etwa wie der gołodupiec [Nacktarsch], mit dem ein Bergbauer gemeint ist, dessen Hütte im Sumpfgebiet steht, also ein völliger Habenichts und Hungerleider. « ${ }^{6}$ Den taniec zbójnicki wiederum gab es wirklich, jedoch war der »Räubertanz«, bevor sich die Herrenkultur seiner annahm, ein Gemeinschaftstanz mit synchron ausgeführten Bewegungen. Aber die Künstler des Jungen Polen sehnten sich eben nach Wildheit, Spontaneität und Individualismus. Deswegen sah Stanisław Witkiewicz, einer der begeisterten Erforscher der podhalischen Kultur, im taniec zbójnicki einen individualistischen Ausbruch:

[...] alle sind bereits im Kreis, und da beginnt ein wahnsinniger, ein besessener, ein verrückter Tanz, bei dem vor dem Hintergrund eines bestimmten allgemeinen Tempos ein jeder, entsprechend seines Temperaments und seiner tänzerischen Fähigkeiten, verschiedenste Bewegungen und Sprünge improvisiert. [...] die ganze Tänzerbande tobt und gebärdet sich wie toll. Arme, Beine fliegen in die Luft, die Metallbeschläge der ciupagi blitzen, alles mengt sich und verwirbelt in einem einzigen Chaos. ${ }^{7}$

Spätere Ethnografen und Liebhaber der Volkskunst hielten Witkiewicz' Schilderung für authentisch. Allerdings wurde »der taniec zbójnicki in seiner modernen Form im Jahr 1910 von Szczęsny Połomski, dem Leiter des neugegründeten Turnvereins Sokół [Falke], erfunden. ${ }^{8}$ Der »erfundene« Tanz kann hier als Synekdoche für Dominanz gelten.

Anfang des 20. Jahrhunderts verfügte die dominierende Kultur über Mittel und Wege, einen von ihr kodifizierten Stil zu verbreiten und im allgemeinen

6 Kroh, Sklep, 90.

7 Ebd., 92.

8 Ebd., 95. 
Bewusstsein zu verankern. Der Tanz wurde also erfunden, ähnlich wie die Holzhäuser im volkstümlich angehauchten Zakopane-Stil, die reich bestickten Hosen, der unglückselige Tschako auf den Köpfen der »Wegelagerer«, die Glasmalerei und Dutzende anderer kultureller Artefakte. Diese wurden zu einer Art ausgeschmückter Version der Kultur des Podhale synthetisiert, in der sämtliche Unterschiede und die tatsächliche Folklore verlorengingen.

Diese Version trug den Sieg davon, denn es war die hübschere Version, in der die ursprüngliche Bescheidenheit von Material und Form verschwunden war. Die Fantasie der Intelligenz triumphierte, da sie die Bevölkerung des Podhale zu Zugeständnissen zwang: eine Feder an jedem Hut, Zierstickereien an jeder Hose, Jugendstil bei der Innenausstattung der Zakopaner Holzhäuser, Malereien von wilden Halunken mit Tschako. Davon profitierte der Tourismus. Die Menschen fuhren nicht ins Podhale, um die »heilige Wahrheit« zu erkunden, sondern um ihre eigene Wahrheit wiederzufinden, die sie sich vorher in Romanen und ethnografischen Texten angelesen und auf Postkarten gesehen hatten. Die wirtschaftliche Abhängigkeit der billigen Arbeitskräfte verwandelte sich in eine handwerkliche Abhängigkeit, indem eine heimische Kulturindustrie oktroyiert wurde. ${ }^{9}$ Der Tourismus förderte ein standardisiertes Kunsthandwerk: Alle wollten die gleichen ciupagi, Hüte, bestickten Hosen, Gürtelschnallen, Spangen, Figuren von "Christus in der Rast« erstehen... Der Tourismus als Einkommensquelle stellte sich als Alternative zu Schafzucht und Landwirtschaft heraus, und infolgedessen wurden die Goralen nach und nach von Schäfern zu Schauspielern, die Volkstümlichkeit inszenierten.

Kroh dekonstruiert somit eine geschichtliche Fiktion, die sich als »Wahrheit» etabliert hat. Doch sein Buch Sklep potrzeb kulturalnych beschreibt nicht nur die Geschichte dieser Aneignung, sondern auch die eines Widerstands, der sich etwa seit der Zwischenkriegszeit in einer anscheinenden Unterwerfung zeigte. Homi Bhabha würde dies "Mimikry« nennen ${ }^{10}$, doch ist dem hinzuzufügen, dass die Mimikry der Goralen nicht die dominante Kultur nachahmte, sondern ein Image der podhalischen Kultur produzierte, das mit der romantisierten Vorstellung der Städter übereinstimmte. Die Goralen täuschten diese aber nicht etwa, weil sie verlogen wären, sondern weil die Touristen immerfort eine am Fließband fa-

9 Über diesen Prozess schreibt Ewa Klekot: »Wenn die in der Traditionalität verankerte regionale Identität als Handelsmarke angesehen wird, so steht sie für die Gestaltung/Entwicklung und Verbreitung der traditionellen Produkte. [...] die Frage [lautet], inwieweit die Verkaufsmöglichkeiten in diesem Fall den Weg zur wirtschaftlichen Emanzipation derer bedeutet, die ihre Identität als Produkt konstruieren.« Ewa Klekot, „Samofolkloryzacja. Współczesna sztuka ludowa z perspektywy krytyki postkolonialnej« [Selbstfolklorisierung. Moderne Volkskunst aus der Sicht der postkolonialen Kritik], in: Kultura Współczesna, 2014, Nr. 1, 86-99, 97.

10 Vgl. Homi K. Bhabha, The Location of Culture, London: Routledge, 1994. 
brizierte, standardisierte, geglättete lokale Kultur erleben wollten. Im historischen Duell erwiesen sich also, wie Kroh argumentiert, die Goralen als schlauer als die Herren: Sie erarbeiteten einen Modus Operandi, der es ihnen gestattet, aus einer ganz naiven Fremdherrschaft Gewinn zu ziehen.

Diese Sicht der Dinge erlaubt dem Autor, eine plauderhafte Schelmengeschichte zu erzählen. Das Buch besitzt weder eine Handlung wie ein Roman, noch argumentiert es wissenschaftlich. Insgesamt wirkt es teils autobiografisch, teils wie eine Abhandlung, denn Kroh widmet einzelne Kapitel bestimmten Elementen der podhalischen Kultur, die zum Fetisch geworden sind. Damit ist der Text aber nicht vollständig charakterisiert. Wichtiger für seinen Zusammenhalt ist seine pikareske Perspektive.

Der picaro ist eine Gaunergestalt, für die Freiheit mehr bedeutet als alle Annehmlichkeiten. In der polnischen Kultur des 17. Jahrhunderts hieß der picaro sowizdrzał und trat in Schelmengeschichten und -stücken auf, in denen Studenten Bürger hinters Licht führten. Später verschwand der sowizdrzał für mehrere Jahrhunderte, bis er im 20. Jahrhundert wieder auftauchte, und zwar bei Witold Gombrowicz, Janusz Rudnicki, Manuela Gretkowska und Andrzej Stasiuk. Auf- und Abtreten des Schelms ergeben sich aus der Entwicklung der Gesellschaft. In dieser gibt es immer Regeln, die nicht von Werten, sondern von arbiträren Bestimmungen abgeleitet sind. So privilegierte beispielsweise die Ständegesellschaft Menschen aus den höheren und daher angeblich »besseren« Schichten; die bürgerliche Meritokratie schreibt Menschen nach äußeren Funktionsmerkmalen bestimmte Werte wie Macht, Klugheit, Hingabe und Kompetenz zu. Wenn ein Edelmann zu sein nicht bedeutet, edel, sondern lediglich adlig geboren zu sein, dann ist das eine aneigbare Rolle. Ähnlich verhält es sich mit der Rolle des Bürgers, Priesters, Bakkalaureus, Medikus. Der picaro deckt deswegen wieder und wieder auf, dass die Gesellschaft auf verinnerlichten Fiktionen basiert. Er findet Vergnügen am irreführenden Spiel, das er stets mit einer Demaskierung enden lässt. Ist die Illusion zerstört, verschwindet er, und die für dumm verkauften Bürger bleiben öffentlich blamiert zurück. Von da an müssen sie in dem Bewusstsein am Spiel der Gesellschaft teilnehmen, dass alles auf einem kollektiven Konstrukt beruht.

So ist es auch bei Kroh: Die podhalische Kultur ist ein einziges großes Konstrukt, das in mehr als 150 Jahren mühevoll von Dichtern und Ethnografen geschaffen wurde. Die Verbindung dieser beiden Bereiche erbrachte eine Narration, die "wahrheitsgetreu« von der natürlichen Schönheit der podhalischen Kultur kündet. In Krohs Schilderung sind die Goralen zu Schelmen geworden, die seit Anfang des 20. Jahrhunderts ihre Herren zum Narren halten. Der goralische picaro muss sich, anders als sein Vorgänger aus dem 17. Jahrhundert, nicht in die Herrenwelt einschleichen; diese Welt steigt ihrerseits zu ihm hinauf in die Berge. Und wenn sie da ist, geben die Einheimischen ihr Schauspiel von der 
unverfälschten Kultur des Podhale zum Besten: Statisten schlüpfen in volkstümliche Goralenkleider, sprechen im Goralendialekt, tanzen Goralentänze, bitten die Gäste in schmucke, im Jugendstil gestaltete Holzhäuschen ... All das zum Vergnügen der Herren und zum eigenen materiellen Nutzen. Auf diese Weise sprechen die tiefergestellten Anderen, die nicht im eigenen Namen sprechen können, mittels der Merkmale einer übergestülpten »Authentizität«. Eine Spur dieser untergeordneten Anderen lässt sich nur in einem verdächtigen Minimalismus erkennen: Die goralische Ökonomie äußert sich nämlich darin, dass exakt und ausschließlich jene Merkmale zur Schau gestellt werden, die angeblich charakteristisch für die Podhale-Kultur sind.

In Krohs Schelmenplauderei enden viele Kapitel mit der Feststellung, die Herren seien wieder einmal übers $\mathrm{Ohr}$ gehauen, also übervorteilt worden. Der Autor stellt sich konsequent auf die Seite der Goralen, die jahrhundertelang in bitterster Armut lebten, bevor es für sie endlich aufwärts ging. Kroh verlacht die Kultur der Herren, der Bürgerlichen und der Intelligenz zu Recht. Doch er geht dabei nicht vor wie ein typischer Verteidiger einer angeeigneten Kultur. Ein solcher schreibt kulturell fremdbestimmten Menschen Einheitlichkeit zu, indem er voraussetzt, dass sie alle sich in derselben Position gegenüber dem Aneigner befinden. In einem solchen Narrativ wären die Goralen untereinander nicht verschieden und hierarchielos. Sie müssten zu dem Schluss kommen, sie hätten gegebenenfalls alle gleichermaßen gelitten und ihre Situation im gleichen Maße verbessert. Die Rechtschaffenheit des Autors ist daran zu erkennen, dass er von Zeit zu Zeit ein Gegennarrativ zu Wort kommen lässt, durch das das goralische Selbstverständnis infrage gestellt wird.

Den ersten Bruch finden wir beim Wandel der podhalischen Kultur. Kroh erörtert nämlich, wie das Schelmenspektakel, das dazu diente, den Städtern so viele dutki [dialektaler Ausdruck für Geld] wie möglich aus der Tasche zu ziehen, zu einer Falle wurde. Als 1980 Johannes Paul II., der allerberühmteste gazda [dialektal für Bergbewohner, Gorale], das Podhale besuchte, sah die ganze Welt die Goralen in Federhüten, Bundschuhen und bestickten Hosen. Und in diesem Moment wurde die als authentisch ausgegebene künstliche Kultur des Podhale normativ. Seither gibt es für die Goralen kein Zurück mehr. Nun können sie nicht mehr zu Hause in aller Stille eine andere Authentizität praktizieren, können sich nicht mehr von der vorgespielten Kultur distanzieren, weil das Schauspiel vor den Augen ganz Polens die Vorspiegelung in einen Grund zum Stolz verwandelte. Die Podhale-Kultur aufzugeben, würde nicht nur materielle Einbußen mit sich bringen, die sich noch verschmerzen ließen, sondern auch einen Prestigeverlust.

Zweitens schildert Krohs Buch eine schreckliche Episode aus der Geschichte des Podhale: die »Aktion Weichsel « 1947, bei der die kommunistische Regierung die Lemken vertrieb. Es war Juli, kurz vor der Erntezeit, doch den Lemkenbauern wurde die Getreideernte nicht mehr erlaubt: Sie mussten die nötigste Habe 
packen und sich am Bahnhof einfinden. Ihre Nachbarn gingen indessen ohne die geringste Scham in die verlassenen Häuser, plünderten, was nicht niet- und nagelfest war, verbrannten den Rest und fuhren zu guter Letzt noch selbst die Ernte ein. Die Bevölkerung des Podhale erwies sich somit als zutiefst gespalten im Verhältnis zum neuen Regime: 1946 waren die Goralen in einer privilegierten Stellung und wussten diese auch zu nutzen. Und das hatte nichts mit Überlistung der Herren zu tun.

Schließlich die dritte Abweichung vom allgemeinen Narrativ: Das Podhale wird an einen Mythos der Abgeschiedenheit gekoppelt. Dank ihrer Isolation hätten die Goralen sich ihren wahren Glauben, ihr Polentum, ihre Volkstümlichkeit, Spontaneität und Kreativität bewahrt, und zwar in Reinform, unberührt von städtischen, bürgerlichen, ethnisch fremden oder intelligenzlerischen Einflüssen. Die Isolation habe die Armut der Goralen verstärkt, womit sie immer noch ihre Habgier rechtfertigen würden. Doch, so Kroh, auch Goralen, die heute luxuriöse Häuser, mehrere Autos und eine Stange Geld besitzen, würden sich aber immer noch als Opfer von Stadt, Regierung oder »Herren« darstellen. Und da sie in ihrem eigenen Narrativ nach wie vor gegen alle Empirie als die Ärmeren aufträten, leiteten sie davon das Recht für sich ab, die »Städter « zu übervorteilen und das Podhale als ihr Eigentum zu behandeln:

[...] irgendwann kamen diese pecki [große flache Flusssteine] in Mode, man errichtete hohe Sockel aus ihnen, nicht zu einem bestimmten Zweck, sondern rein zur Zierde, man baute Toreinfahrten, fasste Zäune ein, und wer weiß was noch alles, viel zu viele dieser Steine wurden abgetragen, der Wasserspiegel in Brunnen und Flüssen sank, und so wurde das Sammeln von Amts wegen verboten, doch die Leute sind eben, wie sie sind, nun gingen sie nachts Steine holen, denn mit ihnen ließ sich gut verdienen, und am Tag fluchten sie, dass die Böden am Flussufer austrockneten. ${ }^{11}$

Überall, wo zur Sprache kam, ein Naturschutzgebiet solle bestimmt oder erweitert werden, begann die örtliche Bevölkerung, die doch von den Künstlern ihrer Heimatliebe wegen in den höchsten Tönen gelobt wurde, wie wild, Bäume abzuholzen, um so viel wie irgend möglich vor den Waldhütern zu retten, bevor es zu spät sein würde. ${ }^{12}$

Die Bewohner der Niederen Beskiden kennen die Bewohner des Podhale persönlich, nicht bloß aus der Literatur, und vielleicht gibt es für sie deshalb keinen besonderen Grund, sie zu lieben. Besonders diejenigen, die hier [...] herkommen, um [ihre Schafe] weiden zu lassen, führen sich auf wie in einem unterworfenen Land. Im Frühling erwarten wir besorgt die Ankunft der Barbaren - der Goralen aus dem Podhale, die mit Schafen und Rindern in diese Gegend kommen. [...] Sind sie weitergezogen, mutet die Hütte an wie eine einsame Insel, um die sich ringsum flachgetrampelter, mit Tierkot bedeckter Boden erstreckt. ${ }^{13}$

11 Kroh, Sklep, 166.

12 Ebd., 203.

13 Ebd., 218. 
Die Goralen behandeln demnach das Podhale wie ihr Privateigentum: Staatliches Eigentum erkennen sie nicht an. Wer also aus dem Staatsforst Holz stiehlt, der bringt es zu Reichtum und macht sich dabei noch über die Herren lustig. Letztlich führt die schelmenhafte Haltung der Goralen somit zur Zerstörung des Podhale. Das Ökosystem wird ärmer, Wiesen verdorren, Wälder schrumpfen. Die Schelmengeschichte wendet sich gegen die Schelme selbst.

Weil Kroh diesem Gegennarrativ eine Stimme gab, durfte er sich nach Erscheinen seines Buches angeblich nicht im Podhale blicken lassen. Haben die Goralen ihm inzwischen verziehen? Das scheint mir weniger entscheidend als die Frage, ob sie in der Lage sind, sich zu ändern.

\section{Abstieg Zwei: Eine Schelmengeschichte mit heilender Kraft}

Wojciech Kuczoks Roman Spiski (Verschwörungen) enthält eine erstaunliche Textstelle. Eine skandalöse, bilderstürmerische, ungeheuerliche Textstelle. Da sagt ein Gast aus der Stadt zu einem Goralen:

[...] ich kenne die Berge. Sie besser zu kennen als ihr ist keine Kunst. Würdet ihr nur alle Jubeljahre mal eure Ärsche hochkriegen und zum Beispiel Biała Woda durchwandern, dann könntet ihr mehr über euch selbst erfahren. Ihr lebt hier am Fuß der Tatra und wisst weniger über sie als die Sonntagsausflügler. ${ }^{14}$

Da sagt ein ceper, er kenne die Berge besser als die Einheimischen, und das sei keine große Kunst, weil die Goralen zu träge seien. Auf so etwas wäre selbst Hegel nicht gekommen! Die denkwürdige Parabel über Herrn und Sklaven aus der Phänomenologie des Geistes findet hier ihre Fortsetzung: Nun ist der Gorale, der einstige Knecht, zum Herren geworden, weil er eine von dem früheren Herrn fabrizierte Kultur in Besitz genommen hat. Doch er hat seinen Vorteil wieder eingebüßt, weil er sich in seiner ökonomischen und kulturellen Abhängigkeit von den Städtern ein bequemes Leben damit eingerichtet hat, die Bedürfnisse anderer zu erfüllen. Was er für Unabhängigkeit gehalten hat, erweist sich als Abhängigkeit; denn ohne die Ansprüche des Herrn besitzt der Gorale keine Identität.

Das Problem des umgekehrten Abhängigkeitsverhältnisses zieht sich durch Kuczoks gesamten Roman. Spiski, ein Meisterwerk der ironischen Stilisierung, besteht aus einer Reihe chronologisch angeordneter Episoden aus dem Leben der Hauptfigur, die jeweils fünf Jahre auseinanderliegen: In der ersten Episode (1982) ist der Protagonist zehn Jahre alt, in der letzten (1999-2000) fast dreißig.

14 Wojciech Kuczok, Spiski. Przygody tatrzańskie [Verschwörungen. Abenteuer in der Tatra], Warschau: WAB, 2010, 191. 
Im ersten Aufzug sehen wir einen verzweifelten Jungen, dessen Vater einen Familienausflug in die Berge plant, obwohl doch gerade Fußballweltmeisterschaft ist und der Fernseher in der Berghütte so einen schlechten Empfang hat. In der letzten Geschichte ist der erwachsene Protagonist ein erfahrener Bergsteiger und Höhlenforscher, dessen Gefühle endlich von der schönsten aller Goralinnen erwidert werden, in die er sich bereits als Kind unsterblich und bis über beide Ohren verliebt hat ... Die Geschichte ist also heiter und geht gut aus - und der Autor kommentierte dies einmal damit, er habe zum ersten Mal alle glücklich machen wollen. Glück und Freude sind jedoch nicht unproblematisch.

Die Probleme springen ins Auge, wenn wir Spiski als Gegenstück zu Kuczoks bekanntesten und bedrückendsten Roman Gnój (Dreckskerl) ${ }^{15}$ betrachten. In jener verkappten Biografie, die in einer verhassten Umgebung aus übelwollenden Menschen spielt, steht der Vater als grausamer Wächter zwischen Kind und Welt, verbietet jede Freude, missachtet die Privatsphäre des Kindes und zerstört dessen Selbstvertrauen. Er ist sadistisch, zudringlich und unbelehrbar, schlägt, demütigt, erniedrigt. Deswegen will der Sohn aus Sorge, tief in ihm könnte sich ein ebenso grausamer Vater eingenistet haben, später keine eigene Familie gründen.

Spiski nimmt diese Konstellation auf: Der Vater versucht weiterhin, seinen Sohn nach Gutdünken zu formen, gibt jedoch nach, als er auf Widerstand stößt; er wendet keine Gewalt an, und so muss kein Freudscher Machtkampf gegen ihn geführt werden. Mehr noch, bei einer seiner späteren Expeditionen gelingt es dem Sohn, den beschädigten Kontakt zum Vater wiederherzustellen, schlussendlich drückt er ihm sogar seine Anerkennung aus. Beide schaffen es dank der Berge, ihrem Leben eine neue Richtung zu geben. Und die Goralin, in die der Junge sich einst verliebte, lädt den inzwischen erwachsenen Protagonisten zu sich nach Hause ein. Das heißt, hier tritt die Bereitschaft, eine eigene Familie zu gründen, an die Stelle der Angst vor einer Wiederholung der Geschichte des Vaters.

Die Erneuerung der Familie bedeutet in Kuczoks Werk die Lösung eines ernsten Problems der bürgerlichen wie der podhalischen Kultur. Die Gesellschaft des Podhale ist nämlich endogam - geheiratet wird nur untereinander. Die Endogamie kollidiert mit der Armut, die die Männer zur Emigration zwingt. Die zurückbleibenden Frauen beschreiten teils aus Langeweile, teils aus Trotz den Pfad der Emanzipation. In Spiski macht sich Kuczok über das Podhaler Patriarchat lustig. Das traditionelle Familienbild schafft Probleme, die auf dem Weg der Tradition nicht mehr gelöst werden können. Der bürgerlichen Familie ergeht es nicht besser: Zwar ist sie weniger traditionalistisch, dafür aber auch weniger

15 Wojciech Kuczok, Gnój [Dreckskerl], Warschau: Wydawnictwo W.A.B., 2003; deutsche Ausgabe: Dreckskerl, übersetzt von Gabriele Leopold, Frankfurt am Main: Suhrkamp, 2007. 
lebendig. Sie entwickelt keine starken Bande und bricht daher leichter auseinander. Die Lösung stellt sich mit der Mischung beider Lebensweisen ein.

Ein zweites Problem nimmt Bezug auf Krohs Buch: Im letzten Teil von Spiski bemerkt der Erzähler, einer der Goralen sei »der treueste Kunde im Laden des kulturellen Bedarfs " gewesen. ${ }^{16}$ Die offene Anknüpfung an Krohs Text führt uns auf eine neue Spur - den Wandel der Lebensstile. So stellt Kuczok die Fortsetzung des Niedergangs dar, der in Sklep potrzeb kulturalnych umrissen wird. In dieser ethnografischen Plauderstunde wird gezeigt, wie die Goralen in eine Falle tappten, die sie selbst gestellt hatten, um ihre Unabhängigkeit gegenüber den Städtern zu wahren. Bei Kuczok sind die Goralen bereits postmodern: Ihr Dialekt ist eine »apokryphe Goralensprache ${ }^{17}$, ihr Glaube eine Mischung aus alten Zauberbräuchen und den neuesten Trends. Sie haben eine Freiheit errungen, die sie demoralisiert hat, fürchten weder Gesetz noch Priester. Ihre wichtigsten Traditionen bestehen darin, Wodka zu trinken, Touristen auszunehmen und die Natur auszubeuten. Zog die Krise bei Kroh erst herauf, so hat sie sich bei Kuczok bereits häuslich eingerichtet: Trägheit und Wodka tragen die Schuld daran, dass die Goralen ihre Berge weniger gut kennen als mancher Reisende, und der Raubbau an der Natur führt zur Katastrophe: "Die Leute verschwören sich gegen die Bäume. [...] wenn du in einen Wald gehst, hörst du aus dem Dickicht nicht wilde Tiere röhren, sondern Kreissägen heulen. ${ }^{18}{ }^{18}$ Deswegen "rächt sich der Wald ${ }^{19}$ und lässt eine seltsame Krankheit die Menschen befallen, die den ganzen Körper mit Moos überzieht.

Das Problem liegt jedoch nicht in Habgier und Faulheit selbst, sondern im versiegten Quell der Erzählung. Das Podhale verkümmert, weil es kein zusammenhängendes Narrativ mehr herzustellen vermag. Alles, was die Goralen leisten können, ist die ritualisierte Reproduktion der alten Geschichten, die unweigerlich Gräben aufreißen - etwa zwischen Goralen und Zugereisten sowie zwischen Mensch und Natur. Es entsteht der Eindruck, die eilfertige Absorption von Moden (z. B. dass die Goralen Fans des »Herrensports « Fußball werden oder Goralinnen sich die »Muschis rasieren«) resultiere aus der verzweifelten Suche nach Verbindungen mit einer Kultur, die weiter verbreitet ist als die eigene. Die Tradition erweist sich im Podhale als vertrocknet, es ist nichts Lebendiges mehr darin. In einer solchen Lage ist eine Art verbindender Stoff von Nutzen, eine Erzählung also, die die Welt erklären und zeigen kann, wie sich Verknüpfungen herstellen lassen.

16 Kuczok, Spiski, 252.

17 Ebd., 203.

18 Ebd., 214.

19 Ebd. 
Und genau darin erfüllt sich die pikareske Mission der Hauptfigur. Hätte der Protagonist die Podhale-Bewohner demütigen wollen, so hätte er ausgesprochen, was ihm durch den Kopf ging: »Faulheit und Habgier erlaubten ihnen keine Ausflüge in die Berge, ihre Kenntnisse über die Tatra beschränkten sich auf den Blick von der Straße aus auf die Włosienica-Lichtung mit dem Bergsee Morskie Oko [Meerauge], zu dem sie mit Pferdefuhrwerken die fußfaule Kundschaft karrten und dafür horrende Summen kassierten. $\aleph^{20}$ Hätte der Protagonist die Goralen demütigen wollen, dann hätte er seine Geliebte aus ihrem Dorf entführt und in die Stadt mitgenommen. Doch in Spiski ist die Aufgabe des Schelms widersprüchlich, ein halsbrecherischer Balanceakt. Er will das Herz der Goralin erobern und bei den Goralen bleiben; er will den Podhalebewohnern vermitteln, dass sie durchtrieben sind, und ihr Denken verändern. Und dafür wird ein neues Narrativ gebraucht.

Durch Kuczoks Buch zieht sich die Behauptung, die Goralen würden so manche Geschichte von Sabała auswendig kennen, ihrem legendären Märchenerzähler, der seinen Nachfahren die wichtigsten Mythen des Tatravolkes überlieferte. Die »Professoren der Musikakademie« lauschen den rezitierten und gesungenen Legenden »entrückt und von >Bauernmanie` erfüllt « ${ }^{21}$. Es entsteht jedoch keine lebendige Erzählung. Gebraucht wird ein Erzähler mit Erfindungsgabe - und genau das ist der junge Protagonist. Er bringt die fehlenden Verbindungsglieder in die podhalische Kultur ein: Er erobert das Herz seiner Goralin und lebt mit ihr zusammen in ihrem Haus, erklimmt Gipfel und klettert in Höhlen, er versieht die alten Legenden mit neuen Elementen. So ersinnt er einen »Werbären«, ein Ungeheuer, das der Verbindung von Mensch und Bär entspringt und in der Tatra lebt. Der Werbär, eine Weiterentwicklung des Werwolfs, gibt einer Welt, die in "platteste Alltäglichkeit «22 abzugleiten droht, das Geheimnisvolle und Gruselige zurück. Derselbe Protagonist erklärt den Goralen mithilfe eines Zaubermärchens die Ursache für den Verfall, indem er an den Volksglauben erinnert, menschliche Missetaten würden von der Natur bestraft, und indem er postmodern die menschliche mit der übernatürlichen Sphäre verbindet.

Kuczok macht seinen Protagonisten also zu einem neuen Sabała, einem Märchenerzähler, der die entzauberte Welt des Podhale wieder verzaubert. Und zum Beweis seiner Fähigkeiten präsentiert er eine Schelmengeschichte mit heilender Kraft.

20 Ebd., 191.

21 Ebd., 136. Die chłopomania (Bauernmanie), die Begeisterung für Folklore und ländliches Leben, war eine Strömung innerhalb des Jungen Polen; A.d. Ü.

22 Ebd., 9. 


\section{Aufstieg}

Die Folkore des Podhale mit ihren Bräuchen und Artefakten speiste zwei Jahrhunderte hindurch eine lebendige Kultur. Heute jedoch übermittelt die Literatur eine beunruhigende Botschaft: Der Quell versiegt. Die Kultur des Podhale implodiert: Da sie lediglich zur Reproduktion verbrauchter Muster fähig ist, bricht sie unter der Last der eigenen Vergangenheit zusammen. Das Narrativ muss von Neuem ersonnen werden. So wie der Goralen-Folk die Musik des Podhale neu verarbeitet, so wie Ensembletänze neu choreographierte Volkstänze sind, so müssen auch die Geschichten aus dem Podhale neu erzählt werden. Dabei kann es nicht um eine einfache Paraphrase gehen, um alten Wein in neuen Schläuchen, sondern es geht um eine Erneuerung der Kultur. Es geht darum, Brücken über die Gräben zu bauen, Gemeinschaft an die Stelle von Absonderung zu setzen. Sklep potrzeb kulturalnych schlägt Alarm; Spiski schlägt eine neue kulturelle Praxis vor. Der hier geschilderte Abstieg hält einen Ausweg bereit. Um diesen Ausweg zu begehen, muss der Aufstieg gewagt werden.

Aus dem Polnischen von Lisa Palmes

\section{Literatur}

Bhabha, Homi K., The Location of Culture. London: Routledge, 1994.

Kiosew, Aleksander. »Uwagi o samo-kolonizujących się kulturach" [Anmerkungen zu Selbst-Kolonisierung der Kulturen], übersetzt von Elżbieta Solak, in : Dekada Literacka, 2000, Nr. 9/10, 14-15.

Klekot, Ewa. »Samofolkloryzacja. Współczesna sztuka ludowa z perspektywy krytyki postkolonialnej « [Selbstfolklorisierung. Moderne Volkskunst aus der Sicht der postkolonialen Kritik], in: Kultura Wspótczesna, 2014, Nr. 1, 86-99.

Kroh, Antoni. Sklep potrzeb kulturalnych [Laden des kulturellen Bedarfs], Warschau: Wydawnictwo Prószyński i S-ka, 1999.

Kuczok, Wojciech. Gnój, Warszawa: Wydawnictwo W.A.B., 2003; deutsche Ausgabe: Dreckskerl. Eine Antibiographie, übersetzt von Gabriele Leopold, Frankfurt am Main: Suhrkamp, 2007.

Ders. Spiski. Przygody tatrzańskie [Verschwörungen. Abenteuer in der Tatra], Warschau: WAB, 2010. 


\section{Kulturlandschaften im Spannungsfeld von Wissenschaft und Didaktik}


Open-Access-Publikation im Sinne der CC-Lizenz BY 4.0

(c) 2020, Vandenhoeck \& Ruprecht GmbH \& Co. KG, Göttingen ISBN Print: 9783847107507 - ISBN E-Lib: 9783737007504 


\section{Thomas Strobel}

\section{Kulturlandschaften in deutschen Geschichtsschulbüchern ${ }^{*}$}

Durch die Anlage blühender griechischer Siedlungen im Raume des Mittelmeeres und der meisten seiner Randmeere traten viele Länder (Spanien, Gallien, Italien, Südengland) zum erstenmal in den Gesichtskreis der Geschichte. ${ }^{1}$

Der Gegensatz zum Deutschen Reich war am stärksten, weil Polen die Kämpfe um den Raum führte, der von slawischen Völkern bewohnt wurde und deshalb zum Kampfobjekt werden mußte. ${ }^{2}$

Die Folgen der industriellen Revolution in England waren nicht nur für dieses Land, sondern für die Welt so bedeutsam, daß sie in der Tat »das Antlitz der Erde veränderten. $\ll^{3}$

Das Konzept von Kulturlandschaft - hier verstanden als »diejenige Landschaft, die mehr oder weniger deutlich unter dem gestaltenden Einfluss des Menschen steht ${ }^{4}{ }^{4}$ und entlang der von Küster benannten Trias von Natur-Kultur-Idee ${ }^{5}$ spielt im Kontext von Schulbüchern in alle Epochen von der Antike bis in die Gegenwart und in eine Vielzahl von Themengebieten hinein, wie anhand der drei eingangs genannten Beispiele illustriert werden konnte.

* Für ihre Recherchen und Impulse sei Katarzyna Kulczycka (Braunschweig), für wichtige Hinweise Prof. Violetta Julkowska (Poznań) herzlich gedankt.

1 Robert Hermann Tenbrock und Hans Erich Stier (Hg.), Urzeit und Altertum. Bis zu den Karolingern (Das Abendland im Werden), Oberstufe Band I, Geschichtliches Unterrichtswerk für höhere Lehranstalten, Paderborn: Schroedel, 3. Auflage 1956, 64.

2 Bernhard Bendfeld u. a. (Hg.), Die Zeit der abendländischen Christenheit. Bis zur Aufklärung (Das Abendland), Oberstufe Band II, Geschichtliches Unterrichtswerk für höhere Lehranstalten, Paderborn: Schroedel, 2. Auflage 1956, 106.

3 Robert Hermann Tenbrock und Karl Thieme (Hg.), Die neueste Zeit. Vom Ursprung der USA bis heute (Europa und die Welt), Oberstufe Band III, Geschichtliches Unterrichtswerk für höhere Lehranstalten, Paderborn: Schroedel, 2. Auflage 1956, 16.

4 Hansjörg Küster, »Landschaft - Naturlandschaft - Kulturlandschaft«, in: ders. (Hg.), Kulturlandschaften. Analyse und Planung, Frankfurt am Main: Peter Lang, 2008, 9-20, 12.

5 Hansjörg Küster, Die Entstehung der Landschaft. Einführung in eine neue Wissenschaft, München: Beck, 2012, 8-10. 
Der Beitrag geht den konzeptionellen Darstellungen und konkreten Ausprägungen des Phänomens Kulturlandschaft in deutschen Schulgeschichtsbüchern nach und richtet seinen Blick darauf, welche Narrationen von Kulturlandschaften die Schulbuchtexte beinhalten und für welche Aspekte sie die Schüler sensibilisieren. Dabei stehen folgende Fragen im Zentrum: Welches Verständnis von Kulturlandschaft liegt Schulbuchtexten zugrunde? Werden konzeptionelle Annahmen der Autorinnen und Autoren zu diesem Thema offengelegt? In welchem Verhältnis stehen in den Schulbüchern die Menschen als Akteure zu der Landschaft, in der sie leben? Welchen Wandlungsprozessen unterlagen Geschichtsbücher in diesem Bereich in den letzten Jahren und Jahrzehnten? Und schließlich angesichts der Entstehung der Untersuchung im Kontext der Deutsch-Polnischen Schulbuchkonferenz: Gibt es hinsichtlich der deutschpolnischen Beziehungsgeschichte spezifische Befunde hinsichtlich des Aspekts der Kulturlandschaft?

Nach einer Vorstellung des untersuchten Quellenkorpus wird das Begriffsverständnis von Kulturlandschaft vorgestellt, das der Untersuchung zugrunde liegt. Im Anschluss bilden sieben ausgewählte Themen die Analyseebenen dafür, wie Kulturlandschaften in deutschen Geschichtsbüchern skizziert werden und welche Aspekte sie umfassen.

\section{Quellenkorpus und Analyseebenen}

Die Untersuchung beruht auf der Analyse fünf breit eingesetzter Schulbuchreihen für die gymnasiale Oberstufe, die im ersten Jahrzehnt nach der Jahrtausendwende in Baden-Württemberg, Berlin, Niedersachsen, Nordrhein-Westfalen und Sachsen zugelassen und teilweise auch noch nach 2010 im Schulbuchgebrauch waren. ${ }^{6}$ Manche von ihnen waren auch in mehreren Bundesländern oder gar in allen genannten Bundesländern zugelassen. ${ }^{7}$ Der Auswahl lag die

6 Sachsen: Ulrich Baumgärtner u. a. (Hg.), Anno, Braunschweig: Westermann, 2005; Berlin (seit 25.01.2004 ohne Zulassungsverfahren): Karin Laschewski-Müller und Robert Rauh (Hg.), Kursbuch Geschichte. Neue Ausgabe. Von der Antike bis zur Gegenwart, Berlin: Cornelsen, 2009; Nordrhein-Westfalen: Tobias Arand u. a., Geschichte und Geschehen, Oberstufe Nordrhein-Westfalen, Stuttgart: Klett, 2011; Baden-Württemberg: Hans-Jürgen Lendzian (Hg.), Zeiten und Menschen. Geschichte Oberstufe, 2 Bände, Paderborn: Schöningh, 2006-2007; Niedersachsen: Frank Bahr (Hg.), Horizonte. Geschichte für die Oberstufe, 2 Bände, Braunschweig: Westermann, 2003.

7 Maximilian Lanzinner (Hg.), Buchners Kompendium Geschichte. Von der Antike bis zur Gegenwart, Bamberg: Buchner, 2008 (zugelassen in: Mecklenburg-Vorpommern, RheinlandPfalz, Sachsen und Thüringen). In allen Bundesländern zugelassen wurde: Daniel Henri, Guillaume le Quintrec und Peter Geiss (Hg.), Histoire/Geschichte. Deutsch-französisches Geschichtsbuch. Gymnasiale Oberstufe, 3 Bände, Leipzig: Klett/ Paris: Nathan, 2006-2011. 
Annahme zugrunde, dass zum einen eine repräsentative Auswahl deutscher Bundesländer (West-Ost, Süd-Nord, Flächenstaat-Stadtstaat) herangezogen werden sollte, zum anderen, dass in der Sekundarstufe II ein höheres fachliches Niveau und damit auch eher eine Behandlung des Phänomens Kulturlandschaft vermutet werden konnte. Diese Bücher wurden kontrastiert mit fünf Schulbuchreihen der Oberstufe von Anfang der 1990er Jahre. ${ }^{8}$ Um längerfristige Entwicklungen aufzuzeigen und um über einen längeren Zeitraum erkennbare Tendenzen noch besser verdeutlichen zu können, wurde ergänzend noch je ein entsprechendes Geschichtsbuch aus den 1950er ${ }^{9}$, den 1960er ${ }^{10}$ und den 1970er Jahren ${ }^{11}$ herangezogen.

Angesichts der Fülle des Materials wurde ein Schwerpunkt auf Abbildungen, also Fotos, Grafiken, Zeichnungen und Gemälde, gelegt - ausgehend von Reichardts Konzept, wonach Bilder kollektiv gebildete Stereotype darstellen, die gesellschaftliche Wahrnehmung und Erinnerungen fixieren und oft auch einprägsamer und wirkungsvoller sind als Schrifttexte. ${ }^{12}$ Von den Abbildungen ausgehend wurden Autorentext, Quellentexte und Arbeitsaufträge in die Analyse miteinbezogen.

Folgende Themen bildeten das Analyseraster der Schulbuchanalyse: 1. Kulturlandschaften explizit, 2. Siedlungsgeschichte, 3. Regionen, 4. Industrialisierung, 5. Kriege, 6. (Landschafts-)Architektur und Erinnerungskultur sowie 7. Politische Instrumentalisierung von Kulturlandschaften.

Die Auswahl der Themen erfolgte sowohl induktiv als auch deduktiv, das heißt, es wurden konzeptionelle Fragen an die Schulbücher gerichtet, bei der thematischen Tiefenbohrung musste aber aus Praktikabilitätsgründen auch von den in den Schulbüchern behandelten Themenbereichen ausgegangen werden.

8 Hilke Günther-Arndt u.a. (Hg.), Geschichtsbuch - Neue Ausgabe. Die Menschen und ihre Geschichte in Darstellungen und Dokumenten, 4 Bände, Berlin: Cornelsen, 1994-1996; Bernhard Müller u. a. (Hg.), Historia. Geschichtsbuch für Gymnasien, 4 Bände, Paderborn: Schöningh, 1993; Hans-W. Ballhausen (Hg.), Geschichte und Geschehen, Ausgabe N Gymnasium, 4 Bände und II für Oberstufe Ausgabe A/B, Stuttgart u. a.: Klett, 1991; Bernhard Heinloth (Hg.), Oldenbourg Geschichte für Gymnasien, 7 Bände, München: Oldenbourg, 1992-1993; Franz-Joseph Schütz (Hg.), Geschichte. Dauer und Wandel bzw. Geschichte. Politik und Gesellschaft, 3 Bände, Berlin: Cornelsen, 1987-1990.

9 Robert Hermann Tenbrock u. a. (Hg.), Geschichtliches Unterrichtswerk für höhere Lehranstalten, Band I-III, Paderborn: Schroedel, 1956.

10 Hans Georg Gundel u.a. (Hg.), Grundriß der Geschichte für die Oberstufe der Höheren Schulen, Zweibändige Ausgabe, Stuttgart: Klett, 1963-1964.

11 Hans-Georg Fernis und Heinrich Haverkamp (Hg.), Grundzüge der Geschichte, Sekundarstufe II, Einbändige Ausgabe, Frankfurt am Main: Diesterweg, 1975.

12 Rolf Reichardt, »Bild- und Mediengeschichte«, in: Joachim Eibach und Günther Lottes (Hg.), Kompass der Geschichtswissenschaft. Ein Handbuch, Göttingen: Vandenhoeck \& Ruprecht, 2002, 219-230. 


\section{Begriffsverständnis von Kulturlandschaft}

Eine Herausforderung auch für diese Studie war der sehr heterogen gebrauchte und ausgefüllte Begriff der Kulturlandschaft. Äußerst instruktiv ist in diesem Zusammenhang Kaufmanns Vorstellung von Landschaften als "Netzwerke, in denen sich politische Visionen, gesellschaftliche Vorstellungen von Natur und Naturverhältnissen, Vorstellungen von geordneten sozialen Verhältnissen und gesellschaftlichen Entwicklungsidealen manifestieren - Netzwerke, in denen sich aber zugleich immer wieder die `Natur ' mit Überraschungen äußert. ${ }^{13}$ Daran anknüpfend ist es sinnvoll, nach Küster drei Dimensionen von Kulturlandschaft zu unterscheiden:

1. Die bereits "vor dem Menschen« existente Natur, also der physische Raum.

2. Die kulturelle Prägung in Form von Besiedlung, Landwirtschaft, Industrie etc., also der materielle Aspekt.

3. Der immaterielle Aspekt, d.h. die Idee: ${ }^{14}$ Die Interpretation und Vorstellung von einer Landschaft - ihre Vorstellung und Emotion, ihr soziokulturelles Sinnsystem als Teil des kollektiven Bewusstseins, das nach Bourdieu auch Ausdruck von Machtverhältnissen ist. ${ }^{15}$

Aus Landschaften werden durch soziale Konstruktion, kulturelle Prägung und Regulierung Kulturlandschaften. Vor diesem Hintergrund ist es naheliegend, nach dem Einfluss des Menschen, also nach den Akteuren dieser Aneignungsprozesse der physischen Landschaft und ihrer kulturellen Überformung zu fragen.

\section{Ergebnisse der Studie}

Wie schlägt sich dieses Konzept von Kulturlandschaft in deutschen Geschichtsbüchern nieder? In Schulbüchern der Bundesrepublik Deutschland der 1950er und 1960er Jahre funktionieren Begriffe wie Raum, Lebensraum, Kulturraum oder Kulturgebiet, der Begriff Kulturlandschaft hingegen wird nicht explizit verwendet. Letzteres gilt für Schulbücher bis heute: Zwar taucht er etwa in einer Quelle in Geschichte und Geschehen von 2011 ein Mal wörtlich auf, hat aber hier keine konzeptionelle Funktion und wird weder erklärt noch durch einen Ar-

13 Stefan Kaufmann, Soziologie der Landschaft, Wiesbaden: VS Verlag für Sozialwissenschaften, 2005, 154.

14 Küster, Die Entstehung der Landschaft, 8-10.

15 Pierre Bourdieu und Loïc J. D. Wacquant, »Die Ziele der reflexiven Soziologie. ChicagoSeminar, Winter 1987«, in: dies. (Hg.), Reflexive Anthropologie, Frankfurt am Main: Suhrkamp, 1996, 95-249. Diesen Hinweis verdanke ich Olaf Kühne. 
beitsauftrag bearbeitet. ${ }^{16}$ Ansonsten gilt der Befund sowohl für die 1990er Jahre als auch für aktuelle Geschichtsbücher: Eine offensichtliche Behandlung von Kulturlandschaften findet vor allem auf einer metaphorischen Ebene statt, d.h. Landschaft funktioniert hier als Sinnbild zum Beispiel für Frieden. Abgebildet werden etwa im Kontext der Romantik entsprechende Gemälde von Caspar David Friedrich ${ }^{17}$ oder von Daniel Chodowiecki im Zusammenhang mit der Aufklärung. ${ }^{18}$

Eine konzeptionelle Auseinandersetzung mit der Thematik Landschaft, Kulturlandschaft, Raum und eine Offenlegung ihrer Grundannahmen findet aber seitens der Schulbuchautorinnen und -autoren nicht statt. Maßgeblich verantwortlich dafür dürften der Zwang zur didaktischen Reduktion und der Platzmangel im Schulbuch sein.

In der Schulbuch-Chronologie ganz am Anfang steht die Thematisierung der Kulturlande der Frühen Hochkulturen und der antiken Kulturlande in Griechenland und Rom. Tenbrock und Stier sprechen 1956 von »Kulturräumen«, in denen Hochkulturen entstanden seien - bemerkenswert allerdings, dass sie diese als "westlich" einordnen. ${ }^{19}$ In aktuellen Geschichtsbüchern ist im Hinblick auf die Antike besonders anschaulich die Karte Attikas, in denen das "Kulturland" grün eingezeichnet ist, was als die bebaubare, nicht gebirgige Fläche Griechenlands erklärt wird. ${ }^{20}$ In Bezug auf das Römische Reich wird der erschließende Charakter der Romanisierung häufig deutlich gemacht anhand des Limes und der Entstehung von Städten aus römischen Militärlagern, besonders an Rhein und Mosel. ${ }^{21}$ In diesem Zusammenhang ist auffällig, dass die geografisch-physischen Bedingungen der Länder der Antike deutlich herausgearbeitet werden, in späteren Epochen aber kaum noch eine Rolle spielen.

Die Siedlungsgeschichte ist sicher eines der naheliegendsten Themen im $\mathrm{Zu}$ sammenhang mit Kulturlandschaften: Menschen erschließen sich Räume, um sie für sich nutzbar zu machen und um Herrschaftsräume zu definieren. In deutschen Geschichtsbüchern kann dies an drei Beispielen illustriert werden:

16 Arand, Geschichte und Geschehen, 82. Der Begriff Kulturlandschaft fällt hier in einem Quellentext zu Veränderungsprozessen infolge des portugiesischen Einflusses an der westafrikanischen Küste im 15./16. Jahrhundert.

17 Caspar David Friedrich, Gemälde »Wanderer über dem Nebelmeer« (1818), in: Daniel Henri u. a. (Hg.), Histoire/Geschichte. Europa und die Welt vom Wiener Kongress bis 1945. Deutschfranzösisches Geschichtsbuch, Gymnasiale Oberstufe, Leipzig: Klett, Nathan, 2008, 131.

18 Daniel Chodowiecki, Kupferstich »Aufklärung« (1791), in: Hans-Jürgen Lendzian (Hg.), Zeiten und Menschen 1, Geschichte Oberstufe, Paderborn: Schöningh, 2007, 207.

19 Tenbrock und Stier (Hg.), Urzeit und Altertum, 28.

20 Lendzian (Hg.), Zeiten und Menschen 1, 14.

21 Ebd., 66. 
Burgen strukturieren die Landschaft, etwa in der Stauferzeit; ${ }^{22}$ Städte entstehen im Mittelalter ${ }^{23}$ europäische Siedler erschließen sich den nordamerikanischen Kontinent. ${ }^{24}$ Ausführlich wird der Landesausbau in Ostmitteleuropa behandelt, der bis in die Gegenwart in Schulbüchern immer wieder als deutsche Ostsiedlung bezeichnet wird. Die Schulbücher der 1950er und 1960er Jahre sind bei diesem Thema geprägt von einem missionarischen, kolonisatorischen Geist, so etwa Geschichte und Geschehen von 1967:

In diesen Ländern [gemeint ist Ostmitteleuropa, der Verfasser] waren zumeist nur von Natur dem Anbau offen stehende Freilandschaften besiedelt. Die extensiv betriebene Landwirtschaft stand auf bescheidener Stufe. Die Anpassung an den kulturellen und wirtschaftlichen Stand des westlichen und südlichen Abendlandes war eine große Aufgabe. Die einheimischen Fürsten konnten auf diesem Wege abendländischen Rang gewinnen. ${ }^{25}$

Die Einteilung in Kulturräume ist hier besonders auffällig: Aus »altdeutschem Kulturgebiet" seien die Siedler »in den Raum [vorgestoßen], der von Slawen dünn besiedelt " gewesen sei, so das Geschichtliche Unterrichtswerk von $1956 .{ }^{26}$ In den aktuellen Schulbüchern ist das Thema wieder präsenter als in den 1990er Jahren - exemplarisch Cornelsens Kursbuch Geschichte, das die sog. Ostsiedlung in den Kontext der "Ostpolitik« der Karolinger und Ottonen einordnet. ${ }^{27}$ Die Deutung ist insgesamt deutlich sachlicher geworden und sie ordnet das Thema in größere Kontexte von Landesausbau ein. Multiperspektivisch hingegen ist die Darstellung weiterhin nicht angelegt, sondern vermittelt die Gestaltung einer Kulturlandschaft allein von einem deutschen Standpunkt aus.

$\mathrm{Zu}$ Kulturlandschaft und Regionen soll hier nicht ins Detail gegangen werden, da mit dem Pruzzenland und Oberschlesien zwei Fallbeispiele in diesem Band gesondert behandelt werden. ${ }^{28}$ Dennoch einige allgemeine Befunde: Die Behandlung historischer Phänomene anhand bestimmter Regionen spielt eine nur geringe Rolle in den deutschen Schulbüchern nach der Jahrtausendwende. In den Schulbüchern der 1950er und 1960er Jahre kommen etwa Schlesien, Westpommern, Pommerellen oder das Pruzzenland immer wieder vor - und zwar beim mittelalterlichen Landesausbau, aber auch bei der Geschichte des Deut-

22 Karl-Heinz Ruffmann (Hg.), Oldenbourg Geschichte für Gymnasien 11, München: Oldenbourg, 1993, 84.

23 Laschewski-Müller und Rauh (Hg.), Kursbuch Geschichte, 85.

24 Berthold Wiegand (Hg.), Geschichte, Politik und Gesellschaft 2. Lern- und Arbeitsbuch für Geschichte in der Gymnasialen Oberstufe. Die Großmächte. Internationale Beziehungen. Deutschland nach 1945, Berlin: Cornelsen, 1993, 54.

25 Fernis und Haverkamp (Hg.), Grundzüge der Geschichte, 117.

26 Bendfeld (Hg.), Die Zeit der abendländischen Christenheit, 82.

27 Laschewski-Müller und Rauh (Hg.), Kursbuch Geschichte, 66-72.

28 Vgl. die Beiträge zu Ostpreußen/Warmia i Mazury und Oberschlesien in diesem Band. 
schen Ordens, den Teilungen Polens und der Entwicklung Preußens. Nicht nur das Thema der Teilungen Polens hat aber in frappierender Weise in den deutschen Schulbüchern an Umfang eingebüßt, auch die erwähnten Regionen als deutsch-polnische Kontaktzonen sind fast vollständig aus den deutschen Geschichtsbüchern verschwunden. Weitet man den Blick in Richtung Westen, so fällt auf, dass auch Elsass-Lothringen kaum einmal gesondert behandelt wird. Das deutsch-französische Geschichtsbuch stellt hier mit seinen Dossiers etwa zu Elsass-Lothringen eine Ausnahme dar. ${ }^{29}$ Beim Thema Industrialisierung setzen deutsche Schulbücher allerdings regionale Schwerpunkte - meist auf das Ruhrgebiet oder das Bundesland, in dem sie zugelassen sind. ${ }^{30}$

Das prägnanteste Beispiel für die Behandlung von Kulturlandschaften ist die Industrialisierung, da sie die grundlegendste Umgestaltung von Landschaften und Lebenswelten der Neuzeit darstellt. Während ältere Schulbücher ein eher mechanisches Bild der Industrialisierung präsentierten und besonderen Wert auf deutsche Erfindungen legten, machen neuere Schulbücher die Dynamik der Veränderungen plastisch deutlich. Insgesamt fällt auf, dass der Fokus sich eher auf die Industrie und die Städte richtet denn auf die umliegenden, nunmehr von Schienennetzen durchzogenen Landschaften. Darstellungen von Erfindungen, zum Beispiel in der englischen Landwirtschaft, sind eine Ausnahme. ${ }^{31}$ Sonst dominieren die urbanen Bereiche, in "Geschichte. Politik und Gesellschaft « etwa die Veränderung von Essen seit 1822. ${ }^{32}$ Erstaunlich ist im Übrigen, dass der Durchsetzung der Eisenbahn implizit eine deutlich wichtigere Rolle zugeschrieben wird als späteren Erfindungen wie dem Automobil oder dem Flugzeug. ${ }^{33}$ Ab den 1970er Jahren bis heute hat insofern ein Wandel stattgefunden, als dass immer stärker auch die Kehrseite der Industrialisierung in den Blick genommen wird - pointiert in Histoire/Geschichte von 2008, wo eine Landidylle mit dem Monster der Stadt kontrastiert wird. ${ }^{34}$

Von ähnlich einschneidender Bedeutung wie die Industrialisierung für die Gestalt von Kulturlandschaften waren nur Kriege. Noch in den 1990er Jahren

29 Dossier "Das Reichsland Elsass-Lothringen «, Dossier »Das Rheinland und das Ruhrgebiet im Zentrum der deutsch-französischen Spannungen", in: Henri (Hg.), Histoire/Geschichte. Europa und die Welt vom Wiener Kongress bis 1945, 58f. und 366f.

$30 \mathrm{Vgl}$. etwa die Entwicklung der Verkehrswege in Bayern im Zuge der Industrialisierung in: Manfred Treml (Hg.), Oldenbourg Geschichte für Gymnasien 12, München: Oldenbourg, 1994, 32.

31 Abbildung zu Erfindungen in der englischen Landwirtschaft im 18. Jahrhundert in: Laschewski-Müller und Rauh (Hg.), Kursbuch Geschichte, 260.

32 Wolfgang W. Mickel (Hg.), Geschichte. Politik und Gesellschaft 1, Lern- und Arbeitsbuch für Geschichte in der gymnasialen Oberstufe. Von der Französischen Revolution bis zum Ende des 2. Weltkrieges, Berlin: Cornelsen, 1991, 190.

33 Vgl. etwa: Lendzian (Hg.), Zeiten und Menschen 1, 396 und 414.

34 Henri (Hg.), Histoire/Geschichte. Europa und die Welt vom Wiener Kongress bis 1945, 101. 
waren nur wenige Bilder zerstörter Städte und Landschaften in den Schulbüchern zu finden, und Gemälde wie »Krieg und Frieden« von Otto Dix standen lediglich pars pro toto für diese. ${ }^{35}$ Aktuell hingegen werden die Folgen von Kriegen viel drastischer und auch länderübergreifend gefasst und es wird aufgezeigt, welchen massiven Veränderungen Kulturlandschaften dabei ausgesetzt sind. Im Kursbuch Geschichte von 2009 etwa werden Fotografien der zerstörten Städte Rotterdam, Murmansk und Dresden nebeneinandergestellt. ${ }^{36}$ Ein Beispiel, wie Kulturlandschaften durchschnitten werden in der Folge von Kriegen und Konflikten, ist die Installierung der Grenze zwischen der DDR und der Bundesrepublik Deutschland 1952 im Harz. ${ }^{37}$ Deutlich wird, dass dem Menschen, der diese Grenzen errichtet, dabei auch die Rolle als potentieller Überwinder derselben zugeschrieben wird - exemplarisch hierfür der Bau und der Fall der Berliner Mauer. ${ }^{38}$ Im Kontext der Behandlung von Kriegen in diesem Zusammenhang ist eine interessante Beobachtung, dass Kriege nicht mehr länger auf die Verschiebung von Grenzen reduziert werden, auf Siege und Niederlagen - in den Blick genommen werden vielmehr auch Austauschprozesse sowie Wissens- und Kulturtransfer etwa zwischen Europa und der arabischen Welt. $^{39}$ Selbiges geschieht ebenfalls im Kontext von Migrationsbewegungen, Entdeckungen und Kolonialgeschichte, sehr instruktiv etwa angelegt durch die provokative Frage: "Warum eroberten nicht die Inka Spanien? « ${ }^{40}$

Landschaftsarchitektur, verstanden als ästhetische und gleichzeitig symbolische und machtpolitisch motivierte Formung von Landschaften durch Gärten, Parks und Schlösser, ist immer wieder durch den Wörlitzer Park oder den Englischen Garten in München, vor allem aber durch das Schloss von Versailles und seine europäische Modellfunktion in Schulbüchern präsent. ${ }^{41}$ Eine deutliche Zunahme verzeichnen in den letzten Jahren auch Denkmäler als architektonische Zeichen von Erinnerungskultur oder das Konzept der Erinnerungsorte besondere Akzente setzt hier im Übrigen das deutsch-französische ${ }^{42}$ und neuerdings auch das deutsch-polnische Geschichtsbuch. ${ }^{43}$

35 Hans-W. Ballhausen (Hg.), Geschichte und Geschehen II, Oberstufe, Ausgabe A/B, Stuttgart u. a.: Klett, 1995, 435.

36 Laschewski-Müller und Rauh (Hg.), Kursbuch Geschichte, 465.

37 Lanzinner (Hg.), Buchners Kompendium Geschichte, 406.

38 Wiegand (Hg.), Geschichte, Politik und Gesellschaft 2, 259 und 299.

39 Lanzinner (Hg.), Buchners Kompendium Geschichte, $38 \mathrm{f}$.

40 Laschewski-Müller und Rauh (Hg.), Kursbuch Geschichte, 178.

41 Lanzinner (Hg.), Buchners Kompendium Geschichte, 120.

42 Dossier »Symbolische Gesten und Erinnerungsorte im deutsch-französischen Verhältnis«, in: Guillaume le Quintrec und Peter Geiss (Hg.), Histoire/Geschichte, Europa und die Welt seit 1945, Leipzig: Klett, Nathan, 2006, $302 \mathrm{f}$.

43 »Vergangenheit in der Gegenwart« zur Schlacht bei Tannenberg/Grunwald, in: Gemeinsame Deutsch-Polnische Schulbuchkommission (Hg.), Europa - Unsere Geschichte. Band 1, Wiesbaden: Eduversum, WSiP, 2016, 211. 
Damit verbunden ist auch die politische Instrumentalisierung von Kulturlandschaften in totalitären Systemen. Fast jedes Schulbuch verfügt über Abbildungen aus dem Nationalsozialismus ${ }^{44}$ oder von Stalin, in dessen Hintergrund Industrielandschaften zu sehen sind, ${ }^{45}$ die die gestalterische Kraft des jeweiligen Führers bzw. Systems unterstreichen. Nur selten allerdings werden die Schülerinnen und Schüler wie in Buchners Kompendium Geschichte durch Arbeitsaufträge dazu aufgefordert, sich im Detail mit den verschiedenen Ebenen der Abbildung auseinanderzusetzen und herauszuarbeiten, welche Vision und welches Verständnis mit der jeweiligen Abbildung vermittelt werden sollte. ${ }^{46}$

\section{Zusammenfassung}

Durch die vorgelegte Untersuchung ist deutlich geworden, dass die den deutschen Geschichtsbüchern zugrundeliegende Perspektive in hohem Maße anthropozentrisch ist. Der Mensch ist es, der die Landschaft formt und diese in vielerlei Hinsicht prägt. Der Mensch ist auf den Abbildungen in der Regel der Akteur, der die Geschicke der Geschichte lenkt, aber auch von Handlungen anderer Menschen stark betroffen ist. ${ }^{47}$ An anderer Stelle verschwindet der Mensch aber auch in der Masse, zum Beispiel im Kontext politischer Bewegungen, ${ }^{48}$ oder ist ohnmächtig gegenüber dem Lauf der Dinge, gegenüber Kriegen, sozioökonomischen Veränderungsprozessen und den Gewalten der Natur. ${ }^{49}$

Kulturlandschaften werden nicht explizit thematisiert oder konzeptionell rückgebunden. Sie scheinen fast zufällig ihren Platz einzunehmen und zurückzutreten hinter Mensch, Industrie und Technik. Dass Schulbücher aber zunehmend den Preis des technischen Fortschritts und negative Folgen menschlichen

44 Vgl. den NS-Druck mit dem Hitler-Zitat »Was die Heimat leistet, muss vor der Geschichte dereinst bestehen können", in dessen Hintergrund ein pflügender Bauer und eine große Industrieanlage abgebildet sind. Lanzinner (Hg.), Buchners Kompendium Geschichte, 348.

45 Frank Bahr u.a., Grundkurse Geschichte, Darmstadt: Winklers Verlag, Gebrüder Grimm, 1994, 472.

46 »Arbeitsaufträge: 1. Erörtern Sie die gesellschaftliche Utopie, die hier entworfen wird. Wie >modern ist die skizzierte Wirtschaftswelt? 2. Analysieren Sie das Verhältnis von `Heimat und Boden`, das sich hier spiegelt. Nehmen Sie unter umweltgeschichtlichen Gesichtspunkten dazu Stellung«, in: Lanzinner (Hg.), Buchners Kompendium Geschichte, 348.

47 Vgl. etwa das eindrucksvolle Foto aus dem Koreakrieg, auf dem amerikanische Soldaten und Zivilisten aneinander vorbei in verschiedene Richtungen gehen, in: Manfred Treml (Hg.), Oldenbourg Geschichte für Gymnasien 13, München: Oldenbourg, 1994, 256.

48 Vgl. Fotografien von Aufständen und Revolutionen, etwa von der russischen Oktoberrevolution, in: Bahr, Grundkurse Geschichte, 455.

49 Vgl. etwa das Foto vor einem amerikanischen Napalmangriff in Vietnam im Juni 1972 fliehender Kinder, in: Lanzinner (Hg.), Buchners Kompendium Geschichte, 488. 
Handelns thematisieren, zeigt, dass sie sich implizit sogar überaus deutlich mit konzeptionellen Annahmen von Kulturlandschaft beschäftigen.

Insgesamt haben Landschaftsabbildungen im deutschen Geschichtsbuch in hohem Maße allegorischen Charakter - sie sind entweder mystifizierend und auf eine goldene Zukunft verweisend oder düster und unheilvoll.

Neuere Schulbücher zeigen einen gewandelten Begriff von Landschaft und Raum. Grenzen werden durchlässiger und offen für kulturellen Austausch. Dennoch verschenken die Schulbücher die Chance, stärker anhand konkreter, den Schülerinnen und Schülern bekannter Kulturlandschaften historische Phänomene mit allen Brüchen und Kontinuitäten zu exemplifizieren.

\section{Literatur}

Arand, Tobias u. a. Geschichte und Geschehen, Oberstufe Nordrhein-Westfalen, Stuttgart: Klett, 2011.

Bahr, Frank (Hg.). Horizonte. Geschichte für die Oberstufe, 2 Bände, Braunschweig: Westermann, 2003.

Bahr, Frank u.a. Grundkurse Geschichte, Darmstadt: Winklers Verlag Gebrüder Grimm, 1994.

Ballhausen, Hans-W. (Hg.). Geschichte und Geschehen, Ausgabe N Gymnasium, 4 Bände und II für Oberstufe Ausgabe A/B, Stuttgart u. a.: Klett, 1991.

Ders. Geschichte und Geschehen II, Oberstufe, Ausgabe A/B, Stuttgart u. a.: Klett, 1995.

Baumgärtner, Ulrich u. a. (Hg.). Anno, Braunschweig: Westermann, 2005.

Bendfeld, Bernhard u.a. (Hg.). Die Zeit der abendländischen Christenheit. Bis zur Aufklärung (Das Abendland), Oberstufe Band II, Geschichtliches Unterrichtswerk für höhere Lehranstalten, Paderborn: Schroedel, 2. Auflage 1956.

Bourdieu, Pierre und Loïc J. D. Wacquant. »Die Ziele der reflexiven Soziologie. ChicagoSeminar, Winter 1987«, in: Reflexive Anthropologie, dies. (Hg.), Frankfurt am Main: Suhrkamp, 1996, 95-249.

Fernis, Hans-Georg und Heinrich Haverkamp (Hg.). Grundzüge der Geschichte, Sekundarstufe II, Einbändige Ausgabe, Frankfurt am Main: Diesterweg, 1975.

Gemeinsame Deutsch-Polnische Schulbuchkommission (Hg.). Europa - Unsere Geschichte, Band 1, Wiesbaden: Eduversum WSiP, 2016.

Gundel, Hans Georg u.a. (Hg.). Grundriß der Geschichte für die Oberstufe der Höheren Schulen, Zweibändige Ausgabe, Stuttgart: Klett, 1963-1964.

Günther-Arndt, Hilke u. a. (Hg.). Geschichtsbuch - Neue Ausgabe. Die Menschen und ihre Geschichte in Darstellungen und Dokumenten, 4 Bände, Berlin: Cornelsen, 1994.

Heinloth, Bernhard (Hg.). Oldenbourg Geschichte für Gymnasien, 7 Bände, München: Oldenbourg, 1992.

Henri, Daniel u. a. (Hg.). Histoire/Geschichte. Europa und die Welt vom Wiener Kongress bis 1945. Deutsch-französisches Geschichtsbuch, Gymnasiale Oberstufe, Leipzig: Klett/ Paris: Nathan, 2008, 131. 
Henri, Daniel, Guillaume le Quintrec und Peter Geiss (Hg.). Histoire/Geschichte. Deutschfranzösisches Geschichtsbuch, Gymnasiale Oberstufe, 3 Bände, Leipzig: Klett/Paris: Nathan, 2006.

Kaufmann, Stefan. Soziologie der Landschaft, Wiesbaden: VS Verlag für Sozialwissenschaften, 2005.

Küster, Hansjörg. "Landschaft - Naturlandschaft - Kulturlandschaft«, in: Kulturlandschaften. Analyse und Planung, ders. (Hg.), Frankfurt am Main: Peter Lang, 2008, 9-20.

Ders. Die Entstehung der Landschaft. Einführung in eine neue Wissenschaft, München: Beck, 2012.

Lanzinner, Maximilian (Hg.). Buchners Kompendium Geschichte. Von der Antike bis zur Gegenwart, Bamberg: Buchner, 2008.

Laschewski-Müller, Karin und Robert Rauh (Hg.). Kursbuch Geschichte. Neue Ausgabe. Von der Antike bis zur Gegenwart, Berlin: Cornelsen, 2009.

Lendzian, Hans-Jürgen (Hg.). Zeiten und Menschen, Geschichte Oberstufe, 2 Bände, Paderborn: Schöningh, 2006.

Ders. (Hg.). Zeiten und Menschen 1. Geschichte Oberstufe, Paderborn: Schöningh, 2007.

Le Quintrec, Guillaume und Peter Geiss (Hg.). Histoire/Geschichte. Europa und die Welt seit 1945, Leipzig: Klett Nathan, 2006.

Mickel, Wolfgang W. (Hg.). Geschichte. Politik und Gesellschaft 1. Lern- und Arbeitsbuch für Geschichte in der gymnasialen Oberstufe. Von der Französischen Revolution bis zum Ende des 2. Weltkrieges, Berlin: Cornelsen, 1991.

Müller, Bernhard u. a. (Hg.). Historia. Geschichtsbuch für Gymnasien, 4 Bände, Paderborn: Schöningh, 1993.

Reichardt, Rolf. "Bild- und Mediengeschichte«, in: Kompass der Geschichtswissenschaft. Ein Handbuch, Joachim Eibach und Günther Lottes (Hg.), Göttingen: Vandenhoeck \& Ruprecht, 2002, 219-230.

Ruffmann, Karl-Heinz (Hg.). Oldenbourg Geschichte für Gymnasien 11, München: Oldenbourg, 1993.

Schütz, Franz-Joseph (Hg.). Geschichte. Dauer und Wandel bzw. Geschichte. Politik und Gesellschaft, 3 Bände, Berlin: Cornelsen, 1990.

Tenbrock, Robert Hermann u. a. (Hg.). Geschichtliches Unterrichtswerk für höhere Lehranstalten, Band I-III, Paderborn: Schroedel, 1956.

Tenbrock, Robert Hermann und Hans Erich Stier (Hg.). Urzeit und Altertum. Bis zu den Karolingern (Das Abendland im Werden), Oberstufe Band I, Geschichtliches Unterrichtswerk für höhere Lehranstalten, Paderborn: Schroedel, 3. Auflage 1956.

Tenbrock, Robert Hermann und Karl Thieme (Hg.). Die neueste Zeit. Vom Ursprung der USA bis heute (Europa und die Welt), Oberstufe Band III, Geschichtliches Unterrichtswerk für höhere Lehranstalten, Paderborn: Schroedel, 2. Auflage 1956.

Treml, Manfred (Hg.). Oldenbourg Geschichte für Gymnasien 12, München: Oldenbourg, 1994.

Ders. (Hg.). Oldenbourg Geschichte für Gymnasien 13, München: Oldenbourg, 1994.

Wiegand, Berthold (Hg.). Geschichte, Politik und Gesellschaft 2. Lern- und Arbeitsbuch für Geschichte in der Gymnasialen Oberstufe. Die Großmächte. Internationale Beziehungen. Deutschland nach 1945, Berlin: Cornelsen, 1993. 
Open-Access-Publikation im Sinne der CC-Lizenz BY 4.0

(c) 2020, Vandenhoeck \& Ruprecht GmbH \& Co. KG, Göttingen ISBN Print: 9783847107507 - ISBN E-Lib: 9783737007504 


\section{Kulturlandschaften in polnischen Geschichtsschulbüchern}

»Unter den Faktoren, die das emotionalen Verhältnis des Menschen zur Natur bestimmen, gibt es noch einen gewichtigen weiteren, und das ist die Bindung an seine Heimat", schrieb zu Beginn des 20. Jahrhunderts Jan Gwalbert Pawlikowski, Professor für Wirtschaftswissenschaften und passionierter Bergsteiger, Fürsprecher der Einrichtung des Tatra-Nationalparks und Verfasser von Schriften über den Naturschutz. ${ }^{1}$ In seinem Artikel "Kultura a natura" (Kultur und Natur) schrieb er über Naturschutz und wechselseitigen Einfluss von Natur und Kultur; er legte dar, was Natur für das Verständnis vom Vaterland bedeutet. Denn wie Robert Traba betont, »die heimatliche Landschaft ist ein wichtiger Faktor für die Verwurzelung im Raum, für die Formung symbolischer Vorstellungen von der eigenen nationalen oder ethnischen Gruppe. $\aleph^{2}$

Auf die große Bedeutung der Landschaft für die Herausbildung eines kollektiven Bewusstseins hat auch Simon Schama hingewiesen; er sagt zur Bedeutung der Natur für nationale Mythen und kollektives Gedächtnis: »National identity $[. .$.$] would lose much of its ferocious enchantment without the mystique$ of a particular landscape tradition: its topography mapped, elaborated, and enriched as a homeland. ${ }^{3}$ Auch Karl Schlögel hat in seinem bekannten Buch Im Raume lesen wir die Zeit die identitätsstiftende Bedeutung von Landschaften betont, denn »Menschen wachsen gewöhnlich nicht in Staaten oder Orten auf, sondern im Mittleren: in Landschaften. ${ }^{4}$ Daraus ergibt sich: "Menschen definieren sich durch Landschaften, aus denen sie kommen, nicht weniger als durch

1 Wanda Grębecka, »Problem ochrony rodzinnego krajobrazu a tożsamość narodowa« [Das Problem des Schutzes der heimatlichen Landschaft und die nationale Identität], in: Kwartalnik Historii Nauki i Techniki 55, 3-4 (2010), 249-266.

2 Robert Traba, "Rozważania o magii miejsca i mitologizacji krajobrazu w Prusach Wschodnich « [Erwägungen über die Magie des Ortes und die Mythologisierung der Landschaft in Ostpreußen], in: Borussia 24/25 (2001), 41.

3 Simon Schama, Landscape and Memory, New York: Knopf, 1995, 15.

4 Karl Schlögel, Im Raume lesen wir die Zeit. Über Zivilisationsgeschichte und Geopolitik, München, Wien: Hanser, 2003, 284. 
den Staat, dessen Bürger sie sind. ${ }^{5}$ Bei der Schaffung dieser Mythen und bei der Identitätsbildung spielen bestimmte Träger, etwa in Gestalt von Malerei oder Literatur, eine große Rolle, weil die Landschaft für beide ein besonders wichtiges Motiv ist. Eine wesentliche Rolle kommt auch anderen Artefakten, z. B. Denkmälern, historischen Gebäuden oder Erinnerungsorten zu, die zugleich auch Bestandteile der Landschaft sind. ${ }^{6}$

Vorstellungen von Landschaft und von dem Raum, den der eigene Staat einnimmt, werden schon in der Schule geschaffen. ${ }^{7}$ Daher ist die Schulbildung der wichtigste Mittler zwischen Landschaft und kollektivem Bewusstsein. ${ }^{8}$ Schulexkursionen dienen der Bildung über die Landschaft des Landes bzw. die nähere Umgebung der Schüler. ${ }^{9}$ Doch ist das Schulbuch zu diesem Zweck wohl noch wichtiger, denn es trägt wesentlich zur Schaffung von Gesellschaften bei. Wolfgang Jacobmeyer hat darauf hingewiesen, dass Schulbücher das meistgelesene und wichtigste Massenmedium sind, das historische Kenntnisse an junge Menschen weitergibt, die sie in einer besonders persönlichkeitsformenden Lebensphase aufnehmen. ${ }^{10}$

Allgemein gesprochen, ist die Funktion von Schulbüchern eine didaktische, gesellschaftliche und politische. Sie bereiten die Schüler auf das Leben in der Gesellschaft (in der nationalen Gemeinschaft) vor, indem sie akzeptierte Normen und Werte vermitteln. Das System der Zulassung zum Schulgebrauch macht Schulbücher zum Ausdruck des staatlichen Willens und Indikator für die nationalen Bilder, die Eigenwahrnehmung und Sicht auf Fremde gestalten. Sie sind wie die Bildungspolitik insgesamt ein Instrument der staatlichen Kontrolle der Erinnerung. ${ }^{11}$ Schulbücher stellen deswegen eine interessante Quelle für die

5 Ebd.

6 Beata Frydryczak, »Krajobraz« [Landschaft], in: Magdalena Saryusz-Wolska und Robert Traba (Hg.), Modi Memorandi. Leksykon kultury pamięci [Modi memorandi. Lexikon der Erinnerungskultur], Warschau: Scholar, 2014, 195-199.

7 Schlögel, Im Raume, 142, 243.

8 Traba, »Rozważania«, 44.

9 Über die Bedeutung der Wandervogelbewegung für die Bildung der deutschen und ostpreußischen nationalen Identität Robert Traba, Wschodniopruskość. Tożsamość regionalna $i$ narodowa $w$ kulturze politycznej Niemiec [Ostpreußentum. Regionale und nationale Identität in der politischen Kultur Deutschlands], Poznań u.a.: Wydawnictwo Poznańskiego Towarzystwa Przyjaciół Nauk, 2005, $223 \mathrm{f}$.

10 Wolfgang Jacobmeyer, Das deutsche Schulgeschichtsbuch 1700-1945. Die erste Epoche seiner Gattungsgeschichte im Spiegel der Vorworte, Band 1, Münster, Berlin: LIT Verlag, 2011, 10.

11 Wolfgang Jacobmeyer, "Niemiecko-polskie rozmowy o podręcznikach szkolnych. Ich znaczenie i perspektywy« [Deutsch-polnische Schulbuchgespräche. Ihre Bedeutung und Perspektiven], in: Elżbieta Traba und Robert Traba, Tematy polsko-niemieckie. Historia, literatura, edukacja [Deutsch-polnische Themen. Geschichte, Literatur, Bildung], Olsztyn: Wspólnota Kulturowa Borussia, 1997, 193; Ewa Nasalska, Polsko-niemieckie dyskursy edukacyjne: lata 1949-1999 [Deutsch-polnische Bildungsdiskurse 1949-1999], Warschau: Scholar, 2004, 87f., 106-108. 
Erforschung von Kulturlandschaften dar, weil sie im Gegensatz zu vielen anderen historischen Publikationen reich bebildert sind.

Die identitätsbildenden Eigenschaften der Landschaft hatten großen Einfluss auf die Schulbücher. Dies ergibt sich aus Stephanie Zlochs Untersuchung, wie die Landschaft der preußischen Länder in den Schulgeschichtsbüchern Polens, Deutschlands, Litauens und Russlands dargestellt wird. Diese Landschaftsbeschreibungen zeigten je nach Standpunkt die Wildheit der preußischen Länder und die zivilisatorische oder aber die destruktive Tätigkeit des Deutschen Ordens. Sie hoben auch das Heldentum der Soldaten hervor, die während des Ersten Weltkriegs in diesen Regionen kämpften. Die Landschaftspräsentation und ihre Funktionen veränderten sich im Laufe der Zeit mit den politischen Bedürfnissen. ${ }^{12}$

Ausgehend von diesem Einfluss von Landschaft und Schulbüchern auf die Gesellschaft, gehe ich der Frage nach, ob und wie Kulturlandschaften in ausgewählten polnischen Schulgeschichtsbüchern heute dargestellt werden und welche Rolle ihnen dabei zukommt.

Kulturlandschaften werden unterschiedlich definiert. Für die Zwecke dieses Textes lege ich Definitionen zugrunde, die ein besseres Verständnis davon ermöglichen, welche Rolle Landschaften in Schulbüchern erfüllen. ${ }^{13}$ Die Landschaft (poln. krajobraz) als solche wird als Terminus in der Malerei synonym auch als paysage (poln. pejzaż, "Landschaftsbild «) bezeichnet. ${ }^{14}$ Die Kulturlandschaft hingegen wird hier so verstanden, wie sie nach Artikel 3, Punkt 14 des polnischen Gesetzes über den Schutz und die Pflege von Denkmälern bündig definiert ist, also als »ein durch menschliche Einwirkung historisch gestalteter Raum, der sowohl Produkte der Zivilisation als auch Naturelemente enthält. ${ }^{15}$ Die so verstandene Landschaft setzt sich demnach aus Bestandteilen der belebten und unbelebten Natur zusammen. Dazu gehört auch der Mensch selbst mit seinen Werkzeugen und den Effekten seiner Arbeit, zu denen wir Gebäude,

12 Izabela Lewandowska und Stefanie Zloch (Hg.), Ziemie pruskie w podręcznikach Polski, Niemiec, Litwy i Rosji. Porównawcza analiza regionalnych konstrukcji tożsamości w XX-XXI wieku [Die preußischen Länder in den Schulbüchern Polens, Deutschlands, Litauens und Russlands. Eine vergleichende Analyse regionaler Identitätskonstruktionen im 20. und 21. Jahrhundert], Olsztyn: Instytut Historii i Stosunków Międzynarodowych Uniwersytet Warmińsko-Mazurski, 2013, 231-256.

13 Mehr zu diesem Thema und Grundlagenliteratur bei Jessica Dubow, "Landscape«, in: Rob Kitchin und Nigel Thrift (Hg.), International Encyclopedia of Human Geography, Band 6, Oxford: Elsevier, 2009, 124-131; Steven Hoelscher, "Landscape Iconography«, in: ebd., 132-139; Karen M. Morin, »Landscape Perception«, in: ebd., 140-145; Frydryczak, »Krajobraz«, 195-199.

14 Frydryczak, »Krajobraz«, 209.

15 »Ustawa z dnia 23 lipca 2003 roku o ochronie zabytków i opiece nad zabytkami« [Gesetz vom 23. Juli 2003 über Schutz und Pflege von Denkmälern], in: Dziennik Ustaw [Gesetzblatt] 2003, Nr. 162, Pos. 1568. 
Städte, Verkehrswege und andere Formen der Infrastruktur zählen können, künstliche Wasserflächen, Gruben, landwirtschaftlich genutzte Felder u. ä. ${ }^{16}$ Kulturlandschaften sind aber auch Reservate und andere Naturenklaven. Sie sind als Kulturerbe ${ }^{17}$ anerkannt und existieren in dieser Form auch nur durch den Eingriff des Menschen.

Die Gestaltung der Landschaft durch aufeinanderfolgende Generationen bedeutet, dass sie sich ständig verändert. Mensch und Natur hinterlassen Spuren in der Landschaft, daher kann sie auch als Palimpsest gelesen werden ${ }^{18}$ : " [T] social-life-as-text metaphor is easily applicable to landscape because it too is a social and cultural production. $"{ }^{19}$ Ist Landschaft ein Text, dann ist ihre Deutung auch eine Art von Lektüre. ${ }^{20}$ Oder wie es bei der Stiftung des Fonds für Zusammenarbeit (Fundacja Funduszu Wspótpracy) heißt: "Die Landschaft ist wie ein Buch, in dem Geschichte und Gegenwart der Umgebung eingeschrieben sind. Dieses Buch enthält jedoch Buchstaben eines anderen Alphabets, andere Worte und Sätze. Die einen hat die Natur geschaffen [...], andere der Mensch [...], wieder andere beide gemeinsam. $\aleph^{21}$ Das Lesen symbolischer Landschaften kann jedoch Schwierigkeiten verursachen, denn mangelnde Vertrautheit mit der entsprechenden Kultur führt zu Entschlüsselungsproblemen.

16 Wiaczesław Andrejczuk, "Funkcje krajobrazu kulturowego" [Funktionen der Kulturlandschaft], in: Krajobraz a człowiek w czasie i przestrzeni [Landschaft und Mensch in Zeit und Raum]. Prace Komisji Krajobrazu Kulturowego [Arbeiten der Kommission für Kulturlandschaft] 20, Sosnowiec: Komisja Krajobrazu Kulturowego PTG, 2013, 69.

17 Jacek Purchla (Hg.), Raport o systemie ochrony dziedzictwa kulturowego w Polsce po roku 1989 [Bericht über das System des Kulturerbeschutzes in Polen seit 1989], Warschau: Narodowe Centrum Kultury, 2009, 47.

18 Frydryczak, »Krajobraz«.

19 Zit. nach James Kneale, Landscapes, Texts and Scriptural Imperialism, University of Sussex, 33, 1998, https://www.academia.edu/29796408/Landscape_as_text, zuletzt geprüft am 18. Juni 2019, 5.

20 Donald W. Meinig, »Reading the landscape: an appreciation of W. G. Hoskins and J. B. Jackson", in: Ders. (Hg.), The Interpretation of Ordinary Landscapes, Oxford u. a.: Oxford University Press, 1979, 195-244. May Theilgaard Watts schrieb bereits 1957, Landschaft sei wie ein Buch, ohne den Menschen zu erwähnen, doch schrieb sie über seine Einwirkung: May Theilgaard Watts, Reading the Landscape. An Adventure in Ecology, New York: Macmillan, 1957, VII. Jüngst über das Lesen der Landschaft Robert Traba, "Historia stosowana. Pamięć i krajobraz jako nośniki badań i edukacji historycznej« [Angewandte Geschichte. Erinnerung und Landschaft als Träger von historischer Forschung und Bildung], in: ders., Przeszłość $w$ teraźniejszości. Polskie spory o historię na początku XXI wieku [Die Vergangenheit in der Gegenwart. Polnische Auseinandersetzungen über Geschichte zu Beginn des 21. Jahrhunderts], Poznań: Wydawnictwo Poznańskie, 2009, 135-148; ders., Wschodniopruskość.

21 Marek Konopka, Ewa Pustoła-Kozłowska und Dorota Matyaszczyk (Hg.), Każde miejsce opowiada swoja historię, czyli rzecz o dziedzictwie wiejskim [Jeder Ort erzählt seine Geschichte, oder Vom dörflichen Erbe], Poznań: Fundacja Fundusz Współpracy, 2. Auflage 2001, 12. Siehe auch http://www.fundacjawspomaganiawsi.pl/ebook/kazde-miejsce-opowiada-swoja-historie/\#/1, zuletzt geprüft am 7. Dezember 2017. 
Bis 1989 hatten die Staatlichen Betriebe für Schulbuchverlage (Państwowe Zakłady Wydawnictw Szkolnych), dann umbenannt in die Schul- und Pädagogikverlage (Wydawnictwa Szkolne i Pedagogiczne), das Schulbuchmonopol in Polen und es gab jeweils nur ein vom Bildungsministerium bestätigtes einheitliches Lehrbuch. Infolge der Wende erschienen Schulbücher, die vom Ministerium für Nationale Bildung (und Sport) genehmigt werden mussten.

Im Lehrplan für das Fach Geschichte und Gesellschaft an Grundschulen von 1999 wie auch in den nachfolgenden Lehrplänen für Grundschulen von 2001 und 2002 wird auf Kulturlandschaften nicht direkt Bezug genommen. Indes finden sich in diesen Dokumenten gleichbleibende Formulierungen zu Regionalgeschichte, zu den unterschiedlichen natürlichen Bedingungen der verschiedenen Regionen Polens, zu natürlichen Ressourcen, zu lokalen Gegebenheiten am eigenen Wohnort sowie dazu, wie natürliche und soziokulturelle Faktoren das Leben in einem bestimmten Gebiet bestimmen. Auch die Vorgaben für die individuelle Lehrstoffgestaltung thematisieren dies im Rahmen von »ökologischer« und »regionaler Bildung«. Darüber hinaus ist von der Beziehung »zum natürlichen und kulturellen Umfeld « sowie von der Bewirtschaftung, den natürlichen und soziokulturellen Umweltfaktoren und der Landschaft der Wohnortumgebung die Rede.

In den Lehrplänen für das Fach Geschichte und Gesellschaft aus den Jahren 2008, 2012 und 2014 findet sich wesentlich weniger zu Kulturlandschaften. ${ }^{22}$ Schülerinnen und Schüler sollen bestimmte Regionen Polens auf der Karte zeigen und beschreiben, wobei auch Kulturlandschaften erwähnt werden können, ohne dass dies jedoch explizit erwähnt würde. ${ }^{23}$ Mit Kulturlandschaften

22 Historia i Społeczeństwo. Treści nauczania - wymagania szczegółowe [Geschichte und Gesellschaft. Lehrinhalte - detaillierte Anforderungen], Pkt. 3.2.

23 »Rozporządzenie Ministra Edukacji Narodowej z dnia 15 lutego 1999 r." [Verordnung des Ministers für Nationale Bildung vom 15. Februar 1999], in: Dziennik Ustaw 1999, Nr. 14, Pos. 129; »Rozporządzenie Ministra Edukacji Narodowej z dnia 21 maja 2001 r. w sprawie podstawy programowej wychowania przedszkolnego, kształcenia ogólnego $\mathrm{w}$ poszczególnych typach szkół oraz kształcenia w profilach w liceach profilowanych. Załącznik nr 2. Podstawa programowa kształcenia ogólnego dla szkół podstawowych i gimnazjów« [Verordnung des Ministers für Nationale Bildung vom 21. Mai 2001 zum Lehrplan für die Vorschulerziehung in bestimmten Schultypen sowie für die Bildung in Schwerpunkten in den profilierten Lyzeen. Anhang Nr. 2. Lehrplan für die Allgemeinbildung für Grundschulen und Gymnasien], in: Dziennik Ustaw 2001, Nr. 61, Pos. 625; »Rozporządzenie Ministra Edukacji Narodowej i Sportu z dnia 26 lutego 2002 r. w sprawie podstawy programowej wychowania przedszkolnego oraz kształcenia ogólnego w poszczególnych typach szkół« [Verordnung des Ministers für Nationale Bildung und Sport vom 26. Februar 2002 zum Lehrplan für die Vorschulerziehung sowie für die Allgemeinbildung in bestimmten Schultypen], in: Dziennik Ustaw 2002, Nr. 51, Pos. 458; Załącznik nr 2, "Podstawa programowa kształcenia ogólnego dla szkół podstawowych i gimnazjów« [Anhang Nr. 2, Lehrplan für die Allgemeinbildung in Grundschulen und Gymnasien]; »Rozporząazenie Ministra Edukacji Narodowej i Sportu z dnia 23 grudnia 2008 r. w sprawie podstawy programowej wychowania przedszkolnego oraz 
verbundene Themen finden sich dagegen in den Grundschullehrplänen für das Fach Natur. ${ }^{24}$

Im Lehrplan für Gymnasien und weiterführende Schulen von 1999 findet sich kein direkter Verweis auf Kulturlandschaften, ja nicht einmal auf Landschaften per se. Der entsprechende Passus im Lehrplan von 2001 für die Mittelschule verlangt, "den Ort des Menschen in der historischen Zeit, seine Beziehungen zur Natur, zur lokalen Gesellschaft, zum Vaterland, zum Kulturkreis, zu anderen Völkern und Religionen « zu erkunden. ${ }^{25}$ In den Lyzeen mit bestimmten Fachschwerpunkten wurde der Begriff der $»$ Region« in das Curriculum eingeführt, unter anderem geht es um »historische Bedingungen der kulturellen Spezifik der Region« und »historische Denkmäler in der Region «. ${ }^{26}$

Erhebliche Änderungen führte der wesentlich präzisere Lehrplan von 2008 ein. Wie zuvor wird der Begriff »Kulturlandschaften« nirgends explizit ge-

kształcenia ogólnego w poszczególnych typach szkół« [Verordnung des Ministers für Nationale Bildung und Sport vom 23. Dezember 2008 zum Lehrplan für die Grundschulerziehung und die Allgemeinbildung in bestimmten Schultypen], in: Dziennik Ustaw 2008, Nr. 4, Pos. 17; Załącznik nr 2, „Podstawa programowa kształcenia ogólnego dla szkół podstawowych" [Anhang Nr. 2, Lehrplan für die Allgemeinbildung in Grundschulen]; »Rozporządzenie Ministra Edukacji Narodowej z dnia 27 sierpnia 2012 r. w sprawie podstawy programowej wychowania przedszkolnego oraz kształcenia ogólnego w poszczególnych typach szkół" [Verordnung des Ministers für Nationale Bildung vom 27. August 2012 zum Lehrplan für die Vorschulerziehung und die Allgemeinbildung in bestimmten Schultypen], in: Dziennik Ustaw 2012, Pos. 977, Załącznik nr 2, "Podstawa programowa kształcenia ogólnego dla szkół podstawowych" [Anhang Nr. 2, Lehrplan für die Allgemeinbildung an Grundschulen]; »Rozporządzenie Ministra Edukacji Narodowej z dnia 30 maja 2014 r. zmieniające rozporządzenie w sprawie podstawy programowej wychowania przedszkolnego oraz kształcenia ogólnego w poszczególnych typach szkól, Załącznik nr 2, Podstawa programowa kształcenia ogólnego dla szkół podstawowych« [Verordnung des Ministers für Nationale Bildung vom 30. Mai 2014 zur Änderung der Lehrplanverordnung für die Vorschulerziehung und die Allgemeinbildung in bestimmten Schultypen, Anhang Nr. 2, Lehrplan für die Allgemeinbildung in Grundschulen], in: Dziennik Ustaw 2014, Pos. 803.

24 In den Lehrplänen von 1999 und 2002 ist von der Landschaft der nächsten Umgebung die Rede, darunter von »Menschen und Kultur«, sowie von Ebenen-, Höhen- und Gebirgslandschaften, darunter von "natürlichen und vom Menschen gestaltete Landschaften.» Im Übrigen heißt es in den Verordnungen von 2008, 2012 und 2014 für das Fach Natur in der Grundschule, Pkte 4.1, 7.2 und 7.3: der Schüler »erkennt im Gelände natürliche (belebte und unbelebte) sowie anthropogene Elemente der Landschaft und weist auf die Abhängigkeiten zwischen ihnen hin." Auch sollen "ausgewählte Landschaften Polens« charakterisiert werden: »die Hochgebirge, die Kalkhöhe, die Tiefebene, die Seenlandschaft, das Küstengebiet, die großstädtische, industrielle und landwirtschaftliche Landschaft«; es sind »Beispiele für die Abhängigkeiten zwischen den Eigenschaften einer Landschaft und Formen menschlicher Tätigkeit zu benennen.« Verordnung des Ministers für Nationale Bildung vom 15. Februar 1999; Verordnungen des Ministers für Nationale Bildung und Sport vom 26. Februar 2002, Anhang Nr. 2; vom 23. Dezember 2008, Anhang Nr. 2; vom 27. August 2012, Anhang Nr. 2; vom 30. Mai 2014, Anhang Nr. 2.

25 Verordnung des Ministers für Nationale Bildung vom 21. Mai 2001, Anhang Nr. 2.

26 Ebd., Anhang Nr. 4, Lehrplan für die Allgemeinbildung an profilierten Lyzeen. 
braucht. ${ }^{27}$ Die Thematisierung von Kulturlandschaften in den Lehrplänen für das Fach Geografie behandelt der Text »Kulturlandschaften in polnischen Geografieschulbüchern" in diesem Band.

In Anlehnung an den Lehrplan von 2008 ist dieser Text in zwei Teile gegliedert. Im ersten werden Beispiele für Kulturlandschaften dargestellt, die sich direkt aus den im Lehrplan formulierten Anforderungen ergeben. Der umfangreichere zweite Teil bringt Beispiele dafür, wie andere Lehrplaninhalte mit Hilfe von Kulturlandschaften illustriert werden, obwohl der Begriff selbst nicht auftaucht. Die Themen, im Zusammenhang mit denen Kulturlandschaften thematisiert werden, sind sechs Aspekten zuzuordnen:

1. Architektur, Siedlungswesen, Städte

2. Erinnerung

3. Herrschaft

4. Wirtschaft

5. Krieg

6. Region

Es liegt in der Natur der Sache, dass die jeweilige Landschaft in vielen Fällen mehreren Aspekten zugeordnet werden kann (so lässt sich z. B. der Hafen von Gdynia unter dem Blickwinkel von Wirtschaft, Verkehr oder Architektur betrachten). Die Untersuchung stützt sich auf ausgewählte Schulbücher für Mittelschulen und weiterführende Schulen auf Basis- und erweitertem Niveau, die auf der Liste des Ministeriums für Nationale Bildung von 2014 aufgeführt sind.

\section{Beziehungen zwischen Mensch und Natur im Lehrplan für das Fach Geschichte für die Mittelschule (2012)}

2012 erfolgte durch eine neue Verordnung zum Schulwesen der Erlass eines neuen Lehrplans, der allerdings nicht substantiell von dem aus dem Jahr 2008

27 Verordnung des Ministers für Nationale Bildung vom 23. Dezember 2008, Anhang Nr. 4, »Podstawa programowa kształcenia ogólnego dla gimnazjów i szkół ponadgimnazjalnych, których ukończenie umożliwia uzyskanie świadectwa dojrzałości po zdaniu egzaminu maturalnego« [Curriculum für die Allgemeinbildung an Mittel- und Oberschulen, deren Beendigung die Erlangung des Reifezeugnisses nach Bestehen der Abiturprüfung ermöglicht], in: Dziennik Ustaw 2008, Nr. 4, Pos. 17. Im Lehrbuch für die weiterführenden Schulen auf erweitertem Niveau des OPERON-Verlags findet sich zwar eine Definition von Kultur, doch ist von Landschaft nicht die Rede. Siehe Roman Czaja, Małgorzata Strzelecka und Jan Wroniszewski, Historia 1, cz. 1. Zakres rozszerzony [Geschichte 1, Teil 1. Erweiterter Bereich], Ciekawi świata [Neugierig auf die Welt], Gdynia: OPERON, 2012, 16. 
abwich. ${ }^{28}$ Der Teil des Lehrplans von 2012 für die Mittelschule erwähnt die Beziehungen zwischen Umwelt und Mensch. Diese Thematik erscheint in den Punkten:

1.2. Vor- und Frühgeschichte: der Schüler »erklärt die Abhängigkeiten zwischen dem geografischen Umfeld und den Lebensbedingungen des Menschen «;

4.1. griechische Zivilisation: der Schüler »erklärt den Einfluss der geografischen Umwelt auf die Wirtschaft und die politische Entwicklung des alten Griechenland «;

31.2. Entwicklung der industriellen Zivilisation: der Schüler »nennt Beispiele für positive und negative Folgen der Industrialisierung, darunter für die natürliche Umwelt«; 36.1. Europa und die Welt um die Wende vom 19. zum 20. Jahrhundert: der Schüler "stellt die Folgen des technischen Umbruchs und des zivilisatorischen Fortschritts dar, darunter für die natürliche Umwelt. ${ }^{29}$

In den Schulbüchern für die Mittelschule sind Beispiele für diese Punkte zu finden. Die Rede ist also von Abhängigkeiten zwischen der geografischen Umwelt und den Lebensbedingungen der Menschen ab dem Moment, in denen sie ihr Nomadendasein aufgaben und sesshaft wurden, wodurch Landwirtschaft, Waldrodung usw. ihren Anfang nahmen. ${ }^{30}$ Als Beispiele dienen Mesopotamien und Ägypten, ${ }^{31}$ aber auch der Einfluss der natürlichen Umwelt auf die Entwicklung der Stadtstaaten im alten Griechenland wird thematisiert.

Verhältnismäßig viele Bezüge zur Landschaft gibt es in den Kapiteln über die Industrialisierung im 19. Jahrhundert, und zwar sowohl im Text als auch in den Abbildungen von Industrielandschaften (Fotos oder Gemälde, z. B. von William Turner). Ein Lehrbuch des Wissenschafts- und Schulbuchverlags PWN fordert die Schüler auf, charakteristische Eigenschaften einer Landschaftsfotografie zu benennen, welche die Krupp-Werke in Essen zeigt. ${ }^{32}$ Das regt an, über die Folgen menschlicher Aktivität und ihren Einfluss auf die Umgestaltung der Landschaft nachzudenken. Eine ähnliche Absicht verfolgt die Frage zu einer Abbildung, die in demselben Schulbuch die Entwicklung der Eisenbahnen in den USA zeigt.

28 Verordnung des Ministers für Nationale Bildung vom 27. August 2012, Anhang Nr. 4, »Podstawa programowa kształcenia ogólnego dla gimnazjów i szkół ponadgimnazjalnych, których ukończenie umożliwia uzyskanie świadectwa dojrzałości po zdaniu egzaminu maturalnego" [Lehrplan für Gymnasien und weiterführende Schulen, deren Abschluss den Erwerb des Reifezeugnisses nach dem Bestehen des Matura-Examens ermöglicht], in: Dziennik Ustaw 2012, Pos. 977. Da dieser Text 2016 verfasst wurde, geht er nicht auf die mit der Bildungsreform in Polen von 2017 einhergehenden Änderungen ein.

29 Verordnung des Ministers für Nationale Bildung vom 27. August 2012, Anhang Nr. 4.

30 Stanisława Roszak (Hg.), Śladami przeszłości. Podręcznik do historii dla klasy pierwszej gimnazjum [Auf den Spuren der Vergangenheit. Geschichtslehrbuch für die erste Klasse des Gymnasiums], Teil 1, Warschau: Nowa Era, 2012, 13.

31 Ebd., 29.

32 Jacek Chachaj und Janusz Drob, Historia. Wiek XIX i wielka wojna. Podręcznik do gimnazjum, klasa III [Geschichte. Das 19. Jahrhundert und der Große Krieg. Lehrbuch für das Gymnasium, Klasse III], Warschau: Wydawnictwo Szkolne PWN, 2011, 56. 
Dort sehen wir im Vordergrund eine Stadt oder eine Siedlung in den kolonisierten Gebieten der Vereinigten Staaten, am Rande eine Gruppe von Indianern auf Pferden und im Hintergrund die weite Landschaft. Ein Zug verlässt die Siedlung in Richtung Steppe, durch die die Eisenbahngleise verlaufen. Wichtig ist dabei die Komposition aus im Vordergrund gezeigter Zivilisation und wilder Natur, der Steppe, durch welche die Eisenbahn fährt. Die von den Schülern zu beantwortende Frage bezieht sich auf die Indianergruppe: »Was bedeutet für sie die Eroberung dieser Gebiete durch den ıweißen Mann $`$ ? ${ }^{33}$ Weiter kommentiert der Verfasser das Bild nicht.

Die Industrialisierung wird natürlich in vielen Geschichtsschulbüchern thematisiert. So schreiben die Autoren eines Buches aus dem Danziger Bildungsverlag (Gdańskie Wydawnictwo Oświatowe) über Arbeiterviertel in den Städten: "Solche Viertel sahen in ganz Europa ähnlich aus. $"{ }^{34}$ Und in einem Schulbuch des WSiP heißt es: "Ein Wald von Schornsteinen. [...] Noch lange danach löste dieser Anblick einen emotionalen Schauer aus, und man assoziierte ihn mit Entwicklung, Modernität, Fortschritt. [...] Alle schauten hoffnungsvoll auf die rauchenden Schornsteine. ${ }^{35}$ Abgebildet sind rauchende Fabrikschlote in Manchester. Und weiter in demselben Schulbuch: "Irgendwo am Horizont ist eine Grube zu sehen, im Vordergrund eine Menge müder Menschen, die nach der Arbeit nach Hause gehen. ${ }^{36}$ Dieses Schulbuch zeigt das Zeitalter der Industrialisierung sehr plastisch und spricht das Vorstellungsvermögen der Schüler an. In einem anderen Lehrbuch aus demselben Verlag finden wir ein ähnliches Narrativ: "In der Epoche des Eisens, des Dampfes und der Kohle [...] drang die Industrielandschaft in das dörfliche Umfeld ein. ${ }^{37}$ Hier werden also faktisch Kulturlandschaften beschrieben, ohne dass der Begriff benutzt wird.

Hervorzuheben ist die didaktische Methode von WSiP in der Rubrik »Was uns aus diesen Jahren geblieben ist«: »Es genügt, auf die Landschaft unserer Städte zu schauen, um zu sehen, wie viel von der industriellen Fabrikbebauung in Łódź, Żyrardów oder Katowice geblieben ist. Heute sind die alten Fabrikbauten oft zu Wohnungen oder Geschäftsräumen mit hohem Standard umgebaut. ${ }^{38}$ Hier wird

33 Ebd., 93.

34 Tomasz Małkowski und Jacek Rześniowiecki, Podróże w czasie. Historia. Podręcznik do gimnazjum, III [Zeitreisen. Geschichte. Lehrbuch für das Gymnasium, III], Gdańsk: Gdańskie Wydawnictwo Oświatowe, 2011, 125.

35 Grzegorz Kucharczyk, Paweł Milcarek und Marek Robak, Przez tysiąclecia i wieki. Historia. Gimnazjum. Podręcznik. Klasa 3 [Durch Jahrtausende und Jahrhunderte. Geschichte. Gymnasium. Lehrbuch. Klasse 3], Warschau: WSiP, 3. Auflage 2014, 79.

36 Ebd., 85.

37 Krzysztof Kowalewski, Igor Kąkolewski und Anita Plumińska-Mieloch, Bliżej historii. Gimnazjum. Podręcznik. Klasa 3 [Der Geschichte näher. Gymnasium. Lehrbuch. Klasse 3], Warschau: WSiP, 5. Auflage 2010, 60.

38 Ebd., 93. 
also die Lehreinheit resümiert und versucht, den Schülerinnen und Schülern die Präsenz und Kontinuität der Vergangenheit bis in die Gegenwart bewusst zu machen, indem der Fortbestand und die Adaption alter Kulturlandschaften angesprochen werden, die durch eine teilweise erhaltene Architektur noch immer lesbar sind.

\section{Beziehungen zwischen Mensch und Natur im Lehrplan für das Fach Geschichte im Lyzeum $^{39}$ (2012)}

Im Lehrplan für die weiterführenden Schulen auf Grundniveau steht nichts über die Beziehungen zwischen Mensch und Natur. Auf erweitertem Niveau findet sich hingegen faktisch eine Wiederholung des Stoffes, der in der Mittelschule zur Antike und zum 19. Jahrhundert vorgesehen ist:

\section{Altertum:}

1.1. Zivilisationen des Nahen und Fernen Ostens: der Schüler: "charakterisiert die geografischen Bedingungen der Entwicklung der Zivilisationen im Nahen und Fernen Osten«;

2.1. Gesellschaft, Politik und Kultur des antiken Griechenland: der Schüler: »charakterisiert die geografischen Bedingungen der griechischen Zivilisation«;

19. Jahrhundert:

2.3. Europa und die Vereinigten Staaten in der Epoche der Industriellen Revolution: der Schüler: »bewertet die wirtschaftlichen, sozialen, kulturellen und ökologischen Folgen der Industriellen Revolution. ${ }^{40}$

Ein Beispiel für ein Schulbuch, das diese Vorgaben erfüllt, stammt aus dem Verlagshaus OPERON. Das Lehrwerk spricht vom Einfluss geografischer Bedingungen auf die Entwicklung der Zivilisation im Zweistromland und von der ausgedehnten Küstenlinie in Griechenland, die den Bau von Häfen begünstigte. ${ }^{41}$ Im einem Schulbuch von Nowa Era findet sich eine Beobachtung zur Industriellen Revolution in Großbritannien: »[...] die bedeutendsten Veränderungen in

39 Anmerkung der Redaktion zum Schultyp Lyzeum: Dieser im polnischen Schulsystem fest etablierte Typ einer weiterführenden Oberschule wurde bereits 2002/2003 einer Reform unterzogen, die eine naturwissenschaftlich ausgerichtete Profilierung dieser allgemeinbildenden Schule mit Abitur-Abschluss anstrebte: So wurde das sogenannte "profilierte Lyzeum" (liceum profilowane) auf erweitertem Niveau mit 15 sogenannten Profilen (etwa Mechatronik, Informatik, Ökonomie) neu geschaffen. Das Lyzeum auf Grundniveau bleibt als Schultyp ebenfalls bestehen; seine Ausrichtung ist geisteswissenschaftlich und zielt auf eine breite Allgemeinbildung ab.

40 Verordnung des Ministers für Nationale Bildung vom 27. August 2012, Anhang 4.

41 Roman Czaja, Małgorzata Strzelecka und Jan Wroniszewski, Historia 1, cz. 1. Zakres rozszerzony. Ciekawi świata [Geschichte 1, Teil 1. Erweiterter Bereich. Neugierig auf die Welt], Gdynia: OPERON, 2012, 40f., $75 \mathrm{f}$. 
der Stadtlandschaft [von Birmingham] traten mit der Industriellen Revolution ein. « ${ }^{42}$ Als wichtiges Thema wird bei der Erörterung der Industrialisierung im 19. und 20. Jahrhundert die Zerstörung der natürlichen Umwelt angesprochen. Dementsprechend sind hier Abbildungen von rauchenden Schornsteinen und von in Gewässer abgeleiteten schädlichen Substanzen zu finden.

\section{Anknüpfungen an den Lehrplan und implizite Thematisierung von Kulturlandschaften}

Die weitere Behandlung von Kulturlandschaften in Lehrbüchern ist nach den bereits erwähnten Aspekten geordnet.

\section{Architektur, Siedlungswesen, Städte}

Ein mit Kulturlandschaften verbundenes Motiv sind in den Schulbüchern reproduzierte, oft aus der Romantik stammende Landschaftsbilder, z. B. Werke von William Turner. Manchmal dienen diese Bilder dazu, ein bestimmtes Thema zu illustrieren. Die Abbildungen zeigen Architektur entweder als Hauptelement der Bildkomposition oder als Hintergrund und veranschaulichen die Lebensbedingungen im behandelten Zeitraum ebenso wie die architektonischen Stilrichtungen. Neben Abbildungen von Burgen, Palästen oder dörflichen Bauten finden sich insbesondere Beispiele städtischer Architektur.

Die Geschichte des Siedlungswesens wird in allen untersuchten Schulbüchern umfassend behandelt. Die Entwicklung der Stadt von ihren Anfängen bis hin zu den urbanen Agglomerationen der Gegenwart wird mit Stadtplänen, Zeichnungen, Bildern und Fotografien vermittelt.

Das antike Siedlungswesen wird durch Abbildungen von städtischen, oft römischen Bauten präsentiert. In einem der untersuchten Schulbücher heißt es, das Forum Romanum sei auf trockengelegten Sümpfen erbaut worden, ${ }^{43}$ auch wenn der Hinweis fehlt, dass es sich hier um ein gutes Beispiel dafür handelt, wie Natur durch die Zivilisation verwandelt wird. Auch das mittelalterliche Siedlungswesen wird umfassend behandelt. Ein bei WSiP erschienes Lehrwerk betont, Besiedlung und Rodung seien der wichtigste Faktor in der wirtschaftlichen

42 Paweł Klint und Piotr Galik, Zrozumieć przeszłość. Dzieje nowożytne. Podręcznik dla liceum ogólnokształcącego i technikum. Zakres rozszerzony, cz. 2 [Vergangenheit verstehen. Geschichte der Neuzeit. Lehrbuch für das allgemeinbildende Lyzeum und das Technikum], Warschau: Nowa Era, 2014, 316.

43 Czaja, Strzelecka und Wroniszewski, Historia 1, 167. 
Entwicklung des Mittelalters gewesen, und die europäische Landschaft Europa habe sich dadurch für immer verändert. ${ }^{44}$

Ein im Lehrplan vorgegebenes wichtiges Thema der mittelalterlichen Geschichte Polens ist die Gründung von Städten nach deutschem Recht. Diese Gründungen waren durch Stadtmauern und ein regelmäßiges Straßennetz gekennzeichnet; die Schulbücher äußern sich allerdings nicht explizit dazu, wie sie die Landschaft veränderten. Ein Schulbuch von WSiP für die Mittelschule zitiert jedoch einen Chronisten des 11. Jahrhunderts mit den poetischen Worten, das Land habe einen "weißen Mantel aus Kirchen « angeleg $\mathrm{t}^{45}$ - ein klarer und positiv konnotierter Verweis auf die Veränderung der Landschaft durch menschliche Hand.

Das Thema "Stadt" wird anhand eines Plans des mittelalterlichen Krakau präsentiert. In der Rubrik "Die Vergangenheit in der Gegenwart" wird die Kontinuität historischer Landschaften in der Gegenwart betont. ${ }^{46}$ Der Verlag Nowa Era verwendet zu ähnlichen Zwecken Luftaufnahmen. Ein Schulbuch für die Mittelschule bringt ein Bild des Warschauer Łazienki-Parks, dessen königliche Residenz sich inmitten von Parkbäumen befindet. ${ }^{47}$ Ein anderes Gymnasiallehrbuch desselben Verlags stellt das Gemälde »Die Krakauer Vorstadt in Warschau vom Nowy Świat aus gesehen" von Bernardo Bellotto, genannt Canaletto, einer modernen Aufnahme desselben Ortes gegenüber. Diese Abbildungen können eine Diskussion dazu anregen, wie sich die Warschauer Stadtlandschaft entwickelt hat. Wie die Bildunterschrift erklärt, erleichterten Canalettos Gemälde Warschaus Wiederaufbau nach dem Zweiten Weltkrieg. Nicht erwähnt wird, dass damit in modifizierter Form eine Stadtlandschaft des 18. Jahrhunderts wiederhergestellt wurde.

Der städtische Raum wird in der neueren Forschung als ein Palimpsest gesehen. ${ }^{48} \mathrm{Er}$ ist demnach ein vielfach überschriebener Text, in dem sich die politische oder militärische Geschichte einer Stadt widerspiegelt, wie sie sich in Zerstörungen und Umbauten ebenso wie in neuen amtlichen Gebäuden und architektonischen Stilrichtungen niederschlug. Die Darstellung einer Kulturlandschaft eines städtischen Zentrums findet sich auf einer Fotografie in einem

44 Krzysztof Kowalewski, Igor Kąkolewski und Anita Plumińska-Mieloch, Bliżej historii. Gimnazjum. Podręcznik. Klasa 1 [Der Geschichte näher. Gymnasium. Lehrbuch. Klasse 1], Warschau: WSiP, 4. Auflage 2014, $206 \mathrm{f}$.

45 Ebd., 213.

46 Ebd., 226, 264.

47 Stanisław Roszak und Anna Łaszkiewicz, Śladami przeszłości. Podręcznik dla klasy trzeciej gimnazjum [Spuren der Vergangenheit. Lehrbuch für die dritte Klasse des Gymnasiums], Warschau: Nowa Era, 2011, 39.

48 Magdalena Saryusz-Wolska, Spotkania czasu z miejscem. Studia o pamięci $i$ miastach [Treffen von Zeit und Ort. Studien zu Erinnerung und Städten], Warschau: Wydawnictwa Uniwersytetu Warszawskiego, 2011, 181. 
Schulbuch von Nowa Era, ohne dass diese Tatsache jedoch thematisiert würde. Das Foto zeigt die Posener Proteste vom Juni $1956 .{ }^{49}$ Hier wird die Chance vergeben, auf das Kaiserschloss aus wilhelminischer Zeit im Hintergrund der Proteste hinzuweisen. Ein solcher Hinweis hätte einen breiteren Kontext der Geschichte Polens herstellen können und die Möglichkeit eröffnet, durch die menschlichen Spuren in einer Kulturlandschaft andere historische Schichten der als Palimpsest gedeuteten Landschaft zu erforschen.

\section{Erinnerung}

Landschaft ist auch für die seit den 1990er Jahren boomende Erinnerungsforschung ein wichtiges Thema. "Alle Geschichte hat einen Ort«, so Karl Schlögel. ${ }^{50}$ Für Jan Assmann spielt der Raum für die Erinnerung geradewegs eine »Hauptrolle«. ${ }^{51}$ In Raum und Landschaft stehen Denkmäler, denkmalgeschützte Bauten und Erinnerungsorte in einem besonderen Verhältnis zur Erinnerung. ${ }^{52}$ An dieser Stelle werden »Erinnerungsorte« im Gegensatz zu Pierre Noras Definiti$\mathrm{on}^{53}$ im engeren topografischen Sinne verstanden. Darüber hinaus besteht eine enge Verbindung zwischen Erinnerung und Herrschaft, die u.a. mit Hilfe von Landschaft und Lehrbüchern versucht, auf die Bürger einzuwirken. Landschaften spiegeln daher die Vergangenheit nicht nur wider, sondern formen ihrerseits auch Erinnerung und Zukunft. Sławomir Kapralski schrieb über den Raum:

Er ist ein Modell der Erinnerung, denn er repräsentiert die Vergangenheit, indem er getarnte Botschaften früherer Ereignisse und Informationen bewahrt, wie die Menschen sich zu den Ereignissen verhielten, die den Raum gestalteten. Andererseits können wir den Raum als Modell für Erinnerung behandeln, als Werkzeug, das unsere Erinnerung und unseren Umgang mit der Vergangenheit formt $[\ldots] .^{54}$

In Schulbüchern sind viele Motive zum Thema Erinnerungskultur zu finden. Architektur ist besonders erinnerungsträchtig und prägend für Kulturlandschaften. Der bekannte italienische Architekt Renzo Piano bemerkt dazu: »[Die

49 Stanisław Roszak, Poznać przeszłość. Wiek XX. Podręcznik do historii dla szkół ponadgimnazjalnych [Die Vergangenheit kennenlernen. 20. Jahrhundert. Geschichtslehrbuch für weiterführende Schulen], Warschau: Nowa Era, 2012, 261.

50 Schlögel, Im Raume, 71.

51 Jan Assmann, Das kulturelle Gedächtnis, $59 f$.

52 Frydryczak, »Krajobraz«, 198.

53 Pierre Nora (Hg.), Les lieux de mémoire, 1-4, Paris: Gallimard, 1997-1998; deutsch: Pierre Nora (Hg.), Erinnerungsorte Frankreichs, München: Beck, 2005.

54 Sławomir Kapralski (Hg.), Pamięć, przestrzeń, tożsamość [Erinnerung, Raum, Identität], Warschau: Scholar, 2010, 40. 
Architektur] ist eine gesellschaftlich gefährliche Kunst, weil ihr alle ausgesetzt sind. ${ }^{55}$ Und Dolores Hayden schreibt:

Many cultures have also attempted to embed public memory in narrative elements of buildings, from imperial monuments in Augustan Rome to doctrinal sculptural programs for Gothic cathedrals. The importance of ordinary buildings for public memory has largely been ignored, although, like monumental architecture, common urban places like union halls, schools, and residences have the power to evoke visual, social memory. ${ }^{56}$

Weil Architektur öffentlich und massenhaft rezipiert wird, hat sie als Trägerin von Information und Erinnerung große Bedeutung, selbst wenn sie sich als Abbildung in einem Schulbuch wiederfindet. Beispiele für solche Abbildungen von für die kollektive Erinnerung bedeutsamen Architekturdenkmälern sind die Burgen in Malbork/Marienburg und Troki/Traken, der Papstpalast in Avignon, die Klagemauer, die Kaaba in Mekka oder das Krantor in Gdańsk/Danzig. ${ }^{57}$

Stadtlandschaften und Erinnerung hängen eng zusammen. Dolores Hayden bemerkt dazu: »Urban landscapes are storehouses for [...] social memories, because natural features such as hills or harbors, as well as streets, buildings, and patterns of settlement, frame the lives of many people and often outlast many lifetimes. ${ }^{58}$ Das gilt für die gesamte Stadtgeschichte. Dazu sagt Magdalena Saryusz-Wolska mit Blick auf die Zeit seit dem Wendejahr 1989, »die Stellung der Städte als Träger historischer Erinnerung « habe "massiv an Bedeutung gewonnen. $"{ }^{59}$ Die Lehrbücher bringen Bilder von Ereignissen innerhalb von Städten, z. B. vom Abriss der Berliner Mauer ${ }^{60}$, die wie zuvor der Mauerbau die Kulturlandschaft einschneidend veränderte.

Denkmäler sind ein wichtiger Träger der Erinnerung. In verschiedenen Sprachen zeugt bereits die Etymologie des Wortes von ihrer Funktionen des Gedenkens. Eine besondere Blütezeit der Denkmalkunst war das 19. Jahrhundert; Eric Hobsbawm spricht geradezu von der »Monumentomanie« dieser Zeit. Denkmäler waren eines der Mittel, um »erfundene Tradition « zu kreieren und Herrschaft zu legitimieren. Auch konnte man mit ihrer Hilfe die für die Ge-

55 Zitiert nach Bogdan Jałowiecki, Czytanie przestrzeni [Räume lesen], Krakau, Rzeszów, Zamość: Konsorcjum Akademickie, 2012, 36.

56 Dolores Hayden, The Power of Place: Urban Landscape as Public History, Cambridge, Mass.: MIT Press, 1996, $46 \mathrm{f}$.

57 Ryszard Kulesza und Krzysztof Kowalewski, Zrozumieć przeszłość..., cz. 1 [Die Vergangenheit verstehen..., Teil 1], Warschau: Nowa Era, 2013, 443, 497, 503, 538.

58 Hayden, Urban Landscape, 9.

59 Saryusz-Wolska, Spotkania, 175.

60 Andrzej Brzozowski und Grzegorz Szczepański, Ku wspótczesności. Dzieje najnowsze 1918-2006. Podręcznik do historii dla klasy I szkół ponadgimnazjalnych - zakres podstawowy [Hin zur Gegenwart. Neueste Geschichte 1918-2016. Geschichtslehrbuch für Klasse I weiterführender Schulen - Grundbereich], Warschau: STENTOR, 2012, 272. 
meinschaft wichtigen Werte propagieren. Und sie sollten Erinnerung an Personen und Ereignisse der Vergangenheit schaffen. Daher errichteten auch die Diktaturen des 20. Jahrhunderts sehr gerne Denkmäler. Weil sie die Staatsmacht unmittelbar widerspiegeln, werden solche Denkmäler nach einem Machtwechsel häufig geschleift. ${ }^{61}$ Der Moment der Zerstörung wie die Lücke, die das Denkmal hinterlässt, stellen eine Legitimation des Neuen und eine neue kollektive Erinnerung her.

Schulbücher bringen zahlreiche Abbildungen von Denkmälern, etwa von Herrscherdenkmälern oder Thriumphbögen, ohne jedoch ihre Bezüge zu Staatsmacht, Erinnerung oder Landschaft zu kommentieren. Ein gutes Beispiel ist das dem Fürsten Józef Poniatowski gesetzte, einem Reiterstandbild des römischen Kaisers Marcus Aurelius nachempfundene Denkmal des dänischen Bildhauers Bertel Thorvaldsen. Es hatte seit dem ersten Entwurf von 1829 eine verwickelte Geschichte und ist ein interessantes Beispiel dafür, wie an kulturelles Erbe angeknüpft wird, worauf ein Schulbuch von Nowa Era hinweist; ein Verweis auf Erinnerungspolitik fehlt allerdings. ${ }^{62}$ So wie in einem Lehrwerk von OPERON für die weiterführenden Schulen wird auch ein Denkmal für die Opfer des Ersten Weltkriegs von Ernst Barlach gezeigt. ${ }^{63}$ Denkmäler dieser Art wurden nach dem Ersten Weltkrieg an sehr vielen Orten aufgestellt und leisteten einen wichtigen Beitrag zur Schaffung von Identität und kollektiver Erinnerung. Diese Deutungsebene wird in den Schulbüchern nicht thematisiert. Ein extremes Beispiel hierfür ist ein Schulbuch für die Mittelschule aus dem OPERON-Verlag, in dem das von Korczak Ziółkowski konzipierte Crazy Horse Memorial in den Black Hills des Bundesstaates South Dakota, USA, abgebildet ist. ${ }^{64}$ Obwohl dieses Denkmal, das aus einem Berg herausgearbeitet wird, einen besonders heftigen Eingriff in die Natur darstellt und eine politische Botschaft transportiert, wird das Thema "Landschaft « nicht angesprochen.

Wesentliche landschaftliche Träger von Erinnerung sind auch Friedhöfe und Gräber. Ob als ausgedehnte Nekropolen oder einsame Gräber formen sie den Raum über den spezifischen Ort hinaus. Sie haben große kulturelle Bedeutung und werden daher wahrgenommen "als eine Form der Kulturlandschaft, die von Grabmalen, Pflanzenbewuchs und Umzäunungen bestimmt ist. Friedhöfe entwickeln sich langsam wie Gärten der Erinnerung [...]. « ${ }^{65}$ Sie dienten seit jeher als Orte der Bestattung und der Erinnerung, später inspirierten sie die Romantiker. Seit dem ausgehenden 19. Jahrhundert wurden sie auch zu wichtigen nationalen

61 Bałus, Pomnik, $387 \mathrm{f}$.

62 Kulesza und Kowalewski, Zrozumieć przeszłość, 233.

63 Burda u. a., Historia najnowsza, cz. 1, 10.

64 Janusz Ustrzycki, Historia 3. Podręcznik dla gimnazjum [Geschichte 3. Lehrbuch für das Gymnasium], Gdynia: Wydawnictwo Pedagogiczne OPERON, 2010, 89.

65 Czapliński u. a., Cmentarz, 83. 
Symbolen. Besonders im 20. Jahrhundert erlangten Soldatenfriedhöfe und Grabmale des Unbekannten Soldaten zentrale Bedeutung. Folter-, Hinrichtungs- und Vernichtungsstätten sind Friedhöfe besonderer Art, darunter die Denkmäler für die Opfer nationalsozialistischer oder sowjetischer Verbrechen. Die Schulbücher bringen nur wenige Abbildungen von Friedhöfen. Hingegen gibt es Bilder von Auschwitz und Katyń und in einem Schulbuch von WSiP sind auf derselben Seite ein christlicher und ein muslimischer Friedhof im ehemaligen Jugoslawien abgebildet. ${ }^{66} \mathrm{Im}$ selben Schulbuch findet sich auch ein besonders interessantes Beispiel mit Bezug zu den stalinistischen Lagern. Es werden katholische und orthodoxe Kreuze im Schnee gezeigt, die Bildunterschrift lautet: »[...] vom System der stalinistischen Lager ist heute nicht viel geblieben. Manchmal sind verwahrloste Friedhöfe oder verfallende Reste von Lagerbauten die einzigen Andenken daran. ${ }^{67}$

Ein anderer Träger der Erinnerung sind auch die häufig in Geschichtsbüchern abgebildeten Ruinen. Dies gilt besonders für das Altertum. Ruinen waren oft eine Inspiration für die Maler der Romantik, die in ihnen eine Allegorie für Vergänglichkeit und Tod sahen. So präsentiert ein Schulbuchs von OPERON für die weiterführenden Schulen auf dem erweiterten Niveau die Ruinen des Forum Romanum und fragt: "Welche Spuren antiker Größe sind an diesem Ort noch immer sichtbar? ${ }^{68}$ Andererseits werden auch Ruinen neueren Ursprungs abgebildet, u. a. die Zerstörungen des Zweiten Weltkriegs - wobei diese Spuren der jüngeren Vergangenheit mitnichten Erinnerungen an vergangene Größe, sondern vielmehr an vergangene Schrecken wecken.

\section{Herrschaft}

Denkmäler und Landschaften mit ihrer Bedeutung für Identitätsbildung und Erinnerungskultur sind häufig Gegenstand staatlicher Erinnerungspolitik. ${ }^{69}$ Dazu sagt Jan Assmann, die Herrschaft sei »ein starkes Inzentiv für Erinnerung «. ${ }^{70}$ Bestimmte Inhalte lassen sich mit Hilfe von Landschaft vermitteln oder sogar aufzwingen. ${ }^{71}$ In den Schulbüchern finden sich Beispiele, wie das Thema

66 Rafał Dolecki u. a., Po prostu Historia. Szkoly ponadgimnazjalne. Zakres podstawowy [Einfach Geschichte. Weiterführende Schulen. Basisbereich], Warschau: WSiP, 2. Auflage 2012, 305.

67 Ebd., 101.

68 Czaja, Strzelecka und Wroniszewski, Historia 1, cz. 1, 167.

69 Bałus, Pomnik, $387 \mathrm{f}$.

70 Assmann, Das kulturelle Gedächtnis, 70.

71 Florian Plit, Krajobraz kulturowy - czym jest? [Kulturlandschaft - was ist das?], Warschau: Uniwersytet Warszawski, Wydział Geografii, 2011, 54, 56. 
Landschaft von Machthabern genutzt wird, ohne dass diese Aneignung jedoch analysiert würde. Beispielsweise ist von römischen Bauwerken die Rede, die in eroberten Territorien errichtet wurden. ${ }^{72}$ Ein gutes Beispiel ist auch die Kolonialarchitektur. Ein Lehrbuch zeigt die Kathedrale von Mexiko-Stadt mit der Bildunterschrift: "Die Kathedrale in Mexiko-Stadt ist eines der hervorragendsten Beispiele für die Kolonialarchitektur. Ihr Bau wurde im 16. Jahrhundert begonnen und erst Anfang des 19. Jahrhunderts abgeschlossen. Der Architekt orientierte sich an gotischen Kirchenbauten in Spanien. ${ }^{73}$ Für den Bau seien Spolien aus Heiligtümern der Azteken verwendet worden, die vorher an diesem Ort gestanden hatten - ein Symbol für die Unterwerfung des Gebietes und seiner Bevölkerung durch Spanien und die katholische Kirche. Es handelt sich also um ein Beispiel für die Aneignung einer Kulturlandschaft und die Ausübung von Herrschaft durch diese Landschaft. In ähnlicher Weise präsentiert Nowa Era ein Bild der peruanischen Stadt Cuzco, zu dem es heißt: »[...] erhalten haben sich nicht nur Heiligtümer und von den Kolonisatoren errichtete Paläste, sondern auch Bauwerke der Inkas. ${ }^{74}$ Die Mischung der beiden Kulturen zeugt somit unausgesprochen vom Reichtum und von der Differenzierung der Kulturlandschaft dieser Stadt.

Der Einfluss neuer Herrschaft auf die Kulturlandschaft lässt sich am Falle Polens in der Teilungszeit beobachten. ${ }^{75}$ Ein Schulbuch aus dem Verlag Nowa Era nennt russischsprachige Inschriften im öffentlichen Raum des russländischen Teilgebiets als Beispiel für die Russifizierung der Stadtlandschaft. ${ }^{76}$ Ähnlich kommentiert wird eine Abbildung in dem Schulbuch des Gdańskie Wydawnictwo Oświatowe zum Umbau des Palais Staszic im byzantinischen Stil. ${ }^{77}$

Eine gute Illustration des Einflusses der Herrschenden auf Kulturlandschaft ist ein Bild von der Umgestaltung von Paris durch Georges-Eugène Haussmann. In einem Schulbuch von PWN mit einem Bild des modernen Paris mit seinen breiten, von Baron Haussmann gezogenen Straßen ist von einem Umbau mit dem Ziel die Rede, den Anforderungen des gewachsenen Verkehrs zu genügen,

72 Czaja, Strzelecka und Wroniszewski, Historia 1, cz. 1, 168.

73 Małkowski und Rześniowiecki, Podróże w czasie, 139.

74 Klint und Galik, Zrozumieć przeszłość, 34.

75 Piotr Paszkiewicz, Pod berłem Romanowów. Sztuka rosyjska w Warszawie, 1815-1915 [Unter dem Zepter der Romanows. Russische Kunst in Warschau 1815-1915], Warschau: Instytut Sztuki, Polska Akademia Nauk, 1991; Dariusz Konstantynow und Piotr Paszkiewicz (Hg.), Kultura i polityka. Wpływ polityki rusyfikacyjnej na kulturę zachodnich rubieży Imperium Rosyjskiego (1772-1915) [Kultur und Politik. Der Einfluss der Russifizierungspolitik auf die Kultur der westlichen Ränder des Russländischen Reiches (1772-1915)], Warschau: Instytut Sztuki Polskiej Akademii Nauk, 1994.

76 Roszak und Łaszkiewicz, Śladami przeszłości, 222.

77 Małkowski und Rześniowiecki, Podróże w czasie, 214. 
der aus der Stadt eine moderne Metropole machte. ${ }^{78}$ Das ist freilich eine grobe Vereinfachung, denn dieser Umbau war nicht zuletzt ein ideologisches Projekt und sollte auch dazu führen, Unruhen in der Hauptstadt leichter bekämpfen zu können. ${ }^{79}$

Die Abbildung des Tempels von Abu Simbel in einem Schulbuch des Verlags OPERON ist ein ausgezeichnetes Beispiel für alles hier bisher Ausgeführte. ${ }^{80}$ Die Bildunterschrift teilt mit, dass das Heiligtum des Gottes Amon Ra auf Befehl des Pharaos Ramses II. im 13. Jh. v. Chr. in Niedernubien entstand. Als die ägyptische Regierung in den 1960er Jahren die Entscheidung für den Bau des AssuanStaudamms traf, wurde der Tempel um 65 Meter flussaufwärts versetzt, damit er nicht überflutet wurde. Unter dem Gesichtspunkt der Kulturlandschaft ist der Tempel in vielfacher Hinsicht ein außergewöhnliches Objekt. Durch den Bau in den Berghang wurde die Landschaft stark verändert. Der Tempel manifestierte die Macht des Pharaos Ramses II., der gleich in vier zwanzig Meter hohen Monumentalstatuen dargestellt ist. Der Assuan-Staudamm seinerseits zeugte von der Modernisierung und Macht Ägyptens unter der Regierung Gamal Abdel Nassers. Der Damm veränderte die Kulturlandschaft der Region stark. Sein Bau erzwang die Verlegung zahlreicher Baudenkmäler, darunter des Tempels von Abu Simbel. Der neue Standort bedeutete weitere Veränderungen der Landschaft. Die Abbildung könnte also hervorragend zur Illustration des Themas Kulturlandschaft genutzt werden - doch wird den Lehrenden hierfür kein Material oder Text an die Hand gegeben.

\section{Wirtschaft}

Ein Bereich, in dem der Mensch seit prähistorischer Zeit auf seine natürliche Umgebung einwirkt, ist die Wirtschaft im weitesten Sinne des Wortes (u. a. durch die Landwirtschaft, die Schaffung von Verkehrswegen, die Industrie). Diese Zusammenhänge werden im Lehrplan leider nur einseitig und ausschließlich für das Altertum und das 19. Jahrhundert aufgezeigt. Dagegen sind in den Schulbüchern mehr Beispiele für diese Zusammenhänge zu finden.

Während im Lehrplan nur vom Einfluss des geografischen Milieus auf den Menschen die Rede ist, erläutert eine Passage aus einem Schulbuch von Nowa Era die Einwirkung des Menschen auf die Natur:

Die Griechen der Antike veränderten das natürliche Milieu ihrer Siedlungsgebiete stark. Durch ihre Aktivitäten verkleinerte sich die bewaldete Fläche bereits in der

78 Chachaj und Drob, Historia, 61.

79 Jałowiecki, Czytanie przestrzeni, 39.

80 Czaja, Strzelecka und Wroniszewski, Historia 1, 28. 
Antike erheblich. Wegen des Mangels an urbarem Land spielte die Ziegenzucht in Griechenland eine große Rolle, denn diese Tiere fraßen den Pflanzenbewuchs der Berghänge. Durch Abholzung, Jagd, Weiden von Rindern, Stadtgründungen und Trockenlegung von Sümpfen ging die Zahl wilder Vögel und Säugetiere zurück. ${ }^{81}$

Im selben Schulbuch findet sich eine unmittelbare Anknüpfung an die Veränderung von Landschaften infolge von in der Neuzeit einsetzender wirtschaftlicher Prozesse. Es betrachtet enclosures in England, durch die im 16. Jahrhundert Ackerland in Weiden umgewandelt wurde. Die Beschreibung dieses Vorgangs ist mit einer Fotografie mit diesem Kommentar illustriert: "Die Felder auf den britischen Inseln sind bis heute durch Stein- oder Sichtschutzmauern eingeteilt und umfriedet, wie sie in der Vergangenheit Schafweiden abgrenzten. ${ }^{82}$ Diese vor etwa 400 Jahren entstandene Kulturlandschaft ist also sehr dauerhaft.

Polnische Schulbücher räumen der Geschichte der Zweiten Polnischen Republik und ihren wirtschaftlichen Erfolgen viel Platz ein. Der Einfluss der Investitionen in die Industrie auf die Natur oder die Kulturlandschaft bleiben unerwähnt, doch in einem Lehrbuch von OPERON sind zwei Fotografien zu finden, die Gdynia vor und während des Baus des Hafens zeigen und somit visuell auf die Thematik verweisen. ${ }^{83}$

Die Entstehung einer Kulturlandschaft wird auch anhand von Beispielen aus der Geschichte der Sowjetunion gezeigt, wenn die Entwicklung der Industrie oder die Verschmutzung der Flüsse besprochen wird. Die Herausbildung einer Kulturlandschaft wird allerdings nicht diskutiert. Allerdings werden Ökologie und Umwelteinflüsse der modernen Industrie durchaus thematisiert. In einem Schulbuch von WSiP sind große Bilder von der Rodung des Tropenwaldes zu finden, der Kommentartext verweist auf die Umweltzerstörung. Dies geht über die Anforderungen des Lehrplans hinaus, in dem nur von den ökologischen Folgen der industriellen Revolution des 19. Jahrhunderts die Rede ist. ${ }^{84}$

Ein wesentliches Element von Kulturlandschaften sind Verkehrssysteme, worunter hier vor allem das Transportwesen von Bedeutung ist. Straßen werden in den Schulbüchern meistens kartografisch dargestellt, manchmal mit Bildern. Ausführlicher besprochen werden die Römerstraßen, Aquädukte und das Straßennetz in den römischen Städten, gewöhnlich mit Karten veranschaulicht. Daneben gibt es Rekonstruktionszeichnungen, die beispielsweise Straßen in einer antiken Landschaft zeigen. ${ }^{85}$ Besonders spannend ist das Thema der Verkehrsweise in Bezug auf den Eisenbahnbau in Polen.

81 Kulesza und Kowalewski, Zrozumieć przeszłość, 72.

82 Klint und Galik, Zrozumieć przeszłość, 313.

83 Burda u. a., Historia najnowsza, cz. 1, 69.

84 Dolecki u.a., Po prostu Historia, 313.

85 Roszak (Hg.), Śladami przeszłości, 125. 


\section{5. $\quad$ Krieg}

Als Hinterlassenschaft der früher allesbeherrschenden politischen Geschichte thematisieren polnische Schulbücher bis heute sehr stark die Kriege. Die Darstellung der Leiden des eigenen Volkes und die Beschreibung des Feindes dienen dem Aufbau nationaler Identität. Bilder zu Krieg, Militär, Waffen und Zerstörungen machen einen großen Teil der Schulbuchabbildungen aus. Vor allem die Zerstörungen durch die beiden Weltkriege werden dargestellt, wobei Zerstörungen und Leiden (und natürlich Veränderung der Kulturlandschaften) durch frühere Konflikte nicht thematisiert werden.

Folge der Kriege waren auch Grenzverschiebungen, durch die die autochthone Bevölkerung mit einer neu hinzuziehenden Bevölkerung konfrontiert wurde und die regionale Kultur und Kulturlandschaft mit der Kultur der Neuankömmlinge zusammenstieß. Dieses Thema wird meist mit Karten zur Veranschaulichung der Grenzveränderungen behandelt. ${ }^{86}$ Dagegen werden nur selten Spuren der früheren staatlichen Zugehörigkeit oder kulturelle Unterschiede erwähnt. Auf die Umsiedlungen in die sogenannten wiedergewonnenen Gebiete verweist ein Schulbuch von OPERON am Beispiel eines Propagandaplakats mit der Parole: "Nad Odrę! Po ziemię ojców i dobrobyt « (An die Oder! Ins Land der Väter, zum Wohlstand) ${ }^{87}$ Neben der Abbildung finden sich erschöpfende Erklärungen zu der Formulierung, welche die angebliche Wiedergewinnung des »Landes der Väter« bezeichnet. Nicht erklärt werden der »Wohlstand « und die Bildkomposition aus Bauernhütte und zerstörtem Anwesen, die der nach Westen ziehende Siedler hinter sich lässt, um dort, nahe der auf der Karte markierten Stadt Breslau/Wrocław, ein gemauertes Haus mit Landwirtschaft vorzufinden. Diese Propagandadarstellung verweist auf Unterschiede im Lebensniveau und eine hier gezielt zugespitzte Verschiedenheit der Kulturlandschaften.

\section{Region}

Bezüge zur Region sind in Schulgeschichtsbüchern selten anzutreffen. Ein Lehrwerk von OPERON für weiterführende Schulen fragt im Zusammenhang

86 Karl Schlögel verweist auf die Dauerhaftigkeit von mental maps, gegen die die Schule nach Grenzänderungen nur wenig auszurichten vermag: „So kann es sein, daß in den Schulen die Kinder schon nach den neuen Lehrbüchern und Atlanten unterrichtet werden, während die Elterngeneration noch immer mit der Karte im Kopf herumläuft, mit der sie selber großgeworden war. [...] Diese Kartenbilder im Kopf leben mit den Generationen.« Schlögel, Im Raume, 86.

87 Burda u.a., Historia najnowsza, cz. 2, 114. 
mit der Christianisierung, ob in der Umgebung der Schüler noch Baudenkmäler der Zisterzienser $\mathrm{zu}$ finden seien. ${ }^{88}$ In einem Lehrbuch für weiterführende Schulen wird Schülerinnern und Schülern im Kapitel über die Zweite Polnische Republik die Aufgabe gestellt zu überprüfen, in welchem Staat sich ihr jetziger Wohnort nach 1918 befand. ${ }^{89}$ Dieser spärliche Bezug zur Region mag daher rühren, dass Schulbuchautorinnen und Autoren eine zentralistische Perspektive einnehmen, damit die Lehrwerke im ganzen Land benutzt werden können. Das Fehlen regionaler Bezüge ist ein Manko der Schulbücher, weil sie so die kulturelle Differenzierung des Landes kaum berücksichtigen, die auch in den Kulturlandschaften zum Ausdruck kommt.

Einen interessanten Versuch zur Durchbrechung dieses Narrativs unternimmt das regional auf Ermland und Masuren ausgerichtete Lehrbuch Dziedzictwo ziem pruskich. Dzieje i kultura Warmii i Mazur. Podręcznik dla młodzieży (Das Erbe der preußischen Länder. Geschichte und Kultur des Ermlands und Masurens. Schulbuch für die Jugend). ${ }^{90}$ Das Buch richtet sich an Grundschulen, Gymnasien und weiterführende Schulen und behandelt Geschichte und Kultur des Ermlands und Masurens von der Urgeschichte bis zur Gegenwart. Auch wenn hier der Platz für eine ausführliche Beschreibung des Lehrwerks $^{91}$ fehlt, sei hervorgehoben, dass in diesem Schulbuch vielleicht erstmals der Begriff »Kulturlandschaft« vorkommt; so heißt es im Vorwort:

Echos der Vergangenheit hören wir in der Kulturlandschaft des Ermlands und Masurens auf Schritt und Tritt. Von der Präsenz der heidnischen Pruzzen zeugen Burgen, Werkzeuge, Geräte und steinerne Statuen pruzzischer Frauen; vom Deutschen Orden gotische Schlösser; von Polen und der polnischen nationalen Identität Kirchen und Bischofspalais; von der Größe der Adelsfamilien, die hier lebten, die Überreste von Palästen preußischer Junker; von den früheren Grenzen vergessene Grenzpfosten und Denkmäler; vom wirtschaftlichen Niveau Kanäle, Brücken, Industriebauten, Kasernen, Landwirtschaften und schließlich, von den Bewohnern selbst, Friedhöfe, Dokumente und Fotografien. ${ }^{92}$

Dieser Ausschnitt fasst die bisherigen Erwägungen über Kulturlandschaften in Schulgeschichtsbüchern sehr treffend zusammen. Leider bleibt das Narrativ in der Darstellung recht traditionell. Der Begriff »Kulturlandschaft« kommt jedoch

88 Czaja, Strzelecka und Wroniszewski, Historia 1, cz. 2, 278.

89 Burda u. a., Historia najnowsza, cz. 1, 19.

90 Izabela Lewandowska (Hg.), Dziedzictwo ziem pruskich. Dzieje i kultura Warmii i Mazur. Podręcznik dla młodzieży [Das Erbe der preußischen Länder. Geschichte und Kultur des Ermlands und Masurens. Schulbuch für die Jugend], Olsztyn: Pracownia Wydawnicza ElSe, 2012.

91 Vgl. die Rezension von Violetta Julkowska, Igor Kąkolewski und Robert Traba, "Jak dydaktyzować historię regionalną?« [Wie geht eine Didaktik der Regionalgeschichte?], in: Borussia 52 (2012), 178-192.

92 Lewandowska (Hg.), Dziedzictwo, 7. 
in Bildunterschriften und Textabschnitten zur Kultur vor. Dort finden sich viele Bezüge zu Kulturlandschaften im Sinne des Eingangszitats dieses Beitrags. Ein solcher Ansatz fehlt in den anderen untersuchten Lehrwerken.

\section{Schlussfolgerungen}

In den vorgestellten Schulbüchern aus der Liste des Ministeriums für Nationale Bildung ist von Kulturlandschaften nicht explizit die Rede. Teilweise ist dies dadurch zu erklären, dass der Lehrplan keine entsprechenden Vorgaben macht, was insofern nicht wundert, als »Kulturlandschaft« zwar ein sehr umfassender und interessanter Begriff zur Interpretation des Raums ist, aber auch zusätzliche didaktische Anforderungen stellt. Deshalb ging es in dieser Untersuchung auch nicht primär um Versäumnisse, sondern vielmehr um die Möglichkeiten einer auf den Begriff "Kulturlandschaften" zurückgreifenden Deutung von Schulbuchinhalten.

In den Lehrbüchern für Lyzeen auf erweitertem Niveau ist etwas weniger von Natur die Rede als in denjenigen für Gymnasien, trotzdem sind die jeweiligen Informationen sehr ähnlich. Wie die Lehrplananalyse zeigt, ist eine Thematisierung von Zusammenhängen zwischen Natur und menschlicher Aktivität lediglich in der Mittelschule und an den weiterführenden Schulen auf erweitertem Niveau vorgesehen.

In Lehrplan und Schulbüchern ist vom Einfluss des natürlichen Milieus auf den Menschen die Rede oder umgekehrt von seiner Einwirkung auf die Umwelt, doch wird dies jeweils als einseitige Beziehung dargestellt, als gebe es keine Wechselwirkung. Im Lehrplan werden zudem nur Beispiele aus dem Altertum und der Industrialisierung des 19. Jahrhunderts genannt, daher finden wir entsprechende Erwähnungen in den Schulbüchern auch hauptsächlich in den Kapiteln über diese beiden Epochen oder in Abschnitten zu Wirtschaftsthemen.

Die obigen Beispiele zeigen jedoch, dass Kulturlandschaften in den Schulbüchern thematisiert werden. Dies geschieht jedoch kaum explizit, denn es scheint, dass sich die Autorinnen und Autoren des Konzepts mit seinen Möglichkeiten und seiner Problematik kaum bewusst sind. Die angeführten Beispiele werden somit vorwiegend als Illustration anderer Lehrplaninhalte genutzt. Weil aber der Begriff "Kulturlandschaft « nicht explizit genannt wird, brechen die Deutungen oftmals gerade an dem Punkt ab, an dem sich die Verbindungen zwischen Mensch, Natur und Kultur deutlich machen ließen. Eine explizite Aufnahme des Begriffs der Kulturlandschaften in den Lehrplan wäre die Voraussetzung, das Konzept didaktisch sinnvoll einzusetzen. Dies würde die Schüler als Rezipienten und zukünftige Mitschöpfer von Kulturlandschaften für das Phänomen sensibilisieren. 
Die Untersuchung hat nicht zuletzt gezeigt, mit welchen Schwächen die Nutzung von Ikonografie in Schulbüchern behaftet ist. Die Bilder werden nicht genügend erläutert, die dominierenden Themen sind Politik- und Militärgeschichte. Auch zu den Regionen und der kulturellen Binnendifferenzierung Polens gibt es zu wenig Informationen. So erfahren Schülerinnen und Schüler an Gymnasien und Lyzeen aus ihren Geschichtsbüchern nicht genug über die kulturellen Einflüsse, die die polnische Kultur - und damit auch die polnischen Kulturlandschaften - geprägt haben.

Ohne das entsprechende Vorwissen aber lässt sich eine Landschaft nicht »lesen«. Daher genügt es nicht, in den Schulbüchern Bilder einer Kulturlandschaft zu präsentieren; sie muss auch erklärt werden. Am Schwierigsten ist das Verständnis von Landschaften fremder Kulturen; aber auch Kulturlandschaften des eigenen Landes sind oft schwer zu entziffern, wenn diese von vergessenen oder marginalisierten sozialen, ethnischen oder nationalen Gruppen geschaffen wurden. Dass das Konzept der Kulturlandschaften im Lehrplan fehlt, ist eine verlorene Chance, denn der Ansatz bietet großes didaktisches Potential.

Aus dem Polnischen von Pascal Trees

\section{Literatur}

Andrejczuk, Wiaczesław [Andrejčuk, Vjačeslav Nikolaevič]. »Funkcje krajobrazu kulturowego" [Funktionen der Kulturlandschaft], in: Krajobraz a człowiek $w$ czasie $i$ przestrzeni [Landschaft und Mensch in Zeit und Raum], Prace Komisji Krajobrazu Kulturowego [Arbeiten der Kommission für Kulturlandschaft] 20, Wiaczesław Andrejczuk und Marek Jóźwiak (Hg.), Sosnowiec: Komisja Krajobrazu Kulturowego PTG, 2013.

Assmann, Jan. Das kulturelle Gedächtnis. Schrift, Erinnerung und politische Identität in frühen Hochkulturen, München: Beck, 3. Auflage 2000.

Brzozowski, Andrzej und Grzegorz Szczepański. Ku współczesności. Dzieje najnowsze 1918-2006. Podręcznik do historii dla klasy I szkół ponadgimnazjalnych - zakres podstawowy [Hin zur Gegenwart. Neueste Geschichte 1918-2016. Lehrbuch Geschichte], Warschau: STENTOR, 2012.

Burda, Bogumiła u. a. Historia najnowsza, cz. 2. Podręcznik dla szkót ponadgimnazjalnych. Zakres podstawowy [Neueste Geschichte, Teil 2. Lehrbuch für weiterführende Schulen. Basisbereich], Gdynia: OPERON, 2013.

Chachaj, Jacek und Janusz Drob. Historia. Wiek XIX $i$ wielka wojna. Podręcznik do gimnazjum, klasa III [Geschichte. Das 19. Jahrhundert und der Große Krieg. Lehrbuch für die Mittelschule, Klasse III], Warschau: Wydawnictwo Szkolne PWN, 2011.

Czaja, Roman, Małgorzata Strzelecka und Jan Wroniszewski. Historia 1, cz. 1. Zakres rozszerzony [Geschichte 1, Teil 1. Erweiterter Bereich]. Ciekawi świata [Neugierig auf die Welt], Gdynia: OPERON, 2012. 
Dolecki, Rafał u. a. Po prostu Historia. Szkoły ponadgimnazjalne. Zakres podstawowy [Einfach Geschichte. Weiterführende Schulen. Basisbereich], Warschau: WSiP, 2. Auflage 2012.

Dubow, Jessica. »Landscape«, in: International Encyclopedia of Human Geography, Band 6, Rob Kitchin und Nigel Thrift (Hg.), Oxford: Elsevier, 2009, 124-131.

Dziennik Ustaw [Gesetzblatt], 1991, Nr. 95.

Dziennik Ustaw [Gesetzblatt], 1999, Nr. 14.

Dziennik Ustaw [Gesetzblatt], 2001, Nr. 61.

Dziennik Ustaw [Gesetzblatt], 2002, Nr. 51.

Dziennik Ustaw [Gesetzblatt], 2003, Nr. 162.

Dziennik Ustaw [Gesetzblatt], 2008, Nr. 4.

Dziennik Ustaw [Gesetzblatt], 2012, Position 977.

Dziennik Ustaw [Gesetzblatt], 2014, Position 803.

Frydryczak, Beata. »Krajobraz« [Landschaft], in: Słownik terminologiczny sztuk pięknych [Terminologisches Wörterbuch der schönen Künste], Warschau: Wydawnictwo Naukowe PWN, 2006, 209.

Dies. "Krajobraz« [Landschaft], in: Modi Memorandi. Leksykon kultury pamięci [Modi memorandi. Lexikon der Erinnerungskultur], Magdalena Saryusz-Wolska und Robert Traba (Hg.), Warschau: Scholar, 2014, 195-199.

Grębecka, Wanda. »Problem ochrony rodzinnego krajobrazu a tożsamość narodowa« [Das Problem des Schutzes der heimatlichen Landschaft und die nationale Identität], in: Kwartalnik Historii Nauki i Techniki [Vierteljahrsschrift für Natur- und Technikgeschichte] 55, 3-4 (2010), 249-266.

Hayden, Dolores. The Power of Place: Urban Landscape as Public History, Cambridge, Mass.: MIT Press, 1996.

Hoelscher, Steven. "Landscape Iconography«, in: International Encyclopedia of Human Geography, Band 6, Rob Kitchin und Nigel Thrift (Hg.), Oxford: Elsevier, 2009, 132-139.

Jacobmeyer, Wolfgang. Das deutsche Schulgeschichtsbuch 1700-1945. Die erste Epoche seiner Gattungsgeschichte im Spiegel der Vorworte, Band 1, Münster/ Berlin: LIT Verlag, 2011.

Jałowiecki, Bogdan. Czytanie przestrzeni [Räume lesen], Kraków/Rzeszów/Zamość: Konsorcjum Akademickie, 2012.

Julkowska, Violetta, Igor Kąkolewski und Robert Traba. »Jak dydaktyzować historię regionalną?« [Wie geht eine Didaktik der Regionalgeschichte?], in: Borussia 52 (2012), 178-192.

Kapralski, Sławomir (Hg.). Pamięć, przestrzeń, tożsamość [Erinnerung, Raum, Identität], Warschau: Scholar, 2010.

Klint, Paweł und Piotr Galik. Zrozumieć przeszłość. Dzieje nowożytne. Podręcznik dla liceum ogólnokształcącego i technikum. Zakres rozszerzony, cz. 2 [Die Vergangenheit verstehen. Geschichte der Neuzeit. Lehrbuch für das allgemeinbildende Lyzeum und das Technikum], Warschau: Nowa Era, 2014.

Kneale, James. Landscapes, Texts and Scriptural Imperialism, University of Sussex, Research Paper 33, 1998, https://www.academia.edu/29796408/Landscape_as_text, zuletzt geprüft am 18. Juni 2019. 
Konopka, Marek, Ewa Pustoła-Kozłowska und Dorota Matyaszczyk (Hg.). Każde miejsce opowiada swoją historię, czyli rzecz o dziedzictwie wiejskim [Jeder Ort erzählt seine Geschichte oder Vom dörflichen Erbe], Poznań: Fundacja Fundusz Współpracy, 2. Auflage 2001.

Konstantynow, Dariusz und Piotr Paszkiewicz (Hg.). Kultura i polityka. Wplyw polityki rusyfikacyjnej na kulture zachodnich rubieży Imperium Rosyjskiego (1772-1915) [Kultur und Politik. Der Einfluss der Russifizierungspolitik auf die Kultur der westlichen Ränder des Russischen Reiches (1772-1915)], Warschau: Instytut Sztuki Polskiej Akademii Nauk, 1994.

Kowalewski, Krzysztof, Igor Kąkolewski und Anita Plumińska-Mieloch. Bliżej historii. Gimnazjum. Podręcznik. Klasa 3 [Der Geschichte näher. Gymnasium. Lehrbuch. Klasse 3], Warschau: WSiP, 5. Auflage 2010.

Dies. Bliżej historii. Gimnazjum. Podręcznik. Klasa 1 [Der Geschichte näher. Gymnasium. Lehrbuch. Klasse 1], Warschau: WSiP, 4. Auflage 2014.

Kucharczyk, Grzegorz, Paweł Milcarek und Marek Robak. Przez tysiąclecia i wieki. Historia. Gimnazjum. Podręcznik. Klasa 3 [Durch Jahrtausende und Jahrhunderte. Geschichte. Gymnasium. Lehrbuch. Klasse 3], Warschau: WSiP, 3. Auflage 2014.

Kulesza, Ryszard und Krzysztof Kowalewski. Zrozumieć przeszłość..., cz. 1 [Die Vergangenheit verstehen..., Teil 1], Warschau: Nowa Era, 2013.

Lewandowska, Izabela (Hg.). Dziedzictwo ziem pruskich. Dzieje i kultura Warmii i Mazur. Podręcznik dla młodzieży [Das Erbe der preußischen Länder. Geschichte und Kultur des Ermlands und Masurens. Schulbuch für die Jugend], Olsztyn: Pracownia Wydawnicza ElSe, 2012.

Lewandowska, Izabela und Stefanie Zloch (Hg.). Ziemie pruskie w podręcznikach Polski, Niemiec, Litwy i Rosji. Porównawcza analiza regionalnych konstrukcji tożsamości $w$ $X X-X X I$ wieku [Die preußischen Länder in den Schulbüchern Polens, Deutschlands, Litauens und Russlands. Eine vergleichende Analyse regionaler Identitätskonstruktionen im 20. und 21. Jahrhundert], Olsztyn: Instytut Historii i Stosunków Międzynarodowych Uniwersytet Warmińsko-Mazurski, 2013.

Małkowski, Tomasz und Jacek Rześniowiecki. Podróże w czasie. Historia. Podręcznik do gimnazjum III [Zeitreisen. Geschichte. Lehrbuch für das Gymnasium, III], Gdańsk: Gdańskie Wyd. Oświatowe, 2011.

Meinig, Donald W. »Reading the landscape: an appreciation of W. G. Hoskins and J. B. Jackson«, in: The interpretation of ordinary landscapes, ders. (Hg.), Oxford u. a.: Oxford University Press, 1979, 195-244.

Morin, Karen M. "Landscape Perception«, in: International Encyclopedia of Human Geography, Band 6, Rob Kitchin und Nigel Thrift (Hg.), Oxford: Elsevier, 2009, 140-145.

Nasalska, Ewa. Polsko-niemieckie dyskursy edukacyjne: lata 1949-1999 [Deutsch-polnische Bildungsdiskurse 1949-1999], Warschau: Scholar, 2004.

Nora, Pierre (Hg.). Les lieux de mémoire, 1-4, Paris: Gallimard, 1997-1998; dt. Ausgabe: Erinnerungsorte Frankreichs, München: Beck, 2005.

Paszkiewicz, Piotr. Pod berłem Romanowów. Sztuka rosyjska $w$ Warszawie, 1815-1915 [Unter dem Zepter der Romanows. Russische Kunst in Warschau 1815-1915], Warschau: Instytut Sztuki, Polska Akademia Nauk, 1991. 
Plit, Florian. Krajobraz kulturowy - czym jest? [Kulturlandschaft - was ist das?], Warschau: Uniwersytet Warszawski, Wydział Geografii, 2011.

Purchla, Jacek (Hg.). Raport o systemie ochrony dziedzictwa kulturowego w Polsce po roku 1989 [Bericht über das System des Kulturerbeschutzes in Polen seit 1989], Warschau: Narodowe Centrum Kultury, 2009.

Roszak, Stanisław. Poznać przeszłość. Wiek XX. Podręcznik do historii dla szkół ponadgimnazjalnych [Die Vergangenheit kennenlernen. 20. Jahrhundert. Geschichtslehrbuch für weiterführende Schulen], Warschau: Nowa Era, 2012.

Ders. (Hg.). Śladami przeszłości. Podręcznik do historii dla klasy pierwszej gimnazjum [Auf den Spuren der Vergangenheit. Geschichtslehrbuch für die erste Klasse des Gymnasiums], Teil 1, Warschau: Nowa Era, 2012.

Roszak, Stanisław und Anna Łaszkiewicz. Śladami przeszłości. Podręcznik dla klasy trzeciej gimnazjum [Auf den Spuren der Vergangenheit. Lehrbuch für die dritte Klasse des Gymnasiums], Warschau: Nowa Era, 2011.

Saryusz-Wolska, Magdalena. Spotkania czasu z miejscem. Studia o pamięci i miastach [Treffen von Zeit und Ort. Studien zu Städten und Erinnerung], Warschau: Wydawnictwa Uniwersytetu Warszawskiego, 2011.

Schama, Simon. Landscape and Memory, New York: Knopf, 1995.

Schlögel, Karl. Im Raume lesen wir die Zeit. Über Zivilisationsgeschichte und Geopolitik, München/ Wien: Hanser, 2003.

Traba, Robert. »Rozważania o magii miejsca i mitologizacji krajobrazu w Prusach Wschodnich" [Erwägungen über die Magie des Ortes und die Mythologisierung der Landschaft in Ostpreußen], in: Borussia 24/25 (2001), 41-66.

Ders. Wschodniopruskość. Tożsamość regionalna i narodowa $w$ kulturze politycznej Niemiec [Ostpreußentum. Regionale und nationale Identität in der politischen Kultur Deutschlands], Poznań u.a.: Wydawnictwo Poznańskiego Towarzystwa Przyjaciół Nauk, 2005; dt. Ausgabe: Ostpreußen - die Konstruktion einer deutschen Provinz. Eine Studie zur regionalen und nationalen Identität 1914-1933, Osnabrück: Fibre, 2010.

Ders. »Historia stosowana. Pamięć i krajobraz jako nośniki badań i edukacji historycznej « [Angewandte Geschichte. Erinnerung und Landschaft als Träger von historischer Forschung und Bildung], in: Przeszłość w teraźniejszości. Polskie spory o historię na początku XXI wieku [Die Vergangenheit in der Gegenwart. Polnische Auseinandersetzungen über Geschichte zu Beginn des 21. Jahrhunderts], ders. (Hg.), Poznań: Wydawnictwo Poznańskie, 2009, 135-148.

Ustrzycki, Janusz. Historia 3. Podręcznik dla gimnazjum [Geschichte 3. Lehrbuch für das Gymnasium], Gdynia: Wydawnictwo Pedagogiczne OPERON, 2010.

Watts, May Theilgaard. Reading the Landscape. An Adventure in Ecology, New York: Macmillan, 1957. 


\section{Kulturlandschaften in polnischen Geografieschulbüchern}

Bei unserer Untersuchung zur Darstellung von Kulturlandschaften in polnischen Geografieschulbüchern stießen wir auf dreierlei Schwierigkeiten. Die erste ergab sich aus der Vielzahl von Erdkundebüchern, mit denen seit dem Krieg gearbeitet wurde und die auch heute noch im Umlauf sind. Anfänglich verhielt sich dies noch anders. Einige Jahre nach dem Zweiten Weltkrieg wurde das Schulwesen zentralisiert und es gab nur einen obligatorischen Unterrichtsplan und ein Schulbuch pro Jahrgangsstufe. ${ }^{1}$ Alle Schulbücher erschienen bei Wydawnictwa Szkolne (Schulverlag; später Wydawnictwa Szkolne i Pedagogiczne, Schul- und Pädagogischer Verlag, kurz WSiP). Die empfohlene einheitliche Einteilung des Unterrichtsstoffes sorgte dafür, dass dasselbe Thema gleichzeitig in Schulen in ganz Polen besprochen wurde. 1989 kam es zur Liberalisierung. Am Anfang gab es nur wenige neue Schulbücher eher informeller Art. Erst nach der Reform des Bildungssystems 1998 und der Verabschiedung des »Curriculums für die Allgemeinbildung in den Grundschulen und Mittelschulen ${ }^{2}$ erschienen neue Schulbücher in größerer Zahl. Seitdem konnte es beliebig viele Unterrichtspläne und Schulbücher geben; es genügte, eine Genehmigung des Ministeriums für Nationale Bildung zu bekommen (2001-2006 Ministerium für Nationale Bildung und Sport, 2005-2006 für Nationale Bildung und Wissenschaft). Später wurden die Voraussetzungen für die Genehmigung verschärft. Die sehr allgemein gehaltenen Vorschriften des nächsten Lehrplans von $2002^{3}$ bewirkten, dass über zwanzig von Verlagen und Methodikzentren der Wojewodschaften eingereichte

1 Unterrichtspläne gaben den zu behandelnden Stoff und den genauen Ablauf des Unterrichts vor.

2 Beschluss des Ministeriums für Nationale Bildung vom 2. November 1998. Im darauffolgenden Jahr wurde das Curriculum für die Lyzeen beschlossen.

3 »Rozporządzenie Ministra Edukacji Narodowej i Sportu z dnia 26 lutego 2002 r. w sprawie podstawy programowej wychowania przedszkolnego oraz kształcenia ogólnego w poszczególnych typach szkół«, [Verordnung des Ministers für Nationale Bildung und Sport vom 26. Februar 2002 zum Curriculum für Vorschulerziehung und allgemeine Bildung in den einzelnen Schultypen], in: Dziennik Ustaw [Gesetzblatt] 2002, Nr. 51, Pos. 458. 
Rahmenprogramme für den Erdkundeunterricht gebilligt wurden. Die Lehrkräfte konnten eines von den 30 für jede Jahrgangsstufe zugelassenen Schulbüchern aussuchen. Darüber hinaus blieben etliche offiziell vom Markt genommene Schulbücher noch jahrelang im Umlauf. Erst nach der vollständigen Implementierung des detaillierteren, 2008 erlassenen "neuen Curriculums « ${ }^{4}$ im Schuljahr 2014/15, das zwei Unterrichtsvarianten zulässt, hat sich die Zahl der Schulbücher deutlich verringert. Einen wesentlichen Einfluss darauf hatten auch sinkende Geburten und infolgedessen die sinkende Auflagen, die viele Verlage verschwinden ließen.

Die zweite Schwierigkeit bei unserer Untersuchung rührt aus der Mehrdeutigkeit der Begriffe »Landschaft « und »Kultur« und folglich aus dem besonders unscharfen Bedeutungsbereich von »Kulturlandschaft» in der polnischen Geografie. Die polnischen Vertreter der Physischen Geografie beziehen letzteren Begriff meist auf die Umwandlung der natürlichen Umwelt durch den Menschen. Das ist auch für viele deutsche und russische Fachvertreter charakteristisch und geht auf Norbert Krebs zurück, ${ }^{5}$ wenn es nicht noch weiter zurückreicht. Die polnischen Kulturgeografen sprechen dagegen von »Kulturlandschaft«, um die sichtbaren Unterschiede zwischen Gebieten zu kennzeichnen, die von unterschiedlichen Kulturkreisen und Religionen geprägt sind. ${ }^{6}$ Auf die daraus resultierenden Missverständnisse hat z.B. Urszula Myga-Piątek aufmerksam gemacht. ${ }^{7}$ Da wir es mit einem vieldeutigen Begriff zu tun haben, ist es bei jedem Fall seiner Anwendung notwendig, den Bedeutungsbereich zu definieren, in dem er in der jeweiligen Aussage auftritt. ${ }^{8}$

Die dritte Schwierigkeit ergibt sich daraus, dass polnische Schulbücher den Begriff Kulturlandschaft generell meiden; der Terminus "Landschaft « bezieht sich dagegen meist nur auf die natürliche Umwelt. ${ }^{9}$ Die in der Zwischenkriegszeit

4 »Podstawa programowa kształcenia ogólnego dla gimnazjów i szkół ponadgimnazjalnych, których ukończenie umożliwia uzyskanie świadectwa dojrzałości po zdaniu egzaminu maturalnego" [Curriculum für die Allgemeinbildung an Gymnasien und Oberschulen, deren Beendigung die Erlangung des Reifezeugnisses nach Bestehen der Abiturprüfung ermöglicht], 2008, Biuletyn Informacji Publicznej, https://archiwum.men.gov.pl/wp-content/uplo ads/2011/02/zalaczniknr4.pdf, zuletzt geprüft am 24. Juli 2019.

5 Norbert Krebs, "Natur und Kulturlandschaft«, in: Zeitschrift der Gesellschaft für Erdkunde zu Berlin 58 (1923), 81-94.

6 Z.B. zahlreiche Artikel in Prace Komisji Krajobrazu Kulturowego 15 (2011), 17 (2012), 19 und 21 (2013).

7 Urzula Myga-Piątek, Krajobrazy kulturowe. Aspekty ewolucyjne i typologiczne [Kulturlandschaften. Aspekte von Evolution und Typologie], Katowice: Uniwersytet Śląski, 2012.

8 Vgl. Florian Plit, Krajobraz kulturowy - czym jest? [Kulturlandschaft - was ist das?], Warschau: Uniwersytet Warszawski, Wydział Geografii i Studiów Regionalnych, 2011, 74.

9 Ein gutes Beispiel für diese Herangehensweise ist ein Foto im Schulbuch von Marek Więckowski, Odkrywamy Świat cz. 1 [Wir entdecken die Welt. Geografielehrbuch für den Gymnasiasten. Teil 1], Warschau: WSiP, 2002, 177. Zu sehen ist eine typische chinesische 
einflussreiche polnische Schule der Kulturlandschaftsgeografie wirkte noch bis in die Nachkriegszeit nach, hauptsächlich dank Maria Dobrowolska. ${ }^{10}$ In kommunistischer Zeit galt die Thematik als politisch inkorrekt und wurde mehrere Jahrzehnte kaum berücksichtigt. Erst seit der Wende hält die Kulturlandschaft wieder öfter in wissenschaftliche Publikationen Einzug, aber sie ist immer noch selten in Schulbüchern zu finden. Dabei scheint die Trägheit bei der Rezeption wissenschaftlicher Forschung ursächlich zu sein, obwohl auch in Schulbüchern viele Fragestellungen zu finden sind, auf die der Terminus angewandt werden könnte.

Aus den genannten Gründen ist dieser Beitrag weit davon entfernt, die Problematik erschöpfend zu behandeln. Vielmehr soll er anhand von ausgewählten Schulbücher ein allgemeines Bild skizzieren und bestimmte Probleme herausarbeiten.

Erstaunlicherweise blieb trotz aller Veränderungen, die es in der polnischen Nachkriegsgeografie gab, und trotz der Bildungsreformen die Herangehensweise an Kulturlandschaften in den Erdkundebüchern größtenteils unverändert. Wie der Begriff der "Kultur« verstanden wurde, kam der ursprünglichen Bedeutung des lateinischen Wortes cultura nahe, das sich auf Bodennutzung bezieht und auf die menschliche materielle Produktion erweitert wurde. "Kulturlandschaft « ist in den Schulbüchern meist die Visualisierung von Bodennutzung und Bebauung, wobei sie in Verbindung mit den natürlichen Umweltbedingungen und der wirtschaftlichen Entwicklungsstufe betrachtet wird. Die geistige Kultur dagegen bleibt außen vor. Lange Zeit wurde nicht einmal ihr Einfluss berücksichtigt, z. B. durch die Religion. Diese Herangehensweise kennzeichnet einen eigenartigen naturwissenschaftlich-ökonomischen Determinismus, der nicht nur von der neuen Kulturgeografie weit entfernt ist, sondern selbst hinter die klassische Konzeption der Kulturlandschaft von Carl Sauer ${ }^{11}$, zahlreiche Arbeiten deutscher und amerikanischer Fotografen aus dem frühen 20. Jahrhundert sowie polnische Vorarbeiten - wie zum Beispiel von Eugeniusz Romer $^{12}$ - zurückfällt.

Vor der Einführung der Mittelschulen wurde Erdkunde an Grundschulen und Oberschulen unterrichtet. In den Grundschulen wurde sie in den Jahrgangs-

Kulturlandschaft: weite, unter Wasser stehende Reisfelder, unterteilt durch Deiche, im Hintergrund steile Berge. Obwohl im Text vom Reisanbau die Rede ist und mit keinem Wort Karstphänomene erwähnt wurden, lautet die Bildunterschrift: „Eine Karstlandschaft in Südchina; die auf dem Foto zu sehenden Hügel sind Karstberge.»

10 Maria Dobrowolska, "Dynamika krajobrazu kulturalnego" [Die Dynamik der Kulturlandschaft], in: Przegląd Geograficzny 21, 3-4 (1948), 152-203.

11 Carl Sauer, »Morphology of landscape«, in: Publications in Geography 2 (1925), 19-54.

12 Eugeniusz Romer, "Istota i życie krajobrazu polskiego« [Wesen und Leben der polnischen Landschaft], in: Czasopismo Geograficzne 13 (1935), 175-187. 
stufen 4-7 und seit der Einführung der achtjährigen Grundschule (1965/66) in den Jahrgangsstufen 4-8 unterrichtet. Dem Unterrichtsplan folgend wurde der Unterricht in Jahrgangsstufe 4 mit einfachen geografischen Beobachtungen aus der Schulumgebung eröffnet, danach folgte Unterricht über die Landschaften Polens. Diesen Titel trug auch meist das Lehrbuch, darunter das mehr als 20 Jahre benutzte Schulbuch von Jan Kądziołka. Dieses kam zuerst 1978 heraus und wurde noch nach der Einführung der Mittelschulen wieder aufgelegt. Hier findet sich nicht zuletzt folgende Passage:

Alles, was wir aus dem Fenster unseres Hauses sehen, ist Teil der Landschaft. In dieser Landschaft können wir natürliche Bestandteile unterscheiden, die also von der Natur selbst hervorgebracht wurden, und Bestandteile, die von Menschen geschaffen wurden. [...] Zu den vom Menschen geschaffenen Bestandteilen zählen wir: Freiland, Böden, Obstgärten, Gärten, Straßen, Eisenbahnstrecken, Dämme, Gräben, Ausschachtungen, Teiche, Talsperren und alle Arten von Bebauung. ${ }^{13}$

Danach lernen die Schülerinnen und Schüler an konkreten Beispielen die Landschaften kennen: Hochgebirge, Mittelgebirge, Kleingebirge, Hochebenen, Tiefebenen und Küstengebiete. Jeder Landschaftstyp wird zunächst durch seine natürlichen Gegebenheiten beschrieben, danach wird eine charakteristische Bewirtschaftungsart besprochen, so z. B. für die Hochebene von Lublin die Landwirtschaft, für die Hochebene von Schlesien der Bergbau, für Küste, Tatragebirge und Große Masurische Seen der Tourismus. Die Schülerinnen und Schüler machen auch einen Spaziergang durch die Straßen von Krakau und Warschau. Am Ende des Schulbuchs haben wir das Kapitel 57, »Kulturlandschaften $«{ }^{14}$ Dort finden wir jedoch keine Informationen zur Kultur, sondern zur Umformung, vor allem der Zerstörung der natürlichen Umwelt. Unterschieden werden städtische, industrielle (städtisch-industrielle), landwirtschaftliche und forstwirtschaftliche Landschaften, wobei letztere als am wenigsten umgestaltet gelten. Dies ist ein ähnlicher Ansatz wie bei Józef Wojtanowicz und Marek Degórski, die Kulturlandschaften nach dem Grad der Eingriffe durch den Menschen einteilen. ${ }^{15}$

In der 5. Jahrgangsstufe ging es um die astronomischen Grundlagen der Geografie und die Landschaften der Erde, basierend auf dem Kontinentalsystem.

13 Jan Kądziołka, Krajobrazy Polski [Landschaften Polens], Warschau: WSiP, 9. Auflage 1992, $11 \mathrm{f}$.; Hervorhebungen der Verfasser.

14 Ebd., 170.

15 Józef Wojtanowicz, Wartości geografii [Werte der Geografie], Lublin: Wydawnictwo Uniwersytetu Marii Curie-Skłodowskiej, 2006; Marek Degórski, „Krajobraz jako obiektywna wizualizacja zjawisk i procesów zachodzących w megasystemie środowiska geograficznego" [Landschaft als objektive Visualisierung von Phänomenen und Prozessen im Megasystem der geografischen Umgebung], in: Prace Komisji Krajobrazu Kulturowego PTG 4 (2005), $13-25$. 
Das machte es schwer, den Begriff der Zonierung zu verstehen. Im Schulbuch von Sławomir Piskorz und Stanisław Zając taucht der Begriff der Landschaft in 19 Kapitelüberschriften auf (z.B. Landschaft der sibirischen Tundra, Hochgebirgslandschaft des Himalaya). ${ }^{16}$ Bei den einzelnen Landschaftstypen werden neben der natürlichen Umwelt auch die Bodenbestellung und Besiedlung thematisiert. Einzelne Kapitel sind eigens bestimmten Landschaften gewidmet: der landwirtschaftlichen (ukrainische Hochebene und chinesischen Tiefebene), der industriellen und städtischen (Nordrhein-Westfalen) und der urbanisierten (Ostküste Nordamerikas) Landschaft. Im Glossar wird »Landschaft«, ähnlich wie bei Alexander von Humboldt, definiert als »die Gesamtheit aller Unterscheidungsmerkmale des jeweiligen Geländes «. ${ }^{17}$ Danach werden alle Merkmale der natürlichen Umwelt aufgezählt, doch dann endet die Definition bezeichnenderweise mit dem Zusatz »sowie die Anzeichen menschlicher Tätigkeit«. Wir sehen hier eine qualitative Veränderung im Vergleich zur Definition aus Jahrgangsstufe 4: Die Landschaft ist die Gesamtheit der Merkmale, die das jeweilige Gebiet auszeichnen.

Wurden in den Jahrgangsstufen 4-5 Kulturlandschaften einseitig und nur am Rande behandelt, so gab es in den Schulbüchern für die höheren Jahrgangsstufen im Grunde überhaupt keinen Platz für sie. Kann man sie in den Schulbüchern für die Jahrgangsstufen 6-7 noch aufspüren (regionale Geografie der Welt), so gilt dies für die Jahrgangsstufe 8 (Geografie Polens) und für das Lyzeum (allgemeine physische und wirtschaftliche Geografie Polens) nicht mehr. Dort wird zwar das Wort Landschaft oft gebraucht, aber es handelt sich dabei um natürliche Landschaften, die eine vereinfachte Version der Klassifizierung von Jerzy Kondracki darstellen, ${ }^{18}$ wie sie später in viele akademische Lehrbücher übernommen wurde.

Die Liberalisierung des Schulbuchmarktes nach 1989 brachte anfänglich keine großen Änderungen. Die Schulbücher der neuen Verlage und Autorinnen und Autoren stellten gewöhnlich modifizierte Fassungen der alten Schulbücher von WSiP dar, sie waren nur bunter, hatten aktuellere Farbfotografien, brachten aber dieselben Inhalte in verkürzter Form. Als Beispiel sei das Schulbuch von Edward Świtalski ${ }^{19}$ für die 5. Klasse genannt, das nur gut halb so lang (100 gegenüber 176 Seiten) wie das analoge Schulbuch von Sławomir Piskorz und

16 Sławomir Piskorz und Stanisław Zając, Geografia 5. Krajobrazy Ziemi [Geografie 5. Landschaften der Erde], Warschau: WSiP, 1982.

17 Ebd., 175.

18 Jerzy Kondracki, »Typy krajobrazu naturalnego ('srodowiska geograficznego) w Polsce» [Typen der Naturlandschaft (der geografischen Umgebung) in Polen], in: Przegląd Geograficzny 67, 1-2 (1960), 17-28.

19 Edward Świtalski, Geografia dla klasy piątej szkoły podstawowej [Geografie für die fünfte Jahrgangsstufe der Grundschule], Toruń: Oficyna Wydawnicza »Turpress«, 1998. 
Stanisław Zając ist. ${ }^{20}$ Das neue Schulbuch enthält eine Besprechung fast derselben Landschaften, es enthält ebenfalls ein geografisches Glossar mit einer fast identischen Definition von »Landschaft« (die nur »das jeweilige Gelände» durch »ein bestimmtes Gelände« ersetzt) und insgesamt kürzer ist. ${ }^{21}$ Eine ganze Seite ist der Aufzählung von Landschaftsbestandteilen gewidmet, wobei Bestandteile der »natürlichen Landschaft« und der »umgestalteten Landschaft» unterschieden werden. ${ }^{22}$ Zur umgestalteten Landschaft gehören Siedlungen, Gebäude, Bodennutzung und Straßen, für jede dieser Kategorien werden weitere Unterkategorien aufgelistet. Dies alles sind zweifellos Bestandteile von Kulturlandschaft, doch scheint es so, als ob der Autor den Begriff bewusst vermeidet. Seine Aufteilung ist nicht überzeugend, denn es bleibt unklar, worin denn die Landschaftsumgestaltungen bestehen sollen, die Straßen oder Bebauung ermöglichen. Katarzyna Ostaszewska, Wojciech Lewandowski und Adam Kaliszuk verwenden den Begriff der "anthropogenen Landschaften«, gehen jedoch auf menschliche Eingriffe nur insoweit ein, dass »in manchen Landschaften sich auch der Einfluss der menschlichen Tätigkeit abzeichne» (Hervorhebungen der Verfasser). ${ }^{23}$

Die Gründung von dreijährigen Mittelschulen 1999 zog viel einschneidendere Änderungen nach sich. Vor allem wurde das Fach Erdkunde in der Grundschule in den Jahrgangsstufen 4-6 ganz abgeschafft, dasselbe galt für Biologie, Chemie und Physik. Zum Ersatz wurde ein einziges Fach eingeführt: Naturkunde. Diese Änderungen hätten für das Fach Erdkunde günstig sein können, da die Anzahl der Unterrichtsstunden summiert und die Geografie in den ziemlich allgemein gehaltenen 21 Themenvorgaben umfassend berücksichtigt wurde. Unter anderem gab es dort drei Punkte, die Landschaften explizit thematisierten. Mehr noch: Punkt 7 (»Landschaft der nächsten Umgebung«) wurde um den Unterpunkt 7.3 »Menschen und Kultur« erweitert. ${ }^{24}$ Die Einführung von Naturkunde an den Grundschulen ging allerdings nur mühsam voran, denn es gab weder Schulbücher noch qualifizierte Lehrkräfte. Einige Jahre wurde als Behelf das Fach unter die Chemie-, Physik-, Biologie- und Erdkundelehrkräfte aufgeteilt, und diese benutzten ihre alten Fachschulbücher für die Grundschulklassen 4-6.

20 Piskorz, Zając, Geografia 5.

21 Świtalski, Geografia, 98.

22 Ebd., 95.

23 Katarzyna Ostaszewska, Wojciech Lewandowski und Adam Kaliszuk, Geografia 5. Krajobrazy świata [Geografie 5. Landschaften der Welt], Warschau: Stentor, 1995, 60; letzte Hervorhebung in der Vorlage.

24 »Rozporządzenie Ministra Edukacji Narodowej i Sportu z dnia 26 lutego 2002 r. w sprawie podstawy programowej wychowania przedszkolnego oraz kształcenia ogólnego w poszczególnych typach szkół« [Verordnung des Ministers für Nationale Bildung und Sport vom 26. Februar 2002 zum Curriculum der Vorschulerziehung sowie Allgemeinbildung in den einzelnen Schultypen], in: Dziennik Ustaw [Gesetzblatt] 2002, Nr. 51, Position 458. 
Die Landschaftsdefinitionen in den ersten Schulbüchern erinnern an den alten Text von Jan Kądziołka: »Die Landschaft ist die Gesamtheit der Merkmale, die ein Gebiet unterscheiden und über sein Aussehen entscheiden. ${ }^{25}$ Anschließend werden natürliche und vom Menschen erzeugte Landschaftsbestandteile unterschieden. ${ }^{26}$ Nach und nach schwand jedoch die Bedeutung der Geografie im Naturkundeunterricht sowie bei der Erarbeitung von Lehrplänen und Schulbüchern, und geografische Inhalte wurden an den Rand gedrängt. Hinsichtlich der Landschaften blieb das Augenmerk auf Naturlandschaften (natürlichen Landschaften). Menschliche Einflüsse wurden dagegen nur am Rande und im Kontext von Umweltzerstörung und -schutz behandelt. So verschwanden die Kulturlandschaften aus den Schulbüchern der Grundschulen.

In den Mittelschulen und den weiterführenden Schulen, vor allem in den allgemeinbildenden Lyzeen, blieb das Fach Erdkunde jedoch erhalten. Es gab neue Lehrpläne und Schulbücher, die jedoch pädagogisch und didaktisch weit hinter dem fachlichen Stand zurückblieben. Dies folgte aus der Überzeugung, dass die alten Ansätze gut gewesen seien und keiner Änderung bedürften. (Diese Kritik ist durchaus selbstkritisch gemeint, denn einer der Koautoren des Lehrplans war Florian Plit.) Die stillschweigende Annahme war, dass die Schülerinnen und Schüler nach der Grundschule über ausreichendes Vorwissen über Landschaften, Klimazonen und ihre Bewirtschaftungsformen verfügten, da die Naturkunde in der Grundschule ja die geografischen Inhalte absorbiert habe. Das sehr allgemein gehaltene Curriculum sah Unterricht zu Kulturlandschaften in den Lyzeen in zwei Themenbereichen vor: »7. Polens Natur-, Bevölkerungs-, Wirtschafts- und Kulturpotenzial« sowie »10. Beispiele von Landschaftsschutz international und in Polen ${ }^{27}{ }^{7}$ Leider wurde alles didaktisch isoliert behandelt und »Landschaft« bezog sich nur auf die natürliche Umwelt. Immer noch fehlte der Begriff »Kulturlandschaft«. Obwohl beispielsweise das weltgeografische Lehrbuch von Wojciech Stankowski ${ }^{28}$ und die polnische Geografie von Stanisław Zając $^{29}$ andere Methoden adaptierten, war das Ergebnis dasselbe. Stankowski bespricht natürliche Umwelt, Besiedlung und Wirtschaft der Kontinente, betrachtet auf 39 Seiten globale, dynamische Probleme von Erdbesiedlung und Umweltveränderungen. Kapitel wie »Die Erde als Zuhause der Menschen« oder

25 Kądziołka, Krajobrazy Polski.

26 Z. B. Jan Mordawski u. a., Przyroda. Podręcznik dla klasy IV [Die Natur. Lehrbuch für Jahrgangsstufe IV], Gdańsk: Wydawnictwo M. Rożak, 2000, 33.

27 »Rozporządzenie Ministra Edukacji Narodowej i Sportu z dnia 26 lutego 2002 r.» [Verordnung des Ministers für Nationale Bildung und Sport vom 26. Februar 2002].

28 Wojciech Stankowski, Geografia. Ziemia planeta człowieka. Podręcznik dla gimnazjum. Część 1 [Geografie. Die Erde als Planet des Menschen. Lehrbuch für das Gymnasium. Teil 1], Poznań: Wydawnictwo eMPi ${ }^{2}, 2001$.

29 Stanisław Zając, Geografia Polski. Podręcznik dla gimnazjum [Geografie Polens. Lehrbuch für das Gymnasium], Warschau: WSiP, 2000. 
»Der Mensch verändert das Antlitz der Erde« legen nahe, den Begriff »Kulturlandschaft« einzuführen. Aber selbst das Wort »Landschaft» wird konsequent gemieden. ${ }^{30}$ Bei Zając finden wir das aus dem Curriculum abgeleitete Kapitel »Das Kulturpotenzial Polens«, darin eine Landkarte der Architekturdenkmäler, doch der Begriff Kulturlandschaft fällt wieder nicht. Über ein Viertel des Buches steht unter der Überschrift »Wanderungen durch Polen - regionaler Überblick«. Von Landschaften ist hier ausführlich die Rede, doch geht es nur um Naturlandschaften. Das Thema Kulturlandschaft wird jedoch im Schulbuch von Mirosława und Andrzej Czerny ${ }^{31}$ zumindest beiläufig thematisiert. Diese sei eine "vom Menschen veränderte Landschaft, bei der die Bodenbestellung, der Bau von Siedlungen, Bergwerken, Fabriken, Straßen und Eisenbahnstrecken die ursprüngliche, also natürliche Landschaft verändert hat «; diese Definition entspricht also der der physikalischen Geografie.

In der Zeit von 1989 bis 2002 war die Konkurrenz auf dem Schulbuchmarkt für das allgemeinbildende Lyzeum viel schwächer. Die Autorinnen und Autoren und Verlage engagierten sich aufgrund geringerer Schülerzahlen und kleinerer Profite viel weniger in diesem Bereich. Für die Berufsschulen, die nicht immer Erdkunde unterrichteten, waren die Auflagen verschwindend niedrig. Angesichts der Tatsache, dass die Mittelschulreform radikale Lehrplanänderungen in den weiterführenden Schulen mit sich bringen würde, wollten die Verlage keine Schulbücher einführen, die nur noch fünf Jahre im Umlauf bleiben würden.

Bis 2002 umfasste das Fach Erdkunde an den allgemeinbildenden Lyzeen die folgenden, durch Mindestanforderungen definierten Themenblöcke: allgemeine physische Geografie, Geografie Polens mit Schwerpunkt Wirtschaft sowie ausgewählte, globale oder europäische soziopolitische Fragen (»Polen in Europa «). Daher thematisierten die Schulbücher zwar natürliche Landschaften und ihre Umformung, ${ }^{32}$ sprachen jedoch nicht von Kulturlandschaften. Infolge des politischen Umbruchs in Mitteleuropa waren die Schulbücher rasch überholt. Bei der Einführung neuer Lehrbücher konnten neue Inhalte zur Geografie Polens eingebracht werden: so gab es Landkarten zu nationalen Minderheiten, religiösen Kultusorten unterschiedlicher Religionen und Stätten, die auf der UNESCO-Welterbeliste standen. Man schrieb über die Phy-

30 Auch Florian Plit mied den Begriff »Landschaft« in seinen Lehrbüchern für das Gymnasium.

31 Andrzej Czerny und Mirosława Czerny, Zagadnienia społeczne i gospodarcze świata. Modut dla gimnazjum 3 [Soziale und ökonomische Fragen der Welt. Modul für das Gymnasium 3], Warschau: Nowa Era, 2000, 182.

32 Z.B. Jerzy Harasymowicz und Zofia Wojtkowicz, Polska w Europie dla klasy III liceum ogólnokształcącego [Polen in Europa für Jahrgangsstufe III des allgemeinbildenden Lyzeums], Toruń: Stowarzyszenie Oświatowców Polskich, 2001; Florian Plit, Jerzy Makowski und Joanna Plit, Polska w dobie przekształceń. Podręcznik geografii dla szkołýsredniej, Warschau: WSiP, 1997. 
siognomie von Städten unterschiedlicher Entstehungszeiten, über Unterschiede bei der Bewirtschaftung und Bebauung der ehemaligen russischen und preußischen Teilungsgebiete sowie in den vormals deutschen Gebieten. ${ }^{33} \mathrm{Ob}$ wohl der Begriff selbst weiterhin nicht verwendet wurde, waren Kulturlandschaften also ein Thema, nicht nur im Sinne der Umformung natürlicher Landschaften, sondern auch als visueller Ausdruck verschiedener Kulturen.

2002 kam der erste Jahrgang von Mittelschulabsolventinnen und -absolventen in die weiterführenden Schulen. Da sich die Berufsbildung in einer Krise befand und Polen in den 1980er Jahren geburtenstarke Jahre erlebt hatte, gab es einen Massenandrang an den Lyzeen; daher wurde diese Schulform für den Schulbuchmarkt besonders wichtig. Nach dem damaligen Curriculum ${ }^{34}$ sollte Erdkunde als Grund- oder Leistungskurs unterrichtet werden. Bei der Erstellung des Curriculums wurde die Kulturgeografie zwar diskutiert, jedoch schließlich nicht aufgenommen. Die allgemein gehaltenen Unterrichtsgegenstände ließen jedoch große Interpretationsspielräume, zumal ein Unterrichtsziel äußerst vage das »Verstehen der Komplexität der Welt« nannte. Die Themenwahl der Schulbücher für das Lyzeum mag auch von den Wissenschaftlerinnen und Wissenschaftlern mitbestimmt worden sein, die als Autorinnen und Autoren an diesen Büchern mitwirkten und denen die Veränderungen in der polnischen Geografie seit 1989 bewusst waren, etwa die wachsende Bedeutung der Humangeografie. Das schlägt sich beispielsweise nieder in der Erwähnung und Abbildung von Objekten der UNESCO-Welterbeliste oder in der häufigen Verwendung von Landkarten der Kuturkreise (Zivilisationen) und deren Beschreibung. Trotzdem taucht der Landschaftsbegriff nur sporadisch auf, und zwar sowohl in Schulbüchern zur Physischen ${ }^{35}$ wie zur Humangeografie. ${ }^{36}$ Dagegen kommt er in schulischen

33 Plit, Makowski und Plit, Polska $w$ dobie przekształceń., 1997.

34 »Rozporządzenie Ministra Edukacji Narodowej i Sportu z dnia 26 lutego 2002 r.» [Verordnung des Ministers für Nationale Bildung und Sport vom 26. Februar 2002].

35 Bogdan Horodyski u. a., Geografia 1. Kształcenie ogólne w zakresie rozszerzonym. Podręcznik dla liceum ogólnokształcącego, liceum profilowanego i technikum [Geografie 1. Allgemeinbildung im erweiterten Bereich. Lehrbuch für das allgemeinbildende und Fachlyzeum sowie das Technikum], Warschau: Nowa Era, 2002; Jan Wójcik, Geografia 1. Ziemia, [Geografie 1. Die Erde], Warschau: Polskie Przedsiębiorstwo Wydawnictw Kartograficznych im. E. Romera - Książnica Atlas, 2002.

36 Roman Domachowski und Ewa Szulc-Dąbrowiecka, Geografia. Cz. 2. Człowiek i jego działalność. Podręcznik dla uczniów liceum ogólnokształcącego, liceum profilowanego i technikum [Geografie. Teil 2. Der Mensch und seine Aktivität. Lehrbuch für Schüler des allgemeinbildenden und Fachlyzeums sowie des Technikums], Warschau: "Żak» Wydawnictwo Edukacyjne Zofii Dobkowskiej, 2003; Jan Mordawski und Wojciech Wiecki, Geografia 2. Geografia i człowiek. Zakres podstawowy. Podręcznik dla liceum ogólnokształcącego, liceum profilowanego i technikum [Geografie 2. Geografie und Mensch. Grundbereich. Lehrbuch für das allgemeinbildende und Fachlyzeum sowie das Technikum], Rumia: Wydawnictwo Pedagogiczne OPERON, 2002. 
Nachschlagewerken gar nicht vor. ${ }^{37}$ Wir finden ihn zwar bei Paweł Wład, doch nur in der Absicht, den Begriff zurückzuweisen ${ }^{38}$ (fast siebzig Jahre zuvor hatte Richard Hartshorne eine ähnliche Position vertreten). ${ }^{39}$ Paweł Wład schreibt:

Anstelle des Begriffs Umwelt benutzt man manchmal den Begriff Landschaft. [...] Merkmale und Bestandteile von Landschaft und natürlicher Umwelt sind gleich. Die Merkmale der Landschaft werden ebenfalls von der menschlichen Bewirtschaftung beeinflusst, die eine Umformung der Naturbedingungen nach sich zieht. Manche Geografen sind der Meinung, dass die Landschaft nur »die Ansicht einer natürlichen Umwelt" sei. ${ }^{40}$

Somit, so Wład, ist die Landschaft sogar ein unnötiger Begriff.

In dem von Dorota Makowska herausgegebenen Schulbuch gewährt Florian Plit der Kultur breiten Raum. ${ }^{41}$ Der Einfluss von Religion auf Bewirtschaftungsarten wird ebenso thematisiert wie die Unterschiede in der regionalen Bodenbewirtschaftung und in der Mentalität zwischen den Einwohnerinnen und Einwohnern der ehemaligen Teilungsgebiete Polens. Globale Unterschiede im Erscheinungsbild von Städten und Dörfern werden durch historische Faktoren zu erklären versucht. Das Kapitel »63. Kulturlandschaften - europäisches, polnisches und lokales Erbe« ist ein Unterrichtsvorschlag. Eine Frage darin lautet: »Welche Bestandteile hältst du für die Kulturlandschaft deiner Umgebung für charakteristisch? « ${ }^{42}$

Die 2008 verabschiedete Bildungsreform brachte radikale Veränderungen. ${ }^{43}$ Sie betraf ab 2009/10 die Mittelschulen, ab 2012/13 auch die Lyzeen. Die vorherigen Curricula waren so vage, dass sie Unterrichtsplänen und Schulbüchern beliebige Interpretationen erlaubten, woraus sich eine Unvergleichbarkeit der Anforderungen und entsprechend Schwierigkeiten beim Schulwechsel ergaben. Einheitliche gesamtpolnische Abschlussprüfungen für Mittelschule und Lyzeum (Abitur) sollten diesen Problemen entgegenwirken, aber die Ergebnisse fielen

37 Janusz Stasiak und Zbigniew Zaniewicz, Geografia. Vademecum maturalne 2008 [Geografie. Vademecum für das Abitur 2008], Gdynia: OPERON, 2006.

38 Paweł Wład, Geografia 1. Bogactwo przyrodnicze Ziemi. Podręcznik dla liceum ogólnokształcącego. Zakres podstawowy. Zakres rozszerzony [Geografie 1. Der Naturreichtum der Erde. Lehrbuch für das allgemeinbildende Lyzeum. Grundbereich. Erweiterter Bereich], Warschau: Ortus, 2007.

39 Richard Hartshorne, »The nature of geography. A critical survey of current thought in the light of the past«, in: Annals of the Association of American Geographers 29, 3 (1939), 173-412.

40 Wład, Geografia 1, 305.

41 Dorota Makowska (Hg.), Geografia. Podręcznik dla liceum ogólnokształcącego, liceum profilowanego i technikum [Geografie. Lehrbuch für das allgemeinbildende und Fachlyzeum sowie das Technikum], Warschau: WSiP, 2002, 271-274.

42 Ebd., 274.

43 »Podstawa programowa». 
anders aus als erwartet: Lehrkräfte verzichteten ganz auf Schulbücher und verwendeten stattdessen Schülerhandreichungen und Sammlungen möglicher Prüfungsaufgaben usw. Das Curriculum von 2008 ist viel detaillierter als seine Vorgänger und macht genaue Vorgaben zum Lehrstoff. Durch weitere Rechtsakte präzisierte das Ministerium für Nationale Bildung auch den vorgegebenen Lehrstoff für die Grundschulen.

Doch auch das Curriculum von 2008 und seine Begleitkommentare lassen keinen Platz für das Konzept der Kulturlandschaften. Geblieben sind die Naturlandschaften, doch auch diese sind marginalisiert. Der Begriff Landschaft erscheint an einigen Stellen des Curriculums für Naturkunde. In den Jahrgangsstufen 4-6 ist von anthropogenen Bestandteilen der nächsten Umgebung die Rede: Die Schülerinnen und Schüler sollen ausgewählte Landschaften Polens, die für sie charakteristischen Formen menschlicher Tätigkeit, die Landschaften ausgewählter Gebiete Europas und der Welt kennenlernen. Naturkunde ist erneut Unterrichtsfach im Lyzeum; auch Schülerinnen und Schüler ohne Erdkunde im Abitur sollen darin unterrichtet werden. Hier finden wir im Curriculum wieder Erwähnungen von Landschaft, allerdings merkwürdig formuliert und schwer $\mathrm{zu}$ interpretieren, zum Beispiel »18.4. Bunte und einheitliche Landschaften« (im Kapitel »Farben und Gerüche der Welt»), »19.4. Jahreszeiten und Landschaft: natürliche und geologische Zyklen«; »22.4 Natürliche und anthropogene Landschaften. Sind >Urbanosaurier` der Kanon der heutigen Schönheit der Welt?«. Vielleicht aufgrund der verschwurbelten Formulierungen finden diese Titel keinen Widerhall in den detaillierten Unterrichtsinhalten. Im Curriculum für Erdkunde finden wir auf Mittelschulniveau überhaupt keine Bezüge zur Landschaft, ebensowenig im Grundkurs für das Lyzeum. Theoretisch kann dort der Begriff »Kulturlandschaft« eingeführt werden, denn in den Lerninhalten finden wir einige Stichworte zur Kultur. So ist in der Mittelschule unter 7.4 von touristischen Landschaftsvorzügen die Rede, unter 9.9 haben wir einen Hinweis auf die mediterrane Kultur, ${ }^{44}$ unter 10.5 auf "Reiskultur«, unter 10.11 auf die kulturelle Differenzierung Nord- und Südamerikas. Konkreter und tatsächlich zum Thema: Im Lyzeum »erklärt der Schüler die Bedeutung regionaler Kultur und Tradition bei der Ausdifferenzierung von Regionen« (unter 1.6). Darüber hinaus wird an mehreren Stellen gefordert, dass die Schülerinnen und Schüler die Wechselbeziehungen zwischen bestimmten Bevölkerungsfragen erklären, sich beim Erklären auf die Kultur beziehen und mit dem Begriff Kulturlandschaft umgehen können sollen. Es bleibt jedoch abzuwarten, inwiefern die Schulbuchautorinnen und -autoren diesen Begriff aufnehmen, werden sie

44 Das Curriculum stellt Wechselbeziehungen zwischen den Fächern her: Im Erdkundeunterricht der Mittelschule kann an die »mediterranen Landschaften« angeknüpft werden, die an der Grundschule im Naturkundeunterricht behandelt wurden. 
doch ohnehin wegen der Verwendung zu vieler Fachtermini kritisiert. Der Landschaftsbegriff taucht im Curriculum für Erdkunde im Lyzeum auf: »4. Erdsphären? - Hydrosphäre. Der Schüler [...] 5. erklärt die landschaftlichen und wirtschaftlichen Funktionen von Flüssen und Seen«; »6. Pedosphäre und Biosphäre. [...] 3) [...] für die einzelnen Landschaftszonen «; »10. Geografie Polens. Natürliche Umwelt. Der Schüler [...] 10.2 beurteilt [...] die Umwelteigenschaften, die über die Landschaft ausgewählter geografischer Gebiete entscheiden«. Die Landschaft wird demnach ausschließlich als Naturlandschaft behandelt, obwohl es im Curriculum Punkte gibt, für die der Kulturlandschaftsbegriff sinnvoll einzusetzen wäre (beispielsweise 8.11: »Einfluss der Religion auf gesellschaftliche und wirtschaftliche Haltungen«).

Die Auflistung anthropogener Landschaftsbestandteile im Naturkunde-Curriculum für die Grundschulen ging in die Terminologie der Schulbücher ein. Das zeigt sich etwa im Schulbuch von Joanna Buniowska, Ewa Frąckowiak und Ewa Gęsa: Die Landschaft ist hier »ein Ausschnitt der Erdoberfläche mit allen dortigen natürlichen oder vom Menschen erzeugten Bestandteilen", wobei unterschieden wird in Naturlandschaft und "anthropogene Landschaft, eine von Menschen geschaffene Landschaft (Straßen, Städte, Parks) «. ${ }^{45}$

Aus den Erdkundebüchern für die Mittelschule ist der Landschaftsbegriff dagegen verschwunden, sogar in Bezug auf die Natur. Als Beispiel sei das bei OPERON erschienene Schulbuch von Grażyna und Waldemar Chmielewski ${ }^{46}$ genannt. Auch in den Büchern für die Oberschule taucht er oft gar nicht auf, ${ }^{47}$ oder er wird nur in Bezug auf die natürliche Umwelt gebraucht. ${ }^{48} \mathrm{Zu}$ den Ausnahmen gehört die Verwendung von »Kulturlandschaften« bei Wojciech Janicki, wenn auch als Ergebnis der Umformung von Natur: „Es gibt also immer weniger Naturlandschaften in der Welt, die allein von Naturkräften geformt wurden. Es überwiegen entschieden Kulturlandschaften, die auch anthropogen genannt werden und infolge einer Modifizierung des ursprünglichen Zustands durch

45 Joanna Buniowska, Ewa Frąckowiak und Ewa Gęsa, Przyroda z klasą. Podręcznik dla klasy 4 szkoly podstawowej [Mit der Klasse in die Natur. Schulbuch für Jahrgangsstufe 4 der Grundschule], Poznań: Wydawnictwo LektorKlett, 2012, 227.

46 Grażyna Chmielewska und Waldemar Chmielewski, Geografia 3. Podręcznik dla gimnazjum [Geografie 3. Lehrbuch für das Gymnasium], Gdynia: OPERON, 2009.

47 Z.B. Wojciech Wiecki und Beata Stachowska, Geografia XXI wieku. Podręcznik dla szkót ponadgimnazjalnych. Zakres podstawowy [Geografie des 21. Jahrhunderts. Lehrbuch für weiterführende Schulen. Grundbereich], Poznań: Wydawnictwo LektorKlett, 2012; obwohl dort u. a. von den kulturellen Entwicklungsdeterminanten die Rede ist.

48 Joanna Szczęsna, Świat się zmienia. Geografia fizyczna. Podręcznik dla liceów i techników. Zakres rozszerzony [Die Welt verändert sich. Physische Geografie. Lehrbuch für Lyzeum und Technikum. Erweiterter Bereich], Warschau: Oficyna Edukacyjna Krzysztof Pazdro, 2012; das Schulbuch beschäftigt sich mit der physischen Geografie, es verwendet die Termini Altund Jungmoränenlandschaften. 
Einwirkung des Menschen entstanden sind. Nicht jede Kulturlandschaft ist jedoch hässlich. ${ }^{49}$

Das hier gezeichnete Bild ist eher pessimistisch. Schülerinnen und Schüler kurz vor dem Abitur brauchen den Terminus Kulturlandschaft nicht zu kennen und wenn sie ihn kennen, werden sie ihn wahrscheinlich ausschließlich auf die Umgestaltung von Naturlandschaften beziehen. Das ist offensichtlich ein Manko und nur durch den Triumph der analytischen Methode im Erdkundeunterricht zu erklären. Dabei erleichert der Begriff der Kulturlandschaft mit seinem synthetischen Charakter die Vermittlung eines ganzheitlichen Weltbildes und ermöglicht den Brückenschlag zwischen Erdkunde, Naturwissenschaften, Geschichte und Kulturwissenschaften.

Die Kulturlandschaft erscheint in den Schulbüchern häufiger implizit als explizit. In den Lehrplänen und Schulbüchern gibt es zwar verhältnismäßig viele Hinweise auf Kulturgeografie und kulturelle Einflüsse auf die regionale Differenzierung der Erdoberfläche - doch sie reichen immer noch nicht aus. Diese Inhalte, die Kulturlandschaften implizit thematisieren, sind reich illustriert, nicht nur mit Fotos. Es gibt bevorzugte Motive: So ist es in der internationalen Geografie die Kulturlandschaft des Islam, bei Polen sprechen die Schulbücher von den Kulturwerten des Karpatenvorlands, Podlachiens oder der Kaschubei, während andere Regionen vernachlässigt werden. Dieses Ungleichgewicht erschwert es, die Besonderheiten von Kulturlandschaften wie zum Beispiel Schlesien, Pommern oder Bieszczady zu verstehen und den polnischen Beitrag zu Kulturerbe und Kulturlandschaften anderer Länder nachzuvollziehen.

Neben den Erdkundebüchern gibt es zahlreiche didaktische Hilfen wie insbesondere Atlanten, in denen Karten mit Titeln wie »Kulturlandschaft«, »Kulturerbe« oder »Kultur« zu finden sind. Zudem gab es im Curriculum lange das fachübergreifende Thema "Regionalbildung. Kulturerbe in der Region«, das zahlreiche Broschüren, Bücher, Fotoalben und andere didaktische Mittel mit regionaler oder lokaler Thematik inspirierte. In vielen von ihnen ist Kulturlandschaft ein Leitmotiv, obwohl der Begriff auch dort nicht fällt. Das Curriculum von 2008 hat die fachübergreifenden Themen aus den Schulen verschwinden lassen, jedoch bewirkte der in den Jahren zuvor gewachsene Regionalismus, dass Regionen heute in den Schulen auch im Erdkundeunterricht stärker präsent sind als vor 1989.

Eine weitere umfassende Reform des Bildungssystems in Polen wird seit 2016 umgesetzt. In den einschlägigen Curriculum-Vorgaben wird der Termi-

49 Wojciech Janicki, Świat się zmienia. Geografia. Podręcznik dla szkót ponadgimnazjalnych. Zakres podstawowy [Die Welt verändert sich. Geografie. Lehrbuch für weiterführende Schulen. Grundbereich], Warschau: Oficyna Edukacyjna Krzysztof Pazdro, 2011, 163. Hervorhebung im Original. 
nus »Kulturlandschaften « nun häufiger verwendet, folglich geschieht es auch in den neu zugelassenen Schulbüchern. Allerdings ist festzuhalten, dass die hierbei (hauptsächlich in Form von Definitionen) verwendeten Begriffsklärungen eher wenig konkret ausfallen, sodass "Kulturlandschaften " vor allem als vom Menschen umgeformte Naturlandschaften vermittelt werden.

Aus dem Polnischen von Marcin Wiatr

\section{Literatur}

Buniowska, Joanna, Ewa Frąckowiak und Ewa Gęsa. Przyroda z klasą. Podręcznik dla klasy 4 szkoły podstawowej [Mit der Klasse in die Natur. Schulbuch für Jahrgangsstufe 4 der Grundschule], Poznań: Wydawnictwo LektorKlett, 2012.

Chmielewska, Grażyna und Waldemar Chmielewski. Geografia 3. Podręcznik dla gimnazjum [Geografie 3. Lehrbuch für die Mittelschule], Gdynia: OPERON, 2009.

Czerny, Andrzej und Mirosława Czerny. Zagadnienia społeczne i gospodarcze świata. Moduł dla gimnazjum 3 [Soziale und ökonomische Fragen der Welt. Modul für die Mittelschule 3], Warschau: Nowa Era, 2000.

Degórski, Marek. »Krajobraz jako obiektywna wizualizacja zjawisk i procesów zachodzących w megasystemie środowiska geograficznego" [Landschaft als objektive Visualisierung von Phänomenen und Prozessen im Megasystem der geografischen Umgebung], in: Prace Komisji Krajobrazu Kulturowego PTG 4 (2005), 13-25.

Dobrowolska, Maria. «Dynamika krajobrazu kulturalnego« [Die Dynamik der Kulturlandschaft], in: Przegląd Geograficzny 21, 3-4 (1948), 152-203.

Domachowski, Roman und Ewa Szulc-Dąbrowiecka. Geografia. Cz. 2. Człowiek i jego działalność. Podręcznik dla uczniów liceum ogólnokształcącego, liceum profilowanego $i$ technikum [Geografie. Teil 2. Der Mensch und seine Aktivität. Lehrbuch für Schüler des allgemeinbildenden und Fachlyzeums sowie des Technikums], Warschau: "Żak" Wydawnictwo Edukacyjne Zofii Dobkowskiej, 2003.

Dziennik Ustaw [Gesetzblatt] 2002, Nr. 51, Position 458.

Harasymowicz, Jerzy und Zofia Wojtkowicz. Polska w Europie dla klasy III liceum ogólnokształcącego [Polen in Europa für Jahrgangsstufe III des allgemeinbildenden Lyzeums], Toruń: Stowarzyszenie Oświatowców Polskich, 2001.

Hartshorne, Richard. »The nature of geography. A critical survey of current thought in the light of the past«, in: Annals of the Association of American Geographers 29, 3 (1939), 173-412.

Horodyski, Bogdan u.a. Geografia 1. Kształcenie ogólne w zakresie rozszerzonym. Podręcznik dla liceum ogólnokształcącego, liceum profilowanego i technikum [Geografie 1. Allgemeinbildung im erweiterten Bereich. Lehrbuch für das allgemeinbildende und Fachlyzeum sowie das Technikum], Warschau: Nowa Era, 2002.

Janicki, Wojciech. Świat się zmienia. Geografia. Podręcznik dla szkół ponadgimnazjalnych. Zakres podstawowy [Die Welt verändert sich. Geografie. Lehrbuch für weiterführende Schulen. Grundbereich], Warschau: Oficyna Edukacyjna Krzysztof Pazdro, 2011. 
Kądziołka, Jan. Krajobrazy Polski [Landschaften Polens], Warschau: WSiP, 9. Auflage 1992.

Kondracki, Jerzy. »Typy krajobrazu naturalnego ('srodowiska geograficznego) w Polsce» [Typen der Naturlandschaft (der geografischen Umgebung) in Polen], in: Przegląd Geograficzny 67, 1-2 (1960), 17-28.

Krebs, Norbert. »Natur und Kulturlandschaft«, in: Zeitschrift der Gesellschaft für Erdkunde zu Berlin 58 (1923), 81-94.

Makowska, Dorota (Hg.). Geografia. Podręcznik dla liceum ogólnokształcącego, liceum profilowanego $i$ technikum [Geografie. Lehrbuch für das allgemeinbildende und Fachlyzeum sowie das Technikum], Warschau: WSiP, 2002.

Mordawski Jan u.a. Przyroda. Podręcznik dla klasy IV [Die Natur. Lehrbuch für Jahrgangsstufe IV], Gdańsk: Wydawnictwo M. Rożak, 2000.

Ders. und Wojciech Wiecki. Geografia 2. Geografia i człowiek. Zakres podstawowy. Podręcznik dla liceum ogólnokształcącego, liceum profilowanego i technikum [Geografie 2. Geografie und Mensch. Grundbereich. Lehrbuch für das allgemeinbildende und Fachlyzeum sowie das Technikum], Rumia: Wydawnictwo Pedagogiczne OPERON, 2002.

Myga-Piątek, Urszula. Krajobrazy kulturowe. Aspekty ewolucyjne i typologiczne [Kulturlandschaften. Aspekte von Evolution und Typologie], Katowice: Uniwersytet Śląski, 2012.

Ostaszewska, Katarzyna, Wojciech Lewandowski und Adam Kaliszuk. Geografia 5. Krajobrazy świata [Geografie 5. Landschaften der Welt], Warschau: Stentor, 1995.

Piskorz, Sławomir und Stanisław Zając. Geografia 5. Krajobrazy Ziemi [Geografie 5. Landschaften der Erde], Warschau: WSiP, 1982.

Plit, Florian. Krajobraz kulturowy - czym jest? [Kulturlandschaft - was ist das?], Warschau: Uniwersytet Warszawski, Wydział Geografii i Studiów Regionalnych, 2011.

Ders., Jerzy Makowski und Joanna Plit. Polska w dobie przekształceń. Podręcznik geografii dla szkoły średniej [Polen in Zeiten der Umwandlung. Lehrbuch der Geografie für die Mittelschule], Warschau: WSiP, 1997.

»Podstawa programowa kształcenia ogólnego dla gimnazjów i szkół ponadgimnazjalnych, których ukończenie umożliwia uzyskanie świadectwa dojrzałości po zdaniu egzaminu maturalnego" [Curriculum für die Allgemeinbildung an Mittel- und Oberschulen, deren Beendigung die Erlangung des Reifezeugnisses nach Bestehen der Abiturprüfung ermöglicht], in: Ministerstwo Edukacji Narodowej (Hg.), Biuletyn Informacji Publicznej, 2008, https://archiwum.men.gov.pl/wp-content/uploads/2011/02/zalaczniknr4. pdf, zuletzt geprüft am 24. Juli 2019.

Romer, Eugeniusz. »Istota i życie krajobrazu polskiego « [Wesen und Leben der polnischen Landschaft], in: Czasopismo Geograficzne 13 (1935), 175-187.

Sauer, Carl. "Morphology of landscape«, in: Publications in Geography 2 (1925), 19-54. Stankowski, Wojciech. Geografia. Ziemia planeta człowieka. Podręcznik dla gimnazjum. Część 1 [Geografie. Die Erde als Planet des Menschen. Lehrbuch für die Mittelschule. Teil 1], Poznań: Wydawnictwo eMPi², 2001.

Stasiak, Janusz und Zbigniew Zaniewicz. Geografia. Vademecum maturalne 2008 [Geografie. Vademecum für das Abitur 2008], Gdynia: OPERON, 2006.

Świtalski, Edward. Geografia dla klasy piątej szkoły podstawowej [Geografie für die fünfte Jahrgangsstufe der Grundschule], Toruń: Oficyna Wydawnicza »Turpress«, 1998. 
Szczęsna, Joanna. Świat się zmienia. Geografia fizyczna. Podręcznik dla liceów i techników. Zakres rozszerzony [Die Welt verändert sich. Physische Geografie. Lehrbuch für Lyzeum und Technikum. Erweiterter Bereich], Warschau: Oficyna Edukacyjna Krzysztof Pazdro, 2012.

Wiecki, Wojciech und Beata Stachowska. Geografia XXI wieku. Podręcznik dla szkót ponadgimnazjalnych. Zakres podstawowy [Geografie des 21. Jahrhunderts. Lehrbuch für weiterführende Schulen. Grundbereich], Poznań: Wydawnictwo LektorKlett, 2012.

Więckowski, Marek. Odkrywamy świat. Podręcznik do geografii dla gimnazjalisty. Część 1 [Wir entdecken die Welt. Geografielehrbuch für den Gymnasiasten. Teil 1], Warschau: WSiP, 2002.

Wład, Paweł. Geografia 1. Bogactwo przyrodnicze Ziemi. Podręcznik dla liceum ogólnokształcącego. Zakres podstawowy. Zakres rozszerzony [Geografie 1. Der Naturreichtum der Erde. Lehrbuch für das allgemeinbildende Lyzeum. Grundbereich. Erweiterter Bereich], Warschau: Ortus, 2007.

Wojciech, Janicki. Świat się zmienia. Geografia. Podręcznik dla szkót ponadgimnazjalnych. Zakres podstawowy [Die Welt verändert sich. Physische Geografie. Lehrbuch für weiterführende Schulen. Grundbereich], Warschau: Oficyna Edukacyjna Krzysztof Pazdro, 2011.

Wójcik, Jan. Geografia 1. Ziemia [Geografie 1. Die Erde], Warschau: Polskie Przedsiębiorstwo Wydawnictw Kartograficznych im. E. Romera - Książnica Atlas, 2002.

Wojtanowicz, Józef. Wartości geografii [Werte der Geografie], Lublin: Wydawnictwo Uniwersytetu Marii Curie-Skłodowskiej, 2006.

Zając, Stanisław. Geografia Polski. Podręcznik dla gimnazjum [Geografie Polens. Lehrbuch für die Mittelschule], Warschau: WSiP, 2000. 


\section{Der ausgeblendete Mensch: Kulturlandschaften in Berliner Geografieschulbüchern ${ }^{\top}$}

Die Landschaft gehört zu den Kernkonzepten der Geografie. Doch trotz ihrer intensiven Erkundung stand sie über die Jahrzehnte nicht immer im Mittelpunkt der geografischen Forschung. Vor dem Hintergrund des viel diskutierten Wandels der Erdoberfläche und der Atmosphäre ist eine Auseinandersetzung mit der Rolle der Landschaft in der Schulbildung besonders zeitgemäß. Dieser Beitrag geht am Beispiel der Darstellung der Kulturlandschaft in Geografieschulbüchern der Frage nach, ob sich die Fachwissenschaft Geografie und die Schulgeografie nach 1969 gleichsinnig entwickelt haben. Zunächst erfolgt eine knappe Zusammenfassung der landschaftsbezogenen Forschung in den Teildisziplinen der Physischen und der Humangeografie. Anschließend werden Stichprobe und Methode beschrieben, gefolgt von den Ergebnissen und deren Diskussion.

\section{Landschaftsbezogene Sichtweisen}

Der Landschaftsbegriff veranschaulicht den multiperspektivischen Zugang zu geografischen Sachverhalten. Die Landschaft ermöglicht gewisse Formen der Regionalisierung, öffnet Wege der physisch-geografischen Raumanalyse und bildet Anknüpfungspunkte zur Materialität des Raumes in der kulturgeografischen Betrachtung. Daher überraschen weder die Vielzahl noch die Vielschichtigkeit der heute in der Geografie gebräuchlichen Definitionen der Landschaft. Die meisten dieser Begriffe sind historisch gewachsen und bedürfen einer Betrachtung im Rahmen einzelner geografischen Teildisziplinen.

1 Die Schreibweise des Faches orientiert sich in der deutschsprachigen Geographie an der alten Rechtschreibung. Der Autor kommt der Redaktion entgegen und ist für diesen Text mit einer einmaligen Abweichung von dieser Norm einverstanden. 
Die materielle Landschaft: Physisch-geografische Perspektiven

Epistemologisch wirkt die Physische Geografie häufig konstant und stabil. Ihre Nähe oder Ferne zur Humangeografie prägt in den meisten Fällen das Selbstverständnis der Geografie.

Grundsätzlich versteht sich die heutige Physische Geografie - im Gegensatz zu ihrer frühen naturbeschreibenden Tradition - als eine Naturwissenschaft, was primär in ihrer Erkenntnisgewinnung zum Ausdruck gebracht wird. Die Stellung der Landschaft lässt sich z. B. anhand der in den Naturwissenschaften allgemein akzeptierten Grenzbegriffe identifizieren (vgl. Abb. 1). So lässt sich die Landschaft zusammen mit der Ökosphäre und der Erde dem Grenzbegriff Gaia zuordnen. Ergänzend ist in den meisten physiogeografischen Subdisziplinen der Grenzbegriff Evolution. Eine eher untergeordnete Rolle spielen in der allgemeinen physisch-geografischen Forschung die Grenzbegriffe Teilchen, Leben und Universum. Unterschiedlich starke Berücksichtigung findet der Grenzbegriff Mensch, der grundsätzlich als Natur-Gesellschaftssystem definiert wird. So lässt sich z. B. im deutschsprachigen Raum eine zunehmende Annäherung an das Konzept des Brückenfaches im Sinne des Mensch-Umwelt-Systems beobachten.

Die Landschaft gehört laut Clifford et al. zu den Basiskonzepten der angelsächsischen Geografie. ${ }^{2}$ Im Kontext der Physischen Geografie besteht der Landschaftsbegriff aus der physischen, biologischen und kulturellen Schicht. ${ }^{3}$ Das primäre Forschungsinteresse lässt sich der physischen Schicht, die aus land forms, materials und processes besteht, zuordnen. Im Gegensatz zu landform, einer Standardkategorie geomorphologischer Erscheinungsformen, beinhaltet land form alle formtragenden Elemente der physischen Schicht. Materials umfasst vor allem Gesteine, Sedimente und Böden, während processes Erscheinungen verschiedener Natur umfassen, deren formgestaltende Wirkung dauerhaft oder temporär sein kann. Zu diesen gehören vulkanische, tektonische, küstenbezogene, fluviale, glaziale, periglaziale, äolische und hangbezogene Prozesse. Gray betont, dass die kulturelle Schicht die Landschaft der Städte und mancher ländlichen Siedlungen beinhaltet, während die biologische Schicht die Regenwälder dominiert. ${ }^{4}$ Hochgebirge und Küstengebiete sind hingegen Landschaften, deren Merkmale vorrangig der physischen Schicht entstammen. Unabhängig vom Gesamtbild, welches ein Ausdruck des Wechselspiels zwischen den drei Schichten ist, sorgen die drei Elemente land forms, materials und processes für eine spezifische Form der Geodiversität.

2 Nicholas Clifford, Sarah Holloway, Stephen P. Rice und Gill Valentine (Hg.), Key Concepts in Geography, London u. a.: SAGE, 2009.

3 Murray Gray, »Landscape: The Physical Layer«, in: Clifford, Holloway, Rice und Valentine (Hg.), Key Concepts in Geography, 265-284.

4 Ebd. 


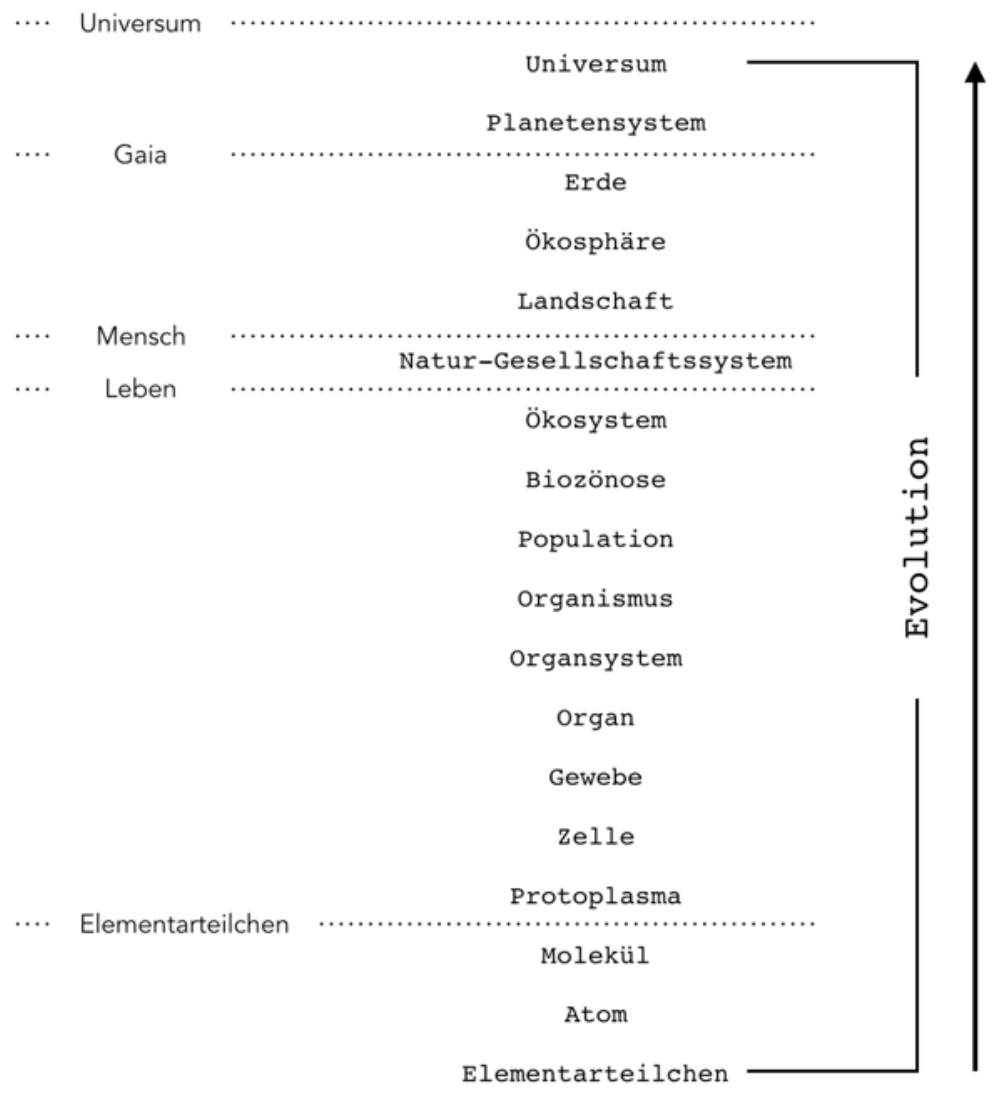

Abb. 1: Naturwissenschaftliche Erkenntnis- und Grenzbegriffe (verändert nach Bechmann ${ }^{5}$ )

Die physisch-geografische Landschaftsforschung der letzten Jahre zeichnet sich durch zwei Schwerpunkte, nämlich eine ausgeprägte angewandte Ausrichtung und eine methodische Vereinheitlichung aus. Auf der einen Seite setzt sich seit geraumer Zeit ein angewandter Blick auf die Landschaft durch. Die jüngste Entwicklung zeigt sich in der Schwerpunktverlagerung auf Ökosystemdienstleistungen in der landschaftsökologischen Forschung. Unter dem Primat der Messbarkeit des Sichtbaren und des Quantifizierbaren verlagert sich der Schwerpunkt der Landschaftsbetrachtung auf das vermeintlich objektiv Wahrnehmbare. Die Erkenntnisse sollen auf verschiedenen Maßstabsebenen u. a. für die Raumplanung von Bedeutung sein.

5 Arnim Bechmann, Ökologischer Landbau - aus der Nische in die Fläche, Barsinghausen: Edition Zukunft, 2009. 
Ein weiterer Ausdruck der angewandten landschaftsbezogenen physiogeografischen Forschung sind einzelne nationale Projekte, die Landschaften definieren, charakterisieren und systematisieren, um die Ergebnisse für Schutzzwecke einsetzen zu können. Vorhaben dieser Art wurden in den letzten zwei Jahrzehnten u.a. in England (z.B. Landscape Character Assessment), Wales (LANDMAP Information System) und Kanada (Parks Canada) durchgeführt. Die Beschreibung und Klassifizierung der Landschaften auf verschiedenen Maßstabsebenen beruhte primär auf Merkmalen der physischen Landschaftsschicht. Die Ergebnisse mündeten indirekt oder als Direktauftrag in Maßnahmen des Naturschutzes im weiteren Sinne.

Der zweite Schwerpunkt landschaftsökologischer Forschung ist methodischer Natur. Geländemethoden erfuhren eine progressive Verdrängung und einen Ersatz durch die Entwicklung fernerkundlicher Technologien und Geografischer Informationssysteme (GIS). Gerade großflächige Erhebungen, die Landschaftstypen abgrenzen sollen, bedienen sich dieser Methoden. Berechnungen und Modellierungen auf der Grundlage von quantifizierbaren Größen und Indikatoren prägen zunehmend die physiogeografische Landschaftsforschung.

Die landschaftsbezogene Forschung in der Physischen Geografie scheint sich somit progressiv einer verdinglichten und materiellen Konzeptualisierung der Landschaft zu verpflichten. Ganz andere Entwicklungen erfuhr die Humangeografie.

Landschaft als ideologischer oder symbolischer Prozess: Humangeografische Perspektiven

Humangeografische Definitionen der Landschaft streben in der Regel keine klare Auffächerung einer messbaren und materiellen Entität in Bestandteile an. Im Gegensatz zur Physischen Geografie, die einen Bedeutungszuwachs der physischen Schicht anstrebt, schreibt die humangeografische Forschung der Materialität der Landschaft im 20. und 21. Jahrhundert eher geringe Bedeutung zu.

Der aus der deutschsprachigen Geografie importierte Landschaftsbegriff löste in der angelsächsischen Geografie am Anfang des 20. Jahrhunderts einen antideterministischen Diskurs aus. ${ }^{6}$ Erst gegen Mitte des 20. Jahrhunderts erlebt die humangeografische Landschaftsforschung eine theoretische Weiter-

6 Karen M. Morin, „Landscape: Representing and Interpreting the World«, in: Clifford, Holloway, Rice und Valentine (Hg.), Key Concepts in Geography, London u. a.: SAGE, 2009, 286-298. 
entwicklung, die sich auf genuin angelsächsische Fallstudien stützt. Studien zu Suburbia und trailer parks lasen die Landschaft als einen Text. The Interpretation of Ordinary Landscapes ${ }^{7}$ fasst den Diskurs der Zeit zusammen und geht von einer gewissen Struktur und somit Ordnung der Landschaft aus, die anhand klarer Regeln wie ein Text dekodiert werden kann. Diese methodische Vorgehensweise führte zu ähnlichen Analysen wie die physiogeograpischen Landschaftskartierungen, jedoch erfolgte keine flächendeckende und kriterienbasierte Erhebung.

Durch die Einflüsse der kritischen Sozialtheorien entwickelte sich in der angelsächsischen Humangeografie eine Bewegung gegen die gängigen Konzepte und Methoden der Landschaftsforschung. Der wesentliche Kritikpunkt bestand darin, dass die Produktion der Landschaften auf keine homogenen Gruppen und einheitlichen Lesarten zurückgeführt werden kann. Die Rolle der ungleichen Machtverhältnisse, die zur Produktion der Landschaft beitrugen oder diese steuerten, gewann an Bedeutung. Vor diesem Hintergrund vollzog sich eine Distanzierung von der textuellen Betrachtung der Landschaft bei einer gleichzeitigen Etablierung der intertextuellen Perspektive. ${ }^{8}$ Landschaft wird dabei zum sozialen Produkt von Gruppen in Machtpositionen, die eine besondere Weltansicht vertreten und diese mittels ihrer Machtposition auch nachhaltig vertreten können. Solche Produkte können und wurden auf der Grundlage von Perspektiven angefochten, die sich auf die Ethnizität, die soziale Schicht, das Geschlecht oder die Sexualität beriefen. Somit wurde die Landschaft zu einem mehrschichtigen Bedeutungsträger und gleichzeitig zum Ort des sozialen Widerstandes gegen Hegemonien von Machtperspektiven. So liest die (exekutive Macht der) Stadt Graffiti als Sachbeschädigung, während andere Gruppen diese für den einzigen Weg des Widerstandes oder sogar für eine Form der Kunst halten. Konflikte entstehen aus diesen vermeintlich konkurrierenden Perspektiven, die allerdings die Unterstützung unterschiedlich starker Machtstrukturen genießen.

Betrachtet man diese Entwicklung in der humangeografischen Landschaftsforschung, so fällt eine zunehmende Loslösung von der Materialität der Landschaft auf. Intertextuelle Lesarten der Landschaft setzen voraus, dass jeder Text und somit jede Landschaft ausschließlich im Kontext anderer Texte gelesen werden kann. Mitte der 1990er Jahre wurden mehrere Stimmen laut, die auf die Gefahren einer Reduzierung der Landschaft auf das exklusiv Visuelle hinwiesen. ${ }^{9}$ Diese Kritik muss wiederum im großen Kontext der Debatte um humangeo-

7 Donald W. Meinig (Hg.), The Interpretation of Ordinary Landscapes: Geographical Essays, New York, Oxford: Oxford University Press, 1979.

8 James Duncan, The City as Text: The Politics of Landscape Interpretation in the Kandyan Kingdom, New York, Cambridge: Cambridge University Press, 1990.

9 Don Mitchell, The Lie of the Land: Migrant Workers and the California Landscape, Minneapolis: University of Minnesota Press, 1996. 
grafische Landschaftsforschung des späten 20. Jahrhunderts betrachtet werden. Karen Morin hebt für diese Zeit zwei dominierende Diskurse hervor, nämlich die marxistischen Ansätze und die feministische Landschaftsforschung. ${ }^{10}$

Die Rückkehr der Materialität und somit die Frage nach der Wechselbeziehung zwischen der Landschaft und ihrer Darstellung prägten die Debatte zwischen marxistischen und poststrukturalistischen Paradigmen. Die für die Landschaftsforschung durchaus förderliche Debatte löste die ihr zu Grunde liegenden Dichotomien Subjekt-Objekt, Betrachter-Betrachtetes, Darstellende-Dargestelltes, Reales-Dargestelltes nicht auf. Sowohl marxistische als auch poststrukturalistische Perspektiven verlegten ihren Forschungsschwerpunkt auf die Betrachtung der Landschaft als Handlungsfeld des Individuums. Diese Sichtweise vereinte die Erforschung der Gestaltung der Landschaft durch den Menschen mit der Analyse der Einflüsse der Landschaft auf den Menschen.

Die feministischen Stimmen bilden den zweiten Diskurs, der die humangeografische Landschaftsforschung am Ende des 20. Jahrhunderts maßgeblich prägte. Der Hauptkritikpunkt feministischer Landschaftsforschung richtet sich nicht nur gegen die Maskulinität der theoretischen Diskurse und Methoden, sondern weist auch auf die fehlende Reflexivität beim Umgang mit der eigenen Sichtweise des männlichen Forschers auf die Landschaft. Wenig überraschend ist, dass feministische Landschaftsforscherinnen sich primär historischen Themen widmeten. ${ }^{11}$ Die Landschaftsforschung profitiert bis heute von den feministischen Perspektiven, dennoch muss noch geklärt werden, ob feministische Geografinnen in ihren Arbeiten zur Landschaft und Männlichkeit selber den Erwartungen gerecht werden, die ihre männlichen Kollegen laut ihrem Vorwurf nicht erfüllen. ${ }^{12}$

Die deutschsprachige geografische Landschaftsforschung erlebte nach dem Kieler Geografentag von 1969 starke Veränderungen. Neben ideologiekritischen Arbeiten erfolgte vor dem Hintergrund der Disziplingeschichte ein konzeptuelles Nach- und Überdenken der Landschaft. ${ }^{13}$

Um die Jahrtausendwende widmete sich die deutschsprachige humangeografische Landschaftsforschung ähnlichen Fragen, wie die angelsächsische Geografie am Anfang des 20. Jahrhunderts. Zu diesen Fragen gehört u. a. die

10 Morin, »Landscape: Representing and Interpreting the World «.

11 Karen M. Morin, »Trains Through the Plains: The Great Plains Landscape of Victorian Women Travellers«, in: Great Plains Quarterly 18 (1998), 235-256.

12 Rachel Woodward, »Warrior Heroes and Little Green Men: Soldiers, Military Training, and the Construction of Rural Masculinities«, in: Rural Sociology 65 (2000), 640-657.

13 Hans-Dietrich Schultz, »Versuch einer ideologiekritischen Skizze zum Landschaftskonzept«, in: Geografiker 6 (1971), 1-12; Hans-Dietrich Schultz, »Wie das Land, so das Volk, wie das Volk, so das Land: Landschafts- und Länderkunde (die klassische Geographie) auf Abwegen«, in: Nils M. Franke und Uwe Pfennig (Hg.), Kontinuitäten im Naturschutz, BadenBaden: Nomos, 2014, 23-79. 
Entkoppelung der Landschaft von ihrer materiellen Grundlage. Im Gegensatz zur angelsächsischen Geografie ${ }^{14}$, scheinen in Deutschland Intension (Begriffsinhalt) und Extension (Begriffsumfang) des Landschaftsbegriffs weitgehend geklärt zu sein: "Landschaften sind [...] keine realen geomorphologischen Gestaltenensembles, sondern Bilder, die sich abhängig vom Wechsel der Jahreszeiten und der aktuell-emotionalen Disposition des Betrachter-Autors im Augenblick der Begegnung gestalten; sie sind Sehfiguren. ${ }^{15}$ Überraschend wirkt dabei das Zusammenschmelzen genuin physiogeografischer Schichttheorien ${ }^{16}$ und der gängigen kritisch-sozialtheoretisch geladenen internationalen Diskurse. Vom Konsens kann jedoch keine Rede sein. Ganz anders ging im selben Jahr Hasse mit dem Landschaftsbegriff um: »Landschaft ist kein wissenschaftlicher Begriff, der durch definitorische Schärfe und Abgrenzung >gefangen` werden könnte. Deshalb ist er (als Fiktion) vielfach kodierbar. [...] Dafür ist er aber ein ganzheitlicher Begriff und steht für das Ganze, wo wir unser Dasein führen. « ${ }^{17}$ Auf der Grundlage dieser und weiterer phänomenologischen Erkenntnisse grenzt Hasse später in Anlehnung an Foucault und am Beispiel des krisenheterotopen Raumes Weltnaturerbe Wattenmeer die erste Natur von der hergestellten Landschaft ab. ${ }^{18}$ Die Landschaft als soziale Hervorbringung unter den Bedingungen des Konstruktivismus wird zu einem Ineinandergreifen der Konstruktion und Konstitution. Dabei bedingt die Anwesenheit des Menschen eine reine Kulturlandschaft.

Vergleicht man den deutschsprachigen und den angelsächsischen Diskurs um die Landschaft, so lassen sich weder eine kontinuierliche Auseinandersetzung mit Landschaftskonzepten, noch konsolidierte kritische Stimmen (aber erste Ansätze ${ }^{19}$ ), wie etwa marxistische oder feministische Arbeiten, identifizieren. Die Landschaftsforschung scheint eher in den Hintergrund der humangeografischen Debatte geraten zu sein.

14 Mitchell, The Lie of the Land.

15 Gerhard Hard, "Landschaft als professionelles Idol«, in: Garten und Landschaft 3 (1991), $13-18,13$.

16 Gray, »Landscape: The Physical Layer«.

17 Jürgen Hasse, Heimat und Landschaft - Über Gartenzwerge, Center Parcs und andere Ästhetisierungen, Wien: Passagen Verlag, 1993, 14.

18 Jürgen Hasse, »Zur mythischen Funktion deklarierter Natur-Landschaften. Das Beispiel des >Weltnaturerbes` Wattenmeer«, in: Ludwig Fischer und Karsten Reise (Hg.), Küstenmentalität und Klimawandel. Küstenwandel als kulturelle und soziale Herausforderung, München: oekom, 2011, 97-113.

19 Olaf Kühne, Landschaft als Konstrukt und die Fragwürdigkeit der Grundlagen der konservierenden Landschaftserhaltung - eine konstruktivistisch-systemtheoretische Betrachtung, Wien: Verein Kritische Geographie, 2005; ders., Landschaft, Geschmack, soziale Distinktion und Macht - von der romantischen Landschaft zur Industriekultur. Eine Betrachtung auf der Grundlage der Soziologie Pierre Bourdieus, Wien: Verein Kritische Geographie, 2006. 
Doch welchen Beitrag leistet die Landschaft zur geografischen Bildung? Wie behandeln in Deutschland zugelassene Schulbücher die Landschaft? Dieser Beitrag geht im Folgenden u. a. diesen Fragen nach.

\section{Methode}

Exemplarisch sollen hier drei Bände der in Berlin zugelassenen TERRA-Reihe des Schulbuchverlages Klett auf die Darstellung von Landschaft hin qualitativ analysiert werden. Da die Vollzeitschulpflicht in der Bundeshauptstadt zehn Jahre beträgt, lag das Augenmerk auf Lehrwerken für die Jahrgangsstufen 5-10 (vor der Jahrgangsstufe 5 erfolgt kein Geografieunterricht ${ }^{20}$ ). Das Buch für die Doppeljahrgangsstufe 5/6 bietet einen Einblick in die Grundschule, die anderen zwei Lehrwerke (Jahrgangsstufen 7/8 und 9/10) lassen sich der Sekundarstufe I zuordnen.

Die Erhebung bediente sich der Text-, Bild- und Inhaltsanalyse. Die Identifizierung aller Segmente, die sich der Landschaft widmen, erfolgte durch In-Vivo-Kodierung. Die Analyse kontinuierlicher und nicht-kontinuierlicher Textelemente wurde in zwei getrennten Schritten vorgenommen. Zu den nichtkontinuierlichen Textelementen gehörten Karten, Fotos, Blockbilder und Profile. Für die Kategorienbildung waren mehrere Iterationen notwendig. Der Erhebungsschritt gestaltete sich für kontinuierliche und nicht-kontinuierliche Textelemente identisch. Die Software MaxQDA unterstützte die Erhebung und die Konsolidierung der Kategorien.

Ein dritter analytischer Schritt beschäftigte sich ausschließlich mit den Aufgabenstellungen und folgte einer abweichenden Methodik. Die Kategorienbildung erfolgte nicht induktiv, sondern bildete die Kompetenz- und Anforderungsbereiche der Bildungsstandards im Fach Geografie für den Mittleren Schulabschluss ${ }^{21}$ als vorgegebene Kategorienstruktur ab. Die im Rahmen der InVivo-Kodierung identifizierten Textstellen konnten so den verschiedenen $\mathrm{Ka}$ tegorientypen zugeordnet werden.

20 Seit der Verfassung des Manuskriptes im Jahr 2014 ist die Geografie in der Berliner Grundschule Teil des Verbundfaches Gesellschaftswissenschaften geworden.

21 Deutsche Gesellschaft für Geographie (DGfG), Bildungsstandards im Fach Geographie für den Mittleren Schulabschluss mit Aufgabenbeispielen, Bonn: Selbstverlag Deutsche Gesellschaft für Geographie, 8. Auflage 2014. 


\section{Berliner Landschaftsspuren}

Die Analyse der kontinuierlichen und nicht-kontinuierlichen Texte ergab vier Bausteine der Landschaftsdarstellung in den untersuchten Geografiebüchern: Begriff, Bild, Profil und Dynamik/Wert. Nach deren Vorstellung wird der Beitrag der Landschaftsdarstellung zur geografischen Bildung der Schülerinnen und Schüler betrachtet.

\section{Begriff}

In jedem der drei untersuchten Schulbücher findet die Landschaft explizite Erwähnung, jedoch in unterschiedlicher Form. Lediglich das Lehrwerk für die Doppeljahrgangsstufe 5/6 definiert die Landschaft und das sogar mehrfach. Die erste Definition führt den Landschaftsbegriff narrativ ein:

Je nach dem Zusammenwirken von Klima, Boden, Oberflächenformen und der Tiersowie Pflanzenwelt haben sich ganz verschiedene Landschaften herausgebildet. [...] Landschaften, die gemeinsame Merkmale aufweisen, fasst man unter einem Begriff zusammen. So spricht man von Waldlandschaften, Industrielandschaften oder auch Hochgebirgslandschaften. ${ }^{22}$

Der Schwerpunkt liegt dabei primär auf der Extension und nur sekundär auf der Intension des Begriffs. Erst später definiert das Schulbuch die Landschaft über die Intension: "Landschaft: Teil der Erdoberfläche, der nach seinem äußeren Erscheinungsbild oder nach Merkmalen des geologischen Baus, Reliefs oder Bodens abgegrenzt wird, z. B. Lüneburger Heide. ${ }^{23}$

Eine nähere Betrachtung der Intension zeigt, dass beide Definitionen einer physiogeografischen Konzeptualisierung folgen. Geologischer Bau, Oberflächenformen und Böden gehören laut Gray zu den land forms und materials der physischen Schicht der Landschaft. ${ }^{24}$ Durch die Berücksichtigung des Klimas (processes als Bestandteil der physischen Schicht), der Tier- und Pflanzenwelt (biologische Schicht) sowie der Industrie (kulturelle Schicht), bildet die Definition den physiogeografischen Landschaftsbegriff von Gray in seiner Gänze $\mathrm{ab}^{25}$ Überraschend wirkt die nachträgliche Reduktion der Intension des Landschaftsbegriffes, indem die zweite Definition sich ausschließlich auf die statischen Elemente land forms und materials der physischen Schicht beschränkt.

22 Dieter Czekalla, Steffen Werner, Michele Barichelli, Bodo Meißner und Silke Pflüger, TERRA Geographie 5/6 Berlin/Brandenburg, Stuttgart und Leipzig: Ernst Klett Verlag, 2011, 116.

23 Ebd., 220.

24 Gray, "Landscape: The Physical Layer«.

25 Ebd. 
Betrachtet man beide Definitionen durch den Filter der humangeografischen Landschaftsforschung, so erinnert besonders die zweite Definition an die erste Hälfte des 20. Jahrhunderts. So wirkt die Landschaft wie eine objektive Realität, die wie ein Text gelesen werden kann. Allerdings klammert die Definition alle anthropogenen Landschaften aus, wodurch der Eindruck ihrer Beschränkung auf die erste Natur entsteht. ${ }^{26}$ Vor dem Hintergrund der Definition von Gerhard Hard führt das Schulbuch für die Doppeljahrgangsstufe 5/6 eine Landschaft ein, die keine Sehfigur, sondern sogar ein reales geomorphologisches Gestaltenensemble ist. ${ }^{27}$

Die Bedeutung der Reihenfolge beider Definitionen relativiert sich allerdings im Kontext der Lehrwerkreihe. Weder das Schulbuch für die Doppeljahrgangsstufe 7/8 noch das Lehrwerk für die Jahrgangsstufen 9 und 10 greifen die Definitionen auf. Sie beinhalten auch keine anderen Landschaftsdefinitionen.

Konsequenter gehen die Lehrwerke mit dem Begriff Großlandschaft um. Am Beispiel der »Großlandschaften in Deutschland « definiert das Lehrbuch für die Doppeljahrgangsstufe 5/6 den Begriff wie folgt:

Aber so unterschiedlich die Landschaften in Deutschland sind - sie lassen sich zu vier Großlandschaften zusammenfassen. Sie werden nach dem Relief, das sind Oberflächenformen wie Berge, Hügel, Täler oder Ebenen und ihrer Höhenlage unterschieden in: Norddeutsches Tiefland, Mittelgebirgsland, Alpenvorland und Alpen. [Hervorhebungen im Original $]^{28}$

Eine ähnliche Definition leitet die »Großlandschaften Nordamerikas« ein:

Aufgrund der Gliederung des Reliefs lassen sich folgende Großlandschaften abgrenzen: [d]ie Nordamerikanischen Kordilleren [...], [d]er Kanadische Schild [...], Innere Ebene [...], [d]ie Küstenebenen [...] [und] [d]ie Appalachen. ${ }^{29}$

Die Abgrenzung der Großlandschaften Südamerikas erfolgt entsprechend: »Ähnlich wie in Nordamerika lassen sich die Großlandschaften Südamerikas aufgrund der klaren Gliederung des Reliefs einfach abgrenzen. ${ }^{30}$

Im Zusammenhang mit der Behandlung der Großlandschaften sind zwei Aspekte von besonderer Wichtigkeit. Erstens fällt eine klare Begriffshierarchie auf: Großlandschaften bestehen aus Landschaften. Zweitens können Großlandschaften - wie Landschaften ${ }^{31}$ - ausschließlich auf der Grundlage der phy-

26 Hasse, "Zur mythischen Funktion deklarierter Natur-Landschaften«.

27 Hard, »Landschaft als professionelles Idol«.

28 Czekalla, Werner, Barichelli, Meißner und Pflüger, TERRA, 26.

29 Karin Krause, Michele Barichelli, Krystyna Kusserow, Bodo Meißner und Silke Pflüger, TERRA Geographie 7/8 Berlin/Brandenburg, Stuttgart und Leipzig: Ernst Klett Verlag, 2012, 8-9.

30 Ebd., 14-15.

31 Czekalla, Werner, Barichelli, Meißner und Pflüger, TERRA, 220. 
sischen Schicht ${ }^{32}$ abgegrenzt werden. Die begriffliche Verwirrung bleibt in der Lehrwerkreihe leider ungelöst.

Die Extension des Landschaftsbegriffes ist zwar bescheiden, sie umfasst dennoch acht Formen der Landschaft: Großlandschaft, Heidelandschaft, Industrielandschaft, Küstenlandschaft, Landschaftssphären, Naturlandschaft, Seenlandschaft, Steppenlandschaft. Ob es sich um die Extension des im Grundschullehrwerk definierten Begriffes handelt, oder ob die Autoren und Autorinnen der beiden Sekundarstufenschulbücher mittels eigenständiger Begriffe konzeptualisieren wollten, bleibt unklar. Auffällig ist dennoch die starke Dominanz solcher Räume, die primär durch die physische Schicht (Seenlandschaft, Küstenlandschaft) oder die biologische Schicht (Heidelandschaft, Steppenlandschaft) definiert werden. Die Industrielandschaft ist der einzige Begriff, der an mehreren Stellen in den drei Lehrwerken Verwendung findet und sich auf eine vorrangig durch die kulturelle Schicht geprägte Landschaft bezieht. Der Begriff der Großlandschaft erinnert an den Begriffs- und Sprachgebrauch einer landeskundlich ausgerichteten Geografie. Die Naturlandschaft wird im Kontext einer Bildung für nachhaltige Entwicklung erwähnt.

Bild

Die untersuchten Berliner Schulbücher beinhalten Landschaftsbilder sowohl in Form von kontinuierlichem als auch nicht-kontinuierlichem Text. Landschaftsbilder finden sich vorrangig auf Doppelseiten, die einen Überblick über einen Raum geben (sog. Terra Orientierung). Die Orientierung zu "Afrika Kontinent der Herausforderungen « beinhaltet vier Bilder (Sahara, Savanne in Kenia, Regenwald in Kamerun, Kap der Guten Hoffnung) und den Arbeitsauftrag, anhand der Fotos »[...] die abgebildeten Landschaften von Norden nach Süden [zu ordnen]. " $^{33}$ Ähnlich erfolgt die Einführung in den Raum »Ostasien und Südasien«, allerdings müssen die vier Fotos (Nepal: Annapurna-Region, Japan: Fudschijama, Guilin: Südchinesisches Bergland, Indien: Küstenlandschaft bei Panaji) jeweils Ostasien oder Südasien zugeordnet werden. ${ }^{34}$ Die Orientierung zu Europa hat das Ziel, anhand von vier Fotos - Landschaft am Fluss Po (Italien), Landschaft in Masuren (Polen), Tschierva-Gletscher (Schweiz) und Landschaft westlich von Clermont-Ferrand (Frankreich) - Naturräume Europas zu identifizieren und die »[...] gezeigten Landschaften von West nach

32 Krause, Barichelli, Kusserow, Meißner und Pflüger, TERRA, 104.

33 Krause, Barichelli, Kusserow, Meißner und Pflüger, TERRA, 104.

34 Ebd., 52. 
Ost [zu ordnen]." ${ }^{35}$ Das Grundschullehrbuch führt die Großlandschaften Deutschlands (Norddeutsches Tiefland, Mittelgebirgsland, Alpenvorland und Alpen) anhand von vier Fotos und einem Profil ein. Die Lernenden müssen die Fotos den Großlandschaften zuordnen und die auf den Fotos abgebildeten Oberflächenformen beschreiben.

Die Lehrbücher der Sekundarstufe beinhalten neben den nicht-kontinuierlichen Textelementen auch Landschaftsbilder in kontinuierlicher Textform. Das Schulbuch für die Doppeljahrgangsstufe 7/8 beschreibt die Inneren Ebenen Nordamerikas wie folgt:

Die weiträumige Landschaft der Inneren Ebenen gliedert sich in die flachwelligen Great Plains im Westen und in das sich daran anschließende Zentrale Tiefland, welches durch das Mississippi-Missouri-Flusssystem geprägt wird. Während noch vor wenigen Jahrhunderten Millionen von Bisons die ausgedehnten Steppen durchstreiften, werden die Inneren Ebenen heute intensiv landwirtschaftlich genutzt. ${ }^{36}$

Die Beschreibung des Landschaftsbildes der südamerikanischen Bergländer erfolgt nach ähnlichem Muster:

[Die Bergländer] können Höhen von 3000 m erreichen. Das Brasilianische Bergland steigt an der Ostküste steil an und fällt zum Landesinneren allmählich ab. Zahlreiche Flüsse, wie São Francisco und Tocantins, durchziehen das Gebiet. Im Inneren der Bergländer schufen die Flüsse mächtige Tafelberge. Wie in Nordamerika haben sich auch in den Bergländern Südamerikas beeindruckende Wasserfälle gebildet. $\mathrm{Zu}$ den bekanntesten gehören die Iguaçu-Wasserfälle an der Grenze zwischen Brasilien und Argentinien. Überzogen werden die Bergländer von Wäldern und Graslandschaften, die vorwiegend als Weiden genutzt werden. Etwa ein Viertel des weltweit produzierten Kaffees wächst hier. ${ }^{37}$

Führt man die kontinuierlichen und nicht-kontinuierlichen Texte zusammen, die Landschaftsbilder beinhalten, so fallen drei wesentliche Aspekte auf. Erstens wirken die Grenzen zwischen den Begriffen Landschaft und Großlandschaft fluid und ungeklärt. Der kontinuierliche Text beschreibt häufig Großlandschaften, die einzelnen Fotos zeigen verschiedene Landschaften. Zwar können unterschiedliche Begriffshierarchien vermutet werden, in Lehrbüchern aber ist eine solche Vorgehensweise eher wenig förderlich. Zweitens berücksichtigen die kontinuierlichen Texte neben der physischen Schicht auch Elemente der biologischen und kulturellen Schicht der Landschaft. ${ }^{38}$ Die meisten nicht-kontinu-

35 Karin Krause, Steffen Werner, Michele Barichelli, Krystyna Kusserow und Bodo Meißner, TERRA Geographie 9/10 Berlin/Brandenburg, Stuttgart und Leipzig: Ernst Klett Verlag, 2013, 102.

36 Krause, Barichelli, Kusserow, Meißner und Pflüger, TERRA, 9.

37 Ebd., 15.

38 Gray, »Landscape: The Physical Layer«. 
ierlichen Texte scheinen eher solche Landschaftsausschnitte zu bevorzugen, die primär von der physischen und biologischen Schicht dominiert werden. Mit der Ausnahme einzelner Fotos (z. B. Nepal, Guilin, Japan) können die anthropogenen Einflüsse - und somit die kulturelle Schicht - lediglich indirekt vermutet werden. Drittens verleihen in vielen Fällen kontinuierliche Texte den einzelnen Fotos einen Landschaftsinhalt. Gerade solche Hinweise, die eine Korrespondenz zwischen Großlandschaften und diesen vermeintlich visualisierenden Fotos herstellen, zeugen von einer Lesart der Landschaft als Text ${ }^{39}$ auf der Grundlage von objektiven Kriterien. Aus der Natur dieser Kriterien ergibt sich ein Konflikt, denn die Bücher definieren Großlandschaften auf der Grundlage der physischen Schicht, während die kontinuierlichen Texte, die diese beschreiben, die beiden anderen Schichten mit berücksichtigen. Die Fotos wiederum versuchen die Spuren des Menschen weitestgehend auszuklammern. Da die drei analysierten Lehrwerke diesbezüglich einer identischen Vorgehensweise folgen, bleiben die wirre Konzeptualisierung und die daraus möglicherweise entstehenden kognitiven Konflikte wahrscheinlich unbemerkt, damit aber auch ungelöst.

\section{Profil}

Neben den Bildern gehören die Profile zu den nicht-kontinuierlichen Textelementen, die sich der Landschaft widmen. Die Lehrwerke der TERRA-Reihe für Berlin beinhalten Landschaftsprofile zu verschiedenen Räumen. Die meisten Profile veranschaulichen die räumlichen Zusammenhänge der Großlandschaften in Form von Blockbildern. Unterstützt werden diese Darstellungen von kartografischem Begleitmaterial, welches den genauen Profilverlauf verortet. Der Profilverlauf ist dabei unterschiedlich. Das Lehrbuch für die Grundschule veranschaulicht die "Großlandschaften in Deutschland ${ }^{40}$ (vgl. Abb. 2) mit Hilfe eines Nord-West-Süd-Ost-Profils durch die Bundesrepublik. West-Ost-Profile zeigen die räumliche Anordnung der Großlandschaften Nord- und Südamerikas. ${ }^{41}$ Die Selbstkontrolle im Rahmen des Kapitels zu »Nordeuropa und Südeuropa: unruhige Natur « beinhaltet ein Landschaftsprofil und einen Arbeitsauftrag: "Ordne die Landschaftsformen Fjord und Schäre der entsprechenden Ziffer im Landschaftsprofil $1 \mathrm{zu}{ }^{42}$

39 Morin, »Landscape: Representing and Interpreting the World «.

40 Czekalla, Werner, Barichelli, Meißner und Pflüger, TERRA, 26-27.

41 Krause, Barichelli, Kusserow, Meißner und Pflüger, TERRA, 8-9, 14-15.

42 Czekalla, Werner, Barichelli, Meißner und Pflüger, TERRA, 160. 


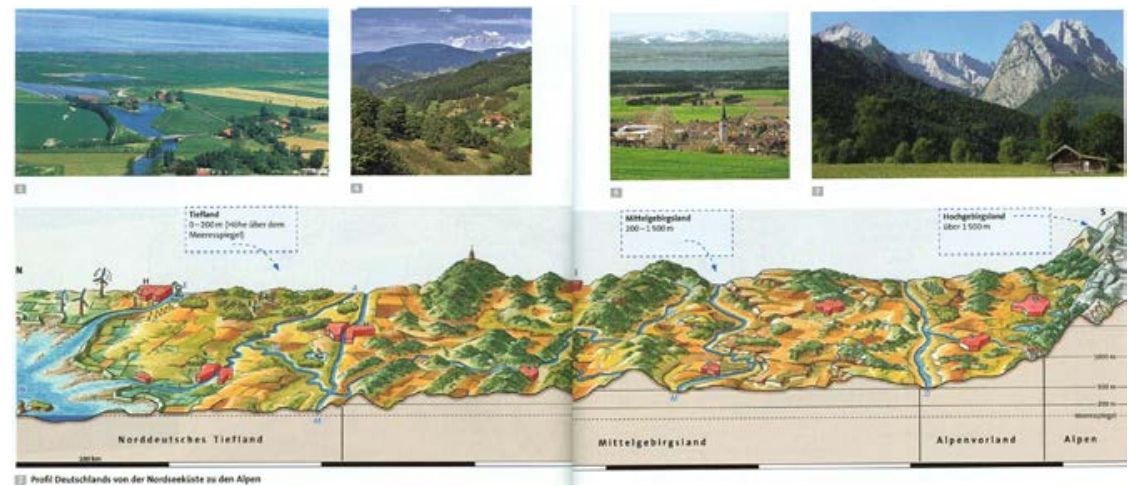

Abb. 2: Nicht-kontinuierliche Darstellungen der Großlandschaften Deutschlands ${ }^{43}$

Die Diskrepanz zwischen der Definition der Großlandschaft und deren Darstellung in nicht-kontinuierlichen Texten gestaltet sich ähnlich wie bei den Bildern. Die Blockbilder, die zwar die wesentlichen Merkmale der Landschaftsprofile immer noch beinhalten, dennoch aber eine dreidimensionale Landschaftsdarstellung ermöglichen, vereinen die rein physischen Schichtelemente der Oberflächenformen mit der biologischen und kulturellen Schicht der Landschaft. ${ }^{44}$ Dass diese Schichten nicht immer klar abgegrenzt werden können, veranschaulicht das Profil zu den Großlandschaften Deutschlands (vgl. Abb. 2), in dem die Oberflächenformen sowohl Vegetation als auch landwirtschaftliche Flächen und verschiedene Siedlungen tragen. Darüber hinaus bilden die Höhe und die Oberflächenformen die primäre Grundlage der Landschaftsprofilzeichnung. Dadurch ist das Dekodieren der Landschaft von vorgegebenen Elementen ausgehend gegeben. ${ }^{45}$ Ähnliches gilt für die Topografie des Raumes und für die räumliche Ausdehnung von landwirtschaftlichen, Wald- oder Siedlungsflächen. Die geografischen Koordinaten wirken hier wegweisend und der Anschein einer vermeintlichen Objektivität begleitet den Zeichnungsprozess. Dass es sich um keine freien (im Gelände) erstellten Landschaftszeichnungen handelt, die einen Spielraum für Sehfiguren ${ }^{46}$ des Individuums ermöglichen könnten, zeigt die direkte Anknüpfung an Karten, die entweder neben den Blockbildern abgebildet oder in einem Atlas abgedruckt sind.

43 Ebd., 52.

44 Gray, »Landscape: The Physical Layer«.

45 Morin, »Landscape: Representing and Interpreting the World".

46 Hard, »Landschaft als professionelles Idol«. 


\section{Dynamik/Wert}

Die ersten drei Bausteine der Landschaftsdarstellung waren statischer Natur. Dennoch beinhalten einzelne Doppelseiten der Berliner Schulbücher Darstellungen, die sich der Dynamik der Landschaft widmen.

Zur Veranschaulichung einzelner Regionen im Umbruch wählt das Lehrbuch für die Doppeljahrgangsstufe 7/8 das Beispiel der »Landschaften aus zweiter Hand ${ }^{47}$ und widmet sich dem Wandel um den Senftenberger See. Kontinuierlicher und nicht-kontinuierlicher Text leisten gleichermaßen einen Beitrag zur Behandlung der Thematik.

Der kontinuierliche Text fasst die Problemstellung zunächst zusammen: »Die Braunkohle ist abgebaut. Nun müssen Maßnahmen ergriffen werden, um die Landschaft wieder nutzbar zu machen. ${ }^{48}$ Anschließend beschreibt der Text die Maßnahmen der land- und forstwirtschaftlichen Rekultivierung, die Wechselwirkung zwischen der Rekultivierung und der Naherholung sowie die Problematik des Naturschutzes vor dem Hintergrund der Rekultivierung. Zwei Fotos, eine Karte und ein Modell ergänzen den kontinuierlichen Text. Die Karte trägt den Titel »Landschaftswandel im Gebiet des Senftenberger Sees«, weist allerdings lediglich mittels ausgewählter Signaturen den Ausgangszustand (Tagebauböschung, geflutetes Tagebaurestloch) und das angestrebte Ziel des Wandels (für Flutung geplantes Tagebaurestloch, Naturschutzgebiet, Radwanderweg, Zeltplatz etc.) aus. Das Modell des Landschaftswandels fasst drei Entwicklungsstadien zusammen: die Landschaft vor, während und nach dem Tagebau. Die beiden Fotos veranschaulichen den bereits vollzogenen Wandel in Form von einem Erholungsgebiet am Senftenberger See und einer Lichtinstallation an der Förderbrücke F 60. Eine Aufgabenstellung geht explizit auf die Landschaft ein: »Beschreibe den Wandel der Landschaft im ehemaligen Braunkohlerevier um Senftenberg bis heute ${ }^{49}{ }^{4}$

Die raumplanerischen Maßnahmen in einem ehemaligen Braunkohlerevier betreffen vorrangig die Oberflächenformen, die Böden und die Gewässer. Die Sukzession der Biozönosen in den wiederhergestellten oder neu entstandenen Biotopen erfolgt graduell. Die (geplante) Nutzung dieser Gebiete durch den Menschen zeigt sich als essentiell bei Entscheidungen, die Lokalisierung, Form und Ausmaße der Oberflächenformen (einschließlich der Wasserflächen) betreffen. Somit ist die Begriffsstruktur in diesem Fall deutlich konsistenter als in anderen Kapiteln der Lehrwerke, da die Landschaft alle drei Schichten nach Gray ${ }^{50}$

47 Krause, Barichelli, Kusserow, Meißner und Pflüger, TERRA, 88-89.

48 Ebd., 88.

49 Ebd., 89.

50 Gray, »Landscape: The Physical Layer«. 
beinhaltet. Doch diese Konsistenz steht im Gegensatz zu den (Groß-)Landschaftsdefinitionen, die alles Biologische und Kulturelle ausgrenzen.

Das Lehrbuch baut einen kausalen Zusammenhang zwischen dem Landschaftswandel und dem Landschaftswert auf. Es entspricht sicherlich den Alltagserfahrungen der Lernenden, sowohl in ländlichen als auch in städtischen Räumen, dass die Nutzung durch den Menschen den Landschaftswandel initiiert, dennoch könnte die Ausklammerung einer möglichen Landschaftsdynamik ohne menschlichen Eingriff (z. B. entlang der Flüsse und Verkehrsachsen oder in Industriebrachen und verlassenen Siedlungen) eine falsche Wahrnehmung der Landschaft und/oder eventuell entsprechende Handlungen in der Landschaft nach sich ziehen.

\section{Landschaft und geografische Bildung}

Neben der kategoriegeleiteten Analyse der Kompetenz- und Anforderungsbereiche soll nun auf die mit dem Inhalt Landschaft verbundenen Bildungsziele eingegangen werden.

Der Geografieunterricht in Deutschland verpflichtet sich seit der Veröffentlichung der Bildungsstandards im Fach Geographie für den Mittleren Schulabschluss ${ }^{51}$ einem kompetenzorientierten Unterricht. Neben den Lernzielen werden die zu erwerbenden Kompetenzen und Standards formuliert. Im Geografieunterricht gilt es diese Standards zu erreichen, wodurch eine Output-Orientierung des Unterrichts geschaffen wurde. Drei Anforderungsbereiche sturkturieren die Arbeit der Lernenden und Lehrenden. Die Aufgabenstellungen beinhalten Operatoren - Verben, die ein messbares Endverhalten der Schüler und Schülerinnen ausdrücken (vgl. Abb. 3).

Durch ihre Operatorennutzung (vgl. Abb. 3) decken die Aufgabenstellungen alle drei Anforderungsbereiche ab. Der Schwerpunkt liegt dabei auf einfachen Operationen der Reproduktion - beschreiben und nennen - des Anforderungsbereiches I. Darüber hinaus fordern weitere Aufgabenstellungen die Lernenden auf, Inhalte zuzuordnen und zu vergleichen. Beide Operatoren (zuordnen, vergleichen) fordern die Reorganisation und den Transfer (Anforderungsbereich II) der Kenntnisse ein. Der Operator begründen gehört zum Anforderungsbereich III (Reflexion). Somit lässt sich die Arbeit mit dem Inhalt Landschaft eher den einfacheren Operationen der ersten beiden Anforderungsbereiche zuordnen.

51 DGfG, Bildungsstandards im Fach Geographie für den Mittleren Schulabschluss mit Aufgabenbeispielen. 


\begin{tabular}{|c|c|}
\hline \multicolumn{2}{|c|}{ Anforderungsbereich I } \\
\hline beschreiben & $\begin{array}{l}\text { Materialaussagen und Kenntnisse (unter einem vorgegeben Aspekt) mit } \\
\text { eigenen Worten zusammenhăngend, geordnet und fachsprachlich ange- } \\
\text { messen wiedergeben }\end{array}$ \\
\hline durchfuhren & $\begin{array}{l}\text { Untersuchungen nach genauen Anleitungen vollziehen, z. B. Experimente, } \\
\text { Erkundungen, Befragungen }\end{array}$ \\
\hline Iokalisieren & $\begin{array}{l}\text { Die Lage eines Ortes, Fusses } 0 . \ddot{A} \text { auf einer Karte verorten/eintragen oder } \\
\text { mit Bezug auf andere răumliche Gegebenhelten beschreben }\end{array}$ \\
\hline nennen & $\begin{array}{l}\text { Informationen und Sachverhalte aus vorgegebenem Material oder Kennt- } \\
\text { nisse ohne Kommentierung wiedergeben }\end{array}$ \\
\hline protokollieren & $\begin{array}{l}\text { Beobachtungen oder die Durchfuhrung von Experimenten detailgenau zeich- } \\
\text { nerisch eirwandfrei bzw. fachsprachlich richtig wedergeben }\end{array}$ \\
\hline \multicolumn{2}{|c|}{ Anforderungsbereich II } \\
\hline analysieren & $\begin{array}{l}\text { Materialien oder Sachverhalte systematisch und gezielt untersuchen, aus- } \\
\text { werten und Strukturen herausarbeiten }\end{array}$ \\
\hline darstellen & $\begin{array}{l}\text { Sachverhalte, Zusammenhănge, Methoden und Bezüge in angemessener } \\
\text { Kommunikationsform strukturiert wiedergeben }\end{array}$ \\
\hline ein-/zuordnen & $\begin{array}{l}\text { Sachverhalte, Răume begründet in einen vorgegebenen Zusammenhang } \\
\text { stellen oder in ein Ordnungsraster einordnen }\end{array}$ \\
\hline erklären & $\begin{array}{l}\text { Informationen und Sachverhalte (Z.B. Erscheinungen, Entwicklungen) so } \\
\text { darstellen, dass Bedingungen, Ursachen, Folgen und Gesetzmäßigkeiten } \\
\text { verständlich werden }\end{array}$ \\
\hline erläutern & $\begin{array}{l}\text { Sachverhalte im Zusammenhang beschreiben und Beziehungen deutlich } \\
\text { machen }\end{array}$ \\
\hline erstellen & $\begin{array}{l}\text { Sachverhalte inhaltlich und methodisch angemessen graphisch darstellen } \\
\text { und mit fachsprachlichen Begriffen beschriften (z. B. Fließschema, Dia- } \\
\text { gramm, Kartenskizze, Mind Map, ...) }\end{array}$ \\
\hline planen & $\begin{array}{l}\text { Zu einem vorgegebenen Problem, einer Fragestellung z. B. eine Experimen- } \\
\text { tieranieitung, Befragung, Raumanalyse erstellen, eine Vorgehenswelse planen }\end{array}$ \\
\hline vergleichen & $\begin{array}{l}\text { Gemeinsamkeiten und Unterschiede gewichtend einander gegenüberstel- } \\
\text { len und ein Ergebnis/Fazit formulieren }\end{array}$ \\
\hline \multicolumn{2}{|c|}{ Anforderungsbereich III } \\
\hline begründen & $\begin{array}{l}\text { Komplexe Grundgedanken argumentath schlussig entwickeln und im } \\
\text { Zusammenhang darstellen }\end{array}$ \\
\hline beurteilen & $\begin{array}{l}\text { Aussagen, Behauptungen, Vorschläge oder Maßnahmen im Zusammen- } \\
\text { hang auf ihre Stichhaltigkeit bzw. Angemessenheit prüfen und dabei die } \\
\text { angewandten Kriterien nennen, ohne persönlich Stellung zu beziehen }\end{array}$ \\
\hline bewerten & $\begin{array}{l}\text { Aussagen, Behauptungen, Vorschläge oder Maßnahmen beurteilen unter } \\
\text { Offenlegung/Reflexion der angewendeten Wertmaßstabe und persönlich } \\
\text { Stellung nehmen }\end{array}$ \\
\hline entwickein & $\begin{array}{l}\text { Sachverhalte und Methoden zielgerichtet miteinander verknüpfen, z. B. eine } \\
\text { Hypothese erstelen, Untersuchungspläne aufstellen, ein Modell entwerfen }\end{array}$ \\
\hline erörtern & $\begin{array}{l}\text { Zu einer vorgegebenen Problemstellung durch Abwägen von Pro- und } \\
\text { Contra-Argumenten ein begründetes Urteil fällen/eine begründete Meinung } \\
\text { formulieren; Synonym: diskutieren }\end{array}$ \\
\hline Uberprüten & $\begin{array}{l}\text { Vorgegebene Aussagen bzw. Behauptungen, Darstellungsweisen an } \\
\text { konkreten Sachverhalten auf ihre innere Stimmigkeit und Angemessenheit } \\
\text { hin untersuchen }\end{array}$ \\
\hline
\end{tabular}

Abb. 3: Anforderungsbereiche und Operatoren in Aufgabenstellungen mit Landschaftsbezug ${ }^{52}$

Der Inhalt Landschaft trägt zur Förderung von drei der sechs Kompetenzbereiche bei (vgl. Abb. 4). Der eindeutige Schwerpunkt liegt dabei auf der Räumlichen Orientierung, gefolgt vom Kompetenzbereich Fachwissen, während die Kompetenzen des Bereiches Erkenntnisgewinnung/Methoden eine eher untergeordnete Rolle spielen.

52 Ebd., 32-33. 


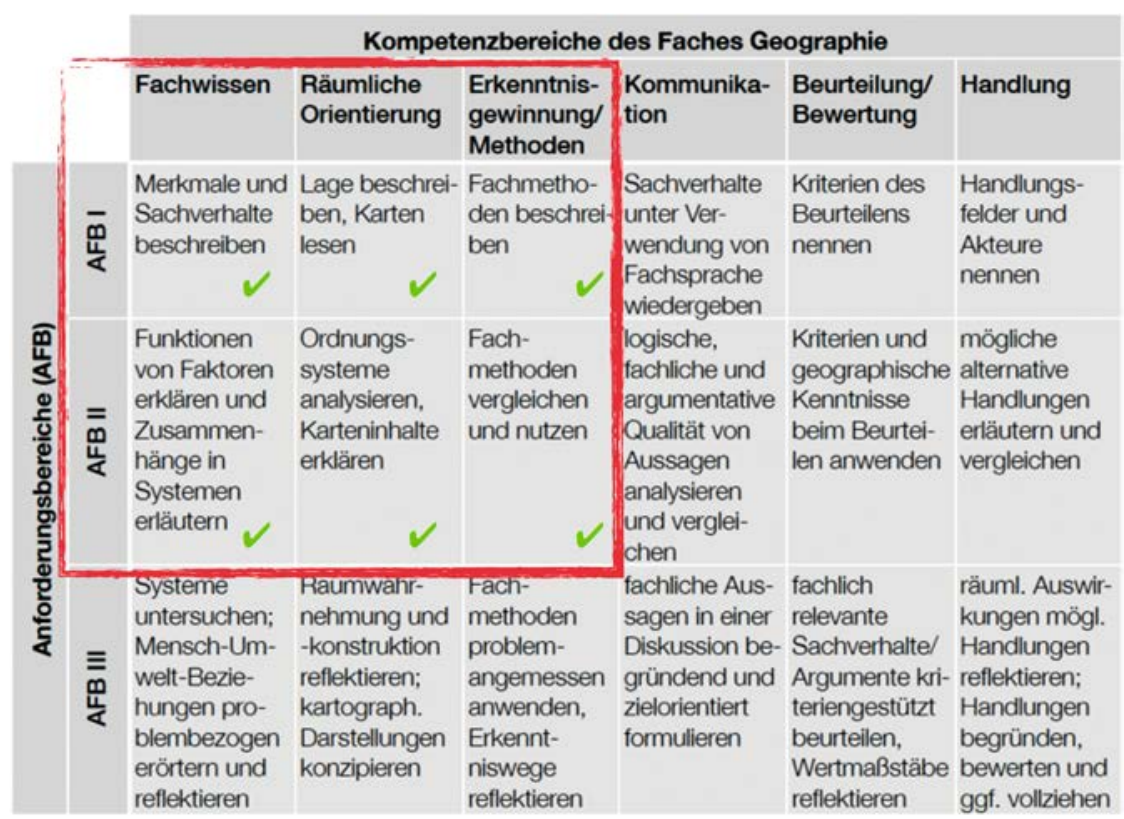

Abb. 4: Kompetenzbereiche in Aufgabenstellungen mit Landschaftsbezug ${ }^{53}$

Der Inhalt Landschaft konsolidiert sich nicht als getrennter thematischer Block in den analysierten Berliner Schulbüchern der Grund- und Sekundarschule. Die Landschaft dient zur Einführung in ausgewählte Räume in Form von Großlandschaften, die eine allgemeine Orientierung bieten sollen. Die Großlandschaften bilden dabei die Grundlage der Räumlichen Orientierung im Sinne des Standards 4 (S4) der Kompetenz O2: »die Lage geographischer Objekte in Bezug auf ausgewählte räumliche Orientierungsraster und Ordnungssysteme (z.B. Lage im Gradnetz) genauer beschreiben ${ }^{54}$. Zwar fordern mehrere Aufgabenstellungen eine Zuordnung von Fotos zu den Profilen oder den Karten ein, jedoch ohne eine Begründung für die Zuordnung zu verlangen.

Sowohl die inkonsistente Begriffsverwendung als auch die mit dem Inhalt Landschaft verbundenen Bildungsziele belegen eine eher unbedeutende Rolle des Themas. Die primäre Aufgabe der Landschaft scheint es zu sein, ein räumliches Ordnungssystem aufzustellen, welches für die Beschäftigung mit ausgewählten Räumen als Voraussetzung gesehen wird. Somit tragen Großlandschaften zur Förderung vom Fachwissen und von räumlicher Orientierungskompetenz bei. Der wesentliche Beitrag der Landschaft scheint aber im Bereich der Erkenntnisgewinnung/Methoden zu liegen. Die meisten Aufgabenstellungen

53 Ebd., 31.

54 Ebd., 17. 
fordern eine Zuordnung von Bildern zu einzelnen modellhaft dargestellten und auf der Grundlage von physischen, biologischen und kulturellen Elementen abgegrenzten Großlandschaften. Dennoch kann in keinem dieser Fälle von einer Methodenschulung gesprochen werden, denn es werden weder die Vorgehensweise der Zuordnung noch die Kriterien, auf deren Grundlage diese erfolgen soll, diskutiert. Die Zuordnungsübungen sind wegen ihrer Multimedialität - sie verbinden nicht-kontinuierliche Texttypen untereinander, aber auch mit kontinuierlichem Text - besonders anspruchsvoll. Darüber hinaus könnte eine methodische Schulung zu einer klaren Bezugnahme auf die vier Raumkonzepte ${ }^{55}$ führen. Landschaften als konstruierte Räume zu verstehen, würde nicht nur einen starken Beitrag zur geografischen Bildung, sondern eine eindeutige Annäherung an die deutschsprachige geografische Debatte um die Landschaft ermöglichen.

\section{Wohin mit der Landschaft?}

Die Landschaftsspuren in den untersuchten Berliner Geografieschulbüchern sind von der wissenschaftlichen Debatte des Faches entkoppelt. Eine physiogeografische Konzeptualisierung des Begriffes scheint breite Unterstützung unter den Autoren und Autorinnen zu genießen, wobei die meisten Textstellen lediglich Teilelemente der gängigen Definitionen aus der Physischen Geografie ${ }^{56}$ übernehmen. Die relativ bescheidene Anzahl an landschaftsbezogenen Begriffen, deren Extension und Intension leider weitgehend ungeklärt bleibt, lässt dennoch weitere Verständnisse von Landschaft vermuten. Dabei scheint Großlandschaft der übergeordnete Begriff für Landschaft und ihre verschiedenen Formen, wie etwa Küsten-, Seen-, Steppen- oder Industrielandschaft zu sein. Ähnliches ergibt sich aus dem Wechselspiel der vier Bausteine, die sich sowohl auf kontinuierliche als auch auf nicht-kontinuierliche Texte stützen. Die unscharfe Konzeptualisierung zeigt sich in der Vermengung ausgewählter Elemente des Landschaftsbegriffs laut Gray. ${ }^{57}$ Gerade Großlandschaften, die streng geomorphologisch abgegrenzt werden, erfahren in Bild und Text eine Darstellung, die Lebewesen und den Menschen gleichwohl beinhalten und damit einen diffusen Geodeterminismus transportieren. Somit lässt sich für die Schulbücher eine traditionelle, auf Oberflächenformen basierende Definition bei einer gleichzeitigen Begriffsverwendung im Sinne von Gray feststellen.

55 Ute Wardenga, »Alte und neue Raumkonzepte für den Geographieunterricht«, in: geographie heute 23 (2002), 8-11.

56 Gray, "Landscape: The Physical Layer «.

57 Ebd. 
Betrachtet man die Ergebnisse vor dem Hintergrund der humangeografischen Landschaftsforschung, so erinnern die Schulbücher an den Diskurs der ersten Hälfte des 20. Jahrhunderts, der die Landschaft als objektiv dekodierbaren Text deutete. Dieser rückblickende Umgang mit der Landschaft wirkt vor dem Hintergrund der deutschsprachigen Debatte noch überraschender. Bereits in den 1990er Jahren betonte Hard, ${ }^{58}$ dass sich Landschaft nicht im Sinne von geomorphologischen Gesamtensembles, sondern als Sehfiguren des Individuums definieren lässt. Zwei Jahrzehnte später betonte Hasse, ${ }^{59}$ dass die erste Natur vollständig durch die Kulturlandschaft ersetzt wurde. Der Widerspruch zwischen dem wissenschaftlichen Diskurs und den hier beispielhaft analysierten Schulbüchern könnte nicht größer sein. Eine explizite Behandlung der Kulturlandschaft findet sich in keinem der analysierten Schulbücher.

Der Bildungsbeitrag des Inhaltes Landschaft in den untersuchten Berliner Geografieschulbüchern ist sehr bescheiden. Die inkonsistente Begriffsverwendung strebt zwar eine gewisse maßstababhängige Strukturierung (Großlandschaften auf kontinentaler oder nationaler Ebene) an, sie scheint aber diesem Anspruch wegen der vielfältigen inneren Widersprüche (konkurrierende Definitionen in kontinuierlichen und nicht-kontinuierlichen Texten) nur in Ansätzen gerecht zu werden. Darüber hinaus vertieft der Versuch, Landschaften lediglich auf der Grundlage des Objektiven und vermeintlich Typischen zu behandeln, die bereits mehrfach beschriebene Kluft zwischen der Wissenschaft Geografie und dem Schulfach. Vor dem Hintergrund der vorliegenden Ergebnisse wirkt die Landschaft in der geografischen Bildung als eine Konstruktion des Zufalls oder ein Begriff mit Inhaltsschwund, welcher ausschließlich der selektiven und inkonsistenten Kompetenzentwicklung, nicht aber der Aneignung eines tiefen geografischen Wissens im Sinne von Michael Young ${ }^{60}$ dient. Anders formuliert: Die Schulgeografie vergibt ein riesiges methodologisches und argumentatives Potential, wenn sie die Landschaft auf Topografie reduziert.

Die Landschaft ist - gerade im deutschsprachigen Kontext - kein unproblematischer Begriff. Ihre Bedeutung für die Disziplin, aber auch für das Individuum, ist unumstritten. Menschen nehmen Landschaften wahr und handeln unterschiedlich in Landschaften. Vermeintlich objektive Landschaftsbilder wie etwa die physiogeografischen Klassifizierungen - führen zu Entscheidungen, die das Leben des Individuums stark beeinflussen können. Die Wahrnehmung und Bewertung dieser Landschaften bleibt dennoch individuell (ebenso wie die darauf resultierenden Handlungen). Auf der Grundlage der Landschaftsele-

58 Hard, »Landschaft als professionelles Idol«.

59 Hasse, »Zur mythischen Funktion deklarierter Natur-Landschaften«.

60 Michael Young, David Lambert, Carolyn Roberts und Martin Roberts, Knowledge and the Future School. Curriculum and Social Justice, London etc.: Bloomsbury Academic, 2014. 
mente, die in den analysierten Geografieschulbüchern bereits vorhanden sind, könnten sicherlich genaue Schritte der (visuellen) Landschaftsanalyse vorgestellt und in der Einleitung einzelner Kapitel oder an anderer Stelle geübt werden. Dies würde den minimalen Anforderungen eines kompetenzorientierten Unterrichts im Sinne des Future 2 Curriculums ${ }^{61}$ sicherlich entsprechen. Wesentlich wichtiger wäre aber die Auseinandersetzung mit den Koordinaten subjektiver Landschaftswahrnehmungen im Sinne von Sehfiguren, ${ }^{62}$ aber jenseits der Bescheidenheit der gegenwärtig propagierten deutschsprachigen Visuellen Geografien. Nur ein solcher Geografieunterricht, der auf der Grundlage vom Expertenwissen reflexiv ist, kann zur Förderung eines powerful disciplinary knowledge $e^{63}$ beitragen.

\section{Literatur}

Bechmann, Arnim. Ökologischer Landbau - aus der Nische in die Fläche, Barsinghausen: Edition Zukunft, 2009.

Clifford, Nicholas, Sarah Holloway, Stephen P. Rice und Gill Valentine (Hg.). Key Concepts in Geography, London u. a.: SAGE, 2009.

Czekalla, Dieter, Steffen Werner, Michele Barichelli, Bodo Meißner und Silke Pflüger. TERRA Geographie 5/6 Berlin/Brandenburg, Stuttgart/Leipzig: Klett, 2011.

Deutsche Gesellschaft für Geographie (DGfG). Bildungsstandards im Fach Geographie für den Mittleren Schulabschluss mit Aufgabenbeispielen, Bonn: Selbstverlag Deutsche Gesellschaft für Geographie, 8. Auflage 2014.

Duncan, James. The City as Text: The Politics of Landscape Interpretation in the Kandyan Kingdom, New York/Cambridge: Cambridge University Press, 1990.

Gray, Murray. "Landscape: The Physical Layer «, in: Key Concepts in Geography, Nicholas Clifford, Sarah Holloway, Stephen P. Rice und Gill Valentine (Hg.), London u. a.: SAGE, 2009, 265-284.

Hard, Gerhard. »Landschaft als professionelles Idol«, in: Garten und Landschaft 3 (1991), 13-18.

Hasse, Jürgen. Heimat und Landschaft - Über Gartenzwerge, Center Parcs und andere Ästhetisierungen, Wien: Passagen Verlag, 1993.

Ders. "Zur mythischen Funktion deklarierter Natur-Landschaften. Das Beispiel des "Weltnaturerbes« Wattenmeer", in: Küstenmentalität und Klimawandel. Küstenwandel als kulturelle und soziale Herausforderung, Ludwig Fischer und Karsten Reise (Hg.), München: oekom, 2011, 97-113.

Krause, Karin, Michele Barichelli, Krystyna Kusserow, Bodo Meißner und Silke Pflüger. TERRA Geographie 7/8 Berlin/Brandenburg, Stuttgart/Leipzig: Klett, 2012.

61 Ebd.

62 Hard, »Landschaft als professionelles Idol«.

63 Young, Lambert, Roberts und Roberts, Knowledge and the Future School. 
Krause, Karin, Steffen Werner, Michele Barichelli, Krystyna Kusserow und Bodo Meißner. TERRA Geographie 9/10 Berlin/Brandenburg, Stuttgart/Leipzig: Klett, 2013.

Kühne, Olaf. Landschaft als Konstrukt und die Fragwürdigkeit der Grundlagen der konservierenden Landschaftserhaltung - eine konstruktivistisch-systemtheoretische Betrachtung, Wien: Verein Kritische Geographie, 2005.

Ders. Landschaft, Geschmack, soziale Distinktion und Macht - von der romantischen Landschaft zur Industriekultur. Eine Betrachtung auf der Grundlage der Soziologie Pierre Bourdieus, Wien: Verein Kritische Geographie, 2006.

Meinig, Donald W. (Hg.). The Interpretation of Ordinary Landscapes: Geographical Essays, New York/Oxford: Oxford University Press, 1979.

Mitchell, Don. The Lie of the Land: Migrant Workers and the California Landscape, Minneapolis: University of Minnesota Press, 1996.

Morin, Karen M. »Trains Through the Plains: The Great Plains Landscape of Victorian Women Travellers«, in: Great Plains Quarterly 18 (1998), 235-256.

Dies. "Landscape: Representing and Interpreting the World", in: Key Concepts in Geography, Nicholas Clifford, Sarah Holloway, Stephen P. Rice und Gill Valentine (Hg.), London u. a.: SAGE, 2009, 286-298.

Schultz, Hans-Dietrich. »Versuch einer ideologiekritischen Skizze zum Landschaftskonzept«, in: Geografiker 6 (1971), 1-12.

Ders. »Wie das Land, so das Volk, wie das Volk, so das Land : Landschafts- und Länderkunde (die klassische Geographie) auf Abwegen «, in: Kontinuitäten im Naturschutz, Nils M. Franke und Uwe Pfennig (Hg.), Baden-Baden: Nomos, 2014, 23-79.

Wardenga, Ute. "Alte und neue Raumkonzepte für den Geographieunterricht«, in: geographie heute 23 (2002), 8-11.

Woodward, Rachel. „Warrior Heroes and Little Green Men: Soldiers, Military Training, and the Construction of Rural Masculinities«, in: Rural Sociology 65 (2000), 640-657.

Young, Michael, David Lambert, Carolyn Roberts und Martin Roberts. Knowledge and the Future School. Curriculum and Social Justice, London et al.: Bloomsbury Academic, 2014. 


\section{Die Region als Landschaft: Ostpreußen/Warmia i Mazury in Geschichts- und Geografieschulbüchern}

Die deutsche Vorstellung von Ostpreußen und die polnische Vorstellung von Warmia i Mazury (Ermland und Masuren) haben eines gemeinsam: Der Bezug auf die Landschaft und, mehr noch, auf die landschaftliche Einzigartigkeit spielt eine herausragende Rolle. Dies ist zunächst einmal einträglich für die regionale Tourismuswirtschaft, es ist aber zugleich auch, und darauf haben Studien der vergangenen Jahre hingewiesen, ein wichtiger Bestandteil von Identitätskonstruktionen - sei es von Flüchtlingen und Vertriebenen, die sich auf diese Weise eine ex-post-Identität und idealisierte Heimat schaffen, ${ }^{1}$ sei es von zivilgesellschaftlich engagierten heutigen Bewohnern Ermlands und Masurens, die seit den 1990er Jahren unter dem Stichwort »offener Regionalismus« eine umfassende Neuentdeckung des historischen und materiellen Erbes der Region vorantreiben, ${ }^{2}$ oder sei es von Schülerinnen und Schülern der Wojewodschaft Ermland und Masuren, die eine erste Beziehung zu ihrer lebensweltlichen Umgebung aufbauen. ${ }^{3}$

Nun ließe sich natürlich fragen, ob denn nicht im mitteleuropäischen Kontext der Schwarzwald, die Alpen oder die Steilküste der Insel Rügen landschaftlich

1 Jutta Faehndrich, »Erinnerungskultur und Umgang mit Vertreibung in Heimatbüchern deutschsprachiger Vertriebener«, in: Zeitschrift für Ostmitteleuropaforschung 52 (2003), 198-199; Elisabeth Fendl (Hg.), Zur Ikonographie des Heimwehs. Erinnerungskultur von Heimatvertriebenen, Freiburg: Johannes Künzig-Institut für ostdeutsche Volkskunde, 2002.

2 Wegweisend waren hier die nur exemplarisch anzuführenden Arbeiten von Robert Traba, Kraina tysiąca granic. Szkice o historii i pamięci, Olsztyn: Stowarzyszenie WK Borussia, 2003; Zbigniew Mazur (Hg.), Wokót niemieckiego dziedzictwa kulturowego na Ziemiach Zachodnich i Pótnocnych, Poznań: Instytut Zachodni, 1997; Ders. (Hg.), Wspólne dziedzictwo? Ze studiów nad stosunkiem do spuścizny kulturowej na Ziemiach Zachodnich i Polnocnych, Poznań: Instytut Zachodni, 2000; Wojciech Łukowski, Społeczne tworzenie ojczyzn. Studium tożsamości mieszkańców Mazur, Warschau: Wydawnictwo Naukowe "Scholar", 2002 sowie die Beiträge in der von Robert Traba und Kazimierz Brakoniecki herausgegebenen Zeitschrift Borussia (1991 ff.).

3 Izabela Lewandowska, »Historyczna świadomość regionalna. $Z$ badań nad młodzieżą licealną Warmii i Mazur", in: Rozprawy i Materiały Ośrodka Badań Naukowych im. Wojciecha Kętrzyńskiego w Olsztynie 214 (2003), 203-204. 
mindestens ebenso einzigartig sind, ${ }^{4}$ und ebenso gewichtig ist der Hinweis, dass in Ostpreußen/Warmia i Mazury durchweg unterschiedliche physisch-geografische Phänomene anzutreffen sind: die Masurische Seenplatte und die samländische Steilküste, das hügelige »Oberland « (Garb Lubawski) und die feuchte Memelniederung. ${ }^{5}$ Die genannten Einwände richten sich zwar kritisch gegen die Verabsolutierung von Landschaft im Sinne einer vermeintlichen Einzigartigkeit, doch begreifen sie Landschaft als eine materiell fassbare Größe, die allenfalls unterschiedlich symbolisch angeeignet wird. Blickt man auf den wissenschaftlichen Diskussionsverlauf, zeigt sich, welch unterschiedliche Konzepte von Landschaft und des Mensch-Landschaft-Verhältnisses existieren.

Landschaft ist stärker ein Begriff der humanistischen Fächer und der Humangeografie als der Naturwissenschaften und der physischen Geografie, die sich bevorzugt einzelnen Geofaktoren wie Klima, Vegetation oder Böden widmen. In dem Bestreben, den naturwissenschaftlichen Positivismus des 19. Jahrhunderts hinter sich zu lassen, begab sich seit Beginn des 20. Jahrhunderts eine einflussreiche Strömung in der deutschen Humangeografie ${ }^{6}$ auf die Suche nach der Individualität, dem »Wesen « einer Landschaft, zugespitzt im Konzept der »dynamischen Länderkunde«: Ein Geofaktor wie Klima oder Vegetation bestimmte den Charakterzug einer Landschaft, und zugleich prägte eine Landschaft die dort lebenden Menschen. Im deutschen fachwissenschaftlichen, vor allem aber im schulgeografischen Kontext wirkte diese Strömung fort im langlebigen Paradigma der Regionalen Geografie, die darum bemüht war, die »natürliche« Einmaligkeit von Landschaften herauszuarbeiten. ${ }^{7}$ Freilich gab es

4 Gregor Thum, »Mythische Landschaften. Das Bild vom `deutschen Osten 20. Jahrhunderts«, in: ders. (Hg.), Traumland Osten. Deutsche Bilder vom östlichen Europa im 20. Jahrhundert, Göttingen: Vandenhoeck \& Ruprecht, 2006, 202-203.

5 Herbert Liedtke, Die Landschaften Ostpreußens. Namen und Abgrenzungen naturgeographischer und historischer Landschaften in Ostpreußen und angrenzenden Gebieten, Daten, Fakten, Literatur zur Geographie Europas 10, Leipzig: Leibniz-Institut für Länderkunde, 2011; Jerzy Kondracki, Geografia regionalna Polski, Warschau: Wydawnictwo Naukowe PWN, 2. Auflage 2000, 86-123.

6 Zur Einbettung in die Disziplingeschichte vgl. auch die Beiträge »Raum, Landschaft und Kulturlandschaft - Annäherungen an komplexe Begriffe» und »Der Wert von Kulturlandschaften für die Umweltbildung in Deutschland aus kultur- und ideengeschichtlicher Perspektive« in diesem Band.

$7 \mathrm{Zu}$ den ideellen und diskursiven Konstruktionen von Landschaft und Natur grundsätzlich: Ludwig Trepl, Die Idee der Landschaft. Eine Kulturgeschichte von der Aufklärung bis zur Ökologiebewegung, Bielefeld: transcript, 2012; einen Überblick über die Forschungsdiskussion bietet Olaf Kühne, »Wie kommt die Landschaft zurück in die Humangeographie? Plädoyer für eine `konstruktivistische Landschaftsgeographie«", in: Geographische Zeitschrift 102 (2014), 68-85; eine wissenschaftstheoretische Erörterung zwischen den Polen Idiografie und Konkretisierung von Natur gibt Ulrich Eisel, »Die Hintergründe des Raumes. Eine Einführung in die Verflechtung von einigen Gedanken«, in: ders., Landschaft und Gesellschaft. Räumliches Denken im Visier, Münster: Verlag Westfälisches Dampfboot, 2009, 15-40. 
in der Auffassung von Landschaft stets auch konkurrierende Strömungen, darunter die im mittel- und osteuropäischen Kontext besonders wirkmächtige Vorstellung vom Menschen als Gestalter von Landschaft. Dabei fand eine Überhöhung des anthropogenen Wirkens statt, in Form von Zivilisierungsutopien und entsprechenden Missionsvorstellungen (»Kulturträgertum«), oder aber, in einer materialistischen Spielart, im Konstrukt eines "neuen Menschen" wie z.B. des homo sovieticus, der die Landschaft nach seinem Willen und zu seinem Wohle formt.

Von diesen stark normativ aufgeladenen Landschaftskonzepten unterschied sich bereits in der ersten Hälfte des 20. Jahrhunderts die Herangehensweise der französischen Geografie und der Annales-Historiker. Ihnen zufolge konnte die menschliche Gestaltungskraft innerhalb einer gegebenen naturräumlichen Ausstattung unterschiedliche Pfade einschlagen und $\mathrm{zu}$ unterschiedlichen Ergebnissen führen. Diesem Possibilismus folgten auch polnische Geografen der Zwischenkriegszeit. ${ }^{8}$ Mit einer stärkeren Betonung auf Individualität und Diversität analysierten amerikanische Geografen um Carl O. Sauer die kulturellen Gepflogenheiten, Werte und Ziele sozialer Gruppen als landschaftsprägend. Der von ihnen verwendete Begriff der "Kulturlandschaft« erhielt so einen weniger deterministischen Charakter. ${ }^{9}$

In den 1960er Jahren kam es dann zu einem bis heute anhaltenden Paradigmenwechsel, der sich nicht nur in einer Abkehr von einem materiellen Landschaftsverständnis, sondern auch in einer intensiven methodischen (Selbst-)Reflexion räumlich interessierter Wissenschaftler ausdrückte. In der behavourial geography ging es nun um die Wahrnehmung von Räumen, Distanzen und natürlicher Umwelt, um die »Welt in den Köpfen« (mental maps). Die Kultur- und Geschichtswissenschaften, die dieses Konzept aufgriffen, verschoben den Akzent von der individuellen zur kollektiven Wahrnehmung und untersuchten mental maps und "imaginierte Landschaften « in nationalen, regionalen oder anderen gruppenspezifischen Semantiken.

In jüngerer Zeit diskutieren Geografen einen handlungstheoretischen Ansatz, der den Menschen beim alltäglichen »Geografie-Machen « analysiert und Landschaft und Raum als abhängige Variablen gesellschaftlichen Handelns

8 Andrzej Lisowski, "Geografia społeczna«, in: Antoni Jackowski, Stanisław Liszewski und Andrzej Richling (Hg.), Historia geografii polskiej, Warschau: Wydawnictwo Naukowe PWN, 2008, 195-198.

9 Paul L. Knox und Sallie A. Marston, Humangeographie, Heidelberg: Springer, Spektrum Akademischer Verlag, 4. Auflage 2008, 319-320; Marc Antrop, »Interacting Cultural, Psychological and Geographical Factors of Landscape Preference», in: Diedrich Bruns, Olaf Kühne, Antje Schönwald und Simone Theile (Hg.), Landscape Culture - Culturing Landscapes. The Differentiated Construction of Landscapes, Wiesbaden: Springer VS, 2015, 61. 
ansieht. ${ }^{10}$ Dagegen entfaltet David Blackbourn in seiner historischen Studie zur deutschen (Wasser-)Landschaft die Erzählung vom Menschen als Gestalter von Landschaft, der stets mit den nicht-intendierten Wirkungen seines Handelns konfrontiert ist. ${ }^{11}$ Einen integrativen Vorschlag unterbreiten Kulturwissenschaftler, die Landschaft als Text verstehen. Anschaulich formuliert, wird eine Landschaft sowohl "geschrieben« (gestaltet, kulturell codiert, diskursiv produziert) als auch "gelesen «, wobei unterschiedliche Lesarten möglich sind. ${ }^{12}$ Dieses Verständnis von Landschaft trägt konstruktivistischen Erkenntnissen Rechnung, ohne Aspekte der Materialität und Performanz zu negieren. Zugleich bietet es einen flexiblen begrifflich-analytischen Rahmen, um die historische und disziplinäre Vielfalt von Landschaftsvorstellungen sichtbar zu machen, und dient daher der folgenden Studie als Leitfaden.

Grundsätzlich kann sich jedes der vorgestellten Konzepte von Landschaft auf einen bestimmten räumlichen Ausschnitt beziehen. Im vorliegenden Beitrag geht es um die Bedeutung von Landschaft für die Konstruktion einer Region. In der gegenwärtigen wissenschaftlichen Diskussion werden Regionen als imagined communities beschrieben, die im Vergleich zur Nation eine größere Flexibilität und Optionalität besitzen und sich stärker auf gemeinsame Erfahrungen, Wissensbestände und Lesarten als auf politische Institutionen richten. Sie ergeben damit eigenwillige räumliche Gebilde ohne klare äußere Konturen, die deswegen aber auch vermeintlich starre staatliche Grenzen überschreiten können. Gleichzeitig sind Regionen in ihrem Inneren selten homogen, sondern beziehen vielmehr wirtschaftliche, gesellschaftliche oder kulturelle Einflüsse von unterschiedlicher Prägekraft, Dauer und Auswirkung ein. Als Resultat dieser Einflüsse kann nun auch eine Landschaft "gemacht « und "geschrieben « werden, die auf vielfältige Weise »lesbar« ist. Region und Landschaft sind damit sich wechselseitig verstärkende Konstruktionen.

Eine solche Perspektive auf Region und Landschaft ist in Schulbüchern noch selten anzutreffen. ${ }^{13}$ Während deutsche Geschichtsschulbücher regionale Bezüge in einem klassischen landesgeschichtlichen Sinn auf das Bundesland ihres Geltungsbereichs beschränken, sind polnische Geschichtsschulbücher bis heute stark zentralstaatlich orientiert. Mit Ausnahme von Kapiteln zur Geschichte des

10 Benno Werlen, Sozialgeographie. Eine Einführung, Bern u. a.: Haupt, 2000, 309-313.

11 David Blackbourn, Die Eroberung der Natur. Die Geschichte der deutschen Landschaft, München: Deutsche Verlagsanstalt, 2007, 27, 28.

12 Knox und Marston, Humangeographie, 381-382.

13 Eine exemplarische Analyse, die vor wenigen Jahren anhand deutscher Schul- und Kindersachbücher vorgenommen wurde, verweist auf eine dominant positivistische Sicht von Landschaft, deren kritischer Impuls sich allenfalls auf die Thematisierung ökologischer Probleme erstreckt: Olaf Kühne, Distinktion - Macht - Landschaft. Zur sozialen Definition von Landschaft, Wiesbaden: VS Verlag für Sozialwissenschaften, 2008, 281-291. 
Deutschen Ordens gibt es daher weder in Deutschland oder Polen ausführliche und didaktisch gut aufbereitete Darstellungen zu Ostpreußen/Warmia i Mazury, vielmehr scheinen viele Textabschnitte, Quellen oder Abbildungen eher nach dem Zufallsprinzip den Weg ins Schulbuch gefunden zu haben. Wohl gerade wegen ihres nicht-intentionalen Charakters bieten aber viele dieser Fragmente sehr interessante Einblicke in den didaktischen Umgang mit Landschaft. In Geografieschulbüchern wird das Thema Region und Landschaft, auch in Bezug auf das konkrete Beispiel Ostpreußen/Warmia i Mazury ausführlicher behandelt, allerdings werden die zugrundeliegenden Konzepte nicht immer explizit gemacht und selten werden den Schülerinnen und Schülern alternative Konzepte vorgestellt.

Die vorliegende Analyse stützt sich auf deutsche und polnische Geschichtsund Geografieschulbücher für die Sekundarstufe von den 1920er Jahren bis heute. ${ }^{14}$ Einen Blick über den deutsch-polnischen Tellerrand bietet der asymmetrische Vergleich mit sowjetischen, russischen und litauischen Geschichtsund Geografieschulbüchern für die Sekundarstufe von den 1950er Jahren bis heute, die sich Teilen des ehemaligen Ostpreußens, nämlich dem Gebiet Kaliningrad und dem Memelland (Klaipedos krastas), widmen.

\section{»Deutsche« Landschaften}

Ostpreußen als eine "deutsche« Landschaft zu präsentieren war in deutschen Geschichts- und Geografieschulbüchern bis in die 1970er Jahre hinein die Regel. Die vorherrschende Lesart bewegte sich dabei in einer Trias von Wildnis-Zivilisierung-Zerfall.

Wenn in deutschen Geschichtsschulbüchern aus der Zeit vor dem Zweiten Weltkrieg die Erzählungen von der Mission des Deutschen Ordens einsetzten, spielten Landschaftsdarstellungen eine hervorgehobene Rolle. Die Sümpfe, Moore und Wälder bildeten die Folie, vor der die Inbesitznahme des Landes durch den Deutschen Orden und die nachfolgende Besiedelung heroische Dimensionen annahm. Ein erster Schritt in der Bezwingung der Natur war der Bau von Burgen und Festungen, die eine architektonisch gestaltete Landschaft er-

14 Die Quellengrundlage beruht auf einem von der Deutschen Forschungsgemeinschaft (DFG) und dem polnischen Wissenschaftsministerium (MNiSW) geförderten Projekt des GeorgEckert-Instituts - Leibniz-Institut für internationale Schulbuchforschung und der Ermländisch-Masurischen Universität, Olsztyn. Als wichtigste Publikation hierzu: Stephanie Zloch und Izabela Lewandowska (Hg.), Das >Pruzzenland als geteilte Erinnerungsregion. Konstruktion und Repräsentation eines europäischen Geschichtsraums in Deutschland, Polen, Litauen und Russland seit 1900, Eckert. Die Schriftenreihe 135, Göttingen: V\& R unipress, 2014. 
gaben: ein dicht gesponnenes Netz von Ordensburgen und »blühenden« Städten ${ }^{15}$ und die Marienburg als "prächtiges" und "herrliches« Wahrzeichen des Deutschordensstaates. ${ }^{16}$ Ein zweiter Schritt war die landwirtschaftliche Umgestaltung von Vegetation und Böden, die deutschen Schulbuchautorinnen und -autoren reichlich Gelegenheit bot, Vorstellungen von »Germanisierung « und deutscher »Kulturträgerschaft « zu entwickeln: »Aus trostloser Wildnis hatte der Orden ein blühendes Land geschaffen, deutsches Land, mit deutschen Blut getränkt«. ${ }^{17}$

Deutsche Geschichtsschulbücher der 1950er Jahre schienen auf den Narrativen der Vorkriegszeit nahezu nahtlos aufzubauen. Leitmotiv war weiterhin die Erschließung und Germanisierung des Landes. ${ }^{18}$ Ein Unterschied zur Vorkriegszeit lag vor allem darin, dass Darstellungen der 1950er Jahre die architektonische und wirtschaftliche Gestaltung des Landes betonten und damit im Umgang mit der Landschaft weniger eine militärische als eine zivilisatorische Perspektive aufzeigten. Darin ist sicherlich auch ein Reflex auf die Erfahrung der deutschen Niederlage im Zweiten Weltkrieg zu sehen.

Die Vorstellung vom Menschen als Gestalter von Landschaft prägte, im Einklang mit der materialistischen Weltsicht, auch die in der DDR erschienenen Schulbücher. Sie thematisierten die Rodung von Wäldern und die Trockenlegung von Sümpfen ebenso sowie die Gründung von Burgen und Städten. Die Darstellungen waren aber nicht nur erzählerisch knapper, sondern schlossen auch den Vorwurf "großer Grausamkeit« des feudalen Deutschen Ordens und der deutschen Siedler gegenüber den einheimischen Pruzzen ein. ${ }^{19}$

15 Arnold Reimann (Hg.), Geschichtswerk für höhere Schulen. Teil 2: Grundbuch für den gesamten Geschichtsunterricht auf Mittel- und Oberstufe. Heft 2: Mittelalter und Reformationszeit, München/Berlin: Oldenbourg, 3. Auflage 1925, 85; Bernhard Kumsteller, Ulrich Haacke und Benno Schneider (Hg.), Geschichtsbuch für die deutsche Jugend. Mittelstufe. Für die Jüngeren, Leipzig: Quelle \& Meyer, 38. Auflage 1935, 121.

16 Hermann Pinnow, Geschichte des deutschen Volkes von den Anfängen bis 1648. Geschichtsbuch für die Mittelklassen höherer Lehranstalten, Band 2, Leipzig/Berlin: Verlag Teubner, 5. Auflage 1925, 57; Wilhelm Schiefer (Hg.), Maier-Schirmeyer. Lehrbuch der Geschichte für höhere Schulen. Mittelstufe. Band 2: Von der germanischen Frühzeit bis zum Westfälischen Frieden, Frankfurt am Main: Diesterweg, 12. Auflage 1937, 119.

17 Bernhard Kumsteller, Ulrich Haacke und Benno Schneider (Hg.), Geschichtsbuch für die deutsche Jugend, Klasse 3, Leipzig: Quelle und Meyer, 1939, 57.

18 Als Beispiele: Eugen Kaier u. a., Grundzüge der Geschichte. Von der Frühgeschichte Europas bis zur Weltpolitik der Gegenwart, Frankfurt am Main u. a.: Diesterweg, 1958, 111; Franz Ebner, Geschichte des Mittelalters. Geschichtswerk für höhere Lehranstalten. Mittelstufe. Band 2: Mittelalter, München: Lurz, 1956, 127.

19 Evgenij A. Kosminskij, Geschichte des Mittelalters, Berlin:Volk und Wissen, 5. Auflage 1952, 160; Wissarion F. Semjonow, Geschichte des Mittelalters, Berlin: Volk und Wissen, 1952, 206-207; Autorenkollektiv, Lehrbuch für den Geschichtsunterricht, 6. Schuljahr, 1. Teil, Berlin/Leipzig: Volk und Wissen, 1951, 79. 
Die Erschließung des Landes war eine fragile Angelegenheit. In der Zeit um 1700 gingen durch Pest, Missernten, Hungersnot und wiederholte Kriegsverwüstungen fast ein Drittel der Einwohner verloren. In einem Schulbuch der 1930er Jahre hieß es: „Friedrich Wilhelm findet Ostpreußen durch die Pest und durch feindliche Mordbrenner entvölkert vor. Dornen und Unkraut überwuchern den Ackerboden. Die leergebrannten Häuser recken ihre verkohlten Dachsparren drohend gen Himmel. Wölfe streichen hungrig um notdürftig errichtete Ställe. ${ }^{20}$

Die Erzählung von Verwüstung, Not und unbändiger Natur mündete allerdings in die Erzählung einer Gegenmaßnahme, nämlich des raschen und erfolgreichen absolutistischen Landesausbaus der preußischen Könige: »In der Gegend von Gumbinnen, Memel und Tilsit wurden allein zwölf Städte und 332 Dörfer neugegründet. ${ }^{21}$ Beliebig oft ließ sich ein solches Narrativ nicht wiederholen, bedeutete dies doch, dass der Landesausbau auf tönernen Füßen stand. Das Lob der Zivilisierung und die Angst vor dem Zerfall standen nahe beieinander.

Nur wenige Passagen gab es, in denen die Lesart der Landschaft als Wildnis positive Konnotationen weckte: Deutsche Schulbücher der Zwischenkriegszeit stilisierten die ostpreußische Landschaft als möglichst rau und undurchdringlich, um die Siege der deutschen Truppen über die russische Armee im Ersten Weltkrieg umso stärker preisen zu können. ${ }^{22}$ Wenige Jahrzehnte später gab es keine positiv konnotierte Wildnis mehr. Das Kapitel zu Flucht, Vertreibung und Umsiedlung der deutschen Bevölkerung war in den Geschichtsschulbüchern ganz im Duktus einer Untergangsstimmung gefasst. Fotografien der Flüchtlingstrecks zeigten trübe winterliche Landschaften und die dazugehörigen Bildunterschriften verkündeten: „Verjagt von Haus und Hof, aus der Heimat vertrieben, auf dem Treck in eine ungewisse Zukunft «. ${ }^{23}$

Die Vorstellung vom Menschen als Gestalter von Landschaft, die die Darstellung Ostpreußens in deutschen Geschichtsschulbüchern bis weit in das

20 Moritz Edelmann und Leo Gruenberg (Hg.), Volkwerden der Deutschen. Geschichtsbuch für höhere Schulen. Klasse 4. Deutsche Geschichte von 1648-1871, Leipzig/Berlin: B.G. Teubner, 1939, 45; ähnlich noch: Hans Herbert Deissler u. a., Grundzüge der Geschichte. Band 3: Vom Westfälischen Frieden bis zum Jahre 1890, Frankfurt am Main u. a.: Diesterweg, 6. Auflage 1970, 54-55.

21 Paul Schmitthenner und Friedrich Fliedner (Hg.), Führer und Völker. Geschichtsbuch für höhere Schulen. Klasse 4. Deutsche Geschichte von 1648 bis 1871, Bielefeld/Leipzig: Velhagen \& Klasing, 1939, 62.

22 Als Beispiel: Walther Gehl, Geschichte. 5. Klasse. Oberschulen, Gymnasien und Oberschulen in Aufbauform. Von der Gründung des Zweiten Reiches bis zur Gegenwart, Breslau: Ferdinand Hirt, 1939, 82.

23 Josef Habisreutinger und Walter Krick, Geschichtliches Werden. Mittelstufe. Band 4: Geschichte der Neuesten Zeit 1815-1950, Bamberg: C.C. Buchner, 2. Auflage 1957, 180. 
20. Jahrhundert hinein prägte, war eng gekoppelt mit Zivilisierungsutopien und Vorstellungen deutscher ethnischer Überlegenheit. Als für Erzählungen über die Zeit nach 1945 keine deutschen Siedler oder Krieger mehr als Gestalter von Landschaft zur Verfügung standen, machte sich eine konzeptionelle Ratlosigkeit bemerkbar. Eine eigentümliche Spannung kennzeichnete daher vor allem die bundesdeutschen Geografieschulbücher der 1950er bis 1970er Jahre, die sich mit gegenwärtigen Entwicklungen zu beschäftigen hatten. Kurz nur widmeten sie sich allerdings der Situation in der Volksrepublik Polen und der Sowjetunion. Der Tenor war eindeutig: »Der forcierte Aufbau Allensteins als >WojwodschaftsHauptstadt ‘ kann nicht darüber hinwegtäuschen, daß die ostpreußische Kulturlandschaft verfällt « ${ }^{24}$ oder: "Im nördlichen Ostpreußen, das die Russen den Distrikt Kaliningrad nennen, hat man große Staatsgüter, sogenannte Sowchosen eingerichtet und für sie Landarbeiter aus allen Teilen der Sowjetunion herbeigeholt. Überall sieht man im Lande russische Soldaten. ${ }^{25}$

Diese Sätze bildeten in der Regel den knappen Anhang eines sich über mehrere Seiten erstreckenden Abschnitts über Ostpreußen, der in Umfang und Gliederung eine »deutsche Landschaft« ebenbürtig etwa mit Westfalen oder Hessen beschrieb. Die Schulbuchautorinnen und -autoren bewegten sich ganz im Rahmen der Regionalen Geografie mit ihrem Postulat der »natürlichen« Einmaligkeit von Landschaften; politische und demografische Veränderungen spielten eine nachgeordnete Rolle. Im Ergebnis wurden damit in den Schulbuchdarstellungen zu Ostpreußen die Umstände aus der Zeit vor dem Zweiten Weltkrieg vermeintlich zeitlos konserviert.

Ausdrücklich wurden, sprachlich im Präsens gehalten, die Nehrungen und die samländische Steilküste ihrer Schönheit wegen gerühmt; ähnliches galt für die Seen und Wälder im Binnenland. ${ }^{26}$ Der Blick richtete sich aber auch auf eingängige Ausdrucksformen gestalteter Landschaft: Das idyllisch beschriebene »ostpreußische Bauernland ${ }^{27}$ oder Königsberg "mit Schloß, Dom und alten, malerischen Fachwerkspeicherhäusern ${ }^{28}$ sollten bei den Schülerinnen und Schülern positive Assoziationen hervorrufen, vor allem aber sollte dies die Marienburg: Dort, an der Nogat, »künden Kirche und Schloß machtvoll von der

24 Christian Degn u. a. (Hg.), Seydlitz. Teil 4: Deutschland und Europa, Kiel/Hannover: Ferdinand Hirt, 5. Auflage 1958, 111.

25 Hans Knübel (Hg.), Länder und Völker. Erdkundliches Unterrichtswerk. Ausgabe A. Band 1: Deutschland und seine Nachbarländer im Süden und Osten, Stuttgart: Klett, 9. Auflage 1959, 35.

26 Ebd.; Wilhelm Schäfer (Hg.), Erdkunde für höhere Lehranstalten. Band 1: Deutsche Landschaften, Paderborn: Schöningh, 21. Auflage 1956, 49-50.

27 Ludwig Bauer (Hg.), Erdkundliches Unterrichtswerk für höhere Lehranstalten. Band 2: Länderkunde von Mitteleuropa, München/Düsseldorf: Oldenbourg, 1953, 182.

28 Knübel (Hg.), Länder und Völker, 35. 
Glaubenskraft, dem Schönheitssinn und der Tapferkeit der Deutschherrenritter . $^{29}$

Allerdings attestierten die Geografieschulbücher der von ihnen präsentierten Landschaft Ostpreußens auch eine gewisse Düsternis. So sprachen sie von "unfruchtbaren Sandebenen«, "mageren Böden « ${ }^{30}$ und vom rauen Klima: "Der Schnee bleibt häufig bis in den April hinein liegen. Vielfach ist noch der Mai und schon der September nicht mehr frei von Frost «. ${ }^{31}$ Nicht weit war es dann zur naturdeterministischen Überzeugung, die Landschaft präge ihre Bewohner: »Schwere Seemanns- und Bauernarbeit formte sie zu nüchtern und zweckmäßig denkenden Menschen. Kernig, entschlossen und mannhaft war ihre Art, gemütstief ihr Fühlen, wortkarg ihr Sprechen. ${ }^{32}$

War dies das "konservative Traumland" und "verlorene Paradies», das als rückständig, wild und unverdorben der modernen industriellen Zivilisation Westdeutschlands gegenübertrat, wie der Historiker Gregor Thum meint ?3 $^{33}$ Oder hielten sich bei den Schülerinnen und Schülern im Westen Deutschlands die Gefühle der Zugehörigkeit und Bewunderung für eine naturdeterministisch gezeichnete Vorkriegslandschaft doch eher in Grenzen? Zweifelsfrei war die jüngere Generation in der Bundesrepublik weit stärker vom umfänglichen gesellschaftlichen und kulturellen Wandel seit den späten 1950er Jahren und der bevorzugten Ausrichtung der mental maps auf Westeuropa und Nordamerika erfasst.

\section{Gemeinsame Landschaften?}

Die didaktischen Umbrüche in der Bundesrepublik Deutschland in den späten 1960er und frühen 1970er Jahren waren eine logische Konsequenz des gesellschaftlichen und kulturellen Wandels. Das Prinzip der Geschichtserzählung und die damit verbundene suggestive Sprache hatten ausgedient; daher nahm auch die Zahl der Landschaftsbeschreibungen in deutschen Geschichtsschulbüchern drastisch ab. Leitender Ansatz war nun die Wirtschafts- und Sozialgeschichte bzw. die Geschichte als historische Sozialwissenschaft.

Der Staat des Deutschen Ordens erschien nun als wirtschaftsstarker, wohl organisierter Staat und Städte wie Danzig, Elbing oder Königsberg nüchtern-

29 Bauer (Hg.), Erdkundliches Unterrichtswerk für höhere Lehranstalten, Band 2, 176.

30 Emil Hinrichs, Erdkunde für höhere Schulen. Band 1: Deutschland und die Länder Europas ringsum, Frankfurt am Main u. a.: Diesterweg, 6. Auflage 1958, 66.

31 Bauer (Hg.), Erdkundliches Unterrichtswerk für höhere Lehranstalten, Band 2, 179.

32 Ebd., 184; ähnlich auch: Degn u. a. (Hg.), Seydlitz, Teil 4, 110.

33 Thum, "Mythische Landschaften«, 207. 
funktional als Handelsstädte an der Ostseeküste. ${ }^{34}$ Gleichzeitig zeigten sich die gewandelten politischen Beziehungen zu Polen. Die Marienburg war nicht länger allein prächtiges Bauwerk des »deutschen Mittelalters«. So war in Bildunterschriften zu lesen:»Die Marienburg an der Nogat, seit 1309 Hochmeistersitz des Deutschen Ritterordens. (Bau des Hochschlosses um 1340, Wiederaufbau nach dem letzten Krieg durch Polen) $\aleph^{35}$ oder, als Arbeitsauftrag formuliert: »Die Marienburg, erbaut zwischen 1272 und 1320, war die Hauptburg des deutschen Ritterordens und Sitz seines Hochmeisters. Schildere dieses Bauwerk und seinen Zweck aus deutscher und aus polnischer Sicht $«{ }^{36}$ Zum ersten Mal erschien hier eine vom Menschen gestaltete Landschaft als gemeinsames, deutsch-polnisches kulturelles Erbe.

Auch die bundesdeutschen Geografieschulbücher waren in den 1970er Jahren von deutlichen Umbrüchen gekennzeichnet. Neu war eine Abbildung der Kaliningrader Innenstadt mit der Bildunterschrift: "Königsberg wird nach den starken Kriegszerstörungen wiederaufgebaut. Im Hintergrund das zerschossene Schloß der Ordensritter und später der preußischen Könige. ${ }^{37}$ Trotz anhaltender Skepsis gegenüber der polnischen und sowjetischen "Verwaltung" war das frühere, ausschließlich auf Niedergang und Verfall nach 1945 abzielende Narrativ erstmals aufgebrochen. Gewürdigt wurde nun eine Gestaltung von (Stadt-)Landschaft, die nicht allein von Deutschen ausging.

Und noch ein weiterer neuer Akzent kam hinzu: Ostpreußen war nun nicht mehr »deutsche Landschaft", sondern fand sich in einem Kapitel über Polen unter der Überschrift "Erholung und Fremdenverkehr". Dabei stellten die Schulbuchautoren fest, dass es an der Nehrungsküste "ausgezeichnete Sandstrände« gebe: »Sie können zu großzügigen Erholungsgebieten ausgebaut werden«. Ähnliche Wertschätzung galt dem Binnenland: ॥Im Bereich des Baltischen Landrückens, der sich durch Pommern, West- und Ostpreußen erstreckt, gibt es über 1000 Seen. Von ihnen sind die Masurischen Seen in weitem Umkreis um die Stadt Allenstein die schönsten und größten. Sie alle bieten Bademöglichkeiten

34 Robert Hermann Tenbrock und Kurt Kluxen (Hg.), Zeiten und Menschen. Geschichtliches Unterrichtswerk. Ausgabe B. Band 2: Die Zeit der abendländischen Christenheit (900-1648), Paderborn: Schöningh, 1976, 110; Heinz Dieter Schmid (Hg.), Fragen an die Geschichte. Geschichtliches Arbeitsbuch für die Sekundarstufe I. Band 2: Die europäische Christenheit, Frankfurt am Main: Hirschgraben, 4. Auflage 1978, 137-138.

35 Tenbrock und Kluxen (Hg.), Zeiten und Menschen, Ausgabe B, Band 2, 111.

36 Schmid (Hg.), Fragen an die Geschichte, Sekundarstufe I, Band 2, 136.

37 Hans Knübel (Hg.), Länder und Völker. Erdkundliches Unterrichtswerk. Ausgabe B. Band 1: Deutsche Landschaften und die Nachbarländer Deutschlands im Süden und Osten, Stuttgart: Klett, 7. Auflage 1970, 35. 
und Gelegenheit zum Wassersport. $"{ }^{38}$ Der Blick im Geografieunterricht richtete sich nun auf Gegenwart und Zukunft der Region und im Sinne einer funktionalistisch orientierten Sozialgeografie war hier erstmals für Ostpreußen/Warmia i Mazury die Möglichkeit formuliert, dass Menschen eine Landschaft in ganz unterschiedlicher Weise nutzen und gestalten können.

Die veränderte Wahrnehmung Ostpreußens in den Geografieschulbüchern war jedoch nur von kurzer Dauer. Die Regionale Geografie trat hinter einer analytischen Allgemeinen Geografie zurück, die Geofaktoren und räumliche Strukturen weitgehend exemplarisch behandelte. Auf diese Weise geriet allenfalls sporadisch Ostpreußen/Warmia i Mazury in das Blickfeld der Geografieschulbücher, als eines von vielen Feriengebieten in Europa. ${ }^{39}$

In deutschen Geschichtsschulbüchern wurden seit den 1990er Jahren dagegen die Narrationen wieder plastischer und landschaftliche Bezüge häufiger hergestellt. Ein wichtiger Impuls war die Kultur- und Alltagsgeschichte. Den Menschen des Mittelalters, so auch den Rittern und Siedlern im Deutschordensstaat, sollte näher über die Schulter geschaut werden:

Hatten die Ordensritter einen Sieg errungen, besetzten sie sofort die wichtigsten Punkte: Vorsprünge an Flussufern und Hügeln, von denen man eine weite Aussicht hatte. Schnell wurden Gräben gezogen, der Wall errichtet, Palisaden und Blockhäuser gebaut. Im Schutz der neuen Burg wurden Handwerker und Händler angesiedelt, auch ihre Hütten mit Graben und Pfahlwerk umschlossen. Eifrig hämmerten Handwerker und Mönche, damit der Bau schnell fertig wurde. ${ }^{40}$

Diese neue Anschaulichkeit und die seit den 1970er Jahren bestimmende deutsch-polnische, zunehmend auch europäische Perspektive auf das kulturelle Erbe der Marienburg trafen allerdings auf manch unreflektierte Traditionsbestände. Ein frappierendes Beispiel stellt eine Geschichtskarte zur mittelalterlichen Besiedlung Mittel- und Osteuropas dar, die in mehreren aktuellen deutschen Geschichtsschulbüchern enthalten ist. Hier wird der Versuch unternommen, mit unterschiedlich farbigen Flächen Aussagen über zeitlichen Verlauf und materielle Rahmenbedingungen des Geschehens zu treffen. "Siedlungsarme» Gebiete wurden in Weiß oder Grau, kartografisch und farbpsychologisch Leere symbolisierend, aber häufiger noch in Grün dargestellt. Nur teilweise verbanden die Schulbuchautoren die Wahl der Farbe Grün in der Kartenlegende mit »Wald,

38 Hans Knübel (Hg.), Länder und Völker. Erdkundliches Unterrichtswerk. Ausgabe B. Band 1: Deutsche Landschaften und die Nachbarländer Deutschlands im Süden und Osten, Stuttgart: Klett, 8. Auflage 1973, 136.

39 Egbert Brodengeier und Christoph Rausch, Terra. Erdkunde 1. Gymnasium NordrheinWestfalen, Stuttgart/Leipzig: Klett, 2008, 189.

40 Hans-Gert Oomen (Hg.), Entdecken und Verstehen 1. Von der Urgeschichte bis zum Mittelalter, Frankfurt am Main: Cornelsen, 1997, 184. 
Sumpf, Ödland, Hochgebirgsfläche ${ }^{41}$ Mehrmals stand die Farbe Grün aber auch für die Siedlungsgebiete der Polen und Tschechen ${ }^{42}$ und legte den Schülerinnen und Schülern auf diese Weise die Vorstellung von unerschlossenen und unzivilisierten Landschaften nahe.

\section{»Polnische« Landschaften}

Von einer "polnischen « Landschaft Warmia i Mazury zu schreiben, war, allen offiziellen propagandistischen Anstrengungen zum Trotz, lange Zeit nicht mit derselben Selbstverständlichkeit verbunden, wie dies in Deutschland für Ostpreußen als »deutsche Landschaft « üblich war. ${ }^{43}$ In den Schulbuchdarstellungen der Volksrepublik Polen war die Herrschaft des Deutschen Ordens nicht durch die Erschließung eines weitgehend noch urwüchsigen Naturraums geprägt, sondern ganz im Gegenteil, von »Verwüstungen« durch die Ordensritter begleitet. ${ }^{44}$ Hier folgten polnische Schulbuchautorinnen und -autoren, ähnlich wie ihre Kollegen in der DDR, nahtlos dem in sowjetischen Geschichtsschulbüchern entwickelten Narrativ. ${ }^{45}$

Umso bemerkenswerter ist der Wandel in der Darstellung und Deutung des Deutschordensstaates seit der politischen Wende 1989. Polnische Geschichtsschulbücher heben nun die Gründung von zahlreichen Städten und Dörfern, das Ansiedlungswesen, das Trockenlegen feuchter Böden oder gar neue »Muster von Verwaltung und Kultur, die bislang in Osteuropa unbekannt waren«, positiv hervor. ${ }^{46}$ Ein Schulbuch zitiert den Historiker Henryk Samsonowicz: »Das Ordensland unterschied sich von den umgebenden Ländern. Die große Zahl stei-

41 Karl-Heinz Zuber und Joachim Cornelissen (Hg.), BSV-Geschichte. 2 GN. Vom Frankenreich bis zum Dreißigjährigen Krieg, München: Oldenbourg, 1994, 199; ähnlich: Hans-Otto Regenhardt (Hg.), Forum Geschichte kompakt. Nordrhein-Westfalen. Band 2,1: Von der Frühen Neuzeit bis zum Ersten Weltkrieg, Berlin: Cornelsen, 2008, 26.

42 Franz Hofmeier und Hans-Otto Regenhardt (Hg.), Forum Geschichte. Ausgabe Bayern. Band 2: Vom Mittelalter bis zum Absolutismus, Berlin: Cornelsen, 2005, 132; Asmut Brückmann (Hg.), Geschichte und Geschehen, Ausgabe A, Band 2, Leipzig: Klett, 2004, 93.

$43 \mathrm{Zu}$ den Ambivalenzen des polnischen »Westgedankens" nach 1945: Grzegorz Strauchold, Myśl zachodnia $i$ je realizacja $w$ Polsce Ludowej $w$ latach 1945-1957, Wrocław: Adam Marszałek, 2003.

44 Władysław Chłapowski, Historia powszechna. Wieki średnie, Warschau: Państwowe Zakłady Wydawnictw Szkolnych, 1958, 150.

45 Anna M. Pankratova (Hg.), Istorija SSSR. Učebnik dlja 8 klassa srednej školy, Teil 1, Moskau: Učebno-pedag. izd., 12. Auflage 1953, 90.

46 Dorota Granoszewska-Babiańska, Dariusz Ostapowicz und Sławomir Suchodolski, Historia. Dzieje państwa i prawa. Teil 2. Podręcznik dla liceum ogólnokształcącego, liceum profilowanego i technikum. Kształcenie ogólne w zakresie podstawowym, Warschau: Nowa Era, 2. Auflage 2005, 62. 
nerner, gemauerter Bauten, gute, sichere Wege, Brücken, Anlegestellen, reiche Städte, schöne gotische Kirchen mit gefliesten Dachspitzen und massive Burgen, die ein Vorbild für die Nachbarn waren - all dies musste auf Neuankömmlinge großen Eindruck machen ${ }^{47}{ }^{47}$

Die "zivilisatorische Leistung ${ }^{48}$ des Deutschen Ordens wird dabei in größere europäische Zusammenhänge eingebettet. Die Architektur der Ordensburgen orientierte sich demnach nicht nur an deutschen, sondern auch niederländischen und anderen westeuropäischen Einflüssen. ${ }^{49}$ In die Bautätigkeit flossen »neueste technische und organisatorische Errungenschaften Westeuropas« ein, ${ }^{50}$ und die Marienburg als »eine der herrlichsten mittelalterlichen Befestigungen in Europa ${ }^{51}$ sei von Zeitgenossen $"$ mit den steinernen Bauten der ungarischen Hauptstadt und der berühmten marmornen Kathedrale in Mailand verglichen « worden. ${ }^{52}$

Die Vorstellungen darüber, wie der Mensch Landschaft gestalten kann, werden in den aktuellen polnischen Geschichtsschulbüchern aber nicht nur durch eine europäische, sondern auch durch eine religiöse Perspektive geprägt. Im Unterschied zur Zwischenkriegszeit, als eine einseitige Markierung konfessioneller und nationaler Trennlinien die Regel war, und zur sozialistischen Zeit, als das Thema Religion praktisch aus den Schulbüchern verbannt war, sind gegenwärtige religiöse Bezugnahmen stärker universell und grenzüberschreitend ausgerichtet. ${ }^{53}$ Auf diese Weise kann auch Ostpreußen/Warmia i Mazury als eine von Menschen aus religiösen Motiven gestaltete Landschaft, als eine »religiöse Landschaft« gelesen werden. Eine Geschichtskarte bildet die mittelalterlichen

47 Marek Kamiński, Grażyna Pańko und Robert Śniegocki, Historia. Średniowiecze. Podręcznik dla I klasy liceum ogólnokształcacego, liceum profilowanego i technikum, Teil 2, Warschau: Nowa Era, 5. Auflage 2006, 204, Übersetzung der Verfasserin.

48 Mikołaj Gładysz, Historia I. Podręcznik dla klasy pierwszej liceum i technikum. Zakres podstawowy i rozszerzony. Teil 2: Od średniowiecza do nowożytności, Gdańsk: Gdańskie Wydawnictwo Oświatowe, 2002, 104.

49 Ewa Wipszycka u. a., Historia dla każdego. Podręcznik. Band 1: Do rewolucji francuskiej, Warschau: PWN, 2002, 342.

50 Tomasz Małkowski und Jacek Rześniowiecki, Historia I. Podręcznik dla klasy I gimnazjum, Gdańsk: GWO, 3. Auflage 2003, 273.

51 Danuta Musiał, Krystyna Polacka und Stanisław Roszak, Przez wieki 1. Podręcznik do historii dla klasy pierwszej gimnazjum obejmujócy okres starożytności i średniowiecza, Straszyn: Nowa Era, 2. Auflage 2005, 150.

52 Tomasz Jurek, Historia. Dzieje najdawniejsze i dawne do schyłku XIV wieku. Średniowiecze. Podręcznik dla gimnazjum, Warschau: Juka-91, 2. Auflage 2002, 206, Übersetzung der Verfasserin.

$53 \mathrm{Zu}$ einem ähnlichen Befund kommt Barbara Christophe, »Religiös und doch modern? Nation und Europa in polnischen und türkischen Geschichtsschulbüchern", in: Geschichte in Wissenschaft und Unterricht 64 (2013), 61-79, 72, 77. 
Bistumssitzen in Königsberg, Frauenburg und Marienwerder ab, ${ }^{54}$ und eine andere Geschichtskarte $\mathrm{zu}$ "Sehenswürdigkeiten der romanischen und gotischen Kunst in Polen « umfasst, anders als es der Titel angibt, nicht nur sakrale Bauwerke in Polen, sondern auch im Staat des Deutschen Ordens. ${ }^{55}$ Für die Frühe Neuzeit verzeichnet eine weitere Geschichtskarte die Jesuitenkollegien in Braniewo/Braunsberg und Reszel/Rößel mit eigenen kartografischen Symbolen ${ }^{56}$ und eine Geschichtskarte zum »Barock in Polen« schließlich auch die auf dem Gebiet des Herzogtums Preußen liegende Basilika von Święta Lipka/Heiligelinde. $^{57}$

Mit der überproportionalen Berücksichtigung von römisch-katholischen Bauwerken ist allerdings auch eine Gelegenheit geschaffen, die »religiöse Landschaft « von Ostpreußen/Warmia i Mazury als eine "polnische Landschaft» zu lesen. Bislang gehen die Autorentexte in den polnischen Geschichtsschulbüchern auf diese Lesart noch nicht ausdrücklich ein.

Für polnische Geografieschulbücher bedeutete die politische Wende nicht in jedem Fall auch eine Wende in den Vorstellungen von Landschaft. Bereits in den 1980 er Jahren war das Interesse an der Regionalen Geografie neu erwacht, ${ }^{58}$ das dann seit den 1990er Jahren durch die Prozesse gesellschaftlich-politischer Demokratisierung und Dezentralisierung weitere Bestärkung fand. Das Paradigma der Regionalen Geografie stand dabei in Polen weniger stark unter Legitimations- bzw. Veränderungsdruck, da es, anders als in Deutschland, so gut wie kaum das Mensch-Landschaft-Verhältnis thematisierte, sondern in einem naturwissenschaftlichen Sinne physisch-geografisch ausgerichtet war und sich eines typologisch-vergleichenden Ansatzes bediente. So sprachen polnische Schulbuchautoren Warmia i Mazury als Teil eines größeren Landschaftsgürtels an, der sich im Nordeuropäischen Tiefland vom Lebuser Land über Großpolen und die Kaschubei bis zum südlichen Litauen erstreckte und durch eine Vielzahl jungeiszeitlicher Seen gekennzeichnet war (daher wurde oft Pojezierze als übergeordneter Begriff gewählt), und so wurden in spezielleren Betrachtungen etwa die masurischen Seen einer geomorphologischen Feingliederung unter-

54 Lech Trzcionkowski und Lech Wojciechowski, Historia. Starożytność i średniowiecze. Podręcznik dla I klasy gimnazjum, Warschau: Wydawnictwo Szkolne PWN, 2002, 109.

55 Paweł Żmudzki, Poznać przeszłość, zrozumieć dziś. Historia. Starożytność - średniowiecze. Klasa 1 liceum i technikum, poziom podstawowy i rozszerzony, Warschau: Stentor, 2005, 341.

56 Jolanta Choińska-Mika und Katarzyna Zielińska, Ludzie, społeczeństwa, cywilizacje. Historia. Historia nowożytna do 1815 roku. Teil 2. Podręcznik dla liceum ogólnokształcącego, liceum profilowanego i technikum, Warschau: WSiP, 2. Auflage 2003, 21.

57 Marek L. Wójcik und Agnieszka Knychalska, Historia 2. Czasy nowożytne. Ze Świata do Polski przez Europe, Warschau: PPWK, 2003, 213.

58 Andrzej Goclowski u. a., »Geografia regionalna«, in: Antoni Jackowski, Stanisław Liszewski und Andrzej Richling (Hg.), Historia geografii polskiej, Warschau: Wydawnictwo Naukowe PWN, 2008, 248-249. 
worfen. ${ }^{59}$ Dabei überwog eine förmlich-nüchterne Sprache, wenn auch in Bezug auf den Geofaktor Klima mitunter von einem "rauen« oder »strengen « kontinentalen Klima die Rede war. ${ }^{60}$

Unübersehbar war dagegen die Wende in der Wirtschafts- und Sozialgeografie. Warmia i Mazury hatte für die Schulbuchautoren der Volksrepublik Polen, die die materialistische Sicht vom wirtschaftenden Menschen als Gestalter von Landschaft zu vertreten hatten und ihren Blick bevorzugt auf industrielle Großprojekte richteten, nur wenig Anschauungsmaterial zu bieten. Harsch urteilte ein polnisches Schulbuch der 1950er Jahre, dass die Wojewodschaftsstadt Olsztyn nur nachgeordnete Bedeutung besitze; eigentlicher zentraler Ort für die Region sei Danzig oder Warschau. ${ }^{61}$ Seit den 1990er Jahren hat sich Warmia i Mazury in den Geografieschulbüchern von einem »Weißen Fleck« in der polnischen Volkswirtschaft $\mathrm{zu}$ einer Region höchster touristischer Attraktivität gewandelt. Mitunter geben einige neuere Schulbücher dabei sogar ihre fachliche Distanz auf und agieren bei der Schilderung natürlicher Sehenswürdigkeiten fast im Stile eines Reiseführers. Systematisch betrachtet hat hier allerdings ein neues Verständnis von Landschaft Einzug gehalten, denn die Darstellung individualisierter Nutzung durch Touristen und Freizeitsportler verweist auf ein großes Spektrum unterschiedlicher Möglichkeiten und Lesarten von Landschaft.

\section{Ein Blick über den deutsch-polnischen Tellerrand: »Russische« und »litauische« Landschaften}

Für Schulkinder in der Sowjetunion stellte sich das nach 1945 neu hinzugekommene Gebiet Kaliningrad sehr widersprüchlich dar. Eine regelrechte Albtraumlandschaft zeichneten die Geschichtsschulbücher: „Die Faschisten errichteten hier mächtige Befestigungsanlagen, eine Vielzahl permanenter Maschinengewehrnester, hoben Tausende von Kilometern an Schützengräben aus und bauten Panzersperren und Stahlbetonhöcker. ${ }^{62}$

59 Besonders ausführlich: Jan Wójcik, Hanna Staniów und Piotr Staniów, Geografia 3. Polska. Liceum ogólnokształcące, liceum profilowane, technikum. Zakres podstawowy - zakres rozszerzony, Warschau: PPKW, 2. Auflage 2005, 81.

60 Edward Dudek und Jan Wójcik, Geografia. Podręcznik dla gimnazjum, Warschau: Wiking, 2001, 79; Teresa Krynicka-Tarnacka, Grażyna Wnuk und Zofia Wojtkowicz, Moje miejsce w Polsce i regionie. Podręcznik geografii dla gimnazjum, Teil 3, Toruń: SOP, 3. Auflage 2001, 73; Jan Kadziołka und Wojciech Janicki, Polska na tle Europy i świata. Podręcznik, Klasa 3, Warschau: Oficyna Wydawniczo-Poligraficzna »ADAM«, 2002, 165.

61 Józef Barbag und Michał Janiszewski, Geografia Polski, Klasa X, Warschau: Państwowe Zakłady Wydawnictw Szkolnych, 1957, 157-159.

62 Maksim P. Kim (Hg.), Istorija SSSR (1938-1972 gg.). Učebnik dlja 10 klassa, Moskau: Proswestschenie, 4. Auflage 1975, 104. Ähnlich noch: Valerij P. Ostrovskij und Aleksej I. Utkin, 
Die Chancen, die in der aktiven Nutzung und Gestaltung von Landschaft liegen konnten, hoben dagegen die Geografieschulbücher hervor. Sie lobten das "milde « maritime Klima und die auch zur Winterzeit weitgehend eisfreien Häfen an der Ostseeküste. Hier wurde die kulturelle Bedingtheit von Landschaftswahrnehmung überaus deutlich, denn Vergleichsmaßstab waren die Verhältnisse Zentralrusslands. Zugleich gab es Anerkennung für das vor dem Krieg Geschaffene: Aus Sicht der Schulbuchautoren war das Gebiet gut mit Eisenbahnstrecken und Autostraßen ausgestattet.

Dem materialistischen Weltbild folgend, nahmen sowjetische Schulbücher eine weitgehend funktionale Perspektive auf Landschaft und den Menschen als ihren Gestalter ein. Demgegenüber ist in den aktuellen russischen Geografieschulbüchern ein Wandel in der Vorstellung von Landschaft zu beobachten. Im Falle des Gebiets Kaliningrad wird lediglich ein Motiv aus sowjetischer Zeit nahtlos weitergeführt: "Das Klima des Gebiets ist gemäßigt und maritim. Es zeichnet sich durch warme Winter und nicht allzu heiße Sommer aus. $"{ }^{63} \mathrm{Neu}$ ist zum einen, dass die Geografieschulbücher nun den »natürlichen Reichtum« des Gebiets Kaliningrad betonen; gemeint sind vor allem die Vorkommen an Bernstein und qualitativ hochwertigem Erdöl. ${ }^{64}$ Der aktuelle Fokus auf Rohstoffvorkommen ersetzt den früheren Fokus auf große Industrieanlagen. Zum anderen gibt es einen unbefangeneren Umgang mit dem historisch-kulturellen Erbe, also mit einer übernommenen, »nicht-russischen « Landschaft. Bauwerke wie der Königsberger Dom, das Kant-Denkmal oder die Königsberger Altstadt werden fast schon wie in einem Reiseführer gepriesen. Eine Wiederentdeckung erfahren die Kurische Nehrung und Badeorte der samländischen Küste wie Zelenogradsk/Cranz und Svetlogorsk/Rauschen. ${ }^{65}$

Litauische Geschichtsschulbücher nehmen für Ostpreußen eine architektonisch gestaltete Landschaft an, bevorzugt veranschaulicht in der Universitätsstadt Königsberg mit ihren im 19. Jahrhundert neu errichteten Lehrgebäuden. ${ }^{66}$ Auch das nördliche Ostpreußen, das im 19. Jahrhundert als Klein-Litauen die Funktion eines kulturellen Zentrums für die litauische Nationalbewegung besaß, erscheint als Gebiet mit einer guten Infrastruktur an Schulen, Druckereien,

Istorija Rossii. XX vek. 11 klass. Učebnik dlja obščeobrazovatel'nych učebnych zavedenij, Moskau: Drofa, 1995, 308, Übersetzung der Verfasserin.

63 Evgenij M. Domogackich, Nikolaj I. Alekseevskij und Nikolaj N. Kljuev, Naselenie i chozjajstvo Rossii. Učebnik dlja 9 klassa obščeobrazovatel'nych učreždenij, Moskau: Russkoe slovo, 3. Auflage 2011, 185, Übersetzung der Verfasserin.

64 Ebd., 185; Aleksandr I. Alekseev, Chozjajstvo i geografičeskie rajony, Moskau: Drofa, 6. Auflage 2005, 146.

65 Viktor P. Dronov (Hg.), Priroda, naselenie, chozjajstvo. Učebnik dlja obščeobrazovatel'nych učreždenij, Moskau: Drofa, 2. Auflage 2004, 131; Alekseev, Chozjajstvo igeografičeskie rajony, 147.

66 Rasa Butvilaitè u. a., Istorijos vadovèlis. 9 klasei, Teil 1, Vilnius: Baltos lankos, 2010, 76. 
Pfarrhäusern und Lehrerseminaren. Klaipedda gilt nach Vilnius als zweite Stadt im heutigen Litauen, in der zu Beginn des 20. Jahrhunderts elektrische Straßenbahnen kursierten. ${ }^{67}$ Neben diesen Ausweisen von Modernität gibt es für Klein-Litauen in den litauischen Schulbüchern allerdings immer wieder auch eine ländlich-dörfliche Charakteristik, unterlegt durch Abbildungen von Wiesen, Feldern, Gutshöfen oder kurischen Fischerbooten. ${ }^{68}$

Die ästhetisierende Lesart von Landschaft, die den Menschen als gestaltende Kraft etwas in den Hintergrund rückt, ist auch den aktuellen litauischen Geografieschulbüchern nicht fremd, etwa bei den Darstellungen zum Memelfluss oder zur Kurischen Nehrung. ${ }^{69}$ Hierin kann auch eine Gegenbewegung gesehen werden $\mathrm{zu}$ dem in sowjetischer Zeit obligatorischen Verweis auf die wirtschaftlich-funktionale Nutzung von Landschaft, im Falle Ostpreußens/KleinLitauens durch Kanäle, Häfen und Fischerei großen Stils. ${ }^{70}$

\section{Zusammenfassung}

Im internationalen Vergleich zeigt sich, wie sehr Darstellungen und Vorstellungen von Landschaft in Schulbüchern abhängig sind von kulturellen, politischen, fachwissenschaftlichen und fachdidaktischen Kontexten, die sich wiederum im Laufe der Jahrzehnte erheblich verändern können. Für das Beispiel Ostpreußen/Warmia i Mazury sind vor allem drei Faktoren hervorzuheben: Zum Ersten gab es mehrere wissenschaftliche Paradigmenwechsel. So boten deutsche Schulbücher lange Zeit die umfangreichsten Landschaftsbeschreibungen, bevor sie, in der didaktischen Umsetzung von Sozialgeschichte und exemplarischer Allgemeiner Geografie, nahezu gänzlich darauf verzichteten. Bei den Schulbüchern Polens, Russlands und Litauens schlug die politische Wende mit einer Abkehr von der in sozialistischer Zeit vorherrschenden wirtschaftlichfunktionalen Perspektive auf Landschaft deutlich zu Buche. Zum zweiten prägte der Vergleich mit anderen, "vertrauten « Landschafterfahrungen die Vorstellung von Ostpreußen. Das stärkste Gegensatzpaar bildeten dabei nicht die deutschen und polnischen, sondern die deutschen und sowjetischen bzw. russischen

67 Ignas Kapleris u.a., Laikas. Istorijos vadovèlis 9 klasei, Teil 2, Vilnius: Briedis, K. Mickevičiaus leidykla, 2006, 207, 209.

68 Juozas Brazauskas und Bronius Makauskas, Lietuvos praeities puslapiai. Vadovèlis 9 klasei, Teil 2, Vilnius: Sviesa, 2003, 106; Remigijus Civinskas und Kastytis Antanaitis, Lietuvos istorija. 12 klasei, Vilnius: Vaga, 2001, 92.

69 Stasys Vaitekūnas und Elena Valančienè, Lietuvos geografija. Gamtinè ir socialinè geografija. 9 klasei, Vilnius: Alma littera, 2004, 69,100-103,134-135; Arūnas Aleknavičius, Lietuvos Geografija. 9 klasei, Vilnius: Vilspa, 1993, 87.

70 Antanas Ivanauskas, Geografija Litovskoj SSR 7-8. Učebnik dlja 7-8 klassov, Kaunas: Šviesa, 4. Auflage 1979, 92, 117-119, 121. 
Schulbücher. Es bestand keine Einigkeit darüber, ob das Klima »rau« oder "mild " war oder ob Ostpreußen wegen seiner schönen Landschaft zu preisen oder eher wegen seiner Festungsbauten und Verschanzungen zu fürchten war. Schließlich waren die Vorstellungen von Ostpreußen/Warmia i Mazury in besonderem Maße von kulturellen Prozessen flankiert, die Verlust und Aneignung von Landschaft im Zuge von Migrationsprozessen verarbeiten. Aufschlussreich sind hier vor allem in den aktuellen Schulbüchern die Darstellungen zum zeitgenössischen Tourismus und Naturschutz, die unterschiedliche Gestaltungen, Nutzungen und somit Schreib- und Lesarten von Landschaft erahnen lassen.

\section{Literatur}

Aleknavičius, Arūnas. Lietuvos Geografija. 9 klasei, Vilnius: Vilspa, 1993.

Alekseev, Aleksandr I. Chozjajstvo i geografičeskie rajony, Moskau: Drofa, 6. Auflage 2005.

Antrop, Marc. "Interacting Cultural, Psychological and Geographical Factors of Landscape Preference", in: Landscape Culture - Culturing Landscapes. The Differentiated Construction of Landscapes, Diedrich Bruns, Olaf Kühne, Antje Schönwald und Simone Theile (Hg.), Wiesbaden: Springer VS, 2015, 53-68.

Autorenkollektiv. Lehrbuch für den Geschichtsunterricht. 6. Schuljahr, 1. Teil, Berlin/ Leipzig: Volk und Wissen, 1951.

Barbag, Józef und Michał Janiszewski. Geografia Polski. Klasa X, Warschau: Państwowe Zakłady Wydawnictw Szkolnych, 1957.

Bauer, Ludwig (Hg.). Erdkundliches Unterrichtswerk für höhere Lehranstalten. Band 2: Länderkunde von Mitteleuropa, München/Düsseldorf: Oldenbourg, 1953.

Blackbourn, David. Die Eroberung der Natur. Die Geschichte der deutschen Landschaft, München: Deutsche Verlagsanstalt, 2007.

Brazauskas, Juozas und Bronius Makauskas. Lietuvos praeities puslapiai. Vadovélis 9 klasei, Teil 2, Vilnius: Sviesa, 2003.

Brodengeier, Egbert und Christoph Rausch. Terra. Erdkunde 1, Gymnasium NordrheinWestfalen, Stuttgart/Leipzig: Klett, 2008.

Brückmann, Asmut (Hg.). Geschichte und Geschehen. Ausgabe A, Band 2, Leipzig: Klett, 2004.

Butvilaite, Rasa u. a. Istorijos vadovèlis. 9 klasei, Teil 1, Vilnius: Baltos lankos, 2010.

Chłapowski, Władysław. Historia powszechna. Wieki średnie, Warschau: Państwowe Zakłady Wydawnictw Szkolnych, 1958.

Choińska-Mika, Jolanta und Katarzyna Zielińska. Ludzie, społeczeństwa, cywilizacje. Historia. Historia nowożytna do 1815 roku. Teil 2, Podręcznik dla liceum ogólnokształcacego, liceum profilowanego i technikum, Warschau: WSiP, 2. Auflage 2003.

Christophe, Barbara. »Religiös und doch modern? Nation und Europa in polnischen und türkischen Geschichtsschulbüchern«, in: Geschichte in Wissenschaft und Unterricht 64 (2013), 61-79.

Civinskas, Remigijus und Kastytis Antanaitis. Lietuvos istorija. 12 klasei, Vilnius: Vaga, 2001. 
Degn, Christian u.a. (Hg.). Seydlitz. Teil 4: Deutschland und Europa, Kiel/Hannover: Ferdinand Hirt, 5. Auflage 1958.

Deissler, Hans Herbert u. a. Grundzüge der Geschichte. Band 3: Vom Westfälischen Frieden bis zum Jahre 1890, Frankfurt am Main u. a.: Diesterweg, 6. Auflage 1970.

Domogackich, Evgenij M., Nikolaj I. Alekseevskij und Nikolaj N. Kljuev. Naselenie i chozjajstvo Rossii. Učebnik dlja 9 klassa obščeobrazovatel'nych učreždenij, Moskau: Russkoe slovo, 3. Auflage 2011.

Dronov, Viktor P. (Hg.). Priroda, naselenie, chozjajstvo. Učebnik dlja ob̌̌čeobrazovatel'nych učreždenij, Moskau: Drofa, 2. Auflage 2004.

Dudek, Edward und Jan Wójcik. Geografia. Podręcznik dla gimnazjum, Warschau: Wiking, 2001.

Ebner, Franz. Geschichte des Mittelalters. Geschichtswerk für höhere Lehranstalten. Mittelstufe. Band 2: Mittelalter, München: Lurz, 1956.

Edelmann, Moritz und Leo Gruenberg (Hg.). Volkwerden der Deutschen. Geschichtsbuch für höhere Schulen. Klasse 4. Deutsche Geschichte von 1648-1871, Leipzig/Berlin: B.G. Teubner, 1939.

Eisel, Ulrich. "Die Hintergründe des Raumes. Eine Einführung in die Verflechtung von einigen Gedanken", in: Landschaft und Gesellschaft. Räumliches Denken im Visier, ders. (Hg.), Münster: Verlag Westfälisches Dampfboot, 2009, 15-40.

Faehndrich, Jutta. »Erinnerungskultur und Umgang mit Vertreibung in Heimatbüchern deutschsprachiger Vertriebener«, in: Zeitschrift für Ostmitteleuropaforschung 52 (2003), 191-229.

Fendl, Elisabeth (Hg.). Zur Ikonographie des Heimwehs. Erinnerungskultur von Heimatvertriebenen, Freiburg: Johannes Künzig-Institut für ostdeutsche Volkskunde, 2002.

Gehl, Walther. Geschichte. 5. Klasse. Oberschulen, Gymnasien und Oberschulen in Aufbauform. Von der Gründung des Zweiten Reiches bis zur Gegenwart, Breslau: Ferdinand Hirt, 1939.

Gładysz, Mikołaj. Historia I. Podręcznik dla klasy pierwszej liceum i technikum. Zakres podstawowy i rozszerzony. Teil 2: Od średniowiecza do nowożytności, Gdańsk: Gdańskie Wydawnictwo Oświatowe, 2002.

Goclowski, Andrzej u.a. "Geografia regionalna«, in: Historia geografii polskiej, Antoni Jackowski, Stanisław Liszewski und Andrzej Richling (Hg.), Warschau: Wydawnictwo Naukowe PWN, 2008, 248-260.

Granoszewska-Babiańska, Dorota, Dariusz Ostapowicz und Sławomir Suchodolski. Historia. Dzieje państwa i prawa. Teil 2. Podręcznik dla liceum ogólnokształcącego, liceum profilowanego i technikum. Kształcenie ogólne w zakresie podstawowym, Warschau: Nowa Era, 2. Auflage 2005.

Habisreutinger, Josef und Walter Krick. Geschichtliches Werden. Mittelstufe. Bd. 4: Geschichte der Neuesten Zeit 1815-1950, Bamberg: C.C. Buchners, 2. Auflage 1957.

Hinrichs, Emil. Erdkunde für höhere Schulen. Band 1: Deutschland und die Länder Europas ringsum, Frankfurt am Main u. a.: Diesterweg, 6. Auflage 1958.

Hofmeier, Franz und Hans-Otto Regenhardt (Hg.). Forum Geschichte. Ausgabe Bayern. Band 2: Vom Mittelalter bis zum Absolutismus, Berlin: Cornelsen, 2005.

Ivanauskas, Antanas. Geografija Litovskoj SSR 7-8. Učebnik dlja 7-8 klassov, Kaunas: Šviesa, 4. Auflage 1979. 
Jurek, Tomasz. Historia. Dzieje najdawniejsze i dawne do schyłku XIV wieku. Średniowiecze. Podręcznik dla gimnazjum, Warschau: Juka-91, 2. Auflage 2002.

Kadziołka, Jan und Wojciech Janicki. Polska na tle Europy i świata. Podręcznik. Klasa 3, Warschau: Oficyna Wydawniczo-Poligraficzna »ADAM«, 2002.

Kaier, Eugen u.a. Grundzüge der Geschichte. Von der Frühgeschichte Europas bis zur Weltpolitik der Gegenwart, Frankfurt am Main u. a.: Diesterweg, 1958.

Kamiński, Marek, Grażyna Pańko und Robert Śniegocki. Historia. Średniowiecze. Podręcznik dla I klasy liceum ogólnokształcącego, liceum profilowanego i technikum, Teil 2, Warschau: Nowa Era, 5. Auflage 2006.

Kapleris, Ignas u. a. Laikas. Istorijos vadovelis 9 klasei, Teil 2, Vilnius: Briedis, K. Mickevičiaus leidykla, 2006.

Kim, Maksim P. (Hg.). Istorija SSSR (1938-1972 gg.). Učebnik dlja 10 klassa, Moskau: Proswestschenie, 4. Auflage 1975.

Knox, Paul L. und Sallie A. Marston. Humangeographie, Heidelberg: Springer, Spektrum Akademischer Verlag, 4. Auflage 2008.

Knübel, Hans (Hg.). Länder und Völker. Erdkundliches Unterrichtswerk. Ausgabe A. Band 1: Deutschland und seine Nachbarländer im Süden und Osten, Stuttgart: Klett, 9. Auflage 1959.

Ders. (Hg.). Länder und Völker. Erdkundliches Unterrichtswerk. Ausgabe B. Band 1: Deutsche Landschaften und die Nachbarländer Deutschlands im Süden und Osten, Stuttgart: Klett, 7. Auflage 1970.

Ders. (Hg.). Länder und Völker. Erdkundliches Unterrichtswerk. Ausgabe B. Band 1: Deutsche Landschaften und die Nachbarländer Deutschlands im Süden und Osten, Stuttgart: Klett, 8. Auflage 1973.

Kondracki, Jerzy. Geografia regionalna Polski, Warschau: Wydawnictwo Naukowe PWN, 2. Auflage 2000.

Kosminskij, Evgenij A. Geschichte des Mittelalters, Berlin: Volk und Wissen, 5. Auflage 1952.

Krynicka-Tarnacka, Teresa, Grażyna Wnuk und Zofia Wojtkowicz. Moje miejsce w Polsce $i$ regionie. Podręcznik geografii dla gimnazjum, Teil 3, Toruń: SOP, 3. Auflage 2001.

Kühne, Olaf. Distinktion - Macht - Landschaft. Zur sozialen Definition von Landschaft, Wiesbaden: VS Verlag für Sozialwissenschaften, 2008.

Ders. »Wie kommt die Landschaft zurück in die Humangeographie? Plädoyer für eine 'konstruktivistische Landschaftsgeographie«", in: Geographische Zeitschrift 102 (2014), 68-85.

Kumsteller, Bernhard, Ulrich Haacke und Benno Schneider (Hg.). Geschichtsbuch für die deutsche Jugend. Klasse 3, Leipzig: Quelle und Meyer, 1939.

Dies. (Hg.). Geschichtsbuch für die deutsche Jugend. Mittelstufe. Für die Jüngeren, Leipzig: Quelle \& Meyer, 38. Auflage 1935.

Lewandowska, Izabela. »Historyczna świadomość regionalna. Z badań nad młodzieżą licealną Warmii i Mazur«, in: Rozprawy i Materiały Ośrodka Badań Naukowych im. Wojciecha Kętrzyńskiego w Olsztynie 214 (2003), 203-204.

Liedtke, Herbert. Die Landschaften Ostpreußens. Namen und Abgrenzungen naturgeographischer und historischer Landschaften in Ostpreußen und angrenzenden Gebieten, Daten, Fakten, Literatur zur Geographie Europas 10, Leipzig: Leibniz-Institut für Länderkunde, 2011. 
Lisowski, Andrzej. »Geografia społeczna«, in: Historia geografii polskiej, Antoni Jackowski, Stanisław Liszewski und Andrzej Richling (Hg.), Warschau: Wydawnictwo Naukowe PWN, 2008, 195-205.

Łukowski, Wojciech. Społeczne tworzenie ojczyzn. Studium tożsamości mieszkańców Mazur, Warschau: Wydawnictwo Naukowe »Scholar«, 2002.

Małkowski, Tomasz und Jacek Rzésniowiecki. Historia I. Podręcznik dla klasy I gimnazjum, Gdańsk: GWO, 3. Auflage 2003.

Mazur, Zbigniew (Hg.). Wokół niemieckiego dziedzictwa kulturowego na Ziemiach Zachodnich i Pólnocnych, Poznań: Instytut Zachodni, 1997.

Ders. (Hg.). Wspólne dziedzictwo? Ze studiów nad stosunkiem do spuścizny kulturowej na Ziemiach Zachodnich i Połnocnych, Poznań: Instytut Zachodni, 2000.

Musiał, Danuta, Krystyna Polacka und Stanisław Roszak. Przez wieki 1. Podręcznik do historii dla klasy pierwszej gimnazjum obejmujócy okres starożytności i średniowiecza, Straszyn: Nowa Era, 2. Auflage 2005.

Oomen, Hans-Gert (Hg.). Entdecken und Verstehen 1. Von der Urgeschichte bis zum Mittelalter, Frankfurt am Main: Cornelsen, 1997.

Ostrovskij, Valerij P. und Aleksiej I. Utkin. Istorija Rossii. XX vek. 11 klass. Učebnik dlja obščeobrazovatel'nych učebnych zavedenij, Moskau: Drofa, 1995.

Pankratova, Anna M. (Hg.). Istorija SSSR. Učebnik dlja 8 klassa srednej školy, Teil 1, Moskau: Učebno-pedag. izd., 12. Auflage 1953.

Pinnow, Hermann. Geschichte des deutschen Volkes von den Anfängen bis 1648. Geschichtsbuch für die Mittelklassen höherer Lehranstalten, Band 2, Leipzig, Berlin: Verlag Teubner, 5. Auflage 1925.

Regenhardt, Hans-Otto (Hg.). Forum Geschichte kompakt. Nordrhein-Westfalen. Band 2,1: Von der Frühen Neuzeit bis zum Ersten Weltkrieg, Berlin: Cornelsen, 2008.

Reimann, Arnold (Hg.). Geschichtswerk für höhere Schulen. Teil 2: Grundbuch für den gesamten Geschichtsunterricht auf Mittel- und Oberstufe. Heft 2: Mittelalter und Reformationszeit, München/Berlin: Oldenbourg, 3. Auflage 1925.

Schäfer, Wilhelm (Hg.). Erdkunde für höhere Lehranstalten. Band 1: Deutsche Landschaften, Paderborn: Schöningh, 21. Auflage 1956.

Schiefer, Wilhelm (Hg.). Maier-Schirmeyer. Lehrbuch der Geschichte für höhere Schulen. Mittelstufe. Band 2: Von der germanischen Frühzeit bis zum Westfälischen Frieden, Frankfurt am Main: Diesterweg, 12. Auflage 1937.

Schmid, Heinz Dieter (Hg.). Fragen an die Geschichte. Geschichtliches Arbeitsbuch für die Sekundarstufe I. Band 2: Die europäische Christenheit, Frankfurt am Main: Hirschgraben , 4. Auflage 1978.

Schmitthenner, Paul und Friedrich Fliedner (Hg.). Führer und Völker. Geschichtsbuch für höhere Schulen. Klasse 4. Deutsche Geschichte von 1648 bis 1871, Bielefeld/Leipzig: Velhagen \& Klasing, 1939.

Semjonow, Wissarion F. Geschichte des Mittelalters, Berlin: Volk und Wissen, 1952.

Strauchold, Grzegorz. Myśl zachodnia i je realizacja w Polsce Ludowej w latach 1945-1957, Wrocław: Adam Marszałek, 2003.

Tenbrock, Robert Hermann und Kurt Kluxen (Hg.). Zeiten und Menschen. Geschichtliches Unterrichtswerk. Ausgabe B. Band 2: Die Zeit der abendländischen Christenheit (900-1648), Paderborn: Schöningh, 1976. 
Thum, Gregor. »Mythische Landschaften. Das Bild vom `deutschen Osten und die Zäsuren des 20. Jahrhunderts", in: Traumland Osten. Deutsche Bilder vom östlichen Europa im 20. Jahrhundert, ders. (Hg.), Göttingen: Vandenhoeck \& Ruprecht, 2006, 181-212.

Traba, Robert. Kraina tysiąca granic. Szkice o historii i pamięci, Olsztyn: Stowarzyszenie WK Borussia, 2003.

Trepl, Ludwig. Die Idee der Landschaft. Eine Kulturgeschichte von der Aufklärung bis zur Ökologiebewegung, Bielefeld: transcript, 2012.

Trzcionkowski, Lech und Lech Wojciechowski. Historia. Starożytność i średniowiecze. Podręcznik dla I klasy gimnazjum, Warschau: Wydawnictwo Szkolne PWN, 2002.

Vaitekūnas, Stasys und Elena Valančienè. Lietuvos geografija. Gamtinè ir socialinè geografija. 9 klasei, Vilnius: Alma littera, 2004.

Werlen, Benno. Sozialgeographie. Eine Einführung, Bern u. a.: Haupt, 2000.

Wipszycka, Ewa u. a. Historia dla każdego. Podręcznik. Band 1: Do rewolucji francuskiej, Warschau: PWN, 2002.

Wójcik, Marek L. und Agnieszka Knychalska. Historia 2. Czasy nowożytne. Ze Świata do Polski przez Europe, Warschau: PPWK, 2003.

Wójcik, Jan, Hanna Staniów und Piotr Staniów. Geografia 3. Polska. Liceum ogólnokształcące, liceum profilowane, technikum. Zakres podstawowy - zakres rozszerzony, Warschau: PPKW, 2. Auflage 2005.

Zloch, Stephanie und Izabela Lewandowska (Hg.). Das >Pruzzenland als geteilte Erinnerungsregion. Konstruktion und Repräsentation eines europäischen Geschichtsraums in Deutschland, Polen, Litauen und Russland seit 1900, Eckert. Die Schriftenreihe 135, Göttingen: V\&R unipress, 2014.

Żmudzki, Paweł. Poznać przeszłość, zrozumieć dziś. Historia. Starożytność- średniowiecze. Klasa 1 liceum i technikum, poziom podstawowy i rozszerzony, Warschau: Stentor, 2005.

Zuber, Karl-Heinz und Joachim Cornelissen (Hg.). BSV-Geschichte. 2 GN. Vom Frankenreich bis zum Dreißigjährigen Krieg, München: Oldenbourg, 1994. 


\section{Eine klaffende Lücke. Zur Präsenz Oberschlesiens als deutsch-polnische Kulturlandschaft in polnischen Bildungsmedien nach 1989}

Schon ein flüchtiger Blick in die Schulbücher vieler europäischer Länder legt offen, dass die nationalen Bildungspolitiken europäische Grenzregionen kaum oder gar nicht wahrnehmen. Es zeigt sich, dass das lange Zeit dominierende Denken in ausschließlich nationalstaatlichen Kategorien populäre Raumvorstellungen außerordentlich verengt und transnationale Verbindungen verdeckt hat. So werden historische Grenzregionen in der Regel als Randgebiete europäischer Geschichte begriffen. Dies aber steht in diametralem Gegensatz zu ihrer historischen und aktuellen Bedeutung, erkennbar etwa daran, dass sie sowohl in der Vergangenheit als auch in der Gegenwart im Mittelpunkt des Interesses der Öffentlichkeit stehen. Gerade wegen ihrer Lage an den wechselnden Grenzen weisen Regionen neben einer scheinbaren Peripherität auch eine bemerkenswerte Zentralität auf. ${ }^{1}$ Sie werden daher - etwa in den Geschichts- und Sozialwissenschaften wie in der Schulbuchforschung - zunehmend als imagined community entdeckt und erschlossen, da sie im Vergleich zur Nation eine größere Flexibilität und Optionalität besitzen und sich stärker aus gemeinsamen Erfahrungen und Wissensbeständen speisen. ${ }^{2}$ Angesichts ihres fluiden und transnationalen Charakters stellen Grenzregionen häufig Kontaktzonen dar, die wichtige Anknüpfungspunkte für die Bildung hybrider und multipler Identitäten bieten und sich jenseits der Deutungskategorien Nation, Staat oder Ethnizität erfassen lassen. ${ }^{3}$ Außerdem kann man hier lang andauernden Phänomenen auf

1 Philipp Ther und Holm Sundhaussen (Hg.), Regionale Bewegungen und Regionalismen in europäischen Zwischenräumen seit der Mitte des 19. Jahrhunderts im Vergleich, Marburg: Herder, 2003, 275-284, hier: XII.

2 Vgl. Bodo von Borries, "'Staatsnation` und `Nationalstaat` - Grenzen und Möglichkeiten multiperspektivischer Betrachtung und relativierender Historisierung", in: Robert Maier (Hg.), Zwischen Zählebigkeit und Zerrinnen. Nationalgeschichte im Schulunterricht in Ostmitteleuropa, Hannover: Hahn, 2004, 281-314, 311.

3 Vgl. Günther Lottes, »Zur Einführung: Staat, Nation, Region - Zu drei Prinzipien der Formationsgeschichte Europas«, in: ders. (Hg.), Region, Nation, Europa. Historische Determinanten der Neugliederung eines Kontinents, Heidelberg: Physica-Verlag, 1992, 10-43; vgl. 
die Spur kommen, etwa der Siedlungsgeschichte als sozialem Prozess, der Bevölkerungs- und Mentalitätsgeschichte, Wirtschafts- und Sozialgeschichte. Damit geraten Entwicklungsvorgänge in den Blick, die alle auf den Strukturwandel von der Vormoderne in die Moderne des 19. und 20. Jahrhunderts angelegt sind. ${ }^{4}$ Nicht zuletzt aufgrund der gegebenen multiethnischen und mehrsprachlichen Sozietät eignen sich historische Grenzregionen gut für die Untersuchung von Nationsbildungsprozessen. Hier kann man den "Grenzen der Nation" nachgehen und wie in einem Labor prüfen, inwiefern traditionelle Grenzregionen als Vorreiter einer postnationalen Entwicklung anzusehen sind, innerhalb der der Nationalismus schrittweise historisiert und um neue, kooperative (regionale) Identitätsangebote erweitert wird. Kurzum: Vom Rand aus sieht man oft mehr, auch wenn man selbst dort schlechter zu sehen ist. Gerade aber diese transnationale Horizonterweiterung und multikulturelle "Speicherfähigkeit« macht Grenzregionen in vielen Bildungsmedien zur terra incognita, es sei denn, sie bieten in ihrer wechselvollen Geschichte historische Momente, die sich in eine nationale Meistererzählung einfügen (lassen). Wie ist es in diesem Kontext um polnische Bildungsmedien, speziell um seit 1989 erschienene Geschichtsschulbücher, bestellt?

Die Fragestellung nach Repräsentationen der historischen Grenzregion Oberschlesien in polnischen Bildungsmedien nach 1989 im Kontext der bildungspolitischen Debatte in Polen stand im Fokus des Forschungsprojektes »Oberschlesien und sein kulturelles Erbe - Erinnerungspolitische Befunde, bildungspolitische Impulse und didaktische Innovationen«, welches am GeorgEckert-Institut (GEI) und am Historischen Seminar der TU Braunschweig unter Beteiligung wissenschaftlicher, bildungspolitischer und zivilgesellschaftlicher Partner aus Polen realisiert wurde. ${ }^{5}$ Im Einzelnen ging das Projekt der Frage nach, ob und in welcher Form diese bis heute multiethnisch geprägte Region mit ihrer wechselvollen Geschichte Eingang in die polnischen Schulbücher gefunden hat. Wird in den Bildungsmedien, denen für die Entwicklung kollektiver Identitäten stets eine bedeutsame Funktion zugesprochen wird, das Transnationale eines multiethnischen Geschichts- und Kulturraums reflektiert, und wenn ja,

auch: Peter Haslinger (Hg.), Regionale und nationale Identitäten. Wechselwirkungen und Spannungsfelder im Zeitalter moderner Staatlichkeit, Würzburg: Ergon-Verlag, 2001.

4 Horst Kuss, "Landesgeschichte oder Regionalgeschichte? Über den Zusammenhang von geschichtswissenschaftlicher Theorie, geschichtsdidaktischer Konzeption und praktischer Anwendung im Unterricht", in: GWU 51 (2000), 388-405, 394.

5 Vgl. Das Projekt (Leitung: Prof. Simone Lässig) wurde in den Jahren 2011-2013 aus Mitteln der Bundebeauftragten für Kultur und Medien gefördert. Polnische Partner des Projektes waren: das Haus der Deutsch-Polnischen Zusammenarbeit in Gleiwitz (HdpZ), das Willy-BrandtZentrum für Deutschland- und Europastudien an der Universität Breslau (WBZ) und das Regionale Fortbildungszentrum für Methodik in Oppeln (WOM). 
wie? $?^{6}$ Dabei fungiert Oberschlesien exemplarisch als eine Region, die für polnische Bildungspolitik und Schulbuchentwicklung eine Herausforderung, aber zugleich eine Chance darstellt, auf Geschichtsbücher und didaktische Konzepte zu setzen, die auf ein offenes Geschichtsbild, Kontroversität und Multiperspektivität abzielen, d.h. nicht nur national definierte Grenzen abstecken, sondern diese durch kultur-, mental-, wirtschafts- und sozialgeschichtliche Topoi überwölben, die Grenzräume neu vermessen und Verständigungsräume schaffen. Handelt es sich ja um eine Region, die höchst lebendige kulturelle und im Wandel begriffene Vielfalt aufweist - über Jahrhunderte haben hier verschiedenste ethnische, religiöse, kulturelle und ökonomische Akteure gewirkt und interagiert, was der Region ein Gepräge verliehen hat, das europäische Vielfalt exemplarisch zum Ausdruck bringt. ${ }^{7}$ Hier sind die Folgen der früheren Lage an der deutsch-polnischen ${ }^{8}$, sowie die Alltagserfahrungen der jetzigen Lage an der polnisch-tschechischen Grenze deutlich wahrnehmbar. Nicht zuletzt leben hier Menschen zusammen, die sich in der europäischen Einheit, der geistigen und politischen, aufgehoben und miteinander verbunden fühlen - Menschen aber, die ihre Identität unterschiedlich definieren, die sich entweder als Polen, Deutsche, Mährer oder regional als Oberschlesier fühlen - wobei im letzteren Fall erst an zweiter Stelle, falls überhaupt, eine Verbindung mit dem Bekenntnis zur Nation - oder gleich mehreren Nationen - hergestellt wird.

Die im Folgenden vorgestellte Schulbuchanalyse stellt die zentralen Befunde vor und eruiert, inwieweit in bildungspolitischer Hinsicht ein Zugriff auf vielschichtige Identitätsbildungsprozesse in multiethnischen Grenzräumen sowohl für innovative Ausrichtung von Schulbüchern als auch für die Entwicklung didaktischer Konzepte verspricht.

6 Die Befunde der Schulbuchanalyse, untermauert durch Leitfaden-Interviews mit Repräsentanten maßgeblicher regionaler Bildungsträger, Interessenverbände und wissenschaftlicher Einrichtungen liegen seit September 2013 als Forschungsbericht vor und erschienen 2016 als Monografie: Marcin Wiatr, Oberschlesien als kulturelles Erbe. Erinnerungspolitische Befunde, bildungspolitische Impulse und didaktische Innovationen, Göttingen: V\& R unipress, 2016.

7 Philipp Ther, »Die Grenzen des Nationalismus: Der Wandel von Identitäten in Oberschlesien von der Mitte des 19. Jahrhunderts bis 1939«, in: Ulrike von Hirschhausen und Jörn Leonhard (Hg.), Nationalismen in Europa. West- und Osteuropa im Vergleich, Göttingen: Wallstein, 2001, 322-346, 344f.

8 Für Danuta Berlińska stellt Oberschlesien im soziologischen Sinne weiterhin ein deutschpolnisches Grenzgebiet dar, vgl. hierzu: Dies., »Identität und nationale Identifikation der Schlesier in der Region Oppeln nach 1989«, in: Kai Struve und Philipp Ther (Hg.), Die Grenzen der Nationen. Identitätenwandel in Oberschlesien in der Neuzeit, Marburg: Herder, 2002, 275-305; vgl. auch: dies., "Symbole einer schwierigen Geschichte im Oppelner Schlesien«, in: Zbigniew Mazur (Hg.), Das deutsche Kulturerbe in den polnischen West- und Nordgebieten, Wiesbaden: Harrassowitz, 2003, 161-183, insbes. 161 sowie Jolanta Tambor, Oberschlesien Sprache und Identität, Hildesheim u. a.: Olms, 2011 [polnische Ausgabe: Mowa Górnoślązaków oraz ich świadomość językowa i etniczna, Katowice: Uniwersytet Śląski, 2006]. 


\section{Schulbuchanalyse}

Oberschlesien eignet sich in vielfacher Weise als schulbuchbezogenes Forschungsfeld. Es ist zum Beispiel interessant, wie Schulbücher, denen für die Entwicklung kollektiver Identitäten eine bedeutsame Funktion zugesprochen wird, das Transnationale eines multiethnischen Geschichts- und Kulturraums reflektieren und wie dies in aktuellen Bildungsprozessen und -medien präsent ist. In diesem Kontext kann eruiert werden, inwieweit Schulbuchautorinnen und -autoren überhaupt dazu fähig sind, sich der Voraussetzung zu stellen, junge Menschen mit »multiple[n] Narrationen, kontroverse[n] Geschichstsbilder[n] und Geschichtsvorstellungen" zu konfrontieren und dabei einen schärferen Blick zu richten auf »jene transnationalen bzw. transregionalen Verflechtungen, Kommunikationsstrukturen, Beziehungsgeschichten und Integrationsprozesse, die es ermöglichen, Peripherien und Zentren historisch zu vermessen und herauszuarbeiten, wie sich beides im Laufe der Jahrhunderte gewandelt hat.«"

\section{(Ober-)Schlesien zur Piastenzeit}

Die Region erscheint zunächst überwiegend als ein Konfliktraum. Dabei gilt: je weiter ein historisches Ereignis oder Phänomen zurückliegt, umso kontroverser und multiperspektivischer werden einschlägige Schulbuchnarrative. Die in polnischen Schulbüchern ausgesprochen traditionsreiche Konfliktgeschichte zwischen Deutschen und Polen in der frühmittelalterlichen Region Schlesien/ Oberschlesien wird nicht mehr fortgesetzt, so wie noch vor dem Wendejahr 1989 mehrfach in den Darstellungen zur Gründung des Piastenreiches und den folgenden Grenzziehungen. Das Thema der Germanen/Slawen, ihrer Präsenz und ihres Status in (Ober-)Schlesien in den vormittelalterlichen Zeiten ist also »evolviert«. So wird gar in einem neueren Narrativ eingeräumt, dass es mangels genauerer Informationen unmöglich sei, die genaue Zeit festzumachen, wann die Slawen sich in Gebieten niederließen, »die später Bestandteil des polnischen Staates werden. $\aleph^{10}$ Direkt danach heißt es in einem Schulbuch von 2003, das als exemplarisch gelten kann: "Vorherige Einwohner in diesen Gebieten waren germanische Völker, die ca. im 3./4. Jh. n. Ch. in andere Gebiete ausgewandert

9 Eckhardt Fuchs und Simone Lässig, »Europa im Schulbuch«, in: Geschichte für heute. Zeitschrift für historisch-politische Bildung 1 (2009), 60-66, 62.

10 Wojciech Mrozowicz und Przemysław Wiszewski, Historia. Średniowiecze. Podręcznik do liceum ogólnokształcącego, profilowanego i technikum - zakres podstawowy i rozszerzony, Wrocław: Wydawnictwa Edukacyjne Wiking, 2003, 160 [Übersetzungen sämtlicher zitierter Passagen durch den Verfasser.]. 
sind. ${ }^{11}$ Die Frage nach dem Siedlungsgebiet germanischer und slawischer Kulturen im relativ kleinen Raum Oberschlesien und nach der Ethnizität der hier ansässigen Stämme (Motto »Wer war hier als Erster? «) wird daher nicht mehr so dominant wie früher in die Raumvorstellung hinein transportiert.

Dies geschieht dagegen schon häufiger in Bezug auf die Gründung und territoriale Ausweitung des Piastenreiches, denn Schlesien/Oberschlesien wird nicht als ein fremder Raum konstruiert, der erst angeeignet werden müsste, sondern fungiert als etwas »Eigenes«. So begegnen wir noch gleich zu Beginn eines einschlägigen Abschnitts in einem kurz nach der Wende herausgegebenen Schulbuch der folgenden Aufgabe: "Schaut Euch bitte die Landkarte Polens im 10.-11. Jh. an. Vergleiche Mieszkos Staatsgrenzen mit den heutigen Grenzen Polens. Wo befinden sich heute die ältesten staatsbildenden Zentren Polens? « ${ }^{12}$

Damit wird der Blick der Schülerinnen und Schüler u.a. auf den Raum Schlesien/Oberschlesien gerichtet und das Bewusstsein dafür gefestigt, diese Region als "urpiastisches«, sprich urpolnisches Gebiet und staatsbildendes Zentrum anzusehen. Tatsächlich aber stand die Region im 9. Jahrhundert unter dem Einfluss des Großmährischen Reiches, was in neueren Schulbuchnarrativen durchaus erwähnt wird. ${ }^{13}$ Dies wurde in Schulbüchern vor 1989 nicht hinlänglich beleuchtet; stattdessen wurde der Eindruck von einer »urpiastischen « Provinz gefestigt. ${ }^{14}$ Diese Optik wird allerdings auch in einem neueren Schulbuch beibehalten. ${ }^{15}$ Erst allmählich wird dieser Blick erweitert, indem darauf hingewiesen wird, der Raum Schlesien/Oberschlesien sei zunächst territorialer Bestandteil Böhmens gewesen ${ }^{16}$ und erst nachträglich - ähnlich wie Pommern oder selbst Kleinpolen - um 990 ans Piastenreich "angeschlossen ${ }^{17}$ oder "gewon-

11 Ebd.

12 Halina Manikowska und Julia Tazbirowa, Historia. Średniowiecze. Podręcznik dla szkót średnich klasy I liceum ogólnokształcącego technikum i liceum zawodowego, Warschau: WSiP, 1993, 48.

13 Vgl.: Bogumiła Burda, Bohdan Halczak, Roman Maciej Józefiak und Małgorzata Szymczak, Historia 1. Część 2. Średniowiecze. Podręcznik. Zakres podstawowy, Gdynia: Wydawnictwo Pedagogiczne OPERON, 2010, 103.

14 Vgl. hierzu: Joanna Wojdon, Propaganda polityczna w podręcznikach dla szkót podstawowych Polski Ludowej (1944-1989), Toruń: Wydawn. Adam Marszałek, 2001; Jerzy Ronikier, Mit i historia. Mitotwórcze funkcje podręczników szkolnych, Krakau: Wydawn. Uniwersytetu Jagiellońskiego, 2002.

15 Adam Wypustek und Marek L. Wojcik, Historia 1. Starożytność. Średniowiecze. Ze świata do Polski przez Europę. Liceum ogólnokształcące; Liceum profilowane; Technikum. Zakres podstawowy i rozszerzony, Warschau: Nowa Era, 2002, 183.

16 Jarosław Nikodem, Historia. Średniowiecze. Podręcznik dla liceum ogólnokształcącego, profilowanego i technikum. Zakres podstawowy i rozszerzony, Warschau: Wydaw. Juka, 2004, 73.

17 Mirella Kurkowska, Jarosław Kurkowski und Maria Radożycka-Paoletti, Zrozumieć współczesny świat. Podręcznik historii dla liceum ogólnokształcącego, profilowanego i technikum, Teil 1, Warschau: Adam, 2002, 77. 
nen ${ }^{18}$ worden. In einigen Büchern wird die bisherige Geschichtsschreibung über die Anfänge des polnischen Staatswesens kritisch reflektiert: »Auch wenn wir Mieszko I. (?-992) für den ersten Herrscher Polens erachten, so regierte er in Wirklichkeit lediglich über lose zusammengewürfelte Stammesgebiete, die noch keinen einheitlichen Namen hatten. ${ }^{19}{ }^{19}$ Die Provinz erscheint generell als ständiges Streitgebiet zwischen den Königreichen Polen und Böhmen. ${ }^{20}$ Die erneute Eroberung Schlesiens 1050 durch den polnischen König Kazimierz Odnowiciel (Kasimir der Erneuerer) wird gar zum Maßstab für »den wahren Erfolg« des Königs erklärt: »[Er] brachte Schlesien unter seine Herrschaft und nahm die Region zum zweiten Mal in der Geschichte Polens den Tschechen [sic] weg. ${ }^{21}$ Die Bedeutung der Grenzen des frühen Piastenreiches, das mit Blick auf die Begründung der Westverschiebung Polens nach 1945 im Zuge einer klassischen Ex-post-Konstruktion zur einer staatsgründungsrelevanten Landschaft mutiert, wird in neueren Schulbuchnarrativen vereinzelt etwas kontroverser reflektiert. So ist in einem Exkurs zum Begriff des sog. "Erzpolentums« einzelner Regionen, wobei auf Schlesien Bezug explizit genommen wird, Folgendes zu lesen:

Nach dem Zweiten Weltkrieg wurde vor allem die Landkarte Polens aus der Zeit um 1000 abgebildet. Denn in diesem Jahr stimmten die Grenzen des Piastenreiches in etwa mit den Nachkriegsgrenzen Polens überein. Frische, neue Grenzen, abgesteckt im Frühjahr 1945, wurden in der Propagandasprache zu... »erzpolnischen« Gebieten erklärt. Dies war allerdings eine Manipulation [...]. Denn schon im Jahre 1002 war der Herrschaftsbereich von Chrobry ein völlig anderer. Noch mehr änderte er sich 1003, noch anders war er im Jahre 1018... usw. Die Meinung, dass z. B. Böhmen »erzpolnisch « sei, weil hier eine Zeit lang ein polnischer Herzog herrschte, würden wir ja als absurd abtun. Die Grenzen der mittelalterlichen Staaten änderten sich stets, ein nationales Zusammengehörigkeitsgefühl im heutigen Sinne bestand damals nicht - die Landkarte Polens von 1000 sollte daher eher mit einiger Distanz betrachtet werden. ${ }^{22}$

Der Raum Schlesien/Oberschlesien wird vor allem beim Thema der feudalen Zersplitterung des Piastenreiches in der zweiten Hälfte des 12. und im 13. Jahrhundert (»Dezentralisierung«) ambivalent besetzt. Die nach dem Tod von Bolesław III Schiefmund 1138 eingetretene Phase der "Dezentralisierung" des Piastenreiches wird u. a. mit dem Erstarken von einzelnen Herrschaftsbezirken, darunter (Ober-)Schlesien, in Verbindung gebracht. Die Region wird als

18 Wypustek und Wojcik, Historia 1, 183.

19 Mikołaj Gładysz, Historia I. Czesść 2. Od średniowiecza do nowożytności. Podręcznik dla klasy pierwszej liceum i technikum. Zakres podstawowy i rozszerzony, Gdańsk: Gdańskie Wydawnictwo Oświatowe, 2002, $56 \mathrm{f}$.

20 Jan Wróbel, Odnaleźć przeszłość. Od starożytności do 1815 roku. Część 1. Podręcznik - liceum ogólnokształcące, liceum profilowane, technikum. Kształcenie w zakresie podstawowym, Warschau: WSiP, 2002, 188.

21 Nikodem, Historia, 90.

22 Wróbel, Odnaleźć przeszłość. Od starożytności do 1815 roku. Częsś́ 1, 159. 
ein Raum wahrgenommen, von dem eine für die staatliche Einheit gefährdende Entwicklung ausgeht. Vor allem wird den durch das deutsche Patriziat dominierten Städten dieser Region wie etwa Breslau eine negative Rolle zugeschrieben, wobei die wirtschaftliche Entwicklung der zentrale Faktor ist, der für die jeweils politischen Strategien zur staatlichen Umorientierung zugunsten Böhmens verantwortlich gemacht wird. ${ }^{23}$ In einem weiteren Narrativ werden die Gründe für die feudale Zersplitterung des Piastenreiches auf mangelnde Gemeinsamkeiten unter den einzelnen Regionen zurückgeführt und mit anderen regionalen Traditionen, Bräuchen, Dialekten sowie »anderen wirtschaftlichen und politischen Interessen « begründet:

Wie ihr schon wisst, entstand das Piastenreich in Folge der Eroberung einiger Regionen, aus denen das heutige Polen besteht. [...] Auf diese Weise wurden einzelne Regionen - Kujawien, Mazowien, Pommern, Kleinpolen, Schlesien - zu Provinzen des Piastenreiches [...]. Doch diese Regionen verbanden noch keinerlei feste Gemeinsamkeiten [...]. Das Polen der ersten Piasten blieb daher (ähnlich wie andere Staatswesen des damaligen Europa) ein Sammelsurium von lose verflochtenen Gebieten $[\ldots] .^{24}$

Auch wenn in neueren Schulbüchern zunehmend die Einsicht Eingang findet, dass im Mittelalter die territoriale Verbundenheit eine große Rolle spielte und »damals lokale Gemeinschaften, so genannte Heimaten [poln. małe ojczyzny] am stärksten ausgeprägt waren [...] und die staatliche oder nationale Solidarität sich erst allmählich [herausbildete] « ${ }^{25}$, so dominiert dennoch folgendes Bild: Während in älteren Narrativen der Provinz ein Zersetzungsstreben der staatlichen Einheit unterstellt wird (»Zersplitterung polnischer Gebiete $\aleph^{26}$ ), wird in neueren Schulbüchern den schlesischen Herzögen das Streben nach Überwindung der territorialen Zersplitterung und der staatlichen Schwäche attestiert. Schlesien erscheint in dieser angespannten, ungewissen Zeit als eine Region, die »zwischen Polen und Böhmen schwebte. ${ }^{27}$ Auch wenn die feudale Zersplitterung des Piastenstaates weiterhin überwiegend negativ gesehen wird und die Schwächung des Piastenreiches, die Bedrohung seitens der Nachbarn, die innere Anarchie mit politischen Intrigen und Meuchelmorden beklagt wird, die insgesamt zur »Ab-

23 Manikowska und Tazbirowa, Historia. Średniowiecze, 139.

24 Gładysz, Historia I. Częśś 2, 79.

25 Tadeusz Cegielski, Włodzimierz Lengauer und Michał Tymowski, Ludzie, społeczeństwa, cywilizacje. Historia. Starożytność i średniowiecze. Cześś I. Podręcznik dla liceum ogólnokształcącego, liceum profilowanego i technikum - zakres podstawowy, Warschau: WSiP, $2002,268$.

26 Manikowska und Tazbirowa, Historia. Średniowiecze, 126.

27 Kurkowska, Kurkowski und Radożycka-Paoletti, Zrozumieć wspótczesny świat, 83. 
hängigkeit der schlesischen Provinz von Böhmen führte[n] ${ }^{28}$, wird diese Einschätzung in neueren Narrativen problematisiert:

[N]och bis vor kurzem [beurteilten] viele Historiker, insbesondere polnische, die Zeit der feudalen Zersplitterung sehr kritisch. Betont wurde vor allem die dauerhafte, fast 150 Jahre andauernde Zeit der Auflösung der zentralen staatlichen Einheit. [...] Man habe danach die Idee des zentralisierten Staates vernachlässigt. So erschienen als schwerste Folge der feudalen Zersplitterung territoriale Verluste. [...] Zunächst verselbständigte sich Pommern und fiel dann gänzlich ab, [...] schließlich sollte sich von Polen auch die Provinz Schlesien entfernen. ${ }^{29}$

Den damaligen Piastenherzögen wurde (seitens der Historiker) auch Kurzsichtigkeit, Engstirnigkeit, Mangel an Patriotismus vorgeworfen. ${ }^{30}$

Die feudale Zersplitterung habe - laut neuerer Narrative - eine Eigendynamik für die wirtschaftliche Entwicklung der einzelnen Provinzen bewirkt und der Anteil an diversen dezentralisierten Machtstrukturen habe allmählich dazu beitragen, eine neue Herrschaftsform hervorzubringen, nämlich die der Standesherrschaft. So wird als positiv herausgestellt, dass Schlesien im 13. Jahrhundert zur "reichsten und bestens urbanisierten Provinz aller polnischen Gebiete [wurde] « ${ }^{31}$. Dieser zivilisatorische Erfolg der Region wird auf die Politik schlesischer Piastenherzöge zurückgeführt: die Initiative und Förderung intensiver Siedlungsmaßnahmen, eine Neuordnung im Rechtswesen und die Anwendung neuer Technologien in Landwirtschaft und Bergbau. Die Auswirkung dieses zivilisatorischen Fortschritts war ein ethnischer Wandel, so dass auch an den Höfen der schlesischen Herzöge deutsche Einflüsse immer stärker wurden. Dieser ethnisch-kulturelle Wandel wird dafür verantwortlich gemacht, »dass die in Schlesien vorherrschenden Stimmungen nicht immer den Bemühungen zur Eingliederung dieser Provinz in den polnischen Staat förderlich waren $[\ldots] . \star^{32}$

\section{Landesausbau im Mittelalter}

In ähnlich kontroverser Weise wird auch über das Konstrukt »Nation« sinniert. Betont wird etwa die Fehlbarkeit nationaler Zuordnungen:

28 Marek Kamiński, Grażyna Pańko und Robert Śniegocki, Historia. Średniowiecze. Podręcznik dla I klasy liceum ogólnokształcącego, liceum profilowanego i technikum, część 2 - kształcenie w zakresie podstawowym i rozszerzonym, Warschau: Nowa Era, 2006, 101.

29 Nikodem, Historia, 130.

30 Gładysz, Historia I. Część 2, 82.

31 Mrozowicz und Wiszewski, Historia, 214.

32 Ebd.; vgl. auch: Gładysz, Historia I. Częśś 2, 44. 
Das Grundkriterium der Teilung in Franzosen, Engländer oder Polen lag nicht in der Herkunft, sondern in der Zugehörigkeit zur jeweiligen Monarchie. [Folglich] war die kulturelle und sprachliche Vielfalt unter den Untertanen etwas ganz Natürliches. [...]. Mittelalterliche Höfe, Armeen und Städte Europas waren voller Ausländer, die sich mit einem neuen Land auch eine neue "Nation« erwählten. [...] [D]er Weg bis hin zur Herausbildung moderner Nationen war noch sehr weit. [...] [Die meisten Europäer] bezeichneten sich als »Hiesige.$^{33}$

Dieses Narrativ, das sich signifikant von einer nationszentrierten, ins Mittelalter zurückprojizierten Sinnzuschreibung losspricht und auf ein europäisches Phänomen verweist, wird bezeichnenderweise dort gebrochen, wo der konkrete Raum wie etwa Schlesien/Oberschlesien in den Blick gerät:

Im Kontakt mit den deutschen Siedlern nahmen Pomoranen, Großpolen oder Schlesier leichter die sie verbindenden ethnischen Gemeinsamkeiten wahr. Die Identifizierung mit der Gemeinschaft von Menschen mit gleicher Sprache und Kultur, die sich zur gemeinsamen Herkunft bekannten, wurde immer stärker. ${ }^{34}$

So habe der zunehmende Zustrom neuer Bevölkerungsteile zwar das »ethnische Antlitz polnischer Regionen im Mittelalter « geändert ${ }^{35}$, doch zugleich die Wahrnehmung der eigenen kulturellen/sprachlichen Eigenart der polnischen Bewohner gefördert und deren eigene Traditionen oder gar die polnische Identität zusätzlich gestärkt. ${ }^{36}$

Insgesamt wird die deutsche Ostsiedlung im Raum Schlesien/Oberschlesien recht ambivalent bewertet. Einerseits wird die "deutsche Kolonisation« als ein positiver Prozess dargestellt, der einen grundlegenden Wandel in Polens Wirtschaft und Gesellschaft im 13. Jahrhundert in Gang setzte. ${ }^{37}$ Andererseits werden negative Folgen herausgestellt. So habe der »Zuzug von Fremden auch Konflikte mit der einheimischen Bevölkerung [verursacht], darunter auch ethnische. ${ }^{38}$ Dem Konfliktpotenzial, das die deutsche Ostsiedlung verkörpert, wird aber auch Positives abgewonnen, denn es habe dem »nationalen Zusammengehörigkeitsgefühl ${ }^{39}$ starke Impulse gegeben. ${ }^{40}$ In diesem Zusammenhang dürfe sogar »von

33 Ebd., 48.

34 Ebd., 48; vgl. auch: Michał Tymowski, Człowiek i historia Część 2. Czasy średniowiecza. Kształcenie $w$ zakresie rozszerzonym. Podręcznik dla liceum ogólnokształcącego, Warschau: WSiP, 2002, 104.

35 Kamiński, Pańko und Śniegocki, Historia, 107.

36 Ebd., 119.

37 Gładysz, Historia I. Część 2, 37; Halina Manikowska, Historia dla maturzysty. Średniowiecze. Podręcznik - szkoły ponadgimnazjalne, zakres rozszerzony, Warschau: PWN, 2007, 254.

38 Krzysztof Polek und Marek Wilczyński, Historia. Ludzie i epoki.. Podręcznik Klasa 1 liceum ogólnokształcące, liceum profilowanym i technikum, Krakau: Znak, 2003, 305.

39 Leszek Wojciechowski, Historia. Średniowiecze. Klasa 1. Częśś 2. Podręcznik do liceum ogólnokształcącego, liceum profilowanego i technikum. Zakres podstawowy, Kielce: MAC EDUKACJA, 2003, 186. 
den Anfängen des polnischen Nationalbewusstseins « ${ }^{41}$ gesprochen werden. Der zunehmend multiethnisch werdende Raum Schlesien/Oberschlesien sollte auf diese Weise zum Selbstvergewisserungsreservoir des überregional Verbindenden werden, um später in eine nationale Identität zu münden. Diese Behauptung wird erst in neueren Schulbuchnarrativen infrage gestellt, denn »im Gegensatz $\mathrm{zu}$ anderen polnischen Regionen, wo sich Siedler rasch assimilierten, [war] der Zustrom der deutschen Siedler so stark, dass in manchen Gegenden Schlesiens [...] im 14. Jahrhundert die slawische Bevölkerung eine Minderheit darstellte und sich schnell germanisierte. ${ }^{42}$ In einem anderen Schulbuch heißt es sogar:

[D]ie Zahl der Deutschen war [hier] so groß, und die deutsche Kultur so attraktiv, dass Mitte des 13. Jahrhunderts ein Germanisierungsprozess mancher gesellschaftlicher Gruppen einsetzte und einen Teil [...] der schlesischen Piastenherzöge erfasste. Diese Herrscher hatten weiterhin ein Zugehörigkeitsgefühl zur Dynastie der Piasten, aber immer häufiger kam es vor, dass sie bereits Deutsch sprachen. Heinrich Probus hatte Ende des 13. Jahrhunderts nach der polnischen Krone und der Einheit der Piastengebiete gestrebt, was ihn nicht daran hinderte, deutsche Gedichte zu schreiben. ${ }^{43}$

(Ober-)Schlesien vom 14. Jahrhundert bis zu den Teilungen

Nach dem Aussterben der Breslauer Piastenlinie war die Region 1335 im Vertrag von Trentschin an die Böhmische Krone zurückgefallen und wurde 1348 förmlich in das Heilige Römische Reich Deutscher Nation eingegliedert. Bis ins 18. Jahrhundert hinein stand sie politisch und kulturell unter dem Einfluss der Habsburgermonarchie. In Bezug auf diesen Zeitraum bleiben Repräsentationen Schlesiens/Oberschlesiens auch in neueren polnischen Schulbüchern lediglich fragmentarisch. Eine intensivere Auseinandersetzung erfolgt erst dann, wenn die räumliche Bedeutung Oberschlesiens eine intensive gesellschaftliche und politische Aufladung erfährt. So stimuliert die von Preußen ausgehende Gefahr für die Polnische Adelsrepublik die Wahrnehmung der schlesischen Provinz. ${ }^{4}$ Zunächst wird der Eroberung (Ober-)Schlesiens durch Preußen infolge der Schlesischen Kriege (1740 bis 1763) eine Schlüsselrolle bei der Festigung der Vormachtstellung im Wettkampf zwischen Österreich und Preußen zugewiesen: »[Es] ging nicht mehr um die schlesische Provinz allein, sondern um die Frage,

40 Vgl. auch: Tymowski, Człowiek i historia, 104; Kamiński, Pańko und Śniegocki, Historia, 119-120.

41 Cegielski, Lengauer und Tymowski, Ludzie, społeczeństwa, cywilizacje. Historia, 261.

42 Burda, Halczak, Józefiak und Szymczak, Historia 1, 181.

43 Cegielski, Lengauer und Tymowski, Ludzie, społeczeństwa, cywilizacje. Historia, 253.

44 Tadeusz Cegielski und Katarzyna Zielińska, Historia 2. Dzieje nowożytne. Podręcznik dla szkót średnich klasy II liceum ogólnokształcącego, Warschau: WSiP, 1993, 285. 
wer die Vorherrschaft in Ostmitteleuropa übernehmen würde. ${ }^{45}$ Damit wird der bis dahin kaum wahrgenommene, verlorengegangene Raum zu einer »reiche[n], hochentwickelte[n], strategisch günstig gelegene[n] «" ${ }^{46}$, stark bevölkerte[n], fruchtbare[n] und an Mineralstoffen reiche[n] Provinz « ${ }^{47}$, die somit »Preußens wirtschaftliches Potenzial maßgeblich [stärkte] « ${ }^{48}$, es militärisch und demografisch aufwertete ${ }^{49}$ und gar einen Wendepunkt einleitete: den Beginn eines "für Deutschland wichtigen preußischen Mythos. ${ }^{50}$ Oberschlesien erscheint als Raum wirtschaftlicher und gesellschaftlicher Modernisierung Preußens. Dabei fällt auf, dass in diesem Kontext viele polnische Schulbücher selbst nach 1989 nicht deutlich genug zwischen tatsächlich "polnischen Teilungsgebieten « und Regionen unterscheiden, die bereits Jahrhunderte zuvor eine Eigenentwicklung außerhalb des polnischen Staates durchlaufen haben. So wird etwa Oberschlesien häufig explizit als preußisches Teilungsgebiet genannt ${ }^{51}$ oder es wird lediglich in kleingedruckter Schrift oder im Nebensatz - eingeräumt, dass die Betrachtung dieser Region als preußisches Teilungsgebiet eher problematisch ${ }^{52}$ oder nur symbolisch ${ }^{53}$ sei.

\section{Oberschlesien zwischen Preußen und der polnischen Nationalbewegung}

Die meistbehandelten Themen, die nun zunehmend in Verbindung mit Oberschlesien in den Vordergrund der Narrative rücken, sind der Kulturkampf Bis-

45 Krystyna Szelągowska, Wykłady z historii powszechnej dla szkoły średniej, Warschau: WSiP, 1994, 166; vgl. auch: Józef Gierowski und Józef Leszczyński, Historia dla klasy 2 liceum ogólnoksztatcącego, Warschau: WSiP, 1990, 261; Cegielski und Zielińska, Historia 2, 269; Katarzyna Zielińska und Zofia Kozłowska, Historia 2. Dzieje Nowożytne 1492-1815. Podręcznik dla klasy II liceum ogólnokształcącego, Warschau: WSiP, 1994, $203 \mathrm{f}$.

46 Szelągowska, Wykłady z historii powszechnej dla szkoły średniej, 170.

47 Marek Kamiński und Robert Śniegocki, Historia. Od renesansu do czasów napoleońskich. Podręcznik dla II klasy liceum ogólnokształcącego, liceum profilowanego i technikum, część 1 - kształcenie w zakresie podstawowym i rozszerzonym, Warschau: Nowa Era, 2006, 217.

48 Gierowski und Leszczyński, Historia dla klasy 2 liceum ogólnokształcących, 377; vgl. auch: Zielińska und Kozłowska, Historia 2, 203.

49 Cegielski und Zielińska, Historia 2, 262, 269; Bogumiła Burda, Bohdan Halczak, Roman Maciej Józefiak, Anna Roszak und Małgorzata Szymczak, Czasy nowożytne. Historia 2. Zakres rozszerzony. Podręcznik dla liceum ogólnokształcącego, Gdynia: OPERON, 2007, 229.

50 Kurkowska, Kurkowski und Radożycka-Paoletti, Zrozumieć współczesny świat, 224.

51 Anna Radziwiłł und Wojciech Roszkowski, Historia 1789-1871. Podręcznik dla szkót średnich, Warschau: PWN, 1995, 208; Waldemar Lazuga, Historia czasów nowożytnych (18151918). Podręcznik dla szkoly średniej, Warschau: Wydawn. Graf Punkt, 1998, 78.

52 Radziwiłł und Roszkowski, Historia 1789-1871, 211.

53 Anna Radziwiłł und Wojciech Roszkowski, Historia dla maturzysty. Wiek XIX. Podręcznik szkoły ponadgimnazjalne, zakres rozszerzony, Warschau: Wydawnictwo Szkolne PWN, 2006, 52. 
marcks und die polnische Nationalbewegung seit der Mitte des 19. Jahrhunderts. In diesem Kontext sorgt der Faktor Religion (der in polnischen Schulbüchern generell häufig in dieser Funktion auftritt) für eine Identifikation und die Aufladung der Raumvorstellung in Bezug auf Oberschlesien mit dem Prädikat »Eigenes«. In einem 1990 erschienenen Schulbuch wird hierzu eine klare Aussage getroffen: "Für das oberschlesische Volk stand sein Glaube immer im Zusammenhang mit der polnischen Sprache, Schule und dem Vaterland. ${ }^{54}$ Aber auch in späteren Schulbuchnarrativen wird der (katholischen) Kirche in konsequenter Weise eine zentrale Rolle bei der Bewahrung der polnischen Sprache, der Vermittlung der nationalen Geschichte und der Etablierung eines nationalpolnischen Bewusstseins bescheinigt. ${ }^{55}$ Fortgesetzt wird dabei die in früheren polnischen Schulbuchnarrativen bereits gängige Gegenüberstellung: katholisch - polnisch, evangelisch - deutsch. ${ }^{56}$ Dabei gerät in den meisten einschlägigen Narrativen aus dem Blick, dass gerade in Oberschlesien - anders als etwa im preußischen Teilungsgebiet Großpolen - sowohl Deutsche, Polen als auch national indifferente Oberschlesier gleichsam katholisch waren. Der Kulturkampf wurde von der einheimischen, oftmals zweisprachigen Bevölkerung vor allem als Bedrohung der eigenen religiösen Identität empfunden. Die Politik Bismarcks stärkte also eher das Zusammengehörigkeitsgefühl aller katholischen Bewohner Oberschlesiens. Lediglich ein Schulbuch entdeckt in dieser Hinsicht Oberschlesien als einen Solidaritätsraum. ${ }^{57}$ Die vielschichtigen, sich einer eindeutigen nationalen Zuordnung entziehenden gesellschaftlichen Verhältnisse in Oberschlesien werden insgesamt selbst in neueren Schulbüchern meist aus nationalstaatlicher Perspektivierung geschildert. Nur vereinzelt steht neben Pauschalformulierungen (»Im 19. Jahrhundert Identifizierte sich ein Großteil der Bevölkerung Schlesiens [eigentl. Oberschlesiens] mit der polnischen Nation. ${ }^{58}{ }$ ) ein Einzelsatz, der eine andere Perspektive aufkommen lässt: „Die Trennungen gingen [hier] sogar mitten durch die Familien. Manchmal sah sich ein Bruder als Deutscher an, während der andere sich als Pole fühlte. " ${ }^{59}$ Bezeichnend bleibt allerdings, dass sämtliche Schulbuchnarrative die regionale Besonderheit der Oberschlesier nur im Gegensatz »deutsch - polnisch« sehen und eine regionale Identifikation, die auch multiple (Mehrfach-)Identitäten zulässt, ignorieren.

54 Andrzej Leszek Szcześniak, Historia 3. Dzieje nowożytne i najnowsze od połowy XIX wieku do roku 1918, Warschau: WSiP, 1990, 166.

55 Grażyna Szelągowska, Historia 3. Dzieje nowożytne i najnowsze 1870-1939. Podręcznik dla klasy III liceum ogólnokształcącego, Warschau: WSiP, 1994, 96.

56 Andrzej Pankowicz, Historia 3. Polska i świat 1815-1939. Podręcznik dla klasy III liceum ogólnokształcącego, Warschau: WSiP, 1996, 79.

57 Mirella Kurkowska und Jarosław Kurkowski, Zrozumieć współczesny świat. Podręcznik Część 2, (1789-1914), Warschau: ADAM, 2004, 59.

58 Burda, Halczak, Józefiak, Roszak und Szymczak, Czasy nowożytne. Historia 2, 386.

59 Ebd., 386. 


\section{Oberschlesien nach den Weltkriegen}

Viel Raum in polnischen Geschichtsschulbüchern nehmen Narrative ein, die sich auf die Zeit nach dem Ende des Ersten Weltkrieges beziehen und hier eine Verbindung zu Oberschlesien herstellen. Dabei fokussieren sie auf die Konsolidierung der Grenzen des wiedergegründeten Polens nach 1918, auf das oberschlesische Plebiszit vom März 1921 und die militärischen Erhebungen (Schlesische Aufstände), folglich auf die im Juni 1922 erfolgte Grenzziehung und die "Rückkehr« (des östlichen Teils) der Industrieregion Oberschlesien zu Polen sowie das Problem der deutschen Minderheit (denn eine pejorative Zuschreibung des Phänomens wird in den meisten Schulbüchern klar herausgestellt). Besonders herausgestellt wird die Bedeutung der Industrieregion Oberschlesien für Polen in der Zwischenkriegszeit. Die Region ist ebenso präsent bei der Thematisierung der deutschen Besatzungspolitik während des Zweiten Weltkrieges im bis 1939 polnischen Teil Oberschlesiens (Volkslisten, Umsiedlungen, Oberschlesier bei der Wehrmacht etc.) sowie der Flucht, Vertreibung und Aussiedlung der Deutschen, wobei die diskriminierende Politik der kommunistischen Regierungen nach 1945 gegenüber der als "Autochthonen « bezeichneten einheimischen Bevölkerung für die Abneigung dieser Gruppe gegenüber der (Re-)Polonisierung verantwortlich gemacht wird: "In der kommunistischen Verwaltung dominierten ungebildete Ankömmlinge, die das vielschichtige Problem der Oberschlesier, Kaschuben oder Masuren in ihrem Kampf um die Bewahrung des Polentums nicht verstanden. Fehler in der Nationalitätenpolitik und Schikanen hatten zur Folge, dass die einheimischen Einwohner dieser Gebiete dem Polentum den Rücken kehrten. ${ }^{60}$ An dieser Stelle wird einmal mehr deutlich, wie dominant eine essentialistische (V-)Erklärung eines sozialen Konstrukts wie des »Polentums« in polnischen Bildungsmedien verankert ist.

Gerade dort, wo eine mehr multiperspektivisch ausgerichtete Darstellung mit einem sozialgeschichtlichen Zugriff angemessen wäre - so etwa in Bezug auf große Migrationsbewegungen und Ausreisewellen aus Polen in den 1970er Jahren (und hier besonders aus Oberschlesien) - werden ökonomisch untermauerte Erklärungsmuster bemüht. So erscheinen Ausreisewellen der »autochthonen Bevölkerung « (Oberschlesier, Masuren) in die Bundesrepublik Deutschland gerade im Fall der oberschlesischen Bevölkerung vorwiegend als eine »in den meisten Fällen ökonomisch [bedingte] « ${ }^{61}$ Arbeitsmigration, was sich übri-

60 Anna Radziwiłł und Wojciech Roszkowski, Historia 1945-1990. Podręcznik dla szkót średnich, Warschau: PWN, 1994, 66.

61 Roman Tusiewicz, Historia 4. Polska wspótczesna 1944-1989. Podręcznik dla klasy IV liceum ogólnokształcącego, Warschau: WSiP, 1993, 244. 
gens mit der (west-)deutschen Interpretation auch weitgehend deckt. ${ }^{62}$ Diesem Phänomen wird in polnischen Schulbüchern relativ viel Platz eingeräumt, wobei die hier geschilderten Gründe, kausalen Zusammenhänge und Auswirkungen nur geringfügig voneinander abweichen. Dabei werden etwaige Fragen der ethnischen oder kulturellen Diskriminierung im privaten und beruflichen Leben (z.B. Verbot des Deutschen als Alltags- und Unterrichtssprache, diskriminierende nationale Verifizierungspolitik, ${ }^{63}$ geringe Ausbildungs- und Aufstiegschancen), wie sie besonders in dem auch nach $1945 \mathrm{im}$ hohen Maße ethnisch gemischten Oberschlesien ausgeprägt waren, ausgeklammert bzw. nicht als ausschlaggebende Beweggründe für eine Ausreise aus Polen erkannt. Ausreisewellen der "autochthonen Bevölkerung« werden folglich meist als eine rein ökonomische Entscheidung interpretiert. Dabei ist auffällig, dass das »ökonomische Motiv« vor allem den Oberschlesiern zugeschrieben wird, wohingegen die Auswanderung der Masuren eher auf die diskriminierende Politik der kommunistischen Führung zurückgeführt wird. Jedenfalls erscheinen die Ausreisewellen als ein für die polnische Wirtschaft, Gesellschaft und (west-)deutschpolnische Wechselbeziehungen nachteiliges Ereignis, auch wenn gelegentlich mit gewisser Genugtuung konstatiert wird, dass damit Polen sich noch stärker zu einem beinahe ethnisch homogenen Land verwandelt habe. ${ }^{64}$ Lediglich in einem Schulbuch begegnen wir einem Narrativ, in dem die Bevölkerungsstruktur in der Volksrepublik Polen kritisch reflektiert wird. Die durch die kommunistische Propaganda - insbesondere auch in den Schulbüchern - verbreitete Vorstellung von Polen als einem ethnisch homogenen Staat wird hier kritisch hinterfragt:

In den jeweiligen Volkszählungen seit 1950 wurde nach der Nationalität schlicht nicht gefragt ([dies erfolgte] erst 2002); man gab vor, es gäbe überhaupt keine Minderheiten. Diese Minderheiten gab es dennoch und sie haben versucht, ihre Identität und Traditionen zu bewahren. Seit 1989 dürfen Minderheiten ihre eigenen kulturellen Institutionen und Einrichtungen sozialer Fürsorge gründen sowie aktiv am politischen Leben teilnehmen. ${ }^{65}$

62 Vgl. hierzu: Ewa Palenga-Möllenbeck, Pendelmigration aus Oberschlesien. Lebensgeschichten in einer transnationalen Region Europas (Kultur und soziale Praxis), Bielefeld: transcript, 2014.

63 Der Begriff beschreibt die sog. Überprüfung der Volkszugehörigkeit in der VR Polen nach 1945 , vor allem in den ehemals deutschen Ost- und nun polnischen Westgebieten.

64 Tusiewicz, Historia 4, 193; Dorota Granoszewska-Babiańska, Dariusz Ostapowicz und Sławomir Suchodolski, Historia 2 - dzieje społeczeństwa i gospodarki, część 1. Podręcznik do liceum ogólnokształcącego, liceum profilowanego i technikum - kształcenie ogólne w zakresie podstawowym i rozszerzonym, Warschau: Nowa Era, 2003, 220.

65 Jerzy Kochanowski und Przemysław Matusik, Człowiek i historia. Część 4. Czasy nowe i najnowsze (XIX i XX wiek). Kształcenie w zakresie rozszerzonym. Podręcznik dla liceum ogólnokształcącego, liceum profilowanego i technikum, Warschau: WSiP, 2004, 260. 
Erst die Erörterung der Volkszählung in Polen im Jahr 2002, in der u. a. nach einer nationalen oder ethnischen Identität gefragt wurde, hat zumindest in zwei Schulbüchern zu einer Erweiterung um die regionale Komponente geführt - die einschlägigen Narrative mit ihrem dominanten, zentralstaatlich ausgerichteten Blick auf Oberschlesien werden hier zumindest ansatzweise modifiziert. Doch insgesamt bleiben die Narrative recht ambivalent. So begegnen wir etwa einer Grafik, die die Bevölkerungsstruktur Polens auf der Grundlage der Ergebnisse der Volkszählung von 2002 darstellt. Im begleitenden Kommentar werden die Schüler aufgefordert, die Ergebnisse der Volkszählung zu analysieren und Regionen zu nennen, in denen nationale und ethnische Minderheiten leben. Besonders interessant ist dabei die folgende Frage:

Berücksichtige vor allem Deutsche und Ukrainer. Kommentiere die Tatsache, dass manche polnische Staatsbürger sich zur »schlesischen Nationalität« bekannt haben. Welche historischen, ökonomischen etc. Gründe für diesen Sachbestand können hier vorliegen $?^{66}$

Die Formulierung " $[\mathrm{M}]$ anche polnische Staatsbürger" ist dabei nicht gerade glücklich gewählt. Denn laut der Volkszählung von 2002 haben sich $173.200^{67}$ (und 2011 bereits ca. $850.000^{68}$ ) polnische Staatsbürger zur oberschlesischen Identität bekannt und gelten inoffiziell als die - neben der deutschen Minderheit - stärkste, allerdings bis heute nicht als ethnische Minderheit anerkannte Bevölkerungsgruppe in Polen. Diese Tatsache wird jedoch in keinem der analysierten Schulbücher weiter verfolgt bzw. problematisiert. Nur in einem einzigen Schulbuch begegnen wir einem Exkurs mit Bezug auf Oberschlesien, der auf diese neusten Entwicklungen rekurriert. Schon die Überschrift »Eine kontroverse Frage: Der Streit um die Identität der Oberschlesier und der Kaschuben « vermittelt, dass es sich um ein öffentlichkeitswirksames Thema handelt. Dabei erscheint Oberschlesien als eine Region, wo besonders intensiv über den Begriff »Identität $^{69}$ diskutiert wird:

66 Ebd., 261.

67 Vgl. http://www.stat.gov.pl/gus/5840_4520_PLK_HTML.htm, Seite ist nicht mehr aktiv, zuletzt geprüft am 10. März 2015.

68 Von den 850.000 Oberschlesiern betrachtet sich immerhin ein Drittel als »dem deutschen und/oder tschechischen Kulturkreis zugehörig" (vgl. Seite 17 des Berichts), http://www.stat. gov.pl/cps/rde/xbcr/gus/PUBL_lu_nps2011_wyniki_nsp2011_22032012.pdf, Seite ist nicht mehr aktiv, zuletzt geprüft am 10. März 2015.

69 Auf das Phänomen der in der nationalen Selbstzuschreibung stark variierenden Identität von multiethnischen, transnational aufgeladenen Räumen wurde im Kontext Oberschlesiens oftmals hingewiesen, vgl. hierzu: Danuta Berlińska, »Identität und nationale Identifikation der Schlesier in der Region Oppeln nach 1989«, in: Kai Struve und Philip Ther (Hg.), Die Grenzen der Nationen. Identitätenwandel in Oberschlesien in der Neuzeit, Marburg: Herder, 2002, 275-305; Grażyna Barbara Szewczyk, »Die Identität des Oberschlesiers im Umfeld von Ideologie und Mythos«, in: Maria K. Lasatowicz und Jürgen Joachimsthaler (Hg.), Nationale 
Manche Oberschlesier und Kaschuben wollten an dieser Stelle ihre Eigenart betonen. Die Bewegung für die Autonomie Schlesiens fordert schon seit einigen Jahren die Anerkennung der Oberschlesier als nationale Minderheit und versucht, aus den in der Region vorkommenden Dialekten eine literarische oberschlesische Sprache herauszubilden. Nach Meinung mancher Autochthoner bewirkte die Polonisierungspolitik der Volksrepublik Polen (Diskriminierung der Traditionen und des Dialekts, die schlicht als »deutsch " galten, Änderung von Vor- und Nachnamen, nationale Verifizierung) mehr Böses als Gutes und trug dazu bei, dass die einheimische Bevölkerung dieser Region nach Deutschland übersiedelte, wo sie... auch als Fremde behandelt werden. Nach Meinung der Oberschlesier haben sich sowohl Polen wie auch Deutsche, vor allem zur Zeit der schlesischen Aufstände, das Recht genommen, die Einheimischen als die »ihren « zu betrachten und über ihr Schicksal zu entscheiden (bis heute hat das Wort Aufständischer im Gebiet um Oppeln einen pejorativen Beiklang). ${ }^{70}$

Im Übungsteil am Ende des Kapitels wird die Aufgabe gestellt, an einigen Beispielen die kulturellen Merkmale der eigenen Heimat und Maßnahmen zur Pflege des Kulturerbes zu erläutern und anhand eines historischen Atlasses die "wechselvolle staatliche Zugehörigkeit solcher Regionen und Städte wie Pommerellen, Danzig, Oberschlesien und Breslau« zu analysieren. Auch sollen die Schülerinnen und Schüler die eigene historisch-geografische Region charakterisieren. ${ }^{71}$ Das alles ist lediglich ein erster (und in den jüngst erschienen Schulbüchern leider nicht weiterentwickelter bzw. konsequent verfolgter) Ansatz, sich mit der wechselvollen Geschichte und den vielfältigen Identitäten der polnischen Regionen auseinanderzusetzen. Es ist zugleich ein Ansatz, der sich

Identität aus germanistischer Perspektive, Opole: Wydawn. Uniwersytetu Opolskiego, 1998, 87-99. Regionalhistorische Identitätsangebote in solchen Grenzregionen, die nach 1918 ihre staatliche Zugehörigkeit u. U. sogar mehrfach gewechselt hatten oder von nationalen Minderheiten bewohnt werden, stehen in besonderem Verdacht, ein "trojanisches Pferd" des Nachbarlandes zu sein. So wird Oberschlesien bis heute mit diesem vereinfachenden Bild und dem generellen Verdacht eines "fremden Identitätsempfindens« konfrontiert. Nur mühsam und schrittweise konnte - nicht zuletzt aufgrund des erfolgreichen Miteinanders zwischen der deutschen Minderheit und der polnischen Mehrheitsbevölkerung seit der Wende von 1989/1990 - Vertrauen aufgebaut werden, wobei dieser Prozess längst noch nicht abgeschlossen ist. Nach den Zahlen des Polnischen Statistikamts fühlen sich immer mehr Menschen regionalen Minderheiten zugehörig: Knapp 850.000 Menschen sehen sich als Oberschlesier an, knapp 230.000 als Kaschuben. Zehn Jahre zuvor hatten sich $173.000 \mathrm{Be}-$ fragte als Oberschlesier und gut 5.000 als Kaschuben bezeichnet. In diesem Kontext sei darauf hingewiesen, dass der Identitätsdiskurs vor allem in den Sozialwissenschaften höchst umstritten ist; vgl. hierzu Ingrid Jungwirth, Zum Identitätsdiskurs in den Sozialwissenschaften, Bielefeld: transcript, 2007.

70 Dorota Granoszewska-Babiańska, Tytus Izdebski, Dariusz Ostapowicz und Sławomir Suchodolski, Historia 3 - dzieje kultury. Podręcznik do liceum ogólnokształcącego, liceum profilowanego i technikum - ksztatcenie ogólne $w$ zakresie podstawowym i rozszerzonym, Warschau: Nowa Era, 2004, 132.

71 Ebd., 132-133. 
- wie das obige Beispiel zeigt - eher durch inhaltliche Widersprüche auszeichnet als durch ein durchdachtes, schlüssiges didaktisches Konzept.

Symptomatisch aber bleibt weiterhin eine negative Aufladung aktueller multiethnischer Räume. Exemplarisch in diesem Kontext ist bis heute das 1998 herausgegebene Geschichtslehrwerk von Andrzej Garlicki. Im Abschnitt zur gesellschaftspolitischen Wende in Polen von 1989 und zu politischen Verhandlungen am Runden Tisch wird die Ausgangslage für den Aufbau der polnischen Demokratie bilanziert. In diesem Zusammenhang wird das Problem der (vermeintlich) verlorengegangenen kulturellen und ethnischen Vielfalt Polens thematisiert: »Polen hat derzeit das glücklichste, vorteilhafteste Territorium in seiner Geschichte und ist im Grunde ein in kultureller Hinsicht homogener Staat.« Weiter verweist der Autor - und folgt damit formal den Leitsätzen der Multiperspektivität - auf Nachteile einer homogenen Gesellschaft mit ihrem »unwiederbringlichen Verlust der kulturellen und nationalen Vielfalt «, wo gerade diese »kulturelle Vielfalt [in der Polnischen Adelsrepublik des 16.-18. Jh.] der polnischen Kultur Entwicklungsimpulse gegeben und diese unglaublich bereichert « habe. Danach wird konstatiert, die ethnisch-kulturelle Vielfalt sei »eine unwiederbringliche Vergangenheit", um abschließend aber $\mathrm{zu}$ einem ausgesprochen positiven Urteil über die verlorene Vielfalt zu kommen: »[V]ielleicht gerade deshalb wurde Polen vor blutigen, tragischen Konflikten wie etwa in Jugoslawien verschont. $"{ }^{72}$ Diesem Satz folgt kein Fragezeichen. Während hier also die Homogenität als Schutz vor gewaltsamen Auseinandersetzungen begriffen wird, wird aktuellen multiethnischen Räumen jegliches positive Potenzial für die Entwicklung des demokratischen Polens abgesprochen. Nicht zuletzt dieses Narrativ zeigt, dass polnische Schulbuchautorinnen und -autoren, Didaktikerinnen und Didaktiker und vor allem Bildungspolitikerinnen und -politiker vor der Herausforderung stehen, sich regionalgeschichtlichen Besonderheiten als Teil auch der eigenen nationalen Tradition zuzuwenden und diese als Bereicherung der nationalen Narrative zu begreifen. ${ }^{73}$

72 Andrzej Garlicki, Historia 1939-1997/98. Polska i świat. Podręcznik dla liceów ogólnokształcacych, Warschau: Scholar, 1998, 402.

73 Vgl. hierzu auch: Agata Nowakowska und Dominika Wielowieyska im Gespräch mit Robert Szuchta: »Program nauczania historii jest do bani«, in: Gazeta Wyborcza, 18. Oktober 2011, http://wyborcza.pl/1,75515,10489824,Program_nauczania_historii_jest_do_bani.html, zuletzt geprüft am 6. März 2019. 


\section{Zentrale Befunde der Schulbuchanalyse}

Die Befunde der Schulbuchanalyse untermauern die Annahme, dass man im Kontext Oberschlesiens - einer nicht nur historisch, sondern auch aktuell multiethnisch geprägten Region Polens - einer vielgestaltigen, von vielen Einflüssen geprägten Kulturlandschaft immer noch skeptisch gegenübersteht. Die Analyse von rund 100 polnischen Schulbüchern für die Sekundarstufe 2, die zwischen 1989/90 und 2013 herausgegeben wurden, zeigt - schon allein quantitativ betrachtet - , dass einschlägige Narrative über Oberschlesien lediglich 0,94 \% des gesamten Analysekorpus ausmachen, Tendenz abnehmend. Oberschlesien wird weiterhin überwiegend in den historischen Perioden und Kontexten erwähnt, die mit der nationalpolnischen Meistererzählung über die Geschichte Oberschlesiens übereinstimmten und erscheint als eine »imaginierte Region zwischen Mythen, Symbolen und Helden in den nationalen Diskursen. ${ }^{74}$ Immerhin lässt sich in qualitativer Hinsicht ein ergiebigerer Befund festhalten, der aber noch keinen Durchbruch bedeutet: Starre Geschichtskonstruktionen werden problematisiert, doch geschieht dies vor allem im Kontext deutlich älterer historischer Ereignisse (etwa der deutschen Siedlungsgeschichte in Oberschlesien oder dem Problem der Grenzen und ethnischen Identitäten im Mittelalter). Dieser Befund mag auf den ersten Blick verwundern, denn polnische Historikerinnen und Historiker wie auch die Schulbuchautorinnen und -autoren haben sich im zunehmenden Maße von dem bis 1989 geltenden normativen Verständnis von Region verabschiedet und eine Entwicklung hin zu einer stärkeren theoretischen und methodischen Reflexion angeregt, die Prozesse der Verflechtung nationaler, regionaler und europäischer Geschichte bewusst aufgreift. Dies zeigt die 2011 vorgelegte Analyse von polnischen Schulbuchnarrativen über Ostpreußen - eine Region, die einen ebenso zerklüfteten Erinnerungsraum darstellt. ${ }^{75}$ Ein lebendiger multiethnischer Raum Oberschlesien mit dichten Siedlungsgebieten von Minderheiten scheint in bildungspolitischer

74 Vgl. Juliane Haubold-Stolle und Bernard Linek (Hg.), Imaginiertes Oberschlesien: Mythen, Symbole und Helden in den nationalen Diskursen, Opole, Marburg: Stowarzyszenie Inst. Ślaski, Herder, 2005, $10 \mathrm{f}$.

75 Stephanie Zloch, $»$ Vergessen und neu entdeckt: Das ehemalige Ostpreußen als imaginierter Raum im Geschichtsunterricht. Eine vergleichende Analyse historischer Narrative und didaktischer Konzepte am Beispiel Deutschlands, Polens und Russlands«, in: Zeitschrift für Geschichtsdidaktik 10 (2011), 22-42, 42; vgl. hierzu auch die einschlägige Monografie: Stephanie Zloch und Izabela Lewandowska (Hg.), Das »Pruzzenland« als geteilte Erinnerungsregion. Konstruktion und Repräsentation eines europäischen Geschichtsraums in Deutschland, Polen, Litauen und Russland seit 1900, Göttingen: V\& R unipress, 2014 (poln. Ausgabe: Ziemie pruskie w podręcznikach Polski, Niemiec, Litwy i Rosji. Porównawcza analiza regionalnych konstrukcji tożsamości $w X X-X X I$ wieku, Olsztyn: Instytut Historii i Stosunków Miedzynarodowych, 2013). 
Hinsicht jedoch eine völlig andere Herausforderung darzustellen. Dies erklärt vielleicht, warum der Paradigmenwechsel von der Politikgeschichte zur Sozialgeschichte, der in der polnischen Schulbuchentwicklung seit 1989 allgemein wahrnehmbar ist, gerade für Oberschlesien nur bedingt zutrifft.

Indessen zeigen die ermittelten Befunde, dass es bei weitem nicht ausreicht,

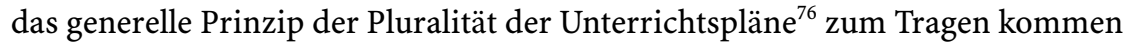
zu lassen, um an Schulen entsprechende Freiräume für bestimmte spezifische Themen - wie etwa Regionalgeschichte - zu schaffen und darüber hinaus etwa Schulbuchverlage und insbesondere Lehrkräfte nachhaltig dazu anzuregen, diese Freiräume mit Inhalt zu füllen. Die vorhandenen gesellschaftlichen Bedarfe nach einer stärkeren Präsenz der Regionalgeschichte in der Schule mögen vielleicht noch durch außerschulische Angebote aufgefangen werden. Aber ohne ein klares Signal seitens der staatlichen Behörden (Bildungsministerium, Bildungsbeauftragte bei den Regierungsvertretern in den einzelnen Wojewodschaften etc.), ohne zielgerichtete und finanziell abgesicherte bildungspolitische Maßnahmen wird die Regionalgeschichte in Polen voraussichtlich nicht als fachübergreifender Bestandteil des Unterrichts (sog. ścieżka międzyprzedmiotowa) flächendeckend angeboten werden und noch weniger als reguläres Unterrichtsfach Eingang in Schulen finden. Diese Einschätzung geht nicht zuletzt aus den Leitfaden-Interviews mit maßgeblichen Akteuren in Bildung, Kultur, Wissenschaft und Kommunalpolitik hervor. Neu ist dabei allerdings die Offenheit, mit der dieses Thema in Polen mittlerweile aufgegriffen wird ${ }^{77}$ sowie eine sich immer deutlicher abzeichnende Erwartungshaltung an den in Bildungsfragen zentral agierenden Staat, in diesem Bereich einen ersten, entscheidenden Schritt zu machen, der nicht zuletzt in Oberschlesien als ein symbolisches Zeichen für eine Wertschätzung des regionalen Kulturerbes - auch seines deutschen Anteils - gewertet werden würde. ${ }^{78}$

76 Lehrkräfte haben die Möglichkeit, eigene Unterrichtspläne zu entwickeln, die auf Wojewodschaftsebene genehmigt werden müssen.

77 Vgl. Anna Świątek, »Licea niekształcące», in: Polityka 40 (2011), 28-30.

78 Dabei gelten hier gleichwohl anspruchsvolle Rahmenbedingungen, denn für Schulbuchnarrative ebenso wie für den Geschichtsunterricht stellen multiethnische Regionen immer eine besondere Herausforderung dar. Ebenso wie das Bedürfnis nach einem verständnisvollen Miteinander entwickelt sich hier, so auch in Oberschlesien, traditionell das Streben nach Abgrenzung und Betonung der eigenen Identität. Charakteristisch ist dabei nicht nur ein Nebeneinander national verschieden zugeordneter Erinnerungsorte, sondern auch die national/regional ganz unterschiedliche Aneignung ein und desselben Ortes. Deshalb ist hier das Spannungsverhältnis zwischen nationaler Bildungspolitik und den regionalen, familiengeschichtlich überlieferten Geschichtsbildern so deutlich wahrnehmbar. Es sind alles Faktoren, die didaktische Implikationen in dem für staatliche Vorgaben sensiblen Bereich der Schulbuchentwicklung in sich bergen. Dennoch muss ein differenziertes historisches Bewusstsein in multiethnischen Regionen keinen Ballast für den Geschichtsunterricht bedeuten, auch wenn sich hier die regionale Erinnerungskultur der Konstruktion einer na- 


\section{Bildungspolitische Konsequenzen und didaktische Implikationen}

Bisherige Repräsentationen Oberschlesiens in polnischen Schulbüchern erscheinen nicht nur fragmentarisch, sondern auch problematisch. Der Region wurde - entgegen dem in Polen seit der Wende von 1989 zunehmenden Interesse der Forschung ${ }^{79}$ - bislang kaum bildungspolitische Bedeutung beigemessen, folglich klafft zwischen gesellschaftlichen Erwartungen nach stärkerer Beachtung der vielfältigen oberschlesischen Geschichte und der vorgefundenen Realität in polnischen Bildungsmedien eine große Lücke. Dieser Umstand lässt sich teilweise daraus erklären, dass die Bildungspolitik in Polen (also auch die Schulbuchzulassung) von zentralen curricularen Vorgaben bestimmt ist und Regionen in bildungspolitischer Hinsicht weiterhin kaum eine Rolle spielen. ${ }^{80}$ Doch bei genauerer Betrachtung zeigt sich, dass Oberschlesien in diesem Kontext eine (negativ aufgeladene) Sonderstellung in Polen einnimmt: Im Gegensatz $\mathrm{zu}$ anderen polnischen Regionen (etwa Kleinpolen oder Masuren) gibt es bis heute keine Schulbücher zur regionalen Geschichte und auch keine polnischen Bildungsmedien, die Oberschlesien in seiner Wirkungsgeschichte angemessen zeigen. $^{81}$

tionalzentrierten historischen Meistererzählung entzieht, die in polnischen Schulbüchern gerade in Bezug auf Oberschlesien noch vielfach anzutreffen ist. Vgl. in diesem Kontext den von Aleida Assmann geprägten Begriff des »Erinnerungsraumes«, Aleida Assmann, Erinnerungsräume. Formen und Wandlungen des kulturellen Gedächtnisses, München: Beck, 1998.

79 Vgl. Robert Traba, »Regionalismus in Polen: Die Quellen des Phänomens und sein neues Gesicht nach 1989«, in: Philipp Ther und Holm Sundhaussen (Hg.), Regionale Bewegungen und Regionalismen in europäischen Zwischenräumen seit der Mitte des 19. Jahrhunderts im Vergleich, Marburg: Herder, 2003, 275-284 sowie Janusz Spyra (Hg.), Kronikaz a historyk. Atuty i słabości regionalnej historiografii. Materiały z konferencji naukowej, Cieszyn: Książnica Cieszyńska, 2007.

80 Vgl. Jerzy Centkowski, "Die Reform der historisch-sozialkundlichen Bildung der Grundschule in Polen «, in: Elisabeth Erdmann, Robert Maier und Susanne Popp (Hg.), Geschichtsunterricht international, Band 117, Hannover: Hahn, 2006, 53-59, 57.

81 Mit dem Problem, Oberschlesien in transnational aufgeladene Schulbuchnarrative zu "übersetzen", stehen polnische Bildungsmedien im europäischen Vergleich nicht allein. Auch die aktuellen deutschen Geschichtsbücher als primäre Unterrichtsmaterialien führen im Moment dahin, dass das historische Bewusstsein für das deutsche Kulturerbe in Mittelund Osteuropa im rasanten Tempo schwindet. Vgl. hierzu: Jörg-Dieter Gauger, Deutsche und Polen im Unterricht. Eine Untersuchung aktueller Lehrpläne/Richtlinien und Schulbücher für Geschichte, Schwalbach/Ts.: Wochenschau-Verlag, 2008. Sowohl polnische als auch deutsche Lehrende, die die Potenziale europäischer Regionalgeschichte im Klassenraum nutzen wollen, stoßen in der Unterrichtspraxis daher oft an Grenzen: Die einschlägigen curricularen Vorgaben bieten herfür kaum Freiraum und vor allem mangelt es an geeigneten Schulbüchern und Unterrichtsmaterialien. Diesem Umstand wollte die deutsch-polnische Website unter http://www.oberschlesien-im-unterricht.net entgegenwirken. Sie stellte neue Perspektiven im Umgang mit ausgewählten Aspekten der Kultur und Geschichte Oberschlesiens vor und regte zur vertieften Beschäftigung mit diesem vermeintlichen Randgebiet Europas 
Die stärksten Impulse, Oberschlesien als multiethnischen Raum im Schulbuch präsenter zu machen, gehen dabei von den in der Region agierenden wissenschaftlichen, zivilgesellschaftlichen und bildungspolitischen Akteuren aus. In den letzten Jahren sind hier die Hinwendung zur regionalen und lokalen Geschichte und der Wunsch nach Regionalgeschichte im Unterricht enorm gewachsen. ${ }^{82}$ Dieser Trend ist nicht nur auf bildungspolitische Aktivitäten und Wünsche der deutschen Minderheit in der Region zurückzuführen, sondern findet auch Resonanz in der breiten Bevölkerung. ${ }^{83}$ In der Wojewodschaft Schlesien haben sich die politisch Verantwortlichen 2011 in spektakulärer Weise dafür ausgesprochen, in den nächsten Jahren erstmalig ein Geschichtsbuch zur Regionalkunde Oberschlesiens zu erstellen, das die kulturelle, sprachliche und ethnische Vielfalt der Region jenseits zentralstaatlicher Perspektivierung spiegelt und für den regulären Einsatz in der Schule gedacht ist. Die Arbeiten koordiniert das im Februar 2012 gegründete Institut für Regionale Forschungen in Katowice (Kattowitz), dem der Historiker Prof. Ryszard Kaczmarek vorsitzt. Solche Vorgänge stoßen vielerorts in Polen auf mangelndes Verständnis, lösen Ängste und Vorbehalte aus, lassen auch manche, für weitgehend überwunden geglaubten Vorurteile wieder in den Vordergrund nicht zuletzt der bildungspolitischen Debatte rücken. Ungeachtet dessen könnten sich die in Oberschlesien postulierten Bestrebungen nach stärkerer Gewichtung der regionalen $\mathrm{Ge}$ schichte, nach weitergehender Erschließung des vielfältigen Kulturerbes sowie nach Überwindung einseitiger Sichtweisen in sehr produktiver Weise mit generellen Herausforderungen treffen, die Europäizität und Heterogenität an das polnische Erziehungssystem stellen. Die Befürchtung aber, ein Regionalgeschichtsbuch für Oberschlesien könnte durch (regionalpolitische) Identitätsstiftung eine Abgrenzung zur nationalpolnischen Mehrheitsidentität zusätzlich fördern, wirkt mit Sicherheit als hemmender Faktor. Natürlich könnte ein innovatives Schulbuch zur regionalen Geschichte, das mittlerweile in einer digi-

an. Die Website, unterfüttert mit Quellenhinweisen, historischen und aktuellen Aufnahmen sowie akustischen Tondokumenten, bot für das Fach Geschichte (in Deutschland ab der 9. Klasse Gymnasium, in Polen ab der 2. Klasse Lyzeum) Anregungen, wie ein Zugang zur komplexen Geschichte Oberschlesiens im Unterricht gelingen kann. Nachdem die Förderung des Projekts ausgelaufen ist, ist diese Seite jedoch nicht mehr aktiv. Die hier verwendeten Materialien und didaktischen Impulse sind allerdings in ein digitales Modul »Oberschlesien - eine europäische Region« des Deutschen Polen-Institus in Darmstadt eingeflossen und sind unter https://www.poleninderschule.de/arbeitsblaetter/landeskunde/landeskunde-oberschle sien-eine-europaeische-region abrufbar.

82 Vgl. Adam Suchoński (Hg.), Nauczanie historii na terenach mieszanych etnicznie. Materialy miedzynarodowej konferencji naukowej, Opole: Dom Współpracy Polsko-Niemieckiej w Gliwicach', >Instytut Historii Uniwersytetu Opolskiegor, 1999.

83 Vgl. Adam Bartoszek, Tomasz Nawrocki und Justyna Kijonka-Niezabitowska, Tożsamość młodych Ślązaków. Między patriotyzmem lokalnym a europejskością, Katowice: Fundacja dla Śląska, 2009, 31. 
talen Ausgabe vorliegt ${ }^{84}$ die vielfach geäußerten Zweifel zu entkräften helfen. Am Ende kommt es aber darauf an, es tatsächlich in Schulen zu bringen. Um den enormen gesellschaftlichen Erwartungen in Oberschlesien entgegenzukommen, wäre ein bildungspolitischer Dialog mit dem Ziel der Überarbeitung curricularer Vorgaben hilfreich. Dies setzt allerdings voraus, dass Regionalgeschichte ihr »inhaltliches Eigengewicht « zurückbekommt und nicht lediglich als "Zulieferer von Beispielen für Verdeutlichung größerer politischer Ereignisse und Vorgänge ${ }^{85}$ angesehen wird. Das wäre auch eine Chance, zentralstaatliche Schulbuchnarrative durch einen multiethnischen und somit multiperspektivischen Ansatz zu erweitern. ${ }^{86}$ So könnte der schulische Umgang mit Oberschlesien ein Beispiel sein für andere europäische Regionen wie etwa Katalonien oder Nordschleswig, Bosnien oder Mazedonien. Denn wie im Fall Oberschlesiens sind auch diese Regionen ein Spiegelbild Europas: Hier hat die transnationale Beziehungsgeschichte ein europäisches Erbe hervorgebracht, das Konflikte ebenso einschließt wie Verbindendes über nationale Grenzen hinweg.

\section{Literatur}

Assmann, Aleida. Erinnerungsräume. Formen und Wandlungen des kulturellen Gedächtnisses, München: Beck, 1998.

Bartoszek, Adam, Tomasz Nawrocki und Justyna Kijonka-Niezabitowska. Tożsamość młodych Ślązaków. Między patriotyzmem lokalnym a europejskością, Katowice: Fundacja dla Śląska, 2009.

Bergmann, Klaus. "Multiperspektivität«, in: Handbuch. Methoden im Geschichtsunterricht, Ulrich Mayer (Hg.), Schwalbach/Ts.: Wochenschau-Verlag, 2004, 65-77.

Berlińska, Danuta. »Identität und nationale Identifikation der Schlesier in der Region Oppeln nach 1989«, in: Die Grenzen der Nationen. Identitätenwandel in Oberschlesien in der Neuzeit, Kai Struve und Philip Ther (Hg.), Marburg: Herder, 2002, 275-305.

Dies. »Symbole einer schwierigen Geschichte im Oppelner Schlesien«, in: Das deutsche Kulturerbe in den polnischen West- und Nordgebieten, Zbigniew Mazur (Hg.), Wiesbaden: Harrassowitz, 2003, 161-183.

Borries, Bodo von. "'Staatsnation` und `Nationalstaat` - Grenzen und Möglichkeiten multiperspektivischer Betrachtung und relativierender Historisierung «, in: Zwi-

84 Siehe: http://edus.ibrbs.pl/. Vgl. hierzu auch die Webpräsenz des Instituts für Regionale Forschungen in Katowice unter http://ibr.bs.katowice.pl/?cat=45, zuetzt geprüft am 06. März 2019.

85 Horst Kuss, "Landesgeschichte oder Regionalgeschichte? Über den Zusammenhang von geschichtswissenschaftlicher Theorie, geschichtsdidaktischer Konzeption und praktischer Anwendung im Unterricht«, in: GWU 51 (2000), 388-405, 403.

86 Klaus Bergmann, "Multiperspektivität«, in: Ulrich Mayer (Hg.), Handbuch. Methoden im Geschichtsunterricht, Schwalbach/Ts.: Wochenschau-Verlag, 2004, 65-77. 
schen Zählebigkeit und Zerrinnen. Nationalgeschichte im Schulunterricht in Ostmitteleuropa, Robert Maier (Hg.), Hannover: Hahn, 2004, 281-314.

Burda, Bogumiła, Bohdan Halczak, Roman Maciej Józefiak, Anna Roszak und Małgorzata Szymczak. Czasy nowożytne. Historia 2. Zakres rozszerzony. Podręcznik dla liceum ogólnokształcącego, Gdynia: OPERON, 2007.

Burda, Bogumiła, Bohdan Halczak, Roman Maciej Józefiak und Małgorzata Szymczak. Historia 1. Część 2. Średniowiecze. Podręcznik. Zakres podstawowy, Gdynia: Wydawnictwo Pedagogiczne OPERON, 2010.

Cegielski, Tadeusz und Katarzyna Zielińska. Historia 2. Dzieje nowożytne. Podręcznik dla szkół średnich klasy II liceum ogólnokształcącego, Warschau: WSiP, 1993.

Cegielski, Tadeusz, Włodzimierz Lengauer und Michał Tymowski. Ludzie, społeczeństwa, cywilizacje. Historia. Starożytność i średniowiecze. Cześć I. Podręcznik dla liceum ogólnokształcącego, liceum profilowanego i technikum - zakres podstawowy, Warschau: WSiP, 2002.

Centkowski, Jerzy. »Die Reform der historisch-sozialkundlichen Bildung der Grundschule in Polen «, in: Geschichtsunterricht international, Band 117, Elisabeth Erdmann, Robert Maier und Susanne Popp (Hg.), Hannover: Hahn, 2006, 53-59.

Fuchs, Eckhardt und Simone Lässig. "Europa im Schulbuch«, in: Geschichte für heute. Zeitschrift für historisch-politische Bildung 1 (2009), 60-66.

Garlicki, Andrzej. Historia 1939-1997/98. Polska i świat. Podręcznik dla liceów ogólnokształcacych, Warschau: Scholar, 1998.

Gauger, Jörg-Dieter. Deutsche und Polen im Unterricht. Eine Untersuchung aktueller Lehrpläne/Richtlinien und Schulbücher für Geschichte, Schwalbach/Ts.: WochenschauVerlag, 2008.

Gierowski, Józef und Józef Leszczyński. Historia dla klasy 2 liceum ogólnokształcącego, Warschau: WSiP, 1990.

Gładysz, Mikołaj. Historia I. Część 2. Od średniowiecza do nowożytności. Podręcznik dla klasy pierwszej liceum i technikum. Zakres podstawowy $i$ rozszerzony, Gdańsk: Gdańskie Wydawnictwo Oświatowe, 2002.

Granoszewska-Babiańska, Dorota, Dariusz Ostapowicz und Sławomir Suchodolski. Historia 2 - dzieje społeczeństwa i gospodarki, część 1. Podręcznik do liceum ogólnokształcącego, liceum profilowanego i technikum - ökształcenie ogólne $w$ zakresie podstawowym i rozszerzonym, Warschau: Nowa Era, 2003.

Granoszewska-Babiańska, Dorota, Tytus Izdebski, Dariusz Ostapowicz und Sławomir Suchodolski. Historia 3 - dzieje kultury. Podręcznik do liceum ogólnokształcącego, liceum profilowanego i technikum - kształcenie ogólne w zakresie podstawowym i rozszerzonym, Warschau: Nowa Era, 2004.

Haslinger, Peter (Hg.). Regionale und nationale Identitäten. Wechselwirkungen und Spannungsfelder im Zeitalter moderner Staatlichkeit, Würzburg: Ergon-Verlag, 2001.

Haubold-Stolle, Juliane und Bernard Linek (Hg.). Imaginiertes Oberschlesien: Mythen, Symbole und Helden in den nationalen Diskursen, Opole/Marburg: Stowarzyszenie Inst. Ślaski, Herder, 2005.

Institut für Regionale Forschungen in Katowice, http://ibr.bs.katowice.pl/?cat=45, zuetzt geprüft am 06. März 2019.

Jungwirth, Ingrid. Zum Identitätsdiskurs in den Sozialwissenschaften, Bielefeld: transcript, 2007. 
Kamiński, Marek und Robert Śniegocki. Historia. Od renesansu do czasów napoleońskich. Podręcznik dla II klasy liceum ogólnokształcącego, liceum profilowanego i technikum, częśś 1 - kształcenie $w$ zakresie podstawowym i rozszerzonym, Warschau: Nowa Era, 2006.

Kamiński, Marek, Grażyna Pańko und Robert Śniegocki. Historia. Średniowiecze. Podręcznik dla I klasy liceum ogólnokształcącego, liceum profilowanego i technikum, część 2 - kształcenie w zakresie podstawowym i rozszerzonym, Warschau: Nowa Era, 2006.

Kochanowski, Jerzy und Przemysław Matusik. Człowiek i historia. Część 4. Czasy nowe i najnowsze (XIX i XX wiek). Kształcenie w zakresie rozszerzonym. Podręcznik dla liceum ogólnokształcącego, liceum profilowanego i technikum, Warschau: WSiP, 2004.

Kurkowska, Mirella und Jarosław Kurkowski. Zrozumieć współczesny świat. Podręcznik Część 2, (1789-1914), Warschau: ADAM, 2004.

Kurkowska, Mirella, Jarosław Kurkowski und Maria Radożycka-Paoletti. Zrozumieć wspótczesny świat. Podręcznik historii dla liceum ogólnokształcącego, profilowanego $i$ technikum, Teil 1, Warschau: Adam, 2002.

Kuss, Horst. »Landesgeschichte oder Regionalgeschichte? Über den Zusammenhang von geschichtswissenschaftlicher Theorie, geschichtsdidaktischer Konzeption und praktischer Anwendung im Unterricht«, in: GWU 51 (2000), 388-405.

Lazuga, Waldemar. Historia czasów nowożytnych (1815-1918). Podręcznik dla szkoły średniej, Warschau: Wydawn. Graf Punkt, 1998.

Lottes, Günther. »Zur Einführung: Staat, Nation, Region - Zu drei Prinzipien der Formationsgeschichte Europas", in: Region, Nation, Europa. Historische Determinanten der Neugliederung eines Kontinents, ders. (Hg.), Heidelberg: Physica-Verlag, 1992, 10-43.

Manikowska, Halina. Historia dla maturzysty. Średniowiecze. Podręcznik - szkoły ponadgimnazjalne, zakres rozszerzony, Warschau: PWN, 2007.

Manikowska, Halina und Julia Tazbirowa. Historia. Średniowiecze. Podręcznik dla szkót średnich klasy I liceum ogólnokształcącego technikum i liceum zawodowego, Warschau: WSiP, 1993.

Mrozowicz, Wojciech und Przemysław Wiszewski. Historia. Średniowiecze. Podręcznik do liceum ogólnokształcącego, profilowanego i technikum - zakres podstawowy i rozszerzony, Wrocław: Wydawnictwa Edukacyjne Wiking, 2003.

Nikodem, Jarosław. Historia. Średniowiecze. Podręcznik dla liceum ogólnokształcącego, profilowanego i technikum. Zakres podstawowy i rozszerzony, Warschau: Wydaw. Juka, 2004.

Nowakowska, Agata und Dominika Wielowieyska im Gespräch mit Robert Szuchta. "Program nauczania historii jest do bani«, in: Gazeta Wyborcza, 18. Oktober 2011, http://wyborcza.pl/1,75515,10489824,Program_nauczania_historii_jest_do_bani.html, zuletzt geprüft am 6. März 2019.

Palenga-Möllenbeck, Ewa. Pendelmigration aus Oberschlesien. Lebensgeschichten in einer transnationalen Region Europas (Kultur und soziale Praxis), Bielefeld: transcript, 2014.

Pankowicz, Andrzej. Historia 3. Polska i świat 1815-1939. Podręcznik dla klasy III liceum ogólnokształcącego, Warschau: WSiP, 1996.

Polek, Krzysztof und Marek Wilczyński. Historia. Ludzie i epoki. Podręcznik Klasa 1 liceum ogólnokształcące, liceum profilowanym i technikum, Kraków: Znak, 2003. 
Radziwiłł, Anna und Wojciech Roszkowski. Historia 1945-1990. Podręcznik dla szkót średnich, Warschau: PWN, 1994.

Dies. Historia 1789-1871. Podręcznik dla szkót średnich, Warschau: PWN, 1995.

Dies. Historia dla maturzysty. Wiek XIX. Podręcznik - szkoły ponadgimnazjalne, zakres rozszerzony, Warschau: Wydawnictwo Szkolne PWN, 2006.

Ronikier, Jerzy. Mit i historia. Mitotwórcze funkcje podręczników szkolnych, Kraków: Wydawn. Uniwersytetu Jagiellońskiego, 2002.

Spyra, Janusz (Hg.). Kronikaz a historyk. Atuty i słabości regionalnej historiografii. Materiały z konferencji naukowej, Cieszyn: Książnica Cieszyńska, 2007.

Suchoński, Adam (Hg.). Nauczanie historii na terenach mieszanych etnicznie. Materialy miedzynarodowej konferencji naukowej, Opole: Dom Współpracy Polsko-Niemieckiej w Gliwicach', >Instytut Historii Uniwersytetu Opolskiegor, 1999.

Świątek, Anna. »Licea niekształcące», in: Polityka 40 (2011), 28-30.

Szcześniak, Andrzej Leszek. Historia 3. Dzieje nowożytne i najnowsze od połowy XIX wieku do roku 1918, Warschau: WSiP, 1990.

Szelągowska, Grażyna. Historia 3. Dzieje nowożytne i najnowsze 1870-1939. Podręcznik dla klasy III liceum ogólnokształcącego, Warschau: WSiP, 1994.

Szelągowska, Krystyna. Wykłady z historii powszechnej dla szkoły średniej, Warschau: WSiP, 1994.

Szewczyk, Grażyna Barbara. »Die Identität des Oberschlesiers im Umfeld von Ideologie und Mythos«, in: Nationale Identität aus germanistischer Perspektive, Maria K. Lasatowicz und Jürgen Joachimsthaler (Hg.), Opole: Wydawn. Uniwersytetu Opolskiego, 1998, 87-99.

Tambor, Jolanta. Oberschlesien - Sprache und Identität, Hildesheim u.a.: Olms, 2011 [polnische Ausgabe: Dies. Mowa Górnoślązaków oraz ich świadomość językowa i etniczna, Katowice: Uniwersytetu Śląskiego, 2006].

Ther, Philipp. «Die Grenzen des Nationalismus: Der Wandel von Identitäten in Oberschlesien von der Mitte des 19. Jahrhunderts bis 1939«, in: Nationalismen in Europa. West- und Osteuropa im Vergleich, Ulrike von Hirschhausen und Jörn Leonhard (Hg.), Göttingen: Wallstein, 2001, 322-346.

Ther, Philipp und Holm Sundhaussen (Hg.). Regionale Bewegungen und Regionalismen in europäischen Zwischenräumen seit der Mitte des 19. Jahrhunderts. im Vergleich, Marburg: Herder, 2003.

Traba, Robert. »Regionalismus in Polen: Die Quellen des Phänomens und sein neues Gesicht nach 1989«, in: Regionale Bewegungen und Regionalismen in europäischen Zwischenräumen seit der Mitte des 19. Jahrhunderts im Vergleich, Philipp Ther und Holm Sundhaussen (Hg.), Marburg: Herder, 2003, 275-284.

Tusiewicz, Roman. Historia 4. Polska współczesna 1944-1989. Podręcznik dla klasy IV liceum ogólnokształcącego, Warschau: WSiP, 1993.

Tymowski, Michał. Człowiek i historia Część 2. Czasy średniowiecza. Kształcenie w zakresie rozszerzonym. Podręcznik dla liceum ogólnokształcącego, Warschau: WSiP, 2002.

Wiatr, Marcin. Oberschlesien als kulturelles Erbe. Erinnerungspolitische Befunde, bildungspolitische Impulse und didaktische Innovationen, Göttingen: V\&R unipress, 2016. 
Wojciechowski, Leszek. Historia. Średniowiecze. Klasa 1. Część 2. Podręcznik do liceum ogólnokształcącego, liceum profilowanego i technikum. Zakres podstawowy, Kielce: MAC EDUKACJA, 2003.

Wojdon, Joanna. Propaganda polityczna w podręcznikach dla szkół podstawowych Polski Ludowej (1944-1989), Toruń: Wydawn. Adam Marszałek, 2001.

Wróbel, Jan. Odnaleźć przeszłość. Od starożytności do 1815 roku. Część 1. Podręcznikliceum ogólnokształcące, liceum profilowane, technikum. Kształcenie w zakresie podstawowym, Warschau: WSiP, 2002.

Wypustek, Adam und Marek L. Wojcik. Historia 1. Starożytność. Średniowiecze. Ze świata do Polski przez Europę. Liceum ogólnoksztatcące; Liceum profilowane; Technikum. Zakres podstawowy i rozszerzony, Warschau: Nowa Era, 2002.

Zielińska, Katarzyna und Zofia Kozłowska. Historia 2. Dzieje Nowożytne 1492-1815. Podręcznik dla klasy II liceum ogólnokształcącego, Warschau: WSiP, 1994.

Zloch, Stephanie. »Vergessen und neu entdeckt: Das ehemalige Ostpreußen als imaginierter Raum im Geschichtsunterricht. Eine vergleichende Analyse historischer Narrative und didaktischer Konzepte am Beispiel Deutschlands, Polens und Russlands«, in: Zeitschrift für Geschichtsdidaktik 10 (2011), 22-42.

Zloch, Stephanie und Izabela Lewandowska (Hg.). Das >Pruzzenland als geteilte Erinnerungsregion. Konstruktion und Repräsentation eines europäischen Geschichtsraums in Deutschland, Polen, Litauen und Russland seit 1900, Göttingen: V\&R unipress, 2014 [poln. Ausgabe: Ziemie pruskie w podręcznikach Polski, Niemiec, Litwy i Rosji. Porównawcza analiza regionalnych konstrukcji tożsamości w XX-XXI wieku, Olsztyn: Instytut Historii i Stosunków Miedzynarodowych, 2013]. 